\title{
Strategies for the De Novo Synthesis of Highly Substituted Pyridine Scaffolds: Unified Total Synthesis of the Limonoid Alkaloids
}

\author{
Alexander W. Schuppe ${ }^{\dagger}$ Yannan Liu, ${ }^{\dagger}$ Yizhou Zhao, Sebastian Ibarraran, David Huang, Emma Wang, \\ Jaehoo Lee, J. Patrick Loria, Timothy R. Newhouse* \\ Department of Chemistry, Yale University, 225 Prospect St., New Haven, \\ Connecticut 06520-8107, United States \\ *E-mail: timothy.newhouse@yale.edu
}

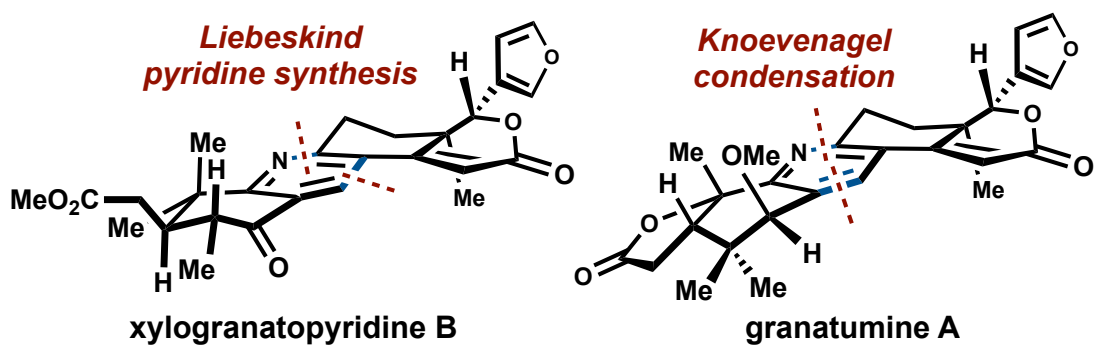

de novo pyridine synthesis as a tool for convergence 


\title{
Strategies for the De Novo Synthesis of Highly Substituted Pyridine Scaf- folds: Unified Total Synthesis of the Limonoid Alkaloids
}

\author{
Alexander W. Schuppe,$^{\dagger}$ Yannan Liu, ${ }^{\dagger}$ Yizhou Zhao, Sebastian Ibarraran, David Huang, Emma Wang, \\ Jaehoo Lee, J. Patrick Loria, Timothy R. Newhouse*
}

Department of Chemistry, Yale University, 225 Prospect Street, New Haven, Connecticut 06520-8107, United States

Supporting Information Placeholder

\begin{abstract}
Highly substituted pyridine scaffolds are found in many biologically active natural products and therapeutics. Accordingly, numerous complementary de novo approaches to obtain differentially substituted pyridines have been disclosed. This article delineates the evolution of the synthetic strategies designed to assemble the demanding tetrasubstituted pyridine core present in the limonoid alkaloids isolated from Xylocarpus granatum, including xylogranatopyridine B, granatumine A and related congeners. The most efficient and convergent construction of the core framework present in xylogranatopyridine B involved a Liebeskind pyridine synthesis and late-stage benzylic oxidation. By contrast, the synthesis of the bislactone limonoid alkaloids, such as granatumine A which exhibited moderate PTP1B-inhibitory activities, necessitated the development of a novel pyran-to-pyridine conversion. In addition, NMR calculations suggested structural misassignment of several limonoid alkaloids, and predicted their $\mathrm{C} 3$-epimers as the correct structures, which was further validated unequivocally through chemical synthesis. While preliminary results of the pNPP assays showed that these bislactone limonoid alkaloids were only weakly inhibitory against PTP1B, C3-deoxy-xylogranatin F, an unnatural synthetic analog, was demonstrated to be more potent than the other congeners.
\end{abstract}

\section{INTRODUCTION}

The limonoid natural products are a diverse family of terpenoids characterized by their structurally conserved C17-furan and various modes of skeletal rearrangements. ${ }^{1,2} \mathrm{~A}$ fascinating sub-family of these natural products, the limonoid alkaloids, are recently isolated from the Chinese mangrove, Xylocarpus granatum. ${ }^{3,4}$ The structural hallmark of the limonoid alkaloids is the tetrasubstituted pyridine embedded in the core structure (Scheme 1), as typified by xylogranatopyridine B (1-1) and granatumine A (1-2). Furthermore, granatumine A (1-2) is a member of the bislactone limonoid alkaloids, in which the Aring has undergone further modification to form a 5-membered lactone ring fused to the 6-membered ring adjacent to the pyridine. For the limited number of bislactone limonoid alkaloids that have been isolated, diversity mainly arises from the oxygen-containing substituents present on the $\mathrm{C} 3$ position (1-2 to 1-4), as depicted in Scheme 1., While the C3-methoxy group was assigned as the $\beta$-epimer for granatumine $\mathrm{A}(\mathbf{1 - 2})$, several other alkaloids in this class were proposed to have an $\alpha$-C3-substituent, such as the case of xylogranatin F (1-3). Surprisingly, granatoine (1-4) was proposed to have the same scaffold as xylogranatin F (1-3), except being diastereomeric at the $\mathrm{C} 3, \mathrm{C} 5$, and $\mathrm{C} 10$ positions. ${ }^{4 \mathrm{a}}$

Traditional methods for pyridine synthesis, including Hantzsch $^{5}$ and Chichibabin ${ }^{6}$ pyridine synthesis, involve amine condensation onto carbonyl compounds, which entails intrinsic restrictions on the substitution patterns of the target pyridines. More recently, there have been numerous methodological advancements in the synthesis of highly substituted pyridines, many of which utilize transition-metal catalyzed crosscoupling. ${ }^{7}$ However, these methodologies have rarely been
Scheme 1. Select Pyridine-Containing Limonoid Alkaloids

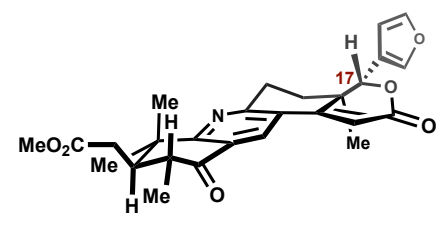

(+)-xylogranatopyridine B (1-1)

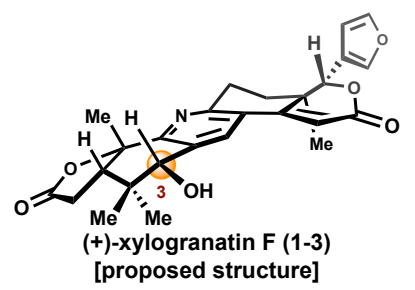

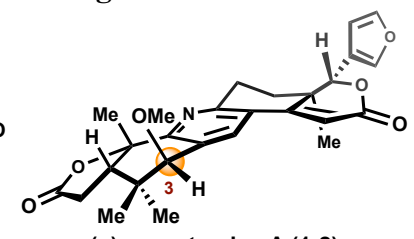

(+)-granatumine A (1-2) [PTP1B inhibitory, $\mathrm{IC}_{50}=23 \mu \mathrm{M}$ ]

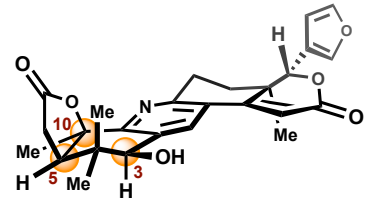

(+)-granatoine (1-4) [proposed structure] tested in the realm of complex molecule synthesis. These limonoid alkaloid natural products inspired a compelling question: what are the most effective ways to use ring synthesis as a tool for convergence in the context of such highly substituted pyridines?

Biosynthetically, it has been suggested that the tetrasubstituted pyridine lodged in the limonoid alkaloids arises from a mexicanolide-type limonoid containing a C9-hydroxyl group such as 2-1 (Scheme 2), ${ }^{4 b}$ or a limonoid at a different oxidation state. According to the biogenetic hypothesis put forth by $\mathrm{Wu}$ and co-workers, upon formation of the $\mathrm{C} 9$-alkoxide, a retroaldol reaction could ensue and thereby cleave the C9-C10 linkage. ${ }^{4 \mathrm{~b}}$ Intermediate $\mathbf{2 - 2}$ could be formed following a protonation of the resulting enolate, and $\beta$-elimination of the $\mathrm{C} 3$ - 


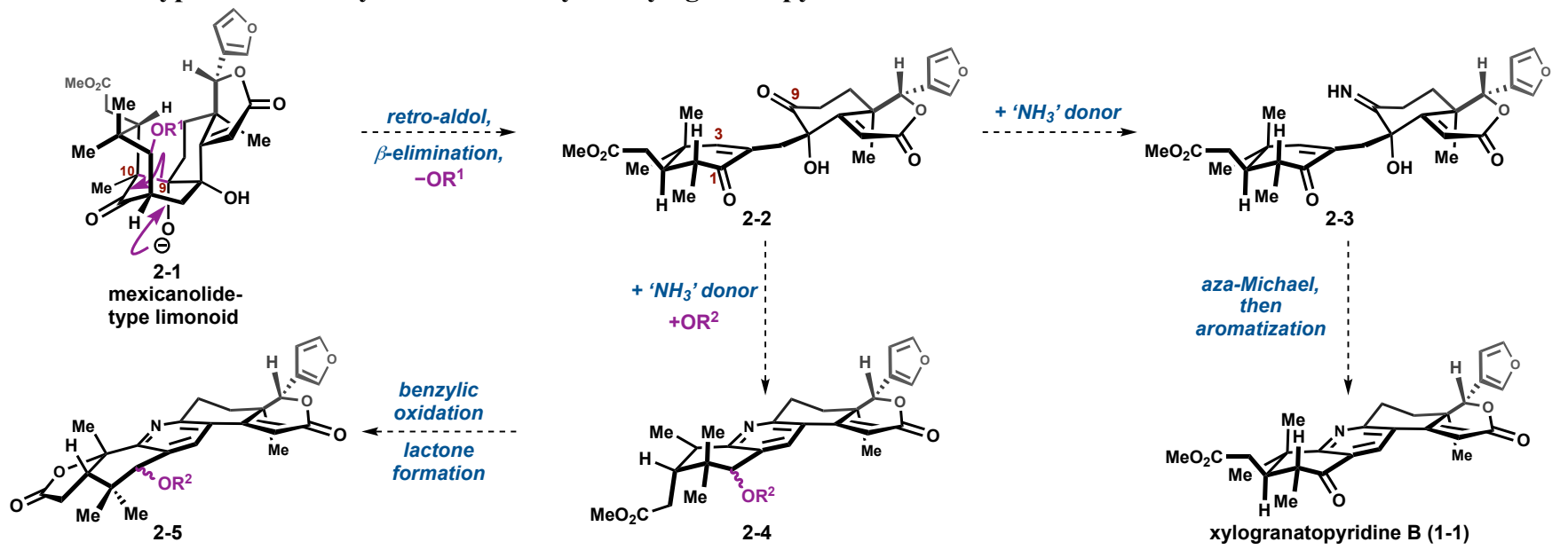

alkoxy group. Guo and co-workers proposed that in the presence of an ammonia equivalent, a condensation onto the C9carbonyl could give rise to $\mathbf{2 - 3}$, followed by an aza-Michael reaction and ensuing aromatization to produce xylogranatopyridine $\mathrm{B}(\mathbf{1 - 1}) .^{3}$ They also postulated that the related bislactone limonoid natural products may arise via a similar condensation event either onto the carbonyl at C9 or C1. Subsequently, after an oxa-Michael reaction with an appropriate oxygen nucleophile and pyridine synthesis, tetracyclic intermediate 2-4 would arise. ${ }^{3}$ The bislactone family members (25) would be furnished by a benzylic oxidation and lactonization. ${ }^{3}$ The co-isolation of xylogranatopyridine B (1-1) and bislactone limonoid alkaloids, such as granatumine A (1-2), suggests the possibility of such a late-stage benzylic oxidation step in the biogenesis. However, this hypothetical biosynthetic pathway has not been experimentally corroborated, and remains largely speculative.

These natural products stimulated the investigation into a convergent pyridine synthesis approach because of their biological activities. The limonoid alkaloids have been found to act on PTP $1 \mathrm{~B},{ }^{3}$ which is a thoroughly investigated yet historically challenging protein to target for therapeutic intervention. ${ }^{8}$ Although PTP1B is classically a target for diabetes, as it regulates insulin production, ${ }^{9}$ it has also been shown to play a complicated role in a number of signaling pathways related to obesity $^{10}$ and oncogenesis. ${ }^{11}$

More recently, PTP1B overactivation has been shown to lead to neuronal cell death through several downstream events, ${ }^{12}$ which hastens the pathological development of neurodegenerative diseases such as Alzheimer's disease. ${ }^{13} \mathrm{Sev}$ eral pieces of data mark PTP1B and associated proteins as promising new targets for neurodegeneration: (1) PTP1B overactivation deactivates tropomyosin receptor kinase $\mathrm{B}$ (TrkB), ${ }^{14}$ which is essential in promoting neuronal cell survival and growth through binding to its ligand, brain-derived neurotrophic factor (BDNF); (2) PTP1B inhibition augments the BDNF signaling pathway, ${ }^{15}$ and was shown to ameliorate schizophrenia-like behaviors in Lmo4-deficient mice, ${ }^{16}$ (3) in a separate study, pharmacological inhibition of PTP1B with trodusquemine prevented hippocampal neuron loss and spatial memory deficits in a mouse model for Alzheimer's Disease (hAPP-J20 mice) ${ }^{17}$ (4) encouragingly, inhibition of PTP1B is demonstrated to be a safe mode of action based on other indications in Phase 1 and Phase $1 \mathrm{~b}$ studies with trodusquemine. ${ }^{18}$

The limonoid alkaloids are structurally novel inhibitors of PTP1B and do so through an unknown mechanism of action (granatumine $\mathrm{A}, \mathrm{IC}_{50}=23 \mu \mathrm{M}$ ). ${ }^{3}$ Our long-term interest in these molecules derives from the hypothesis that they may bind to an uncharacterized allosteric site. We recently documented the chemical synthesis of several limonoid alkaloids including xylogranatopyridine B (1-1) ${ }^{2 \mathrm{f}}$ and granatumine A (12), ${ }^{2 \mathrm{~g}}$ through a late-stage pyridine synthesis. The development of such approaches enabled both an efficient access to these natural products and related analogs for SAR studies. Herein we describe the evolution of the synthetic strategies toward these limonoid alkaloids, as well as structural revision of several related natural products guided by NMR-computation. Preliminary PTP1B inhibitory activities of several limonoid alkaloids and their synthetic analogs are also reported.

\section{RESULTS AND DISCUSSION}

Retrosynthetic Considerations of Xylogranatopyridine B. The aforementioned biosynthetic pathway takes a stereochemically dense mexicanolide (2-1) and inserts a highly functionalized pyridine at the center. A more effective synthetic approach to enable analog synthesis would be to dissect the pyridine in half, generating two fragments of similar complexity.

Scheme 3. Three Strategies to Access Xylogranatopyridine B

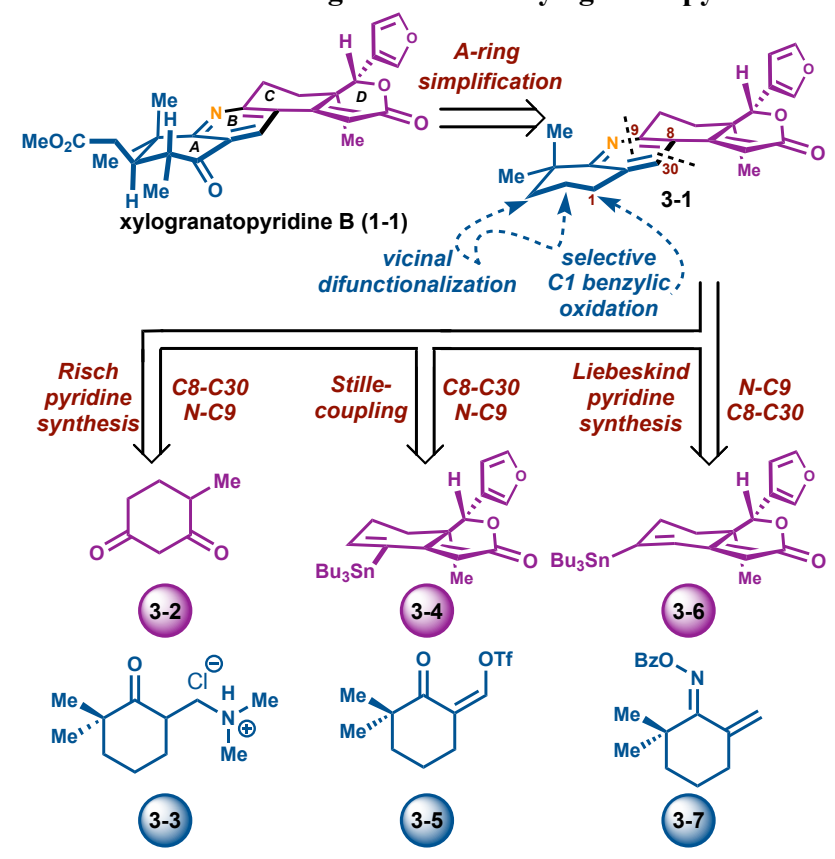


Scheme 4. First-Generation Synthetic Effort Toward Xylogranatopyridine B Through Risch Pyridine Synthesis ${ }^{a}$
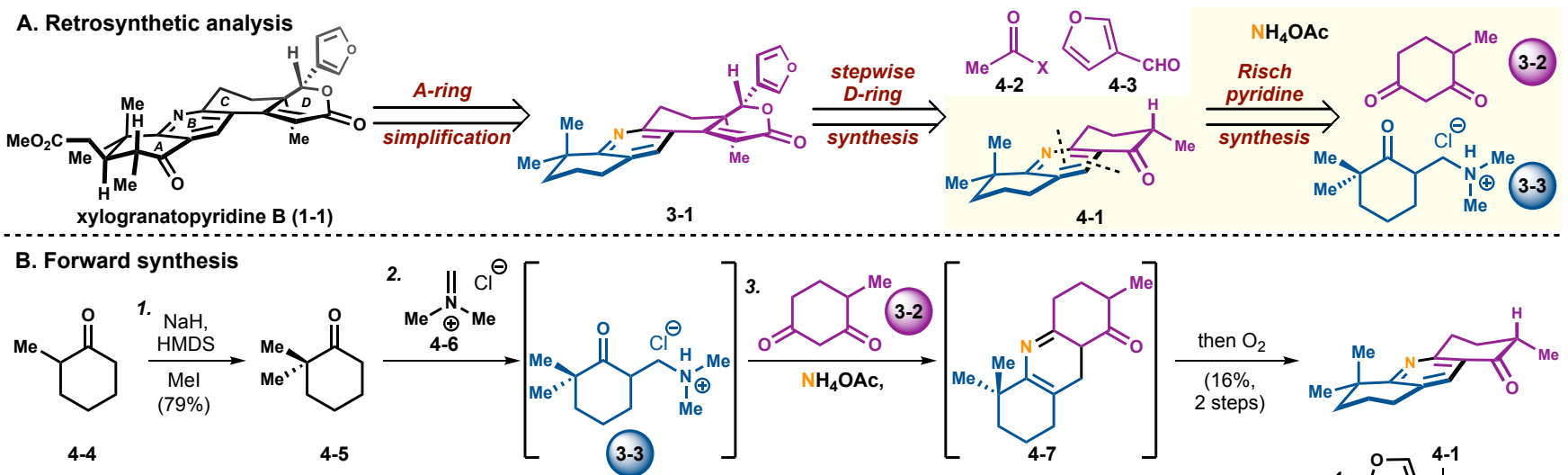

- low material throughput

- linear sequence
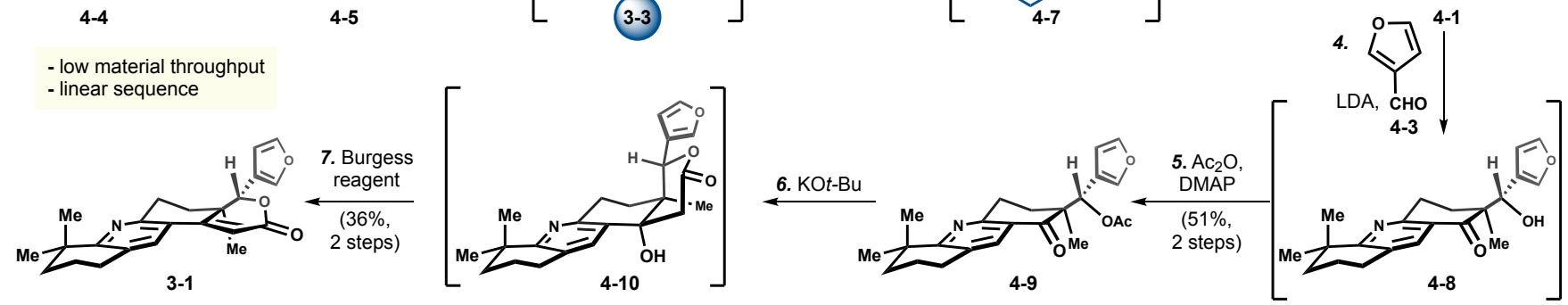

${ }^{a}$ Reagents and conditions: (1) NaH (1.1 equiv), THF, $65^{\circ} \mathrm{C}, 2 \mathrm{~h}$, then $\operatorname{HMDS}\left(0.15\right.$ equiv), $15 \mathrm{~m}$, then MeI (1.1 equiv), $0{ }^{\circ} \mathrm{C}, 3 \mathrm{~h}, 79 \%$; $(2)$ $N, N$-dimethylmethyleneiminium chloride (4-6, 1.1 equiv), $\mathrm{MeCN}, 80^{\circ} \mathrm{C}, 1 \mathrm{~h}$; (3) 3-3 (1.2 equiv), 3-2 (1.0 equiv), $\mathrm{NH}_{4} \mathrm{OAc}(3.0$ equiv), $\mathrm{EtOH}, 80^{\circ} \mathrm{C}, 14 \mathrm{~h}$, then $\mathrm{O}_{2}, 1 \mathrm{~h}, 16 \%$ over two steps; (4) LDA (1.1 equiv), 3-furaldehyde (1.2 equiv), $\mathrm{THF},-78^{\circ} \mathrm{C}, 0.5 \mathrm{~h} ;(5) \mathrm{Ac} 2 \mathrm{O}(3.5$ equiv), DMAP (0.2 equiv), pyridine (5.0 equiv), $\mathrm{CH}_{2} \mathrm{Cl}_{2}, 0$ to $23{ }^{\circ} \mathrm{C}, 51 \%$ over two steps, $4: 1 \mathrm{dr}$; (6) $\mathrm{KO} t$ - $\mathrm{Bu}(1.2 \mathrm{equiv})$, THF, $-78{ }^{\circ} \mathrm{C}, 0.5$ $\mathrm{h}$; (7) Burgess reagent ( 1.5 equiv), $\mathrm{PhMe}, 80^{\circ} \mathrm{C}, 1 \mathrm{~h}, 36 \%$ over two steps.

We began our retrosynthetic analysis of xylogranatopyridine B (1-1) with structural simplification of the limonoid A-ring, which would give intermediate 3-1 (Scheme 3). In a forward sense, a selective benzylic oxidation and vicinal difunctionalization of 3-1 would allow for the introduction of requisite moieties. With access to the tetracyclic core (3-1) regarded as a key structural goal, it was hypothesized that the tetrasubstituted pyridine could be constructed by a variety of ring synthesis strategies. Accordingly, several pathways were considered and implemented. Initially, we planned that 3-1 could be obtained via a stepwise Risch pyridine synthesis, employing 1,3-diketone 3-2 and $\beta$-amino ketone hydrochloride 3-3, to assemble the $\mathrm{C} 8-\mathrm{C} 30$ and the critical N-C9 linkage. ${ }^{19}$ Further retrosynthetic reasoning led us to consider several cross-coupling approaches to synthesize the demanding pyridine core. A Stille coupling strategy between a stannane such as 3-4 and a vinyl triflate 3-5 could result in 3-1 after subsequent condensation of an ammonia equivalent and oxidative $6 \pi$-electrocyclization. Alternatively, initial formation of the challenging $\mathrm{N}-\mathrm{C} 9$ bond followed by the $\mathrm{C} 8-\mathrm{C} 30$ bond, through a Liebeskind pyridine synthesis between 3-6 and 3-7, would fashion the central pyridine. ${ }^{7 \mathrm{c}}$

Risch Pyridine Synthesis. Insight from the work of Risch and co-workers on the Kröhnke-type pyridine synthesis, ${ }^{19}$ led us to surmise that the tetracyclic core of xylogranatopyridine B (1-1) could be assembled in a stepwise fashion and through the late-stage A-ring modification of 3-1, as depicted in Scheme 4A. It was proposed that $\mathbf{3 - 1}$ could be forged from the tricyclic pyridine fragment 4-1 via a four-step sequence involving aldol, acylation, intramolecular acetate aldol, and dehydration. Furthermore, the pyridine substructure in 4-1 could be assembled by a three-component coupling utilizing 1,3diketone 3-2, $\beta$-amino ketone hydrochloride 3-3, and ammonium acetate (Scheme 4A). ${ }^{19}$ This approach would allow for early introduction of the central pyridine structure, obviating the need to tame the reactivity of the nucleophilic furan or the electrophilic lactone.

The synthesis of 1-1 began with a thermodynamic methylation of 2-methylcyclohexanone (4-4) to produce 4-5 in 79\% yield (Scheme 4B). ${ }^{20}$ Employing Böhme's salt (4-6), ${ }^{21}$ 4-5 was converted to $3-3,{ }^{22}$ which was directly subjected to the pyridine synthesis conditions. Treatment of crude 3-3 with known 1,3-diketone 3-2 ${ }^{23}$ and $\mathrm{NH}_{4} \mathrm{OAc}$ resulted in an intermediate dihydropyridine 4-7 after alkylation and successive condensation reactions. Oxidation of 4-7 occurred upon sparging oxygen through the reaction mixture, producing the tricyclic pyridine 4-1 in an unoptimized 16\% yield over two steps. Deprotonation of ketone 4-1 with LDA and trapping with 3-furaldehyde (4-3) led to alcohol 4-8 as a 4:1 mixture of diastereomers, which was acetylated in a separate operation to form 4-9 in $51 \%$ yield over two steps. An intramolecular acetate aldol reaction was initiated by deprotonation of 4-9 with $\mathrm{KO} t$ - $\mathrm{Bu}$, to reveal an intermediate tertiary alcohol 4-10. Subsequent dehydration of the resulting alcohol 4-10 with Burgess reagent gave rise to 3-1 in $36 \%$ yield over two steps, which possesses the tetracyclic core of xylogranatopyridine B (1-1). Although the main carboskeleton could be constructed following this approach, the low yielding reaction sequence and linear nature of this strategy rendered it undesirable. Therefore, alternative coupling approaches were pursued to access xylogranatopyridine B (1-1).

Stille Coupling Strategy. In order to maximize the synthetic efficiency, our revised route to assemble the tetracyclic pyridine core of xylogranatopyridine B (1-1) focused on a Stille cross-coupling reaction between stannane $3-4,{ }^{24,25}$ and known vinyl triflate 3-5 (Scheme 5A). ${ }^{26}$ An aza-triene intermediate could be generated from the product of this Stille coupling (51) through condensation with an ammonia equivalent. The tetracyclic core of 1-1 could be formed following a $6 \pi$-electrocyclization and aromatization. ${ }^{27}$ 
Scheme 5. Second-Generation Synthetic Effort Toward Xylogranatopyridine B Through Stille Coupling ${ }^{a}$

A. Retrosynthetic analysis
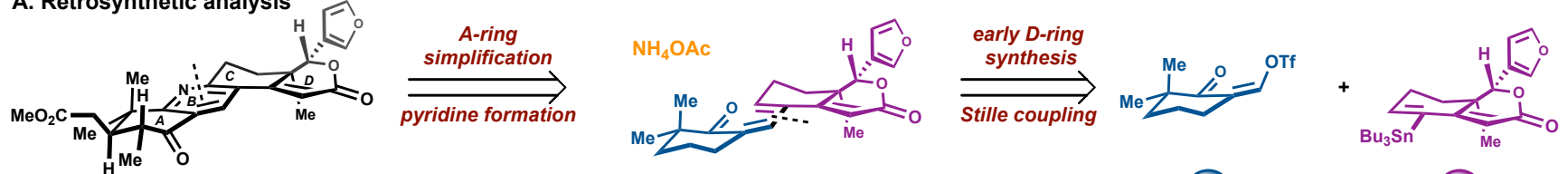

xylogranatopyridine $B(1-1)$

5-1
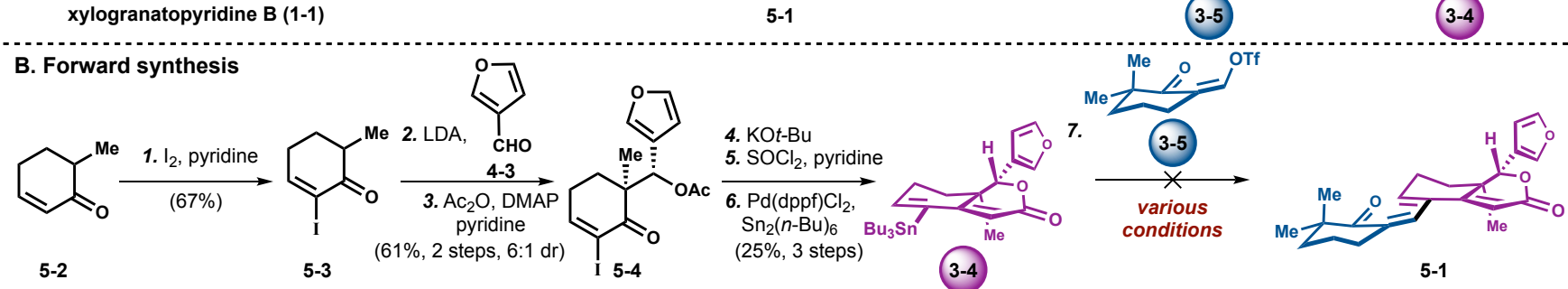

${ }^{a}$ Reagents and conditions: (1) $\mathrm{I}_{2}$ (1.3 equiv), pyridine (2.7 equiv), $\mathrm{CH}_{2} \mathrm{Cl}_{2}, 0$ to $23{ }^{\circ} \mathrm{C}, 3 \mathrm{~h}, 67 \%$; (2) LDA (1.2 equiv), 3 -furaldehyde (1.2 equiv), $-78^{\circ} \mathrm{C}$, THF, $0.5 \mathrm{~h}$; (3) $\mathrm{Ac}_{2} \mathrm{O}$ (2.0 equiv), DMAP ( 0.1 equiv), pyridine (3.0 equiv), $\mathrm{CH}_{2} \mathrm{Cl}_{2}, 0$ to $23{ }^{\circ} \mathrm{C}, 0.5 \mathrm{~h}, 61 \%$ over two steps, 6:1 dr; (4) KOt-Bu (1.2 equiv), $-78{ }^{\circ} \mathrm{C}$, THF, $15 \mathrm{~m}$; (5) $\mathrm{SOCl}_{2}$ (2.0 equiv), pyridine (3.0 equiv), $\mathrm{CH}_{2} \mathrm{Cl}_{2}, 0$ to $23{ }^{\circ} \mathrm{C}, 0.5 \mathrm{~h}, 48 \%$ over two steps; (6) $\mathrm{Pd}(\mathrm{dppf}) \mathrm{Cl}_{2}(10 \mathrm{~mol} \%), \mathrm{Sn}_{2}(n \text {-Bu })_{6}\left(1.2\right.$ equiv), 1,4-dioxane, $100{ }^{\circ} \mathrm{C}, 12 \mathrm{~h}, 52 \%$.

The construction of the stannane fragment (3-4) commenced with an iodination of 6-methylcyclohexenone (5-2), which was readily prepared by our laboratory's previously reported scalable ozonolytic fragmentation of dihydrocarvone, ${ }^{28}$ to form known iodo-enone 5-3 in 67\% yield (Scheme 5B). A moderately diastereoselective aldol reaction between the lithium enolate of 5-3 and 3-furaldehyde (4-3) revealed an intermediate alcohol with $6: 1 \mathrm{dr}$, which could be acylated in a separate operation to provide acetate 5-4 in $61 \%$ yield over two steps. Treatment of 5-4 with $\mathrm{KO} t$-Bu furnished an intermediate alcohol, which was dehydrated in the presence of thionyl chloride and pyridine. Subjection of the resulting vinyl iodide intermediate to Pd-catalyzed stannylation could lead to the stannane fragment (3-4) in 25\% yield over three steps.

With the stannane fragment in hand, the Stille coupling with vinyl triflate 3-5 was explored. The attempted cross-coupling with Corey's conditions ${ }^{29}$ utilizing $\mathrm{Pd}\left(\mathrm{PPh}_{3}\right)_{4}, \mathrm{CuCl}$, and $\mathrm{LiCl}$ resulted only in proto-destannylation and decomposition of 35. Furthermore, modification of ligands, copper salts, or other additives employed did not lead to the desired coupling product. Additionally, it was found that the neat triflate rapidly decomposed under ambient conditions. In order to attenuate these undesired pathways and obtain 5-1, we attempted to switch the polarity of the coupling partners. However, conversion of the $\beta$-triflate to the $\beta$-stannyl enone by Pd-catalyzed conditions or nucleophilic addition of a stannyl metal-species was unsuccessful (not shown). Due to the difficulty of realizing the tetracyclic core of xylogranatopyridine B (1-1) by a Stille cross-coupling approach, we explored alternative pyridine synthesis strategies.

Liebeskind Pyridine Synthesis. Our revised retrosynthetic analysis began with structural simplification of the A-ring to access the key tetracyclic intermediate (3-1), as described in Scheme 6A. As an alternative to the initial construction of the $\mathrm{C} 8-\mathrm{C} 30$ bond, formation the crucial N-C9 bond of the pyridine at an early stage might be advantageous (Scheme 6A). The central ring of 1-1 could be assembled via a modified Liebeskind pyridine synthesis, which entails a Chan-Lam-type cross-coupling with an achiral oxime such as 3-7, and a stannane fragment such as $3-6,{ }^{7 \mathrm{c}}$ to construct the $\mathrm{N}-\mathrm{C} 9$ bond first, followed by an oxidative $6 \pi$-electrocyclization to subsequently form the $\mathrm{C} 8-\mathrm{C} 30$ connection. The less precedented stannane 3-6 was eventually chosen as the coupling partner in the Chan-Lam-type coupling, rather than the typical boronic

acid coupling partner, due to its relative ease of preparation and stability.

In order to prepare $\beta$-stannyl dienoate 3-6, a stepwise activation approach ${ }^{30,31}$ using 1,3-cyclohexanedione (6-2) was initially pursued (Scheme 6B). Sequential formation of the $\beta$ ethoxyenone, methylation at the ketone $\alpha$-position, and tributylstannyl lithium addition gave rise to 6-1 in 26\% yield over three steps. Although this protocol was viable to produce large quantities of the desired $\beta$-stannyl enone (6-1), we hypothesized that it would be possible to generate it directly from the enone precursor, thereby avoiding the costly 1,3-diketones.

Based on insight gleaned from our previous work on Pdcatalyzed carbonyl dehydrogenation, ${ }^{32}$ we anticipated that stannane 6-1 could be accessed by direct conversion of an abundantly available enone precursor, 6-methylcyclohexenone (5-2) ${ }^{28}$ through a bimetallic enolate intermediate 6-4 (Scheme 6C). This approach would require a selective transmetallation of an allyl palladium species 6-3 with the metal enolate, rather than transmetallation with the allyl-stannane, to form a palladium enolate that could regenerate the enone functionality via $\beta$-hydride elimination.

Various stannyl-metal nucleophiles were explored in order to perturb the identity of the bimetallic enolate species involved in this selective transmetallation (Scheme 6C). Contrary to our previous reports regarding zinc enolate-mediated carbonyl $\alpha, \beta$-dehydrogenation, we found that the lithium enolate generated by a conjugate addition of tributylstannyl lithium to 6-methylcyclohexenone (5-2) underwent efficient $\alpha, \beta$ dehydrogenation to provide 6-1 in 50\% isolated yield, and $57 \%{ }^{1} \mathrm{H}-\mathrm{NMR}$ yield, using our previously developed palladium and allyl oxidant system for ketone dehydrogenation (entry 1 ). ${ }^{32 \mathrm{~d}}$ We observed a yield of $15 \%$ for the starting enone and $3 \%$ yield of the $\beta$-allyl enone side product $\mathbf{6 - 5}$, which may arise from Stille-type cross-coupling with stannane 6-1. ${ }^{33}$ Consistent with this suggestion, when additional equivalents of oxidant were used, the amount of the allylation side product (6$5)$ increased (entry 2). To demonstrate that the recovered enone (5-2) did not arise from incomplete conversion of the conjugate addition step, enone 5-2 was treated with $\mathrm{Bu}_{3} \mathrm{SnLi}$, which formed 6-6 in 87\% isolated yield with full consumption of 5-2. The regeneration of the enone starting material (5-2) may be due to proto-destannylation or a $\beta$-tin elimination mechanism. ${ }^{34}$ The efficiency of zinc- and copper-based stannyl nucleophiles were also investigated (entry 3-6); ${ }^{35,36}$ however, these approaches resulted in a diminished yield of 
Scheme 6. Third-Generation Synthetic Effort Toward Xylogranatopyridine B Through Liebeskind Pyridine Synthesis ${ }^{a}$

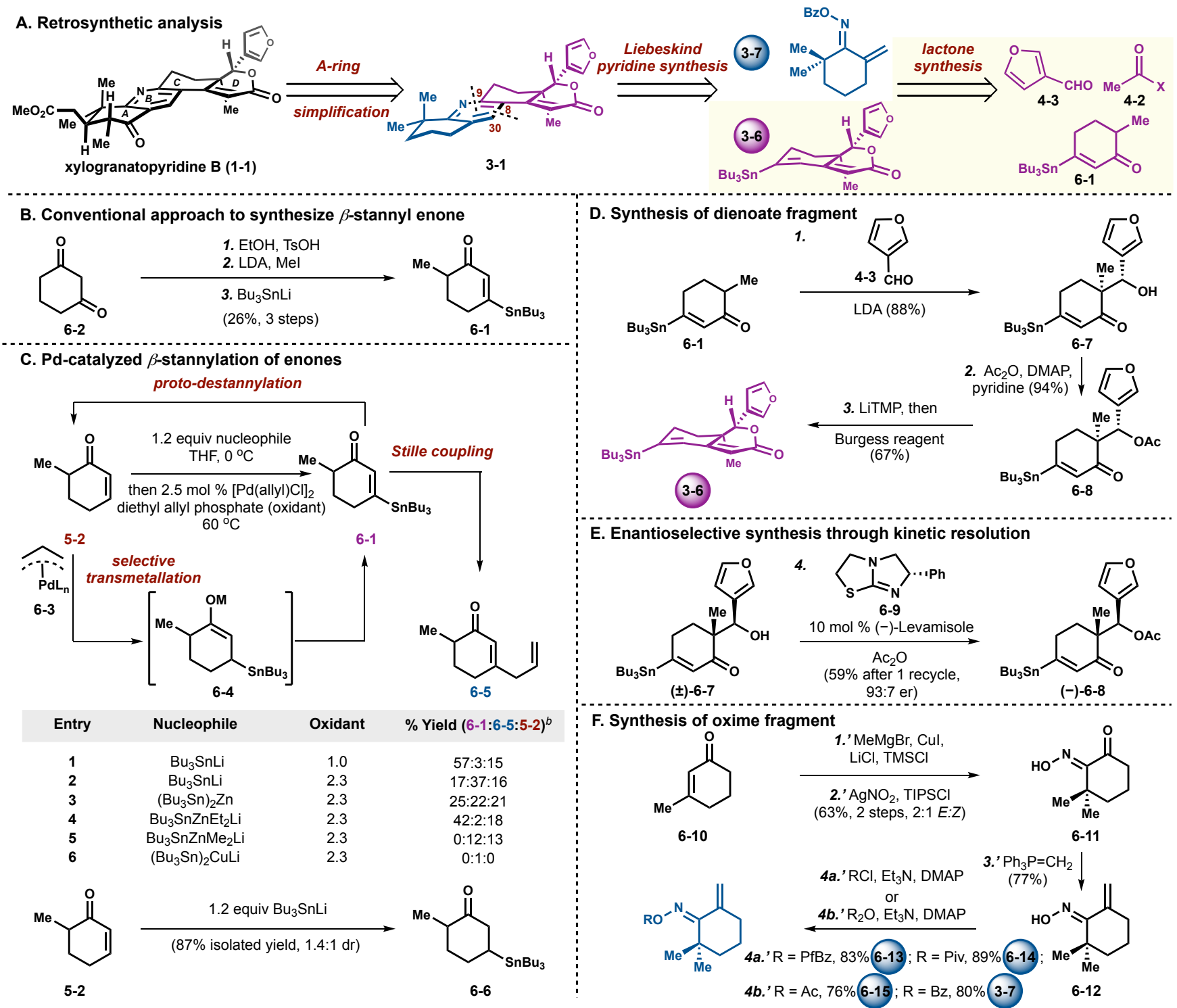

${ }^{a}$ Reagents and conditions: (1) LDA (1.1 equiv), 3-furaldehyde ( 1.2 equiv), $-78{ }^{\circ} \mathrm{C}$, THF, $0.5 \mathrm{~h}, 88 \%$; (2) $\mathrm{Ac}_{2} \mathrm{O}$ (2.0 equiv), pyridine (3.0 equiv), DMAP ( 0.1 equiv), $0{ }^{\circ} \mathrm{C}, \mathrm{CH}_{2} \mathrm{Cl}_{2}, 0.5 \mathrm{~h}, 94 \%$; (3) LiTMP ( 2.5 equiv), -78 to $23{ }^{\circ} \mathrm{C}, \mathrm{THF}, 1 \mathrm{~h}$, then Burgess reagent (3.0 equiv), 60 ${ }^{\circ} \mathrm{C}, 2 \mathrm{~h}, 67 \%$; (4) (-)-Levamisole ( $10 \mathrm{~mol} \%$ ), $\mathrm{Ac}_{2} \mathrm{O}$ ( 0.5 equiv), $0{ }^{\circ} \mathrm{C}$, PhMe, $6 \mathrm{~h}, 43 \%, 93: 7 \mathrm{er}, 59 \%$ after 1 recycle; ( $\left.1{ }^{\prime}\right) \mathrm{LiCl}(0.1$ equiv), $\mathrm{CuI}(5 \mathrm{~mol} \%), \mathrm{TMSCl}\left(1.1\right.$ equiv), $\mathrm{MeMgBr}\left(1.2\right.$ equiv), $\left.-40^{\circ} \mathrm{C}, \mathrm{THF}, 10 \mathrm{~m} ; 2^{\prime}\right) \mathrm{AgNO}_{2}$ (1.2 equiv), $\mathrm{TIPSCl}\left(1.4\right.$ equiv), $-40^{\circ} \mathrm{C}, \mathrm{MeCN}$, $2 \mathrm{~h}$, then -40 to $-20^{\circ} \mathrm{C}, 2 \mathrm{~h}, 63 \%$ over two steps; ( $\left.3^{\prime}\right) \mathrm{Ph}_{3} \mathrm{P}=\mathrm{CH}_{2}$ (3.0 equiv), $\mathrm{PhMe}, 23$ to $60{ }^{\circ} \mathrm{C}, 1.5 \mathrm{~h}, 77 \%$; (4a') $\mathrm{RCl}$ (1.1 equiv), $\mathrm{Et}_{3} \mathrm{~N}$ (2.0 equiv), DMAP ( 0.1 equiv), $\mathrm{CH}_{2} \mathrm{Cl}_{2}, 0$ to $23{ }^{\circ} \mathrm{C}, 1 \mathrm{~h}, \mathrm{R}=$ Pentafluorobenzoyl (PfBz), 83\%, $\mathrm{R}=\mathrm{Piv}, 89 \%$; ( $4 \mathrm{~b}$ ') For $\mathrm{R}=\mathrm{Bz}, \mathrm{Bz} 2 \mathrm{O}(1.1$ equiv), $\mathrm{Et}_{3} \mathrm{~N}$ (2.0 equiv), DMAP ( 0.1 equiv), $\mathrm{CH}_{2} \mathrm{Cl}_{2}, 0$ to $23^{\circ} \mathrm{C}, 1 \mathrm{~h}, 80 \%$; For $\mathrm{R}=\mathrm{Ac}, \mathrm{Ac}_{2} \mathrm{O}$ (2.0 equiv), $\mathrm{Et}_{3} \mathrm{~N}$ (3.0 equiv), DMAP (0.1 equiv), $\mathrm{CH}_{2} \mathrm{Cl}_{2}, 0$ to $23{ }^{\circ} \mathrm{C}, 1 \mathrm{~h}, 76 \%$. ${ }^{b}$ Yield of the crude reaction mixture on $0.2 \mathrm{mmol}$ scale, was determined by ${ }^{1} \mathrm{H}$ NMR using $1,3,5-$ trimethoxybenzene as an internal standard.

the desired product. Stannyl enone 6-1 was obtained in 50\% isolated yield on a 35 -gram scale from the enone starting material (5-2).

With a robust process to form stannyl enone (6-1) developed, the synthesis of the elaborated coupling partner was investigated (Scheme 6D). A diastereoselective aldol reaction between the lithium enolate of 6-1 and 3-furaldehyde (4-3) provided an intermediate benzylic alcohol (6-7) in $88 \%$ yield, which was acylated in a separate operation to provide acetate 6-8 in $94 \%$ yield. Deprotonation of 6-8 with LiTMP initiated an intramolecular acetate aldol, followed by dehydration with Burgess reagent to provide $\beta$-stannyl dienoate 3-6 in $67 \%$ yield. The racemic synthesis of 3-6 could be rendered asymmetric through the use of Birman's acylative kinetic resolution of alcohol ( \pm )-6-7 employing commercially available (-)-Levamisole catalyst (6-9), ${ }^{37}$ providing acetate (-)-6-8 in 93:7 er and $43 \%$ yield on decagram scale (Scheme $6 \mathrm{E}$ ). The unreacted alcohol could be converted back to $\beta$-stannyl enone (6-1) in $89 \%$ yield by a retro-aldol elicited by $\mathrm{K}_{2} \mathrm{CO}_{3} / \mathrm{MeOH}$, and a total yield of $59 \%$ of (-)-6-8 could be obtained after one round of recycling. Boron or titanium-mediated enantioselective aldol reaction ${ }^{38}$ were also pursued to synthesize 6-7; however, these protocols resulted in minimal 6-7.

The preparation of the oxime fragment commenced with a dimethylcuprate conjugate addition to 3-methyl-2-cyclohexenone (6-10) and subsequent trapping of the ensuing enolate with TMSCl to provide an intermediate enoxysilane (Scheme $6 \mathrm{~F}$ ). Using conditions developed by Yamamoto, the enoxysilane was oxidized to the $\alpha$-keto oxime (6-11) in $63 \%$ 
Scheme 7. Optimization of Fragment Coupling Partners for the Liebeskind Pyridine Synthesis

A. Optimization of nucleophilic fragment

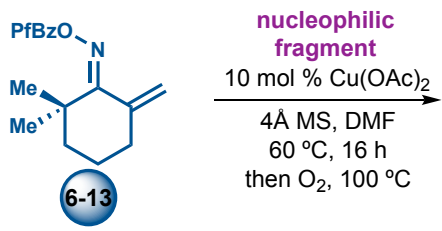

used in the original protocol

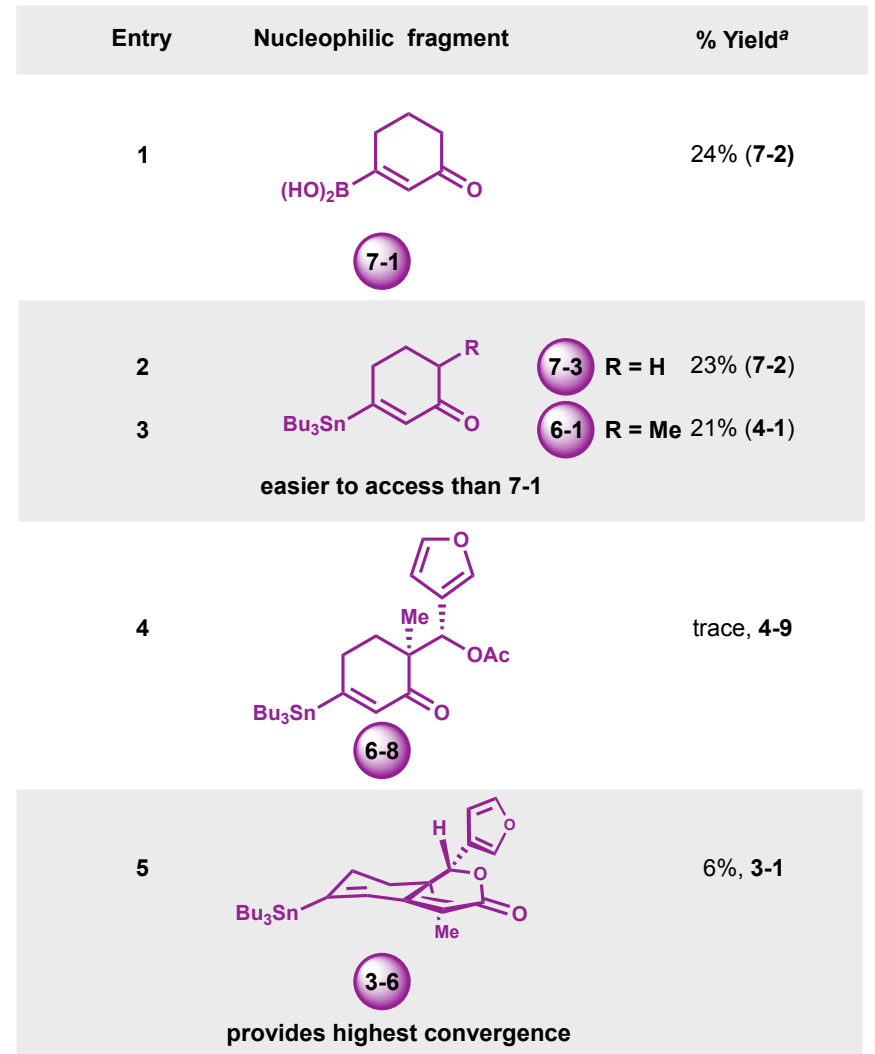

B. Optimization of oxime fragment

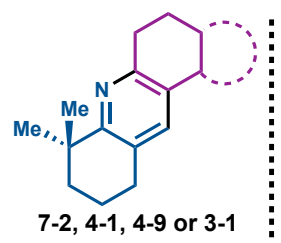<smiles>CCC(C)C1=CC(=O)C([SnH3])CC1</smiles>

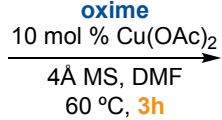

then $\mathrm{O}_{2}, 100^{\circ} \mathrm{C}$

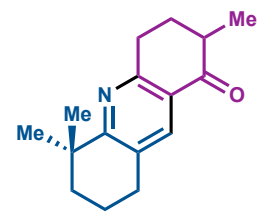

4-1

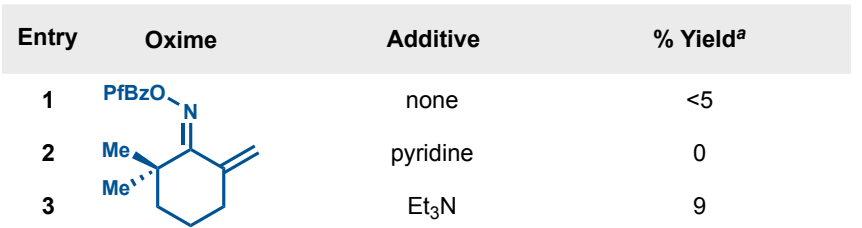

6-13
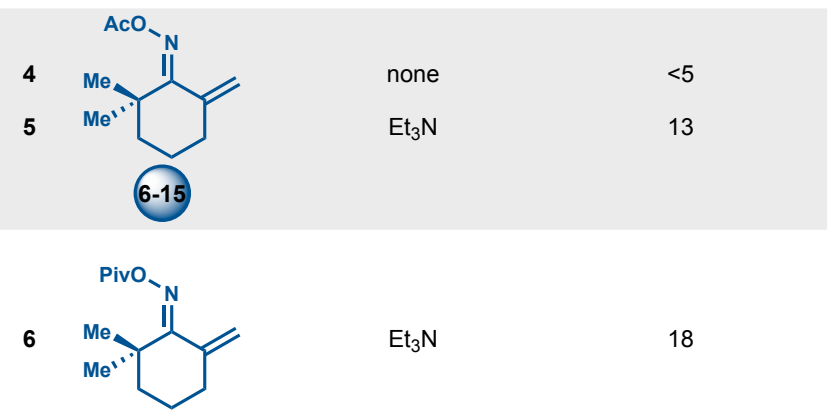

$\mathrm{Et}_{3} \mathrm{~N}$

18

6-14

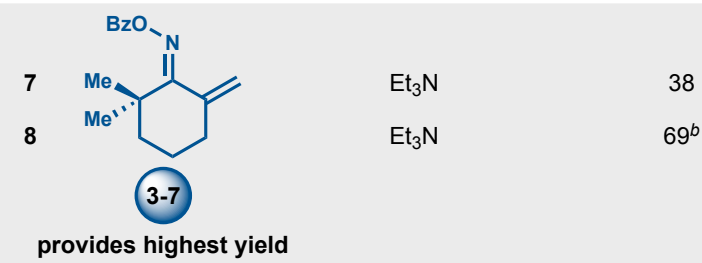

${ }^{a}$ Yield of the crude reaction mixture on $0.1 \mathrm{mmol}$ scale, was determined by ${ }^{1} \mathrm{H}$ NMR using 1,3,5-trimethoxybenzene as an internal standard. ${ }^{b} 16 \mathrm{~h}$.

yield over the two-step vicinal difunctionalization of enone 610. ${ }^{39}$ Modification of the oxidant to $\mathrm{NaNO}_{2}$ or tetrabutylammonium nitrite resulted in diminished yields. Methylenation of the $\alpha$-keto oxime afforded exocyclic alkene 6-12 in excellent yield (77\%) when salt-free methyl Wittig conditions were employed. Employing alternative methylenation conditions resulted in substrate decomposition. Subsequent acylation of the oxime provided a library of oxime coupling partners with varied steric and electronic properties (3-7, and 6-13 to 6-15) in 76-89\% yield.

Next, we began our investigation of the Liebeskind pyridine synthesis $^{7 \mathrm{c}}$ toward forming the central ring in xylogranatopyridine $\mathrm{B}$ (1-1) (Scheme 7). This pyridine synthesis entails an initial $\mathrm{C}-\mathrm{N}$ bond formation followed by an oxidative $6 \pi-$ electrocyclization to reveal the pyridine substructure. Subjection of a pentafluorobenzoyl oxime (6-13) and a vinyl boronic acid (7-1) to the reaction conditions previously reported by Liebeskind and co-workers (Scheme 7A) ${ }^{7 \mathrm{c}}$, the tricyclic pyridine product 7-2 was formed in moderate yield (24\%, entry 1$)$. The vinyl boronic acid employed for this transformation could be synthesized in four steps from 1,3-cyclohexanedione (62). ${ }^{40}$ Modification of the nucleophilic coupling fragment to the readily accessible $\beta$-stannyl enones (7-3 and 6-1) provided the corresponding pyridine products (7-2 and 4-1) with similar efficiency to that of the boronic acid (7-1), in $23 \%$ and $21 \%$ yield, respectively (entries 2-3). Increasing the structural complexity to stannyl acetate 6-8 resulted in trace 4-9, potentially due to the propensity of this substrate to rapidly undergo deacetylation and retro-aldol (entry 4). Furthermore, employing stannyl dienoate 3-6 led to a $6 \%$ yield of the pyridine product 3-1 (entry 5).

During the optimization of the nucleophilic coupling fragment, it was postulated that the addition of base or modification of the acyl group on the oxime may have a beneficial effect (Scheme 7B). When pyridine was added to the reaction mixture, the desired reaction was inhibited, while the formation of other side products still persisted (entry 2). The addition of triethylamine greatly suppressed the undesired reactivity, but only $9 \%$ yield of 4-1 was observed (entry 3 ). Subjecting acetylated oxime (6-15) to the standard conditions prevented side product formation, but only trace product was obtained (entry 4); however, the addition of triethylamine increased the yield of 4-1 to $13 \%$ (entry 5). Alteration of the oxime coupling partner to the pivalate (6-14) resulted in a modest increase in the yield ( $18 \%$, entry 6$)$. Finally, when the oxime benzoate (3-7) was utilized in the Liebeskind pyridine synthesis, the desired product (4-1) was obtained in 38\% yield (entry 
Scheme 8. Reaction Conditions Optimization of the Liebeskind Pyridine Synthesis

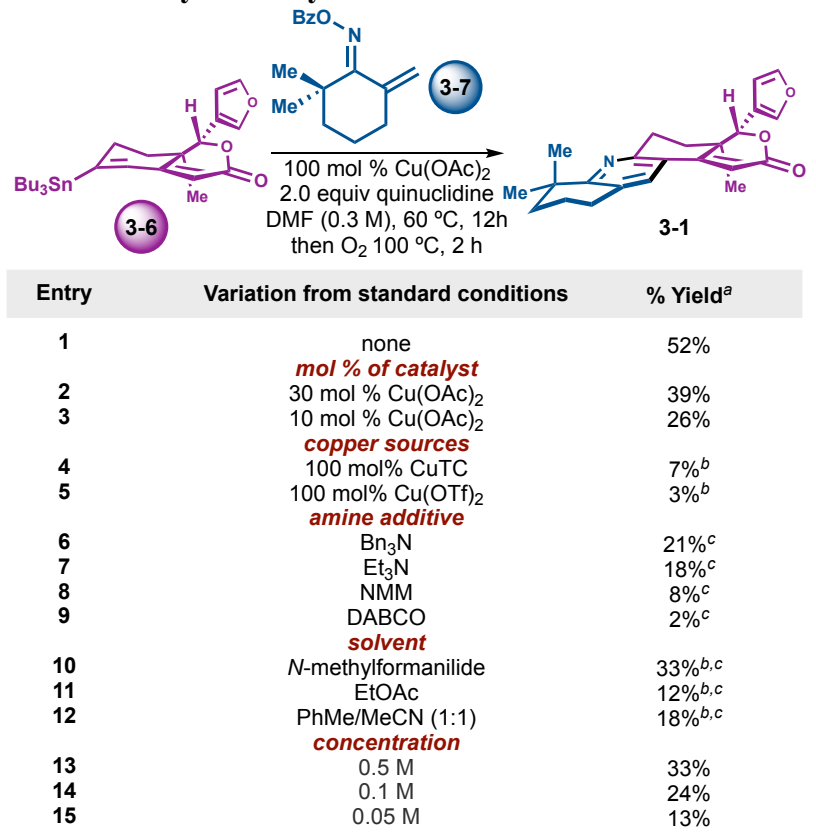

${ }^{a}$ Yield of the crude reaction mixture on $0.1 \mathrm{mmol}$ scale, was determined by ${ }^{1} \mathrm{H}$ NMR using 1,3,5-trimethoxybenzene as an internal standard. ${ }^{b} .0$ equiv $\mathrm{Et}_{3} \mathrm{~N}$ was utilized instead of quinuclidine. ${ }^{c} 30 \mathrm{~mol} \%$ of $\mathrm{Cu}(\mathrm{OAc})_{2}$ was used.

7). Through extending the reaction time to 16 hours, a $69 \%$ yield of the tricyclic pyridine (4-1) was furnished (entry 8).

To maximize synthetic convergence, we turned our attention to reinvestigating the challenging pyridine synthesis between the stannyl dienoate (3-6) and the oxime benzoate (37). After extensive interrogation of reaction conditions (Scheme 8), we determined that the use of stoichiometric $\mathrm{Cu}(\mathrm{OAc})_{2}$ coupled with quinuclidine as an amine additive resulted in a substantially greater yield of pyridine 3-1 (52\%, entry 1)..$^{41,42}$ Decreasing the amount of $\mathrm{Cu}(\mathrm{OAc})_{2}$ had a deleterious effect on the product yield (entries 2-3). Additionally, a variety of common copper salts such as $\mathrm{CuTC}, \mathrm{Cu}(\mathrm{OTf})_{2}$, etc., were examined in this reaction, which only produced minimal 3-1 (entries 4-5). Employing other transition metals (e.g., Pd or $\mathrm{Ni})^{43}$ were not effective in accessing 3-1. Replacing quinuclidine with various trialkylamines, including $\mathrm{Bn}_{3} \mathrm{~N}, \mathrm{Et}_{3} \mathrm{~N}$, NMM or DABCO, greatly decreased the yields (entries 6-9). Aside from amine additives, phosphines, fluoride sources, and other bases were also parameters that were screened, but these approaches all resulted in diminished yields of 3-1 (not shown). Modification of solvents to, e.g., $N$-methylformanilide, EtOAc, $\mathrm{PhMe} / \mathrm{MeCN}$, or adjustment of concentration also led to eroded yields of the pyridine product (entries 1015).

Completion of the Synthesis of Xylogranatopyridine B. With a scalable route to the tetracyclic carbon framework of xylogranatopyridine B (1-1) established, we explored the siteselective benzylic oxidation of the more electron-rich metaposition $(\mathrm{C} 1)$ over the more electron-deficient ortho-position (C11) (Scheme 9). An extensive examination of oxidants identified a $\mathrm{Cr}(\mathrm{V})$-complex, recently used by Baran for allylic oxidation, ${ }^{44}$ as the optimal reagent for oxidation of the C1-benzylic position. The use of 10 equivalents of $\mathrm{Cr}(\mathrm{V})$ provided benzylic ketone 9-1 in $56 \%$ yield with $27 \%$ recovered 3-1.
Although these chromium-mediated oxidation conditions provided the highest yield of 9-1 on up to $0.5 \mathrm{~g}$ scale, an alternative approach was employed on larger scales.

In order to improve the scalability of the C1-selective benzylic oxidation, conditions involving the generation of a tertbutoxy radical from various metal salts were investigated. It was determined that treatment of 3-1 with catalytic $\mathrm{Mn}(\mathrm{OAc})_{3}$ in the presence of excess $t$-BuOOH provided 9-1 in $33 \%{ }^{1} \mathrm{H}$ NMR yield, which was ultimately the most scalable set of conditions. On two-gram scale, 9-1 was obtained in 34\% yield along with $47 \%$ of the recovered starting material (3-1). Altering the metal salt had little effect on the yield (Scheme 9, Table 1). Stahl's Co-catalyzed oxidation system ${ }^{45}$ resulted in a good yield of 9-1, whereas the $\mathrm{Cu}$-catalyzed system $^{46}$ only gave decomposition (see Supporting Information Scheme SI1 for more details). Utilizing $\mathrm{Pd}(\mathrm{OAc})_{2}$ and benzoquinone or Van Humbeck's conditions ${ }^{47}$ failed to form any desired product. Additional established strategies to oxidize the benzylic position of heterocycles, such as $\mathrm{SeO}_{2}, \mathrm{IBX}^{48}$ or other Cr-based oxidants, resulted in poor conversion and decomposition.

An $\alpha, \beta$-dehydrogenation was conducted on benzylic ketone 9-1, using the conditions previously described by our laboratory with allyl diethyl phosphate (9-2) as the oxidant, ${ }^{32}$ to provide enone 9-3 in 67\% yield on one-gram scale (Scheme 9). Enone 9-3 was engaged by a silyl-ketene acetal (9-4) in the presence of catalytic TBSOTf to furnish the Mukaiyama-Michael product 9-5 as a 1:1 mixture of diastereomers at C5. Attempts to improve the diastereoselectivity of the 1,4-addition through a stepwise malonate addition ${ }^{49}$ or Corey-Chaykovsky cyclopropanation ${ }^{50}$ were unsuccessful.

A fluoride-mediated methylation of 9-5, initiated by tetramethyl ammonium fluoride (TMAF), provided xylogranatopyridine $\mathrm{B}$ (1-1) in $23 \%$ yield and a 1:1 mixture of diastereomers at $\mathrm{C} 10$. Further purification afforded diastereomerically pure xylogranatopyridine $\mathrm{B}$ (1-1) in $11 \%$ yield. The addition of both HMPA and $4 \AA$ molecular sieves as additives were found to be crucial to boost the yield of 1-1 (Scheme 9, Table 2). Although utilizing $\mathrm{BTAF}^{51}$ led to comparable results, employing alternative fluoride sources, such as TBAF, tetrabutylammonium difluorotriphenylsilicate (TBAT), TASF(Et), ${ }^{52}$ CsF, etc., resulted primarily in the desilylated ketone 9-6 (see Supporting Information Scheme SI2 for more details). Attempts to utilize other protocols for the direct conversion of enoxysilanes (9-5) to methyl ketones (1-1), such as Fleming's silyl lithium conditions ${ }^{53}$ or Yamamoto's Lewis-acid mediated methylation methodology, ${ }^{54}$ proved futile as epimerization was observed in all cases. Alkylation of ketone 9-6 was also pursued to access xylogranatopyridine B (1-1). However, only reactive enolates formed from NaHMDS or KHMDS with HMPA as co-solvent provided trace desired product as a 1:1 mixture of diastereomers (Scheme 9, Table 3).

To circumvent the unselective enolate alkylation, cyclopropanation of the diastereomeric enoxysilanes and regioselective opening was pursued (Scheme 9) ${ }^{55,56}$ Simmons-Smith cyclopropanation $^{57}$ of 9-5 proceeded with high diastereoselectivity ( $>20: 1 \mathrm{dr}$ ). In situ deprotection of the intermediate siloxycyclopropane with TBAT provided cyclopropanol in 75\% combined yield as a mixture of C5-epimers, and in 31\% isolated yield as the single desired diastereomer 9-7. The use of Ziese's dimer, $\left[\mathrm{PtCl}_{2}\left(\mathrm{C}_{2} \mathrm{H}_{4}\right)\right]_{2},{ }^{58}$ initiated a regioselective opening of cyclopropanol 9-7 to form xylogranatopyridine B (1-1) in 69\% yield. Remarkably, this protocol avoided the facile epimerization of the highly acidic methyl ketone in 1-1, which was the central challenge with the $\alpha$-methylation approach. Careful 

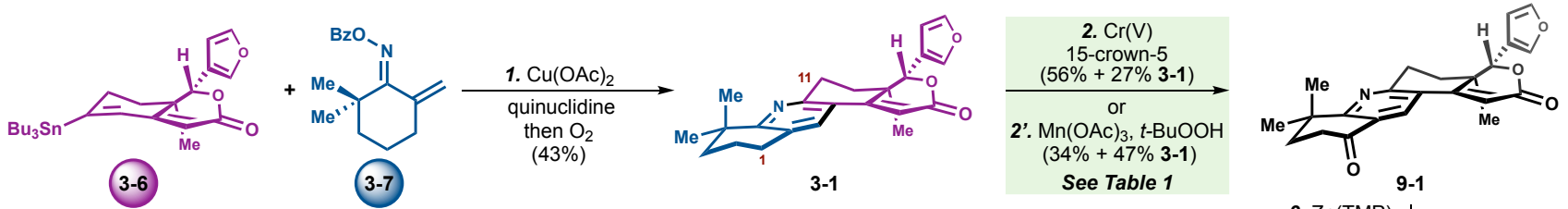

See Table

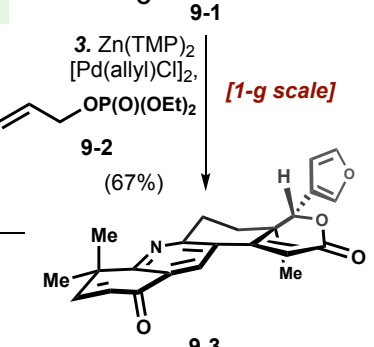

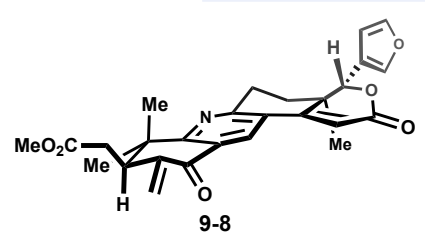

Table 1

Conditions

$\mathrm{Co}(\mathrm{OAc})_{2}, \mathrm{NHP}$

$\mathrm{Pd}(\mathrm{OAc})_{2}, \mathrm{BQ}, 1,4$-dioxane/AcOH

$\mathrm{SeO}_{2}, 1,4$-dioxane/AcOH

IBX, $\mathrm{C}_{6} \mathrm{~F}_{6} / \mathrm{DMSO}$

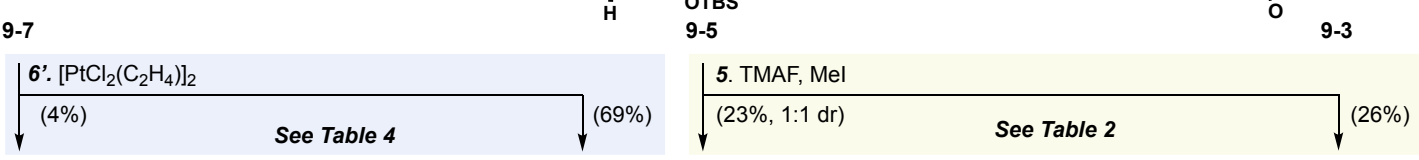
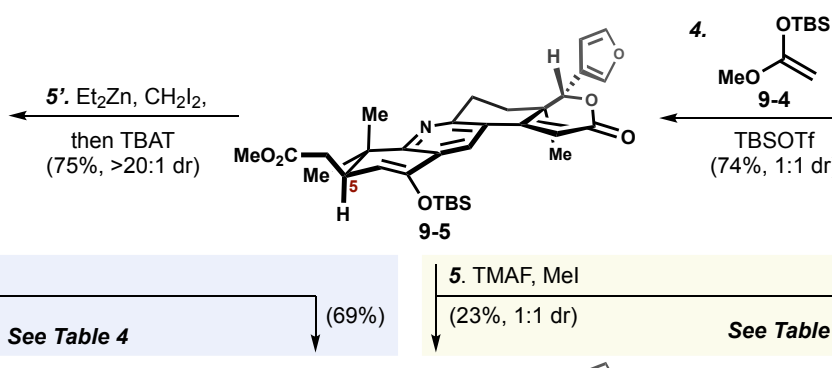

TBSOTf

$(74 \%, 1: 1 \mathrm{dr})$

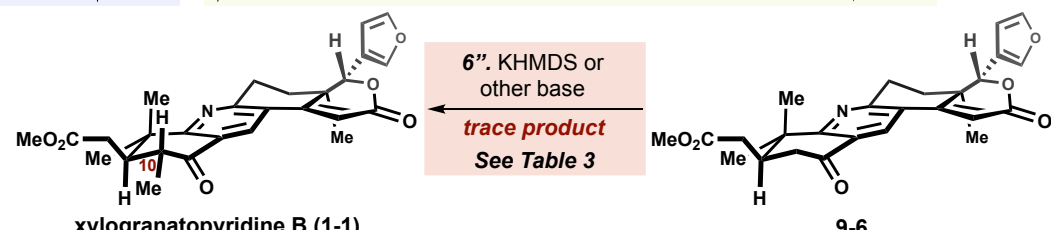

xylogranatopyridine B (1-1)

Table 2

$\%$ Yield $(9-6: 1-1)^{b}$

TMAF, Mel, HMPA, $4 \AA$ MS $\quad 27: 25^{c}$

41 (68) TMAF, Mel, HMPA

0 (8) TMAF, Mel, $4 \AA$ MS

$4(18)$

7 (94)

$39: 13^{c}$

$41: 6^{c}$

$42: 12^{c}$

Table 3
Conditions
LDA, HMPA
NaHMDS, HMPA
KHMDS, HMPA
KHMDS
KOt-Bu, $t$-BuOH

BTAF, Mel, 4Å MS

$24: 25$

${ }^{a}$ Reagents and conditions: (1) $\mathrm{Cu}(\mathrm{OAc})_{2}\left(1.0\right.$ equiv), quinuclidine (2.0 equiv), 3-6 (1.0 equiv), 3-7 ( 1.5 equiv), $60{ }^{\circ} \mathrm{C}, \mathrm{DMF}, 12 \mathrm{~h}$, then $\mathrm{O}_{2}(1$ atm), 43\%; (2) $\mathrm{Cr}(\mathrm{V})=\mathrm{Na}\left[\mathrm{OCr}\left(\mathrm{O}_{2} \mathrm{COC}\left(\mathrm{CH}_{3}\right) \mathrm{C}_{2} \mathrm{H}_{5}\right)_{2}\right]$ (10.0 equiv), 15-crown-5 (0.5 equiv), $75{ }^{\circ} \mathrm{C}, \mathrm{MeCN}, 14 \mathrm{~h}, 56 \%$ 9-1 + 27\% 3-1; (2') $10 \mathrm{~mol} \% \mathrm{Mn}(\mathrm{OAc})_{3} \cdot 2 \mathrm{H}_{2} \mathrm{O}, t-\mathrm{BuOOH}$ (4.0 equiv), $\mathrm{MeCN}, 23^{\circ} \mathrm{C}, 16 \mathrm{~h}, 34 \%$ 9-1 + 47\% 3-1; (3) Zn(TMP) 2 (1.4 equiv), [Pd(allyl)Cl] 2 (5 mol $\%$ ), diethyl allyl phosphate ( 1.2 equiv), $85^{\circ} \mathrm{C}, 1 \mathrm{~h}, 67 \%$; (4) TBSOTf ( 0.05 equiv), 9-4 (1.5 equiv), $\mathrm{CH}_{2} \mathrm{Cl}_{2}, 0$ to $23{ }^{\circ} \mathrm{C}, 0.5 \mathrm{~h}, 74 \%, 1: 1 \mathrm{dr}$ at C5; (5) TMAF (1.5 equiv), MeI (2.0 equiv), $4 \AA \mathrm{MS}, \mathrm{DME},-40$ to $23{ }^{\circ} \mathrm{C}, 1 \mathrm{~h}, 23 \%$ 1-1 (1:1 dr at C10) + 26\% 9-6; (5') Et 2 Zn (2.0 equiv), $\mathrm{CH}_{2} \mathrm{I}_{2}$ (4.0 equiv), 0 to $23^{\circ} \mathrm{C}$, PhMe, $6 \mathrm{~h}$, then TBAT (10.0 equiv) in THF, $12 \mathrm{~h}, 75 \%,>20: 1 \mathrm{dr} ;\left(6^{\prime}\right)\left[\mathrm{PtCl}_{2}\left(\mathrm{C}_{2} \mathrm{H}_{4}\right)\right]_{2}\left(10 \mathrm{~mol}^{\circ}\right), \mathrm{CH}_{2} \mathrm{Cl}_{2}, 23$ ${ }^{\circ} \mathrm{C}, 5 \mathrm{~h}, 69 \%$ 1-1 $+4 \%$ 9-8. ${ }^{b}$ Yield of the crude reaction mixture on $0.01 \mathrm{mmol}$ scale, was determined by ${ }^{1} \mathrm{H}$ NMR using $1,3,5$-trimethoxybenzene as an internal standard. Conversion of starting material in parenthesis. ${ }^{c} 1: 1 \mathrm{dr} .{ }^{d}$ Reaction mixture was heated to $100{ }^{\circ} \mathrm{C}$ for $12 \mathrm{~h} .{ }^{e} \mathrm{Reaction}$ mixture was heated to $60^{\circ} \mathrm{C}$. ${ }^{f}$ Reaction was conducted at $23{ }^{\circ} \mathrm{C}$.

examination of the reaction of 9-7 with Ziese's dimer showed a minor side product was produced in $4 \%$ yield, which was characterized as the exocyclic enone 9-8. This enone side product (9-8) may arise from initial isomerization of the cyclopropane to the allylic alcohol,${ }^{55}$ and subsequent aerobic oxidation to the enone.

While Pd-catalyzed cyclopropane opening conditions only resulted in low conversion to the undesired enone side product (9-8) without any formation of the desired product (1-1), ${ }^{59}$ acid-catalyzed cyclopropane opening conditions, such as Amberlyst $15^{60}$ led to partial decomposition of the starting material 9-7 (Scheme 9, Table 4). Treatment of 9-7 with $\mathrm{TsOH}^{61}$ gave the desired product (1-1) as a 1:1 mixture of $\mathrm{C} 10$ diastereomers in low yield. This result was attributed to the highly epimerizable $\alpha$-position and the inability of the methyl ester containing substituent to control the facial selectivity of protonation. Zinc-mediated cyclopropanol opening conditions afforded enone (9-8) as the sole product in $16 \%$ yield, ${ }^{62}$ and radical opening conditions furnished a complex mixture of products (see Supporting Information Scheme SI3 for more details). ${ }^{63}$ Direct acid-catalyzed opening of the siloxycyclopro- panol was also attempted (not shown). However, xylogranatopyridine $\mathrm{B}$ (1-1) was formed as a minor product and a $1: 1$ mixture of diastereomers. Additional commonly employed cyclopropane opening conditions, such as $\mathrm{HF}$-pyridine, $\mathrm{NaOMe}$, and $\mathrm{Pd} / \mathrm{C}$-catalyzed hydrogenation ${ }^{64}$ all suffered from poor regioselectivity in this context.

The evolution of strategies toward the eleven-step synthesis of xylogranatopyridine B (1-1) demonstrated that the key to the development of this efficient synthetic route was the early introduction of the pyridine nitrogen, and the highly convergent nature of the fragment coupling approach. An enabling selective late-stage benzylic oxidation, followed by vicinal difunctionalization allowed for the installment of the remaining requisite functionalities in 1-1.

Synthesis of Bislactone Limonoid Alkaloids. With a viable route to xylogranatopyridine B (1-1) established, the synthesis of more structurally complex bislactone limonoids, such as granatumine A (1-2), were pursued. In addition to the characteristic central pyridine substructure, the bislactone limonoid alkaloids contain a lactone moiety appended onto the limonoid B-ring. Based on the speculated biosynthetic hypothesis on how the limonoid alkaloids arise, ${ }^{3,4}$ we reasoned that 


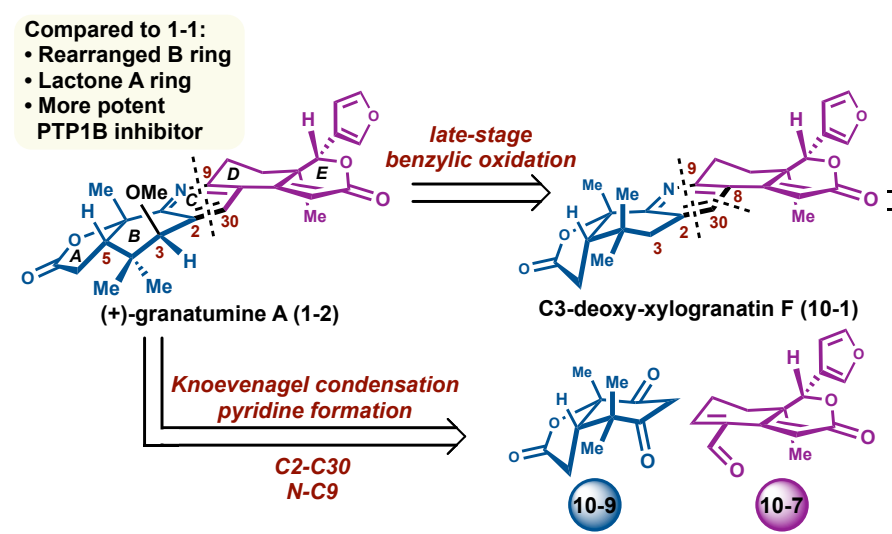

granatoine (1-4) may be structurally misassigned, as the epimerization of the $\mathrm{C} 5$ position is not likely to occur. Therefore, we turned to the total synthesis of this class of limonoids to help resolve this issue. In addition, the bislactone limonoid alkaloids were especially compelling as it is these members that were reported to exhibit modest PTP1B inhibition. ${ }^{3}$

Our general retrosynthetic logic toward the bislactone alkaloids entailed the fragment coupling and tandem pyridine synthesis of an AB- and DE-fragment (Scheme 10), akin to our approach to xylogranatopyridine B (1-1). It was speculated that an analogous late-stage benzylic oxidation of C3-deoxyxylogranatin F (10-1) could introduce the requisite C3-oxidation state after unifying the two components together. Several strategies were considered to allow for expedited access to this core architecture (10-1). A Liebeskind pyridine synthesis (cf. Scheme 8-9), ${ }^{7 \mathrm{c}}$ between stannane 3-6 and oxime 10-2 could furnish C3-deoxy-xylogranatin F (10-1) directly. An alkylation approach was also considered between allylic bromide 10-3 and $\alpha$-sulfonyl oxime 10-6, which after sulfone elimination and $6 \pi$-electrocyclization, could form 3-deoxy-xylogranin F (10-1). Alternatively, by swapping the $\mathrm{R}^{1}$ and $\mathrm{R}^{2}$ substituent on the two fragments, a polarity-reversed alkylation sequence between allylic sulfone 10-4 and $\alpha$-bromo oxime 10-5 could be envisaged. Complementary approaches involving a Mukaiyama aldol between aldehyde 10-7 and enoxysilane 10-8 followed by condensation, or a Knoevenagel condensation between aldehyde 10-7 and 1,3-diketone 10-9, which would allow for early introduction of the $\mathrm{C} 3$-oxidation state, were also imagined to assemble the core structure in 1-2 after condensation of an ammonia equivalent and $6 \pi$-electrocyclization.

Attempted Synthesis of Granatumine A by Liebeskind Pyridine Synthesis. Retrosynthetically, we extrapolated that granatumine A (1-2) may be accessed through similar late-stage benzylic oxidation strategy (Scheme 11A), analogous to that in the synthesis of xylogranatopyridine $\mathrm{B}$ (c.f. Scheme 6A). The central pyridine could be forged by a Liebeskind pyridine synthesis between stannane fragment 3-6 and oxime-lactone 10-2. ${ }^{7 \mathrm{c}}$ It was conjectured that 10-2 could be further derived from simple commercially available terpene building-blocks (11-1).

The optimal starting unit for the oxime fragment was $\alpha$-ionone (11-1), a widely available terpene building block, ${ }^{65}$ as it possesses many of the necessary structural features and oxidation states which are present in the oxime coupling fragment (10-2). One challenge with employing $\alpha$-ionone (11-1) is that it is available as the racemate, and thus would need to be resolved prior to the fragment union. Although there are copious

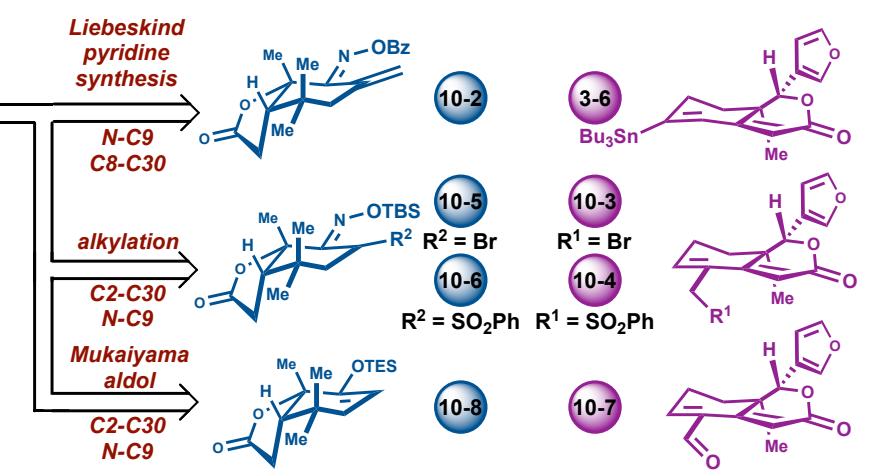

stepwise routes to access enantioenriched $\alpha$-ionone (11-1), ${ }^{66}$ we regarded a direct kinetic resolution as optimal for an expedited synthesis of 11-2. The viability of this approach was guaranteed by a previously reported synthesis of (-)-epoxy- $\alpha$ ionone (11-2) via lipase-resolution, albeit over a five-step sequence (Scheme 11B). ${ }^{67}$

The attempted synthesis of the oxime fragment commenced with kinetic resolution of $\alpha$-ionone (11-1) using Jacobsen's commercially available $(S, S)$-Mn-Salen epoxidation catalyst, 4-PPNO, and buffered bleach as the terminal oxidant to provide (-)-11-2 in 43\% yield, 89:11 er, and 10:1 dr on 100 gram scale (Scheme 11B). ${ }^{68,69,70}$ Examination of alternative metal Salen catalysts or oxidants resulted in diminished yield and er. $^{71}$ Additionally, Shi epoxidation conditions failed to convert 11-1 to 11-2. ${ }^{72}$

A hydrosilylation of the enone functionality in 11-2 with $[\mathrm{Rh}(\mathrm{COD})(\mathrm{OH})]_{2}$ and phenyldimethylsilane afforded enoxysilane 11-3 in $89 \%$ yield on decagram scale. ${ }^{73}$ Replacement of phenyldimethylsilane with triethylsilane resulted in diminished yield, while utilizing $\left[\mathrm{RhH}\left(\mathrm{PPh}_{3}\right)_{4}\right]$ as the catalyst completely suppressed the desired reactivity (Scheme 11, Table 1) ${ }^{74}$ Other transition metal-catalyzed or -mediated hydrosilylation conditions, such as those invovling Stryker's reagent ${ }^{75}$ Karstedt's catalyst, ${ }^{76}$ or Pd-catalyzed conditions, ${ }^{77}$ afforded the desired product (11-3) in decreased yields. Subjection of enoxysilane 11-3 to ozonolytic oxidative cleavage conditions followed by addition of Jones reagent resulted in 11-5 in 51\% yield. The product 11-5 may arise from cyclization of the carboxylic acid onto a tertiary carbocation (11-4). This pathway is suggested as retention of stereochemistry is observed, which is presumably due to geometric constraints that preclude an $\mathrm{S}_{\mathrm{N}} 2$-type epoxide opening. ${ }^{78}$ Treatment of 11-5 with Böhme's salt ${ }^{21}$ gave rise to an intermediate ammonium salt (11-6), and after $\beta$-elimination an unstable exocyclic enone intermediate 11-7 was observed. Enone 11-7 was characterized as a crude mixture of compounds and was found to decompose rapidly while neat, or in $\mathrm{CDCl}_{3}$ with a half-life of approximately two hours at room temperature.

Condensation of 11-7 to form oxime coupling partner 10-2 with $O$-benzoylhydroxylamine ${ }^{79}$ or related hydroxylamines were unsuccessful, and provided complex mixtures of products. The side products may arise as a result of competitive aza-Michael and other side pathways due to the highly electrophilic enone $\beta$-position. Various additional strategies to reach 10-2 were also investigated unsuccessfully, including formation of an isoxazole or Michaelis-Arbuzov rearrangement ${ }^{80}$ on the $\alpha$-bromo oxime and subsequent Horner- 
Scheme 11. First-Generation Synthetic Effort Toward (+)-Granatumine A Through Liebeskind Pyridine Synthesis ${ }^{a}$
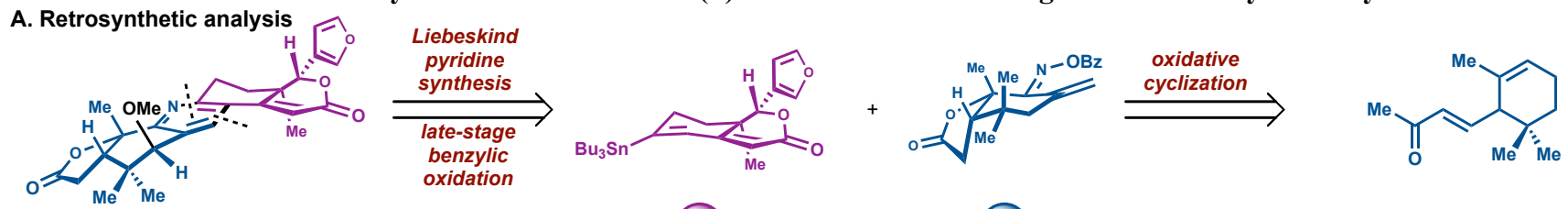

(+)-granatumine A (1-2)

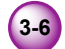

11-1
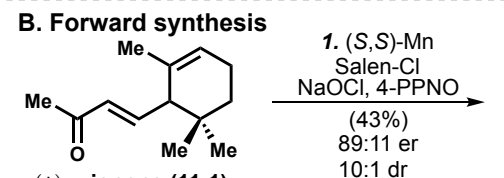

$( \pm)$ - $\alpha$-ionone (11-1)

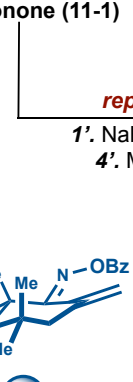

reported resolution of $\alpha$-ionone

$\mathrm{NaBH}_{4}, 2^{\prime}$. $\mathrm{Ac}_{2} \mathrm{O}, 3^{\prime}$ '. lipase resolution
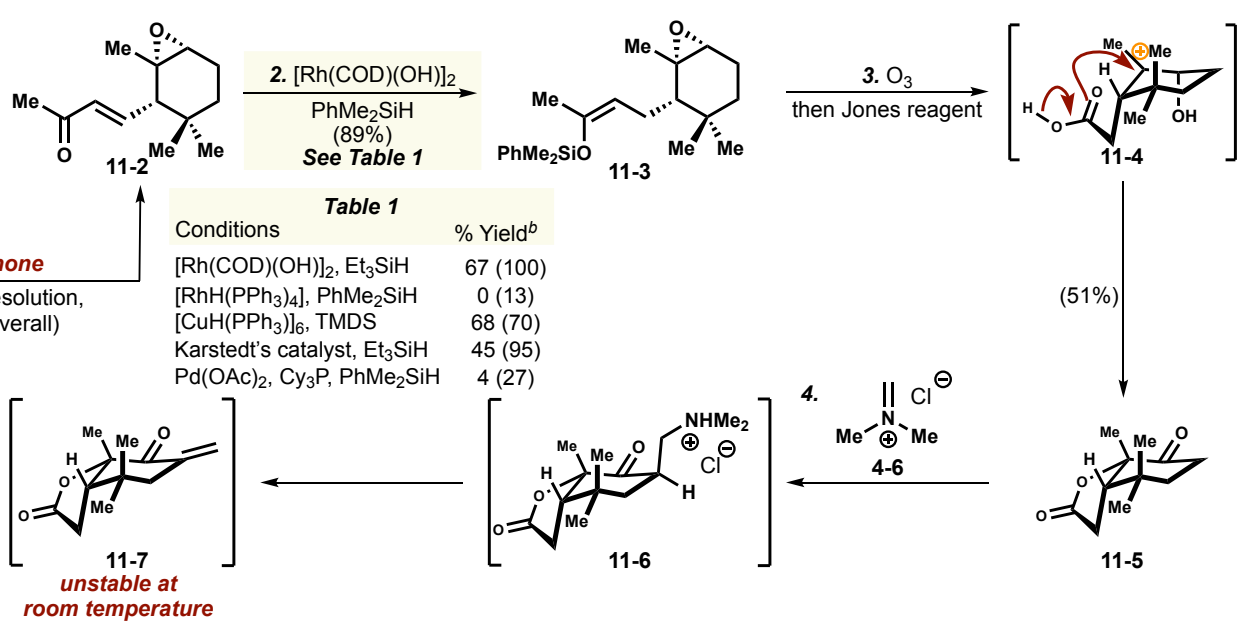

Table 1

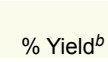

$67(100)$

$\begin{array}{lr}\mathrm{Rh}(\mathrm{COD})(\mathrm{OH})]_{2}, \mathrm{Et}_{3} \mathrm{SiH} & 67(100) \\ & 0(13)\end{array}$ $\left[\mathrm{CuH}\left(\mathrm{PPh}_{3}\right)\right]_{6}, \mathrm{TMDS} \quad 68(70)$ Karstedt's catalyst, $\mathrm{Et}_{3} \mathrm{SiH} \quad 45(95)$ $\mathrm{Pd}(\mathrm{OAc})_{2}, \mathrm{Cy}_{3} \mathrm{P}, \mathrm{PhMe}_{2} \mathrm{SiH} \quad 4(27)$
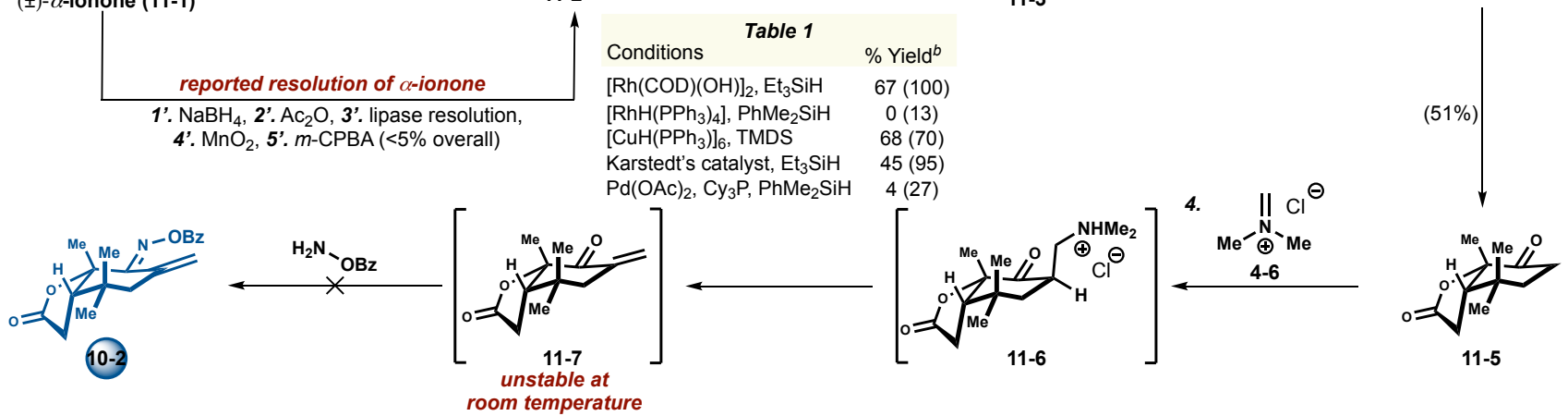

${ }^{a}$ Reagents and conditions: (1) $5 \mathrm{~mol} \%(S, S)-(+)-N, N^{\prime}$-Bis(3,5-di-tert-butylsalicylidene)-1,2-cyclohexanediaminomanganese(III) chloride, 4phenylpyridine- $N$-oxide (5 mol \%), aq. $\mathrm{NaOCl}$ (1 equiv), $\mathrm{CH}_{2} \mathrm{Cl}_{2}, 0$ to $23{ }^{\circ} \mathrm{C}, 43 \%, 89: 11 \mathrm{er}, 10: 1 \mathrm{dr} ;(2) 1 \mathrm{~mol} \%[\mathrm{Rh}(\mathrm{COD})(\mathrm{OH})]_{2}$, $\mathrm{PhMe}_{2} \mathrm{SiH}$ (1.3 equiv), THF, 23 to $60^{\circ} \mathrm{C}, 2 \mathrm{~h}, 89 \%$; (3) $\mathrm{O}_{3}$, acetone, $-78^{\circ} \mathrm{C} 0.5 \mathrm{~h}$, then Jones reagent $\left(2.0\right.$ equiv), 0 to $23{ }^{\circ} \mathrm{C}, 2 \mathrm{~h}, 51 \%$; $(4)$ $\mathrm{N}, \mathrm{N}$-dimethylmethyleneiminium chloride (1.1 equiv), MeCN, $70{ }^{\circ} \mathrm{C}, 1 \mathrm{~h} .{ }^{b}$ Yield of the crude reaction mixture on $0.01 \mathrm{mmol}$ scale, was determined by ${ }^{1} \mathrm{H}$ NMR using 1,3,5-trimethoxybenzene as an internal standard. Conversion of starting material in parenthesis.

Wadsworth-Emmons reaction. Due to the challenge of synthesizing the exocyclic $\alpha, \beta$-unsaturated oxime (10-2), alternative strategies for the formation of the central pyridine were pursued.

Attempted Fragment Coupling by Alkylation. As installation of the exocyclic $\alpha, \beta$-unsaturated oxime substructure (10-2) did not appear to be feasible, our retrosynthetic analysis was revised to construct the $\mathrm{C} 2-\mathrm{C} 30$ connection instead of the C8-C30 connection. It was envisioned that the pyridine could be assembled by an alkylation between a modified oxime (105 or 10-6) and a dienoate fragment (10-3 or 10-4), followed by a desulfurization and $6 \pi$-electrocyclization cascade (Scheme 12A). The aforementioned dienoate fragment (10-3 or 10-4) could come from a selective allylic functionalization of $(+)-$ pyroangolensolide (12-1), a degraded limonoid, which in turn could be synthesized from three simple building blocks (4-2, 4-3 and 12-2). The oxime fragment (10-5 or 10-6) could arise from functional group manipulation of the previously described ketone 11-5.

The synthesis of the dienoate fragment began with the dehydrogenation of ketone 12-2 (Scheme 12B). Surveying known procedures for the production of 2,6-dimethylcyclohex-2-en-1-one (e.g., by Birch reduction or bromination/elimination) resulted in irreproducible results on large scale. However, our laboratory's Pd-catalyzed ketone dehydrogenation methodology ${ }^{32 \mathrm{~d}}$ smoothly converted ketone $\mathbf{1 2 - 2}$ to the corresponding enone $\mathbf{1 2 - 3}$ in $76 \%$ yield on 100 -gram scale. This practical ketone dehydrogenation condition allowed for the use of inexpensive allyl acetate as oxidant and LDA as base. ${ }^{81}$ A diastereoselective aldol reaction with 3-furaldehyde (4-3) was performed on the resulting enone (12-3), which led to alcohol 12-4 in 82\% yield. An acylative kinetic resolution with (+)-tetramisole (12-5) ${ }^{37,82}$ was conducted on benzylic alcohol
$( \pm)-\mathbf{1 2 - 4}$, forming acetate $(+)-\mathbf{1 2 - 6}$ in $41 \%$ yield and $91: 9$ er with $46 \%$ recovered $(-)-12-4$. The unreacted enantiomer could be recycled to 12-3 in the presence of $\mathrm{K}_{2} \mathrm{CO}_{3}$ and $\mathrm{MeOH}$ in $85 \%$ yield. A total yield of $57 \%$ of $(+)-12-6$ could be obtained after one round of recycling. An intramolecular aldol occurred upon treatment of 12-6 with LiHMDS, and dehydration of the resulting alcohol with Burgess reagent formed the degraded limonoid (+)-pyroangolensolide (12-1) in 80\% yield. The absolute configuration of 12-1 was confirmed by X-ray diffraction. $^{2 \mathrm{~g}}$

The conversionof $(+)$-pyroangolensolide (12-1) to $(+)$-azedaralide (12-7) by site-selective allylic oxidation ${ }^{83}$ is an established synthetic challenge ${ }^{84}$ Previous attempts to directly convert pyroangolensolide to 12-7 using commonly encountered allylic oxidation conditions, such as $\mathrm{SeO}_{2} / t-\mathrm{BuOOH}$, $\mathrm{Pd}(\mathrm{OAc})_{2}$, and $\mathrm{Hg}(\mathrm{OAc})_{2}$, resulted only in trace 12-7. ${ }^{84}$ After surveying a range of allylic oxidation conditions, we discovered that azedaralide (12-7) was formed smoothly upon treatment of 12-1 with $\mathrm{SeO}_{2}$ and $\mathrm{Na}_{2} \mathrm{HPO}_{4}$, which resulted in $31 \%$ yield of 12-7, 28\% yield of aldehyde 10-7, and 27\% recovered starting material (12-1). Modification of these conditions with other additives resulted in a diminished yield of 12-7 (see Supporting Information Scheme SI4 for more details). Treatment of 12-7 with Dess-Martin periodinane formed aldehyde 10-7 in $52 \%$ yield over two steps. Alternatively, bromination of allylic alcohol 12-7 with $\mathrm{PBr}_{3}$ afforded bromide $\mathbf{1 0 - 3}$ in $43 \%$ yield, which was then manipulated to sulfone 10-4 in $94 \%$ yield upon treatment with $\mathrm{NaSO}_{2} \mathrm{Ph}$.

The preparation of the oxime fragment (10-5 and 10-6) began with a condensation of hydroxylamine on the previously described ketone 11-5 (cf. Scheme 11B). The resulting oxime was silylated, providing a protected oxime (12-8) in $69 \%$ over two steps (Scheme 12C). Bromination of the oxime $\alpha$-position 

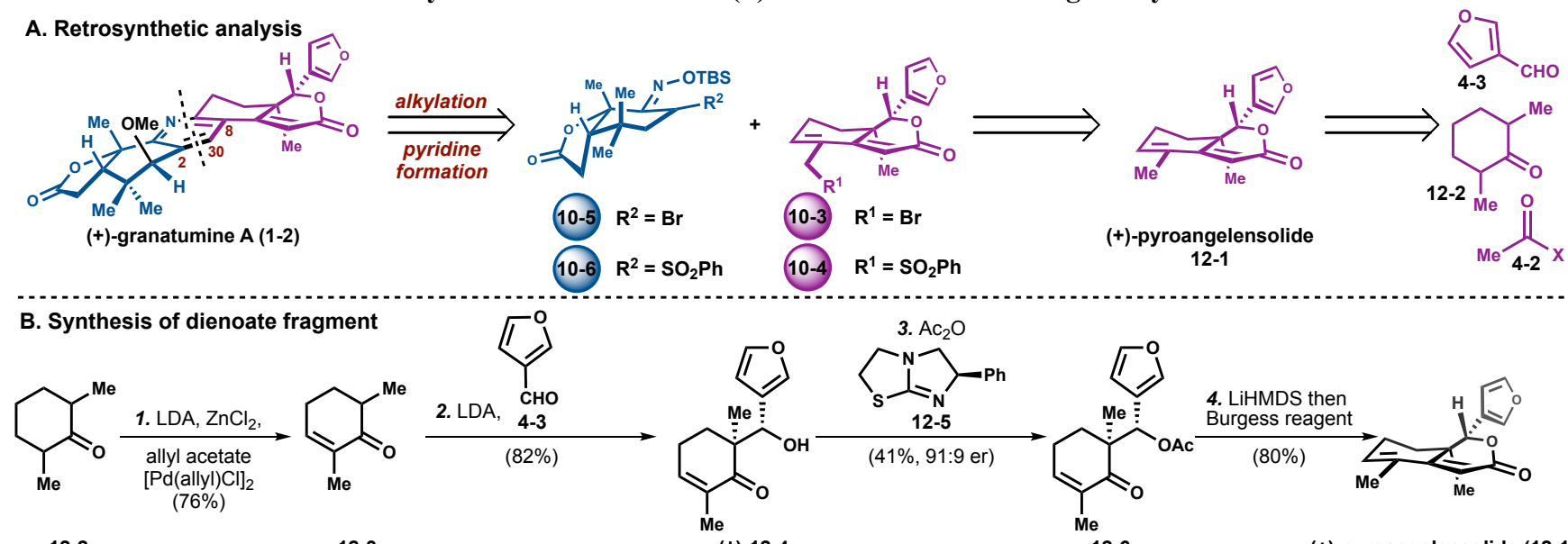

$12-2$

12-3

(士)-12-4

12-6

(+)-pyroangelensolide (12-1)
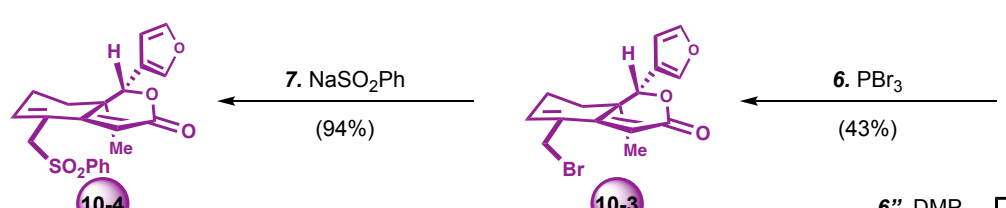

10-4

10-3
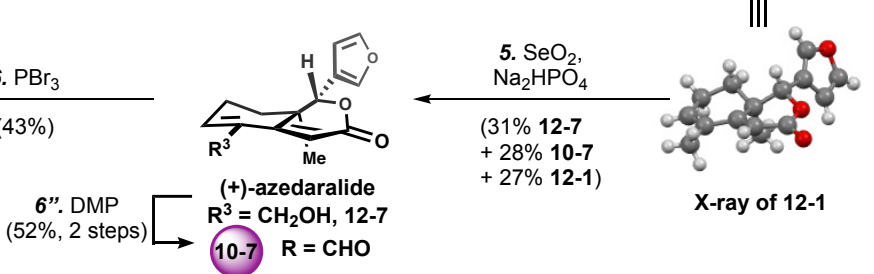

X-ray of 12-1

C. Synthesis of oxime fragment

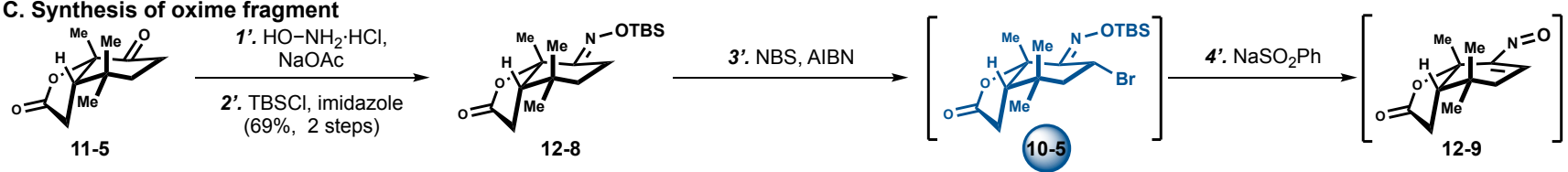

11-5

12-8

$10-5$

$(2: 1 \mathrm{dr})$
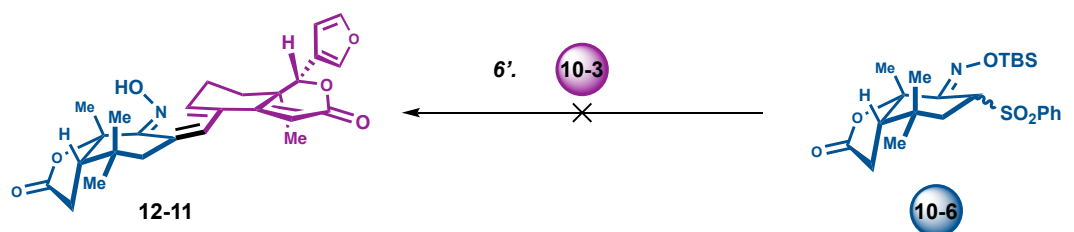

(10-6

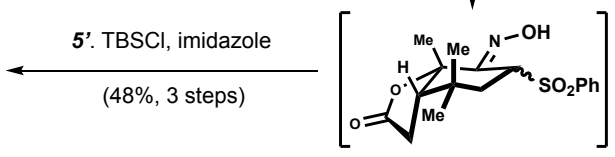

12-10

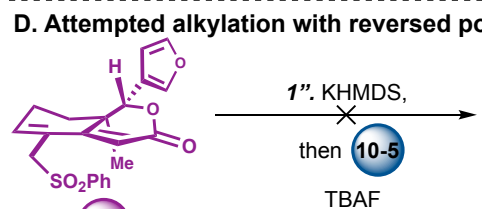

10-4

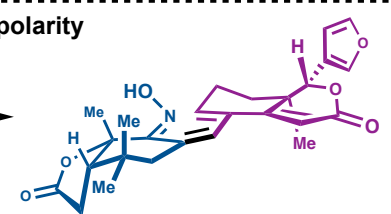

12-11
E. Main side reaction pathway

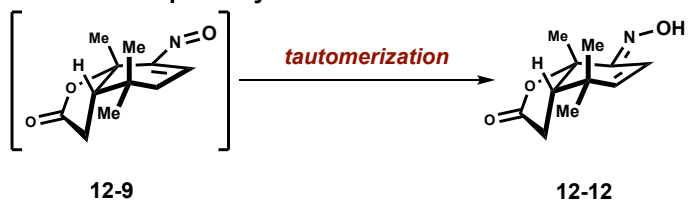

${ }^{a}$ Reagents and conditions: (1) LDA (1.5 equiv), $\mathrm{ZnCl}_{2}\left(2.0\right.$ equiv), $-40{ }^{\circ} \mathrm{C}$, THF, $0.5 \mathrm{~h}$, then allyl acetate $\left(1.2\right.$ equiv), $1 \mathrm{~mol} \%[\mathrm{Pd}(\text { allyl }) \mathrm{Cl}]_{2}$, $60{ }^{\circ} \mathrm{C}, 5 \mathrm{~h}, 76 \%$; (2) LDA (1.2 equiv), 3-furaldehyde (1.2 equiv), $-78{ }^{\circ} \mathrm{C}$, THF, $0.5 \mathrm{~h}, 82 \%$; (3) $10 \mathrm{~mol} \%(+)$-tetramisole (12-5), Ac $2 \mathrm{O}(0.5$ equiv), PhMe, $0{ }^{\circ} \mathrm{C}, 10 \mathrm{~h}, 41 \%$ 12-6 (91:9 er) $+46 \%$ (-)-12-4; (4) LiHMDS (4.0 equiv), -78 to $23{ }^{\circ} \mathrm{C}, 4 \mathrm{~h}$, then Burgess reagent (4.0 equiv), $60{ }^{\circ} \mathrm{C}, 3 \mathrm{~h}, 80 \%$; (5) $\mathrm{SeO}_{2}$ (2.5 equiv), $\mathrm{Na}_{2} \mathrm{HPO}_{4}$ (5.0 equiv), 1,4-dioxane, $100{ }^{\circ} \mathrm{C}, 14 \mathrm{~h}, 31 \% \mathbf{1 2 - 7}+28 \% \mathbf{1 0 - 7}+27 \% \mathbf{1 2 - 1} ;(6) \mathrm{PBr}_{3}(1.2$ equiv), $\mathrm{CH}_{2} \mathrm{Cl}_{2}, 0$ to $23{ }^{\circ} \mathrm{C}, 43 \%$; (6”) Dess-Martin periodinane (1.5 equiv), $\mathrm{CH}_{2} \mathrm{Cl}_{2}, 23{ }^{\circ} \mathrm{C}, 1 \mathrm{~h}, 52 \%$ over two steps; (7) $\mathrm{NaSO}{ }_{2} \mathrm{Ph}$ (1.5 equiv), DMF, $45^{\circ} \mathrm{C}, 1 \mathrm{~h}, 94 \%$; (1') $\mathrm{HO}-\mathrm{NH}_{2} \cdot \mathrm{HCl}$ (2.0 equiv), $\mathrm{NaOAc}$ (1.5 equiv), EtOH, $23^{\circ} \mathrm{C}, 0.5$ h; ( $\left.2^{\prime}\right)$ TBSCl (1.5 equiv), imidazole (3.5 equiv), DMF/CH $\mathrm{CH}_{2} \mathrm{Cl}_{2}$ (1:2), 0 to $23^{\circ} \mathrm{C}, 14 \mathrm{~h}, 69 \%$ over two steps; (3') NBS (1.2 equiv), $\mathrm{AIBN}\left(0.1\right.$ equiv), $\mathrm{CCl}_{4}, 7^{\circ}{ }^{\circ} \mathrm{C} ;\left(4^{\prime}\right) \mathrm{NaSO}_{2} \mathrm{Ph}$ (2.0 equiv), DMF, $45^{\circ} \mathrm{C}, 18 \mathrm{~h}, 2: 1 \mathrm{dr}$; (5') TBSCl (1.5 equiv), imidazole (3.5 equiv), $\mathrm{DMF} / \mathrm{CH}_{2} \mathrm{Cl}_{2}(1: 2), 0$ to $23{ }^{\circ} \mathrm{C}, 14 \mathrm{~h}, 48 \%$ over three steps.

yielded 10-5, which upon subjection to Denmark's conditions formed vinyl nitroso (12-9). ${ }^{85,86}$ Selective 1,4-addition of $\mathrm{NaSO}_{2} \mathrm{Ph}$ to 12-9 provided sulfone 12-10 in 2:1 dr, which was then reprotected as the TBS-oxime 10-6, resulting in a $48 \%$ yield over three steps. The fragment coupling of oxime 10-6 with 10-3 to give 12-11 was attempted with a variety of bases, which resulted only in formation of the $\alpha, \beta$-unsaturated oxime (12-12) as a side product. A Tsuji-Trost type allylation of the $\alpha$-sulfonyl oxime (10-6) was also unsuccessful in delivering the desired product. ${ }^{87}$
To circumvent the reactivity issues presented with alkylation of the $\alpha$-sulfonyl oxime (10-6), we reversed the polarity of the fragments in the coupling step (Scheme 12D). Using Weinreb's conditions, ${ }^{88}$ sulfone 10-4 was deprotonated and added into the $\alpha$-bromo oxime (10-5), which resulted only in formation of the elimination side product (12-12). We suspected that this side product may arise from base-mediated formation of vinyl nitroso compound 12-9, which may undergo an ensuing tautomerization to give rise to 12-12 
Scheme 13. Third-Generation Synthetic Effort Toward (+)-Granatumine A Through Mukaiyama Aldol ${ }^{a}$

A. Retrosynthetic analysis

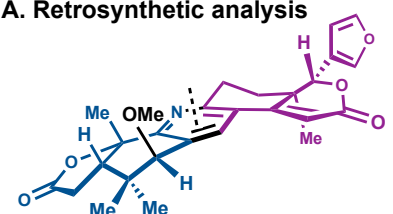

(+)-granatumine A (1-2)

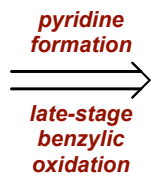

oxidation

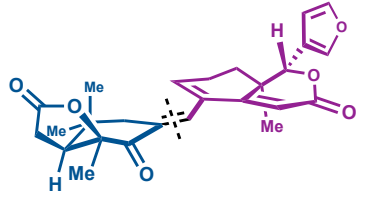

13-1
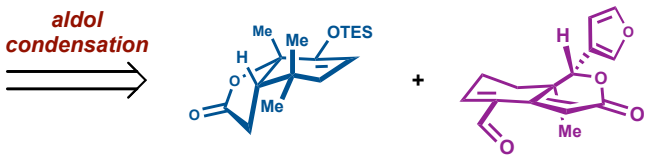

10-7

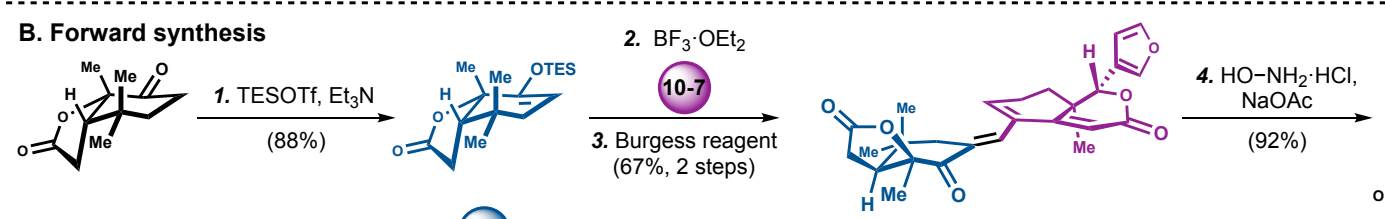

11-5

(10-8)

13-1

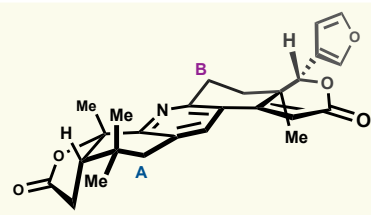

C3-deoxy-xylogranatin $F(\mathbf{1 0 - 1 )}$

3-1

radical $A$ is more stable than radical $B$ by $0.3-0.9 \mathrm{kcal} / \mathrm{mol}$

radical $B$ is more stable than radical A by $2.6-2.8 \mathrm{kcal} / \mathrm{mol}$

carbocation $A$ is more stable than carbocation B by $3.5-5.5 \mathrm{kcal} / \mathrm{mol}$ carbocation $B$ energy is comparable to that of carbocation $A$

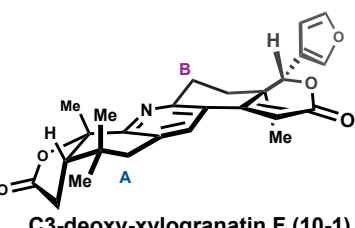

C. Computational investigation ${ }^{b}$

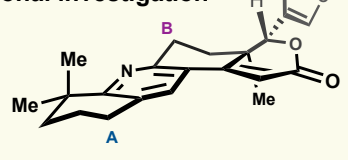

${ }^{a}$ Reagents and conditions: (1) TESOTf (1.2 equiv), $\mathrm{Et}_{3} \mathrm{~N}$ (2.0 equiv), $\mathrm{CH}_{2} \mathrm{Cl}_{2}, 0$ to $23^{\circ} \mathrm{C}, 2 \mathrm{~h}, 88 \%$; (2) 10-7 (1.0 equiv), $\mathrm{BF}_{3} \cdot \mathrm{OEt}_{2}(0.1$ equiv), $\mathrm{CH}_{2} \mathrm{Cl}_{2},-78$ to $23^{\circ} \mathrm{C}$; (3) Burgess Reagent (1.5 equiv), PhMe, $80{ }^{\circ} \mathrm{C}, 1.5 \mathrm{~h}, 67 \%$ over two steps; (4) $\mathrm{HO}-\mathrm{NH}_{2} \cdot \mathrm{HCl}$ (1.5 equiv), $\mathrm{NaOAc}$ (2.0 equiv), EtOH, $80{ }^{\circ} \mathrm{C}, 14 \mathrm{~h}, 92 \% .{ }^{b} \mathrm{UB} 3 \mathrm{LYP} / 6-311++\mathrm{G}(\mathrm{d}, \mathrm{p}) / / \mathrm{UB} 3 \mathrm{LYP} / 6-31+\mathrm{G}(\mathrm{d}, \mathrm{p}), \omega \mathrm{B} 97 \mathrm{x}-\mathrm{D} / 6-311++\mathrm{G}(\mathrm{d}, \mathrm{p}) / / \omega \mathrm{B} 97 \mathrm{x}-\mathrm{D} / 6-31+\mathrm{G}(\mathrm{d}, \mathrm{p})$, and M06-2X/6-311++G(d,p)//M06-2X/6-31+G(d,p) levels of theory were used in the computational evaluation.

(Scheme 12E). Due to the challenges associated with this alkylation step, other approaches to access the central pyridine core were explored.

\section{Mukaiyama Aldol and Attempted Benzylic Oxida-}

tion. We posited that a late-stage introduction of the pyridine nitrogen and the $\mathrm{C} 3$-oxidation state after the fragment coupling could offer an alternative strategic disconnection and preclude the undesired reactivity from the aforementioned oxime fragment (Scheme 13A). The central pyridine could arise from condensation and $6 \pi$-electrocyclization of the dienone moiety in 13-1, which could be accessed via a Mukaiyamaaldol ${ }^{89}$ between the dienoate fragment $\mathbf{1 0 - 7}$ and the enoxysilane fragment 10-8 (Scheme 13A).

With a robust route to the dienoate (10-7) and the keto-lactone (11-5) already established (cf. Scheme 12B and Scheme $11 \mathrm{~B}$, respectively), we turned to synthesizing the enoxysilane (10-8) and pursuing the fragment coupling (Scheme 13B). The enoxysilane fragment (10-8) was prepared by formation of the triethylsilyl enol ether of 11-5. Treatment of 10-8 and dienoate 10-7 with catalytic $\mathrm{BF}_{3} \cdot \mathrm{OEt}_{2}$ initiated a Mukaiyama-aldol reaction, which resulted in an intermediate alcohol. Treatment of the intermediate aldol product with Burgess reagent formed coupling product $13-1$ in $67 \%$ yield over the two steps. Condensation of hydroxylamine onto the ketone functionality led to an aza-triene intermediate, which underwent a $6 \pi$-electrocyclization and loss of water to form C3-deoxy-xylogranatin F (10-1) in excellent yield (92\%). A selective benzylic oxidation of 10-1 at position A, which would be analogous to the benzylic oxidation described in the synthesis of xylogranatopyridine B (1-1), was planned to furnish C3-keto-xylogranatin $\mathrm{F}$ (13-2).

However, after attempting benzylic oxidation conditions, similar to the conditions described in Scheme 9, conversion to 13-2 was not observed. Puzzled by this result, the calculated energies of the radicals and carbocations at positions $\mathrm{A}$ and $\mathrm{B}$ for C3-deoxy-xylogranatin F (10-1) and the corresponding tetracyclic intermediate (3-1) in the xylogranatopyridine $\mathrm{B}$ route were examined (Scheme 13C). Interestingly, DFT calculations at three different levels of theory showed that while carbocation A energy for the tetracyclic intermediate (3-1) en route to xylogranatopyridine $\mathrm{B}$ is $3.5-5.5 \mathrm{kcal} / \mathrm{mol}$ more stable than the corresponding carbocation $\mathrm{B}$, the carbocation $\mathrm{A}$ and $\mathrm{B}$ have comparable energies for the more electron deficient $\mathrm{C} 3$ deoxy-xylogranatin $\mathrm{F}$ (10-1). In addition, while radical $\mathrm{A}$ and $\mathrm{B}$ for 3-1 have similar energies, radical $\mathrm{B}$ for 10-1 is 2.6-2.8 $\mathrm{kcal} / \mathrm{mol}$ more stable than radical A. These calculations indicated that the selectivity would likely favor the position B in the case of 10-1, especially considering steric effects. ${ }^{90}$ That said, initial attempts did not lead to either oxidation product for the more deactivated substrate. Therefore, we developed alternative plans with early introduction of the $\mathrm{C} 3$ oxidation state.

Synthesis of GA by a Pyran-to-Pyridine Conversion. In order to install the necessary oxidation state prior to pyridine formation, a Knoevenagel condensation strategy was considered, in which the requisite $\mathrm{C} 3$-alcohol could be obtained after a selective ketone reduction. The resulting $2 \mathrm{H}$-pyran (15-1) from the Knoevenagel condensation and spontaneous oxa- $6 \pi$ electrocyclization may serve as a protecting group to differentiate the two ketones for reduction (Scheme 15A). Furthermore, the following $2 \mathrm{H}$-pyran to pyridine conversion would allow for construction of the tetrasubstituted pyridine core bearing the desired benzylic alcohol (Scheme 15A). This approach would retrosynthetically involve aldehyde 10-7 and 1,3-diketone 10-9. As a scalable route to the 10-7 had already been achieved, as discussed in Scheme 12B, we focused on developing an efficient route to 1,3-diketone 10-9. Several approaches were examined to synthesize the challenging 1,3- 
Scheme 14. Synthetic Approaches to the 1,3-Diketone Fragment $^{a}$

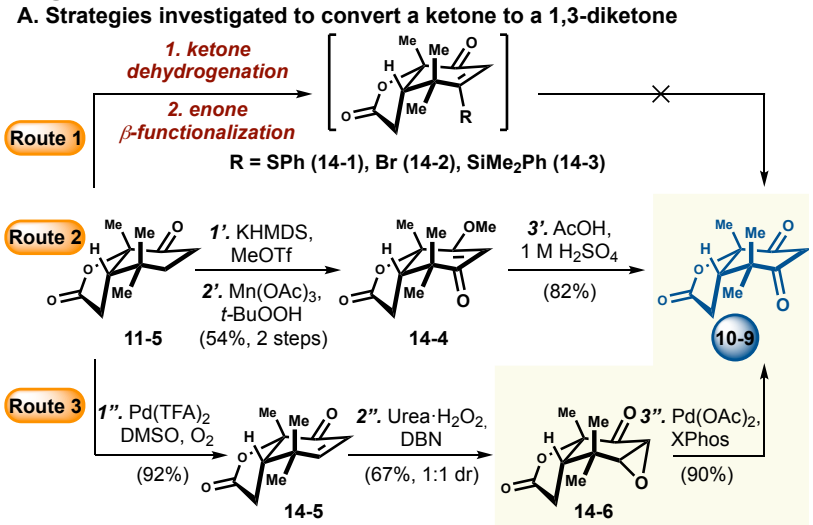

B. Optimization of the epoxyketone rearrangement

\begin{tabular}{|c|c|c|c|}
\hline Entry $^{b}$ & Catalyst & Ligand & $\%$ Yield $^{c}$ \\
\hline \multicolumn{4}{|c|}{ reported conditions } \\
\hline $1^{d}$ & $5 \mathrm{~mol} \% \mathrm{Pd}\left(\mathrm{PPh}_{3}\right)_{4}$ & $5 \mathrm{~mol} \%$ dppe & $0(19)$ \\
\hline \multicolumn{4}{|c|}{ ligand screen } \\
\hline 2 & $5 \mathrm{~mol} \% \mathrm{Pd}(\mathrm{OAc})_{2}$ & $5 \mathrm{~mol} \%$ dppe & $0(24)$ \\
\hline 3 & $5 \mathrm{~mol} \% \mathrm{Pd}(\mathrm{OAc})_{2}$ & $5 \mathrm{~mol} \% \mathrm{PPh}_{3}$ & $0(9)$ \\
\hline 4 & $5 \mathrm{~mol} \% \mathrm{Pd}(\mathrm{OAc})_{2}$ & $5 \mathrm{~mol} \%$ rac-BINAP & $79(99)$ \\
\hline 5 & $5 \mathrm{~mol} \% \mathrm{Pd}(\mathrm{OAc})_{2}$ & 5 mol \% CyJohnPhos & $87(99)$ \\
\hline 6 & $5 \mathrm{~mol} \% \mathrm{Pd}(\mathrm{OAc})_{2}$ & $5 \mathrm{~mol} \% t$-BuXPhos & $93(99)$ \\
\hline 7 & $5 \mathrm{~mol} \% \mathrm{Pd}(\mathrm{OAc})_{2}$ & $5 \mathrm{~mol} \%$ XPhos & 99 (99) \\
\hline 8 & $5 \mathrm{~mol} \% \mathrm{Pd}(\mathrm{OAc})_{2}$ & $5 \mathrm{~mol} \%$ XPhos, $20 \mathrm{~mol}^{\%} \mathrm{Et}_{3} \mathrm{~N}$ & $0(99)$ \\
\hline \multicolumn{4}{|c|}{$P d$ catalyst screen } \\
\hline 9 & $5 \mathrm{~mol} \%$ XPhos Pd G3 & - & $97(99)$ \\
\hline 10 & $5 \mathrm{~mol} \% \mathrm{Pd}_{2}(\mathrm{dba})_{3}$ & $5 \mathrm{~mol} \%$ XPhos & $72(99)$ \\
\hline
\end{tabular}

${ }^{a}$ Reagents and conditions: ( 1 ') KHMDS (1.1 equiv), MeOTf (1.1 equiv), THF, -78 to $23{ }^{\circ} \mathrm{C}, 1.5 \mathrm{~h}$; (2') $\mathrm{Mn}(\mathrm{OAc})_{3} \cdot 2 \mathrm{H}_{2} \mathrm{O}(20 \mathrm{~mol}$ $\%$ ), $t$-BuOOH (5.0 equiv), EtOAc, $65{ }^{\circ} \mathrm{C}, 14 \mathrm{~h}, 54 \%$ over two steps; (3') $\mathrm{AcOH} / \mathrm{H}_{2} \mathrm{SO}_{4}(1: 1), 100{ }^{\circ} \mathrm{C}, 14 \mathrm{~h}, 82 \%$; (1' ') $\mathrm{Pd}(\mathrm{TFA})_{2}$ (5 mol \%), DMSO (10 mol \%), $\mathrm{O}_{2}(1 \mathrm{~atm}), \mathrm{AcOH}, 80^{\circ} \mathrm{C}, 12 \mathrm{~h}$, 92\%; (2") Urea $\mathrm{H}_{2} \mathrm{O}_{2}$ (3.0 equiv), DBN (3.0 equiv), $\mathrm{H}_{2} \mathrm{O}$ (9.0 equiv), THF, 0 to $23{ }^{\circ} \mathrm{C}, 5 \mathrm{~h}, 67 \%, 1: 1 \mathrm{dr}$; (3') $\mathrm{Pd}(\mathrm{OAc})_{2}(5 \mathrm{~mol}$ \%), XPhos (5 mol \%), PhMe, $120^{\circ} \mathrm{C}, 15 \mathrm{~h}, 90 \% .{ }^{b} 1,4$-Dioxane was used as solvent unless otherwise specified. ${ }^{c}$ Yield of the crude reaction mixture, using $0.2 \mathrm{mmol} \mathbf{1 4 - 6}$, was determined by ${ }^{1} \mathrm{H}$ NMR using 1,2-dibromomethane as an internal standard. Conversion of 14-6 in parenthesis. ${ }^{d}$ Toluene was used as solvent.

diketone substructure (10-9), including enone $\beta$-functionalization (Scheme 14A, route 1), acidic hydrolysis of a vinylogous ester (route 2), or Pd-mediated epoxyketone rearrangement (route 3 ).

Our initial route began with the selective dehydrogenation of ketone 11-5. Although enoxysilane formation, $\alpha$-selenation, and selenide oxidation/elimination provided the desired enone (14-5) in $23 \%$ over three steps (not shown), a more efficient strategy was pursued, and Stahl's aerobic $\alpha, \beta$-dehydrogenation condition ${ }^{91}$ was found to deliver enone $\mathbf{1 4 - 5}$ in $92 \%$ isolated yield on multi-gram scale. Employing other single-step ketone dehydrogenation methods, including conditions developed by our laboratory, ${ }^{32 \mathrm{~d}} \mathrm{IBX},{ }^{92}$ or the Mukaiyama reagent, ${ }^{93}$ resulted in unselective product formation or incomplete conversion. We then sought to selectively functionalize the $\beta$-position of enone 14-5 with various nucleophiles, which could subsequently be converted to the 1,3-diketone (10-9). A $\beta$-thioenone (14-1) and $\beta$-bromoenone (14-2) were synthesized, but the following acidic or basic treatment only resulted in trace conversion to 10-9. Moreover, oxidation of a $\beta$-silyl enone (14-3) also failed to give the 1,3-diketone (10-9) and only led to decomposition of the starting material (14-3). ${ }^{94}$
Given that a $\beta$-functionalized enone (14-1 to 14-3) might not be the ideal 1,3-diketone precursor, an alternative route was investigated, in which an allylic oxidation served as the method to introduce the C3-oxidation state. Formation of the methyl enol ether (14-4) occurred smoothly upon treatment of 11-5 with KHMDS and MeOTf, which proved to be a suitable substrate for allylic oxidation following the precedent set by the Corey-Yu oxidation. ${ }^{95}$ A subsequent Mn-catalyzed allylic oxidation provided vinylogous ester $14-4$ in $54 \%$ over two steps (Scheme 14A). Hydrolysis of the methyl enol ether (144) with $\mathrm{AcOH}$ in aqueous $\mathrm{H}_{2} \mathrm{SO}_{4}$ revealed the 1,3-diketone (10-9) in $82 \%$ yield. ${ }^{96}$ Modification of the methyl enol ether to the vinyl acetate or vinyl triflate significantly diminished the yield of 10-9.

Although the allylic oxidation approach successfully furnished the desired 1,3-diketone (10-9), a more efficient and scalable strategy to reach 10-9 was imagined: a Pd-catalyzed isomerization of an $\alpha, \beta$-epoxyketone (14-6). Nucleophilic epoxidation of 14-5 gave rise to 14-6 in $67 \%$ yield as an inconsequential 1:1 mixture of diastereomers. Subjection of the epoxide (14-6) to conditions previously reported by Suzuki ${ }^{97}$ and others ${ }^{98}$ was ineffective and resulted primarily in the reformation of the enone (14-5) (Scheme 14B, entry 1), which led us to examine other possible catalysts and ligands that could catalyze this transformation. A broad investigation of phosphine ligands and Pd pre-catalysts led to the discovery of $\mathrm{Pd}(\mathrm{OAc})_{2}$ and XPhos as the optimal conditions to afford the 1,3-diketone 10-9 in 99\% yield on $0.2 \mathrm{mmol}$ scale (entry 7), and $90 \%$ yield on gram scale. Employing other phosphine ligands such as dppe, $\mathrm{Ph}_{3} \mathrm{P}, \mathrm{BINAP}$ (entries 2-4), biaryl-phosphine ligands (entries 5-6) or other Pd-catalysts (entries 9-10) gave diminished yields. Furthermore, employing $\mathrm{Et}_{3} \mathrm{~N}$ as an additive completely suppressed product formation (entry 8).

With a scalable route to $\mathbf{1 0 - 9}$, we first attempted a telescoped Risch type pyridine synthesis by subjecting 10-7, 10-9 and an amine source, such as hydroxylamine or ammonium acetate, to the condensation conditions (Scheme 15B). However, this process only gave a complex mixture of products. We then turned to a stepwise strategy involving a Knoevenagel condensation between 10-7 and 10-9, and mediated by ethylenediammonium diacetate. ${ }^{99}$ After the formation of the presumed enedione intermediate, a spontaneous thermal oxa- $6 \pi$-electrocyclization delivered $2 H$-pyran $\mathbf{1 5 - 1}$ as the only product in $47 \%$ yield from crude 10-7 (see Supporting Information Scheme SI5 for more details).

In order to gain further insight into the diastereo- and regioselectivity of the oxa- $6 \pi$-electrocyclization, we conducted DFT calculations on all four possible reaction pathways leading to the corresponding 2H-pyran adducts (Scheme 16A). The computational results at $\omega \mathrm{B} 97 \mathrm{x}-\mathrm{D} / 6-$ $311+\mathrm{G}(2 \mathrm{~d}, \mathrm{p}) / / \omega \mathrm{B} 97 \mathrm{x}-\mathrm{D} / 6-31+\mathrm{G}(\mathrm{d}, \mathrm{p})^{100}$ level of theory suggest that the formation of C9- $\beta$-pyran (15-1) is the thermodynamic product and C9- $\alpha$-pyran (16-1) is kinetically favored. More specifically, the ground state energy of C9- $\beta$-pyran (151) is $3.3 \mathrm{kcal} / \mathrm{mol}$ lower than that of its C9-epimer (16-1) and $2.8 \mathrm{kcal} / \mathrm{mol}$ lower than that of its regioisomer, C9- $\beta$-pyranregioisomer (16-2). On the other hand, the energy of the transition state TS-a (16-3) leading to the formation of C9- $\beta$-pyran (15-1) is $1.1 \mathrm{kcal} / \mathrm{mol}$ higher than that of TS-b (16-4) leading to the formation of C9- $\alpha$-pyran (16-1). Furthermore, formation of both pyran regioisomers (16-2 and 16-7) are kinetically less favorable than that of the C9- $\beta$-pyran (15-1). These computational results implied that if $2 H$-pyran formation were reversible and under thermodynamic control, then C9- $\beta$-pyran 
Scheme 15. Fourth-Generation Synthetic Effort Toward (+)-Granatumine A, (+)-Xylogranatin F, and (+)-Granatoine Employing a Pyran-to-Pyridine Conversion ${ }^{a}$
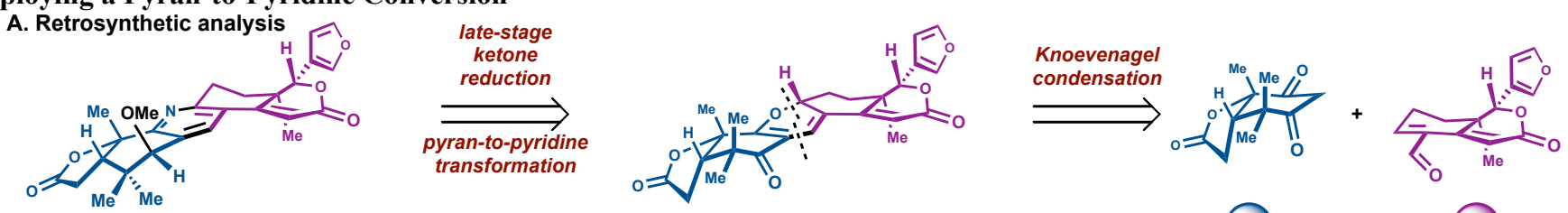

(+)-granatumine A (1-2)

15-1

(10-9)
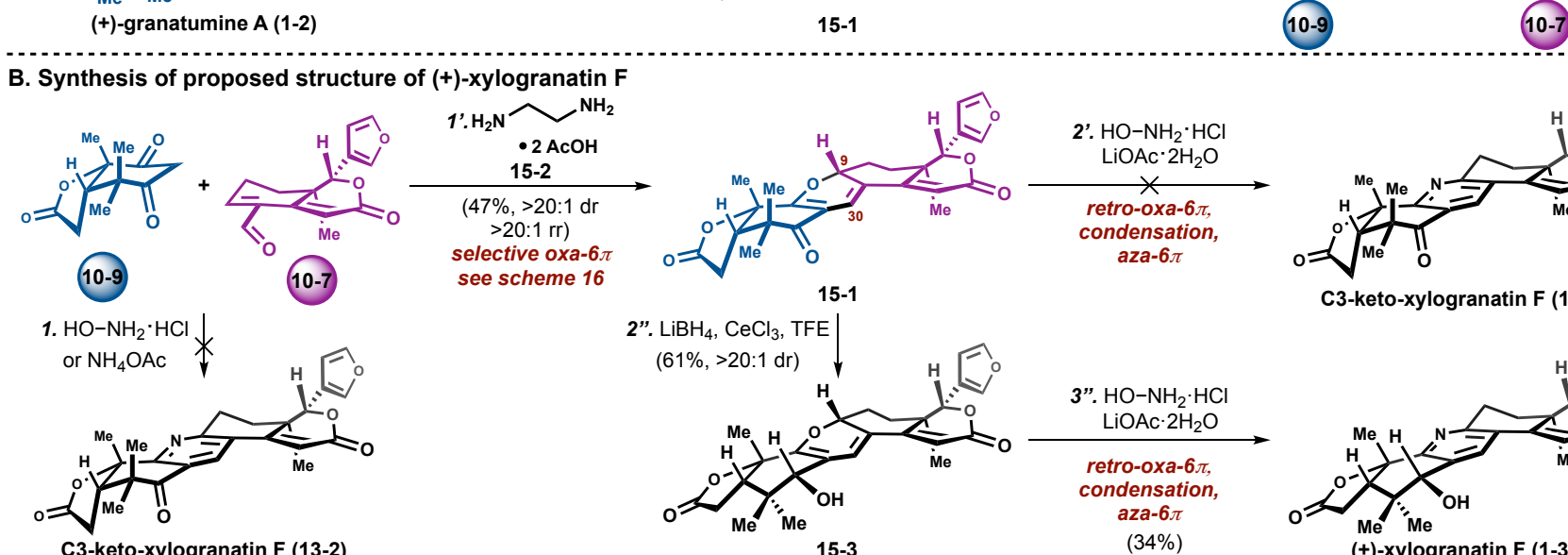

selective oxa-6 $\pi$ see scheme 16
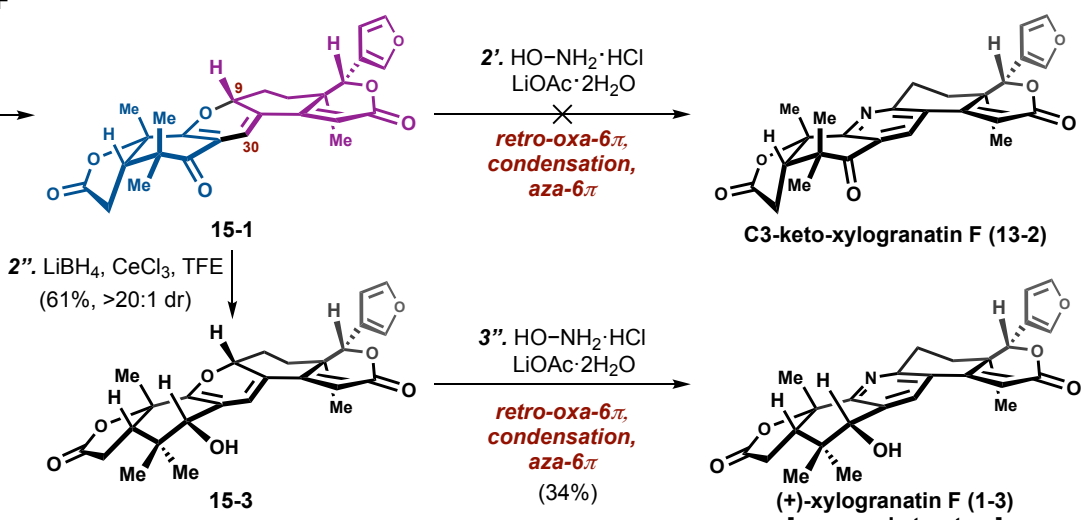

C. Synthesis of proposed structure of (+)-granatoine

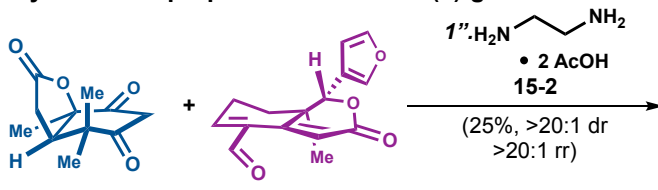

(10-7)

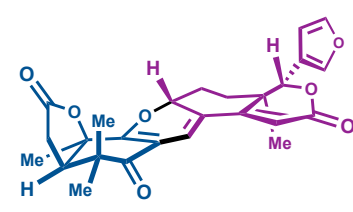

$15-5$
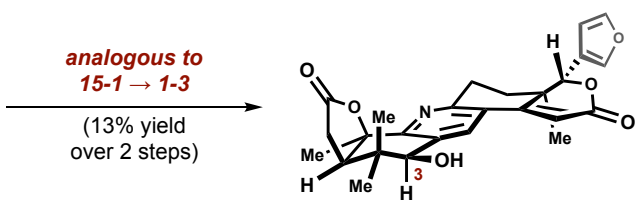

(+)-granatoine (1-4)

[proposed structure]

${ }^{a}$ Reagents and conditions: ( 1 ') ethylenediammonium diacetate (0.7 equiv), 10-7 (1.5 equiv), $\left(\mathrm{CH}_{2} \mathrm{Cl}\right)_{2}, 65{ }^{\circ} \mathrm{C}, 4 \mathrm{~h}, 47 \%$; (2') $\mathrm{LiBH}_{4}(4.5$ equiv), $\mathrm{CeCl}_{3} \cdot 7 \mathrm{H}_{2} \mathrm{O}$ ( 4.5 equiv), $\mathrm{CF}_{3} \mathrm{CH}_{2} \mathrm{OH} / \mathrm{THF}(1: 1), 0$ to $23^{\circ} \mathrm{C}, 3 \mathrm{~h}, 61 \%$; (3'”) $\mathrm{HO}-\mathrm{NH}_{2} \cdot \mathrm{HCl}$ (5.0 equiv), $\mathrm{LiOAc} \cdot \mathrm{H}_{2} \mathrm{O}$ (6.0 equiv), $\mathrm{MeOH}, 80^{\circ} \mathrm{C}, 12 \mathrm{~h}, 34 \%$; (1’) ethylenediammonium diacetate ( 0.9 equiv), 10-7 (1.5 equiv), $\left(\mathrm{CH}_{2} \mathrm{Cl}\right) 2,65^{\circ} \mathrm{C}, 4 \mathrm{~h}, 25 \%$.

(15-1) would predominate. To test this hypothesis, the C9- $\beta$ pyran-regioisomer (16-2) was re-subjected to the reaction conditions and the exclusive isomer observed was the C9- $\beta$-pyran (15-1) in 69\% yield (Scheme 16B). This result implies the pyran formation is indeed under thermodynamic control. The mechanistic pathway for its formation occurs through a retro$6 \pi$-electrocyclization, alkene isomerization (16-5 $\rightarrow \mathbf{1 6 - 6})$, and oxa- $6 \pi$-electrocyclization. A depiction of the reaction pathway for the formation of C9- $\beta$-pyran (15-1) is detailed in Scheme 16C. ${ }^{101}$

Direct conversion of $2 H$-pyran 15-1 to C3-keto-xylogranatin $\mathrm{F}(\mathbf{1 3 - 2})$ via a retro-oxa- $6 \pi$-electrocyclization, condensation with an amine source, and subsequent $6 \pi$-electrocyclization of the aza-triene was unsuccessful (Scheme 15B). This is likely due to competitive ketone condensation prior to retrooxa- $6 \pi$-electrocyclization, which led to the undesired pyridine regioisomer. We surmised that prior reduction of the $\mathrm{C} 3-\mathrm{ke}-$ tone would avoid this undesired pathway. Among the standard ketone reduction conditions examined, only the Luche reduction performed in $\mathrm{MeOH} / \mathrm{THF}$ provided alcohol 15-3, although significant decomposition resulting from the 1,6-addition of methoxide into the $\mathrm{C} 30$ position was observed. Utilizing a less nucleophilic alcohol, 2,2,2-trifluoroethanol, suppressed this degradation pathway, and the allylic alcohol 15-3 was formed in $61 \%$ yield as a single diastereomer (see Supporting Information Scheme SI6 for more details). Treatment of the resulting alcohol (15-3) with hydroxylamine in reflux- ing ethanol elicited a retro- $6 \pi$-electrocyclization, ${ }^{102}$ oxime formation, and aza- $6 \pi$-electrocyclization sequence. After subsequent loss of water, the proposed structure of xylogranatin $\mathrm{F}$ (1-3) was formed in 34\% yield (see Supporting Information Scheme SI7 for more details). ${ }^{103}$ However, the spectroscopic data of the compound we synthesized did not match those from the original isolation report, which made us suspect structural misassignment.

Meanwhile, we discovered the ${ }^{13} \mathrm{C}-\mathrm{NMR}$ chemical shifts of granatoine (1-4) reported by Lin and co-workers ${ }^{4 \mathrm{a}}$ and those of xylogranatin F (1-3) reported by Bringmann and co-workers ${ }^{4 b}$ were nearly identical, which suggested both groups had isolated the same compound. Due to the ease of access to the proposed structure of granatoine (1-4) using the synthetic route we developed, we undertook its synthesis to obtain experimental NMR data for the proposed structure. Employing the enantiomer of the 1,3-diketone fragment (15-4) and aldehyde fragment 10-7, we prepared granatoine over three steps in a similar fashion, whose ${ }^{13} \mathrm{C}-\mathrm{NMR}$ chemical shifts did not match either of those reported by Lin and co-workers or those by Bringmann and co-workers.

At this juncture, we turned to ${ }^{1} \mathrm{H}$ - and ${ }^{13} \mathrm{C}-\mathrm{NMR}$ DFT calculations to resolve this ambiguity (Scheme 17). ${ }^{104}$ Based on the hypothetical biosynthesis and the discrepancy of the C3-stereochemistry among these bislactone limonoid alkaloids, we suspected that the C3-epimer of the proposed structure (17-1) might be the correct structure of xylogranatin F. With this in mind, two diastereomeric structures at the $\mathrm{C} 3$ position were 


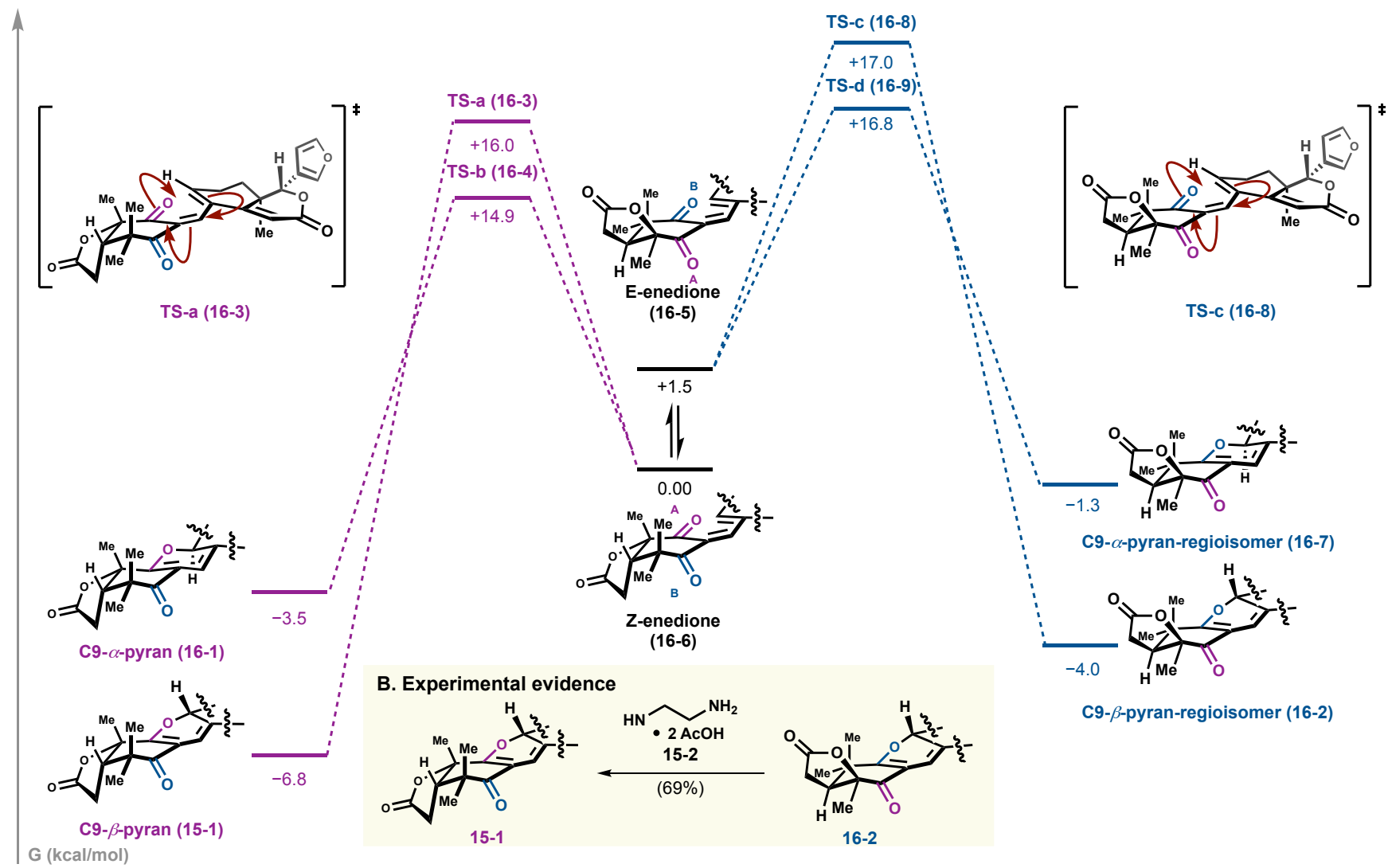

C. Reaction pathway

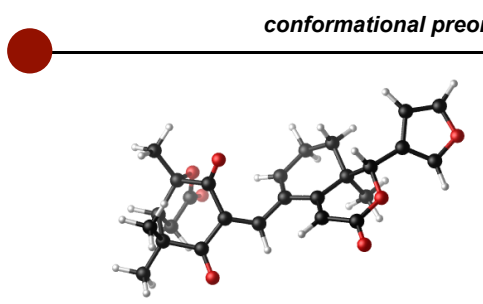

Z-enedione (16-6)

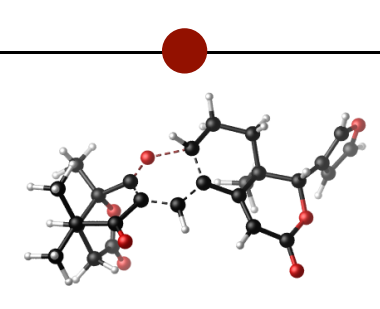

TS-a (16-3)
$6 \pi$ electrocyclization

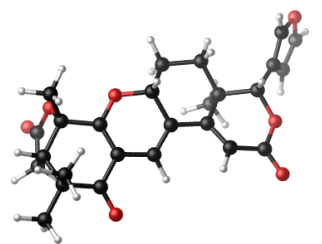

C9- $\beta$-pyran (15-1)

${ }^{a}$ Calculations were performed using $\omega \mathrm{B} 97 \mathrm{x}-\mathrm{D} / 6-311+\mathrm{G}(2 \mathrm{~d}, \mathrm{p}) / / \omega \mathrm{B} 97 \mathrm{x}-\mathrm{D} / 6-31+\mathrm{G}(\mathrm{d}, \mathrm{p})$. Free energies (in kcal/mol).

generated and subjected to DFT NMR calculations at mPW1PW91/6-311+G(2d,p)//B3LYP/6-31+G(d,p) level of theory (Scheme 17A). Analysis of the NMR calculation results suggest that the $\mathrm{C} 3$-epimer of the xylogranatin F structure (171) proposed by Bringmann and co-workers was indeed a closer match for the experimental data: the ${ }^{13} \mathrm{C}$-NMR chemical shifts of B-ring carbons and those in vicinity, such as $\mathrm{C} 4, \mathrm{C} 5$, and C29, match the reported values more closely. Furthermore, from a statistical standpoint, the overall mean absolute error (MAE) and root-mean-square deviation (RMSD) were both lower for the revised structure (17-1). Similarly, the C3-epimers of $(+)$-xylogranatin $G(\mathbf{1 7 - 5}),{ }^{4 b}(+)$-xylogranatin $H(\mathbf{1 7 -}$ 6), ${ }^{4 \mathrm{~b}}$ and $(+)$-hainangranatumin $\mathrm{G}(\mathbf{1 7 - 7})^{4 \mathrm{c}}$ were all shown to more closely match the reported ${ }^{13} \mathrm{C}-\mathrm{NMR}$ chemical shifts than their originally proposed structures (17-2 to 17-4) respectively (Scheme 17A). In the same vein, the proposed structure of (+)-granatumine A (1-2), which possesses the C3-substituent on the $\beta$-face as the aforementioned revised structures of its congeners, was corroborated to be the more likely structure than its presumed $\mathrm{C} 3$-epimer (17-8). All these computation results were submitted to statistical analysis using the DP4 method, ${ }^{105}$ and the results clearly supported the above conclusions.

After confirming the structural misassignment with NMR calculations, we sought to validate the structure prediction through chemical synthesis (Scheme 18). An X-ray diffraction structure of the experimentally obtained sample of xylogranatin $\mathrm{F}$ (1-3) was acquired, ${ }^{2 \mathrm{~g}}$ which clearly showed that we synthesized the proposed structure of xylogranatin F (1-3) with the C3-hydroxyl group on the $\alpha$-face. In order to invert the stereochemistry at $\mathrm{C} 3$, a tosylate (18-1), mesylate (18-2) and phosphate (18-3) were prepared. However, the attempted $\mathrm{S}_{\mathrm{N}} 2$ displacement with various nucleophiles failed to give the desired stereochemical outcome, and instead the undesired stereochemistry was observed presumably via an $S_{N} 1$ pathway (see Supporting Information Scheme SI8 for more details). Fortunately, modifying the leaving group from acetate to chloride allowed for partial inversion of the $\mathrm{C} 3$-stereocenter. When $\mathrm{NaOMe}$ or $\mathrm{Zn}(\mathrm{OAc})_{2}$ were utilized as nucleophiles, 1:1 dr was 
Scheme 17. Structure Revision of Four Bislactone Limonoid Alkaloids and Structural Corroboration of (+)-Granatumine A Guided by GIAO NMR Computation ${ }^{a}$

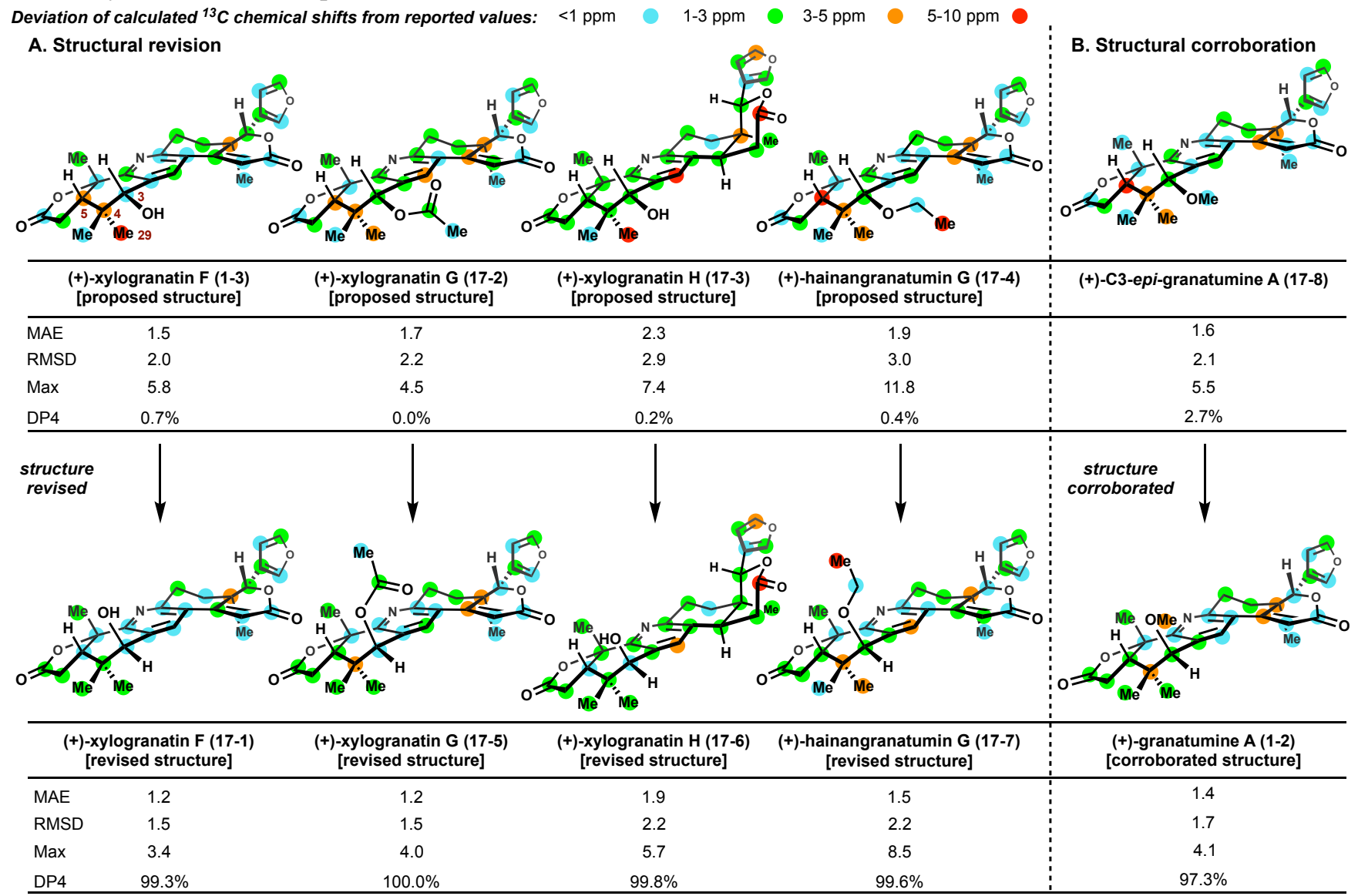

${ }^{a}$ Geometry optimization calculations were performed using B3LYP/6-31+G(d,p) level of theory with the SMD solvation method (chloroform), while NMR single point calculations were conducted using mPW1PW91/6-311+G(2d,p) for all the above calculations.

observed in both cases, and (+)-granatumine A (1-2) as well as the revised structure of $(+)$-xylogranatin $\mathrm{G}(\mathbf{1 7 - 5})(\mathrm{C} 3-\beta$ acetoxy substituent as determined by NMR calculations) were isolated with $41 \%$ and $37 \%$ yields, respectively. Furthermore, hydrolysis of the revised structure of $(+)$-xylogranatin $\mathrm{G}(\mathbf{1 7}-$ 5) provided alcohol 17-1 in $87 \%$ yield, whose spectral data matched those of naturally occuringg $(+)$-xylogranatin $F$. The synthesis of the revised structure of $(+)$-xylogranatin $G(\mathbf{1 7 - 5})$ and $(+)$-xylogranatin F (17-1) unequivocally confirmed our hypothesis for structural reassignment derived from the NMR predictions, and demonstrated the utility of NMR calculations in assisting structural assignment and revision in this context.

Scheme 18. Completion of the Synthesis of $(+)$-Granatumine A, the Revised Structures of (+)-Xylogranatin G and (+)-Xylogranatin $\mathbf{F}^{a}$

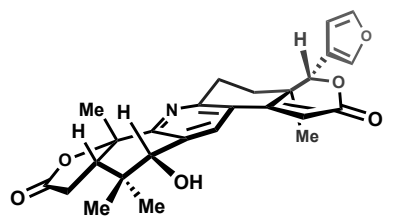

(+)-xylogranatin F (1-3) [proposed structure]

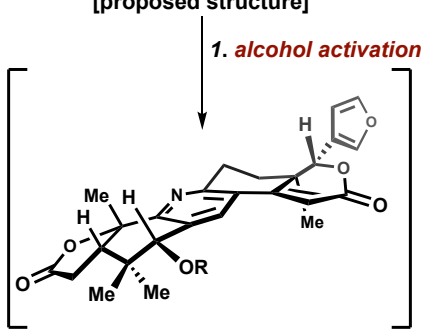

$R=$ Ts (18-1), Ms (18-2), PO(OEt) 2 (18-3)

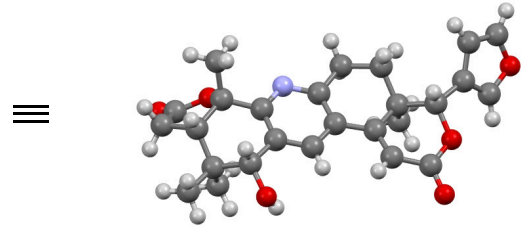

(+)-xylogranatin F (1-3) [X-ray of proposed structure]

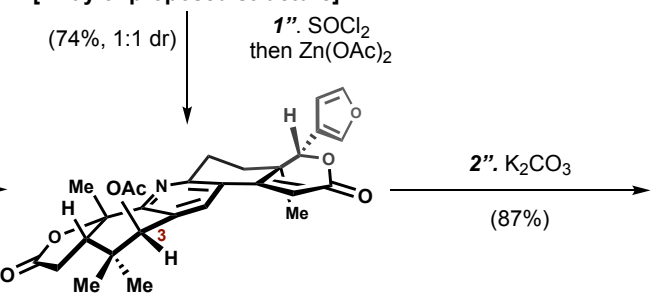

(+)-xylogranatin G (17-5)
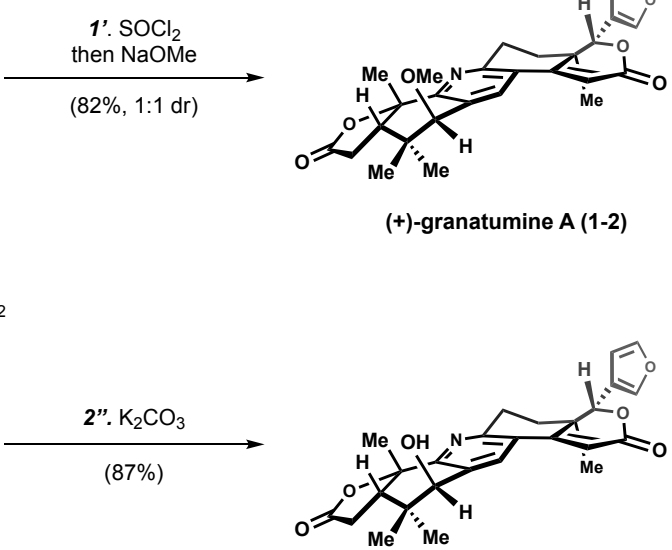

(+)-xylogranatin F (17-1) [revised structure]

${ }^{a}$ Reagents and conditions: (1') $\mathrm{SOCl}_{2}$ (7.0 equiv), $\mathrm{CH}_{2} \mathrm{Cl}_{2}, 40^{\circ} \mathrm{C}, 12 \mathrm{~h}$, then $\mathrm{NaOMe}\left(10.0\right.$ equiv), $\mathrm{MeOH}, 70{ }^{\circ} \mathrm{C}, 5 \mathrm{~h}, 82 \%, 1: 1 \mathrm{dr}$; $\left(1^{\prime}\right.$ ') $\mathrm{SOCl}_{2}$ (7.0 equiv), $\mathrm{CH}_{2} \mathrm{Cl}_{2}, 40^{\circ} \mathrm{C}, 12 \mathrm{~h}$, then $\mathrm{Zn}(\mathrm{OAc})_{2}$ (10.0 equiv), $\mathrm{AcOH}, 100{ }^{\circ} \mathrm{C}, 12 \mathrm{~h}, 74 \%, 1: 1 \mathrm{dr} ;\left(2^{\prime}\right.$ ') $\mathrm{K}_{2} \mathrm{CO}_{3}\left(7.0\right.$ equiv), $\mathrm{MeOH}^{\circ}$ $60{ }^{\circ} \mathrm{C}, 5 \mathrm{~h}, 87 \%$. 
Scheme 19. Preliminary Results of PTP1B Inhibitory Activities of Selected Bislactone Limonoid Alkaloids and An$\operatorname{alogs}^{a}$

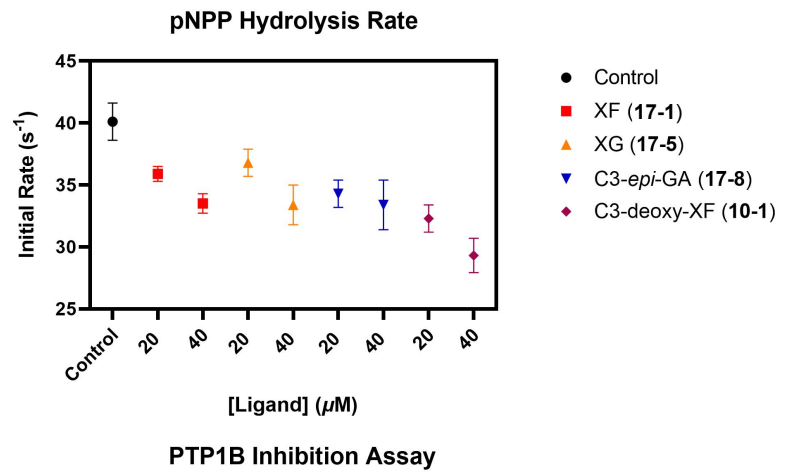

${ }^{a} \mathrm{XF}=$ xylogranatin $\mathrm{F}(\mathbf{1 7 - 1}), \mathrm{XG}=$ xylogranatin $\mathrm{G}(\mathbf{1 7 - 5}), \mathrm{C} 3-$ epi-GA = C3-epi-granatumine A (17-8), C3-deoxy-XF = C3-deoxy-xylogranatin F (10-1)

The diversity of C3-substituents in this family sparked our curiosity about their biosynthetic origins. We speculated this diversity may be an artifact of isolation. The principal observation that suggested this hypothesis is that granatumine A (12), which possesses a C3-methoxy group, was isolated from $\mathrm{MeOH} .{ }^{3}$ Whereas hainangranatumin $\mathrm{G}$, which possesses a C3ethoxy unit was isolated from EtOH. ${ }^{4 \mathrm{c}}$ Meanwhile xylogranatin $\mathrm{G}(\mathbf{1 7 - 5}, \mathrm{C} 3=\beta$-OAc) xylogranatin $\mathrm{F}(\mathbf{1 7 - 1}, \mathrm{C} 3=\beta-\mathrm{OH})$ were isolated from $\mathrm{EtOH} .{ }^{4 \mathrm{~b}}$ However, degradation was not observed when xylogranatin F (1-1) or xylogranatin G (17-5) were subjected to various acidic or neutral conditions with $\mathrm{MeOH}$ or EtOH as solvent. This study implies that if these were artifacts of isolation, they are not derived from xylograntin F (1-1) or xylogranatin G (17-5), and instead are derived from some other labile natural product that may not have been isolated yet.

After obtaining these bislactone limonoid alkaloid natural products, we also evaluated their PTP1B inhibitory activities using the pNPP hydrolysis assay (Scheme 19). Preliminary results showed while other congeners such xylogranatin F (171), xylogranatin G (17-5), and C3-epi-granatumine A (17-8) displayed only weak inhibitory activities against PTP1B, C3deoxy-xylogranatin F (10-1) is more potent than the naturally occurring pyridine alkaloids showing $30 \%$ PTP1B inhibition at $40 \mu \mathrm{M}$.

While the complete PTP1B-inhibitory profile of these limonoid alkaloids and their full structure-activity relationships are not available yet, our findings herein can enable scalable and rapid access to these compounds and their analogs to facilitate the understanding of their biological relevance.

\section{CONCLUSION}

This report chronicles our full investigation into the use of pyridine ring synthesis as a tool for convergence to access limonoid alkaloids. Convergent synthesis is often lauded for the concise longest linear sequences inherent to these strategies, and the ability to generate analogs through iterative fragment coupling reactions. An additional benefit highlighted through our study is that convergent approaches allow for flexible modification of strategy when key steps fail, as individual fragments can be diversified more easily than the complex intermediates that arise through linear strategies.
This study also shows how the development of methodology advances synthetic efficiency; methodological improvements included scalable Pd-catalyzed ketone-to-enone dehydrogenation, Pd-catalyzed oxidative enone $\beta$-stannylation, Pdcatalyzed epoxyketone rearrangement, and use of a stannane coupling partner in the Liebeskind pyridine synthesis. Furthermore, strategic deployment of modern computational techniques helped direct our total synthesis campaigns through structural reassignment by NMR calculations and feasibility assessments of proposed transformations.

\section{ASSOCIATED CONTENT}

\section{Supporting Information}

The Supporting Information is available free of charge on the ACS Publications website. Experimental procedures, and spectroscopic data for all new compounds including ${ }^{1} \mathrm{H}$ - and ${ }^{13} \mathrm{C}-\mathrm{NMR}$ spectra (PDF), Crystallographic data (CIF).

\section{AUTHOR INFORMATION}

\section{Corresponding Author}

Timothy R. Newhouse - Department of Chemistry, Yale University, New Haven, Connecticut 06511, United States; orcid.org/0000-0001-8741-7236

Email: timothy.newhouse@yale.edu

\section{Authors}

Alexander W. Schuppe - Department of Chemistry, Yale University, New Haven, Connecticut 06511, United States; orcid.org /0000-0001-6002-9110;

Yannan Liu - Department of Chemistry, Yale University, New Haven, Connecticut 06511, United States; orcid.org/0000-00015781-2729;

Yizhou Zhao - Department of Chemistry, Yale University, New Haven, Connecticut 06511, United States;

Sebastian Ibarraran - Department of Chemistry, Yale University, New Haven, Connecticut 06511, United States;

David Huang - Department of Chemistry, Yale University, New Haven, Connecticut 06511, United States; orcid.org/0000-00027179-0738;

Jaehoo Lee - Department of Chemistry, Yale University, New Haven, Connecticut 06511, United States;

Emma Wang - Department of Chemistry, Yale University, New Haven, Connecticut 06511, United States;

Patrick J. Loria - Department of Chemistry, Yale University, New Haven, Connecticut 06511, United States;

\section{Author contributions}

${ }^{\dagger}$ A.W.S. and Y. L. contributed equally to this paper.

Notes

The authors declare no competing financial interest.

\section{ACKNOWLEDGMENT}

We gratefully acknowledge Dr. Brandon Mercado for X-ray crystallography of compound 12-1, 12-10 and 1-3. Financial support for this work was provided by Yale University, Amgen, the Dreyfus Foundation, the Sloan Foundation, Bristol-Myers Squibb (Graduate Fellowship to A.W.S. and D.H.), the National Science Foundation (GRFP to A.W.S), Roberts Fellowship (to Y.L.), Dox Fellowship (to Y.L. and D.H.), and the NIH (5R01-GM118614, 5R01-GM112781, and 2T32GM008283). We gratefully acknowledge the National Science 
Foundation for financial support in the establishment of the Yale University High Performance Computing (HPC) Center (CNS 08-21132).

${ }^{1}$ For recent reviews on limonoids, see: (a) Tan, Q.; Luo, X. Meliaceous Limonoids: Chemistry and Biological Activities. Chem. Rev. 2011, 111, 7437-7522. (b) Heasley, B. Synthesis of Limonoid Natural Products. Eur. J. Org. Chem. 2011, 2011, 19-46. (c) Fu, S.; Liu, B. Recent Progress in the Synthesis of Limonoids and Limonoid-like Natural Produts. Org. Chem. Front. 2020, 7, 1903-1947.

${ }^{2}$ For recent limonoid total syntheses, see: (a) Behenna, D. C.; Corey, E. J. Simple Enantioselective Approach to Synthetic Limonoids. J. Am. Chem. Soc. 2008, 130, 6720-6721. (b) Faber, J. M.; Eger, W. A.; Williams, C. M. Enantioselective Total Synthesis of the Mexicanolides: Khayasin, Proceranolide, and Mexicanolide. J. Org. Chem. 2012, 77, 8913-8921. (c) Yamashita, S.; Naruko, A.; Nakazawa, Y.; Zhao, L.; Hayashi, Y.; Hirama, M. Total Synthesis of Limonin. Angew. Chem., Int. Ed. 2015, 54, 8538-8541. (d) Lv, C.; Yan, X.; Tu, Q.; Di, Y.; Yuan, C.; Fang, X.; Ben-David, Y.; Xia, L.; Gong, J.; Shen, Y.; Yang, Z.; Hao, X. Isolation and Asymmetric Total Synthesis of Perforanoid A. Angew. Chem., Int. Ed. 2016, 55, 7539-7543. (e) Schuppe, A. W.; Newhouse, T. R. Assembly of the Limonoid Architecture by a Divergent Approach: Total Synthesis of $( \pm)$-Andirolide $\mathrm{N}$ via $( \pm)$-8 $\alpha$-Hydroxycarapin. $J$. Am. Chem. Soc. 2017, 139, 631-634. (f) Schuppe, A. W.; Huang, D.; Chen, Y.; Newhouse, T. R. Total Synthesis of (-)Xylogranatopyridine B via a Palladium-Catalyzed Oxidative Stannylation of Enones. J. Am. Chem. Soc. 2018, 140, 20622066. (g) Schuppe, A. W.; Zhao, Y.; Liu. Y.; Newhouse, T. R. Total Synthesis of (+)-Granatumine A and Related Bislactone Limonoid Alkaloids via a Pyran to Pyridine Interconversion. J. Am. Chem. Soc. 2019, 141, 9191-9126. (h) Pinkerton, D. M.; Chow, S.; Eisa, N. H.; Kainth, K.; Vanden Berg, T. J.; Burns, J. M.; Guddat, L. W.; Savage, G. P.; Chadli, A.; Williams, C. M. Synthesis of the seco-Limonoid BCD Ring System Identifies a Hsp90 Chaperon Machinery (p23) Inhibitor. Chem. - Eur. J. 2019, 25, 1451-1455.

${ }^{3}$ For the isolation of xylogranatopyridine B and granatumine A, see: Zhou, Z.-F.; Lui, H. L.; Zhang, W.; Kurtán, T.; Mándi, A.; Bényei, A.; Li, J.; Taglialatela-Scafati, O.; Guo, Y.-W. Bioactive Rearranged Limonoids from the Chinese Mangrove Xylocarpus granatum Koenig. Tetrahedron 2014, 70, 64446449.

${ }^{4}$ For recent isolation of other limonoid alkaloids, see: (a) Cui, J.; Ouyang, J.; Deng, Z.; Lin, W. Structure Elucidation of an Unprecedented Alkaloid and a New Limonoid from Xylocarpus granatum. Magn. Reson. Chem. 2008, 46, 894-897. (b) Wu, J.; Zhang, S.; Bruhn, T.; Xiao, Q.; Ding, H.; Bringmann, G. Xylogranatins F-R: Antifeedants from the Chinese Mangrove, Xylocarpus granatum, A New Biogenetic Pathway to Tetranortriterpenoids. Chem. - Eur. J. 2008, 14, 1129-1144. (c) Pan, J.-Y.; Chen, S.-L.; Li, M.-Y.; Li, J.; Yang, M.-H.; Wu, J. Limonoids from the Seeds of a Hainan Mangrove, Xylocarpus granatum. J. Nat. Prod. 2010, 73, 1672-1679. (d) Li, J.; Guo, Y.; Zhou, Z.; Liu, H.; Gao, L. Chinese Patent CN 103880854 A, June 25, 2014.

${ }^{5}$ Name Reactions in Heterocyclic Chemistry; Li, J. J., Corey, E. J., Eds; Wiley: New Jersey, 2005; p 304.

\section{REFERENCES}

${ }^{6}$ Name Reactions in Heterocyclic Chemistry; Li, J. J., Corey, E. J., Eds; Wiley: New Jersey, 2005; p 308.

${ }^{7}$ (a) Movassaghi, M.; Hill, M. D. Synthesis of Substituted Pyridine Derivatives via the Ruthenium-Catalyzed Cycloisomerization of 3-Azadienynes. J. Am. Chem. Soc. 2006, 128, 45924593. (b) Movassaghi, M.; Hill, M. D.; Ahmad, O. K. Direct Synthesis of Pyridine Derivatives. J. Am. Chem. Soc. 2007, 129, 10096-10097. (c) Liu, S.; Liebeskind, L. S. A Simple, Modular Synthesis of Substituted Pyridines. J. Am. Chem. Soc. 2008, 130, 6918-6919. (d) Colby, D. A.; Bergman, R. G.; Ellman, J. A. Synthesis of Dihydropyridines and Pyridines from Imines and Alkynes via $\mathrm{C}-\mathrm{H}$ Activation. J. Am. Chem. Soc. 2008, 130, 3645-3651. (e) Manning, J. R.; Davies, H. M. L. J. Am. Chem. Soc. 2008, 130, 8602-8603. (f) Chen, M.; Micalizio, G. C. Three-Component Coupling Sequence for the Regiospecific Synthesis of Substituted Pyridines. J. Am. Chem. Soc., 2012, 134, 1352-1356. (g) Wei, Y.; Yoshikai, N. Modular Pyridine Synthesis from Oximes and Enals through Synergistic Copper/Iminium Catalysis. J. Am. Chem. Soc., 2013, 135, 3756-3759. (h) Neely, J. M.; Rovis, T. Rh(III)Catalyzed Decarboxylative Coupling of Acrylic Acids with Unsaturated Oxime Esters: Carboxylic Acids Serve as Traceless Activators. J. Am. Chem. Soc., 2014, 136, 2735-2738.

${ }^{8}$ Tonks, N. K. PTP1B: From the Sidelines to the Front Lines! FEBS Lett. 2003, 546, 140-148.

${ }^{9}$ Galic, S.; Hauser, C.; Kahn, B. B.; Haj, F. G.; Neel, B. G.; Tonks, N. K.; Tiganis, T. Coordinated Regulation of Insulin Signaling by the Protein Tyrosine Phosphatases PTP1B and TCPTP. Mol. Cell. Biol. 2005, 25, 819-829.

${ }^{10}$ Zabolotny, J. M.; Bence-Hanulec, K. K.; Stricker-Krongrad, A.; Haj, F.; Wang, Y. P.; Minokoshi, Y.; Kim, Y. B.; Elmquist, J. K.; Tartaglia, L. A.; Kahn, B. B.; Neel, B. G. PTP1B Regulates Leptin Signal Transduction in Vivo, Dev. Cell 2002, 2, 489495

${ }^{11}$ (a) Johnson, T. O.; Ermolieff, J.; Jirousek, M. R. Protein Tyrosine Phosphatase 1B Inhibitors for Diabetes. Nat. Drug Discov. 2002, 1, 696-709. (b) Yip, S.-C.; Saha, S.; Chernoff, J. PTP1B: a Double Agent in Metabolism and Oncogenesis. Trends Biochem. Sci. 2010, 35, 442-449. (c) Feldhammer, M.; Uetani, N.; Miranda-Saavedra, D.; Tremblay, M. L. PTP1B: a Simple Enzyme for a Complex World. Crit. Rev. Biochem. Mol. Biol. 2013, 48, 430-445.

12 (a) Pandey, N. R.; Zhou, X.; Qin, Z.; Zaman, T.; Gomez-Smith, M.; Keyhanian, K. The LIM Domain Only 4 Protein is a Metabolic Responsive Inhibitor of Protein Tyrosine Phosphatase 1B that Controls Hypothalamic Leptin Signaling. J. Neurosci. 2013, 33, 12647-12655. (b) Pandey, N. R.; Zhou, X.; Zaman, T.; Cruz, S. A.; Qin, Z.; Lu, M. LMO4 is Required to Maintain Hypothalamic Insulin Signaling. Biochem. Biophys. Res. Commun. 2014, 450, 666-672.

${ }^{13}$ (a) Vieira, M. N. N.; Silva, N. M. L.; Ferreira, S. T.; De Felice, F. G. Protein Tyrosine Phosphatase 1B (PTP1B): A Potential Target for Alzheimer's Therapy? Front. Aging Neurosci. 2017, 9, 1-9. (b) Vieira, M. N. N.; Lima-Filho, R. A. S.; De Felice, F. G. Connecting Alzheimer's Disease to Diabetes: Underlying Mechanisms and Potential Therapeutic Targets. Neuropharmacology 2018, 136, 160-171. 
${ }^{14}$ Espanel, X.; Huguenin-Reggiani, M.; Hooft van Huijsduijnen, R. The SPOT Technique as a Tool for Studying Protein Tyrosine Phosphatase Substrate Specificities. Protein Sci. 2002, 11, 2326-2334.

${ }^{15}$ Ozek, C.; Kanoski, S. E.; Zhang, Z.-Y.; Grill, H. J.; Bence, K. K. Protein-tyrosine Phosphatase 1B (PTP1B) Is a Novel Regulator of Central Brain-derived Neurotrophic Factor and Tropomyosin Receptor Kinase B (TrkB) Signaling. J. Bio. Chem. 2014, 289, 31682-31692.

${ }^{16}$ Qin, Z.; Zhang, L.; Cruz, S. A.; Stewart, A. F. R.; Chen, H.-H. Activation of Tyrosine Phosphatase PTP1B in Pyramidal Neurons Impairs Endocannabinoid Signaling by Tyrosine Receptor Kinase TrkB and Causes Schizophrenia-like Behaviors in Mice. Neuropsychopharmacology 2020, 1884-1895.

${ }^{17}$ Ricke, K. M.; Cruz. S. A.; Qin, Z.; Farrokhi, K.; Sharmin, F.; Zhang, L.; Zasloff, M. A.; Stewart, A. F. R.; Chen, H.-H. Neuronal Protein Tyrosine Phosphatase 1B Hastens Amyloid BAssociated Alzheimer's Disease in Mice. J. Neurosci. 2020, 40, 1581-1593.

18 (a) Smith, A. M.; Maguire-Nguyen, K. K.; Rando, T. A.; Zasloff, M. A.; Strange, K. B.; Yin, V. P. The Protein Tyrosine Phosphatase 1B Inhibitor MSI-1436 Stimulates Regeneration of Heart and Multiple Other Tissues. Regen. Med. 2017, 2, 110. (b) Genaera Corporation Provides Highlights of Positive Phase 1 Trodusquemine (MSI-1436) Data. https://www.biospace.com/article/releases/genaera-corporation-provideshighlights-of-positive-phase-1-trodusquemine-msi-1436data-/ (2007) (c) Genaera Corporation Presents Preliminary Phase 1b Data for Trodusquemine (MSI-1436). https://www.biospace.com/article/releases/genaera-corporation-presents-preliminary-phase-1b-data-for-trodusqueminemsi-1436-/ (2009)

${ }^{19}$ (a) Keuper, R.; Risch, N. Facile Synthesis of Polycyclic Pyridines, Bipyridines, and Oligopyridines. Liebigs Ann. 1996, 5, 717-723. (b) Sielemann, D.; Keuper, R.; Risch, N. Efficient Preparation of Substituted 5,6,7,8-Tetrahydroquinolines and Octahydroacridine Derivatives. J. Prakt. Chem. 1999, 341, 487-491. (c) Sielemann, D.; Keuper, R.; Risch, N. Synthesis of Novel Functionalized Bi- and Oligopyridines. Eur. J. Org. Chem. 2000, 3, 543-548.

${ }^{20}$ Cernijenko, A.; Risgaard, R.; Baran, P. S. 11-Steps Total Synthesis of (-)-Maoecrystal V. J. Am. Chem. Soc. 2016, 138, 9425-9428.

${ }^{21}$ Böhme, H.; Mundlos, E.; Herboth, O.-E. Über Darstellung und Eigenschaften $\alpha$-Halogenierter Amine. Chem. Ber. 1957, 90, 2003-2008.

${ }^{22}$ Rochin, C.; Babot, O.; Duboudin, D. F. A Convenient Regioselective Synthesis of Mannich Bases. Synthesis 1986, 8, 667668.

${ }^{23}$ Piers, E.; Grierson, J. R.; Lau, C. K.; Nagakura, I. Synthesis of $\beta$-Chloro, $\beta$-Bromo, and $\beta$-Iodo $\alpha, \beta$-Unsaturated Ketones Can. J. Chem. 1982, 60, 210-223.

${ }^{24}$ For reviews on Stille coupling, see: (a) Stille, J. K. The Palladium-Catalyzed Cross-Coupling Reactions of Organotin Reagents with Organic Electrophile. Angew. Chem., Int. Ed. 1986, 25, 508-524. (b) Cordovilla, C.; Bartolomé, C.; Martínez-Ilarduya, J. M.; Espinet, P. The Stille Reaction, 38 Years Later. ACS Catal. 2015, 5, 3040-3053.

${ }^{25}$ For a review of palladium-catalyzed reactions in total synthesis, see: Nicolaou, K. C.; Bulger, P. G.; Sarlah, D. Palladium-Catalyzed Cross-Coupling Reactions in Total Synthesis. Angew. Chem., Int. Ed. 2005, 44, 4442-4489.
${ }^{26}$ Overman, L. E.; Velthuisen, E. J. Scope and Facial Selectivity of the Prins-Pinacol Synthesis of Attached Rings. J. Org. Chem. 2006, 71, 1581-1587.

${ }^{27}$ Maynard, D. F.; Okamura, W. H. $6 \pi$-Electrocyclization of 1Azatrienes to 1,2-Dihydropyridines. J. Org. Chem. 1995, 60, 1763-1771.

${ }^{28}$ Huang, D.; Schuppe, A. W.; Liang, M. Z.; Newhouse, T. R. Scalable Procedure for the Fragmentation of Hydroperoxides Mediated by Copper and Iron Tetrafluoroborate Salts. Org. Biomol. Chem. 2016, 14, 6197-6200.

${ }^{29}$ Han, X.; Stoltz, B. M.; Corey, E. J. Cuprous Chloride Accelerated Stille Reactions. A General and Efficient Coupling System for Sterically Congested Substrates and for Enantioselective Synthesis. J. Am. Chem. Soc. 1999, 121, 7600-7605.

${ }^{30}$ For seminal studies on $\beta$-functionalized enone synthesis via 1,3diones, see: Stork, G.; Danheiser, R. L. Regiospecific Alkylation of Cyclic $\beta$-Diketone Enol Ethers. General Synthesis of 4-Alkylcyclohexenones. J. Org. Chem. 1973, 38, 1775-1776.

${ }^{31}$ Piers, E.; Morton, H. E.; Chong, J. M. (Trialkylstannyl)copper(I) Reagents: Preparation and Reaction with $\alpha, \beta$-Unsaturated Carbonyl Systems. Preparation of $\beta$-Trialkylstannyl $\alpha, \beta$ Unsaturated Ketones. Can. J. Chem. 1987, 65, 78-87.

32 (a) Chen, Y.; Romaire, J. P.; Newhouse, T. R. Palladium-Catalyzed $\alpha, \beta$-Dehydrogenation of Esters and Nitriles. J. Am. Chem. Soc. 2015, 137, 5875-5878. (b) Chen, Y.; Turlik, A.; Newhouse, T. R. Amide $\alpha, \beta$-Dehydrogenation Using AllylPalladium Catalysis and a Hindered Monodentate Anilide. $J$. Am. Chem. Soc. 2016, 138, 1166-1169. (c) Turlik, A.; Chen, Y.; Newhouse, T. R. Dehydrogenation Adjacent to Carbonyls Using Palladium-Allyl Intermediates. Synlett 2016, 27, 331336. (d) Chen, Y.; Huang, D.; Zhao, Y. Newhouse, T. R. AllylPalladium-Catalyzed Ketone Dehydrogenation Enables Telescoping with Enone $\alpha, \beta$-Vicinal Difunctionalization. Angew. Chem., Int. Ed. 2017, 56, 8258-8262. (e) Zhao, Y.; Chen, Y.; Newhouse, T. R. Allyl-Palladium-Catalyzed $\alpha, \beta$-Dehydrogenation of Carboxylic Acids via Enediolates. Angew. Chem., Int. Ed. 2017, 56, 13122-13125. (e) Huang, D.; Zhao, Y.; Newhouse, T. R. Synthesis of Cyclic Enones by Allyl-Palladium-Catalyzed $\alpha, \beta$-Dehydrogenation. Org. Lett. 2018, 20, 684-687.

${ }^{33}$ Liebeskind, L. S.; Foster, B. S. Stannylquinones. Synthesis and Utilization as Quinone Carbanion Synthetic Equivalents. $J$. Am. Chem. Soc. 1990, 112, 8612-8613.

${ }^{34}$ (a) Fujiwara, J.; Sato, T. Dependence of the Lewis Acid-Induced Reaction of $\beta$-Stannyl Ketones upon Substitution Pattern: Cyclopropanation versus 1,2-Alkyl Migration. Bull. Chem. Soc. Jpn. 1993, 66, 1258-1264. (b) Shirakawa, E.; Yoshida, H.; Nakao, Y.; Hiyama, T. Mechanistic Aspects of Palladium-Catalyzed Allylstannylation of Alkynes. Org. Lett. 2000, 2, 2209-2211. (c) Martín-Matute, M.; Buñuel, E.; Méndez, M.; Nieto-Oberhuber, C.; Cárdenas, D. J.; Echavarren, A. M. Allyl Stannanes as Electrophiles or Nucleophiles in the Palladium-catalyzed Reactions with Alkynes. J. Organomet. Chem. 2003, 687, 410-419.

${ }^{35}$ Matsubara, S.; Hibino, J.-I.; Morizawa, Y.; Oshima, K.; Nozaki, H. Regio- and Stereo-selective Synthesis of Vinylstannanes. Transition-metal Catalyzed Stannylmetalation of Acetylenes and Conversion of Vinyl triflates and Vinyl Iodides into Vinylstannanes. J. Organomet. Chem. 1985, 285, 163.

${ }^{36}$ Morita, Y.; Suzuki, M.; Noyori, R. An Organozinc Aid in Alkylation and Acylation of Lithium Enolates. J. Org. Chem. 1989, 54, 1785-1787. 
${ }^{37}$ (a) Birman, V. B.; Li, X. Benzotetramisole: A Remarkably Enantioselective Acyl Transfer Catalyst. Org. Lett. 2006, 8, 1351-1354. (b) Ortiz, A.; Benkovics, T.; Beutner, G. L.; Shi, Z.; Bultman, M.; Nye, J.; Sfouggatakis, C.; Kronenthal, D. R. Scalable Synthesis of the Potent HIV Inhibitor BMS-986001 by Non-Enzymatic Dynamic Kinetic Asymmetric Transformation (DYKAT). Angew. Chem., Int. Ed. 2015, 54, 71857188 .

38 (a) Cowden, C. J.; Paterson, I. Asymmetric Aldol Reactions Using Boron Enolates. Org. React. 1997, 51, 1-200. (b) NerzStormes, M.; Thornton, E. R. Asymmetric Aldol Reactions. Use of the Titanium Enolate of a Chiral $N$-Acyloxazolidinone to Reverse Diastereofacial Selectivities. J. Org. Chem. 1991, 56, 2489-2498.

${ }^{39}$ Baidya, M.; Yamamoto, H. Metal Nitrite: A Powerful Oxidizing Reagent. J. Am. Chem. Soc. 2011, 133, 13880-13882.

${ }^{40}$ Feng, C.; Wang, H.; Xu, L.; Li, P. N-B Dative Bond-induced [3.3.0] Bicyclic Boronate-tethered Exo-selective Intramolecular Diels-Alder Reaction. Org. Biomol. Chem. 2015, 13, 7136-7139.

${ }^{41}$ For reviews on Chan-Lam coupling that discuss common additives, see: (a) Ley, S. V.; Thomas, A. W. Modern Synthetic Methods for Copper-Mediated C(aryl)-O, C(aryl) $-\mathrm{N}$, and C(aryl) -S Bond Formation. Angew. Chem., Int. Ed. 2003, 42, 5400-5449. (b) Qiao, J. X.; Lam, P. Y. S. Copper-Promoted Carbon-Heteroatom Bond Cross-Coupling with Boronic Acids and Derivatives. Synthesis 2011, 6, 829-856.

${ }^{42}$ For a recent study on the mechanism of the Chan-Lam reaction, see: Vantourout, J. C.; Miras, H. N.; Isidro-Llobert, A.; Sproules, S.; Watson, A. J. B. Spectroscopic Studies of the Chan-Lam Amination: A Mechanism-Inspired Solution to Boronic Ester Reactivity. J. Am. Chem. Soc. 2017, 139, 47694779.

${ }^{43}$ Gerfaud, T.; Neuville, L.; Zhu, J. Palladium-Catalyzed Annulation of Acyloximes with Arynes (or Alkynes): Synthesis of Phenanthridines and Isoquinolines. Angew. Chem., Int. Ed. 2009, 48, 572-577.

${ }^{44}$ Wilde, N. C.; Isomura, M.; Mendoza, A.; Baran, P. S. TwoPhase Synthesis of (-)-Taxuyunnanine D. J. Am. Chem. Soc. 2014, 136, 4909-4912.

${ }^{45}$ Hruszkewycz, D. P.; Miles, K. C.; Thiel, O. R.; Stahl, S. S. Co/NHPI-mediated Aerobic Oxygenation of Benzylic C-H Bonds in Pharmaceutically Relevant Molecules. Chem. Sci. 2017, 8, 1282-1287.

${ }^{46}$ Allen, S. E.; Walvoord, R. R.; Padilla-Salinas, R.; Kozlowski, M. C. Aerobic Copper-Catalyzed Organic Reactions. Chem. Rev. 2013, 113, 6234-6458.

${ }^{47}$ Cooper, J. C.; Luo, C.; Kameyama, R.; Humbeck, J. F. V. Combined Iron/Hydroxytriazole Dual Catalytic System for Site Selective Oxidation Adjacent to Azaheterocycles. J. Am. Chem. Soc. 2018, 140, 1243-1246.

${ }^{48}$ Nicolaou, K. C.; Baran, P. S.; Zhong, Y.-L. Selective Oxidation at Carbon Adjacent to Aromatic Systems with IBX. J. Am. Chem. Soc. 2001, 123, 3183-3185.

${ }^{49}$ Majima, K.; Takita, R.; Okada, A.; Ohshima, T.; Shibasaki, M. Catalytic Asymmetric Michael Reaction of $\beta$-Keto Esters: Effects of the Linker Heteroatom in Linked-BINOL. J. Am. Chem. Soc. 2003, 125, 15837-15845.

${ }^{50}$ Pellissier, H. Recent Developments in Asymmetric Cyclopropanation. Tetrahedron 2008, 64, 7041-7095.

${ }^{51}$ (a) Kuwajima, I.; Nakmura, E.; Shimizu, M. Fluoride-mediated Reactions of Enol Silyl Ethers. Regiospecific Monoalkylation of Ketones. J. Am. Chem. Soc. 1982, 104, 1025-1030. (b) Zhao, L.; Tsukano, C.; Kwon, E.; Shirakawa, H.; Kaneko, S.; Takemoto, Y.; Hirama, M. Competent Route to Unsymmetric Dimer Architectures: Total Syntheses of (-)-Lycodine and (-)-Complanadines A and B, and Evaluation of Their Neurite Outgrowth Activities. Chem. - Eur. J. 2017, 23, 802-812.

${ }^{52}$ Noyori, R.; Nishida, I.; Sakata, J. Tris(dialkylamino)sulfonium Enolates. Synthesis, Structure, and Reactions. J. Am. Chem. Soc. 1983, 105, 1598-1608.

${ }^{53}$ Fleming, I.; Roberts, R. S.; Smith, S. C. The Preparation and Analysis of the Phenyldimethylsilyllithium Reagent and its Reaction with Silyl Enol Ethers. J. Chem. Soc., Perkin Trans. 1 1998, 1209-1214.

${ }^{54}$ Maruoka, K.; Sato, J.; Yamamoto, H. Methylaluminum Bis(4bromo-2,6-di-tert-butylphenoxide) as a Key Reagent for Effecting Primary $\alpha$-Alkylation of Carbonyl Compounds. J. Am. Chem. Soc. 1992, 114, 4422-4423.

${ }^{55}$ For reviews involving opening of cyclopropanol, see: (a) Sugimura, T.; Sugimura, T.; Ryu, I. Isomerization of Oxygen-substituted Cyclopropanes by Metal Catalysis. J. Synth. Org. Chem., Jpn. 2000, 58, 1100. (b) Kulinkovich, O. G. The Chemistry of Cyclopropanols. Chem. Rev. 2003, 103, 25972632. (c) Nikolaev, A.; Orellana, A. Transition-Metal-Catalyzed $\mathrm{C}-\mathrm{C}$ and $\mathrm{C}-\mathrm{X}$ Bond-Forming Reactions Using Cyclopropanols. Synthesis 2016, 48, 1741-1768.

${ }^{56}$ For reviews on the strategic use of cyclopropanes in natural product total synthesis, see: Ebner, C.; Carreira, E. M. Cyclopropanation Strategies in Recent Total Syntheses. Chem. Rev. 2017, 117, 11651-11679. (b) Cai, X.; Liang, W.; Dai, M. Total Syntheses via Cyclopropanols. Tetrahedron 2019, 75, 193208.

${ }^{57}$ Lebel, H.; Marcoux, J.-F.; Molinaro, C.; Charette, A. B. Stereoselective Cyclopropanation Reactions. Chem. Rev. 2003, 103, 977-1050.

${ }^{58}$ (a) Ikura, K.; Ryu, I.; Ogawa, A.; Sonoda, N. Synthesis, Characterization, and Properties of Ethylene-coordinated Complexes of $\beta$-Platinum(II) Ketones. Organometallics 1991, 10, 528-529. (b) Ikura, K.; Ryu, I.; Kambe, N.; Sonoda, N. Room Temperature Isomerization of Siloxycyclopropanes to Silyl Ethers of 2-Methylenealkanols Catalyzed by Zeise's Dimer. $J$. Am. Chem. Soc., 1992, 114, 1520-1521. (c) Hoberg, J. O.; Jennings, P. W. Platinum(II)-Catalyzed Isomerization of Alkoxycyclopropanes to Alkylated Ketones. Organometallics 1996, 15, 3902-3904.

59 (a) Park, S.-B.; Cha, J. K. Palladium-Mediated Ring Opening of Hydroxycyclopropanes. Org. Lett. 2000, 2, 147-149. (b) Okumoto, H.; Jinnai, T.; Shimizu, H.; Harada, Y.; Mishima, H.; Suzuki, A. Pd-Catalyzed Ring Opening of Cyclopropanols. Synlett 2000, 5, 629-630.

${ }^{60}$ Schreiber, S. L.; Smith, D. B.; Schulte, G. Stereochemical Studies of Simple Cyclooctyl Systems. J. Org. Chem. 1989, 54, 5994-5996.

${ }^{61}$ Li, L.-Z.; Xiao, B.; Guo, Q.-X.; Xue, S. Ring-opening of Tertiary Cyclopropanols Derived from $\beta$-Diketones. Tetrahedron 2006, 62, 7762-7771.

${ }^{62}$ Ryu, I.; Murai, S.; Sonoda, N. The Reaction of Enol Ethers with Simmons-Smith Reagent. The Formation of Allylic Ethers. Chem. Lett. 1976, 1049-1050.

${ }^{63}$ Ryu, I.; Matsumoto, K.; Kameyama, Y.; Ando, M.; Kusumoto, N.; Ogawa, A.; Kambe, N.; Murai, S.; Sonoda, N. $\beta$-Cop- 
per(II) Ketones. Generation, Coupling, and Highly Stereoselective Trapping by Electron-deficient Acetylenes. J. Am. Chem. Soc. 1993, 115, 12330-12339.

${ }^{64}$ Shan, M.; O’Doherty, G. A. Synthesis of Carbasugar C-1 Phosphates via Pd-Catalyzed Cyclopropanol Ring Opening. Org. Lett. 2008, 10, 3381-3384.

${ }^{65}$ Brill, Z. G.; Condakes, Ting, C. P.; Maimone, T. J. Navigating the Chiral Pool in the Total Synthesis of Complex Terpene Natural Products. Chem. Rev. 2017, 117, 11753-11795.

${ }^{66}$ (a) Fehr, C.; Guntern, O. Efficient Synthesis of Enantiomerically Pure $\alpha$-Ionone from (R)- and (S)- $\alpha$-Damascone. Helv. Chim. Acta 1992, 75, 1023-1028. (b) Soorukram, D.; Knochel, P. Enantioselective Synthesis of $\alpha$-Ionone Derivatives Using an Anti $\mathrm{S}_{\mathrm{N}} 2$ ' Substitution of Functionalized Zinc Organometallics. Org. Lett. 2004, 6, 2409-2411. (c) Bovolenta, M.; Castronovo, F.; Vadalà, A.; Zanoni, G.; Vidari, G. A Simple and Efficient Highly Enantioselective Synthesis of $\alpha$-Ionone and $\alpha$-Damascone. J. Org. Chem. 2004, 69, 8959-8962.

${ }^{67}$ Aleu, J.; Brenna, E.; Fuganti, C.; Serra, S. Lipase-mediated Synthesis of the Enantiomeric Forms of 4,5-Epoxy-4,5-dihydro- $\alpha$-ionone and 5,6-Epoxy-5,6-dihydro- $\beta$-ionone. A New Direct Access to Enantiopure $(R)$ - and $(S)$ - $\alpha$-Ionone. J. Chem. Soc., Perkin Trans. 1 1999, 271-278.

${ }^{68}$ (a) Jacobsen, E. N.; Zhang, W.; Muci, A. R.; Ecker, J. R.; Deng, L. Highly Enantioselective Epoxidation Catalysts Derived from 1,2-Diaminocyclohexane. J. Am. Chem. Soc. 1991, 113, 7063-7064. (b) Brandes, B. D.; Jacobsen, E. N. Highly Enantioselective, Catalytic Epoxidation of Trisubstituted Olefins. J. Org. Chem. 1994, 59, 4378-4380.

${ }^{69}$ For examples of kinetic resolutions using Mn-Salen catalysts, see: (a) Vander, S. L.; Jacobsen, E. N. Kinetic Resolution of Racemic Chromenes via Asymmetric Epoxidation: Synthesis of (+)-Teretifolione B. J. Org. Chem. 1995, 60, 5380-5381. (b) Noguchi, Y.; Irie, R.; Fukuda, T.; Katsuki, T. Mn-salen Catalyzed Asymmetric Epoxidation of ( \pm )-3-Alkylindene: Reagent-dependent Stereoselectivity. Tetrahedron Lett. 1996, 37, 4533-4536.

${ }^{70}$ For a review on Mn-Salen catalyzed epoxidations, see: Katsuki, T. Some Recent Advances in Metallosalen Chemistry. Synlett 2003, 281-297.

${ }^{71}$ (a) Katsuki, T. Catalytic Asymmetric Oxidations Using Optically Active (Salen)manganese(III) Complexes as Catalysts. Coord. Chem. Rev. 1995, 140, 189-214. (b) Katsuki, T. Mnsalen Catalyst, Competitor of Enzymes, for Asymmetric Epoxidation. J. Mol. Catal. A Chem. 1996, 113, 87-107. (c) Katsuki, T. Chiral Metallosalen Complexes: Structures and Catalyst Tuning for Asymmetric Epoxidation and Cyclopropanation. Adv. Synth. Catal. 2002, 344, 131-147. (d) Irie, R.; Uchida, T.; Matsumoto, K. Katsuki Catalysts for Asymmetric Oxidation: Design Concepts, Serendipities for Breakthroughs, and Applications. Chem. Lett. 2015, 44, 1268-1283.

${ }^{72}$ Tu, Y.; Wang, Z.-X.; Shi, Y. An Efficient Asymmetric Epoxidation Method for trans-Olefins Mediated by a Fructose-Derived Ketone. J. Am. Chem. Soc. 1996, 118, 9806-9807.

${ }^{73}$ Mori, A.; Kato, T. $[\mathrm{Rh}(\mathrm{OH})(\mathrm{cod})] 2$ (cod = 1,5-Cyclooctadiene): A Highly Efficient Catalyst for 1,4-Hydrosilylation of $\alpha, \beta-U n-$ saturated Carbonyl Compounds. Synlett 2002, 7, 1167-1169.

74 (a) Watanabe, H.; Asami, M.; Nagai, Y. Convenient Laboratory Synthsis of Vinylic Silicon Compounds via the Reaction of Acetylene with Hydrosilanes Catalyzed by Group-VIII Metal Phosphine Complexes. J. Organomet. Chem. 1980, 195, 363-
373. (b) Riener, K.; Höger, M. P.; Gigler, P.; Kühn, F. E. Rhodium-Catalyzed Hydrosilylation of Ketones: Catalyst Development and Mechanistic Insights. ACS Catal. 2012, 2, 613621.

${ }^{75}$ Mahoney, W. S.; Brestensky, D. M.; Stryker, J. M. Selective Hydride-mediated Conjugate Reduction of $\alpha, \beta$-Unsaturated Carbonyl Compounds Using $\left[\left(\mathrm{Ph}_{3} \mathrm{P}\right) \mathrm{CuH}\right]_{6}$. J. Am. Chem. Soc. 1988, 110, 291-293.

${ }^{76}$ (a) Johnson, C. R.; Raheja, R. K. Hydrosilylation of Enones: Platinum Divinyltetramethyldisiloxane Complex in the Preparation of Triisopropylsilyl and Triphenylsilyl Enol Ethers. $J$. Org. Chem. 1994, 59, 2287-2288. (b) Deutsch, C.; Krause, N.; Lipshutz, B. H. CuH-Catalyzed Reactions. Chem. Rev. 2008, 108, 2916-2927.

77 (a) Four, P.; Guibe, F. Palladium-catalyzed Conjugate Reduction of $\alpha-\beta$-Unsaturated Carbonyl Compound with Tributyltin Hydride. The Promoting Influence of the Presence of Protonic or Lewis Acids. Tetrahedron Lett. 1982, 23, 1825-1828. (b) Sumida, Y.; Yorimitsu, H.; Oshima, K. Palladium-Catalyzed Preparation of Silyl Enolates from $\alpha, \beta$-Unsaturated Ketones or Cyclopropyl Ketones with Hydrosilanes. J. Org. Chem. 2009, 74, 7986-7989.

${ }^{78}$ Abe, H.; Ogura, Y.; Kobayashi, T.; Ito, H. Total Synthesis of Paralemnolide A. Org. Lett. 2017, 19, 5996-5999.

${ }^{79}$ Carpino, L. A.; Giza, C. A.; Carpino, B. A. O-Acylhydroxylamines. I. Synthesis of O-Benzoylhydroxylamine. J. Am. Chem. Soc. 1959, 81, 955-957.

${ }^{80}$ Bhattacharya, A. K.; Thyagarjan, G. Michaelis-Arbuzov Rearrangement. Chem. Rev. 1981, 81, 415-430.

${ }^{81}$ Szewczyk, S. M.; Zhao, Y.; Sakai, H. A.; Dube, P.; Newhouse, T. R. $\alpha, \beta$-Dehydrogenation of Esters with Free O-H and N-H Functionalities via Allyl-Palladium Catalysis. Tetrahedron, 2018, 74, 3293-3300.

${ }^{82}$ Bullock, M. W.; Hand, J. J.; Waletzky, E. Resolution and Racemization of $d l$-Tetramisole, $d l$-6-Phenyl-2,3,5,6-tetrahydroimidazo-[2,1-b]thiazole. J. Med. Chem. 1968, 11, 169171.

${ }^{83}$ Nakamura, A.; Nakada, M. Allylic Oxidations in Natural Product Synthesis. Synthesis 2013, 45, 1421-1451.

${ }^{84}$ Baker, L. A.; Williams, C. M.; Bernhardt, P. V.; Yanik, G. W. Azedaralide: Total Synthesis, Relative and Absolute Stereochemical Assignment. Tetrahedron 2006, 62, 7355-7360.

${ }^{85}$ For a recent review of vinyl nitroso compounds, see: Boyko, Y. D.; Dorokhov, V. S.; Sukhorukov, A. Y.; Ioffe, S. Conjugated Nitrosoalkenes as Michael Acceptors in Carbon-Carbon Bond Forming Reactions: A Review and Perspective. Beilstein J. Org. Chem. 2017, 13, 2214-2234.

${ }^{86}$ Demark, S. E.; Dappen, M. S. $\alpha$-Chloro Ketoximes as Precursors of Nitrosoalkenes: Preparation, Stereochemistry and Conformation. J. Org. Chem. 1984, 49, 798-806.

${ }^{87}$ Trost, B. M.; Barrett, D. Synthesis and Alkylation of Cyclopentane $\beta$-Ketoxime Sulones. $\alpha, \alpha$-Methylation-Alkynylation of Cyclopentanone. Tetrahedron, 1996, 52, 6903-6912.

${ }^{88}$ (a) Illia, K.; Kumar, P.; Weinreb, S. M. Construction of Bridged and Fused Ring Systems via Intramolecular Michael Reactions of Vinylnitroso Compounds. J. Am. Chem. Soc. 2007, 129, 10342-10343. (b) Sengupta, R.; Witek, J. A.; Weinreb, S. M. Stereochemical Investigation of Conjugate Additions of Carbon- and Heteronucleophiles to Ring-Substituted Nitrosocyclohexenes. Tetrahedron 2011, 67, 8229-8234.

${ }^{89}$ For reviews on the Mukaiyama-aldol reaction, see: (a) Matsuo, J.-i.; Murakami, M. The Mukaiyama Aldol Reaction: 40 Years 
of Continuous Development. Angew. Chem., Int. Ed. 2013, 52, 9109-9118. (b) Kan, S. B. J.; Ng, K. K.-H.; Paterson, I. The Impact of the Mukaiyama Aldol Reaction in Total Synthesis. Angew. Chem., Int. Ed. 2013, 52, 9097-9108.

${ }^{90}$ Newhouse, T. R.; Baran, P. S. If C-H Bonds Could Talk: Selective C-H Bond Oxidation. Angew. Chem., Int. Ed. 2011, 50, 3362-3374.

${ }^{91}$ Diao, T.; Stahl, S. S. Synthesis of Cyclic Enones via Direct Palladium-Catalyzed Aerobic Dehydrogenation of Ketones. $J$. Am. Chem. Soc. 2011, 133, 14566-14569.

92 Turlik, A.; Chen, Y.; Scruse, A. C.; Newhouse, T. R. Convergent Total Synthesis of Principinol D, a Rearranged Kaurane Diterpenoid. J. Am. Chem. Soc. 2019, 141, 8088-8092.

${ }^{93}$ Mukaiyama, T.; Matsuo, J.-i.; Kitagawa, H. A New and OnePot Synthesis of $\alpha, \beta$-Unsaturated Ketones by Dehydrogenation of Various Ketones with N-tert-Butyl Phenylsulfinimidoyl Chloride. Chem. Lett. 2000, 29, 1250-1251.

${ }^{94}$ Elkin, M.; Scruse, A. C.; Turlik, A.; Newhouse, T. R. Computational and Synthetic Investigation of Cationic Rearrangement in the Putative Biosynthesis of Justicane Triterpenoids. Angew. Chem., Int. Ed. 2019, 58, 1025-1029.

95 (a) Yu, J.-Q.; Corey, E. J. A Mild, Catalytic, and Highly Selective Method for the Oxidation of $\alpha, \beta$-Enones to 1,4-Enediones. J. Am. Chem. Soc. 2003, 125, 3232-3233. (b) Elkin, M.; Szewczyk, S. M.; Scruse, A. C.; Newhouse, T. R. Total Synthesis of $( \pm)$-Berkeleynone A. J. Am. Chem. Soc. 2017, 139, 1790-1793.

${ }^{96}$ Petersen, A. B.; Konotop, G.; Hanafiah, N. H. M.; Hammershøj, P.; Raab, M. S. Krämer, A.; Clausem, M. H. Strategies for Improving the Solubility and Metabolic Stability of Griseofulvin Analogues. Eur. J. Med. Chem. 2016, 116, 210-215.

${ }^{97}$ (a) Suzuki, M. A.; Noyori, W. R. Palladium(0)-Catalyzed Reaction of $\alpha, \beta$-Epoxy Ketones Leading to $\beta$-Diketones. J. Am. Chem. Soc. 1980, 102, 2095-2096. (b) Suzuki, M.; Watanabe, A.; Noyori, R. Palladium(0)-Catalyzed Isomerization of $\alpha, \beta$ Epoxy Ketones to 1,3-Diketones. Recl. Trav. Chim. Pays-Bas 1988, 107, 230-236.

98 (a) Inouye, Y.; Kojima, T.; Owada, J.; Kakisawa, H. Preparation of Bicyclo[3.3.1]nonane-2,4-dione Derivatives. Bull. Chem. Soc. Jpn. 1987, 60, 4369-4375. (b) Ragan, J. A.; Makowski, T. W.; am Ende, D. J.; Clifford, P. J.; Young, G. R.; Conrad, A. K.; Eisenbeis, S. A. A Practical Synthesis of Cycloheptane1,3-dione. Org. Proc. Res. Dev. 1998, 2, 379-381. (c) Sharp, M. J.; Fang, F. G. Efficient Construction of 6-Azasteroids: Dual Inhibitors of Steroidal $5 \alpha$-Reductase. Bioorg. Med.
Chem. Lett. 1998, 8, 3291-3294. (d) Lehmann, T. E.; Kuhn, O.; Krüger, J. Process Development and Pilot Plant Scale Synthesis of Spiro[3.5]nonane-6,8-dione. Org. Proc. Res. Dev. 2003, 7, 913-916. (e) For a review, see: Muzart, J. Pd-Mediated Reactions of Epoxides. Eur. J. Org. Chem. 2011, 47174741.

${ }^{99}$ Riveira, M. J.; Quiroga, G. N.; Mata, E. G.; Gandon, V.; Mischne, M. P. Cycloisomerization of Conjugated Trienones and Isomeric 2H-Pyrans: Unified Strategy toward Cyclopenta[b]furans. J. Org. Chem. 2015, 80, 6515-6519.

${ }^{100}$ Phillips, E. M.; Mesganaw, T.; Patel, A.; Duttwyler, S.; Mercado, B. Q.; Houk, K. N.; Ellman, J. A. Synthesis of ent-Ketorfanol via a $\mathrm{C}-\mathrm{H}$ Alkenylation/Torquoselective $6 \pi$ Electrocyclization Cascade. Angew. Chem., Int. Ed. 2015, 54, 12044-12048.

${ }^{101}$ For a review on electrocyclization reactions in biomimetic synthesis, see: Beaudry, C. M.; Malerich, J. P.; Trauner, D. Biosynthetic and Biomimetic Electrocyclizations. Chem. Rev. 2005, 105, 4757-4778.

${ }^{102}$ For select examples of retro-oxa- $6 \pi$-electrocyclizations, see: (a) Cerfontain, H.; Geenevasen, J. A.; van Noort, P. C. M. Photochemistry of Dienones. Part 7. On the Photosensitized Isomerization of (E)- $\beta$-Ionone and its Isomeric $\alpha$-Pyran. Evidence for Exciplex Formation between the $\alpha$-Pyran and Fluoren-9one. J. Chem. Soc., Perkin Trans. 2 1980, 1057-1062. (b) Sastry, M. N. V.; Claessens, S.; Habonimana, P.; De Kimpe, N. Synthesis of the Natural Products 3-Hydroxymollugin and 3-Methoxymollugin. J. Org. Chem. 2010, 75, 2274-2280. (c) Hall, A. J.; Roche, S. P.; West, L. M. Synthesis of Briarane Diterpenoids: Biomimetic Transannular Oxa- $6 \pi$-electrocyclization Induced by a UVA/UVC Photoswitch. Org. Lett. 2017, 19, 576-579.

${ }^{103}$ (a) Micale, N.; Zappala, M.; Grasso, S. Synthesis and Antitumor Activity of 1,3-Benzodioxole Derivatives. Farmaco 2002, 57, 853-859. (b) Asai, T.; Tsukada, K.; Ise, S.; Shirata, N.; Hashimoto, M.; Fujii, I.; Gomi, K.; Nakagawara, K.; Kodama, E. N.; Oshima, Y. Use of a Biosynthetic Intermediate to Explore the Chemical Diversity of Pseudo-natural Fungal Polyketides. Nat. Chem. 2015, 7, 737-743.

104 Liu. Y.; Holt, T. A.; Kutateladze, A.; Newhouse, T. R. Stereochemical Revision of Xylogranatin $\mathrm{F}$ by GIAO and DU8+ NMR Calculations. Chirality. 2020, 32, 515-523.

${ }^{105}$ Smith, S. G.; Goodman, J. M. Assigning Stereochemistry to Single Diastereoisomers by GIAO NMR Calculation: The DP4 Probability. J. Am. Chem. Soc. 2010, 132, 12946-12959. 


\title{
Strategies for the De Novo Synthesis of Highly Substituted Pyridine Scaffolds: Unified Total Synthesis of the Limonoid Alkaloids
}

\author{
Alexander W. Schuppe,$^{\dagger}$ Yannan Liu, ${ }^{\dagger}$ Yizhou Zhao, Sebastian Ibarraran, David Huang, Emma Wang, \\ Jaehoo Lee, J. Patrick Loria, Timothy R. Newhouse* \\ Department of Chemistry, Yale University, 225 Prospect St., New Haven, \\ Connecticut 06520-8107, United States \\ *E-mail: timothy.newhouse@yale.edu
}


Synthesis and spectroscopic data for tricyclic pyridine (4-1)

Synthesis and spectroscopic data for pyridine acetate (4-9).

SI13-SI17

Synthesis of tetracyclic pyridine (3-1) SI18

Synthesis and spectroscopic data for iodoacetate (5-4).

SI19-SI24

Synthesis and spectroscopic data for iododienoate (SI-3).

SI25-SI27

Synthesis and spectroscopic data for stannyl dienoate (3-4)

SI28-SI30

General procedures for $\beta$-stannylation screen

SI31-SI32

Synthesis and spectroscopic data for $\beta$-allylation product (6-5)

SI32-SI34

Synthesis and spectroscopic data for $\beta$-stannyl ketone (6-6)

SI35-SI37

Synthesis and spectroscopic data for PfBz-oxime (6-13)

SI38-SI41

Synthesis and spectroscopic data for Ac-oxime (6-15)

SI42-SI44

Synthesis and spectroscopic data for Piv-oxime (6-14)

SI45-SI47

Synthesis and spectroscopic data for $\beta$-stannyl enone (7-3)

SI48-SI50

General procedure for Liebeskind pyridine synthesis screen SI51

Synthesis and spectroscopic data for des-methyl pyridine (7-2)

Synthesis of ketone (9-1) using $\mathrm{Mn}(\mathrm{OAc})_{3}$

SI51-SI53

Synthesis and spectroscopic data for benzylic ketone (9-6) SI54

Synthesis of xylogranatopyridine B (1-1) by fluoride alkylation

SI55-SI59

Synthesis and spectroscopic data for TBS-cyclopropanol (SI-5) SI60

Synthesis and spectroscopic data for enone (9-8)

SI61-SI63

Synthesis and spectroscopic data for exocyclic enone (11-7)

SI64-SI69

Synthesis and spectroscopic data for allylic bromide (10-3)

SI70-SI74

Synthesis and spectroscopic data for allylic sulfone (10-4)

SI75-SI77

Synthesis and spectroscopic data for TBS-oxime (12-8)

SI78-SI80

Synthesis and spectroscopic data for TBS-sulfone (10-6).

SI81-SI83

Synthesis and spectroscopic data for $\alpha, \beta$-unsaturated oxime (12-12)

SI84-SI87

Synthesis and spectroscopic data for TES-enol ether (13-2)

Synthesis and spectroscopic data for Mukaiyama aldol coupling product (13-1).. SI94-SI100

Synthesis and spectroscopic data for C3-deoxy-xylogranatin F (10-1).

Synthesis and spectroscopic data for methyl enol ether (SI-7)

SI101-SI103

Synthesis and spectroscopic data for vinylogous ester (14-4)

SI104-SI106

Synthesis of 1,3-diketone (10-9) from the vinylogous ester SI107-SI109

Synthesis and spectroscopic data for pyran (15-5)

SI110

Synthesis and spectroscopic data for pyran alcohol (SI-8)

Synthesis and spectroscopic data for $(+)$-granatoine (1-4)

SI111-SI113

$\mathrm{X}$-ray experimental for sulfone $(+)-\mathbf{1 2 - 1 0}$

SI114-SI116

SI117-SI122

PTP1B inhibition assay

SI123-SI125

Computational general information

SI126

Benzylic oxidation calculations

SI127

Pyran formation calculations

SI127-SI159

GIAO NMR calculations

SI160-SI168

References

SI169-SI330

SI331-SI332 


\section{General Experimental}

General Experimental Procedures: All reactions were carried out under an inert nitrogen atmosphere with dry solvents under anhydrous conditions unless otherwise stated. All reactions were capped with a rubber septum, or Teflon-coated silicon microwave cap unless otherwise stated. Stainless steel cannula or syringe were used to transfer solvent, and air- and moisture- sensitive liquid reagents. Reactions were monitored by thin-layer chromatography (TLC) and carried out on $0.25 \mathrm{~mm}$ Merck silica gel plates (60F254) using UV light as the visualizing agent and potassium permanganate or an acidic solution of $p$ anisaldehyde as developing agents. Flash column chromatography employed SiliaFlash ${ }^{\circledR}$ P $60(40-60 \mu \mathrm{m}$, 230-400 mesh) silica gel purchased from SiliCycle Inc. Ozonolysis reactions were conducted using an A2Z Ozone 856689005177 SP - 16G Swimming Pool Ozone Generator with a 16000 MG/H adjustable ozone concentration.

Materials: All reaction solvents were purified using a Seca solvent purification system by Glass Contour with the exception of trifluoroethanol, 1,4-dioxane, 1,2-dichloroethane (DCE) and ethyl acetate (EtOAc). Trifluoroethanol was distilled over $\mathrm{CaSO}_{4}$. 1,4-dioxane, DCE were purchased from Sigma-Aldrich and used as received. $N, N$-diisopropylamine, and triethylamine were distilled over $\mathrm{CaH}_{2} . n-\mathrm{BuLi}(2.5 \mathrm{M}$ in hexanes), $\mathrm{Zn}(\mathrm{TMP}) 2\left(0.5 \mathrm{M}\right.$ in toluene), $\mathrm{MeMgBr}\left(3.0 \mathrm{M}\right.$ in $\left.\mathrm{Et}_{2} \mathrm{O}\right), \mathrm{Et}_{2} \mathrm{Zn}(15 \mathrm{wt} \%$ in toluene or $1.0 \mathrm{M}$ in hexanes), $\mathrm{Me} 2 \mathrm{Zn}\left(2.0 \mathrm{M}\right.$ in toluene), $\mathrm{MeLi}\left(1.6 \mathrm{M}\right.$ in $\left.\mathrm{Et}_{2} \mathrm{O}\right)$, dicyclopentylzinc $\left(0.4 \mathrm{M}\right.$ in $\left.\mathrm{Et}_{2} \mathrm{O}\right)$, diisoproylzinc (1.0 M in toluene), cyclohexylmagnesium chloride (1.0 $\mathrm{M}$ in 2-MeTHF), KHMDS, and $\mathrm{LiBH}_{4}\left(2.0 \mathrm{M}\right.$ in THF) were purchased from Sigma-Aldrich. $[\mathrm{Pd}(\text { allyl }) \mathrm{Cl}]_{2}$, and $[\mathrm{Rh}(\mathrm{cod})(\mathrm{OH})]_{2}$, $\mathrm{Pd}(\mathrm{OAc})_{2}$, and $\mathrm{Pd}(\mathrm{TFA})_{2}$ were purchased from Strem Chemicals. $(S, S)-(+)-N, N^{\prime}$-Bis(3,5-di-tertbutylsalicylidene)-1,2-cyclohexanediaminomanganese(III) chloride was purchased from Combi-Blocks. $\mathrm{SeO}_{2}$ was purchased from Oakwood, and ground to a fine powder prior to use. Burgess reagent was prepared by a known procedure ${ }^{1}$ and recrystallized from THF. Commercial concentrated Clorox ${ }^{\circledR}$ bleach solution was used as received. The molarity of $n$-BuLi solutions were determined by titration with $N$ benzylbenzamide. All other reagents were used as received without further purification, unless otherwise stated.

Instrumentation: All new compounds were characterized by means of ${ }^{1} \mathrm{H} \mathrm{NMR},{ }^{13} \mathrm{C}$ NMR, ${ }^{19} \mathrm{~F}$ NMR, FT-IR (thin film), and HR-MS. Copies of the ${ }^{1} \mathrm{H}$ - and ${ }^{13} \mathrm{C}-\mathrm{NMR}$ spectra can be found at the end of each experimental procedure. NMR spectra were recorded using a Varian $400 \mathrm{MHz}$ NMR spectrometer, Varian $500 \mathrm{MHz}$ NMR spectrometer, or a Varian $600 \mathrm{MHz}$ NMR spectrometer. All ${ }^{1} \mathrm{H}-\mathrm{NMR}$ data are reported in $\delta$ units, parts per million ( $\mathrm{ppm})$, and were calibrated relative to the signals for residual chloroform (7.26 $\mathrm{ppm})$ in deuterochloroform $\left(\mathrm{CDCl}_{3}\right)$ or residual benzene $(7.16 \mathrm{ppm})$ in deuterobenzene $\left(\mathrm{C}_{6} \mathrm{D}_{6}\right)$. All ${ }^{13} \mathrm{C}$ NMR data are reported in ppm relative to $\mathrm{CDCl}_{3}(77.16 \mathrm{ppm})$ and were obtained with ${ }^{1} \mathrm{H}$ decoupling unless otherwise stated. The following abbreviations or combinations thereof were used to explain the multiplicities: $\mathrm{s}=$ singlet, $\mathrm{d}=$ doublet, $\mathrm{t}=$ triplet, $\mathrm{q}=$ quartet, $\mathrm{br}=$ broad, $\mathrm{m}=$ multiplet, and $\mathrm{a}=$ apparent . All IR spectra were taken on an FT-IR/Raman Thermo Nicolet 6700. High resolution mass spectra (HRMS) were recorded on a Bruker microTOF mass spectrometer using ESI-TOF (electrospray ionizationtime of flight). Optical rotation data was obtained using a Perkin-Elmer 341 and Autopol VI automatic polarimeter. HPLC data was obtained using Agilent 1260 HPLC. 


\section{Optimization Schemes}

\section{Scheme SI1. Optimization of the Benzylic Oxidation}

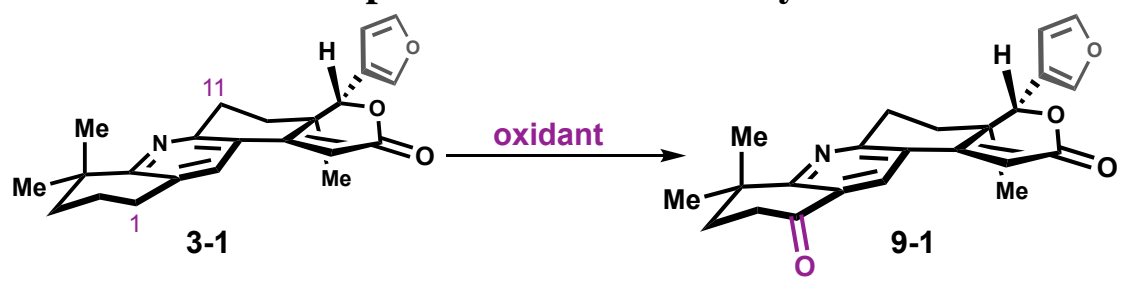

\begin{tabular}{|c|c|c|c|}
\hline Entry & Conditions & Solvent & $\%$ Yield $^{a}$ \\
\hline \multicolumn{4}{|c|}{ chromium oxidants } \\
\hline 1 & $\mathrm{Cr}(\mathrm{V})$ (10 equiv), 15-crown-5 & $\mathrm{MeCN}$ & $61(69)^{b}$ \\
\hline 2 & PCC (1 equiv), NaOAc, Celite & DMF & $0(7)^{c}$ \\
\hline 3 & PDC (1 equiv), $\mathrm{NaOAc}$, Celite & DMF & $0(12)^{d}$ \\
\hline 4 & $\mathrm{CrO}_{3}$ (3 equiv), imid. & $\mathrm{CH}_{2} \mathrm{Cl}_{2}$ & $0(10)^{d}$ \\
\hline 5 & $\mathrm{CrO}_{3}$ (3 equiv), DMPU & $\mathrm{CH}_{2} \mathrm{Cl}_{2}$ & $0(46)^{d}$ \\
\hline 6 & $\mathrm{CrO}_{3}$ (3 equiv), 1,3-DMP & $\mathrm{CH}_{2} \mathrm{Cl}_{2}$ & $0(13)^{d}$ \\
\hline 7 & $\mathrm{CrO}_{3}$ (3 equiv), 2,2'-bipyridine & $\mathrm{CH}_{2} \mathrm{Cl}_{2}$ & $0(0)^{d}$ \\
\hline \multicolumn{4}{|c|}{ TBHP + metal salt } \\
\hline 9 & $10 \mathrm{~mol} \% \mathrm{Mn}(\mathrm{OAc})_{3}$, TBHP & $\mathrm{MeCN}$ & $33(67)^{d, e}$ \\
\hline 10 & $10 \mathrm{~mol} \% \mathrm{Mn}(\mathrm{OAc})_{2}, \mathrm{TBHP}$ & $\mathrm{MeCN}$ & $31(69)^{d, e}$ \\
\hline 11 & $10 \mathrm{~mol} \% \mathrm{Mn}(\mathrm{OTf})_{2}, \mathrm{TBHP}$ & $\mathrm{MeCN}$ & $27(60)^{d, e}$ \\
\hline 12 & $10 \mathrm{~mol} \% \mathrm{Mn}(\mathrm{TMP}) \mathrm{Cl}$, TBHP & $\mathrm{MeCN}$ & $35(68)^{d, e}$ \\
\hline 13 & $10 \mathrm{~mol} \% \mathrm{Pd} / \mathrm{C}$, TBHP & $\mathrm{MeCN}$ & $22(40)^{d, e}$ \\
\hline 14 & $\mathrm{Sc}(\mathrm{OTf})_{3}$, picolinic acid, TBHP & $\mathrm{py} / \mathrm{AcOH}$ & $26(82)^{c, e}$ \\
\hline \multicolumn{4}{|c|}{ other oxidants } \\
\hline 15 & $\mathrm{SeO}_{2}$ (10 equiv) & 1,4-dioxane/AcOH (10:1) & $4(18)^{c}$ \\
\hline 16 & IBX (3 equiv) & $\mathrm{C}_{6} \mathrm{~F}_{6} / \mathrm{DMSO}(2: 1)$ & $7(94)^{c}$ \\
\hline 17 & $10 \mathrm{~mol} \% \mathrm{Co}(\mathrm{OAc})_{2}, \mathrm{NHPI}$ & EtOAc & $41(68)^{d}$ \\
\hline 18 & $10 \mathrm{~mol} \% \mathrm{Cu}(\mathrm{OAc})_{2}, \mathrm{NHPI},(\mathrm{BzO})_{2}$ & $\mathrm{MeCN}$ & $7(100)^{d}$ \\
\hline 19 & $10 \mathrm{~mol} \% \mathrm{Pd}(\mathrm{OAc})_{2}, \mathrm{BQ}$ & 1,4-dioxane/AcOH (2:1) & $0(8)^{c}$ \\
\hline & $=$ highest yield $\quad=$ most scalable & & \\
\hline
\end{tabular}

${ }^{a}$ Yield of the crude reaction mixture on $0.03 \mathrm{mmol}$ scale, was determined by ${ }^{1} \mathrm{H}$ NMR using 1,3,5-trimethoxybenzene as an internal standard. Conversion of 3-1 in parenthesis. ${ }^{b}$ The reaction mixture was heated to $80{ }^{\circ} \mathrm{C}$. The reaction mixture was heated to $85^{\circ} \mathrm{C}$. ${ }^{d} \mathrm{The}$ reaction mixture was stirred at $23^{\circ} \mathrm{C} .{ }^{e} 5.0$ equiv of anhydrous TBHP in decane.

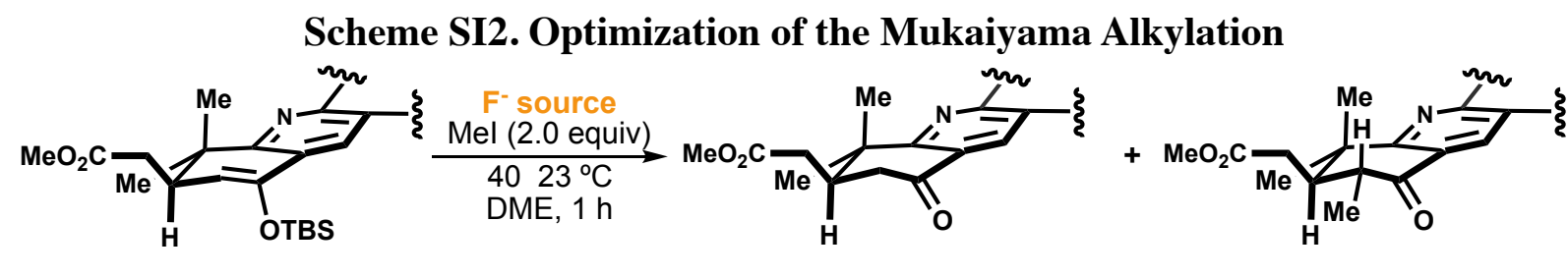

9-5

$9-6$

xylogranatopyridine B (1-1)

$\begin{array}{cccc}\text { Entry } & \text { F }^{-} \text {source } & \text { Additive } & \text { \% Yield (9-6:1-1) } \\ & & & \\ \mathbf{1} & \text { TMAF } & \text { HMPA + 4A MS } & 27: 25^{b} \\ \mathbf{2} & \text { TMAF } & \text { HMPA } & 39: 13^{b} \\ \mathbf{3} & \text { TMAF } & 4 \AA \mathrm{MS} & 41: 6^{b} \\ \mathbf{4} & \text { TMAF } & \text { none } & 48: 3^{b} \\ \mathbf{5} & \text { TBAF } & 4 \AA \mathrm{MS} & 66: 0 \\ \mathbf{6} & \text { TBAT } & 4 \AA \mathrm{MS} & 56: 0 \\ \mathbf{7} & \text { TASF(Et) } & 4 \AA \mathrm{MS} & 42: 12^{b} \\ \mathbf{8} & \mathrm{BTAF} & 4 \AA \mathrm{MS} & 24: 25 \\ \mathbf{9} & \mathrm{CsF} & 4 \AA \mathrm{MS} & 23: 0^{b}\end{array}$

${ }^{a}$ Yield of the crude reaction mixture on $0.01 \mathrm{mmol}$ scale, was determined by ${ }^{1} \mathrm{H}$ NMR using 1,3,5-trimethoxybenzene as an internal standard. Conversion of 9-5 in parenthesis. ${ }^{b} 1: 1 \mathrm{dr}$. 


\section{Scheme SI3. Optimization of the Cyclopropane Opening}

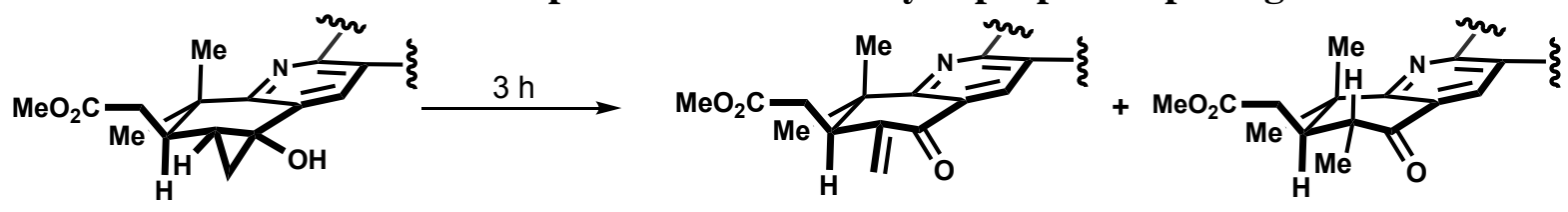

9-7

9-8

xylogranatopyridine B (1-1)

$\begin{array}{cc}\text { Entry } & \text { Conditions } \\ \mathbf{1} & 10 \mathrm{~mol} \mathrm{\%}\left[\mathrm{PtCl}_{2}\left(\mathrm{C}_{2} \mathrm{H}_{4}\right)\right]_{2} \\ \mathbf{2} & 10 \mathrm{~mol} \mathrm{\%}\left[\mathrm{PtCl}_{2}\left(\mathrm{C}_{2} \mathrm{H}_{4}\right)\right]_{2} \\ \mathbf{3} & 10 \mathrm{~mol} \mathrm{\%}\left[\mathrm{PtCl}_{2}\left(\mathrm{C}_{2} \mathrm{H}_{4}\right)\right]_{2} \\ \mathbf{4} & 10 \mathrm{~mol} \mathrm{\%}\left[\mathrm{PtCl}_{2}\left(\mathrm{C}_{2} \mathrm{H}_{4}\right)\right]_{2} \\ \mathbf{5} & 10 \mathrm{~mol} \mathrm{\%} \mathrm{PdCl} 2, \mathrm{CSA} \\ \mathbf{6} & \mathrm{Amberylst} 15 \\ \mathbf{7} & \mathrm{TsOH}(3 \text { equiv) } \\ \mathbf{8} & \mathrm{Et} \mathrm{Zn} \\ \mathbf{9} & \mathrm{Cu}\left(\mathrm{BF}_{4}\right)_{2}\end{array}$

Solvent

$\%$ Yield(1-1:9-8) ${ }^{a}$

DCM 73:4 $(100)^{c}$

DCE $\quad 48: 7(100)^{c}$

$\mathrm{Et}_{2} \mathrm{O} \quad 19: 33(81)^{c}$

$\mathrm{CF}_{3} \mathrm{Ph} \quad 25: 18(79)^{d}$

$\mathrm{MeCN} \quad 0: 16(46)^{e}$

PhMe 0:0 (73)

PhMe/DCE (3:1)

$\mathrm{PhMe}$

$23^{b}: 7(69)^{e}$

$\mathrm{MeOH}$

$0: 16(46)^{d}$

complex mixture ${ }^{c}$

${ }^{a}$ Yield of the crude reaction mixture on $0.01 \mathrm{mmol}$ scale, was determined by ${ }^{1} \mathrm{H}$ NMR using 1,3,5-trimethoxybenzene as an internal standard. Conversion of 9-7 in parenthesis. ${ }^{b} 1: 1 \mathrm{dr}$. ${ }^{c}$ reaction was conducted at $23{ }^{\circ} \mathrm{C}$. ${ }^{d}$ reaction mixture was heated to $60{ }^{\circ} \mathrm{C}$. ${ }^{e}$ reaction mixture was heated to $100{ }^{\circ} \mathrm{C}$ for $12 \mathrm{~h}$.

\section{Scheme SI4. Optimization of the Allylic Oxidation}

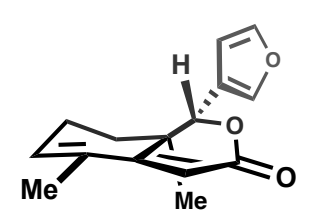

12-1

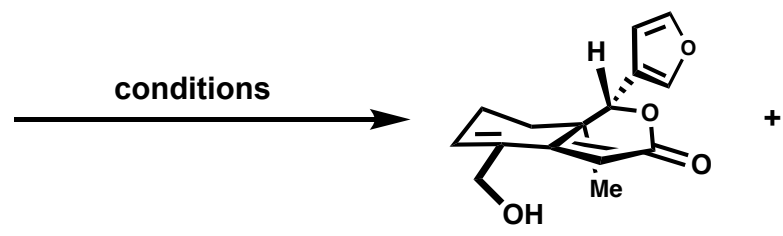

12-7

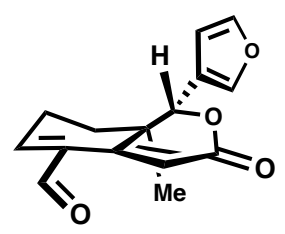

10-7

\begin{tabular}{|c|c|c|c|c|}
\hline Entry & Oxidant & Additive & $\begin{array}{c}\text { Solvent/ } \\
\text { Temperatue/Time }\end{array}$ & $\%$ Yield (12-7:12-1:10-7) ${ }^{a}$ \\
\hline & \multicolumn{4}{|c|}{ oxidant stoichiometry } \\
\hline 1 & 10.0 equiv $\mathrm{SeO}_{2}$ & 5.0 equiv $\mathrm{Na}_{2} \mathrm{HPO}_{4}$ & dioxane, $100^{\circ} \mathrm{C}, 15 \mathrm{~h}$ & $48: 21: 21$ \\
\hline 2 & 5.0 equiv $\mathrm{SeO}_{2}$ & 5.0 equiv $\mathrm{Na}_{2} \mathrm{HPO}_{4}$ & dioxane, $100^{\circ} \mathrm{C}, 15 \mathrm{~h}$ & $47: 20: 19$ \\
\hline 3 & 2.5 equiv $\mathrm{SeO}_{2}$ & 5.0 equiv $\mathrm{Na}_{2} \mathrm{HPO}_{4}$ & dioxane, $100^{\circ} \mathrm{C}, 15 \mathrm{~h}$ & $45: 22: 20$ \\
\hline \multirow[t]{2}{*}{4} & 1.5 equiv $\mathrm{SeO}_{2}$ & 5.0 equiv $\mathrm{Na}_{2} \mathrm{HPO}_{4}$ & dioxane, $100^{\circ} \mathrm{C}, 15 \mathrm{~h}$ & $36: 49: 9$ \\
\hline & \multicolumn{4}{|c|}{ additive } \\
\hline 5 & 2.5 equiv $\mathrm{SeO}_{2}$ & 5.0 equiv $\mathrm{K}_{2} \mathrm{HPO}_{4}$ & dioxane, $100^{\circ} \mathrm{C}, 15 \mathrm{~h}$ & $27: 59: 6$ \\
\hline 6 & 2.5 equiv $\mathrm{SeO}_{2}$ & 5.0 equiv $\mathrm{Na}_{2} \mathrm{HPO}_{4}+15 \mathrm{mg}$ sand & dioxane, $100^{\circ} \mathrm{C}, 15 \mathrm{~h}$ & $29: 35: 12$ \\
\hline 7 & 2.5 equiv $\mathrm{SeO}_{2}$ & 5.0 equiv $\mathrm{Na}_{2} \mathrm{HPO}_{4}+15 \mathrm{mg} \mathrm{SiO}_{2}$ & dioxane, $100^{\circ} \mathrm{C}, 15 \mathrm{~h}$ & $25: 39: 9$ \\
\hline \multirow[t]{2}{*}{8} & 2.5 equiv $\mathrm{SeO}_{2}$ & 5.0 equiv TBHP + 5.0 equiv py & dioxane, $100^{\circ} \mathrm{C}, 15 \mathrm{~h}$ & $6: 88: 1$ \\
\hline & \multicolumn{4}{|c|}{ other oxidants } \\
\hline 9 & 3.0 equiv $\mathrm{CrO}_{3}$ & 3.0 equiv 3,5-dimethylpyrazole & $\mathrm{DCM}, 23^{\circ} \mathrm{C}, 15 \mathrm{~h}$ & $0: 53: 0$ \\
\hline 10 & $1 \mathrm{~mol} \% \mathrm{Rh}_{2}(\mathrm{cap})_{4}$ & 0.5 equiv $\mathrm{K}_{2} \mathrm{CO}_{3}, 5.0$ equiv TBHP & $\mathrm{DCM}, 23^{\circ} \mathrm{C}, 15 \mathrm{~h}$ & $5: 0: 4$ \\
\hline 11 & 0.3 equiv $\mathrm{Mn}(\mathrm{OAc})_{3}$ & 5.0 equiv TBHP & $\mathrm{CH}_{3} \mathrm{CN}, 80^{\circ} \mathrm{C}, 15 \mathrm{~h}$ & $16: 19: 0$ \\
\hline 12 & $\mathrm{Cr}(\mathrm{V})^{b}$ & 5.0 equiv TBHP, 15 -crown-5 & $\mathrm{CH}_{3} \mathrm{CN}, 80^{\circ} \mathrm{C}, 15 \mathrm{~h}$ & $0: 77: 0$ \\
\hline 13 & 0.2 equiv $\mathrm{Pd}(\mathrm{OH})_{2}$ on $\mathrm{C}$ & 0.25 equiv $\mathrm{K}_{2} \mathrm{CO}_{3}, 5.0$ equiv TBHP & $\mathrm{DCM}, 23^{\circ} \mathrm{C}, 17 \mathrm{~h}$ & $15: 15: 0$ \\
\hline 14 & 0.5 equiv $\mathrm{CuBr}$ & 5.0 equiv TBHP & benzene, $60^{\circ} \mathrm{C}, 17 \mathrm{~h}$ & $0: 0: 0$ \\
\hline 15 & 0.5 equiv Cul & 5.0 equiv TBHP & $\mathrm{CH}_{3} \mathrm{CN}, 60^{\circ} \mathrm{C}, 17 \mathrm{~h}$ & $5: 45: 0$ \\
\hline 16 & $5 \mathrm{~mol} \% \mathrm{RuCl}_{3} \cdot \mathrm{H}_{2} \mathrm{O}$ & 10.0 equiv TBHP & DCE, $23^{\circ} \mathrm{C}, 17 \mathrm{~h}$ & $0: 18: 0$ \\
\hline 17 & 0.1 equiv $\mathrm{Co}(\mathrm{acac})_{2}$ & 0.5 equiv NHPI, $\mathrm{O}_{2}$ & $\mathrm{CH}_{3} \mathrm{CN}, 60^{\circ} \mathrm{C}, 17 \mathrm{~h}$ & $8: 53: 0$ \\
\hline 18 & 0.1 equiv $\mathrm{Co}(\mathrm{OAc})_{2} \cdot 4 \mathrm{H}_{2} \mathrm{O}$ & 0.5 equiv NHPI, $\mathrm{O}_{2}$ & HFIP, $23^{\circ} \mathrm{C}, 17 \mathrm{~h}$ & $7: 29: 0$ \\
\hline 19 & 0.2 equiv $\mathrm{FeCl}_{3}$ & 10.0 equiv TBHP & $\mathrm{CH}_{3} \mathrm{CN}, 60^{\circ} \mathrm{C}, 17 \mathrm{~h}$ & $9: 69: 0$ \\
\hline
\end{tabular}

${ }^{a}$ Yield of the crude reaction mixture on $0.2 \mathrm{mmol}$ scale, was determined by ${ }^{1} \mathrm{H}$ NMR using 1,2-dibromomethane as an internal standard. Conversion of 12-1 in parenthesis. ${ }^{b} \mathrm{Cr}(\mathrm{V})=\mathrm{Na}[\mathrm{OCr}(\mathrm{O} 2 \mathrm{COC}(\mathrm{CH} 3) \mathrm{C} 2 \mathrm{H} 5) 2]$. 


\section{Scheme SI5. Optimization of the Knoevenagel Condensation}

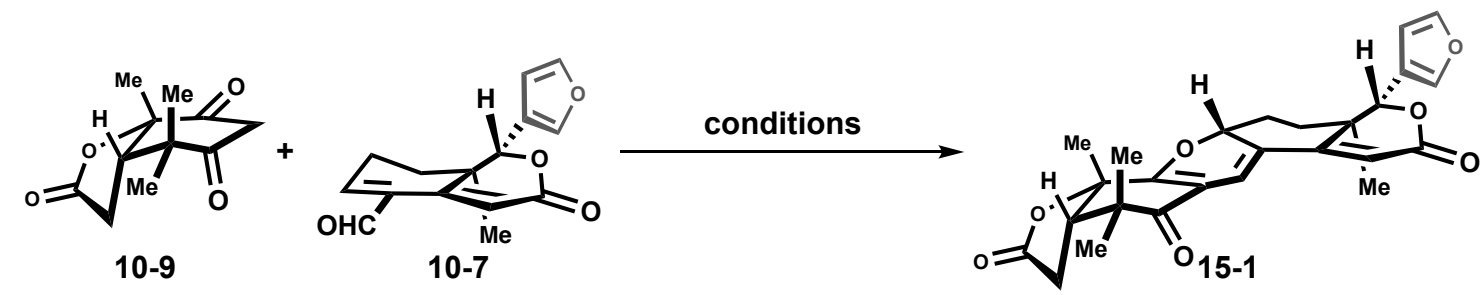

\begin{tabular}{|c|c|c|c|c|}
\hline Entry & Catalyst & Solvent & Temperature & $\%$ Yielc \\
\hline \multicolumn{5}{|c|}{ base + solvent } \\
\hline 1 & DBU & $\mathrm{MeCN}$ & $23^{\circ} \mathrm{C}$ & 0 \\
\hline 2 & piperidine/AcOH (0.1 equiv) & THF & $50^{\circ} \mathrm{C}$ & 5 \\
\hline 3 & $\mathrm{Et}_{3} \mathrm{~N}$ & $\mathrm{EtOH}$ & $65^{\circ} \mathrm{C}$ & 0 \\
\hline 4 & $\mathrm{BF}_{3} \cdot \mathrm{OEt}_{2}$ & THF & $-78^{\circ} \mathrm{C}$ to $23^{\circ} \mathrm{C}$ & 0 \\
\hline 5 & $\mathrm{Zn}(\mathrm{TMP})_{2}$ & THF & $-78^{\circ} \mathrm{C}$ to $23^{\circ} \mathrm{C}$ & 0 \\
\hline 6 & KHMDS & THF & $-78^{\circ} \mathrm{C}$ to $23^{\circ} \mathrm{C}$ & 0 \\
\hline 7 & NaHMDS & THF & $-78^{\circ} \mathrm{C}$ to $23^{\circ} \mathrm{C}$ & 0 \\
\hline 8 & $\mathrm{NaHMDS}+\mathrm{TiCl}(i-\mathrm{PrO})_{3}$ & THF & $-78^{\circ} \mathrm{C}$ to $23^{\circ} \mathrm{C}$ & 0 \\
\hline 9 & EDDA & DCM & $35^{\circ} \mathrm{C}$ & 25 \\
\hline \multicolumn{5}{|c|}{ solvent } \\
\hline 10 & 0.5 equiv EDDA & DCE & $65^{\circ} \mathrm{C}$ & 48 \\
\hline 11 & 0.5 equiv EDDA & $\mathrm{PhCF}_{3}$ & $65^{\circ} \mathrm{C}$ & 16 \\
\hline 12 & 0.5 equiv EDDA & DMSO & $65^{\circ} \mathrm{C}$ & 4 \\
\hline 13 & 0.5 equiv EDDA & $\mathrm{MeCN}$ & $65^{\circ} \mathrm{C}$ & 32 \\
\hline 14 & 0.5 equiv EDDA & $\mathrm{DCE}^{b}$ & $65^{\circ} \mathrm{C}$ & 52 \\
\hline 15 & 0.5 equiv EDDA & DCE & $85^{\circ} \mathrm{C}$ & 57 \\
\hline 16 & 1.0 equiv EDDA & DCE & $65^{\circ} \mathrm{C}$ & 42 \\
\hline 17 & 0.7 equiv EDDA & $\mathrm{DCE}^{b}$ & $65^{\circ} \mathrm{C}$ & 68 \\
\hline
\end{tabular}

${ }^{a}$ Yield of the crude reaction mixture on $0.05 \mathrm{mmol}$ scale, was determined by ${ }^{1} \mathrm{H}$ NMR using 1,2-dibromomethane as an internal standard.

${ }^{b}$ No aqueous workup was conducted. 


\section{Scheme SI6. Optimization of the Pyran Reduction}
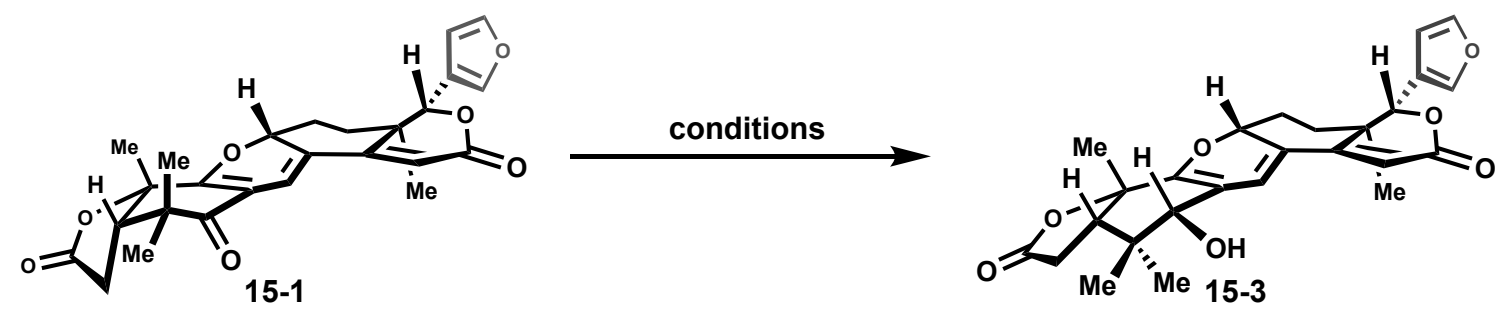

\begin{tabular}{|c|c|c|c|c|}
\hline Entry & Conditions & Solvent & Temperature/Time & $\%$ Yield $^{a}$ \\
\hline \multicolumn{5}{|c|}{ other reductants } \\
\hline 1 & 2.0 equiv $\mathrm{NaBH}(\mathrm{OAc})_{3}$ & THF & $0^{\circ} \mathrm{C}$ to $23^{\circ} \mathrm{C}, 2 \mathrm{~h}$ & $0(15)$ \\
\hline 2 & 2.0 equiv $\mathrm{Zn}(\mathrm{BH})_{4}$ & THF & $0^{\circ} \mathrm{C}$ to $23^{\circ} \mathrm{C}, 2 \mathrm{~h}$ & $0(99)$ \\
\hline 3 & 2.4 equiv $\mathrm{LiBuBH}_{3}$ & THF & $-78^{\circ} \mathrm{C}, 2 \mathrm{~h}$ & $0(99)$ \\
\hline 4 & 9.0 equiv $\mathrm{BH}_{3} \cdot \mathrm{DMS}, 0.5$ equiv $\mathrm{CBS}$ ligand & THF & $-20^{\circ} \mathrm{C}$ to $23^{\circ} \mathrm{C}, 12 \mathrm{~h}$ & $0(99)$ \\
\hline 5 & 0.2 equiv $\mathrm{Ce}(\mathrm{OTf})_{3} \cdot \mathrm{xH}_{2} \mathrm{O}, 4.0$ equiv $\mathrm{NaBH}_{4}$ & 2-MeTHF & $0^{\circ} \mathrm{C}$ to $23^{\circ} \mathrm{C}, 2 \mathrm{~h}$ & $0(99)$ \\
\hline 6 & 2.0 equiv $\mathrm{LiEt}_{3} \mathrm{BH}$ & THF & $-30^{\circ} \mathrm{C}, 2 \mathrm{~h}$ & $0(99)$ \\
\hline 7 & $\begin{array}{c}0.2 \text { equiv } \mathrm{Cu}(\mathrm{OAc})_{2} \cdot \mathrm{H}_{2} \mathrm{O}, 0.2 \text { equiv } \mathrm{SEGPHOS}, \\
3.0 \text { equiv DEMS }\end{array}$ & $\mathrm{Et}_{2} \mathrm{O}$ & $-20^{\circ} \mathrm{C}$ to $23^{\circ} \mathrm{C}, 12 \mathrm{~h}$ & $0(99)$ \\
\hline \multicolumn{5}{|c|}{ solvent for Luche reduction } \\
\hline 8 & 2.0 equiv $\mathrm{CeCl}_{3} \cdot 7 \mathrm{H}_{2} \mathrm{O}, 4.0$ equiv $\mathrm{NaBH}_{4}$ & $\mathrm{MeOH} / \mathrm{THF}$ & $0^{\circ} \mathrm{C}$ to $23^{\circ} \mathrm{C}, 1 \mathrm{~h}$ & $42(99)$ \\
\hline 9 & 2.0 equiv $\mathrm{CeCl}_{3} \cdot 7 \mathrm{H}_{2} \mathrm{O}, 4.0$ equiv $\mathrm{NaBH}_{4}$ & $t$-BuOH/THF & $0^{\circ} \mathrm{C}$ to $23^{\circ} \mathrm{C}, 1 \mathrm{~h}$ & $40(99)$ \\
\hline 10 & 2.0 equiv $\mathrm{CeCl}_{3} \cdot 7 \mathrm{H}_{2} \mathrm{O}, 4.0$ equiv $\mathrm{NaBH}_{4}$ & $\mathrm{CF}_{3} \mathrm{CH}_{2} \mathrm{OH} / \mathrm{THF}$ & $0^{\circ} \mathrm{C}$ to $23^{\circ} \mathrm{C}, 1 \mathrm{~h}$ & $50(99)$ \\
\hline 11 & 2.0 equiv $\mathrm{CeCl}_{3} \cdot 7 \mathrm{H}_{2} \mathrm{O}, 4.0$ equiv $\mathrm{LiBH}_{4}$ & $\mathrm{CF}_{3} \mathrm{CH}_{2} \mathrm{OH} / \mathrm{THF}$ & $0^{\circ} \mathrm{C}$ to $23^{\circ} \mathrm{C}, 3 \mathrm{~h}$ & $43(70)$ \\
\hline 12 & 2.0 equiv $\mathrm{CeCl}_{3} \cdot 7 \mathrm{H}_{2} \mathrm{O}, 4.0$ equiv $\mathrm{LiBH}_{4}$ & $\left(\mathrm{CF}_{3}\right)_{2} \mathrm{CHOH} / \mathrm{THF}$ & $=0^{\circ} \mathrm{C}$ to $23^{\circ} \mathrm{C}, 3 \mathrm{~h}$ & $18(66)$ \\
\hline 13 & 4.0 equiv $\mathrm{CeCl}_{3} \cdot 7 \mathrm{H}_{2} \mathrm{O}, 4.0$ equiv $\mathrm{LiBH}_{4}$ & $\mathrm{CF}_{3} \mathrm{CH}_{2} \mathrm{OH} / \mathrm{THF}$ & $0^{\circ} \mathrm{C}$ to $23^{\circ} \mathrm{C}, 3 \mathrm{~h}$ & $64(99)$ \\
\hline
\end{tabular}

${ }^{a}$ Yield of the crude reaction mixture on $0.05 \mathrm{mmol}$ scale, was determined by ${ }^{1} \mathrm{H}$ NMR using 1,2-dibromomethane as an internal standard. Conversion of 15-1 in parenthesis. 


\section{Scheme SI7. Optimization of the Pyran-to-Pyridine Conversion}

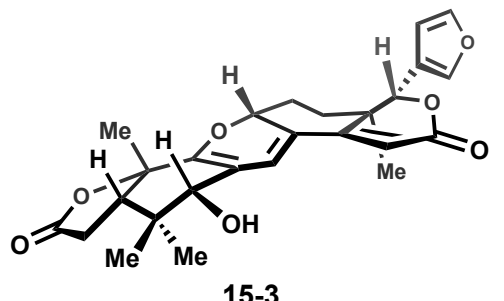

15-3

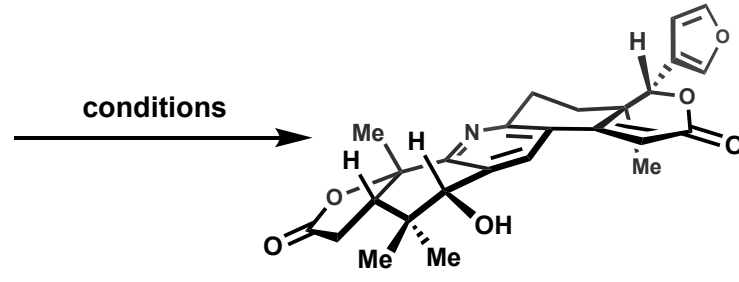

1-3

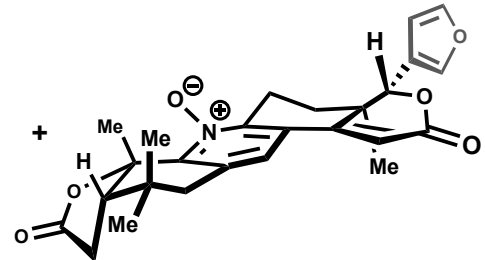

SI-1

\begin{tabular}{|c|c|c|c|c|c|}
\hline Entry & N source & Base / Acid & Solvent / Temp & $\%$ Yield $(1-3)^{a}$ & $\%$ Yield (SI-1) ${ }^{a}$ \\
\hline \multicolumn{6}{|c|}{ other $N$ sources } \\
\hline 1 & $\mathrm{MeO}-\mathrm{NH}_{2} \cdot \mathrm{HCl}$ & $\mathrm{NaOAc} \cdot 3 \mathrm{H}_{2} \mathrm{O}$ & $\mathrm{EtOH}, 80^{\circ} \mathrm{C}$ & 1 & 0 \\
\hline 2 & $\mathrm{MeO}-\mathrm{NH}_{2} \cdot \mathrm{HCl}$ & $\mathrm{NaOAc} \cdot 3 \mathrm{H}_{2} \mathrm{O}$ & $\mathrm{MeOH}, 80^{\circ} \mathrm{C}$ & 5 & 0 \\
\hline 3 & $\mathrm{Me}_{2} \mathrm{~N}-\mathrm{NH}_{2}$ & $\mathrm{TsOH} \cdot \mathrm{H}_{2} \mathrm{O}$ & PhMe, $120^{\circ} \mathrm{C}$ & 0 & 0 \\
\hline 4 & $\mathrm{NH}_{4} \mathrm{OAc}$ then $\mathrm{O}_{2}$ & - & $\mathrm{EtOH}, 80^{\circ} \mathrm{C}$ & 1 & 0 \\
\hline 5 & $\mathrm{NH}_{4} \mathrm{OAc}$ then $\mathrm{O}_{2}$ & - & $\mathrm{AcOH}, 80^{\circ} \mathrm{C}$ & 0 & 0 \\
\hline 6 & $\mathrm{BzO}-\mathrm{NH}_{2} \cdot \mathrm{HCl}$ & $\mathrm{LiOAc} \cdot 2 \mathrm{H}_{2} \mathrm{O}$ & $\mathrm{MeOH}, 80^{\circ} \mathrm{C}$ & 0 & 0 \\
\hline 7 & $\mathrm{BzO}-\mathrm{NH}_{2}$ & $\mathrm{LiOAc} \cdot 2 \mathrm{H}_{2} \mathrm{O}$ & $\mathrm{MeOH}, 80^{\circ} \mathrm{C}$ & 0 & 0 \\
\hline 8 & TIPSO-NH $\mathrm{N}_{2}$ & $\mathrm{LiOAc} \cdot 2 \mathrm{H}_{2} \mathrm{O}$ & $\mathrm{MeOH}, 80^{\circ} \mathrm{C}$ & 5 & 0 \\
\hline 9 & $\mathrm{BnO}-\mathrm{NH}_{2}$ & $\mathrm{LiOAc} \cdot 2 \mathrm{H}_{2} \mathrm{O}$ & $\mathrm{MeOH}, 80^{\circ} \mathrm{C}$ & 0 & 0 \\
\hline 10 & (2,4-dinitrophenyl)hydrazine & $\mathrm{LiOAc} \cdot 2 \mathrm{H}_{2} \mathrm{O}$ & $\mathrm{MeOH}, 80^{\circ} \mathrm{C}$ & 0 & 0 \\
\hline 12 & $\mathrm{HO}-\mathrm{NH}_{2} \cdot \mathrm{HCl}$ & base + solvent & $\mathrm{AcOH}, 80^{\circ} \mathrm{C}$ & 0 & 0 \\
\hline 13 & $\mathrm{HO}-\mathrm{NH}_{2} \cdot \mathrm{HCl}$ & - & $\mathrm{MeOH}, 80^{\circ} \mathrm{C}$ & 2 & 2 \\
\hline 14 & $\mathrm{HO}-\mathrm{NH}_{2} \cdot \mathrm{HCl}$ & $\mathrm{NaOAc} \cdot 3 \mathrm{H}_{2} \mathrm{O}$ & $\mathrm{EtOH}, 90^{\circ} \mathrm{C}$ & 24 & 31 \\
\hline 15 & $\mathrm{HO}-\mathrm{NH}_{2} \cdot \mathrm{HCl}$ & $\mathrm{NaOAc} \cdot 3 \mathrm{H}_{2} \mathrm{O}$ & $t-\mathrm{BuOH}, 100^{\circ} \mathrm{C}$ & 18 & 10 \\
\hline 16 & $\mathrm{HO}-\mathrm{NH}_{2} \cdot \mathrm{HCl}$ & $\mathrm{NaOAc} \cdot 3 \mathrm{H}_{2} \mathrm{O}$ & $n-\mathrm{BuOH}, 100^{\circ} \mathrm{C}$ & 18 & 16 \\
\hline 17 & $\mathrm{HO}-\mathrm{NH}_{2} \cdot \mathrm{HCl}$ & $\mathrm{LiOAc} \cdot 2 \mathrm{H}_{2} \mathrm{O}$ & $\mathrm{MeOH}, 80^{\circ} \mathrm{C}$ & 35 & 38 \\
\hline 18 & $\mathrm{HO}-\mathrm{NH}_{2} \cdot \mathrm{HCl}$ & $\mathrm{LiOAc} \cdot 2 \mathrm{H}_{2} \mathrm{O}$ & benzene, $80^{\circ} \mathrm{C}$ & 0 & 0 \\
\hline 19 & $\mathrm{HO}-\mathrm{NH}_{2} \cdot \mathrm{HCl}$ & $\mathrm{LiOAc} \cdot 2 \mathrm{H}_{2} \mathrm{O}$ & PhMe, $100^{\circ} \mathrm{C}$ & 0 & 0 \\
\hline 20 & $\mathrm{HO}-\mathrm{NH}_{2} \cdot \mathrm{HCl}$ & $\mathrm{LiOAc} \cdot 2 \mathrm{H}_{2} \mathrm{O}$ & $\mathrm{CH}_{3} \mathrm{CN}, 60^{\circ} \mathrm{C}$ & 4 & 16 \\
\hline 21 & $\mathrm{HO}-\mathrm{NH}_{2} \cdot \mathrm{HCl}$ & $\mathrm{LiOAc} \cdot 2 \mathrm{H}_{2} \mathrm{O}^{b}$ & $\mathrm{MeOH}, 80^{\circ} \mathrm{C}$ & 15 & 27 \\
\hline 24 & $\mathrm{HO}-\mathrm{NH}_{2} \cdot \mathrm{HCl}$ & $\mathrm{NaHCO}_{3}$ & $\mathrm{MeOH}, 80^{\circ} \mathrm{C}$ & 9 & 0 \\
\hline 25 & $\mathrm{HO}-\mathrm{NH}_{2} \cdot \mathrm{HCl}$ & $\mathrm{Na}_{2} \mathrm{CO}_{3}$ & $\mathrm{MeOH}, 80^{\circ} \mathrm{C}$ & 3 & 0 \\
\hline
\end{tabular}

${ }^{a}$ Yield of the crude reaction mixture on $0.05 \mathrm{mmol}$ scale, was determined by ${ }^{1} \mathrm{H}$ NMR using 1,2-dibromomethane as an internal standard.

${ }^{b} 4 \AA$ MS was added as an additive ${ }^{c}$ Amberlyst 21 was added as an additive. 


\section{Scheme SI8. Optimization of the Nucleophilic Substitution}

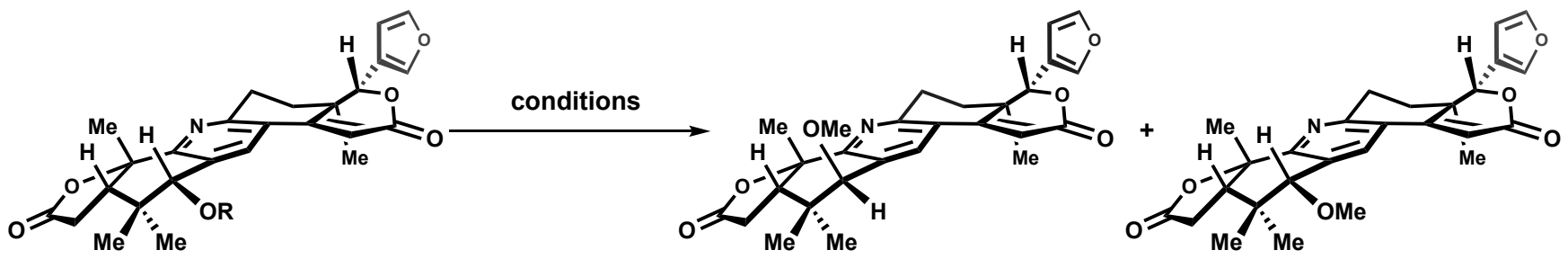

$R=T s(18-1), M s(18-2), P O(O E t)_{2}(18-3)$

(+)-granatumine A (1-2)

(+)-epi-granatumine A (17-8)

\begin{tabular}{|c|c|c|c|c|c|}
\hline Entry & $\mathbf{R}$ & Nucleophile & Solvent & Temperature / Time & Ratio (1-2:17-8) ${ }^{a}$ \\
\hline \multicolumn{6}{|c|}{ tosylate + solvent } \\
\hline 1 & \multirow{4}{*}{ Ts } & - & $\mathrm{MeOH}$ & $70^{\circ} \mathrm{C}, 2 \mathrm{~h}$ & $1: 6$ \\
\hline 2 & & $\mathrm{MeONa}^{b}$ & $\mathrm{MeOH}$ & $70^{\circ} \mathrm{C}, 2 \mathrm{~h}$ & $1: 6$ \\
\hline 3 & & $\mathrm{MeONa}$ & acetone & $70^{\circ} \mathrm{C}, 2 \mathrm{~h}$ & decomposition \\
\hline 4 & & $\mathrm{MeONa}^{b}$ & $\mathrm{CH}_{3} \mathrm{CN}$ & $70^{\circ} \mathrm{C}, 2 \mathrm{~h}$ & decomposition \\
\hline \multicolumn{6}{|c|}{ mesylate + solvent } \\
\hline 5 & \multirow{2}{*}{ Ms } & - & $\mathrm{MeOH}$ & $70^{\circ} \mathrm{C}, 2 \mathrm{~h}$ & $1: 10$ \\
\hline 6 & & $\mathrm{MeONa}$ & DMF & $70^{\circ} \mathrm{C}, 12 \mathrm{~h}$ & decomposition \\
\hline \multicolumn{6}{|c|}{ phosphate + solvent } \\
\hline 7 & \multirow{3}{*}{$\mathrm{PO}(\mathrm{OEt})_{2}$} & $\mathrm{MeONa}^{b}$ & $\mathrm{MeOH}$ & $70^{\circ} \mathrm{C}, 2 \mathrm{~h}$ & $1: 10$ \\
\hline 8 & & $\mathrm{MeONa}$ & DMF & $70^{\circ} \mathrm{C}, 12 \mathrm{~h}$ & no reaction \\
\hline 9 & & $\mathrm{MeONa}^{b}$ & $\mathrm{CH}_{3} \mathrm{CN}$ & $70^{\circ} \mathrm{C}, 2 \mathrm{~h}$ & decomposition \\
\hline
\end{tabular}

${ }^{a}$ Yield of the crude reaction mixture on $0.05 \mathrm{mmol}$ scale, was determined by ${ }^{1} \mathrm{H}$ NMR using 1,2-dibromomethane as an internal standard.

${ }^{b}$ Sodium methoxide was added as a solution in methanol. 


\section{Experimental Procedures and Characterization Data}

Synthesis of tricyclic pyridine (4-1):

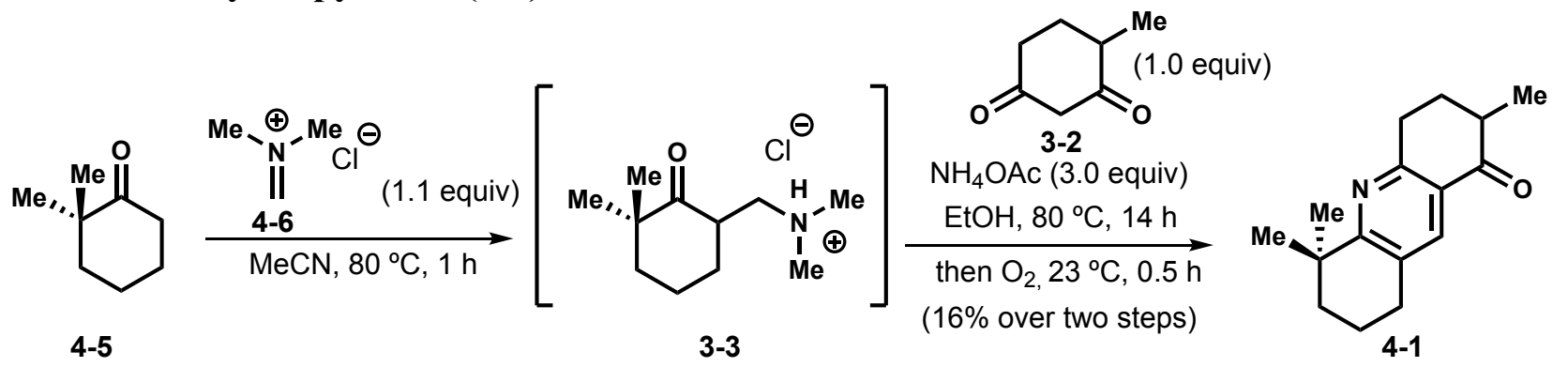

To a flame-dried $250-\mathrm{mL}$ round-bottomed flask equipped with a magnetic stir bar was added ketone 4-3 (16.4 g, $129 \mathrm{mmol}, 1.0$ equiv) and $\mathrm{MeCN}(65 \mathrm{~mL}, 2.0 \mathrm{M})$. To the stirred reaction mixture was added Böhme's salt 4-6 (13.3 g, $142 \mathrm{mmol}, 1.1$ equiv). The reaction vessel was fitted with an oven-dried reflux condenser, and the reaction apparatus was transferred to an $80^{\circ} \mathrm{C}$ pre-warmed oil bath. After stirring at $80^{\circ} \mathrm{C}$ for one hour, the reaction apparatus was removed from the oil bath and allowed to cool to room temperature. Once at room temperature, the reaction mixture was concentrated under reduced pressure by rotary evaporation to provide 3-3 as a colorless solid, which was used without further purification $(25.1 \mathrm{~g}, 88 \%)$

To a flame-dried $250-\mathrm{mL}$ round-bottomed flask equipped with a magnetic stir bar was added diketone 3-2 (12.0 g, $95.1 \mathrm{mmol}, 1.0$ equiv) and $\mathrm{EtOH}(190 \mathrm{~mL}, 0.5 \mathrm{M})$. To the stirred reaction mixture was added ammonium salt 3-3 $(25.1 \mathrm{~g}, 114 \mathrm{mmol}, 1.2$ equiv) and ammonium acetate $(22.0 \mathrm{~g}, 285 \mathrm{mmol}$, 3.0 equiv). The reaction vessel was fitted with an oven-dried reflux condenser, and the reaction apparatus was transferred to an $80^{\circ} \mathrm{C}$ pre-warmed oil bath.

After stirring at $80^{\circ} \mathrm{C}$ for 14 hours, the reaction apparatus was removed from the oil bath and allowed to cool to room temperature. Once at room temperature, $\mathrm{O}_{2}$ was bubbled through the reaction for 30 minutes. Following this, the reaction was concentrated under reduced pressure by rotary evaporation to give a yellow solid, which was dissolved in EtOAc $(50 \mathrm{~mL})$ and water $(100 \mathrm{~mL})$. The layers were separated, and the aqueous layer was extracted with EtOAc $(2 \times 50 \mathrm{~mL})$. The combined organic extracts were washed with brine $(50 \mathrm{~mL})$, dried over anhydrous $\mathrm{Na}_{2} \mathrm{SO}_{4}$, filtered and concentrated under reduced pressure by rotary evaporation to give a yellow viscous oil. Purification by flash column chromatography on silica gel $\left(2 \% \mathrm{Et}_{2} \mathrm{O} /\right.$ hexanes to $10 \% \mathrm{Et}_{2} \mathrm{O} /$ hexanes$)$ afforded $4-1$ (5.1 g, 16\% over two steps) as a colorless solid.

\section{Rf: $0.13\left(5 \% \mathrm{Et}_{2} \mathrm{O} /\right.$ hexanes, $\left.\mathrm{KMnO}_{4}\right)$}

${ }^{1} \mathbf{H}$ NMR $\left(600 \mathrm{MHz}, \mathrm{CDCl}_{3}\right): \delta 7.89(\mathrm{~s}, 1 \mathrm{H}), 3.11-3.08(\mathrm{~m}, 2 \mathrm{H}), 2.78(\mathrm{t}, J=6.2 \mathrm{~Hz}, 2 \mathrm{H}), 2.59-2.53(\mathrm{~m}$, $1 \mathrm{H}), 2.22$ (dq, $J=13.5,4.5 \mathrm{~Hz}, 1 \mathrm{H}), 1.90-1.84(\mathrm{~m}, 1 \mathrm{H}), 1.82-1.74$ (m, 4H), 1.33 (s, 3H), 1.32 (s, 3H), $1.25(\mathrm{~d}, J=6.8 \mathrm{~Hz}, 3 \mathrm{H})$

${ }^{13}$ C NMR (151 MHz, $\left.\mathrm{CDCl}_{3}\right): \delta 200.9,169.2,160.5,135.5,129.8,125.3,42.3,38.9,37.4,31.8,30.4$, $30.2,30.2,29.9,19.3,15.4$

IR $\left(\mathrm{cm}^{-1}\right): 2931,2866,1708,1686,1592,1456,1427,1355,1208,1115,1031,914$

ESI-HRMS (m/z): [M+H] $]^{+}$calc'd for $\mathrm{C}_{16} \mathrm{H}_{22} \mathrm{NO}^{+}: 243.1623$; found: 243.1631 . 


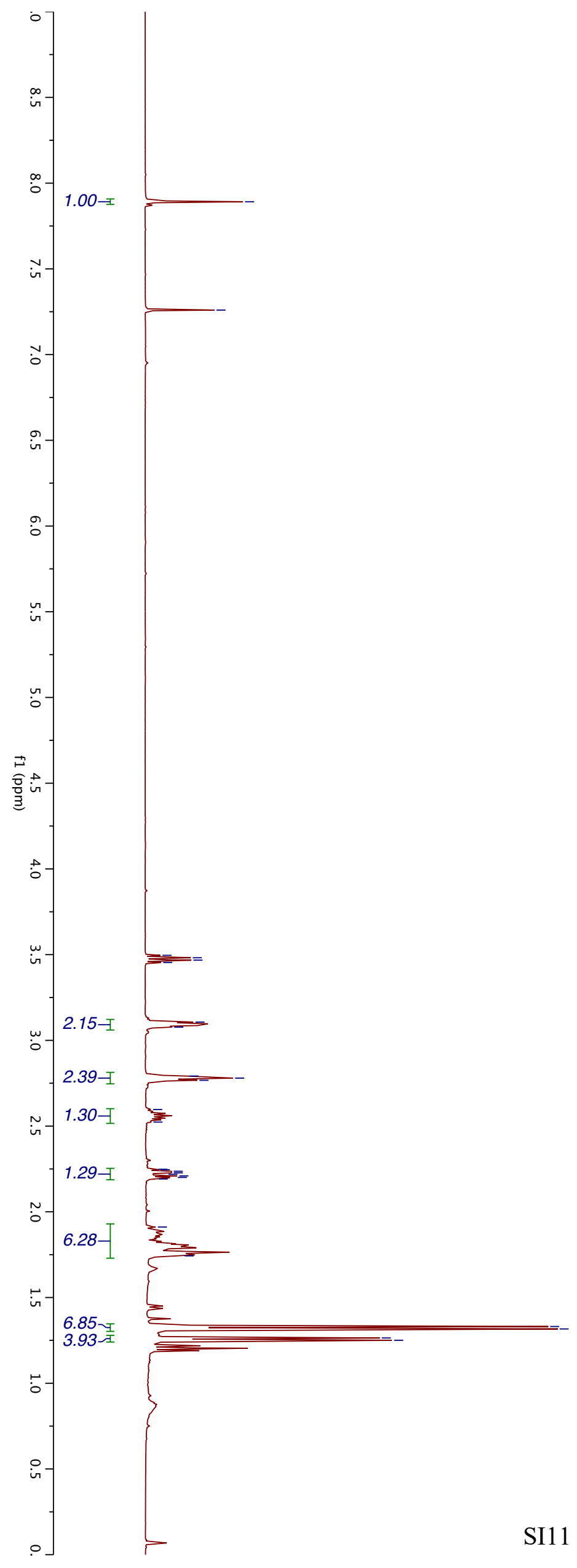

$-7.89$

$-7.26$

3.50

$-3.48$

$-3.47$

3.45

$\begin{array}{r}3.11 \\ \hdashline .08\end{array}$

2.79

2.78
2.77

$ح 2.60$

2.52

2.25
-2.25

$-2.25$

223

2.22

2.21

$-2.20$

2.19

1.91

$[1.74$

- 1.33

1.32

1.26

โ1.25 


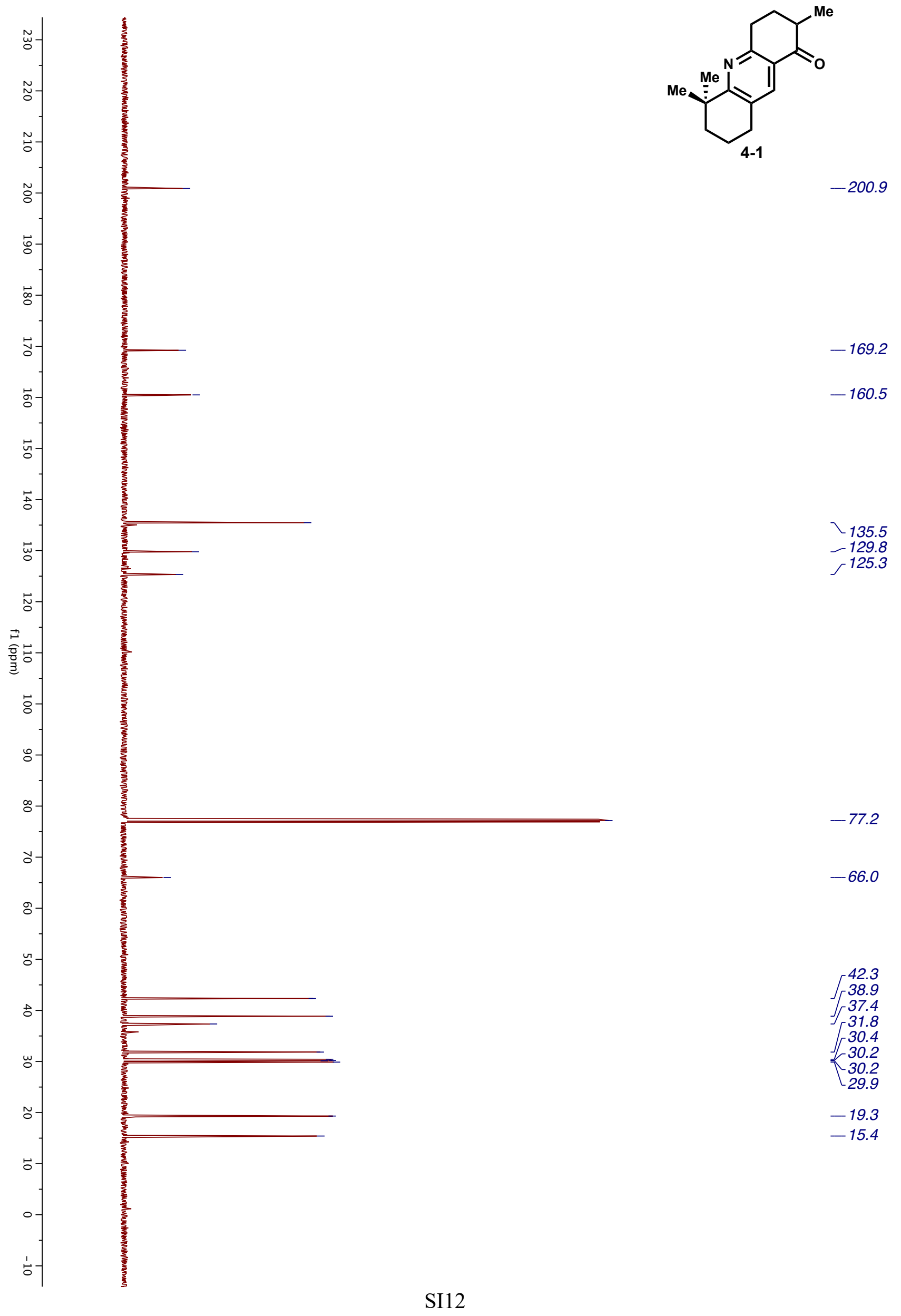




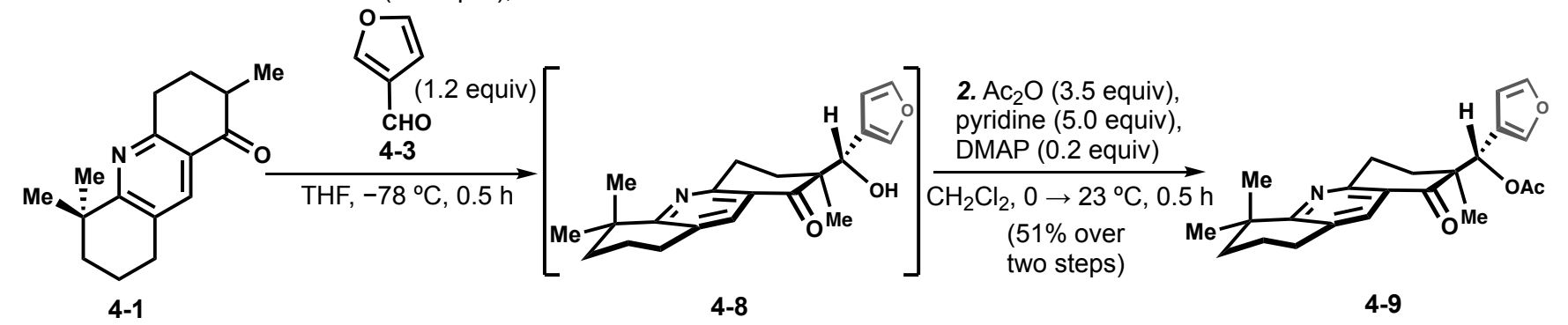

To a flame-dried $250-\mathrm{mL}$ round-bottomed flask equipped with a magnetic stir bar was added THF $(42 \mathrm{~mL}, 0.5 \mathrm{M})$ and diisopropylamine $(3.5 \mathrm{~mL}, 25.1 \mathrm{mmol}, 1.2$ equiv). The reaction mixture was cooled to $0{ }^{\circ} \mathrm{C}$ by transferring the reaction apparatus to an ice-water bath. The reaction mixture was allowed to stir for 10 minutes at $0{ }^{\circ} \mathrm{C}$ before $n$-BuLi $(9.5 \mathrm{~mL}, 23.1 \mathrm{mmol}, 1.1$ equiv, $2.5 \mathrm{M}$ in hexanes) was added dropwise over 5 minutes to the reaction mixture.

After stirring for 25 minutes at $0{ }^{\circ} \mathrm{C}$, the reaction vessel was transferred to a $-78{ }^{\circ} \mathrm{C}$ saturated dryice acetone bath and stirred for 10 minutes before a solution of pyridine 4-1 (5.1 g, $21.0 \mathrm{mmol}, 1.0$ equiv) in THF $(21 \mathrm{~mL}, 1.0 \mathrm{M})$ was added dropwise over 5 minutes. The reaction mixture was stirred for 30 minutes at $-78{ }^{\circ} \mathrm{C}$, before 3-furaldehyde (4-3), freshly distilled at $30{ }^{\circ} \mathrm{C}$ (200 mtorr) over $7 \%(\mathrm{w} / \mathrm{v})$ $\mathrm{Na}_{2} \mathrm{CO}_{3}$ (2.2 mL, $25.1 \mathrm{mmol}, 1.2$ equiv), was added dropwise over 5 minutes.

After stirring at $-78{ }^{\circ} \mathrm{C}$ for 30 minutes, sat. $\mathrm{NH}_{4} \mathrm{Cl}$ in $\mathrm{THF}(30 \mathrm{~mL})$ and $\mathrm{Et}_{2} \mathrm{O}(30 \mathrm{~mL})$ were added to the reaction mixture, and the reaction vessel was removed from the dry-ice acetone bath. After warming to room temperature, the layers were separated and the aqueous layer was extracted with $\mathrm{Et}_{2} \mathrm{O}(2 \times 20$ $\mathrm{mL})$. The combined organic extracts were washed with brine $(25 \mathrm{~mL})$, dried over anhydrous $\mathrm{Na}_{2} \mathrm{SO}_{4}$, filtered, and concentrated under reduced pressure by rotary evaporation to provide 4-8 as a crude yellow oil (4.2 g).

To a flame-dried 100-mL round-bottomed flask equipped with a magnetic stir bar was added crude alcohol 4-8 (4.2 g, $12.1 \mathrm{mmol}, 1.0$ equiv) and $\mathrm{CH}_{2} \mathrm{Cl}_{2}(21 \mathrm{~mL}, 0.5 \mathrm{M})$. The reaction vessel was then placed in a $0{ }^{\circ} \mathrm{C}$ ice-water bath. To the stirred reaction mixture was added acetic anhydride $(3.9 \mathrm{~mL}, 42 \mathrm{mmol}$, 3.5 equiv) dropwise over 5 minutes. Following this, 4-(dimethylamino)pyridine (260 mg, $2.4 \mathrm{mmol}, 0.2$ equiv) was added in one portion. After stirring for 5 minutes at $0{ }^{\circ} \mathrm{C}$, pyridine $(5.1 \mathrm{~mL}, 63.0 \mathrm{mmol}, 5.0$ equiv) was added dropwise over 5 minutes and then the reaction flask was transferred to an ambient temperature water bath.

After the reaction had stirred at room temperature for 30 minutes, the reaction mixture was diluted with water $(30 \mathrm{~mL})$. The layers were separated, and the aqueous layer was extracted with 1:1 hexanes/Et $2 \mathrm{O}$ $(2 \times 50 \mathrm{~mL})$. The combined organic extracts were washed with brine $(2 \times 50 \mathrm{~mL})$, dried over anhydrous $\mathrm{Na}_{2} \mathrm{SO}_{4}$, filtered and concentrated under reduced pressure by rotary evaporation to give a yellow viscous

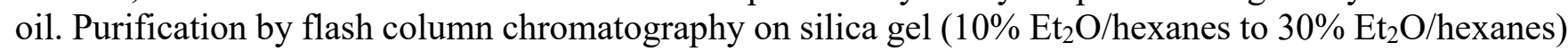
afforded 4-9 ( $4.1 \mathrm{~g}, 51 \%$ over two steps) as a colorless solid.

Rf: 0.4 (15\% EtOAc/hexanes, $p$-anisaldehyde)

${ }^{1}$ H NMR $\left(500 \mathrm{MHz}, \mathrm{CDCl}_{3}\right): \delta 7.88(\mathrm{~s}, 1 \mathrm{H}), 7.33(\mathrm{~s}, 1 \mathrm{H}), 7.29(\mathrm{~s}, 1 \mathrm{H}), 6.47(\mathrm{~s}, 1 \mathrm{H}), 6.33(\mathrm{~s}, 1 \mathrm{H}), 3.06(\mathrm{t}$, $J=6.5 \mathrm{~Hz}, 2 \mathrm{H}), 2.77(\mathrm{t}, J=6.2 \mathrm{~Hz}, 2 \mathrm{H}), 2.10(\mathrm{~s}, 3 \mathrm{H}), 2.08-2.01(\mathrm{~m}, 2 \mathrm{H}), 1.83-1.72(\mathrm{~m}, 4 \mathrm{H}), 1.31(\mathrm{~s}$, $6 \mathrm{H}), 1.29(\mathrm{~s}, 3 \mathrm{H})$

${ }^{13}$ C NMR (126 MHz, $\left.\mathrm{CDCl}_{3}\right): \delta 199.9,170.0,169.8,159.1,142.7,140.9,136.1,130.2,124.5,122.5$, $110.3,72.1,49.3,38.8,37.4,30.2,30.2,29.9,28.5,28.0,21.1,19.3,19.2$

IR $\left(\mathrm{cm}^{-1}\right): 2834,1750,1680,1592,1555,1444,1429,1373,1232,1164,1025,791,772,602$

ESI-HRMS (m/z): [M+H] $]^{+}$calc'd for $\mathrm{C}_{23} \mathrm{H}_{28} \mathrm{NO}_{4}{ }^{+}: 382.2013$; found: 382.2017 


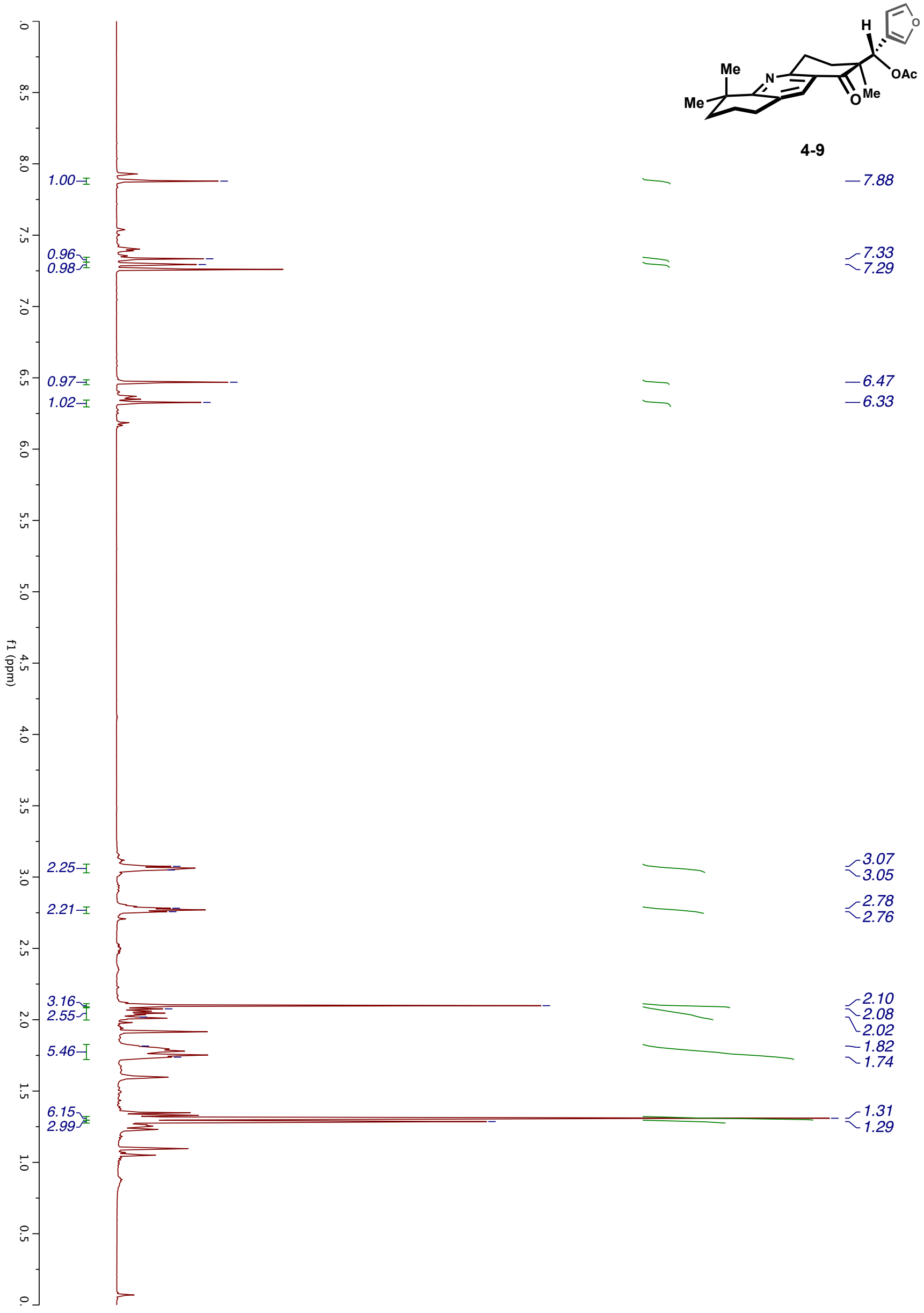




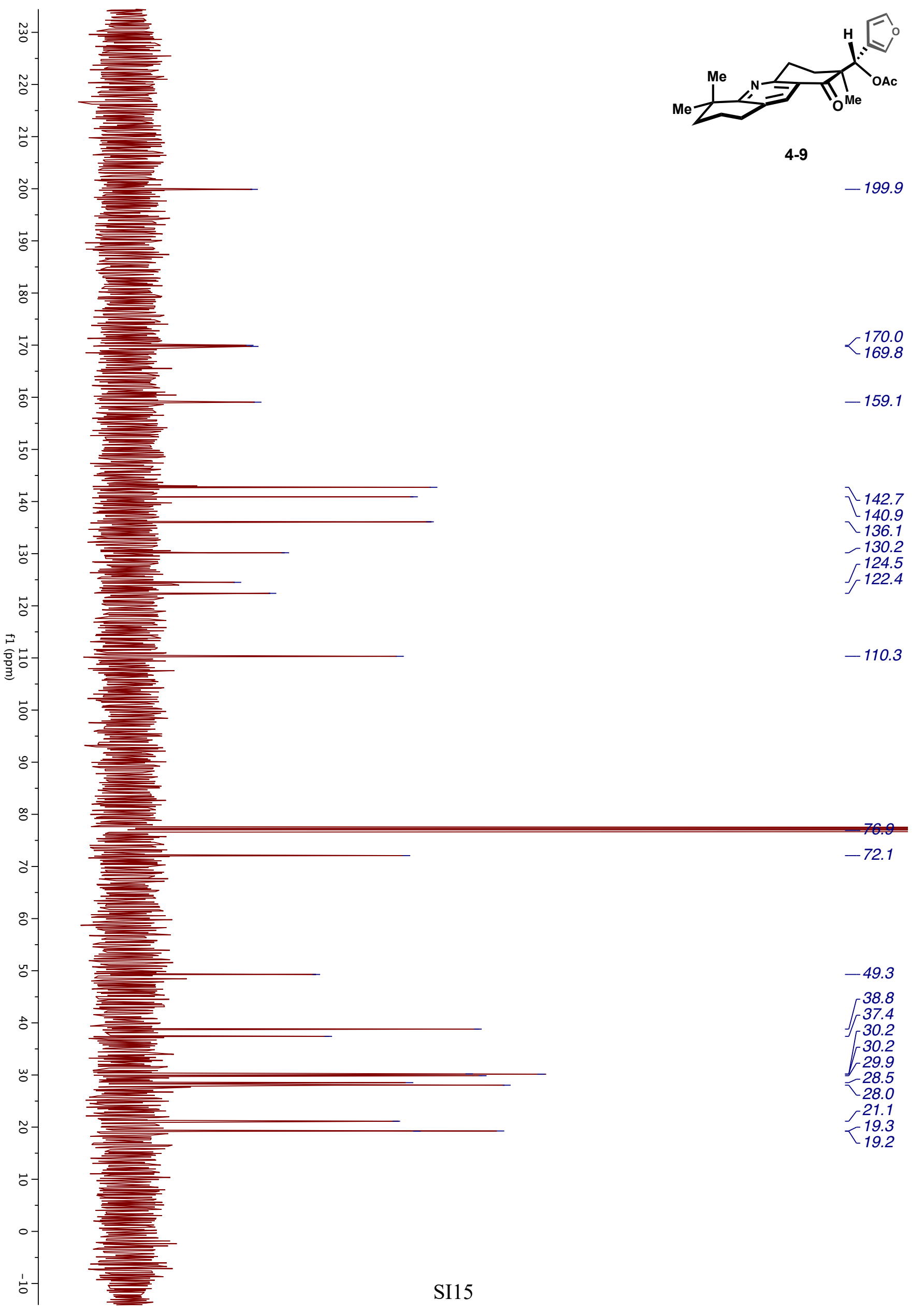




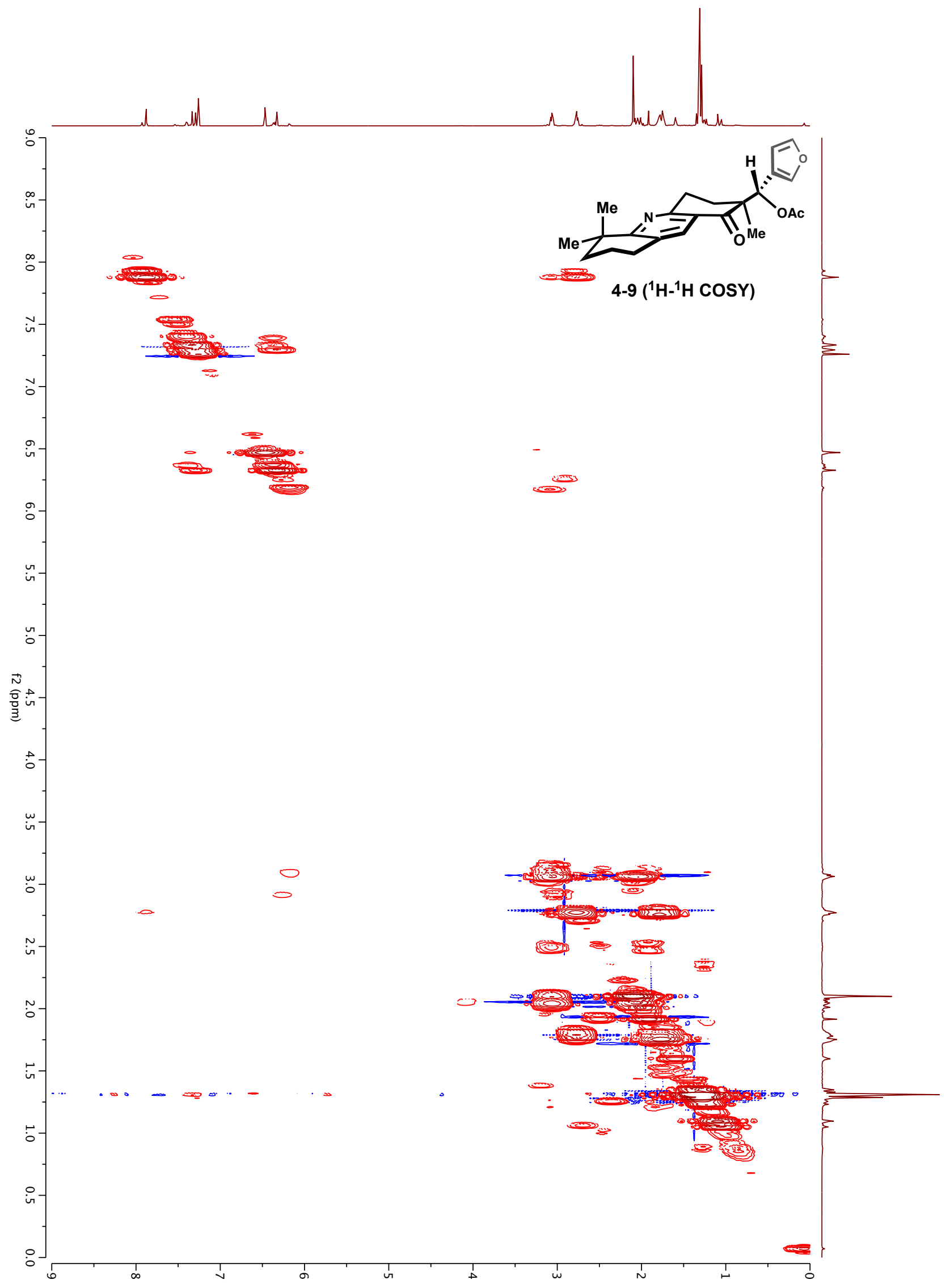

f1 (ppm) 


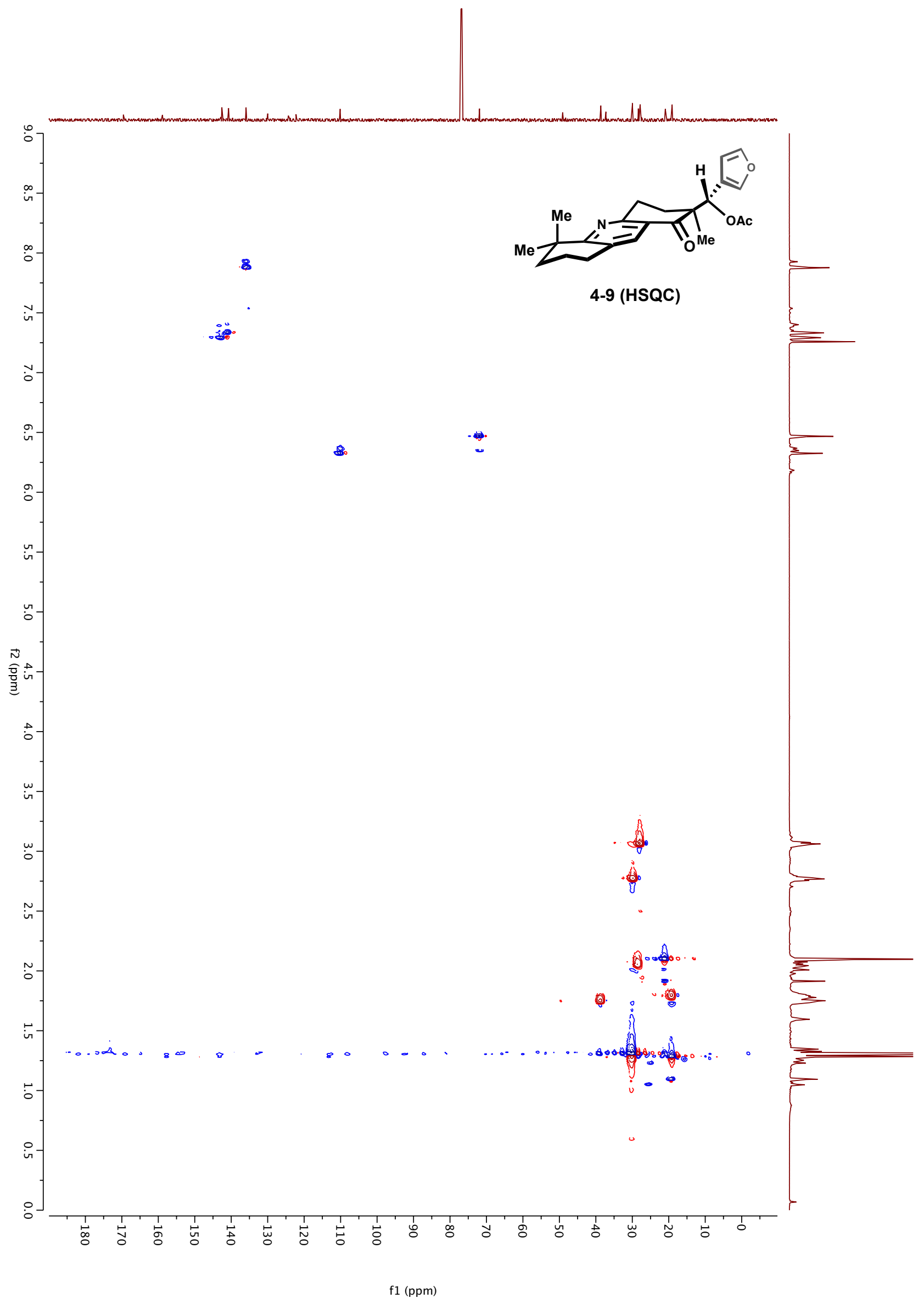


Synthesis of tetracyclic pyridine (3-1):

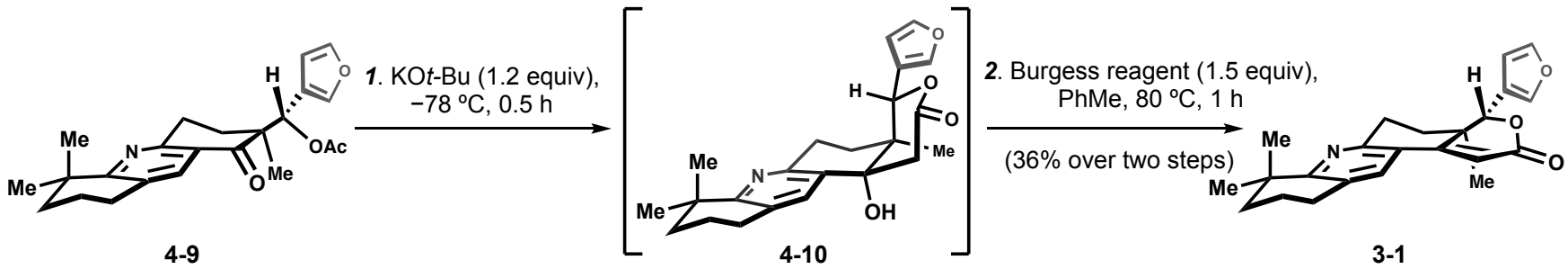

An evacuated flame-dried 250-mL round-bottomed flask equipped with a magnetic stir bar and a Schlenk adapter was brought into a glovebox. Once in the glovebox, the flask was filled with nitrogen atmosphere. Solid $\mathrm{KO} t$-Bu (1.5 g, $12.89 \mathrm{mmol}, 1.2$ equiv) was added and the flask was sealed. The flask was removed from the glovebox, and the flask was evacuated and backfilled with nitrogen three times using a dual manifold Schlenk line. The Schlenk adapter was replaced with a rubber septum and the flask was placed under a nitrogen atmosphere.

To this flask was added THF $(108 \mathrm{~mL}, 0.1 \mathrm{M})$, and the reaction mixture was allowed to stir at room temperature for 10 minutes to allow for complete dissolution of $\mathrm{KO} t$ - $\mathrm{Bu}$. The reaction vessel was transferred to a $-78{ }^{\circ} \mathrm{C}$ saturated dry-ice acetone bath and stirred for 10 minutes before a solution of acetate 4-9 (4.1 g, $10.8 \mathrm{mmol}, 1.0$ equiv) in THF $(11 \mathrm{~mL}, 1.0 \mathrm{M})$ was added over 5 minutes, resulting in a yellow solution. After stirring for 0.5 hour at $-78^{\circ} \mathrm{C}$, sat. aq. $\mathrm{NH}_{4} \mathrm{Cl}(25 \mathrm{~mL})$ was added to the reaction mixture and the reaction vessel was removed from the dry-ice acetone bath and allowed to warm to room temperature. Once at room temperature, the layers were separated and the aqueous layer was extracted with $\mathrm{Et}_{2} \mathrm{O}(2 \times 50 \mathrm{~mL})$. The combined organic extracts were washed with brine $(25 \mathrm{~mL})$, dried over anhydrous $\mathrm{Na}_{2} \mathrm{SO}_{4}$, filtered, and concentrated under reduced pressure by rotary evaporation to provide 4$\mathbf{1 0}$ as a crude yellow oil $(3.9 \mathrm{~g})$.

To a flame-dried 100-mL round-bottomed flask equipped with a magnetic stir bar was added crude alcohol 4-10 (3.9 g, $9.96 \mathrm{mmol}, 1.0$ equiv), PhMe (20 mL, 0.5 M), and Burgess reagent (3.6 g, $14.9 \mathrm{mmol}$, 1.5 equiv). The reaction vessel was fitted with an oven-dried reflux condenser, and the reaction apparatus was transferred to an $80^{\circ} \mathrm{C}$ preheated oil bath.

After the reaction had stirred at $80{ }^{\circ} \mathrm{C}$ for one hour, the reaction vessel was removed from the oil bath and allowed to cool to room temperature. Once at room temperature, the reaction mixture was diluted with water $(20 \mathrm{~mL})$, and the layers were separated. The aqueous layer was extracted with $\mathrm{Et}_{2} \mathrm{O}(2 \times 50$ $\mathrm{mL})$. The combined organic extracts were washed with brine $(25 \mathrm{~mL})$, dried over anhydrous $\mathrm{Na}_{2} \mathrm{SO}_{4}$, filtered, and concentrated under reduced pressure by rotary evaporation to provide a crude brown oil. Purification by flash column chromatography on silica gel $\left(50 \% \mathrm{Et}_{2} \mathrm{O} / \mathrm{h}_{\text {hexanes to } 75 \% \mathrm{Et}} \mathrm{O} / \mathrm{hexanes}\right)$ afforded 3-1 (1.4 g, 36\% over two steps) as a colorless solid.

The spectral data matched that which was previously reported. ${ }^{2}$ 


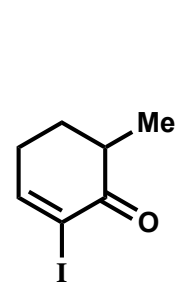

5-3

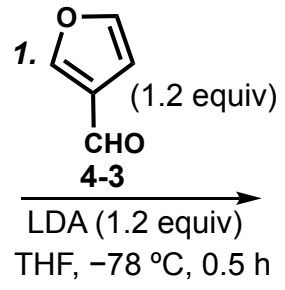

THF, $-78^{\circ} \mathrm{C}, 0.5 \mathrm{~h}$

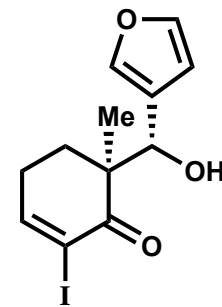

SI-2

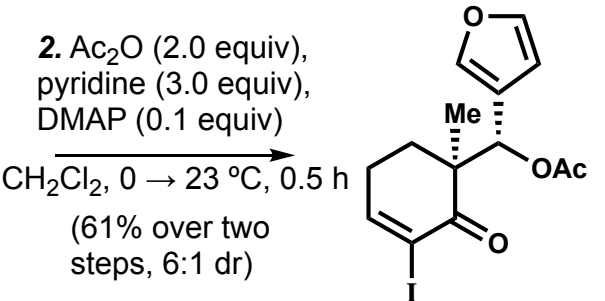

5-4

Step 1

To a flame-dried $250-\mathrm{mL}$ round-bottomed flask equipped with a magnetic stir bar was added THF $(120 \mathrm{~mL}, 0.5 \mathrm{M})$ and diisopropylamine $(10.1 \mathrm{~mL}, 72.0 \mathrm{mmol}, 1.2$ equiv). The reaction mixture was cooled to $0{ }^{\circ} \mathrm{C}$ by transferring the reaction apparatus to an ice-water bath. The reaction mixture was allowed to stir for 10 minutes at $0^{\circ} \mathrm{C}$ before $n$-BuLi $(28.8 \mathrm{~mL}, 72.0 \mathrm{mmol}, 1.2$ equiv, $2.5 \mathrm{M}$ in hexanes) was added dropwise over 5 minutes to the stirred reaction mixture.

After stirring for 25 minutes at $0{ }^{\circ} \mathrm{C}$, the reaction vessel was transferred to a $-78{ }^{\circ} \mathrm{C}$ saturated dryice acetone bath and stirred for 10 minutes before a solution of iodide 5-3 (14.2 g, $60.0 \mathrm{mmol}, 1.0$ equiv) in THF $(30 \mathrm{~mL}, 2.0 \mathrm{M})$ was added dropwise over 5 minutes, resulting in a pale-yellow reaction mixture. The reaction mixture was stirred for 30 minutes at $-78^{\circ} \mathrm{C}$, before 3-furaldehyde (4-3), freshly distilled at $30{ }^{\circ} \mathrm{C}$ (200 mtorr) over $7 \%$ (w/v) $\mathrm{Na}_{2} \mathrm{CO}_{3}(6.23 \mathrm{~mL}, 72.0 \mathrm{mmol}, 1.2$ equiv), was added dropwise over 5 minutes.

After stirring at $-78^{\circ} \mathrm{C}$ for 30 minutes, sat. $\mathrm{NH}_{4} \mathrm{Cl}$ in $\mathrm{THF}(30 \mathrm{~mL})$ and $\mathrm{Et}_{2} \mathrm{O}(30 \mathrm{~mL})$ were added to the reaction mixture sequentially, and the reaction vessel was removed from the dry-ice acetone bath. After warming to room temperature, the layers were separated and the aqueous layer was extracted with $\mathrm{Et}_{2} \mathrm{O}(2 \times 20 \mathrm{~mL})$. The combined organic extracts were washed with brine $(25 \mathrm{~mL})$, dried over anhydrous $\mathrm{Na}_{2} \mathrm{SO}_{4}$, filtered, and concentrated under reduced pressure by rotary evaporation to provide alcohol SI-2 as a crude yellow oil and a 6:1 mixture of diastereomers. An analytically pure sample of the alcohol SI-2 could be obtained by flash column chromatography on silica gel (hexanes/EtOAc 6:1); however, in practice the crude material was utilized in the next step without further purification.

$\mathbf{R}_{\mathbf{f}}: 0.22\left(25 \% \mathrm{Et}_{2} \mathrm{O} /\right.$ hexanes, $p$-anisaldehyde $)$

${ }^{1} \mathbf{H}$ NMR $\left(600 \mathrm{MHz}, \mathrm{CDCl}_{3}\right): \delta 7.73(\mathrm{dd}, J=5.9,2.8 \mathrm{~Hz}, 1 \mathrm{H}), 7.38(\mathrm{~s}, 1 \mathrm{H}), 7.37(\mathrm{~s}, 1 \mathrm{H}), 6.37(\mathrm{~s}, 1 \mathrm{H}), 4.96$ $(\mathrm{d}, J=2.2 \mathrm{~Hz}, 1 \mathrm{H}), 3.93(\mathrm{~d}, J=2.3 \mathrm{~Hz}, 1 \mathrm{H}), 2.54-2.48(\mathrm{~m}, 1 \mathrm{H}), 2.38$ (dddd, $J=19.9,5.6,2.7,2.7 \mathrm{~Hz}$, $1 \mathrm{H}), 1.85$ (ddd, $J=13.7,10.7,5.4 \mathrm{~Hz}, 1 \mathrm{H}), 1.64(\mathrm{ddd}, J=13.9,5.3,3.0 \mathrm{~Hz}, 1 \mathrm{H}), 1.25(\mathrm{~s}, 3 \mathrm{H})$

${ }^{13}$ C NMR (151 MHz, $\left.\mathrm{CDCl}_{3}\right): \delta 199.5,159.4,142.8,140.8,123.8,110.2,102.3,71.7,49.2,30.7,27.2$, 15.4

IR $\left(\mathrm{cm}^{-1}\right): 3486,1674,1593,1325,1161,1022,875$

ESI-HRMS (m/z): $[\mathrm{M}+\mathrm{Na}]^{+}$calc' $d$ for $\mathrm{C}_{12} \mathrm{H}_{13} \mathrm{IO}_{3} \mathrm{Na}^{+}$: 354.9802 ; found: 354.9803 


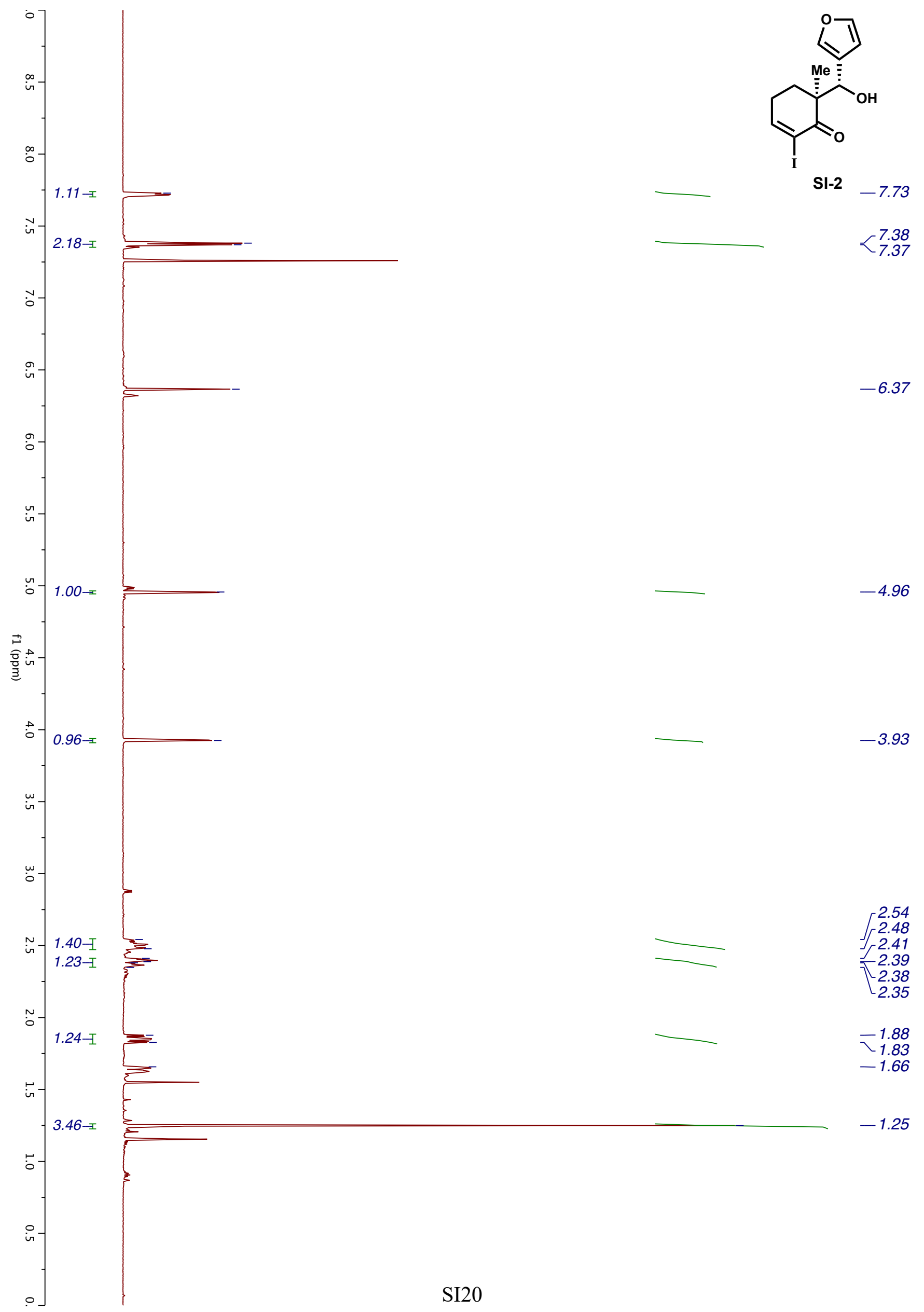




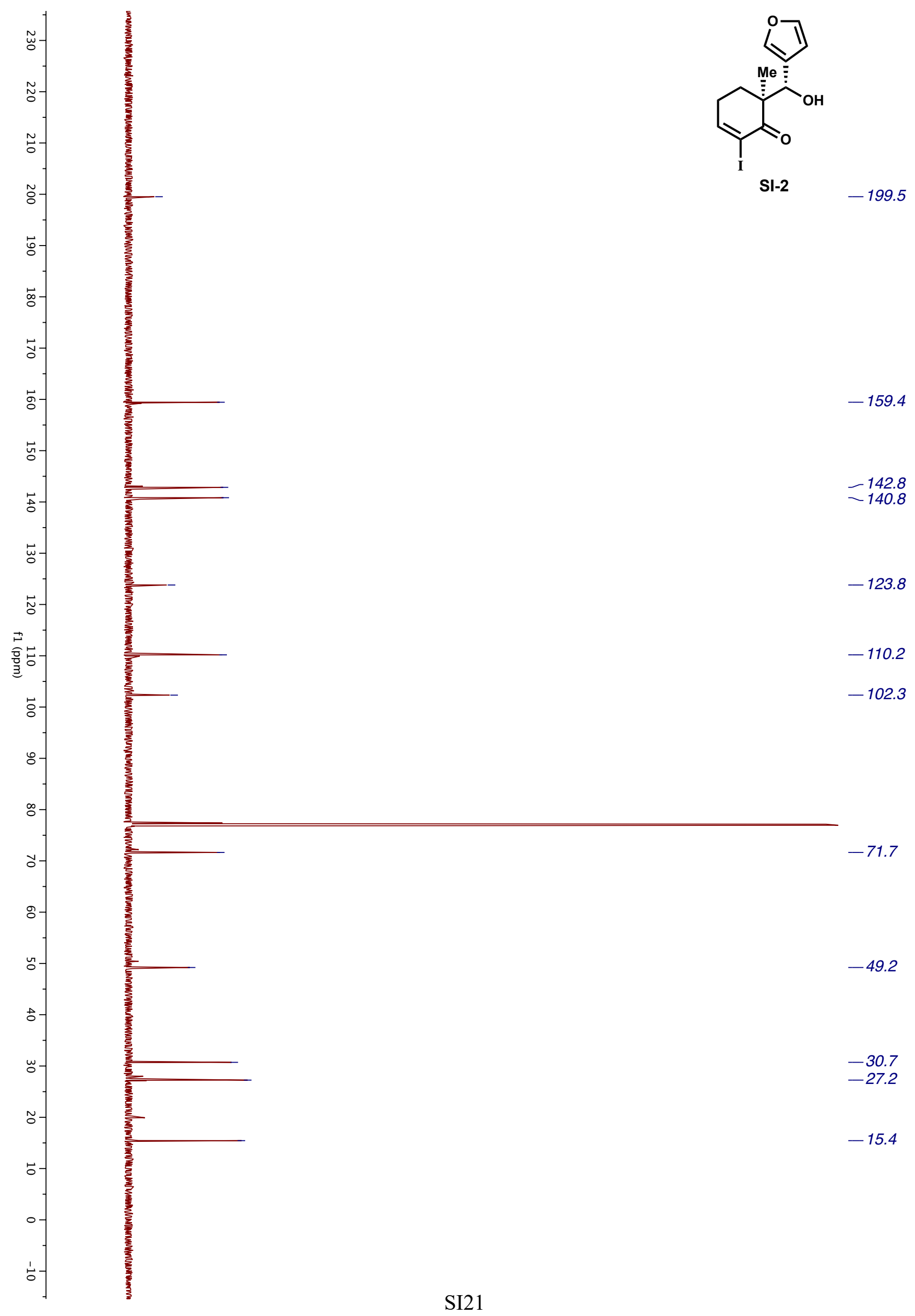




\section{Step 2}

To a flame-dried 100-mL round-bottomed flask equipped with a magnetic stir bar was added crude alcohol 5-3 (60.0 mmol, 1.0 equiv) and $\mathrm{CH}_{2} \mathrm{Cl}_{2}(60 \mathrm{~mL}, 1.0 \mathrm{M})$. The reaction vessel was placed in a $0{ }^{\circ} \mathrm{C}$ ice-water bath. To the stirred reaction mixture was added acetic anhydride (11.4 mL, $120 \mathrm{mmol}, 2.0$ equiv) dropwise over 2 minutes. Following this, 4-(dimethylamino)pyridine (733 mg, $6.0 \mathrm{mmol}, 0.1$ equiv) was added in one portion. After stirring for 5 minutes at $0{ }^{\circ} \mathrm{C}$, pyridine $(14.6 \mathrm{~mL}, 180 \mathrm{mmol}, 3.0$ equiv) was added dropwise over 5 minutes. The reaction vessel was then transferred to an ambient temperature water bath.

After the reaction mixture had stirred at room temperature for 30 minutes, the reaction mixture was diluted with water $(100 \mathrm{~mL})$. The layers were separated, and the aqueous layer was extracted with 1:1 hexanes/EtOAc $(3 \times 50 \mathrm{~mL})$. The combined organic extracts were washed with brine $(2 \times 50 \mathrm{~mL})$, dried over anhydrous $\mathrm{Na}_{2} \mathrm{SO}_{4}$, filtered and concentrated under reduced pressure by rotary evaporation to give a yellow viscous oil. Purification by flash column chromatography on silica gel (hexanes/EtOAc 7:1) afforded 5-4 (13.6 g, 61\% over two steps) as a yellow solid and a 6:1 mixture of diastereomers.

$\mathbf{R}_{\mathbf{f}}: 0.3\left(25 \% \mathrm{Et}_{2} \mathrm{O} /\right.$ hexanes, $p$-anisaldehyde $)$

${ }^{1} \mathbf{H}$ NMR (600 MHz, $\left.\mathrm{CDCl}_{3}\right): \delta 7.63(\mathrm{t}, J=4.3 \mathrm{~Hz}, 1 \mathrm{H}), 7.32(\mathrm{~s}, 1 \mathrm{H}), 7.31(\mathrm{~s}, 1 \mathrm{H}), 6.35(\mathrm{~s}, 1 \mathrm{H}), 6.29$ (s, $1 \mathrm{H}), 2.47-2.44(\mathrm{~m}, 2 \mathrm{H}), 2.07(\mathrm{~s}, 3 \mathrm{H}), 2.01-1.96(\mathrm{~m}, 1 \mathrm{H}), 1.92(\mathrm{dt}, J=14.0,5.2 \mathrm{~Hz}, 1 \mathrm{H}), 1.22(\mathrm{~s}, 3 \mathrm{H})$

${ }^{13}$ C NMR (151 MHz, $\left.\mathrm{CDCl}_{3}\right): \delta 194.1,169.7,157.7,142.9,140.9,121.9,110.1,103.0,71.6,49.7,29.1$, $27.0,21.1,19.3$

IR $\left(\mathrm{cm}^{-1}\right): 1747,1680,1233,1164,1026,739$

ESI-HRMS (m/z): [M+H] $]^{+}$calc'd for $\mathrm{C}_{14} \mathrm{H}_{16} \mathrm{IO}_{4}$ : 375.0088 ; found: 375.0097 


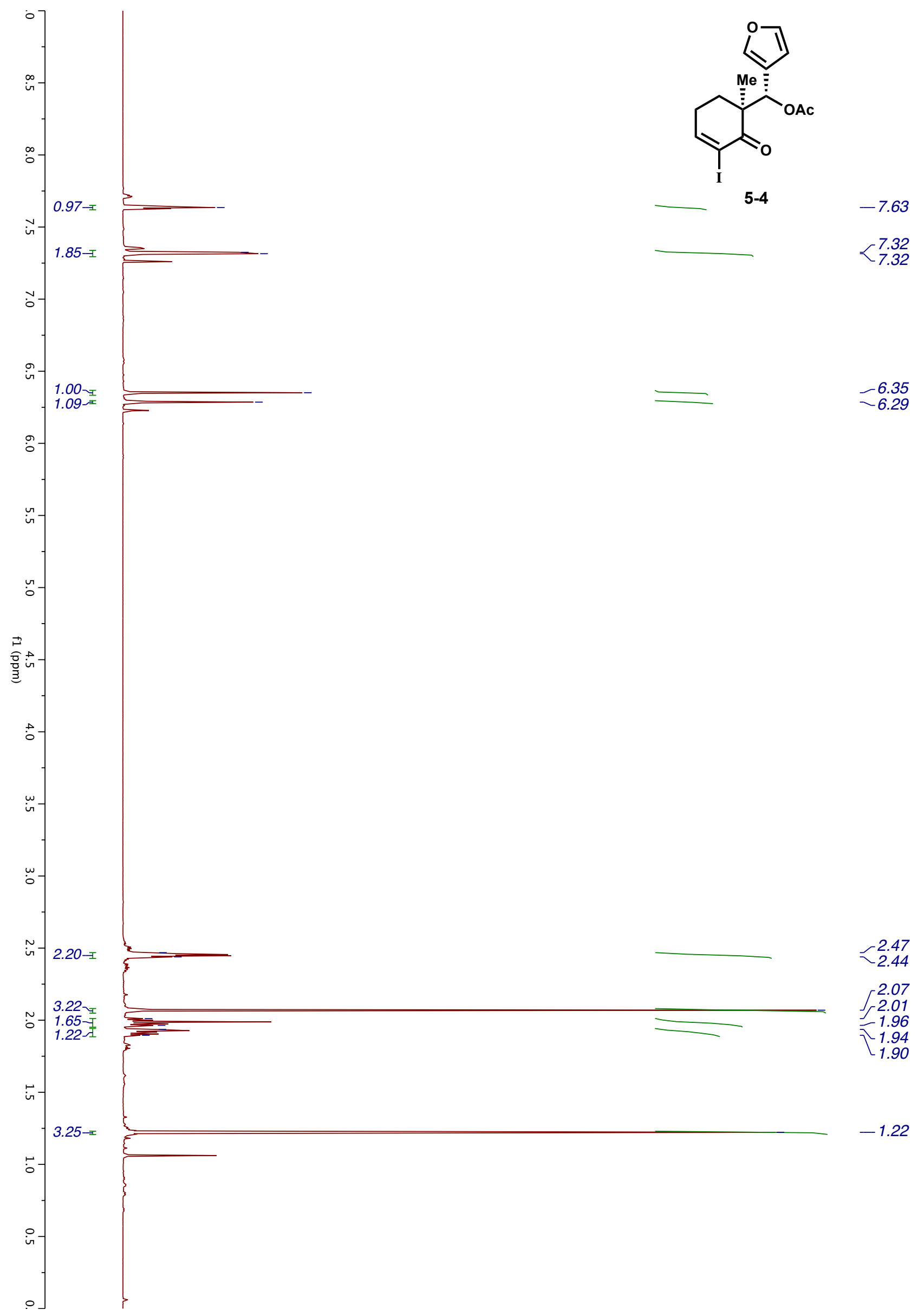



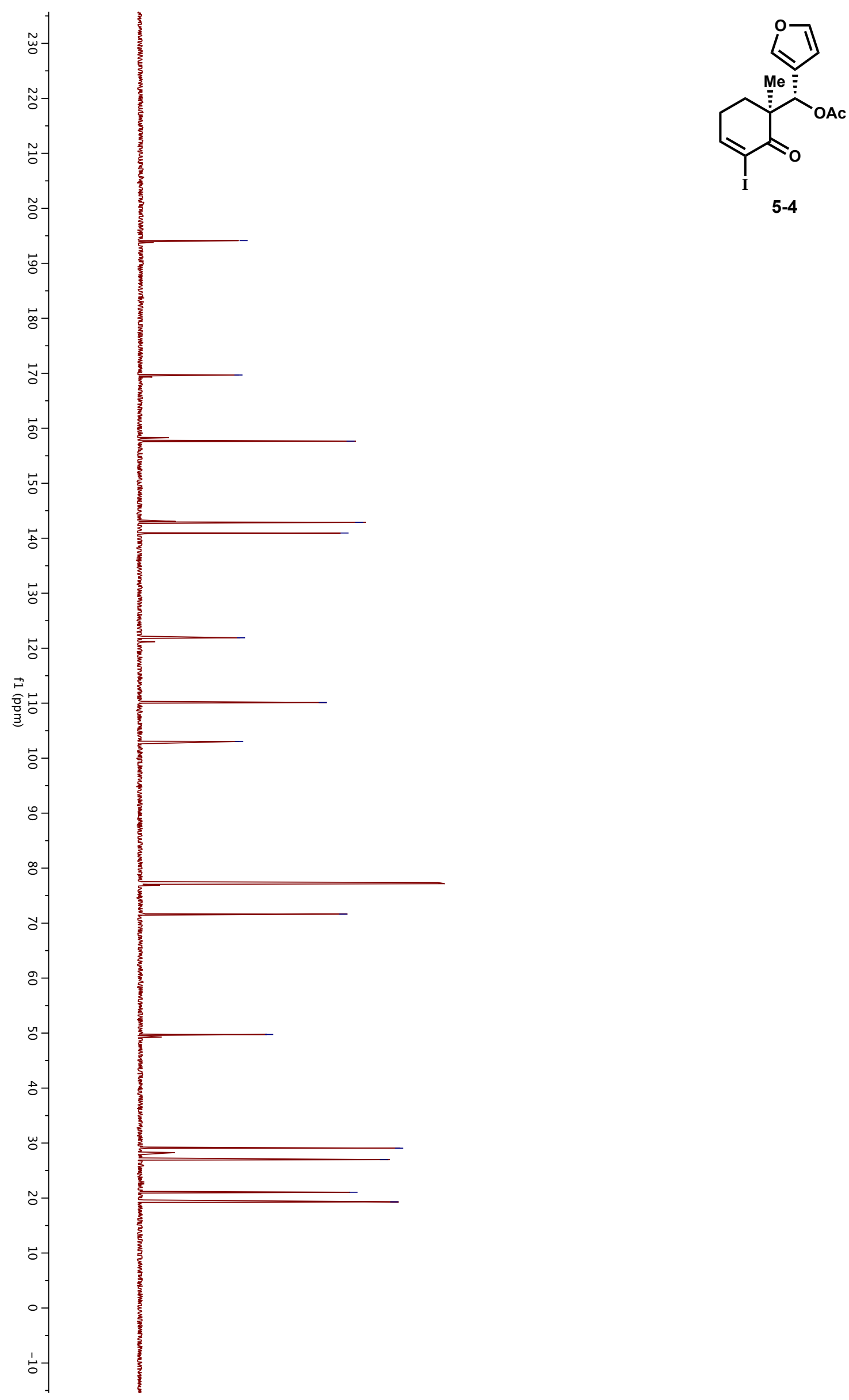

$-194.1$

$-169.7$

$-157.7$

$-142.9$

$\sim 140.9$

$-121.9$

$-110.1$

$-103.0$

$-71.6$

$-49.7$

29.1
$\sim 27.0$

21.1
-19.3 

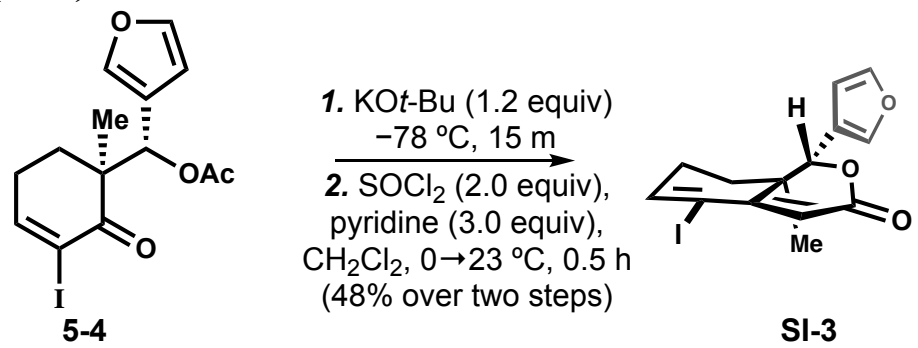

Step 1:

An evacuated flame-dried 250-mL round-bottomed flask equipped with a magnetic stir bar and a Schlenk adapter was brought into a glovebox. Once in the glovebox, the flask was filled with a nitrogen atmosphere. Solid KOt-Bu (540 mg, $4.8 \mathrm{mmol}, 1.2$ equiv) was added and the flask was sealed. The flask was removed from the glovebox, and the flask was evacuated and backfilled with nitrogen three times using a dual manifold Schlenk line. The Schlenk adapter was replaced with a rubber septum and the flask was placed under a nitrogen atmosphere.

To this flask was added THF $(40 \mathrm{~mL}, 0.1 \mathrm{M})$ via cannula, and this mixture was allowed to stir at room temperature for 2 minutes to allow for complete dissolution of $\mathrm{KO} t$-Bu. The reaction vessel was transferred to a $-78^{\circ} \mathrm{C}$ saturated dry-ice acetone bath and allowed to stir for 10 minutes before a solution of acetate 5-4 (1.5 g, $4.0 \mathrm{mmol}, 1.0$ equiv) in THF $(11 \mathrm{~mL}, 1.0 \mathrm{M})$ was added over 5 minutes, resulting in a yellow reaction mixture. After the reaction mixture had stirred for 15 minutes at $-78{ }^{\circ} \mathrm{C}$, sat. aq. $\mathrm{NH}_{4} \mathrm{Cl}$ $(25 \mathrm{~mL})$ was added to the reaction mixture and the reaction vessel was removed from the dry-ice acetone bath. Once at room temperature, the layers were separated and the aqueous layer was extracted with EtOAc $(2 \times 50 \mathrm{~mL})$. The combined organic extracts were washed with brine $(25 \mathrm{~mL})$, dried over anhydrous $\mathrm{Na}_{2} \mathrm{SO}_{4}$, filtered, and concentrated under reduced pressure by rotary evaporation to provide a crude yellow oil.

\section{Step 2:}

To a flame-dried 100-mL round-bottomed flask equipped with a magnetic stir bar was added crude intermediate alcohol and $\mathrm{CH}_{2} \mathrm{Cl}_{2}(15 \mathrm{~mL}, 0.3 \mathrm{M})$. The reaction vessel was transferred to an ice-water bath cooled to $0{ }^{\circ} \mathrm{C}$, and pyridine $(0.97 \mathrm{~mL}, 12.0 \mathrm{mmol}, 3.0$ equiv) was added dropwise over one minute. Following this, thionyl chloride $(0.58 \mathrm{~mL}, 8.0 \mathrm{mmol}, 2.0$ equiv) was added dropwise over five minutes. After the addition was complete, the reaction vessel was removed from the ice-water bath and allowed to warm to room temperature.

After stirring at room temperature for 30 minutes, sat. aq. $\mathrm{NaHCO}_{3}(10 \mathrm{~mL})$ was added dropwise to the reaction mixture and the layers were separated. The aqueous layer was extracted with $\mathrm{CH}_{2} \mathrm{Cl}_{2}(3 \mathrm{x}$ $15 \mathrm{~mL})$. The combined organic extracts were washed with brine $(15 \mathrm{~mL})$, dried over anhydrous $\mathrm{Na}_{2} \mathrm{SO}_{4}$, filtered and concentrated under reduced pressure by rotary evaporation to give a yellow viscous oil. Purification by flash column chromatography on silica gel (hexanes/EtOAc 4:1) afforded SI-3 (680 mg, $48 \%$ over two steps) as a yellow solid.

Rf: $0.32\left(25 \% \mathrm{Et}_{2} \mathrm{O} /\right.$ hexanes, $p$-anisaldehyde)

${ }^{1}$ H NMR $\left(600 \mathrm{MHz}, \mathrm{CDCl}_{3}\right): \delta 7.49(\mathrm{~s}, 1 \mathrm{H}), 7.44(\mathrm{t}, J=1.8 \mathrm{~Hz}, 1 \mathrm{H}), 7.08(\mathrm{dd}, J=6.2,2.7 \mathrm{~Hz}, 1 \mathrm{H}), 6.45$ $(\mathrm{s}, 1 \mathrm{H}), 6.17(\mathrm{~s}, 1 \mathrm{H}), 5.13(\mathrm{~s}, 1 \mathrm{H}), 2.49-2.42(\mathrm{~m}, 1 \mathrm{H}), 2.39-2.32(\mathrm{~m}, 1 \mathrm{H}), 1.56(\mathrm{dd}, J=3.6,9.0 \mathrm{~Hz}, 2 \mathrm{H})$, $1.09(\mathrm{~s}, 3 \mathrm{H})$

${ }^{13}$ C NMR (151 MHz, $\left.\mathrm{CDCl}_{3}\right): \delta 165.4,157.5,150.3,143.3,141.4,121.0,119.6,110.1,94.9,80.9,39.5$, $29.4,26.8,16.3$

IR $\left(\mathrm{cm}^{-1}\right): 1708,1630,1427,1264,1164,1077,1025,767,702$

ESI-HRMS (m/z): $[\mathrm{M}+\mathrm{H}]^{+}$calc'd for $\mathrm{C}_{14} \mathrm{H}_{14} \mathrm{IO}_{3}{ }^{+}: 356.9982$; found: 356.9982 

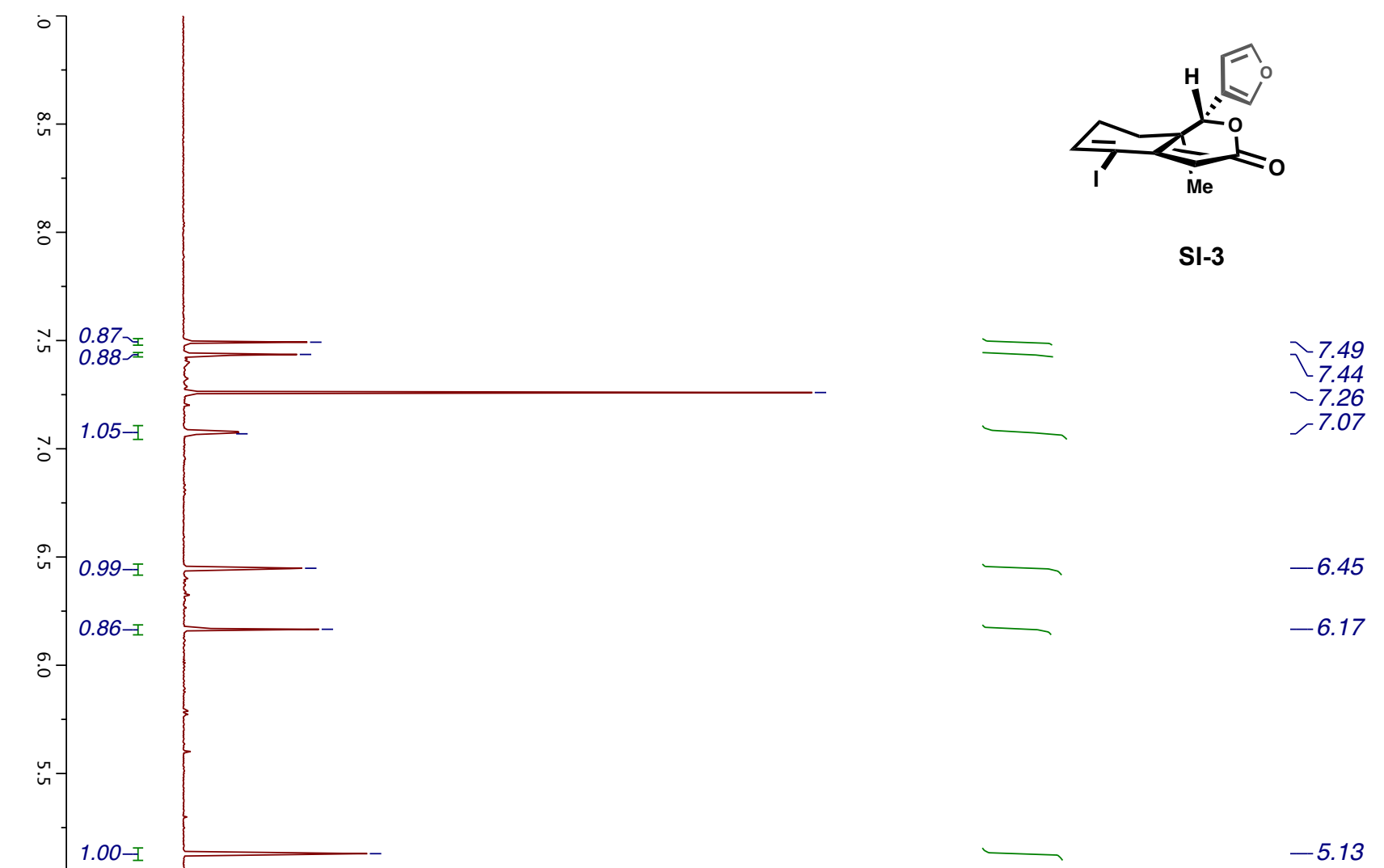

을

$$
\vec{\ominus}
$$

ir

$\ddot{\omega}$$$
\tilde{i}
$$

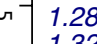$$
\text { . }
$$

$2.41-$

3.23 -
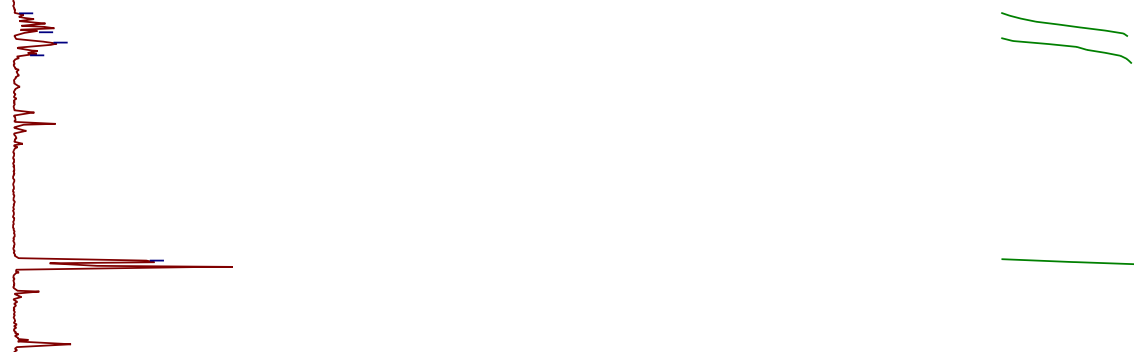

2.49
-2.42

$-2.38$

$\backslash 2.33$

$-1.57$

$-1.09$ 


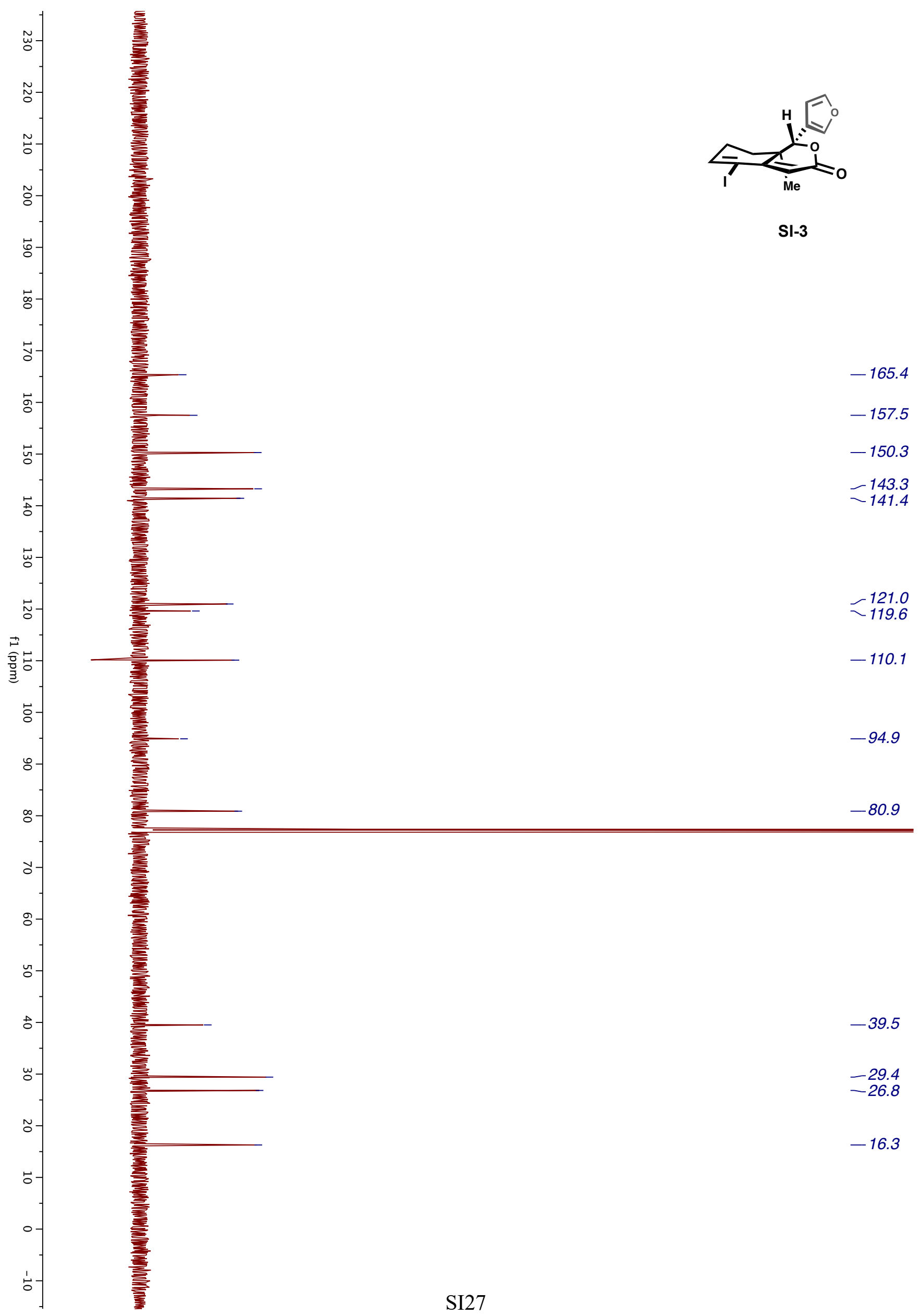


Synthesis of stannyl dienoate (3-4):

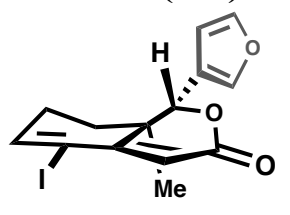

SI-3

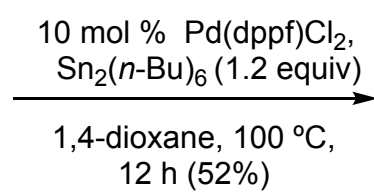

$12 \mathrm{~h}(52 \%)$

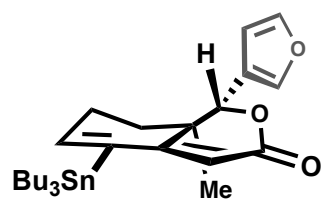

3-4

To a flame dried $20-\mathrm{mL}$ microwave vial equipped with a magnetic stir bar was added $\mathrm{Pd}(\mathrm{dppf}) \mathrm{Cl}_{2}$ (9.8 mg, $0.014 \mathrm{mmol}, 10 \mathrm{~mol} \%$ ). The vial was sealed with a Teflon microwave cap, and then evacuated and backfilled with nitrogen three times using a dual manifold Schlenk line. To the reaction mixture was added a degassed solution of iodide SI-3 $(50.0 \mathrm{mg}, 0.14 \mathrm{mmol}, 1.0$ equiv) in 1,4-dioxane $(0.28 \mathrm{~mL}, 0.5 \mathrm{M}$, degassed by freeze-pump-thaw) and $\mathrm{Sn}_{2}(n-\mathrm{Bu})_{6}(97.4 \mathrm{mg}, 0.17 \mathrm{mmol}, 1.2$ equiv). The reaction vessel was then moved to an oil bath, which was then heated to $100{ }^{\circ} \mathrm{C}$.

After the reaction had stirred at $100^{\circ} \mathrm{C}$ for 12 hours, the reaction vessel was removed from the oil bath and allowed to cool to room temperature. Once at room temperature, the reaction mixture was diluted with water $(10 \mathrm{~mL})$, and the layers were separated. The aqueous layer was extracted with $\mathrm{Et}_{2} \mathrm{O}(3 \times 5 \mathrm{~mL})$. The combined organic extracts were washed with brine $(5 \mathrm{~mL})$, dried over anhydrous $\mathrm{Na}_{2} \mathrm{SO}_{4}$, filtered and concentrated under reduced pressure by rotary evaporation to give a brown oil. Purification by flash column chromatography on silica gel (hexanes/Et $2 \mathrm{O} 12: 1$ ) afforded 3-4 (37.9 $\mathrm{mg}, 52 \%)$ as a colorless oil.

$\mathbf{R}_{\mathbf{f}}: 0.17$ (15\% Et $2 \mathrm{O} /$ hexanes, $p$-anisaldehyde)

${ }^{1}$ H NMR $\left(500 \mathrm{MHz}, \mathrm{CDCl}_{3}\right): \delta 7.47(\mathrm{~s}, 1 \mathrm{H}), 7.42(\mathrm{t}, J=1.7 \mathrm{~Hz}, 1 \mathrm{H}), 6.45(\mathrm{~m}, 2 \mathrm{H}), 5.63(\mathrm{~s}, 1 \mathrm{H}), 5.10(\mathrm{~s}$, $1 \mathrm{H}), 2.39-2.27(\mathrm{~m}, 2 \mathrm{H}), 1.67-1.61(\mathrm{~m}, 1 \mathrm{H}), 1.53-1.44(\mathrm{~m}, 6 \mathrm{H}), 1.38-1.28(\mathrm{~m}, 7 \mathrm{H}), 1.03(\mathrm{~s}, 3 \mathrm{H}), 1.02-$ $0.98(\mathrm{~m}, 6 \mathrm{H}), 0.94-0.87(\mathrm{~m}, 9 \mathrm{H})$

${ }^{13}$ C NMR (151 MHz, $\left.\mathrm{CDCl}_{3}\right): \delta 166.2,163.7,149.5,143.0,141.2,137.6,120.4,114.5,110.3,80.9,37.9$, $29.8,29.2,28.0,27.4,27.0,25.0,17.7,16.2,13.8,13.8,10.3$

IR $\left(\mathrm{cm}^{-1}\right): 2955,2923,2872,2853,1712,1595,1572,1463,1257,1166,1074,1026,898,725,602$

ESI-HRMS (m/z): $[\mathrm{M}+\mathrm{H}]^{+}$calc'd for $\mathrm{C}_{26} \mathrm{H}_{41} \mathrm{O}_{3} \mathrm{Sn}^{+}$: 521.2072; found: 521.2071 


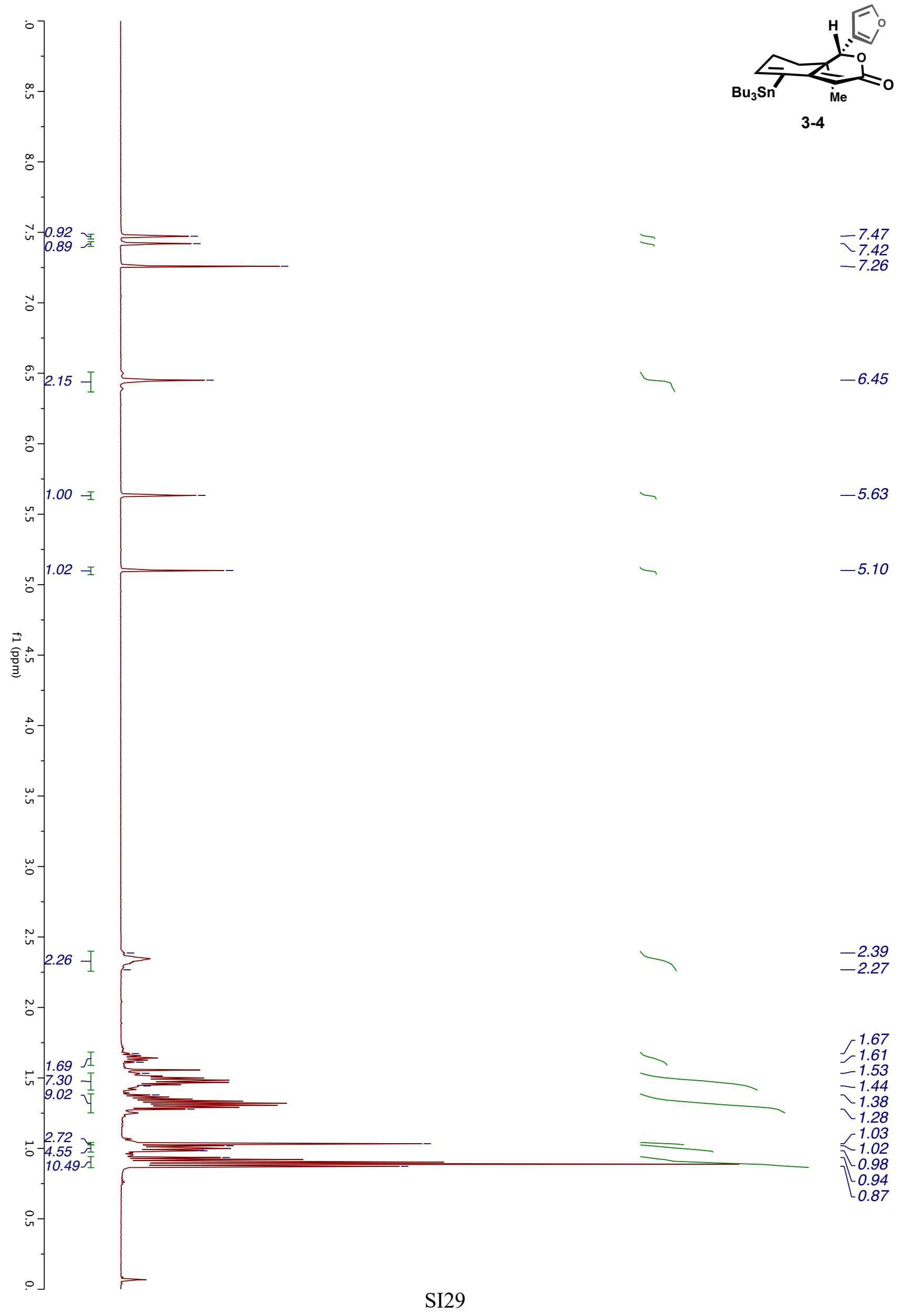



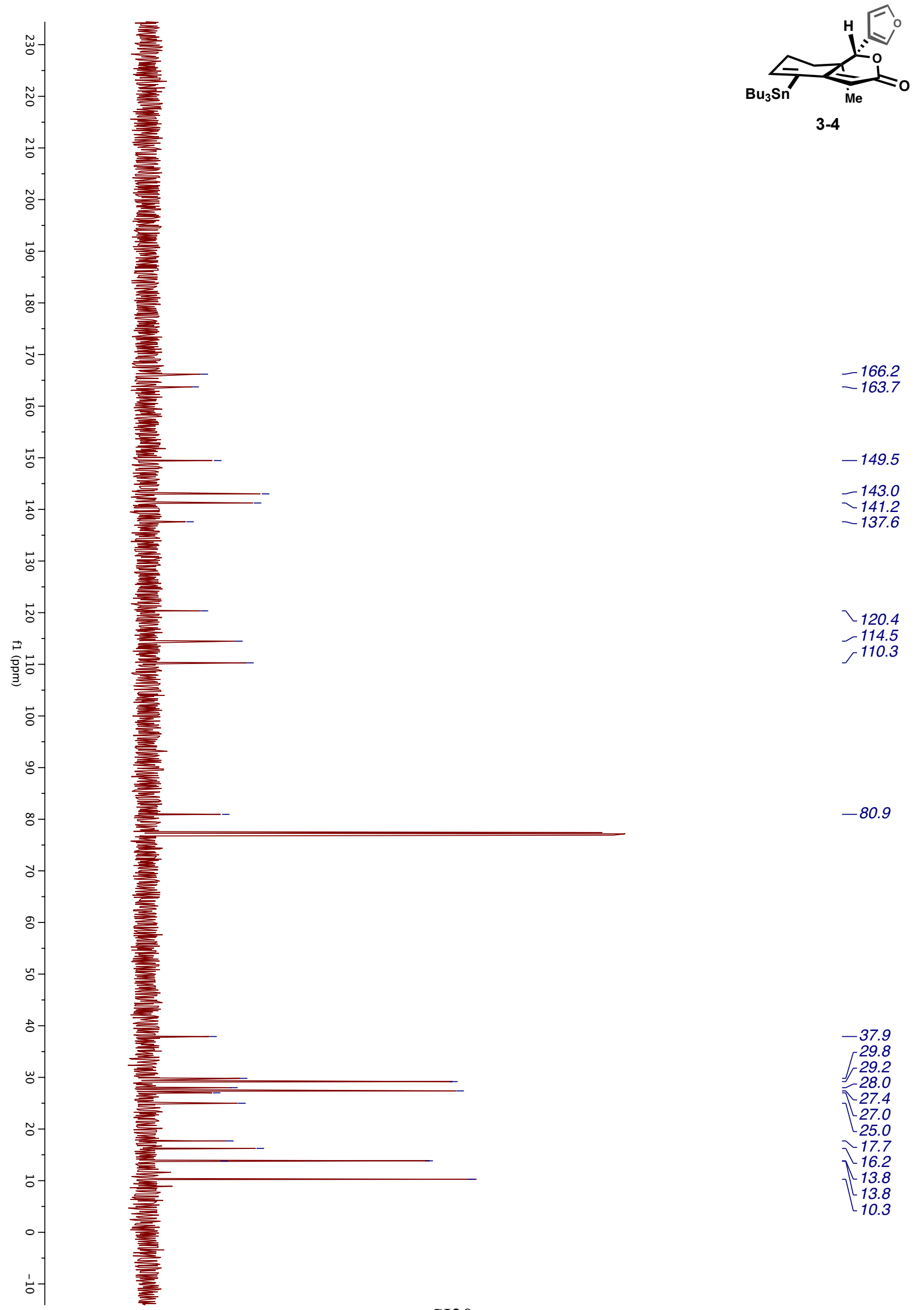

$\chi_{120.4}$

$-114.5$

$\tau^{110.3}$

$-80.9$ 
General procedures for $\boldsymbol{\beta}$-stannylation screen:

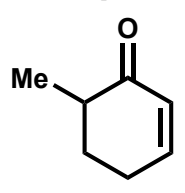

$5-2$

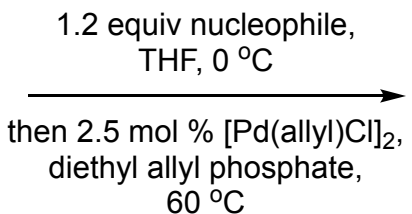

$60^{\circ} \mathrm{C}$

\section{Preparation of nucleophilic species}

\section{Entries 1* and 2}

To a flame-dried microwave vial equipped with a magnetic stir bar was added THF ( $0.5 \mathrm{~mL} 0.4$ $\mathrm{M})$ and diisopropylamine ( $36 \mu \mathrm{L}, 0.26 \mathrm{mmol}, 1.3$ equiv). The reaction mixture was cooled to $0{ }^{\circ} \mathrm{C}$ by transferring the reaction apparatus to an ice-water bath. The reaction mixture was stirred for 10 minutes at $0{ }^{\circ} \mathrm{C}$, before $n$ - BuLi $(0.10 \mathrm{~mL}, 0.24 \mathrm{mmol}, 1.2$ equiv, $2.5 \mathrm{M}$ in hexanes) was added dropwise to the reaction. After stirring for 15 minutes at $0{ }^{\circ} \mathrm{C}, \mathrm{Bu} 3 \mathrm{SnH}(65 \mu \mathrm{L}, 0.24 \mathrm{mmol}, 1.2$ equiv) was added to the reaction mixture and the reaction mixture was stirred at $0{ }^{\circ} \mathrm{C}$ for an additional 30 minutes to give a yellow solution.

\section{Entry 3}

To a flame-dried microwave vial equipped with a magnetic stir bar was added THF $(0.5 \mathrm{~mL} 0.4$ $\mathrm{M})$ and diisopropylamine $\left(72 \mu \mathrm{L}, 0.52 \mathrm{mmol}, 1.3\right.$ equiv). The reaction mixture was cooled to $0{ }^{\circ} \mathrm{C}$ by transferring the reaction apparatus to an ice-water bath. The reaction mixture was stirred for 10 minutes at $0{ }^{\circ} \mathrm{C}$, before $n$-BuLi $(0.20 \mathrm{~mL}, 0.48 \mathrm{mmol}, 2.4$ equiv, $2.5 \mathrm{M}$ in hexanes) was added dropwise to the reaction. After stirring for 15 minutes at $0{ }^{\circ} \mathrm{C}, \mathrm{Bu}_{3} \mathrm{SnH}(130 \mu \mathrm{L}, 0.48 \mathrm{mmol}, 1.2$ equiv) was added to the reaction mixture and the reaction mixture was stirred at $0{ }^{\circ} \mathrm{C}$ for an additional 30 minutes to give a yellow solution. To this mixture was added $\mathrm{ZnCl}_{2}\left(0.13 \mathrm{~mL}, 1.9 \mathrm{M}\right.$ in 2-MeTHF, $0.24 \mathrm{mmol}, 1.2$ equiv) at $0{ }^{\circ} \mathrm{C}$ and the reaction mixture was stirred for an additional 30 minutes.

\section{Entry 4}

To a flame-dried microwave vial equipped with a magnetic stir bar was added THF $(0.5 \mathrm{~mL} 0.4$ $\mathrm{M})$ and diisopropylamine ( $36 \mu \mathrm{L}, 0.26 \mathrm{mmol}, 1.3$ equiv). The reaction mixture was cooled to $0{ }^{\circ} \mathrm{C}$ by transferring the reaction apparatus to an ice-water bath. The reaction mixture was stirred for 10 minutes at $0{ }^{\circ} \mathrm{C}$, before $n$-BuLi $(0.10 \mathrm{~mL}, 0.24 \mathrm{mmol}, 1.2$ equiv, $2.5 \mathrm{M}$ in hexanes) was added dropwise to the reaction. After stirring for 15 minutes at $0{ }^{\circ} \mathrm{C}, \mathrm{Bu}_{3} \mathrm{SnH}(65 \mu \mathrm{L}, 0.24 \mathrm{mmol}, 1.2$ equiv) was added to the reaction mixture and the reaction mixture was stirred at $0{ }^{\circ} \mathrm{C}$ for an additional 30 minutes to give a yellow solution. To this mixture was added $\mathrm{Et}_{2} \mathrm{Zn}(0.20 \mathrm{~mL}, 0.20 \mathrm{mmol}, 1.0$ equiv, $1.0 \mathrm{M}$ in hexanes $)$ dropwise at $0{ }^{\circ} \mathrm{C}$ and the reaction mixture was stirred for an additional 30 minutes.

\section{Entry 5}

To a flame-dried microwave vial equipped with a magnetic stir bar was added THF $(0.5 \mathrm{~mL} 0.4$ M) and diisopropylamine ( $36 \mu \mathrm{L}, 0.26 \mathrm{mmol}, 1.3$ equiv). The reaction mixture was cooled to $0{ }^{\circ} \mathrm{C}$ by transferring the reaction apparatus to an ice-water bath. The reaction mixture was stirred for 10 minutes at $0{ }^{\circ} \mathrm{C}$, before $n$-BuLi $(0.10 \mathrm{~mL}, 0.24 \mathrm{mmol}, 1.2$ equiv, $2.5 \mathrm{M}$ in hexanes) was added dropwise to the reaction. After stirring for 15 minutes at $0{ }^{\circ} \mathrm{C}, \mathrm{Bu} 3 \mathrm{SnH}(65 \mu \mathrm{L}, 0.24 \mathrm{mmol}, 1.2$ equiv) was added to the reaction mixture and the reaction mixture was stirred at $0{ }^{\circ} \mathrm{C}$ for an additional 30 minutes to give a yellow solution. To this mixture was added $\mathrm{Et}_{2} \mathrm{Zn}(0.20 \mathrm{~mL}, 0.20 \mathrm{mmol}, 1.0$ equiv, $1.0 \mathrm{M}$ in hexanes $)$ dropwise at $0{ }^{\circ} \mathrm{C}$ and the reaction mixture was stirred for an additional 30 minutes. To this mixture was added $\mathrm{Me}_{2} \mathrm{Zn}\left(0.10 \mathrm{~mL}, 0.20 \mathrm{mmol}, 1.0\right.$ equiv, $2.0 \mathrm{M}$ in toluene) dropwise at $0{ }^{\circ} \mathrm{C}$ and the reaction mixture was stirred for an additional 30 minutes.

\section{Entry 6}

To a flame-dried microwave vial equipped with a magnetic stir bar was added THF ( $0.5 \mathrm{~mL} 0.4$ $\mathrm{M})$ and diisopropylamine ( $72 \mu \mathrm{L}, 0.52 \mathrm{mmol}, 1.3$ equiv). The reaction mixture was cooled to $0{ }^{\circ} \mathrm{C}$ by transferring the reaction apparatus to an ice-water bath. The reaction mixture was stirred for 10 minutes at $0{ }^{\circ} \mathrm{C}$, before $n$-BuLi $(0.20 \mathrm{~mL}, 0.48 \mathrm{mmol}, 2.4$ equiv, $2.5 \mathrm{M}$ in hexanes) was added dropwise to the reaction. After stirring for 15 minutes at $0{ }^{\circ} \mathrm{C}, \mathrm{Bu}_{3} \mathrm{SnH}(130 \mu \mathrm{L}, 0.48 \mathrm{mmol}, 1.2$ equiv) was added to the 
reaction mixture and the reaction mixture was stirred at $0{ }^{\circ} \mathrm{C}$ for an additional 30 minutes to give a yellow solution. This mixture was transferred to a $0{ }^{\circ} \mathrm{C}$ suspension of $\mathrm{CuI}(46 \mathrm{mg}, 0.24 \mathrm{mmol}, 1.2$ equiv) in $\mathrm{THF}$ $(0.5 \mathrm{~mL}, 0.48 \mathrm{M})$ and stirred for an additional 30 minutes.

To the reaction mixture was added 5-2 $(22 \mathrm{mg}, 0.20 \mathrm{mmol}, 1.0$ equiv) dropwise and the resulting mixture was stirred at $0{ }^{\circ} \mathrm{C}$ for 30 minutes before a solution of [Pd(allyl)Cl] $2(1.8 \mathrm{mg}, 0.005 \mathrm{mmol}, 2.5$ $\mathrm{mol} \%)$ and diethyl allyl phosphate $(82 \mu \mathrm{L}, 0.46 \mathrm{mmol}, 2.3 \text { equiv })^{*}$ in THF $(0.20 \mathrm{~mL})$ was quickly added. The reaction vessel was then moved to a preheated $60{ }^{\circ} \mathrm{C}$ oil bath until a black precipitate formed out of the reaction (ca.15 minutes after heating).

Upon formation of palladium precipitate, the reaction vessel was immediately removed from the oil bath and sat. aq. $\mathrm{NH}_{4} \mathrm{Cl}(5 \mathrm{~mL})$ was added to the hot reaction mixture. The reaction mixture was diluted with $\mathrm{Et}_{2} \mathrm{O}(5 \mathrm{~mL})$ and the organic phase was separated. The aqueous phase was extracted with $\mathrm{Et}_{2} \mathrm{O}(2 \mathrm{x}$ $5 \mathrm{~mL})$ and the combined organic extracts were washed with brine $(15 \mathrm{~mL})$, dried with $\mathrm{Na}_{2} \mathrm{SO}_{4}$, filtered, and concentrated under reduced pressure by rotary evaporation.

*For entry 1 , fewer equivalents of diethyl allyl phosphate $(35.6 \mu \mathrm{L}, 0.2 \mathrm{mmol}, 1.0$ equiv) was used.

\section{$\beta$-allylation byproduct (6-5)}

Rf: $0.35\left(25 \% \mathrm{Et}_{2} \mathrm{O} /\right.$ hexanes, $\left.\mathrm{KMnO}_{4}\right)$

${ }^{1}$ H NMR (400 MHz, $\left.\mathrm{CDCl}_{3}\right): \delta 5.86(\mathrm{~s}, 1 \mathrm{H}), 5.79(\mathrm{ddt}, J=17.1,10.4,6.9 \mathrm{~Hz}, 1 \mathrm{H}), 5.15-5.10(\mathrm{~m}, 2 \mathrm{H})$, $2.93(\mathrm{~d}, J=6.9 \mathrm{~Hz}, 2 \mathrm{H}), 2.40-2.26(\mathrm{~m}, 3 \mathrm{H}), 2.06(\mathrm{dq}, J=13.5,4.6 \mathrm{~Hz}, 1 \mathrm{H}), 1.74-1.64(\mathrm{~m}, 1 \mathrm{H}), 1.13$ $(\mathrm{d}, J=6.8 \mathrm{~Hz}, 3 \mathrm{H})$

${ }^{13}$ C NMR (101 MHz, $\left.\mathrm{CDCl}_{3}\right): \delta 202.3,163.0,133.6,125.9,118.3,42.1,40.9,30.9,29.2,15.2$

IR $\left(\mathrm{cm}^{-1}\right): 1666,1628,1455,1427,1371,1206,995,914,872$

ESI-HRMS (m/z): $[\mathrm{M}+\mathrm{H}]^{+}$calc'd for $\mathrm{C}_{10} \mathrm{H}_{15} \mathrm{O}^{+}:$: 151.1117; found: 151.1117 

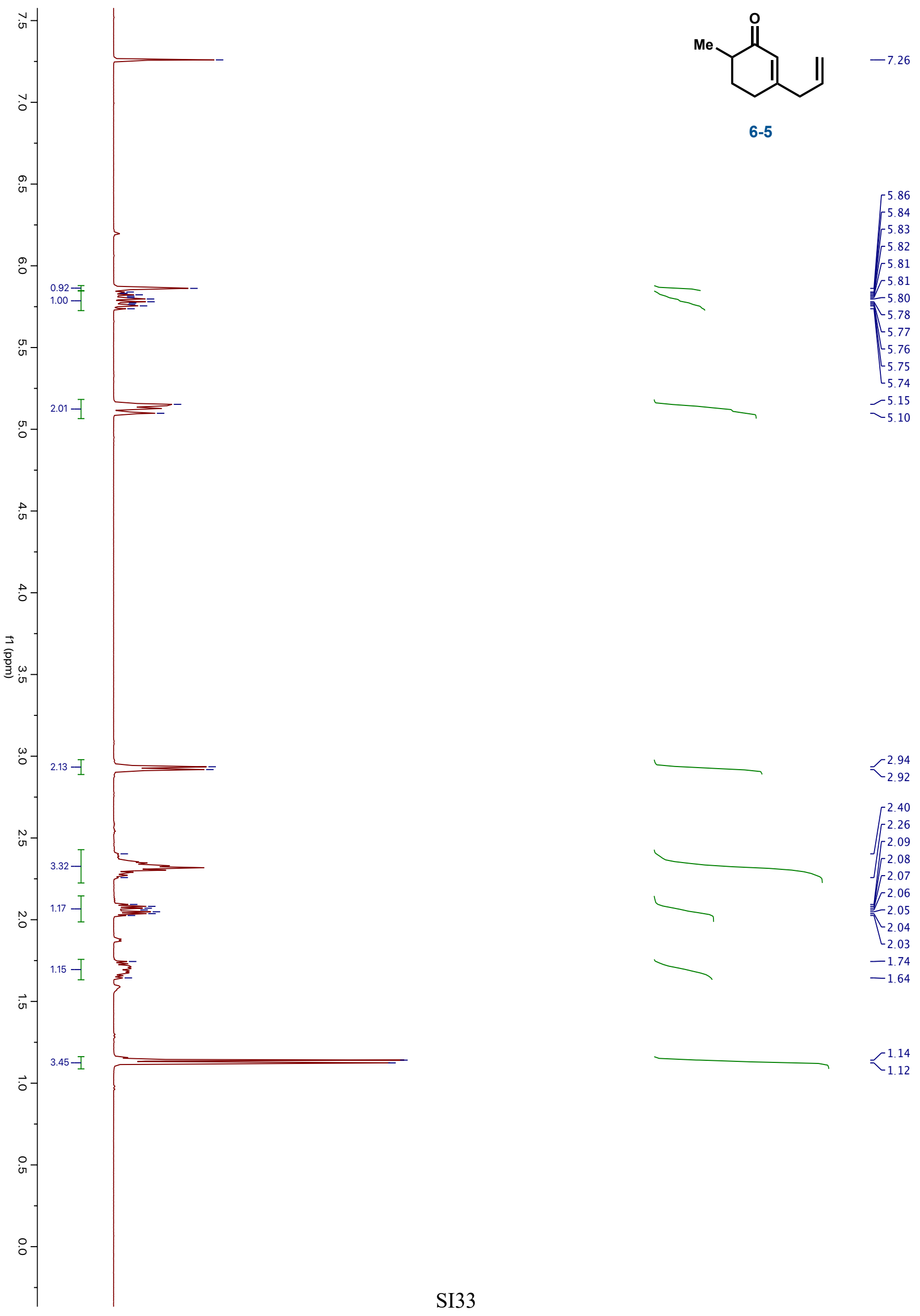


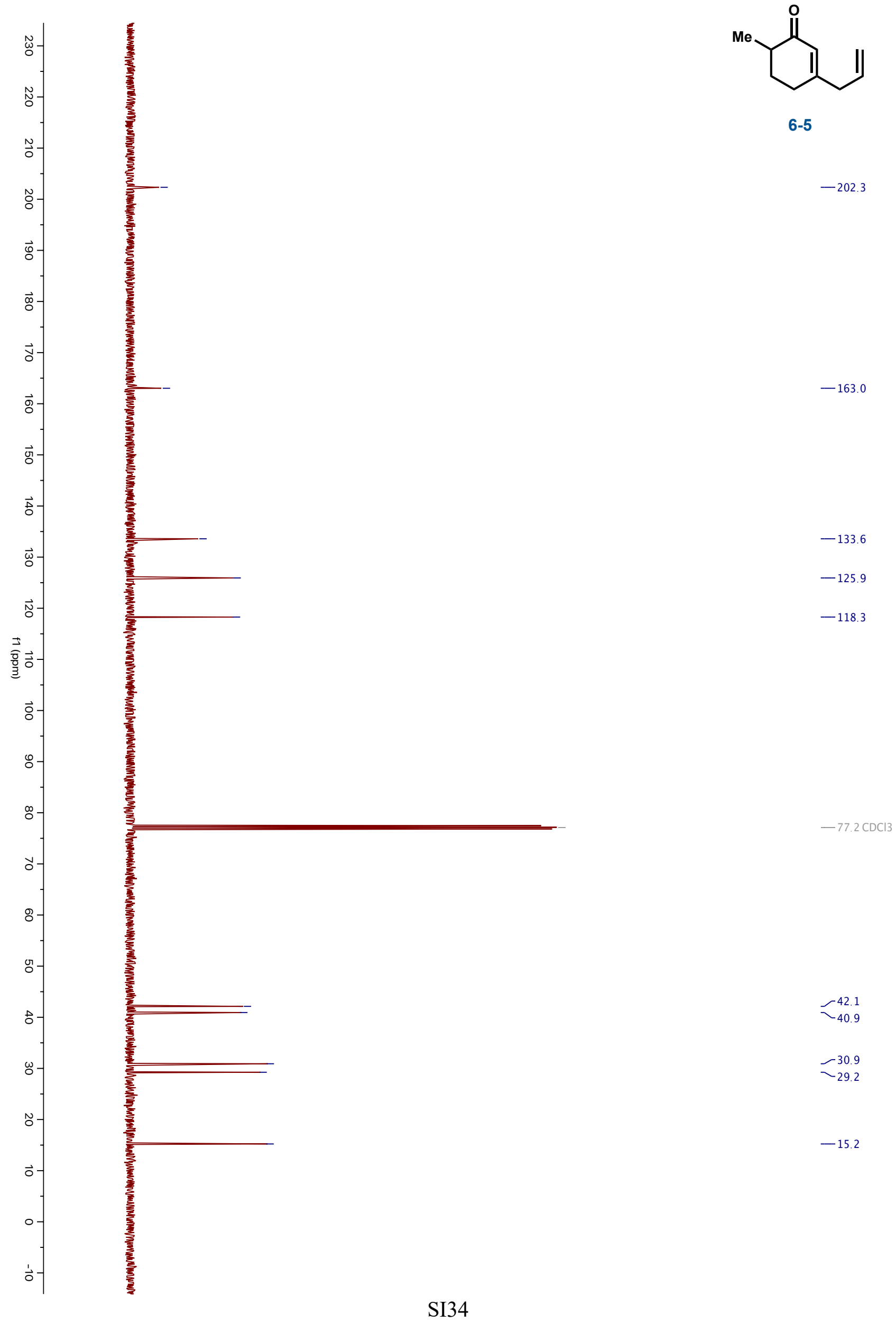


<smiles>CC1CCC=CC1=O</smiles>

5-2

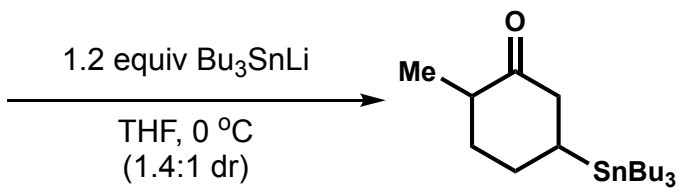

6-6

To a flame-dried microwave vial equipped with a magnetic stir bar was added THF (1.0 mL 0.5 $\mathrm{M})$ and diisopropylamine $\left(91 \mu \mathrm{L}, 0.65 \mathrm{mmol}, 1.3\right.$ equiv). The reaction mixture was cooled to $0{ }^{\circ} \mathrm{C}$ by transferring the reaction apparatus to an ice-water bath. The reaction mixture was stirred for 10 minutes at $0{ }^{\circ} \mathrm{C}$, before $n$-BuLi $(0.24 \mathrm{~mL}, 0.6 \mathrm{mmol}, 1.2$ equiv, $2.5 \mathrm{M}$ in hexanes $)$ was added dropwise to the reaction. After stirring for 15 minutes at $0{ }^{\circ} \mathrm{C}, \mathrm{Bu} 3 \mathrm{SnH}(0.16 \mathrm{~mL}, 0.24 \mathrm{mmol}, 1.2$ equiv) was added to the reaction mixture. After the reaction mixture was stirred at $0{ }^{\circ} \mathrm{C}$ for an additional 30 minutes, a yellow reaction mixture formed. To the reaction mixture was added 5-2 (55.1 $\mathrm{mg}, 0.5 \mathrm{mmol}, 1.0$ equiv) dropwise and the resulting mixture was stirred at $0{ }^{\circ} \mathrm{C}$ for 30 minutes.

After stirring at $0{ }^{\circ} \mathrm{C}$ for 30 minutes, the reaction mixture was diluted with sat. aq. $\mathrm{NH}_{4} \mathrm{Cl}(5 \mathrm{~mL})$. The reaction mixture was diluted with $\mathrm{Et}_{2} \mathrm{O}(5 \mathrm{~mL})$ and the organic phase was separated. The aqueous phase was extracted with $\mathrm{Et}_{2} \mathrm{O}(2 \times 5 \mathrm{~mL})$ and the combined organic extracts were washed with brine (15 $\mathrm{mL}$ ), dried with $\mathrm{Na}_{2} \mathrm{SO}_{4}$, filtered, and concentrated under reduced pressure by rotary evaporation. Purification by flash column chromatography on silica gel $\left(5 \% \mathrm{Et}_{2} \mathrm{O} /\right.$ hexanes) afforded 6-6 (174.5 mg, $87 \%$ ) as a colorless oil and a 1.4:1 mixture of diastereomers.

R: $0.6\left(20 \% \mathrm{Et}_{2} \mathrm{O} /\right.$ hexanes, $\left.\mathrm{KMnO}_{4}\right)$

${ }^{1} \mathbf{H}$ NMR $\left(400 \mathrm{MHz}, \mathrm{CDCl}_{3}\right)$ : (mixture of diastereomers) $\delta 2.59-2.33(\mathrm{~m}, 6 \mathrm{H}), 2.21-2.15(\mathrm{~m}, 1 \mathrm{H}), 2.06-$ $1.99(\mathrm{~m}, 1.4 \mathrm{H}), 1.94-1.72(\mathrm{~m}, 4 \mathrm{H}), 1.40-1.40(\mathrm{~m}, 18 \mathrm{H}), 1.33-1.24(\mathrm{~m}, 18 \mathrm{H}), 1.09(\mathrm{~d}, J=6.9 \mathrm{~Hz}, 3 \mathrm{H})$, $0.99(\mathrm{~d}, 6.4 \mathrm{~Hz}, 3 \mathrm{H}), 0.89-0.80(\mathrm{~m}, 43 \mathrm{H})$

${ }^{13} \mathbf{C}$ NMR (101 MHz, $\mathrm{CDCl}_{3}$ ): (mixture of diastereomers) $\delta$ 214.9, 214.4, 46.8, 45.9, 45.1, 44.5, 41.2, $36.6,30.9,29.4,29.4,27.7,27.6,27.4,26.6,25.2,15.9,14.9,13.8,8.7,8.2$

IR $\left(\mathrm{cm}^{-1}\right): 1748,1710,1457,1377,1187,1073,1047,864,687,662$

ESI-HRMS (m/z): $[\mathrm{M}+\mathrm{H}]^{+}$calc'd for $\mathrm{C}_{19} \mathrm{H}_{39} \mathrm{OSn}^{+}$: 403.2017; found: 403.2022 


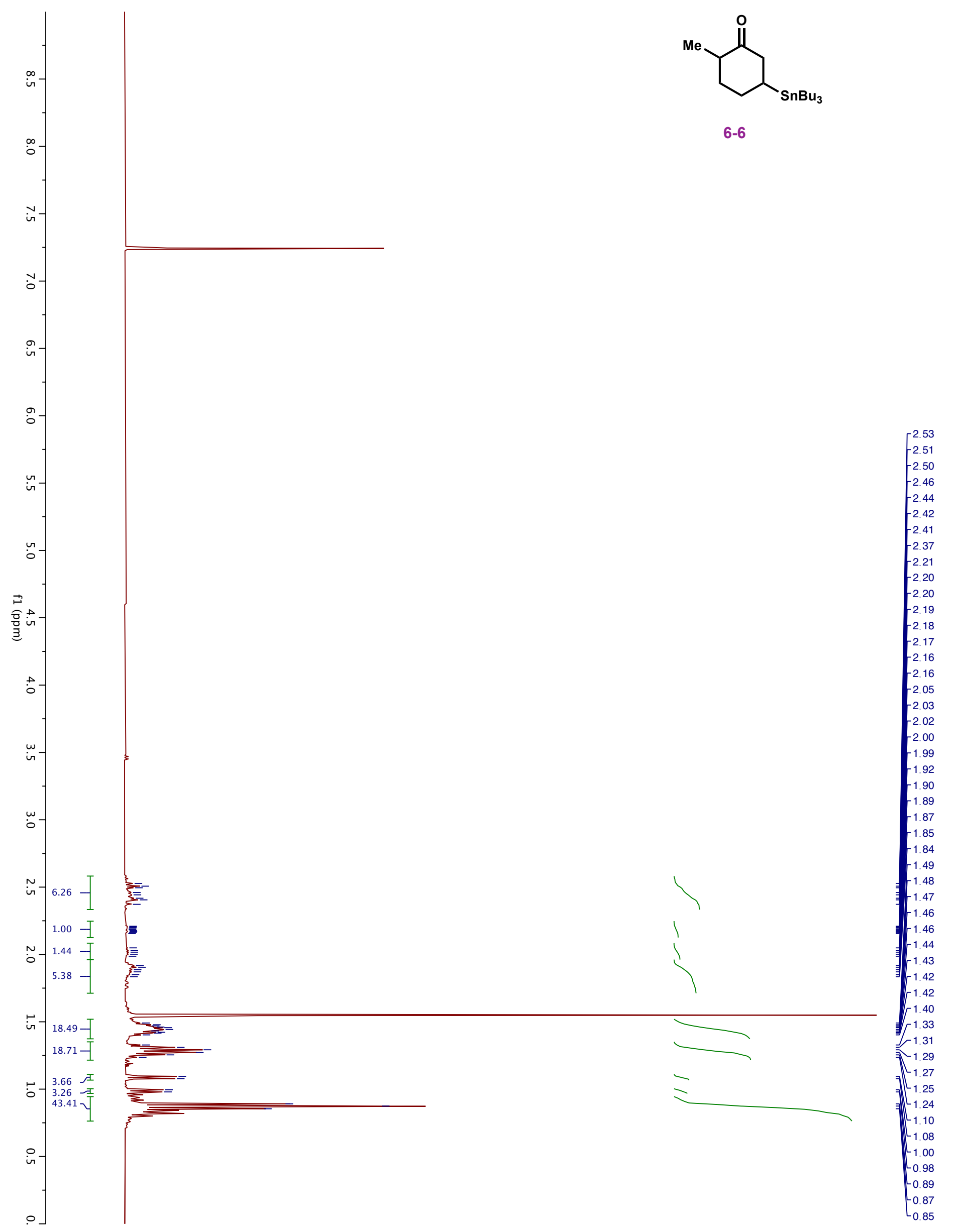




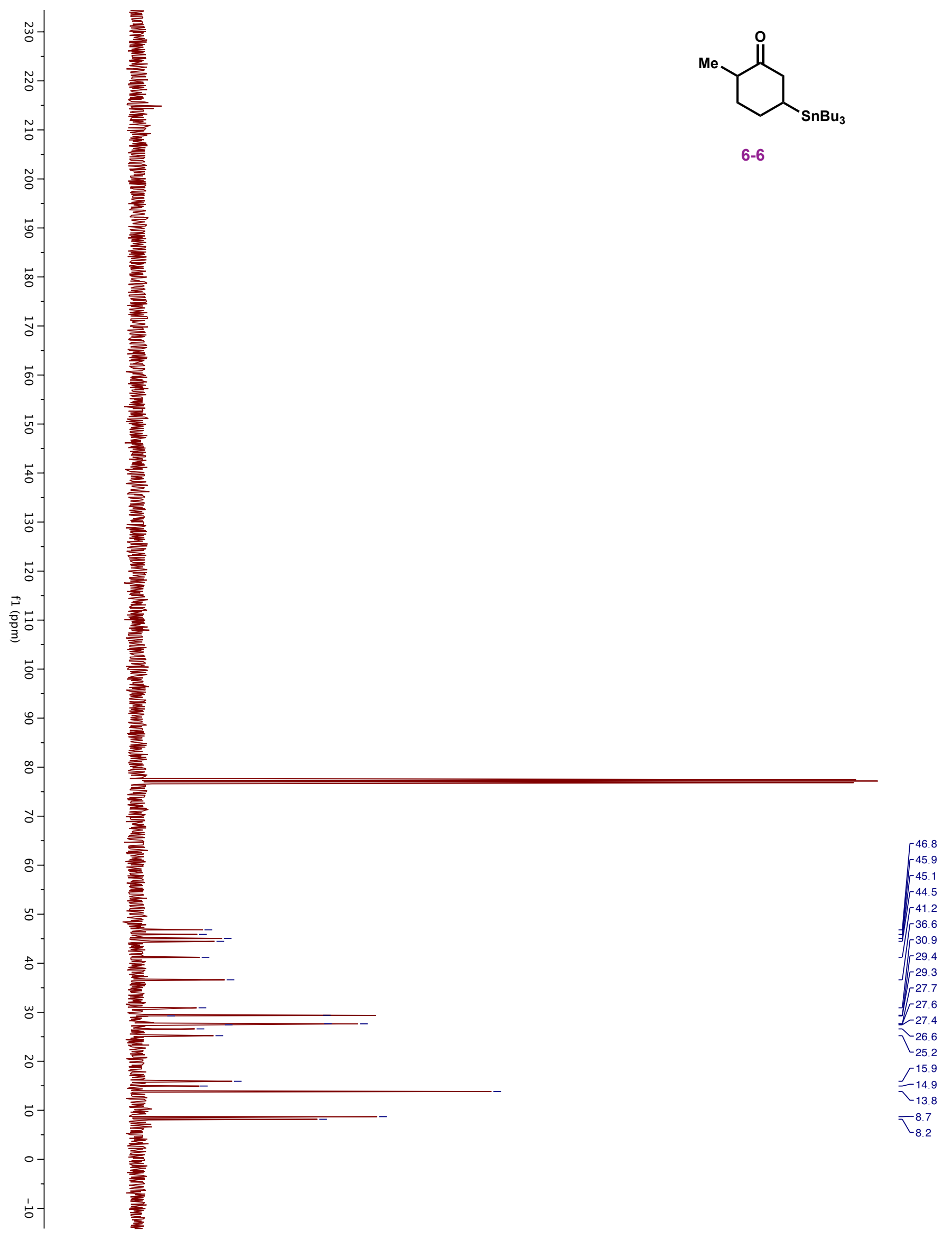


Synthesis of PfBz-oxime (6-13):
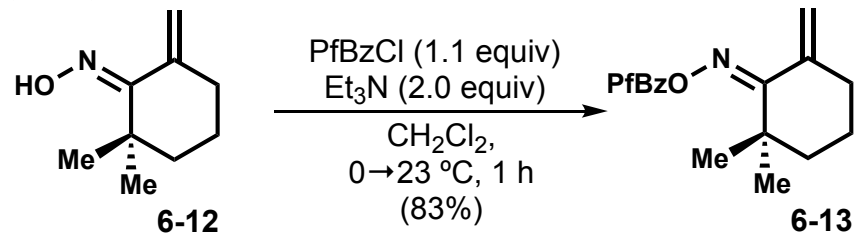

To a flame-dried 5-mL microwave vial with a magnetic stir bar was added $E$-oxime 6-12 (50.0 mg, $0.33 \mathrm{mmol}, 1.0$ equiv), and $\mathrm{CH}_{2} \mathrm{Cl}_{2}(320 \mu \mathrm{L}, 1.0 \mathrm{M})$. The reaction vessel was moved to a $0{ }^{\circ} \mathrm{C}$ icewater bath, and triethylamine ( $92 \mu \mathrm{L}, 0.65 \mathrm{mmol}, 2.0$ equiv) was added dropwise to the reaction mixture. After stirring at $0{ }^{\circ} \mathrm{C}$ for 5 minutes, pentafluorobenzoyl chloride $(51 \mu \mathrm{L}, 0.36 \mathrm{mmol}, 1.1$ equiv) was added dropwise to the reaction mixture. The reaction vessel was removed from the ice-water bath, and the reaction mixture was allowed to stir at room temperature.

After the reaction mixture had stirred at room temperature for 1 hour, the reaction mixture was diluted with 1:1 sat. aq. $\mathrm{NaHCO}_{3} /$ brine $(5 \mathrm{~mL})$ and the layers were separated. The aqueous layer was extracted with $\mathrm{Et}_{2} \mathrm{O}(3 \times 5 \mathrm{~mL})$. The combined organic extracts were washed with brine $(5 \mathrm{~mL})$, dried over anhydrous $\mathrm{Na}_{2} \mathrm{SO}_{4}$, filtered and concentrated under reduced pressure by rotary evaporation to give a crude yellow solid. Purification by flash column chromatography on silica gel $\left(10 \% \mathrm{Et}_{2} \mathrm{O} / \mathrm{h}_{\text {hexanes }}\right.$ to $50 \%$ $\mathrm{Et}_{2} \mathrm{O} /$ hexanes) afforded 6-13 (94.1 $\left.\mathrm{mg}, 83 \%\right)$ as a colorless oil.

Rf: $0.45\left(10 \% \mathrm{Et}_{2} \mathrm{O} /\right.$ hexanes, $\left.\mathrm{KMnO}_{4}\right)$

${ }^{1} \mathbf{H}$ NMR $\left(500 \mathrm{MHz}, \mathrm{CDCl}_{3}\right): \delta 5.33(\mathrm{~d}, J=1.4 \mathrm{~Hz}, 1 \mathrm{H}), 5.08(\mathrm{~s}, 1 \mathrm{H}), 2.35-2.28(\mathrm{~m}, 2 \mathrm{H}), 1.75-1.67$ (m, $4 \mathrm{H}), 1.24(\mathrm{~s}, 6 \mathrm{H})$

${ }^{13}$ C NMR (151 MHz, $\left.\mathrm{CDCl}_{3}\right): \delta 174.6,157.4,146.4,144.2,137.7,117.7,41.3,40.7,36.7,25.8,22.6$

${ }^{19}$ F NMR (471 MHz, $\left.\mathrm{CDCl}_{3}\right): \delta-137.57(\mathrm{~m}, J=14.1,4.8 \mathrm{~Hz}),-148.71(\mathrm{tt}, J=20.8,4.4 \mathrm{~Hz}),-160.20--$ $160.38(\mathrm{~m})$

IR $\left(\mathrm{cm}^{-1}\right): 1764,1697,1653,1522,1499,1367,1325,1194,1098,993,897,856$

ESI-HRMS (m/z): $[\mathrm{M}+\mathrm{H}]^{+}$calc'd for $\mathrm{C}_{16} \mathrm{H}_{15} \mathrm{~F}_{5} \mathrm{NO}_{2}^{+}: 348.1017$; found: 348.1021 


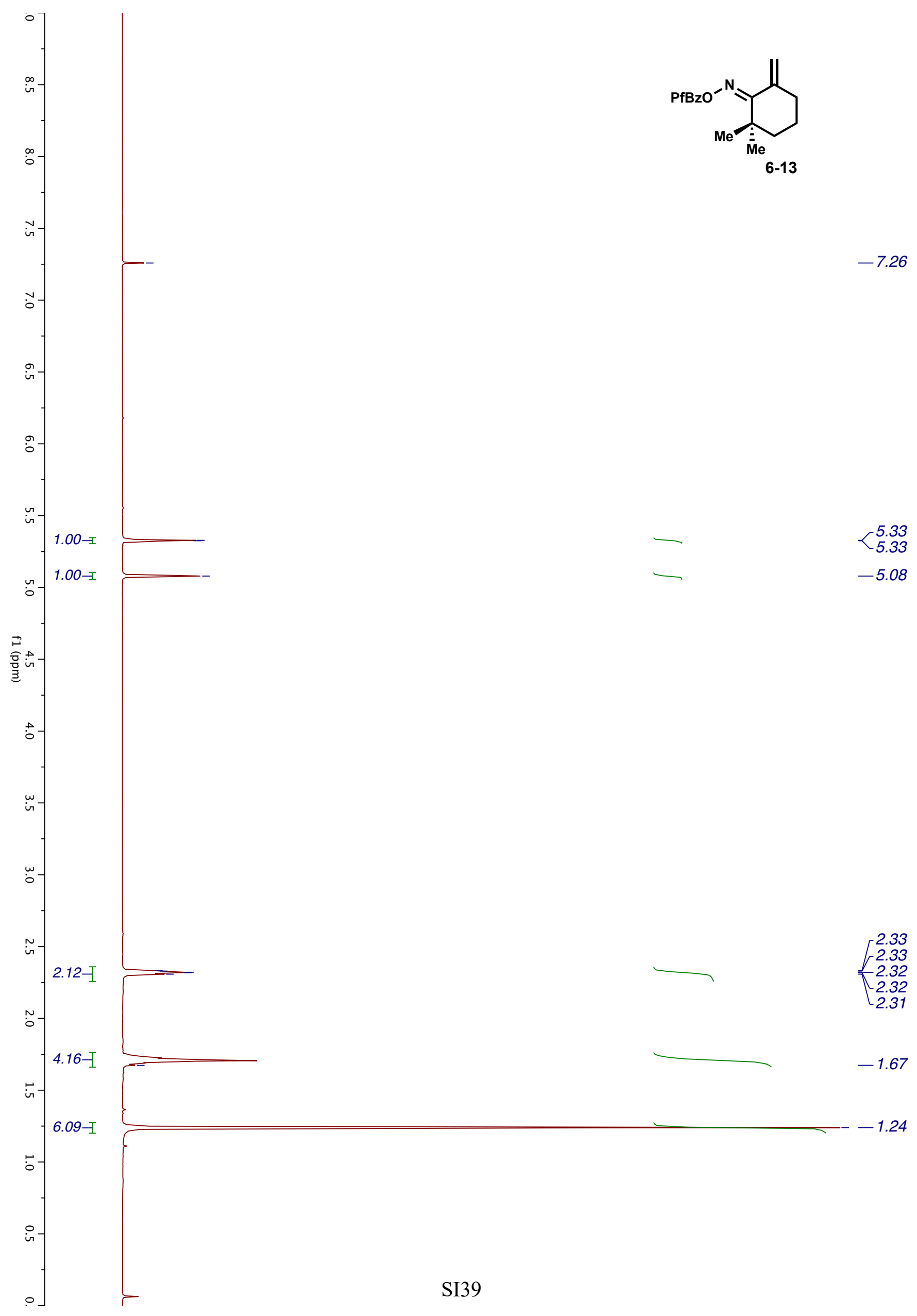




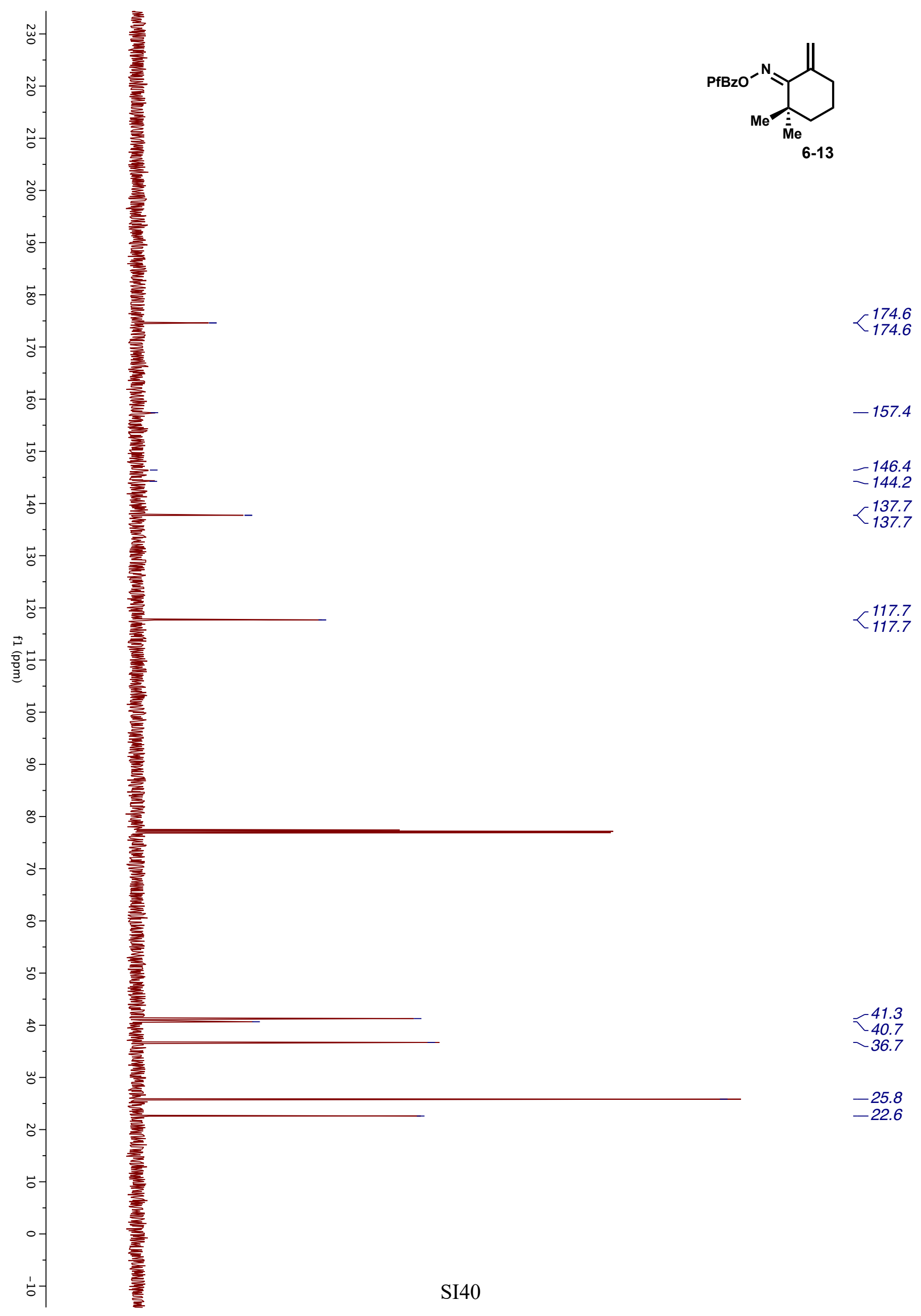




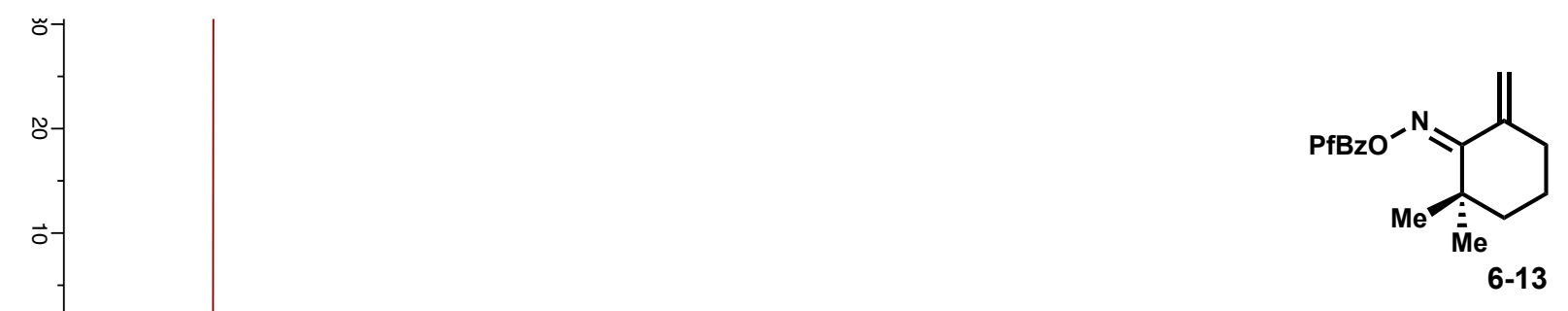

흠

ก่

غ்

t่

ํํㅇ

த்

ปे

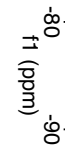

홍

ثे

\section{立}

$\dot{\vec{\omega}}$

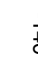

\section{政}



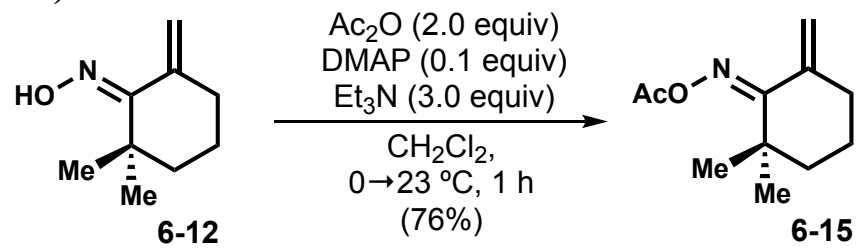

To a flame-dried 5-mL microwave vial with a magnetic stir bar was added $E$-oxime 6-12 (50 mg, $0.33 \mathrm{mmol}, 1.0$ equiv), and $\mathrm{CH}_{2} \mathrm{Cl}_{2}(320 \mu \mathrm{L}, 1.0 \mathrm{M})$. The reaction vessel was moved to a $0{ }^{\circ} \mathrm{C}$ ice-water bath, and triethylamine (140 $\mu \mathrm{L}, 0.98 \mathrm{mmol}, 3.0$ equiv) was added dropwise over 5 minutes. After the reaction mixture had stirred at $0{ }^{\circ} \mathrm{C}$ for 5 minutes, acetic anhydride $(67 \mu \mathrm{L}, 0.65 \mathrm{mmol}, 2.0$ equiv) was added dropwise to the reaction mixture. Following this, 4-(dimethylamino)pyridine (4.0 $\mathrm{mg}, 0.044 \mathrm{mmol}$, 0.1 equiv) was added to the reaction mixture in one portion. The reaction vessel was removed from the ice-water bath, and the reaction mixture was allowed to stir at room temperature.

After the reaction mixture had stirred at room temperature for 1 hour, the reaction mixture was diluted with 1:1 sat. aq. $\mathrm{NaHCO}_{3} /$ brine $(5 \mathrm{~mL})$ and the layers were separated. The aqueous layer was extracted with $\mathrm{Et}_{2} \mathrm{O}(3 \mathrm{x} 5 \mathrm{~mL})$. The combined organic extracts were washed with brine $(5 \mathrm{~mL})$, dried over anhydrous $\mathrm{Na}_{2} \mathrm{SO}_{4}$, filtered and concentrated under reduced pressure by rotary evaporation to give a crude yellow solid. Purification by flash column chromatography on silica gel $\left(10 \% \mathrm{Et}_{2} \mathrm{O} / \mathrm{h}_{\text {hexanes to } 20 \%}\right.$ $\mathrm{Et}_{2} \mathrm{O} /$ hexanes) afforded 6-15 as a colorless oil (48 mg, 76\%).

Rf: $0.56\left(25 \% \mathrm{Et}_{2} \mathrm{O} /\right.$ hexanes, $\left.\mathrm{KMnO}_{4}\right)$

${ }^{1} \mathbf{H}$ NMR $\left(500 \mathrm{MHz}, \mathrm{CDCl}_{3}\right): \delta 5.30(\mathrm{~d}, J=1.6 \mathrm{~Hz}, 1 \mathrm{H}), 5.02(\mathrm{~s}, 1 \mathrm{H}), 2.29(\mathrm{t}, J=6.0 \mathrm{~Hz}, 2 \mathrm{H}), 2.10(\mathrm{~s}$, $3 \mathrm{H}), 1.71-1.63(\mathrm{~m}, 4 \mathrm{H}), 1.19(\mathrm{~s}, 6 \mathrm{H})$

${ }^{13} \mathrm{C}$ NMR (126 MHz, $\left.\mathrm{CDCl}_{3}\right): \delta 172.1,169.7,138.0,117.1,41.2,40.1,36.8,25.9,22.6,20.0$

IR $\left(\mathrm{cm}^{-1}\right): 1768,1441,1386,1365,1209,999,949,923,894,864$

ESI-HRMS (m/z): $[\mathrm{M}+\mathrm{H}]^{+}$calc' $d$ for $\mathrm{C}_{11} \mathrm{H}_{18} \mathrm{NO}_{2}{ }^{+}: 196.1332$; found: 196.1336 


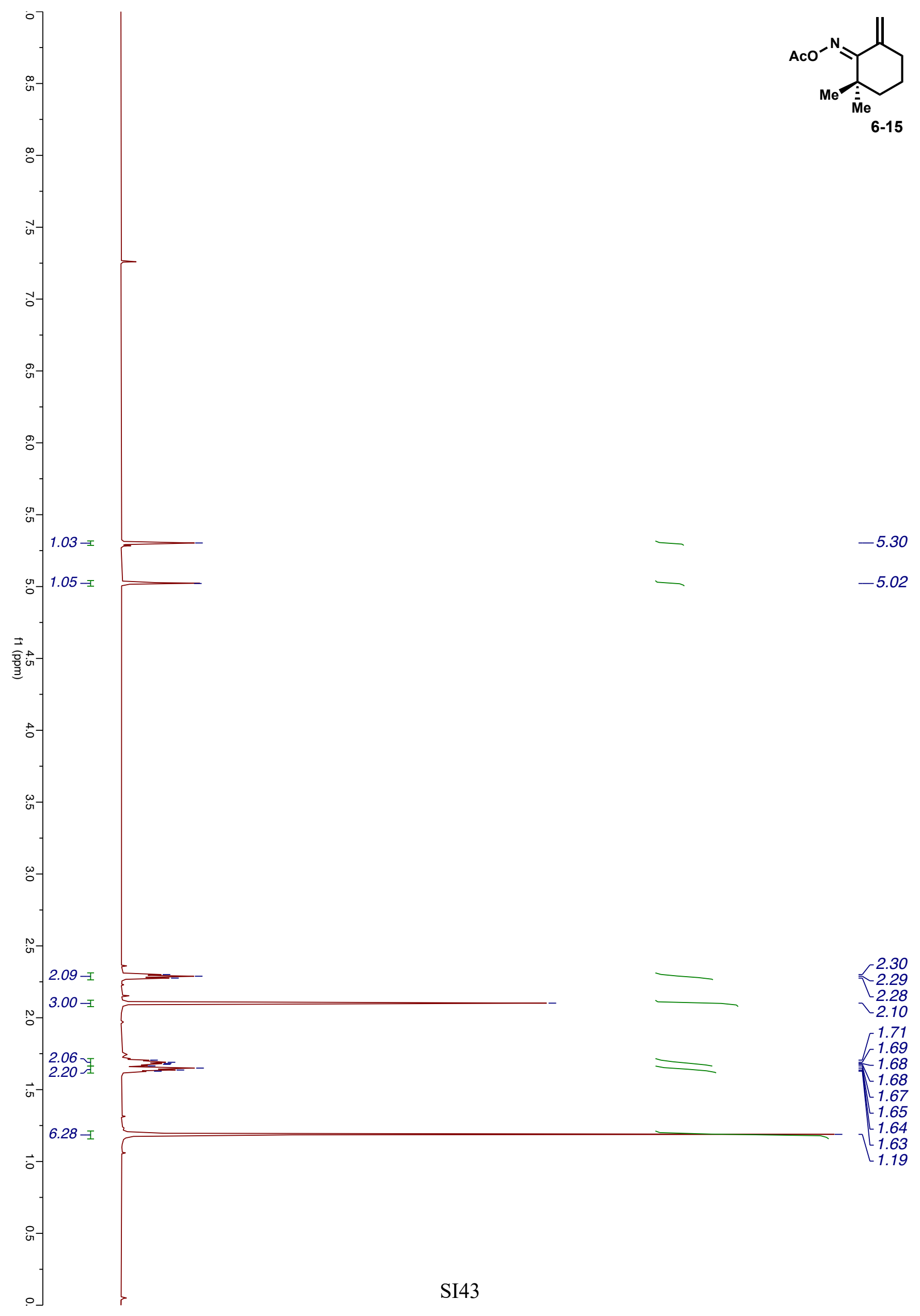




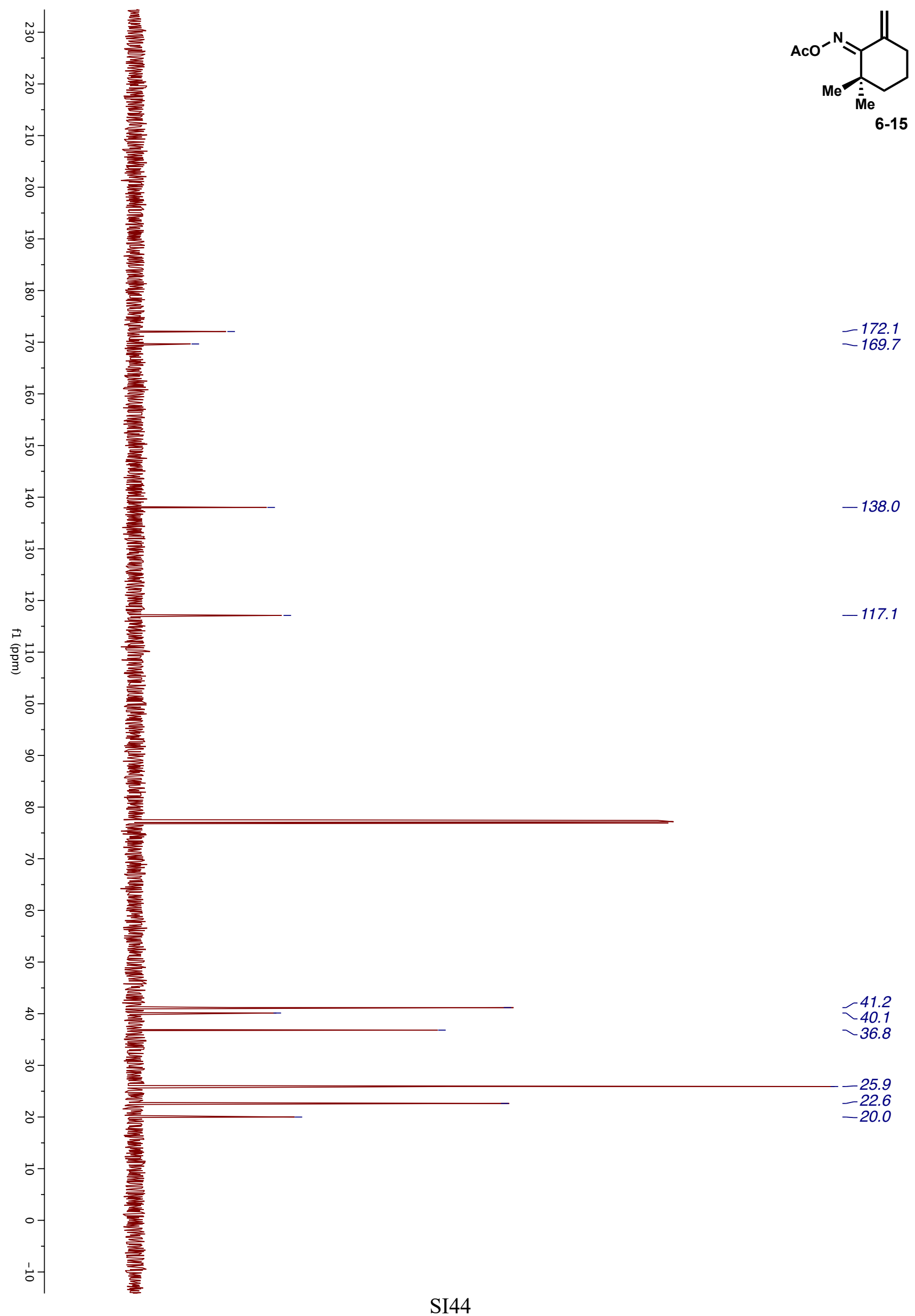




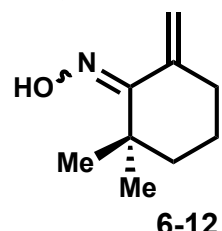

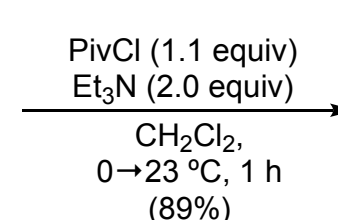

$(89 \%)$

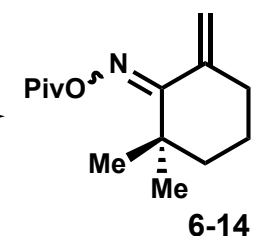

6-14

To a flame-dried 5-mL microwave vial with a magnetic stir bar was added oxime 6-12 (50 mg, $0.33 \mathrm{mmol}, 1.0$ equiv) as a mixture of isomers, and $\mathrm{CH}_{2} \mathrm{Cl}_{2}(320 \mu \mathrm{L}, 1.0 \mathrm{M})$. The reaction vessel was moved to a $0{ }^{\circ} \mathrm{C}$ ice-water bath, and triethylamine $(92 \mu \mathrm{L}, 0.65 \mathrm{mmol}, 2.0$ equiv) was added dropwise to the reaction mixture. After stirring at $0{ }^{\circ} \mathrm{C}$ for 5 minutes, $\mathrm{PivCl}(45 \mathrm{mg}, 0.36 \mathrm{mmol}, 1.1$ equiv) was added dropwise to the reaction mixture. The reaction vessel was removed from the ice-water bath, and the reaction mixture was allowed to stir at room temperature.

After the reaction mixture had stirred at room temperature for 1 hour, the reaction mixture was diluted with 1:1 sat. aq. $\mathrm{NaHCO}_{3} /$ brine $(5 \mathrm{~mL})$ and the layers were separated. The aqueous layer was extracted with $\mathrm{Et}_{2} \mathrm{O}(3 \times 5 \mathrm{~mL})$. The combined organic extracts were washed with brine $(5 \mathrm{~mL})$, dried over anhydrous $\mathrm{Na}_{2} \mathrm{SO}_{4}$, filtered and concentrated under reduced pressure by rotary evaporation to give a crude yellow solid as a 1.5:1 E: Z mixture. Purification by flash column chromatography on silica gel (10\% $\mathrm{Et}_{2} \mathrm{O} /$ hexanes to $50 \% \mathrm{Et}_{2} \mathrm{O} /$ hexanes) afforded 6-14 as a 1.4:1 E:Z mixture $(69.7 \mathrm{mg}, 89 \%)$ as an colorless oil.

$\mathbf{R}_{\mathbf{f}}: 0.28\left(20 \% \mathrm{Et}_{2} \mathrm{O} /\right.$ hexanes, $\left.\mathrm{KMnO}_{4}\right)$

${ }^{1} \mathbf{H}$ NMR (500 MHz, $\left.\mathrm{CDCl}_{3}\right)$ : (major isomer) $\delta 5.31(\mathrm{~s}, 1 \mathrm{H}), 5.01(\mathrm{~s}, 1 \mathrm{H}), 2.30(\mathrm{t}, J=6.0 \mathrm{~Hz}, 2 \mathrm{H}), 1.73-$ $1.65(\mathrm{~m}, 4 \mathrm{H}), 1.30(\mathrm{~s}, 6 \mathrm{H}), 1.21(\mathrm{~s}, 9 \mathrm{H})$

(minor isomer) $\delta 5.45(\mathrm{~s}, 1 \mathrm{H}), 5.03(\mathrm{~s}, 1 \mathrm{H}), 2.44(\mathrm{t}, J=7.2 \mathrm{~Hz}, 2 \mathrm{H}), 1.73-1.65(\mathrm{~m}, 2 \mathrm{H}), 1.52-1.48(\mathrm{~m}$, $2 \mathrm{H}), 1.34(\mathrm{~s}, 6 \mathrm{H}), 1.22(\mathrm{~s}, 9 \mathrm{H})$

${ }^{13} \mathrm{C}$ NMR (126 MHz, $\mathrm{CDCl}_{3}$ ): (mixture of isomers) $\delta 175.9,173.1,171.3,141.1,138.4,118.3,116.7$, $41.2,40.6,40.3,39.6,38.7,38.6,36.8,31.2,27.5,27.3,26.0,25.9,22.7,19.7$

IR $\left(\mathrm{cm}^{-1}\right): 1756,1479,1459,1365,1271,1126,1076,1026,910,871$

ESI-HRMS (m/z): $[\mathrm{M}+\mathrm{H}]^{+}$calc'd for $\mathrm{C}_{14} \mathrm{H}_{24} \mathrm{O}_{2}{ }^{+}: 238.1802$; found: 238.1802 


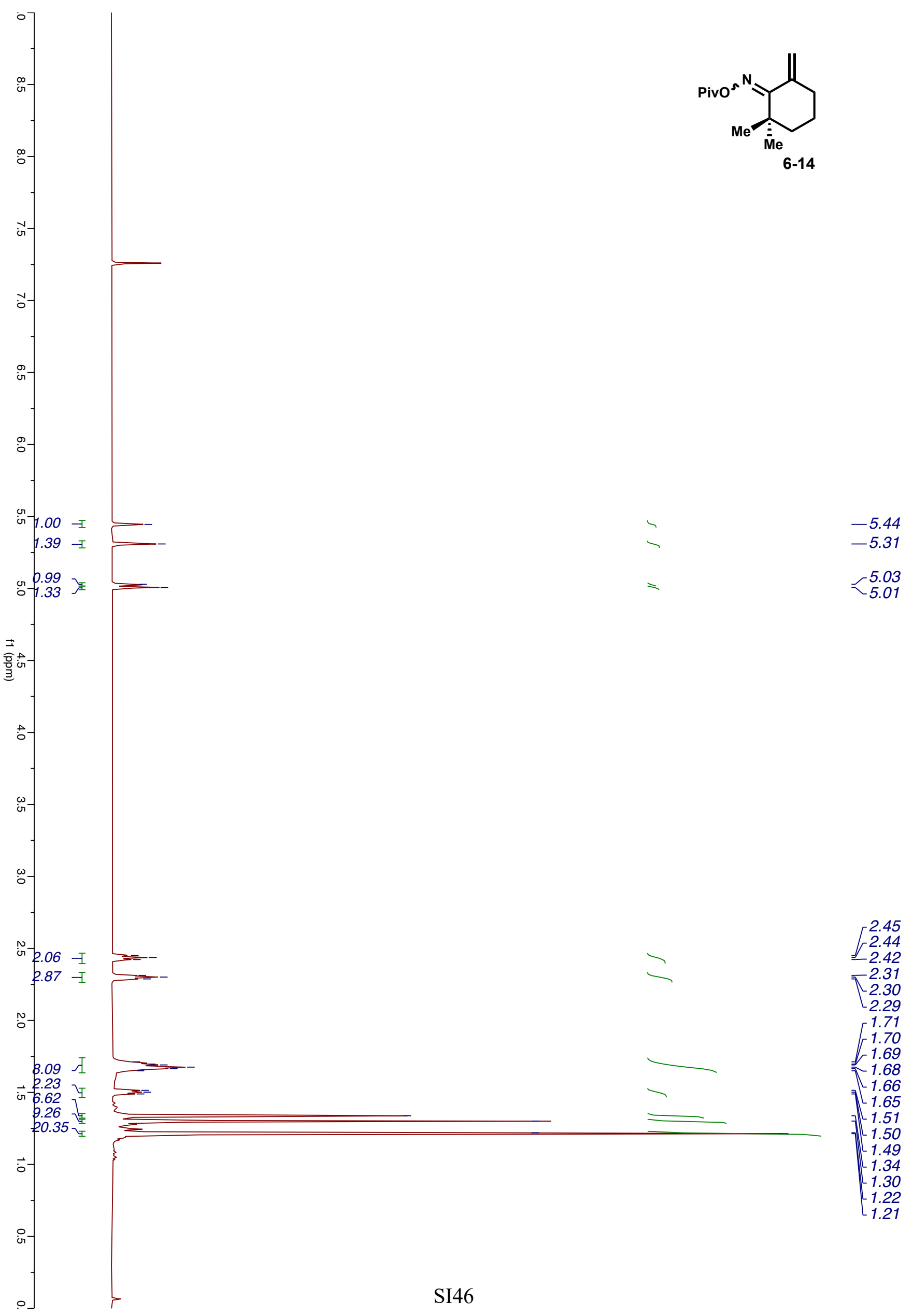




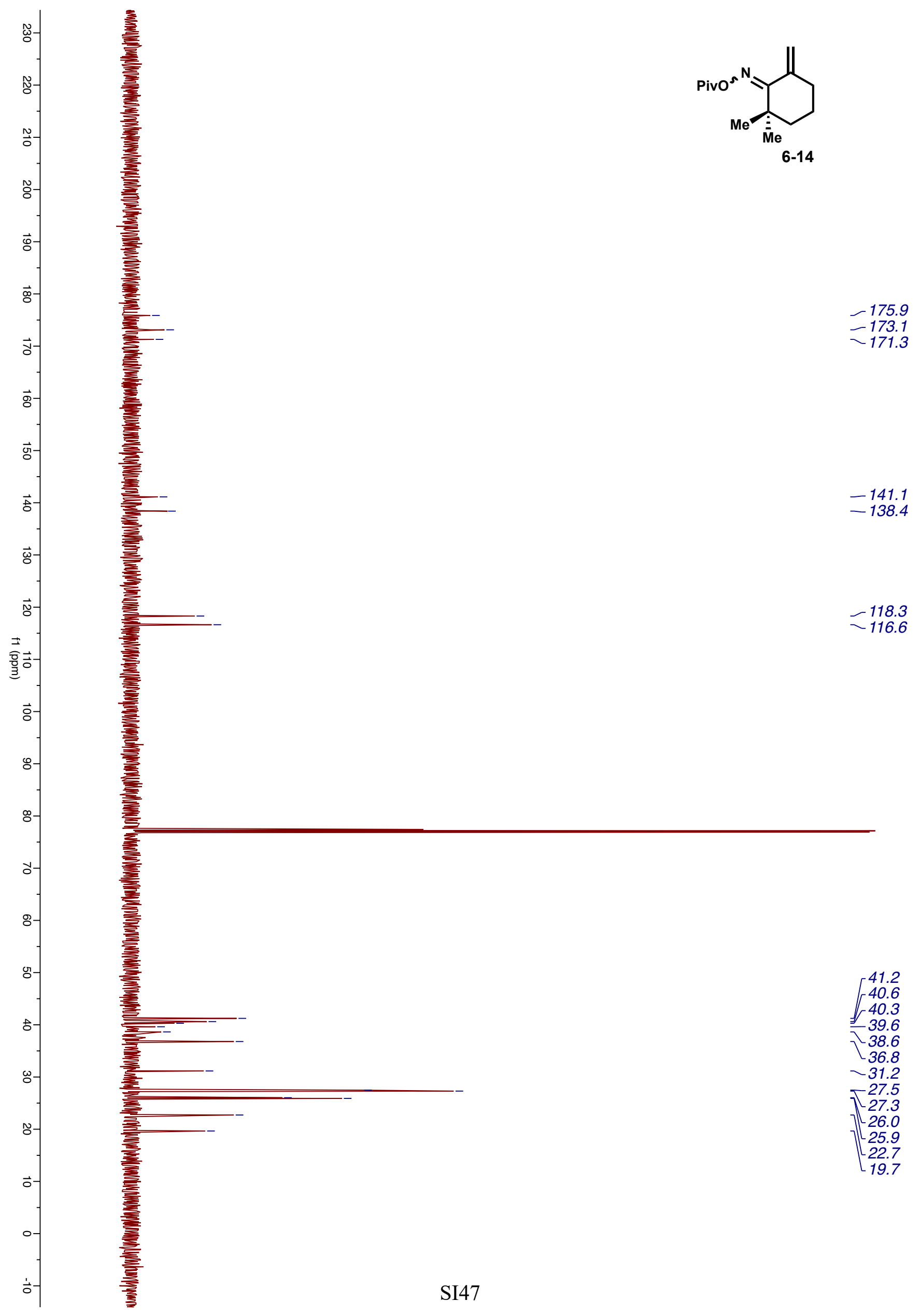



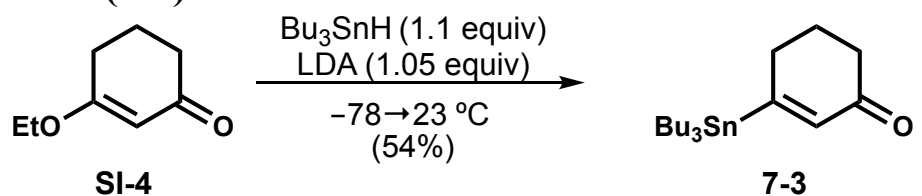

To a flame-dried $25-\mathrm{mL}$ round-bottomed flask equipped with a magnetic stir bar, was added THF $(2 \mathrm{~mL}, 0.5 \mathrm{M})$ and diisopropylamine $(147 \mu \mathrm{L}, 1.1 \mathrm{mmol}, 1.1$ equiv). The reaction mixture was cooled to $0{ }^{\circ} \mathrm{C}$ by transferring the reaction apparatus to an ice-water bath. The reaction mixture was allowed to stir for 5 minutes at $0{ }^{\circ} \mathrm{C}$, before $n$-BuLi $(0.44 \mathrm{~mL}, 1.05 \mathrm{mmol}, 1.05$ equiv, $2.5 \mathrm{M}$ in hexanes) was added dropwise to reaction mixture over 3 minutes.

After stirring for 25 minutes at $0{ }^{\circ} \mathrm{C}, \mathrm{Bu}_{3} \mathrm{SnH}(0.29 \mathrm{~mL}, 1.1 \mathrm{mmol}, 1.1$ equiv) was added dropwise to the reaction mixture over 3 minutes at $0{ }^{\circ} \mathrm{C}$, resulting in a yellow reaction mixture. Once the reaction mixture had stirred for an additional 10 minutes at $0{ }^{\circ} \mathrm{C}$, the reaction vessel was transferred to a $-78^{\circ} \mathrm{C}$ saturated dry-ice acetone bath, and the reaction mixture was allowed to stir for 5 minutes at $-78{ }^{\circ} \mathrm{C}$. To the reaction mixture was added a solution of $\beta$-ethoxy enone SI-4 (140 mg, $1.0 \mathrm{mmol}, 1.0$ equiv) in THF $(1.0 \mathrm{~mL}, 1.0 \mathrm{M})$ dropwise over 5 minutes, which resulted in an orange reaction mixture.

After stirring at $-78{ }^{\circ} \mathrm{C}$ for 30 minutes, the dry-ice acetone bath was replaced with a room temperature water bath, and the reaction mixture was allowed to stir at room temperature for 2 hours. To the reaction mixture was added sat. aq. $\mathrm{NH}_{4} \mathrm{Cl}(3 \mathrm{~mL})$ and $\mathrm{Et}_{2} \mathrm{O}(5 \mathrm{~mL})$. The layers were separated, and the aqueous layer was extracted with $\mathrm{Et}_{2} \mathrm{O}(3 \times 5 \mathrm{~mL})$. The combined organic extracts were washed with brine $(15 \mathrm{~mL})$, dried over anhydrous $\mathrm{Na}_{2} \mathrm{SO}_{4}$, filtered, and concentrated under reduced pressure by rotary evaporation to provide a crude yellow oil. Purification by flash column chromatography on silica gel (100\% hexanes to $10 \% \mathrm{Et}_{2} \mathrm{O} /$ hexanes) afforded $7-3$ (209 $\left.\mathrm{mg}, 54 \%\right)$ as a colorless oil.

R. $0.4\left(20 \% \mathrm{Et}_{2} \mathrm{O} /\right.$ hexanes, $\left.\mathrm{KMnO}_{4}\right)$

${ }^{1} \mathbf{H}$ NMR $\left(500 \mathrm{MHz}, \mathrm{CDCl}_{3}\right): \delta 6.24($ at, $J=25.0 \mathrm{~Hz}, 1 \mathrm{H}), 2.49(\mathrm{atd}, J=5.9,2.1 \mathrm{~Hz}, 2 \mathrm{H}), 2.40(\mathrm{dd}, J=$ $6.5,6.5 \mathrm{~Hz}, 2 \mathrm{H}), 2.02-1.95(\mathrm{~m}, 2 \mathrm{H}), 1.56-1.41(\mathrm{~m}, 6 \mathrm{H}), 1.34-1.27(\mathrm{~m}, 6 \mathrm{H}), 0.98$ (at, $J=8.5 \mathrm{~Hz}, 5 \mathrm{H})$, $0.90(\mathrm{t}, J=7.5 \mathrm{~Hz}, 10 \mathrm{H})$

${ }^{13}$ C NMR $\left(151 \mathrm{MHz}, \mathrm{CDCl}_{3}\right): \delta 197.1,175.2,139.0,38.4,33.0,29.2,27.4,23.9,13.8,9.5$

IR $\left(\mathrm{cm}^{-1}\right): 2955,2924,2871,2853,1671,1464,1249,1181,952,896,772,690,664,599$

ESI-HRMS (m/z): $[\mathrm{M}+\mathrm{H}]^{+}$calc'd for $\mathrm{C}_{18} \mathrm{H}_{35} \mathrm{O}_{3} \mathrm{Sn}^{+}: 387.1704$; found: 387.1710 


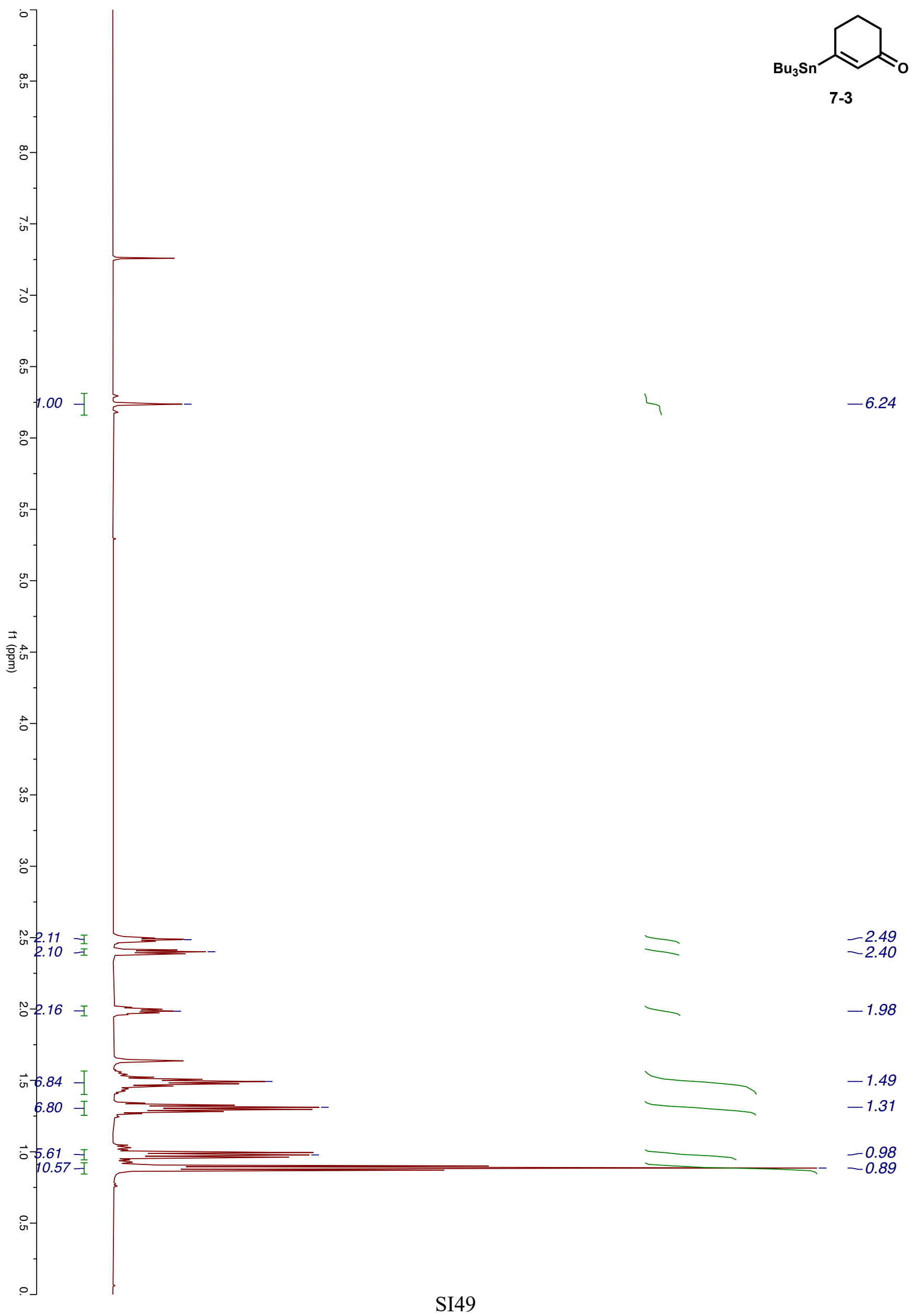




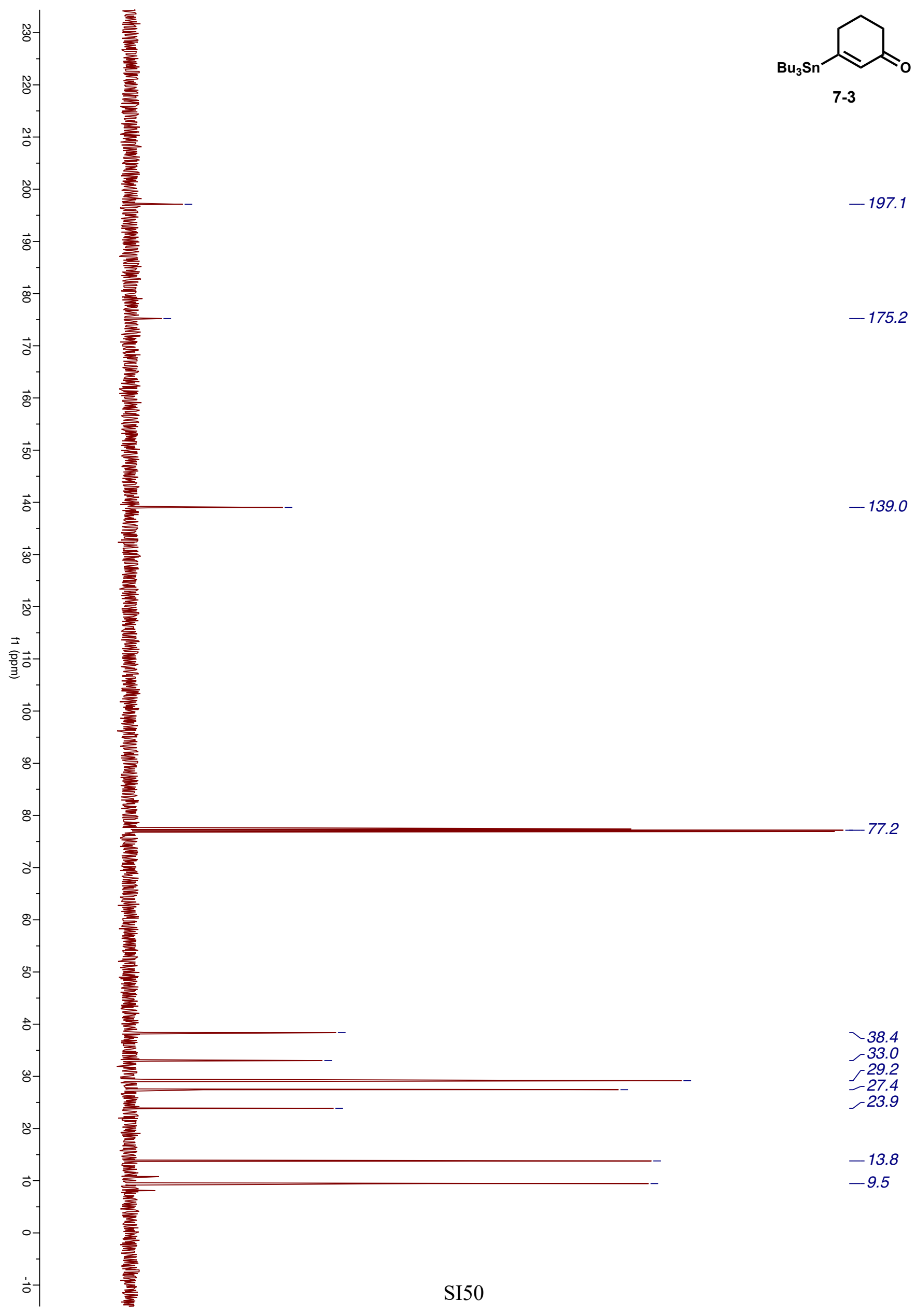




\section{General procedure for Liebeskind pyridine synthesis screen:}

To a flame-dried $10-\mathrm{mL}$ microwave vial with a magnetic stir bar was added $4 \AA \mathrm{MS}$ (10 mg). The reaction vial containing molecular sieves was flame-dried for 2 min under vacuum and then back filled with nitrogen using a dual manifold Schlenk line. This process was repeated 3 times. After the reaction vessel had cooled to room temperature, $\mathrm{Cu}(\mathrm{OAc})_{2}(5.4 \mathrm{mg}, 0.03 \mathrm{mmol}, 30 \mathrm{~mol} \%)$, and oxime $(0.15 \mathrm{mmol}$, 1.5 equiv) were added to the reaction vessel. The vial was sealed with a Teflon microwave cap, and then evacuated and backfilled with nitrogen three times using a dual manifold Schlenk line. A solution of stannane or boronic acid $(0.1 \mathrm{mmol}, 1.0$ equiv) in DMF $(0.5 \mathrm{~mL}, 0.2 \mathrm{M})$ was added to the reaction mixture. If an additive was added to the reaction it was added following the addition of DMF solution, and the reaction vessel was moved to a $60{ }^{\circ} \mathrm{C}$ oil-bath and heated for the stated time.

Once the stated time had elapsed, $\mathrm{O}_{2}$ was bubbled through the reaction mixture for 2 minutes. The oil bath temperature was then increased to $100{ }^{\circ} \mathrm{C}$. After stirring at $80{ }^{\circ} \mathrm{C}$ for 1 hour, the reaction vessel was removed from the oil bath and allowed to cool to room temperature. Once at room temperature, the reaction mixture was diluted with water $(5 \mathrm{~mL})$ and EtOAc $(5 \mathrm{~mL})$. The layers were separated, and the aqueous layer was extracted with EtOAc $(3 \times 5 \mathrm{~mL})$. The combined organic extracts were washed with brine ( $5 \mathrm{~mL} \times 2 \mathrm{~mL})$, dried over anhydrous $\mathrm{Na}_{2} \mathrm{SO}_{4}$, filtered, and concentrated under reduced pressure by rotary evaporation to provide a crude brown oil.

\section{Synthesis of des-methyl pyridine (7-2):}
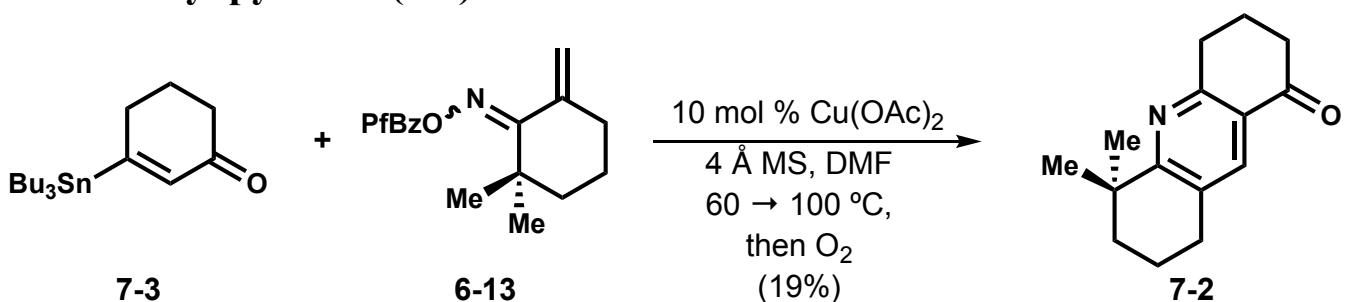

General procedure was followed with stannane 7-3 (38.6 mg, $0.1 \mathrm{mmol}, 1.0$ equiv) and oxime 6$13(52.1 \mathrm{mg}, 0.15 \mathrm{mmol}, 1.5 \mathrm{equiv})$. The reaction vessel was initially left at $60{ }^{\circ} \mathrm{C}$ for 16 hours, before temperature was increased to $100{ }^{\circ} \mathrm{C}$. Purification by flash column chromatography on silica gel $(5 \%$ hexanes to $15 \% \mathrm{Et}_{2} \mathrm{O} /$ hexanes) afforded 7-2 (4.6 mg, 19\%) as a colorless oil.

Rf: $0.11\left(5 \% \mathrm{Et}_{2} \mathrm{O} /\right.$ hexanes, $\left.\mathrm{KMnO}_{4}\right)$

${ }^{1} \mathbf{H}$ NMR $\left(600 \mathrm{MHz}, \mathrm{CDCl}_{3}\right): \delta 7.89(\mathrm{~s}, 1 \mathrm{H}), 3.06(\mathrm{t}, J=6.2 \mathrm{~Hz}, 2 \mathrm{H}), 2.78(\mathrm{t}, J=6.3 \mathrm{~Hz}, 2 \mathrm{H}), 2.63(\mathrm{dd}, J$ $=7.3,5.8 \mathrm{~Hz}, 2 \mathrm{H}), 2.18-2.12(\mathrm{~m}, 2 \mathrm{H}), 1.82-1.78(\mathrm{~m}, 2 \mathrm{H}), 1.77-1.75(\mathrm{~m}, 2 \mathrm{H}), 1.32(\mathrm{~s}, 6 \mathrm{H})$

${ }^{13} \mathbf{C}$ NMR $\left(151 \mathrm{MHz}, \mathrm{CDCl}_{3}\right): \delta 198.9,169.5,160.8,135.2,129.9,125.6,38.8,37.4,32.5,30.2,29.9$, $22.3,19.3$

IR $\left(\mathrm{cm}^{-1}\right): 1708,1686,1592,1456,1427,1225,1115,1031,914,785$

ESI-HRMS (m/z): [M+H] $]^{+}$calc'd for $\mathrm{C}_{15} \mathrm{H}_{20} \mathrm{NO}^{+}: 230.1539$; found: 230.1536 


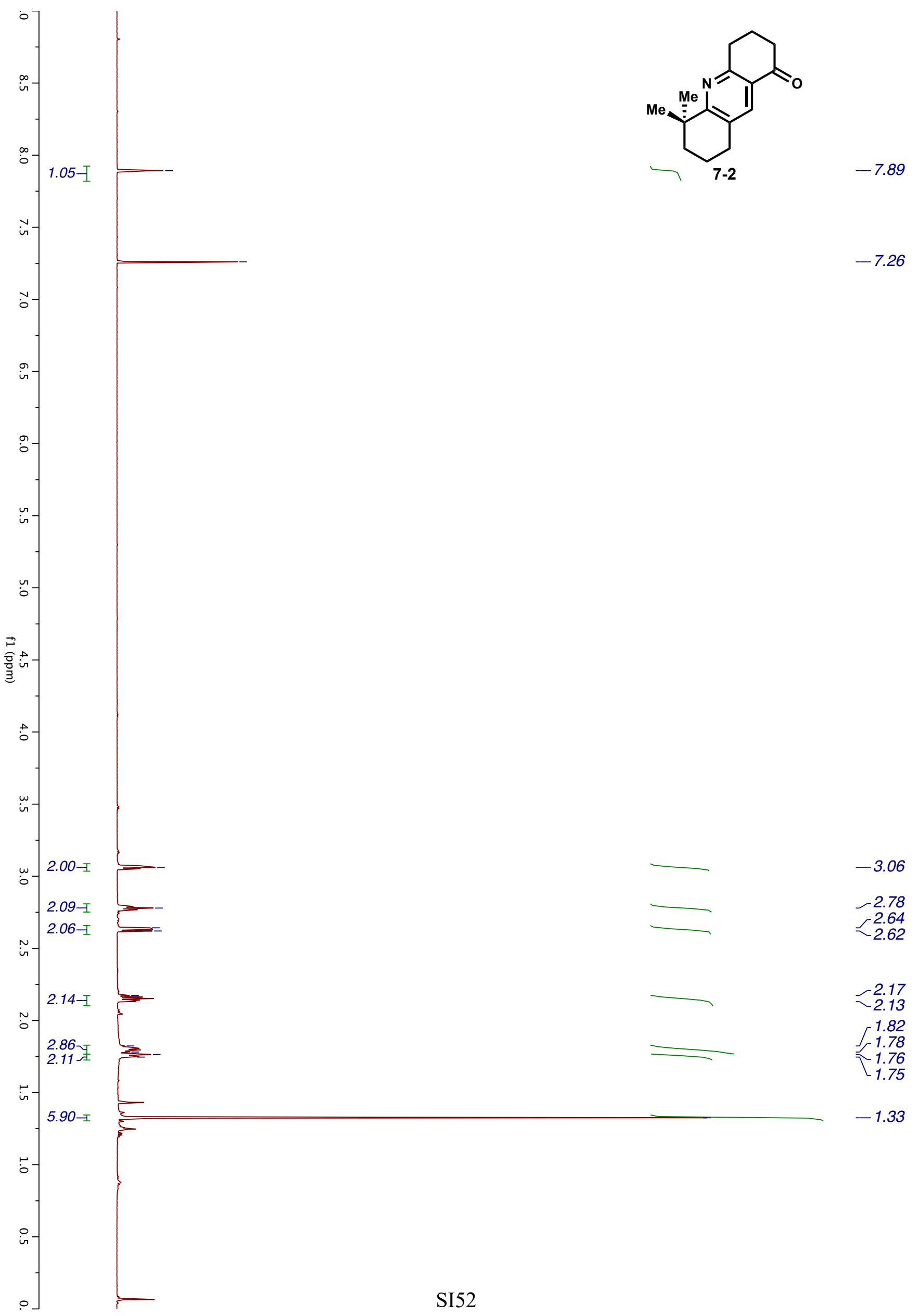




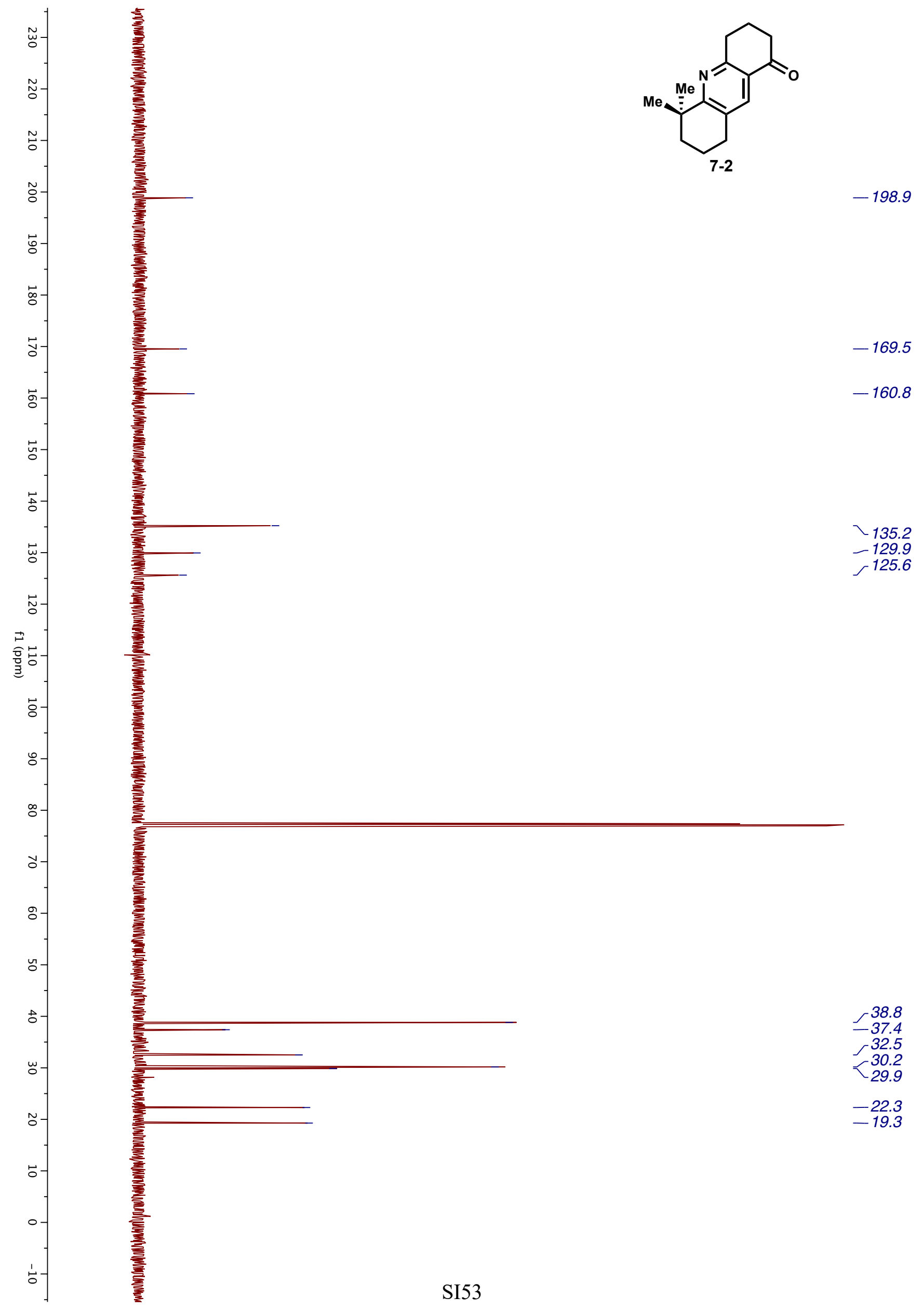


Synthesis of ketone (9-1) using $\operatorname{Mn}(\mathrm{OAc})_{3}$ :

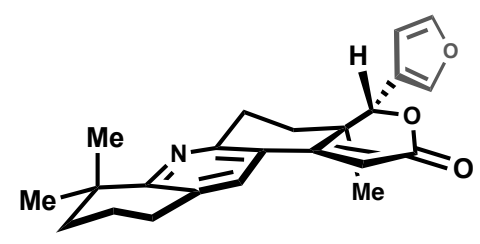

3-1
$\mathrm{Mn}(\mathrm{OAc})_{3}(10 \mathrm{~mol} \%)$, TBHP (4.0 equiv),

$\mathrm{MeCN}, 23^{\circ} \mathrm{C}, 16 \mathrm{~h}$ $(34 \%+47 \%$ SM $)$

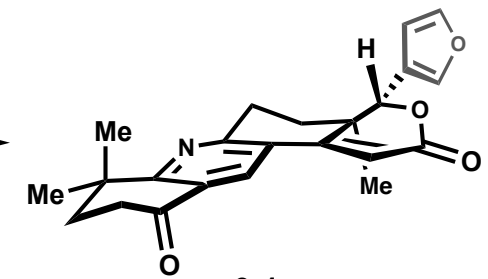

9-1

To a flame-dried 250-mL Teflon-sealed Schlenk flask equipped with a magnetic stir bar was added pyridine 3-1 (2.0 g, $5.5 \mathrm{mmol}, 1.0$ equiv), $\mathrm{Mn}(\mathrm{OAc})_{3} \cdot 2 \mathrm{H}_{2} \mathrm{O}$ (14.8 mg, $5.5 \mathrm{mmol}, 10 \mathrm{~mol} \%$ ), and $\mathrm{MeCN}$ $(55 \mathrm{~mL}, 0.1 \mathrm{M})$. To the reaction mixture was added anhydrous TBHP $(4.0 \mathrm{~mL}, 22.0 \mathrm{mmol}, 4.0$ equiv, 5.5 $\mathrm{M}$ in decane) at room temperature. The reaction vessel was then sealed and placed in a room temperature sonication bath for 5 minutes. The reaction mixture was removed from the sonication bath and then allowed to stir at room temperature.

After stirring at room temperature for 16 hours, the reaction mixture was diluted with water (150 $\mathrm{mL})$ and the layers were separated. The aqueous layer was extracted with EtOAc $(3 \times 50 \mathrm{~mL})$. The combined organic extracts were washed with brine $(100 \mathrm{~mL})$, dried over anhydrous $\mathrm{Na}_{2} \mathrm{SO}_{4}$, filtered, and concentrated under reduced pressure by rotary evaporation to provide a crude yellow oil. Purification by flash column chromatography on silica gel (5\% EtOAc/hexanes to 30\% EtOAc/hexanes) afforded 9-1 (707 mg, 34\%) as a colorless foam and recovered 3-1 (938 $\mathrm{mg}, 47 \%)$ as a yellow oil.

The spectral data matched that which was previously reported. ${ }^{2}$ 

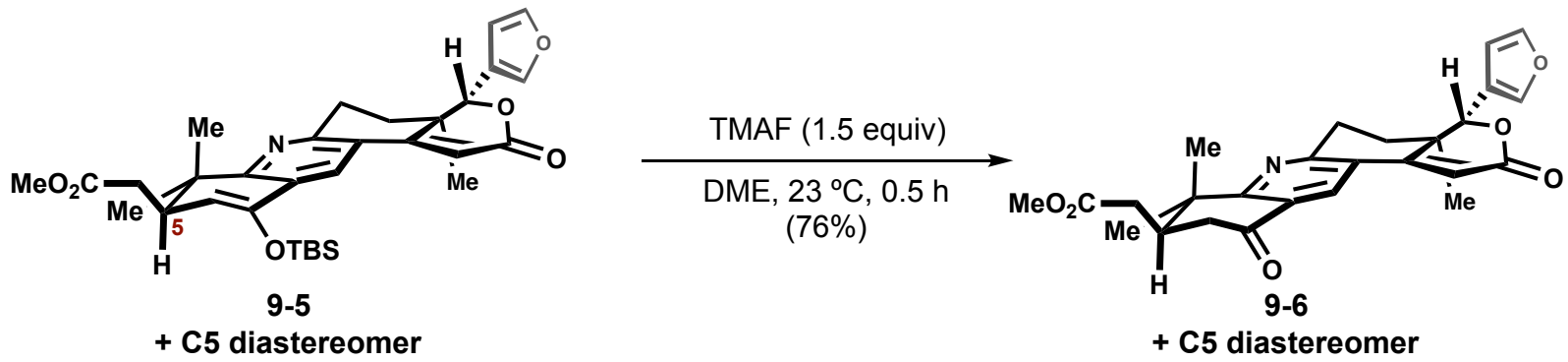

To a flame-dried 10-mL microwave vial with a magnetic stir bar was added enoxysilane 9-5 (28.0 $\mathrm{mg}, 0.05 \mathrm{mmol}, 1.0$ equiv) as a mixture of diastereomers and $\operatorname{DME}(250 \mu \mathrm{L}, 0.2 \mathrm{M})$. To the stirred reaction mixture was added tetramethylammonium fluoride $(6.9 \mathrm{mg}, 0.075 \mathrm{mmol}, 1.5$ equiv), which resulted in a red reaction mixture. After stirring at room temperature for 30 minutes, the reaction was diluted with water $(5 \mathrm{~mL})$, and the layers were separated.

The aqueous layer was extracted with EtOAc $(3 \times 5 \mathrm{~mL})$. The combined organic extracts were washed with brine $(5 \mathrm{~mL})$, dried over anhydrous $\mathrm{Na}_{2} \mathrm{SO}_{4}$, filtered and concentrated under reduced pressure by rotary evaporation to give a crude colorless solid. Purification by flash column chromatography on silica gel (80\% $\mathrm{Et}_{2} \mathrm{O} /$ hexanes) afforded 9-6 (17.1 $\left.\mathrm{mg}, 76 \%\right)$ as a colorless foam.

$\mathbf{R}_{\mathbf{f}}: 0.23\left(80 \% \mathrm{Et}_{2} \mathrm{O} /\right.$ hexanes, $p$-anisaldehyde)

${ }^{1} \mathbf{H}$ NMR (600 MHz, $\left.\mathrm{CDCl}_{3}\right)$ : (mixture of diastereomers) $\delta 8.63(\mathrm{~s}, 1 \mathrm{H}), 8.62(\mathrm{~s}, 1 \mathrm{H}), 7.55(\mathrm{t}, J=0.6 \mathrm{~Hz}$, $2 \mathrm{H}), 7.47(\mathrm{t}, J=1.7 \mathrm{~Hz}, 2 \mathrm{H}), 6.63(\mathrm{~s}, 1 \mathrm{H}), 6.62(\mathrm{~s}, 1 \mathrm{H}), 6.51(\mathrm{~d}, J=1.7 \mathrm{~Hz}, 2 \mathrm{H}), 5.22(\mathrm{~s}, 2 \mathrm{H}), 3.71(\mathrm{~s}$, $6 \mathrm{H}), 3.18-3.12(\mathrm{~m}, 2 \mathrm{H}), 3.08-2.99(\mathrm{~m}, 2 \mathrm{H}), 2.89$ (adt, $J=17.0,3.7 \mathrm{~Hz}, 2 \mathrm{H}), 2.72$ (dd, $J=15.4,3.6 \mathrm{~Hz}$, 2H), 2.69-2.64 (m, 2H), $2.63-2.58(\mathrm{~m}, 2 \mathrm{H}), 2.23(\mathrm{ddd}, J=15.4,9.9,2.3 \mathrm{~Hz}, 2 \mathrm{H}), 1.86-1.81(\mathrm{~m}, 2 \mathrm{H})$, $1.52(\mathrm{~s}, 3 \mathrm{H}), 1.52(\mathrm{~s}, 3 \mathrm{H}), 1.30(\mathrm{~s}, 3 \mathrm{H}), 1.30(\mathrm{~s}, 3 \mathrm{H}), 1.14(\mathrm{~s}, 6 \mathrm{H})$

${ }^{13} \mathbf{C}$ NMR (151 MHz, $\mathrm{CDCl}_{3}$ ): (mixture of diastereomers) $\delta$ 195.9, 172.9, 170.5, 165.0, 162.0, 156.7, $143.4,141.5,132.5,132.4,125.2,123.1,120.0,111.6,111.4,110.2,80.8,52.1,40.5,40.2,39.9,37.7$, $35.6,30.2,30.1,29.9,28.8,28.8,27.1,26.9,23.3,23.1,16.0$

IR $\left(\mathrm{cm}^{-1}\right): 1720,1587,1434,1260,1163,1026$

ESI-HRMS (m/z): $[\mathrm{M}+\mathrm{H}]^{+}$calc'd for $\mathrm{C}_{26} \mathrm{H}_{28} \mathrm{NO}_{6}{ }^{+}$: 450.1911 ; found: 450.1910 


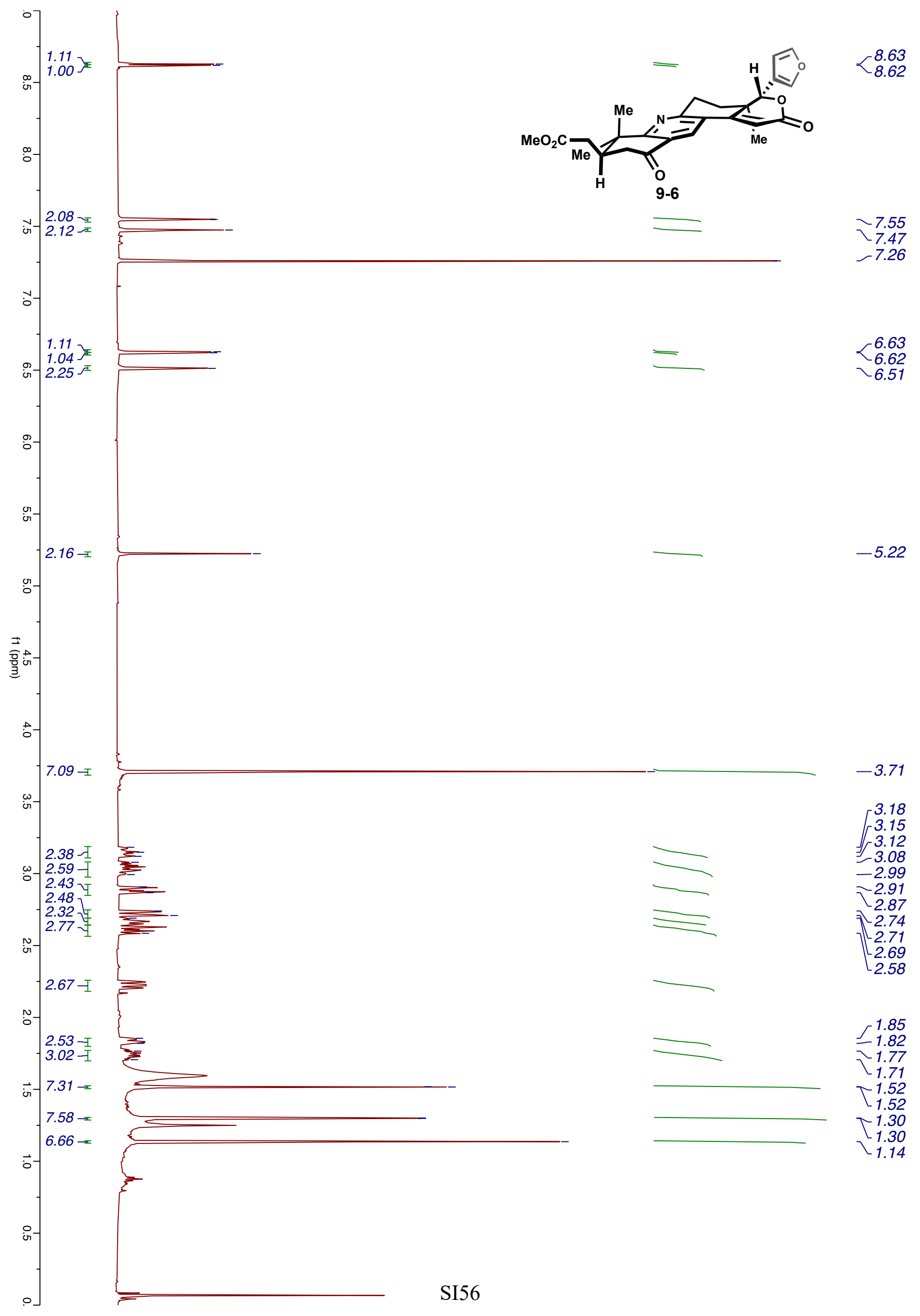




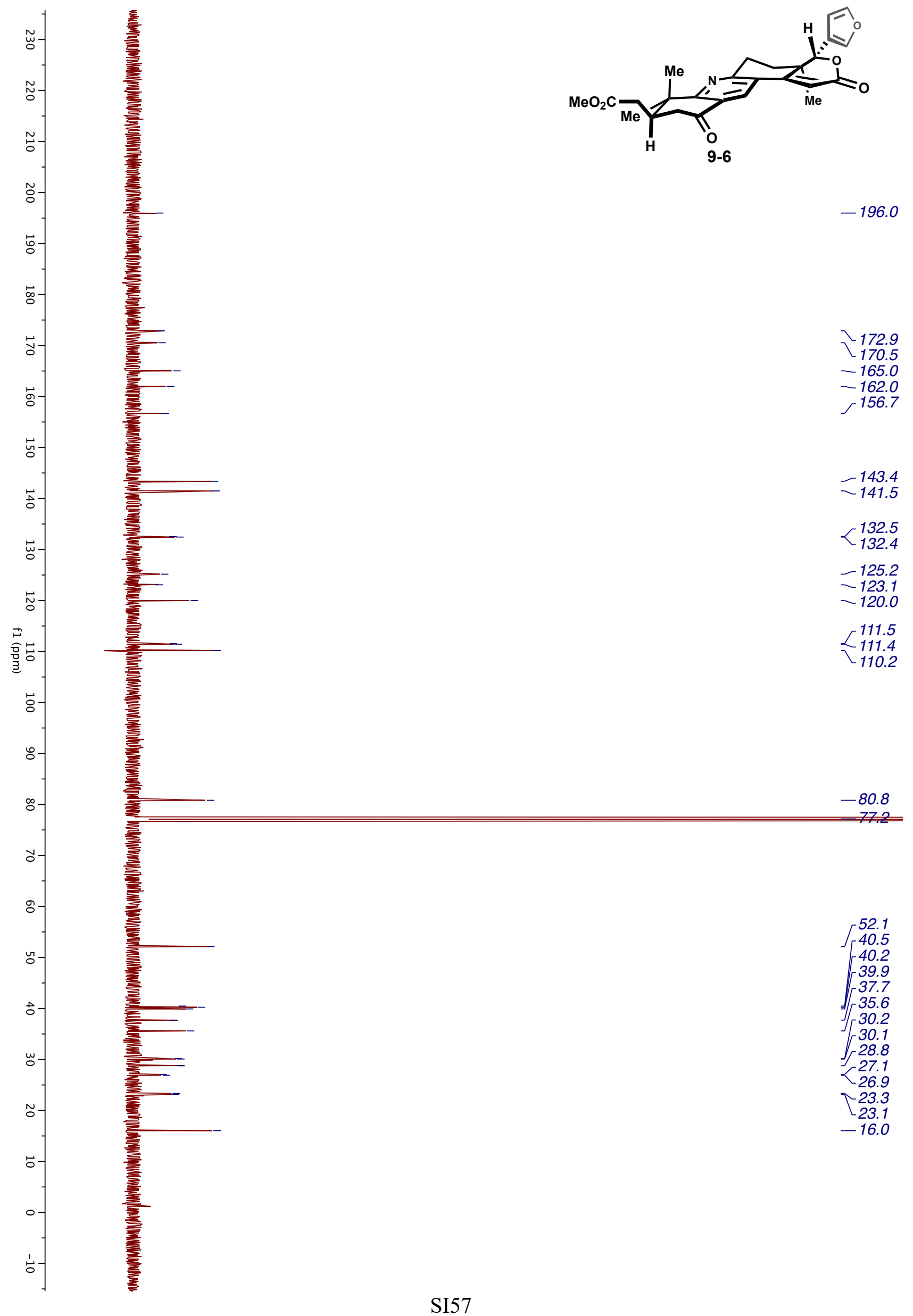




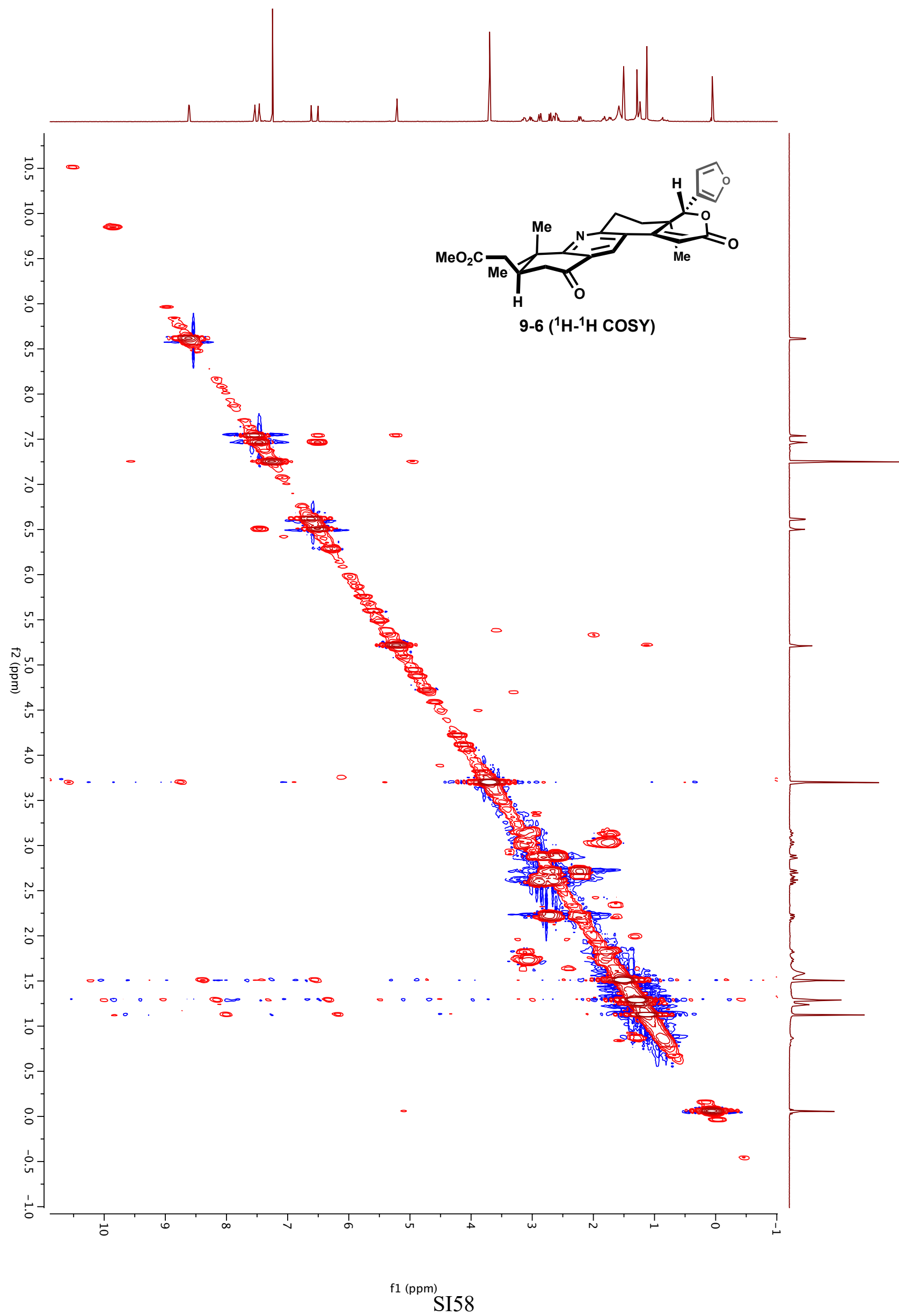




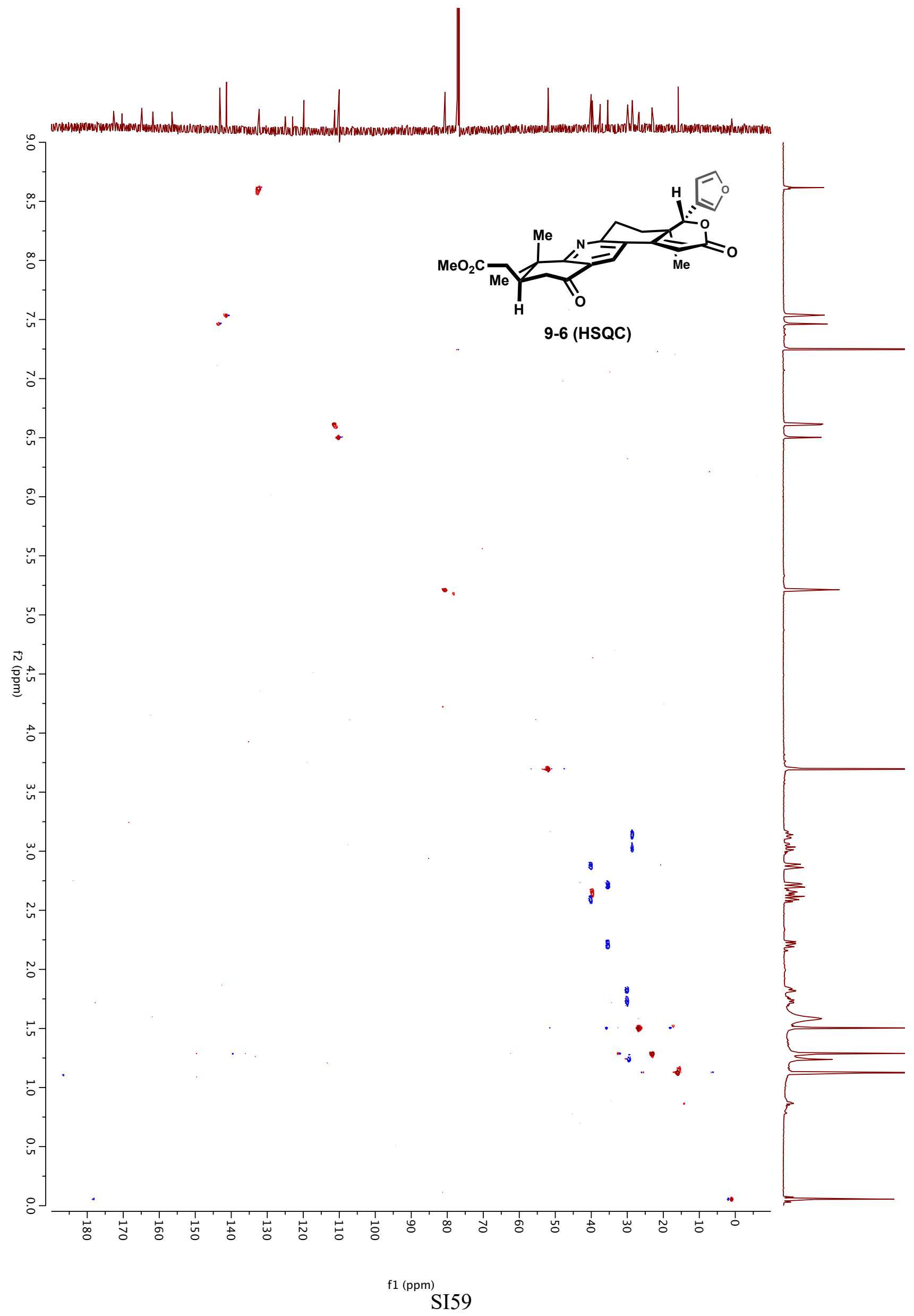


Synthesis of xylogranatopyridine B (1-1) by fluoride alkylation:

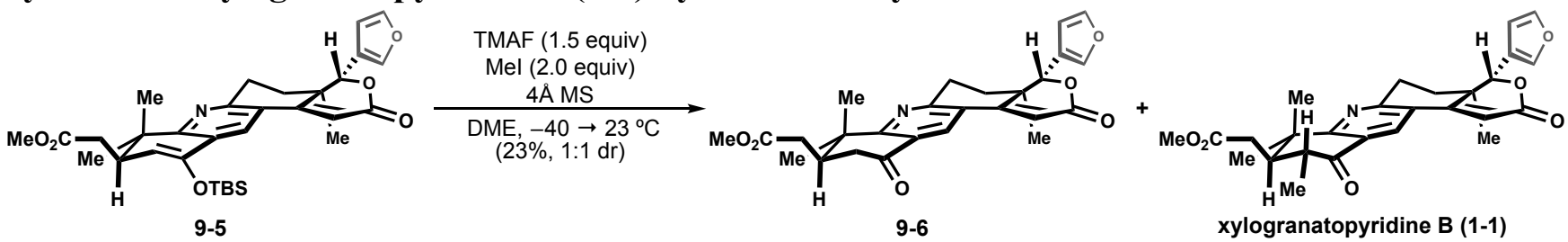

To a flame-dried $10-\mathrm{mL}$ microwave vial with a magnetic stir bar was added $4 \AA \mathrm{MS}$ (10 mg). The reaction vial containing molecular sieves was flame-dried for 2 minutes under vacuum and then back filled with nitrogen using a dual manifold Schlenk line. This process was repeated 3 times. After the reaction vessel had cooled to room temperature, enoxysilane 9-5 (30.0 $\mathrm{mg}, 0.053 \mathrm{mmol}, 1.0$ equiv) and $\operatorname{DME}(260 \mu \mathrm{L}, 0.2 \mathrm{M})$ was added. To the stirred reaction mixture was added iodomethane $(7 \mu \mathrm{L}, 0.106$ mmol, 2.0 equiv). The reaction vessel as then transferred to a $-40{ }^{\circ} \mathrm{C}$ dry-ice acetonitrile bath, and allowed to stir for 5 minutes. Following this, tetramethylammonium fluoride ( $7.4 \mathrm{mg}, 0.075 \mathrm{mmol}, 1.5 \mathrm{equiv}$ ) was added, which resulted in a red reaction mixture. After stirring at $-40{ }^{\circ} \mathrm{C}$ for 30 minutes, the reaction vessel was removed from the dry-ice acetonitrile bath and allowed to gradually warm to room temperature.

After stirring at room temperature for 30 minutes, the reaction mixture was diluted with sat. aq. $\mathrm{NH}_{4} \mathrm{Cl}(5 \mathrm{~mL})$. The aqueous layer was extracted with EtOAc $(3 \times 5 \mathrm{~mL})$. The combined organic extracts were washed with brine $(5 \mathrm{~mL})$, dried over anhydrous $\mathrm{Na}_{2} \mathrm{SO}_{4}$, filtered and concentrated under reduced pressure by rotary evaporation to give a crude colorless solid. Purification by flash column chromatography on silica gel $\left(80 \% \mathrm{Et}_{2} \mathrm{O} /\right.$ hexanes) afforded the title compound as a colorless foam (5.6 $\mathrm{mg}, 23 \%, 1: 1$ mixture of diastereomers) and ketone 9-6 (6.2 $\mathrm{mg}, 26 \%)$ as a colorless foam. Further purification by preparatory thin layer chromatography $\left(10 \% \mathrm{Et}_{2} \mathrm{O} / \mathrm{CH}_{2} \mathrm{Cl}_{2}\right)$ afforded diastereomerically pure xylogranatopyridine B $(2.7 \mathrm{mg}, 11 \%)$ as a colorless foam.

The spectral data matched that which was previously reported. ${ }^{2}$ 
Synthesis of TBS-cyclopropanol (SI-5):
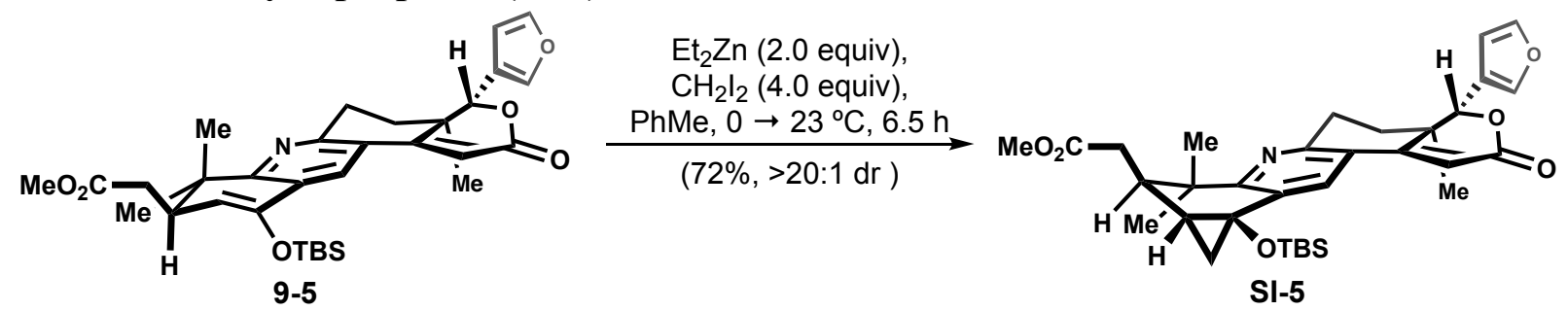

To a flame-dried 20-mL microwave vial equipped with a magnetic stir bar was added ester 9-5 (100.0 mg, $0.18 \mathrm{mmol}, 1.0$ equiv) and $\mathrm{PhMe}(0.9 \mathrm{~mL}, 0.2 \mathrm{M})$. The reaction vessel was then transferred to a $0{ }^{\circ} \mathrm{C}$ ice-water bath. To the reaction mixture was added $\mathrm{Et}_{2} \mathrm{Zn}(430 \mu \mathrm{L}, 0.35 \mathrm{mmol}, 2.0$ equiv, 15 wt. $\%$ in $\mathrm{PhMe}$ ) dropwise over two minutes, resulting in an orange reaction mixture. After stirring at $0{ }^{\circ} \mathrm{C}$ for 5 minutes, diiodomethane $(57 \mu \mathrm{L}, 0.71 \mathrm{mmol}, 4.0$ equiv) was added dropwise. The reaction vessel was removed from the ice-water bath and allowed to stir at room temperature.

After the reaction mixture was stirred for 6 hours at room temperature, sat. aq. $\mathrm{NH}_{4} \mathrm{Cl}(10 \mathrm{~mL})$ was added and the layers were separated. The aqueous layer was extracted with EtOAc $(3 \times 20 \mathrm{~mL})$. The combined organic extracts were washed with brine $(15 \mathrm{~mL})$, dried over anhydrous $\mathrm{Na}_{2} \mathrm{SO}_{4}$, filtered and concentrated under reduced pressure by rotary evaporation to give a yellow foam. Purification by flash column chromatography on silica gel (10\% EtOAc/hexanes to 35\% EtOAc/hexanes) afforded SI-5 (73.6 $\mathrm{mg}, 72 \%)$ as a colorless foam.

$\mathbf{R}_{\mathbf{f}}: 0.12\left(50 \% \mathrm{Et}_{2} \mathrm{O} /\right.$ hexanes, $p$-anisaldehyde $)$

${ }^{1}$ H NMR $\left(600 \mathrm{MHz}, \mathrm{CDCl}_{3}\right): \delta 8.18(\mathrm{~s}, 1 \mathrm{H}), 7.54(\mathrm{~s}, 1 \mathrm{H}), 7.46(\mathrm{t}, J=1.7 \mathrm{~Hz}, 1 \mathrm{H}), 6.51(\mathrm{dd}, J=1.9,0.8$ $\mathrm{Hz}, 1 \mathrm{H}), 6.46(\mathrm{~s}, 1 \mathrm{H}), 5.21(\mathrm{~s}, 1 \mathrm{H}), 3.73(\mathrm{~s}, 3 \mathrm{H}), 3.06-2.95(\mathrm{~m}, 2 \mathrm{H}), 2.74(\mathrm{dd}, J=14.8,4.2 \mathrm{~Hz}, 1 \mathrm{H})$, $2.46(\mathrm{dd}, J=14.8,10.8 \mathrm{~Hz}, 1 \mathrm{H}), 1.86(\mathrm{ddd}, J=10.5,5.9,4.2 \mathrm{~Hz}, 1 \mathrm{H}), 1.79$ (ddd, $J=13.0,5.1,2.3 \mathrm{~Hz}$, $1 \mathrm{H}), 1.70(\mathrm{ddd}, J=12.8,6.0,6.0 \mathrm{~Hz}, 1 \mathrm{H}), 1.50(\mathrm{dd}, J=9.7,5.5 \mathrm{~Hz}, 1 \mathrm{H}), 1.34(\mathrm{~s}, 3 \mathrm{H}), 1.28-1.26(\mathrm{~m}$, $1 \mathrm{H}), 1.25(\mathrm{~s}, 3 \mathrm{H}), 1.15(\mathrm{~s}, 3 \mathrm{H}), 0.85(\mathrm{~s}, 9 \mathrm{H}), 0.62(\mathrm{t}, J=5.6 \mathrm{~Hz}, 1 \mathrm{H}), 0.15(\mathrm{~s}, 3 \mathrm{H}),-0.05(\mathrm{~s}, 3 \mathrm{H})$

${ }^{13} \mathrm{C}$ NMR $\left(151 \mathrm{MHz}, \mathrm{CDCl}_{3}\right): \delta 173.6,166.7,165.5,158.3,155.1,143.2,141.5,133.5,132.5,122.1$, $120.2,110.3,109.6,80.9,54.9,51.9,47.8,39.8,37.7,37.1,30.7,28.2,27.3,25.7,24.3,24.1,24.1,18.0$, $16.1,-2.8,-2.9$

IR $\left(\mathrm{cm}^{-1}\right): 2958,2929,2879,1780,1732,1458,1382,1246,1131,1093,1003,963$

ESI-HRMS (m/z): $[\mathrm{M}+\mathrm{H}]^{+}$calc'd for $\mathrm{C}_{33} \mathrm{H}_{44} \mathrm{O}_{6} \mathrm{Si}^{+}$: 578.2932 ; found: 578.2928 


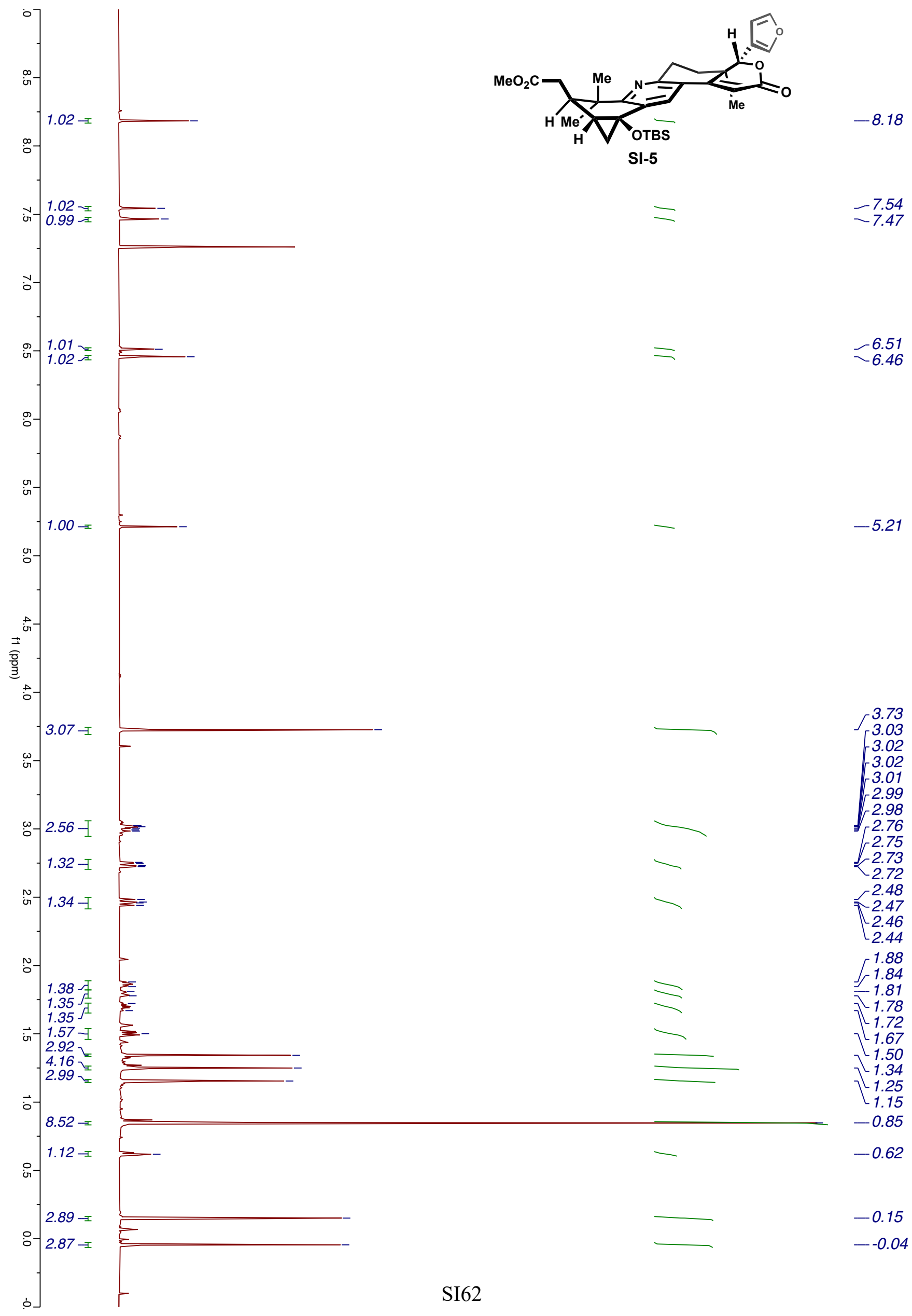




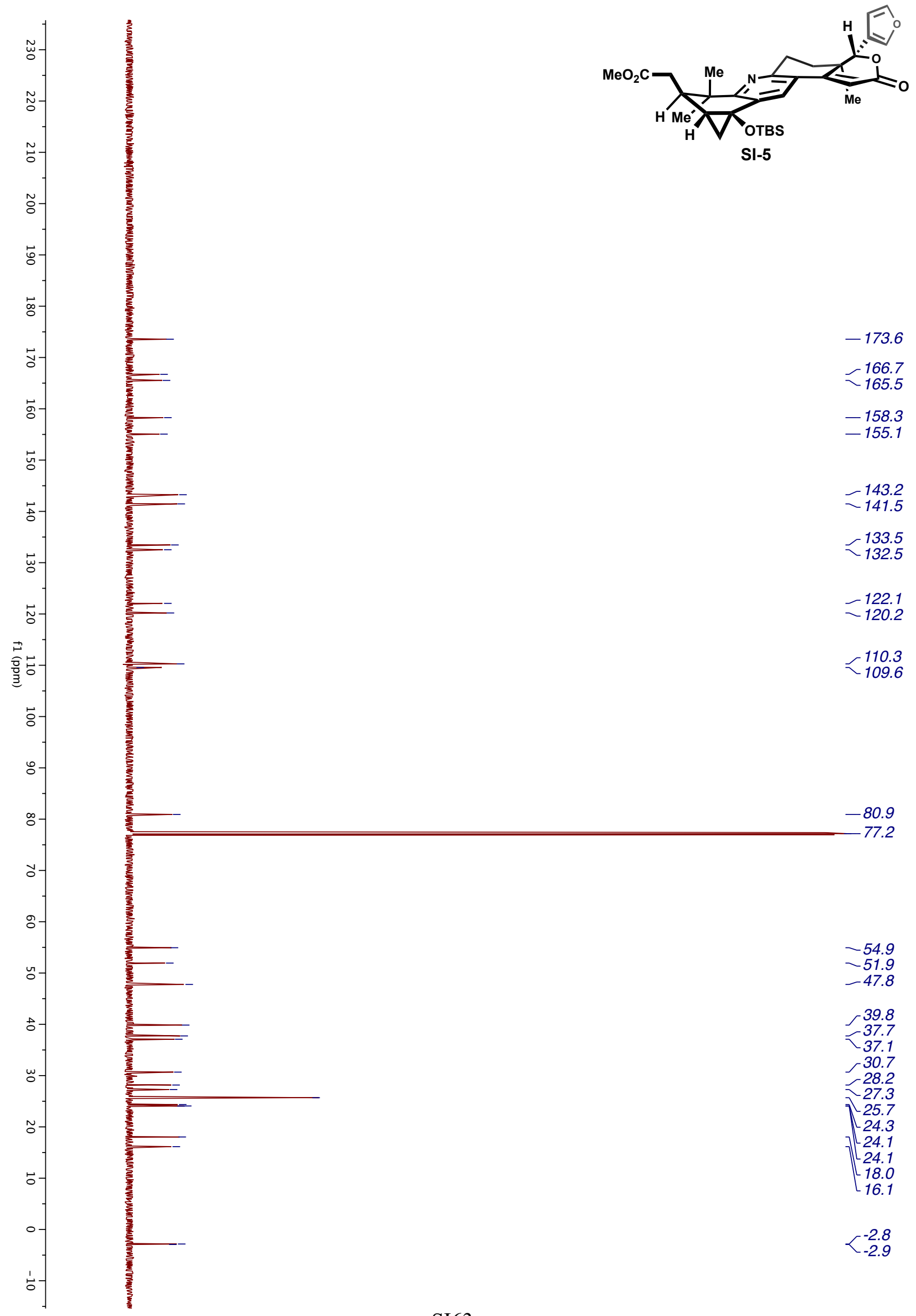


Synthesis of enone (9-8):

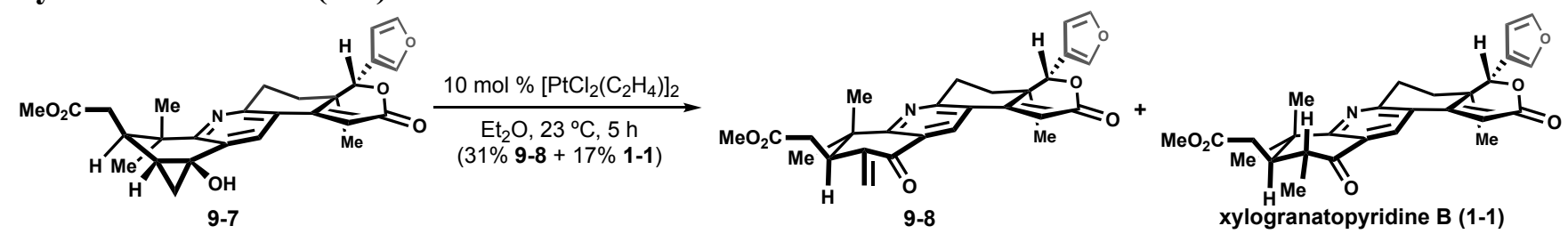

An evacuated flame-dried 5-mL microwave vial equipped with a magnetic stir bar was brought into a glove box and filled with nitrogen. Zeise's dimer (1.6 mg, $0.0043 \mathrm{mmol}, 10 \mathrm{~mol} \%$ ) was added to the microwave vial. The microwave vial was removed from the glove box. The vial was evacuated and backfilled with nitrogen, and this process was repeated three times. To the reaction mixture was added a solution of cyclopropanol 9-7 (20.0 mg, $0.043 \mathrm{mmol}, 1.0$ equiv) in $\mathrm{Et}_{2} \mathrm{O}(0.43 \mathrm{~mL}, 0.1 \mathrm{M})$ at room temperature.

After the reaction mixture was allowed to stir at room temperature for 5 hours, water $(5 \mathrm{~mL})$ was added and the layers were separated. The aqueous layer was extracted with EtOAc $(3 \times 5 \mathrm{~mL})$. The combined organic extracts were washed with brine $(5 \mathrm{~mL})$, dried over anhydrous $\mathrm{Na}_{2} \mathrm{SO}_{4}$, filtered and concentrated under reduced pressure by rotary evaporation to give a yellow foam. Purification by preparatory thin layer chromatography $\left(10 \% \mathrm{Et}_{2} \mathrm{O} / \mathrm{CH}_{2} \mathrm{Cl}_{2}\right)$ afforded 9-8 $(6.2 \mathrm{mg}, 31 \%)$ as a colorless foam, and xylogranatopyridine $\mathrm{B}(3.4 \mathrm{mg}, 17 \%)$ as a colorless foam.

$\mathbf{R}_{\mathbf{f}}: 0.35$ (50\% EtOAc/hexanes, $p$-anisaldehyde)

${ }^{1}$ H NMR (600 MHz, $\left.\mathrm{CDCl}_{3}\right): \delta 8.70(\mathrm{~s}, 1 \mathrm{H}), 7.55(\mathrm{~s}, 1 \mathrm{H}), 7.47(\mathrm{~s}, 1 \mathrm{H}), 6.55(\mathrm{~s}, 1 \mathrm{H}), 6.51(\mathrm{~s}, 1 \mathrm{H}), 6.39(\mathrm{~s}$, $1 \mathrm{H}), 5.59(\mathrm{~s}, 1 \mathrm{H}), 5.23(\mathrm{~s}, 1 \mathrm{H}), 3.61(\mathrm{~s}, 3 \mathrm{H}), 3.29(\mathrm{dd}, J=10.6,4.3 \mathrm{~Hz}, 1 \mathrm{H}), 3.20-3.13(\mathrm{~m}, 1 \mathrm{H}), 3.08-$ $3.00(\mathrm{~m}, 1 \mathrm{H}), 2.74-2.66(\mathrm{~m}, 1 \mathrm{H}), 2.16(\mathrm{dd}, J=15.2,10.6 \mathrm{~Hz}, 1 \mathrm{H}), 1.84(\mathrm{dd}, J=13.2,5.2 \mathrm{~Hz}, 1 \mathrm{H}), 1.74$ $(\operatorname{atd}, J=13.1,5.1 \mathrm{~Hz}, 1 \mathrm{H}), 1.46(\mathrm{~s}, 3 \mathrm{H}), 1.35(\mathrm{~s}, 3 \mathrm{H}), 1.14(\mathrm{~s}, 3 \mathrm{H})$

${ }^{13} \mathbf{C}$ NMR $\left(151 \mathrm{MHz}, \mathrm{CDCl}_{3}\right): \delta 185.7,172.2,169.4,164.9,161.8,156.5,143.3,141.3,133.2,125.6$, $125.2,123.3,119.8,111.3,110.0,80.7,77.3,51.7,49.3,41.1,37.5,36.1,30.8,29.9,28.7,23.6,15.9$

IR $\left(\mathrm{cm}^{-1}\right): 1720,1682,1614,1586,1416,1260,1164,1024,875,819$

ESI-HRMS (m/z): $[\mathrm{M}+\mathrm{H}]^{+}$calc'd for $\mathrm{C}_{27} \mathrm{H}_{28} \mathrm{O}_{6}{ }^{+}$: 462.1911; found: 462.1913 

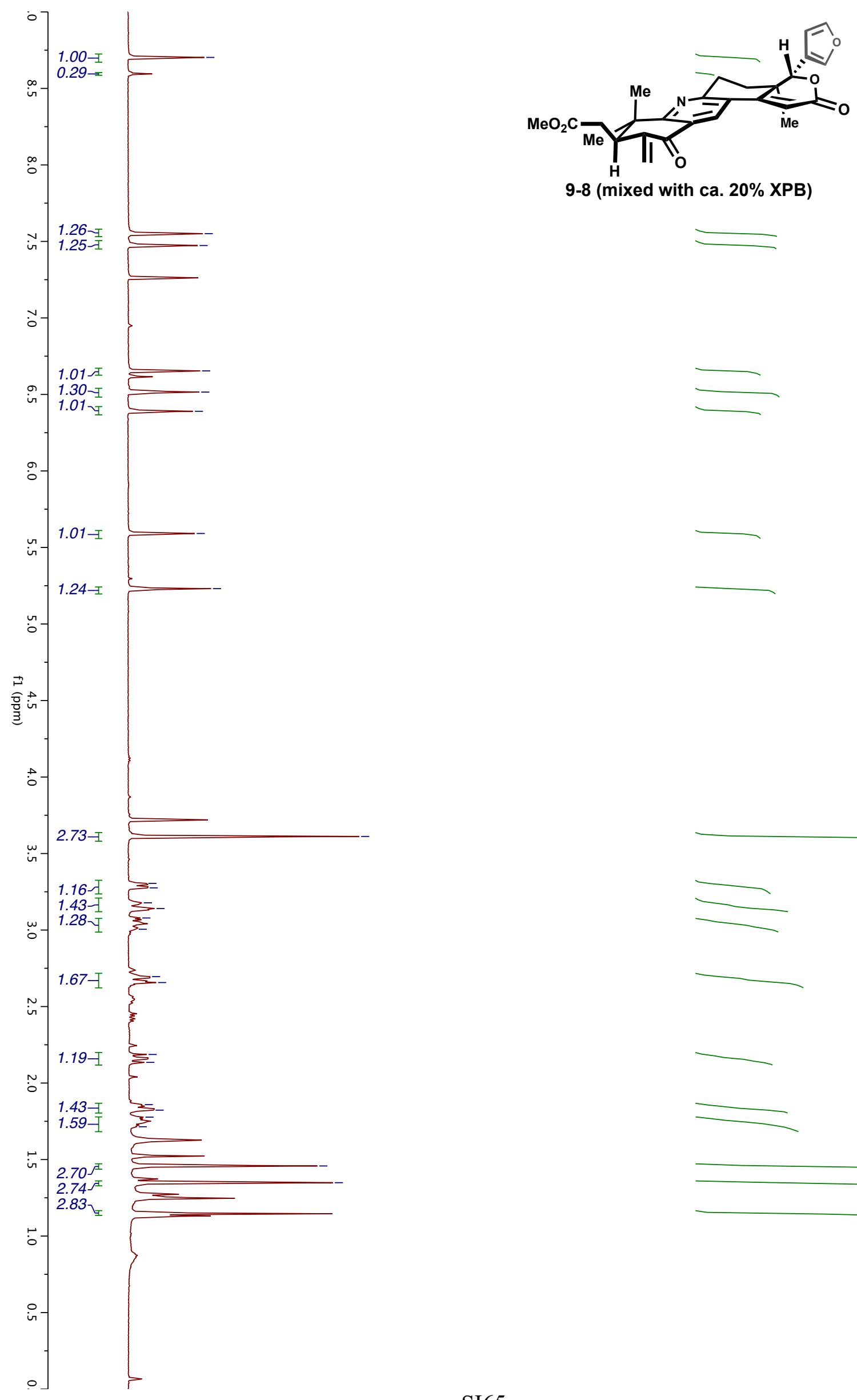

$-8.70$

9-8 (mixed with ca. $20 \%$ XPB)
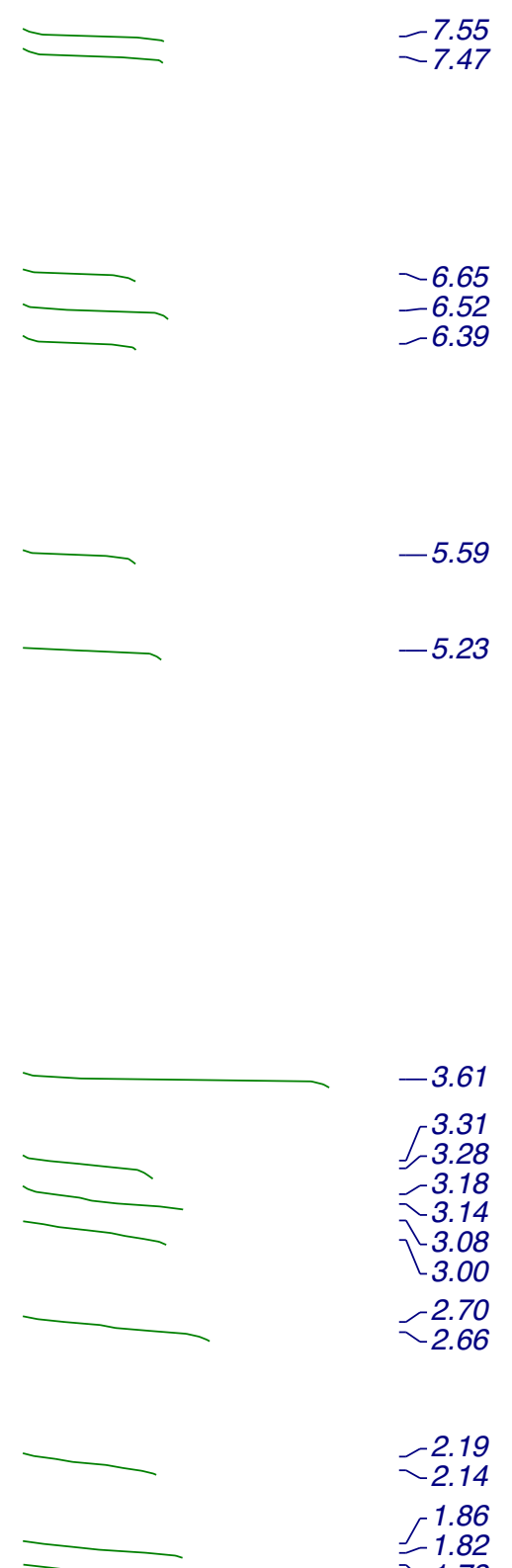

$-1.82$

\} 1 . 7 8

$-1.46$

$-1.35$ 


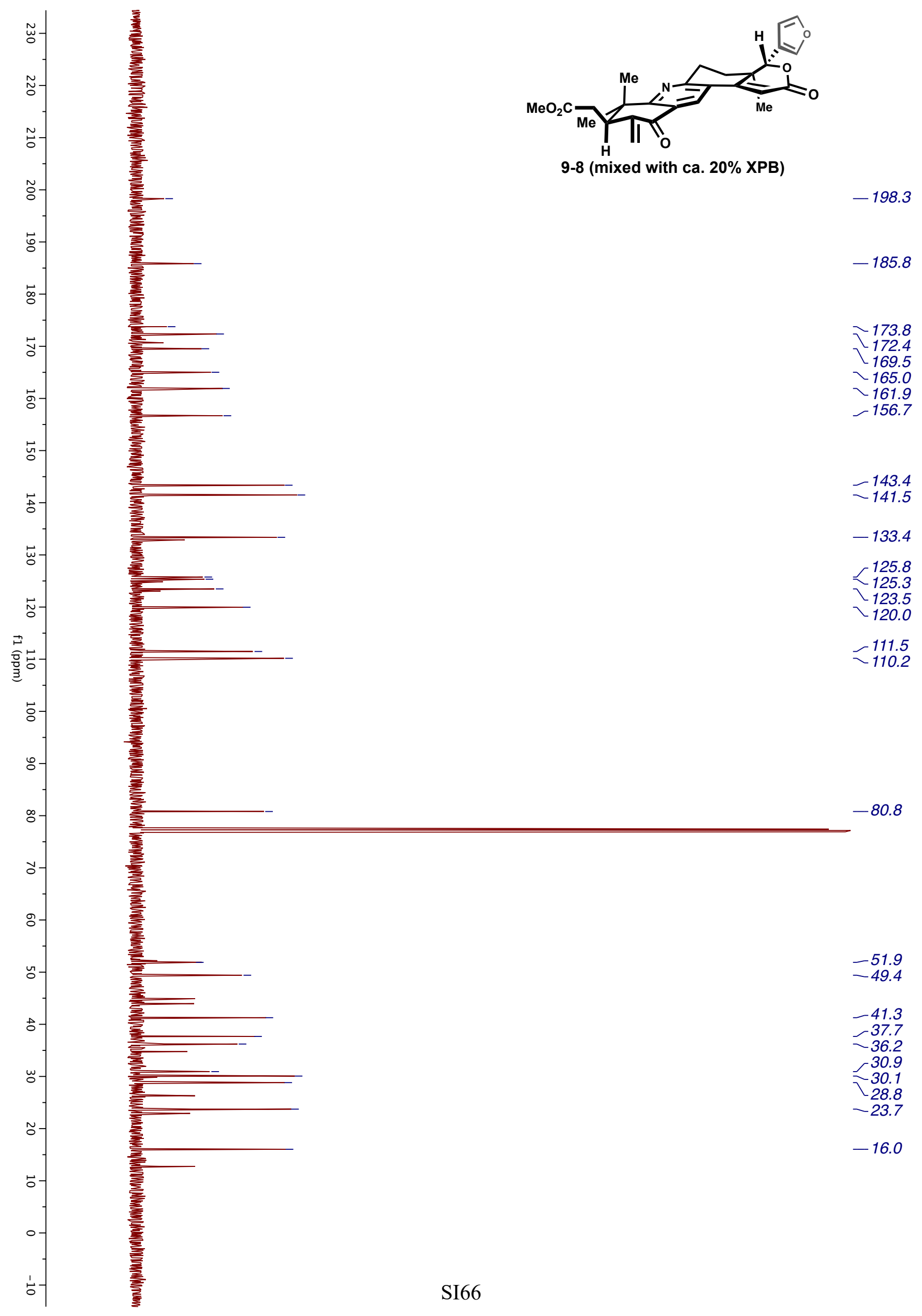




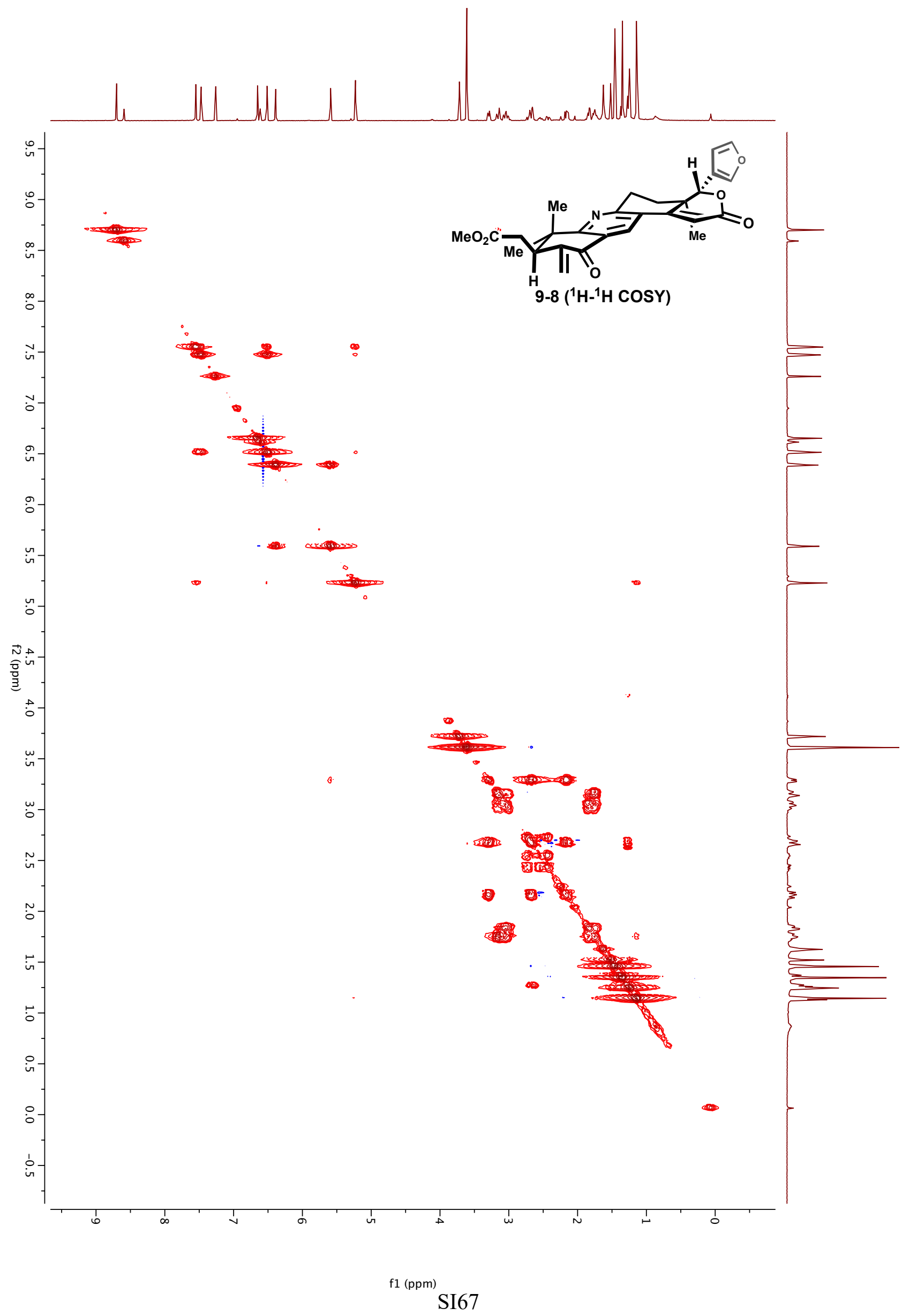




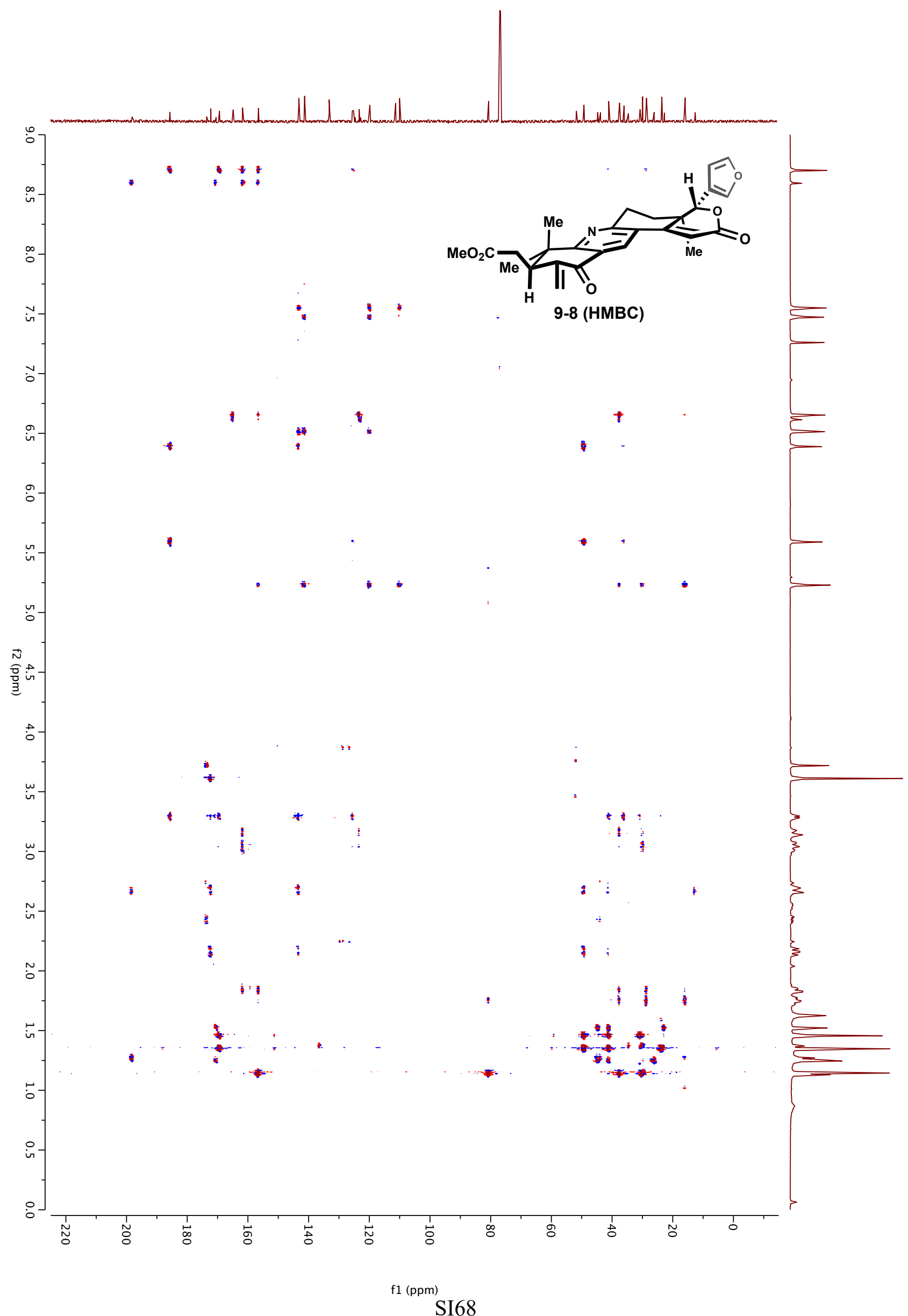




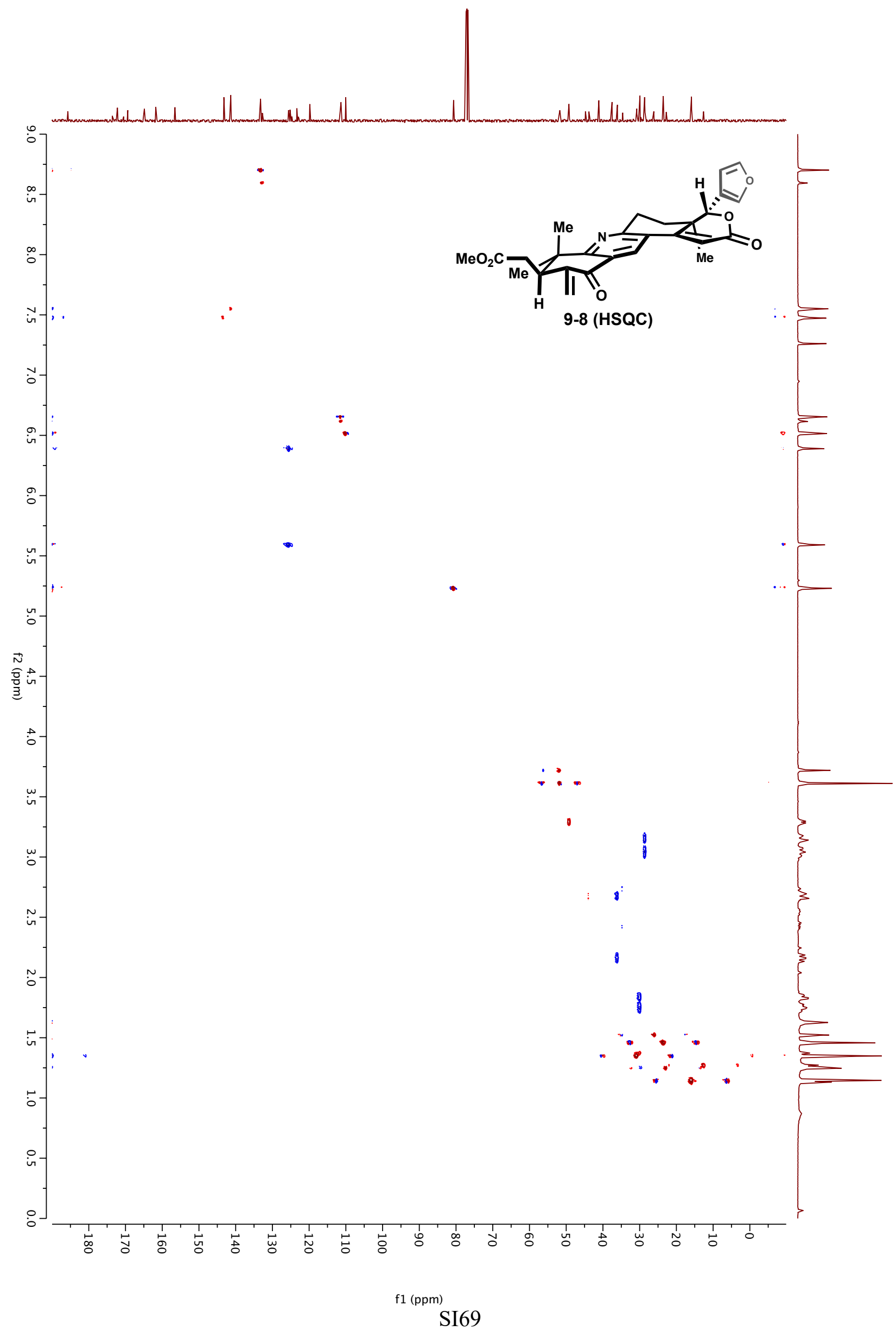


Synthesis of exocyclic enone (11-7):

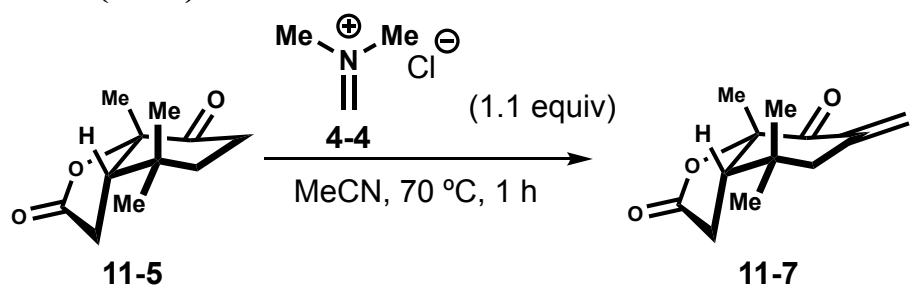

To a flame-dried 5-mL microwave vial equipped with a magnetic stir bar was added ketone 11-5 (15 mg, $0.076 \mathrm{mmol}, 1.0$ equiv), $N, N$-dimethylmethyleneiminium chloride ( $8 \mathrm{mg}, 0.084 \mathrm{mmol}, 1.1$ equiv) and $\mathrm{MeCN}(0.15 \mathrm{~mL}, 0.5 \mathrm{M})$. The reaction vessel was sealed with a Teflon-coated silicon microwave cap and moved to a $70{ }^{\circ} \mathrm{C}$ preheated oil-bath. After stirring at $70{ }^{\circ} \mathrm{C}$ for one hour, the reaction vessel was removed from the oil bath and allowed to cool to room temperature. Once at room temperature the reaction mixture was concentrated under reduced pressure by rotary evaporation to give 11-7 as a yellow oil (12 $\mathrm{mg}$ ), which was used without further purification.

Note: This compound rapidly decomposed when neat at room temperature. Therefore, only partially characterization has been obtained.

Rf: $0.21\left(65 \% \mathrm{Et}_{2} \mathrm{O} /\right.$ hexanes, $\left.\mathrm{KMnO}_{4}\right)$

${ }^{1} \mathbf{H}$ NMR $\left(500 \mathrm{MHz}, \mathrm{CDCl}_{3}\right): \delta 6.23(\mathrm{dd}, J=1.7 \mathrm{~Hz}, 1 \mathrm{H}), 5.40(\mathrm{~d}, J=1.7 \mathrm{f} \mathrm{Hz}, 1 \mathrm{H}), 2.80(\mathrm{dd}, J=18.4$, $9.9 \mathrm{~Hz}, 1 \mathrm{H}), 2.59-2.51(\mathrm{~m}, 2 \mathrm{H}), 2.49-2.44(\mathrm{~m}, 2 \mathrm{H}), 1.54$ (s, 3H), 1.05 (s, 3H), 0.89 (s, 3H)

${ }^{13} \mathbf{C}$ NMR $\left(151 \mathrm{MHz}, \mathrm{CDCl}_{3}\right): \delta 196.1,174.6,139.3,126.3,85.8,52.6,42.7,32.1,31.1,28.7,26.1,23.2$ 


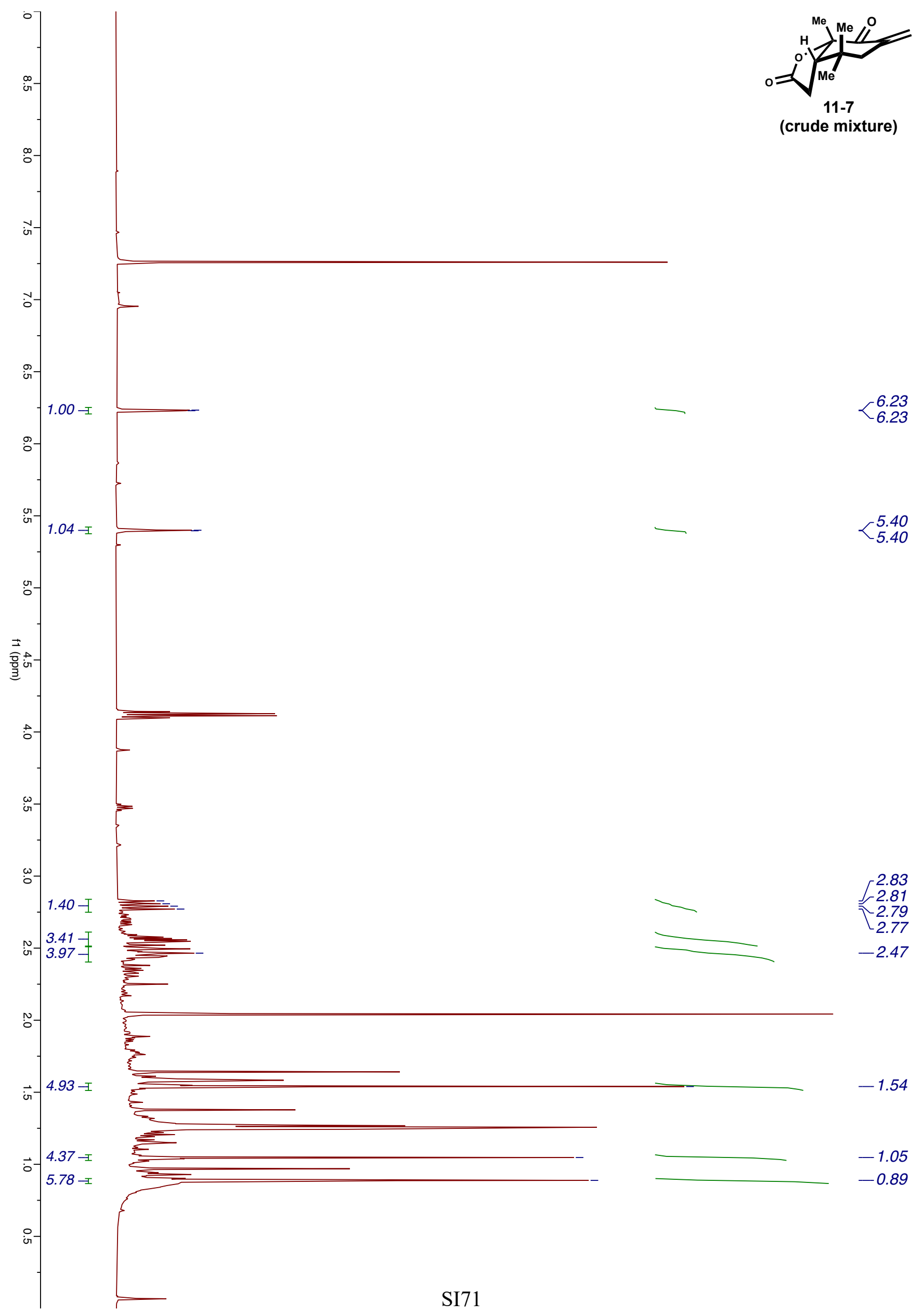




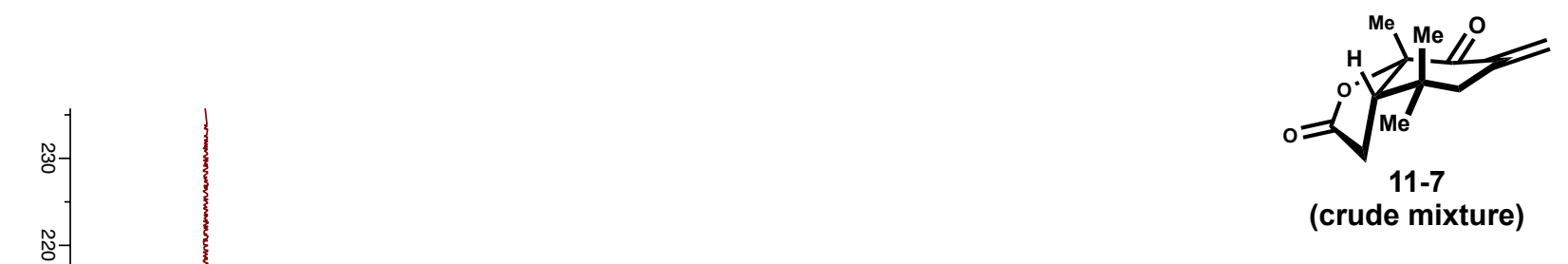




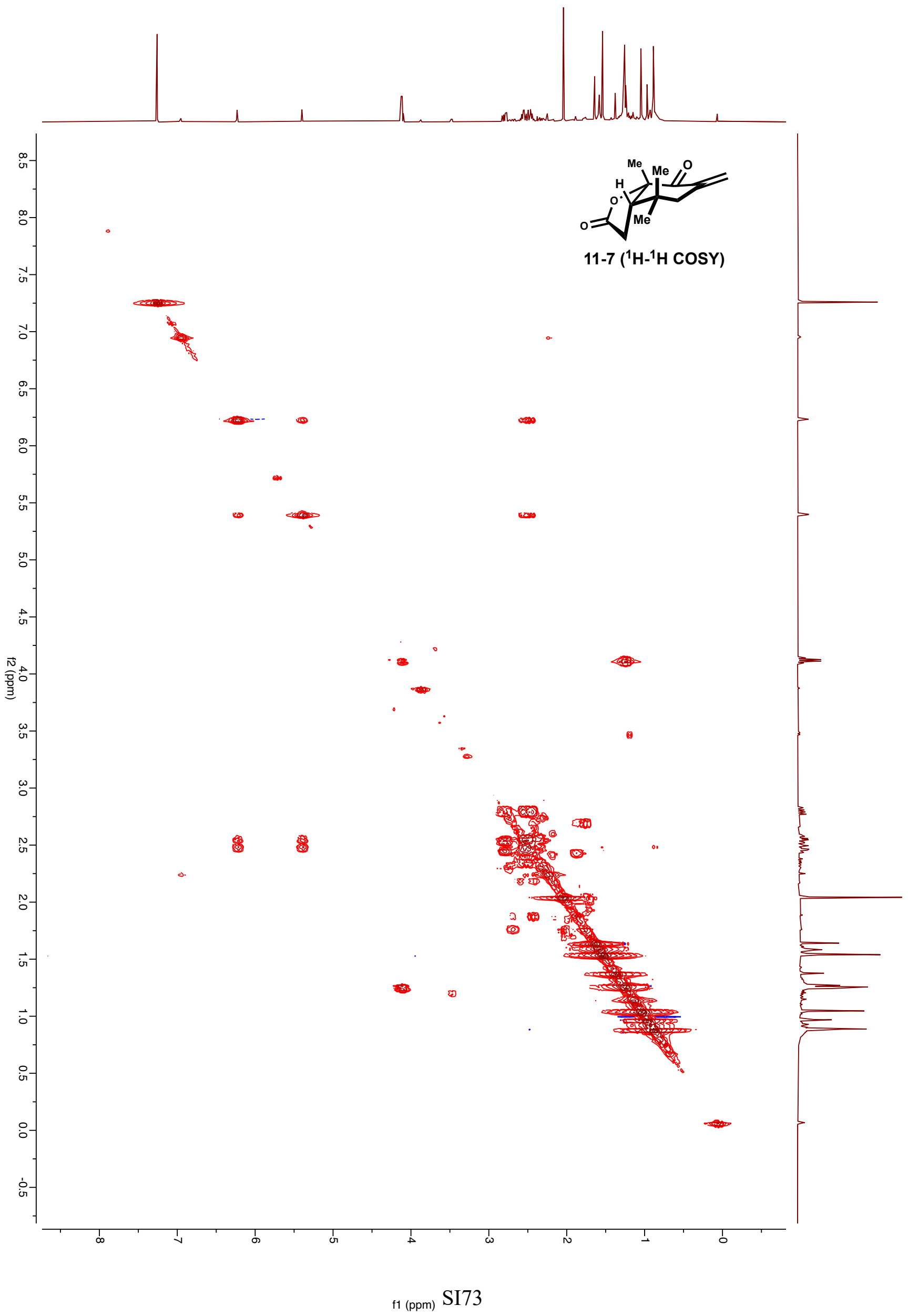




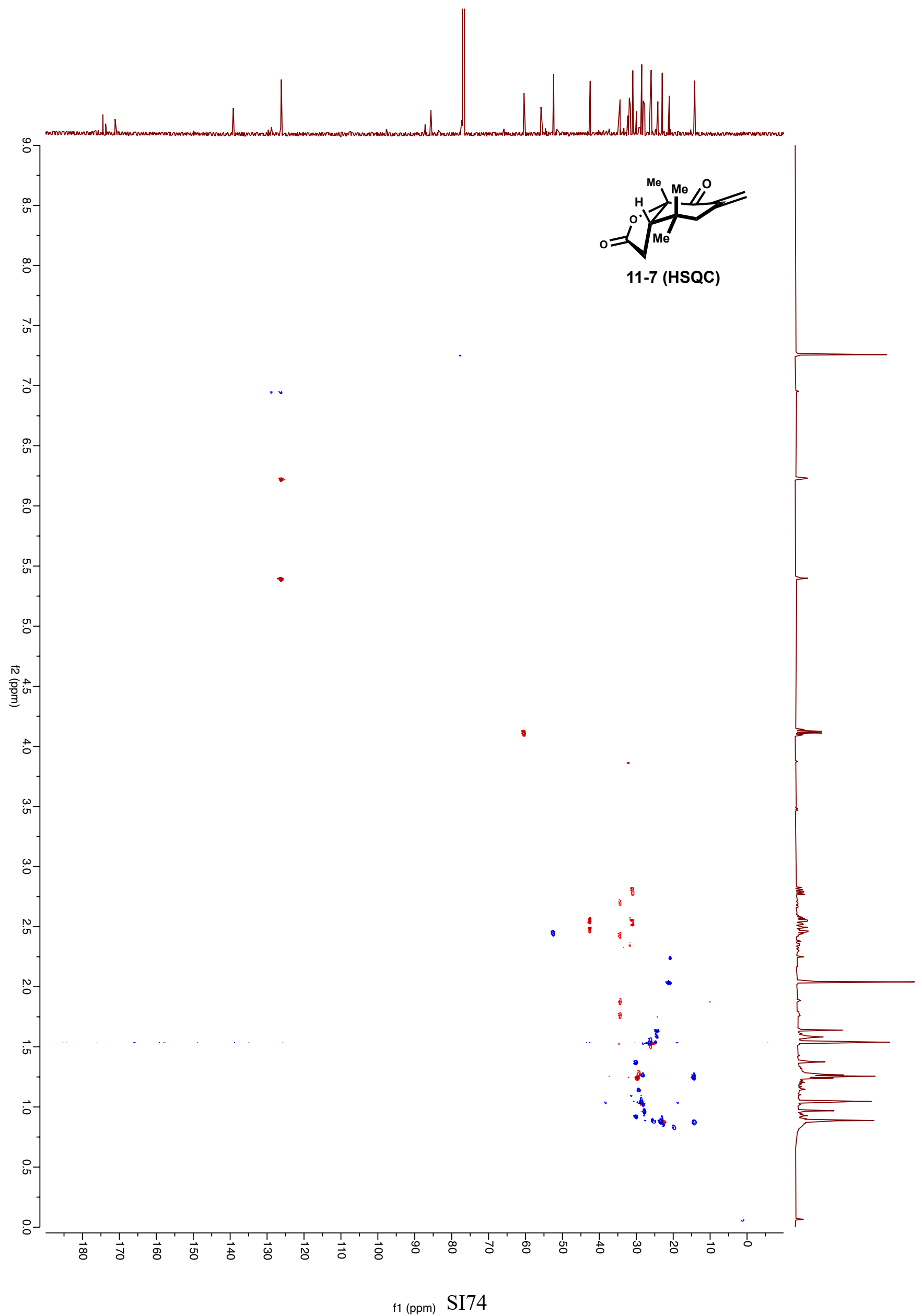


Synthesis of allylic bromide (10-3):

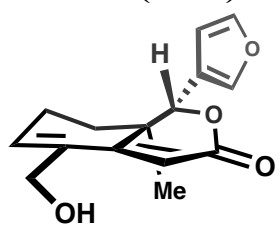

$(+)$-azedaralide (12-7)

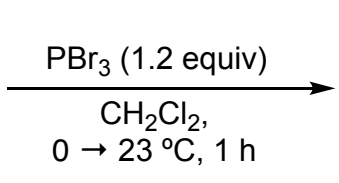

$0 \rightarrow 23^{\circ} \mathrm{C}, 1 \mathrm{~h}$

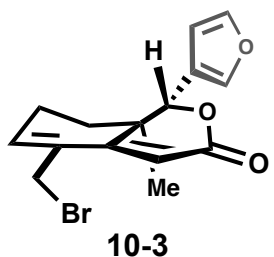

10-3

To a flame-dried 20-mL microwave vial equipped with a magnetic stir bar was added azedaralide 12-7 (300.0 mg, $1.15 \mathrm{mmol}, 1.0$ equiv) and $\mathrm{CH}_{2} \mathrm{Cl}_{2}(5.8 \mathrm{~mL}, 0.2 \mathrm{M})$. The reaction vessel was then transferred to a $0{ }^{\circ} \mathrm{C}$ ice-water bath, and $\mathrm{PBr}_{3}(130 \mu \mathrm{L}, 1.38 \mathrm{mmol}, 1.2$ equiv) was added dropwise. The reaction vessel was then removed from the ice-water bath, and allowed to warm to room temperature.

After stirring at room temperature for one hour, the reaction vessel was again transferred to a $0{ }^{\circ} \mathrm{C}$ ice-water bath, and sat. aq. $\mathrm{NaHCO}_{3}(5 \mathrm{~mL})$ was added dropwise to the reaction mixture. The layers were separated, and the aqueous layer was extracted with $\mathrm{CH}_{2} \mathrm{Cl}_{2}(3 \times 20 \mathrm{~mL})$. The combined organic extracts were washed with brine $(15 \mathrm{~mL})$, dried over anhydrous $\mathrm{Na}_{2} \mathrm{SO}_{4}$, filtered and concentrated under reduced pressure by rotary evaporation to give a yellow oil. Purification by flash column chromatography on silica gel (10\% EtOAc/hexanes to 30\% EtOAc/hexanes) afforded 10-3 (159 mg, 43\%) as a yellow foam.

Rf: $0.81\left(65 \% \mathrm{Et}_{2} \mathrm{O} /\right.$ hexanes, $p$-anisaldehyde)

${ }^{1}$ H NMR $\left(500 \mathrm{MHz}, \mathrm{CDCl}_{3}\right): \delta 7.49(\mathrm{~s}, 1 \mathrm{H}), 7.44(\mathrm{~s}, 1 \mathrm{H}), 6.57-6.52(\mathrm{~m}, 1 \mathrm{H}), 6.46(\mathrm{~s}, 1 \mathrm{H}), 6.08(\mathrm{~s}, 1 \mathrm{H})$, $5.17(\mathrm{~s}, 1 \mathrm{H}), 4.14(\mathrm{~d}, J=10.8 \mathrm{~Hz}, 1 \mathrm{H}), 4.11(\mathrm{~d}, J=10.8 \mathrm{~Hz}, 1 \mathrm{H}), 2.41-2.27(\mathrm{~m}, 2 \mathrm{H}), 1.52-1.43(\mathrm{~m}$, 2H), 1.04 (s 3H)

${ }^{13} \mathrm{C}$ NMR (151 MHz, $\left.\mathrm{CDCl}_{3}\right): \delta 165.5,155.7,143.2,141.3,140.7,131.1,120.1,111.9,110.2,80.7,37.3$, $30.8,29.5,22.7,16.1$

IR $\left(\mathrm{cm}^{-1}\right): 1710,1626,1261,1164,1026,875$

ESI-HRMS (m/z): $[\mathrm{M}+\mathrm{H}]^{+}$calc'd for $\mathrm{C}_{15} \mathrm{H}_{16} \mathrm{BrO}_{3}{ }^{+}: 323.0277$; found: 323.0276

$[\boldsymbol{\alpha}]_{\boldsymbol{D}}^{\mathbf{2 0 . 0}}:+243.6^{\circ}\left(\mathrm{c} 1.0, \mathrm{CHCl}_{3}\right)$ 


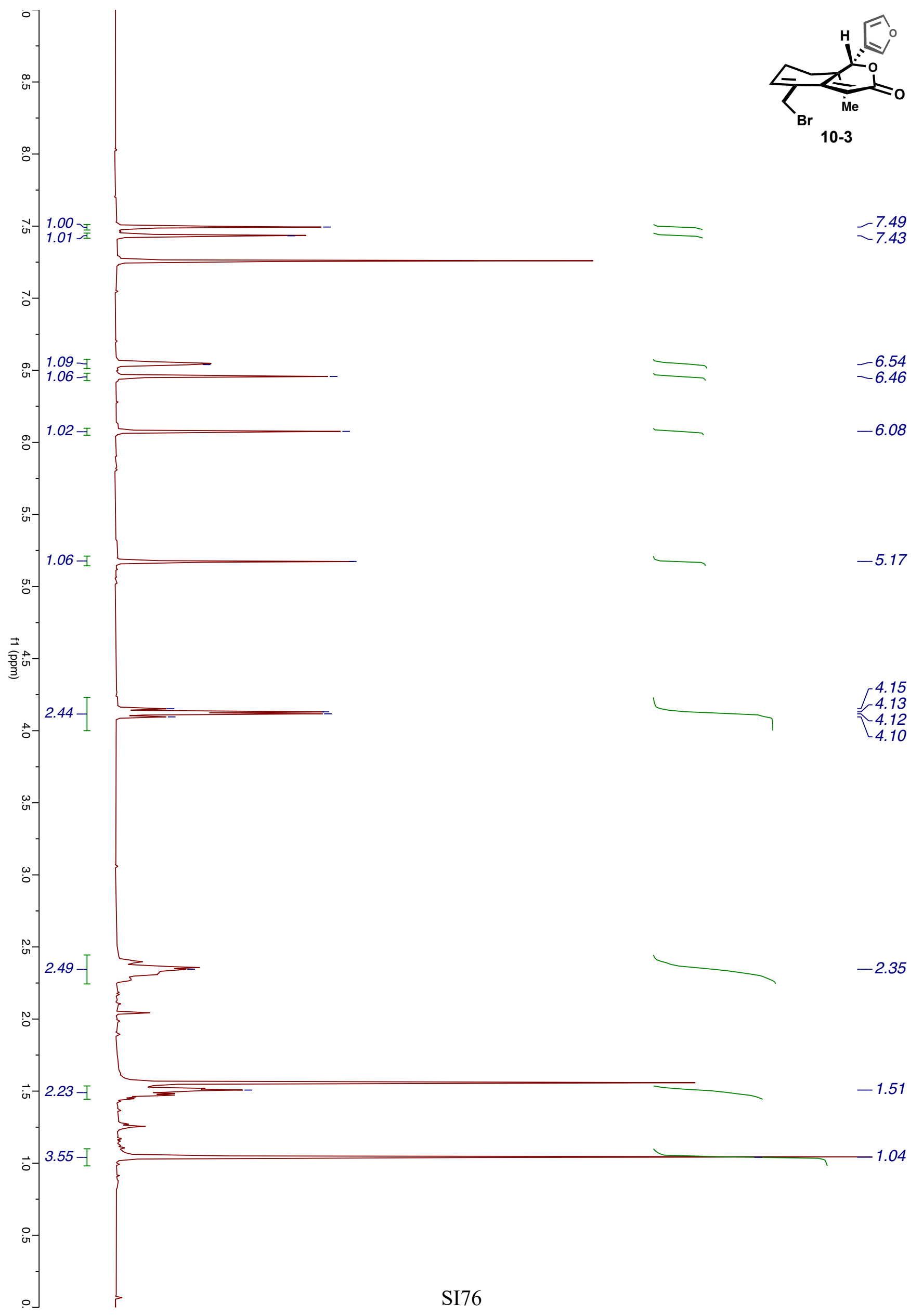




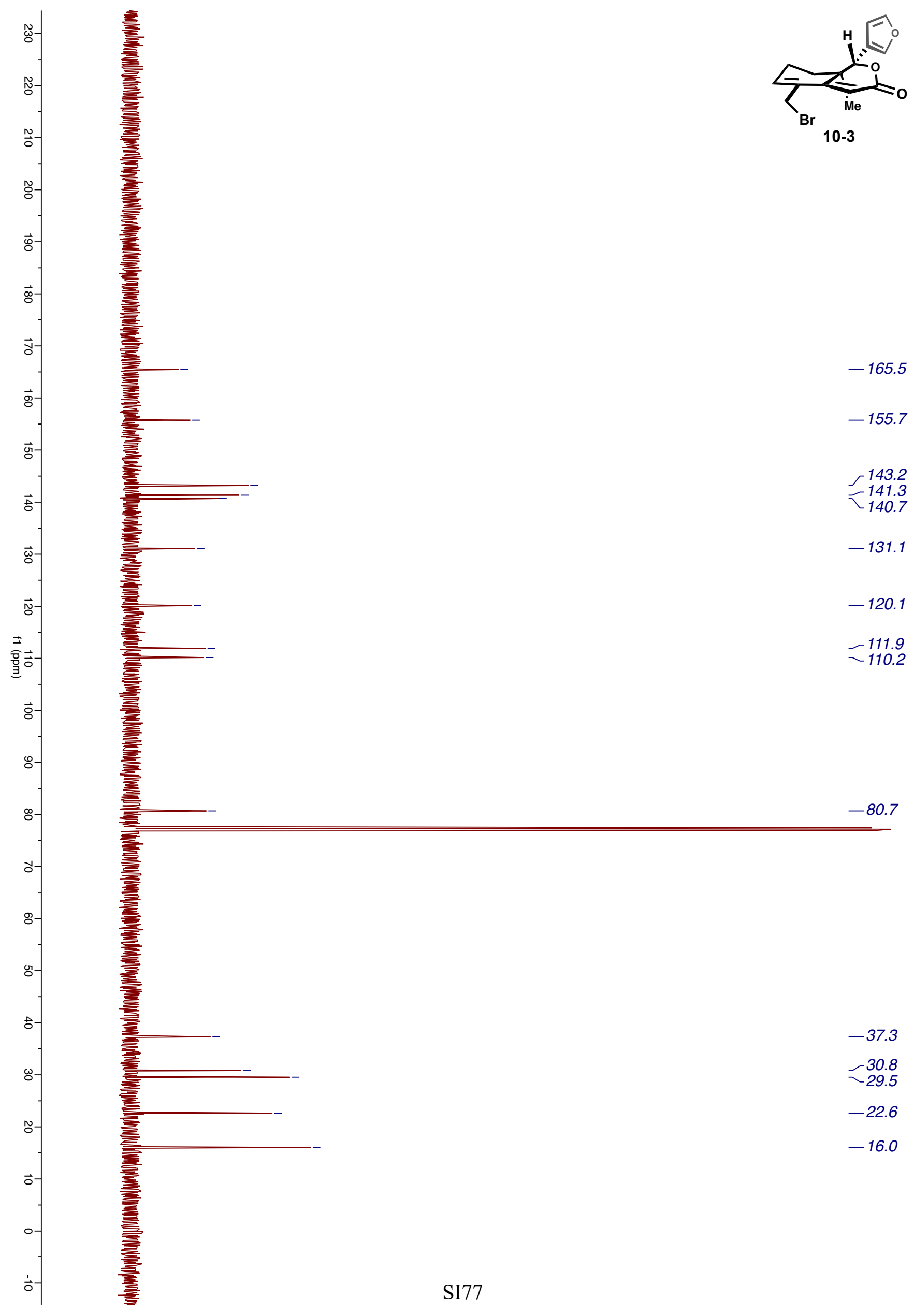




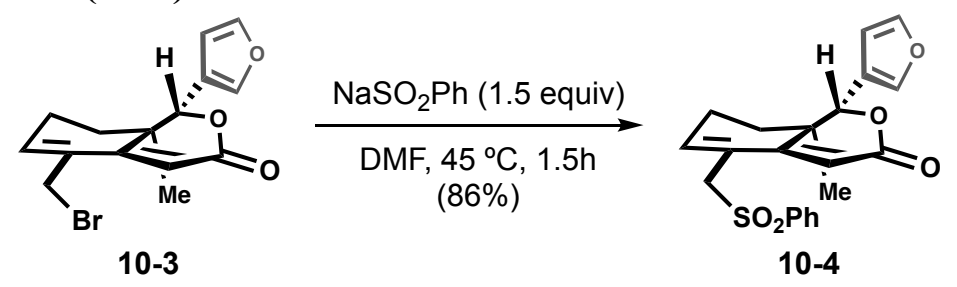

To a flame-dried 5-mL microwave vial equipped with a magnetic stir bar was added benzene sulfinic acid sodium salt (30.0 mg, $0.185 \mathrm{mmol}, 1.5$ equiv) and bromide 10-3 (40.0 mg, $0.124 \mathrm{mmol}, 1.0$ equiv). The reaction vial was sealed with a Teflon-coated silicon microwave cap, and the DMF $(0.12 \mathrm{~mL}$, $1.0 \mathrm{M}$ ) was added to the reaction mixture. The reaction vessel was then transferred to a $45{ }^{\circ} \mathrm{C}$ preheated oil bath.

After stirring at $45^{\circ} \mathrm{C}$ for 1.5 hours, the reaction vessel was removed from the oil bath and allowed to cool to room temperature. Once at room temperature, the reaction mixture was diluted with water (10 $\mathrm{mL})$ and EtOAc $(2 \mathrm{~mL})$ and the layers were separated. The combined organic extracts were washed with brine $(3 \times 15 \mathrm{~mL})$, dried over anhydrous $\mathrm{Na}_{2} \mathrm{SO}_{4}$, filtered and concentrated under reduced pressure by rotary evaporation to give a light-yellow solid, which was triturated with $\mathrm{Et}_{2} \mathrm{O}(5 \mathrm{~mL})$. The light-yellow solid was filtered and dried under vacuum to afford 10-4 $(41.3 \mathrm{mg}, 86 \%)$, which was used without further purification.

$\mathbf{R}_{\mathbf{f}}: 0.23$ (85\% EtOAc/hexanes, $p$-anisaldehyde)

${ }^{1} \mathbf{H}$ NMR $\left(600 \mathrm{MHz}, \mathrm{CDCl}_{3}\right): \delta 7.89(\mathrm{~d}, J=8.4 \mathrm{~Hz}, 2 \mathrm{H}), 7.68(\mathrm{t}, J=7.5 \mathrm{~Hz}, 1 \mathrm{H}), 7.58(\mathrm{t}, J=7.8 \mathrm{~Hz}, 2 \mathrm{H})$, $7.48(\mathrm{~s}, 1 \mathrm{H}), 7.42(\mathrm{t}, J=1.7 \mathrm{~Hz}, 1 \mathrm{H}), 6.44(\mathrm{dd}, J=6.0,2.6 \mathrm{~Hz}, 1 \mathrm{H}), 6.41(\mathrm{~d}, J=1.7 \mathrm{~Hz}, 1 \mathrm{H}), 5.69(\mathrm{~s}$, $1 \mathrm{H}), 5.00(\mathrm{~s}, 1 \mathrm{H}), 4.00(\mathrm{~s}, 2 \mathrm{H}), 2.40(\mathrm{dtd}, J=20.1,5.8,1.7 \mathrm{~Hz}, 1 \mathrm{H}), 2.35-2.30(\mathrm{~m}, 1 \mathrm{H}), 1.49(\mathrm{dd}, \mathrm{J}=$ $12.7,4.5 \mathrm{~Hz}, 1 \mathrm{H}), 1.41$ (atd, $J=12.2,5.8 \mathrm{~Hz}, 1 \mathrm{H}), 0.94(\mathrm{~s}, 3 \mathrm{H})$

${ }^{13} \mathrm{C}$ NMR $\left(151 \mathrm{MHz}, \mathrm{CDCl}_{3}\right): \delta 165.1,156.6,145.3,143.2,141.4,138.6,134.4,129.5,128.7,122.6$, $119.9,111.7,110.1,80.5,58.7,37.6,29.3,23.0,16.1$

IR $\left(\mathrm{cm}^{-1}\right): 1712,1623,1307,1261,1159,1026,875$

ESI-HRMS (m/z): $[\mathrm{M}+\mathrm{Na}]^{+}$calc'd for $\mathrm{C}_{21} \mathrm{H}_{20} \mathrm{O}_{5} \mathrm{SNa}^{+}$: 407.0924 ; found: 407.919

$[\alpha]_{D}^{20.0}:+119.4^{\circ}\left(c 0.33, \mathrm{CHCl}_{3}\right)$ 


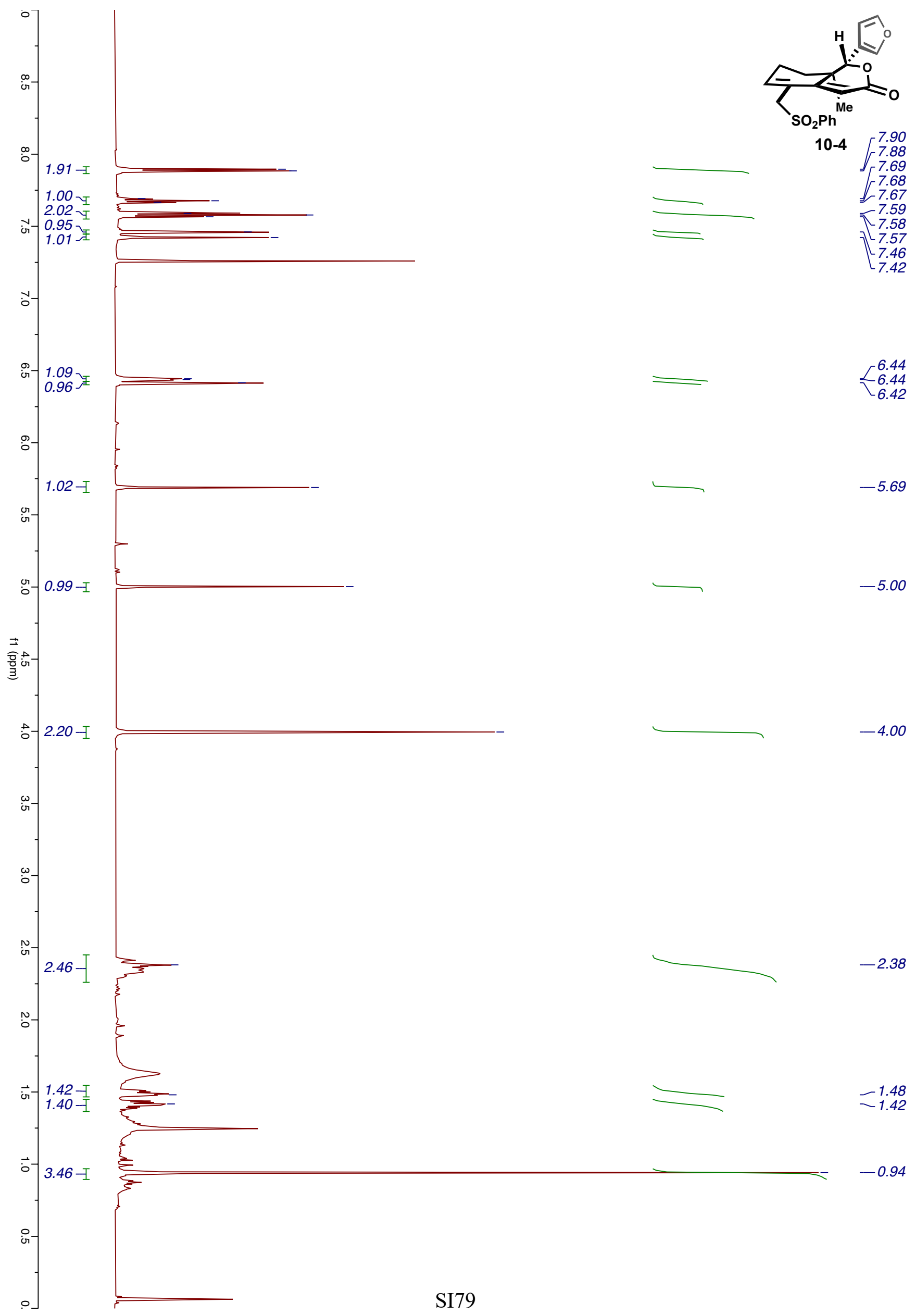




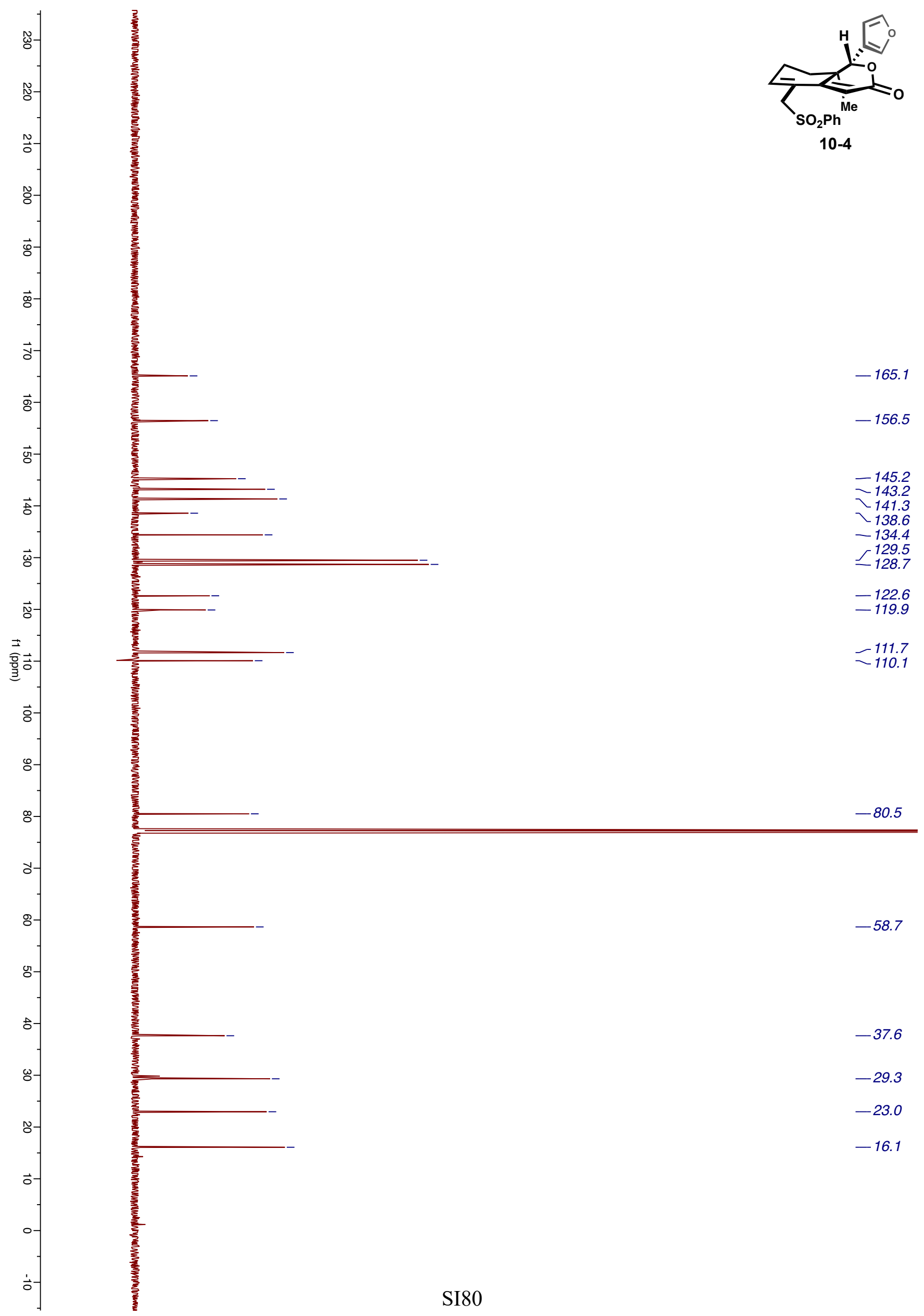


Synthesis of TBS-oxime (12-8):

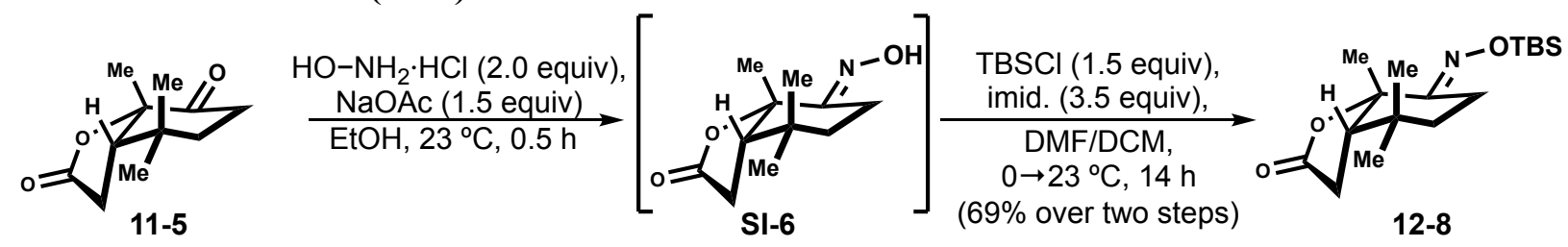

To a flame-dried 50-mL round-bottomed flask equipped with a magnetic stir bar was added ketone $11-5$ (1.0 g, $5.1 \mathrm{mmol}, 1.0$ equiv), hydroxylamine hydrochloride (710 $\mathrm{mg}, 10.2 \mathrm{mmol}, 2.0$ equiv), and sodium acetate $(627 \mathrm{mg}, 7.65 \mathrm{mmol}, 1.5$ equiv). To the reaction mixture was added EtOH $(10 \mathrm{~mL}, 0.5$ $\mathrm{M})$. The reaction mixture was allowed to stir at room temperature for 30 minutes before the reaction mixture was concentrated under reduced pressure by rotary evaporation to give crude SI-6 as a colorless solid (954 mg, 89\%).

To a flame-dried 50-mL round-bottomed flask equipped with a magnetic stir bar was added crude oxime SI-6 (900.0 mg, $4.58 \mathrm{mmol}, 1.0$ equiv) as a solution in 1:2 DMF: $\mathrm{CH}_{2} \mathrm{Cl}_{2}(4.5 \mathrm{~mL}, 1.0 \mathrm{M})$. The reaction vessel was then moved to a $0{ }^{\circ} \mathrm{C}$ ice-water bath. To the reaction mixture was added imidazole (1.09 g, $16.1 \mathrm{mmol}, 3.5$ equiv) and TBSCl ( $746 \mathrm{mg}, 6.87 \mathrm{mmol}, 1.5$ equiv), and the reaction vessel was removed from the ice-water bath and allowed to warm to room temperature.

After stirring at room temperature for 14 hours, the reaction mixture was diluted with sat. aq. $\mathrm{NaHCO}_{3}(15 \mathrm{~mL})$. The layers were separated, and the aqueous layer was extracted with EtOAc $(3 \mathrm{x} 20$ $\mathrm{mL})$. The combined organic extracts were washed with brine $(15 \mathrm{~mL})$, dried over anhydrous $\mathrm{Na}_{2} \mathrm{SO}_{4}$, filtered and concentrated under reduced pressure by rotary evaporation to give a yellow oil. Purification by flash column chromatography on silica gel (5\% EtOAc/hexanes to $20 \%$ EtOAc/hexanes) afforded 12$8(1.14 \mathrm{~g}, 69 \%$ over two steps) as a colorless foam.

Rf: $0.34\left(20 \% \mathrm{Et}_{2} \mathrm{O} /\right.$ hexanes, $\left.\mathrm{KMnO}_{4}\right)$

${ }^{1} \mathbf{H}$ NMR $\left(600 \mathrm{MHz}, \mathrm{CDCl}_{3}\right): \delta 2.75$ (ddd, $\left.J=17.4,6.5,4.7 \mathrm{~Hz}, 1 \mathrm{H}\right), 2.64(\mathrm{dd}, J=18.0,9.0 \mathrm{~Hz}, 1 \mathrm{H}), 2.51$ (ddd, $J=17.4,10.2,6.5 \mathrm{~Hz}, 1 \mathrm{H}), 2.44$ (dd, $J=18.0,6.8 \mathrm{~Hz}, 1 \mathrm{H}), 2.18$ (ddd, $J=8.5,6.7,1.3 \mathrm{~Hz}, 1 \mathrm{H}$ ), $1.63(\mathrm{~s}, 3 \mathrm{H}), 1.56$ (ddd, $J=14.0,10.2,6.5 \mathrm{~Hz}, 1 \mathrm{H}), 1.41$ (dddd, $J=14.0,6.3,4.7,1.4 \mathrm{~Hz}, 1 \mathrm{H}), 1.03$ (s, $3 \mathrm{H}), 0.92(\mathrm{~s}, 9 \mathrm{H}), 0.91(\mathrm{~s}, 3 \mathrm{H}), 0.16(\mathrm{~s}, 6 \mathrm{H})$

${ }^{13} \mathrm{C}$ NMR $\left(151 \mathrm{MHz}, \mathrm{CDCl}_{3}\right): \delta 175.7,160.7,85.5,53.2,32.1,32.0,31.7,28.2,27.2,26.4,26.2,19.2$, $18.3,-5.1,-5.1$

IR $\left(\mathrm{cm}^{-1}\right): 1768,1668,1472,1389,1265,955,834,772,702$

ESI-HRMS (m/z): [M+H] $]^{+}$calc'd for $\mathrm{C}_{17} \mathrm{H}_{32} \mathrm{NO}_{3} \mathrm{Si}^{+}: 326.2146$; found: 326.2153

$[\boldsymbol{\alpha}]_{D}^{20.0}:-37.8^{\circ}\left(c 1.0, \mathrm{CHCl}_{3}\right)$ 


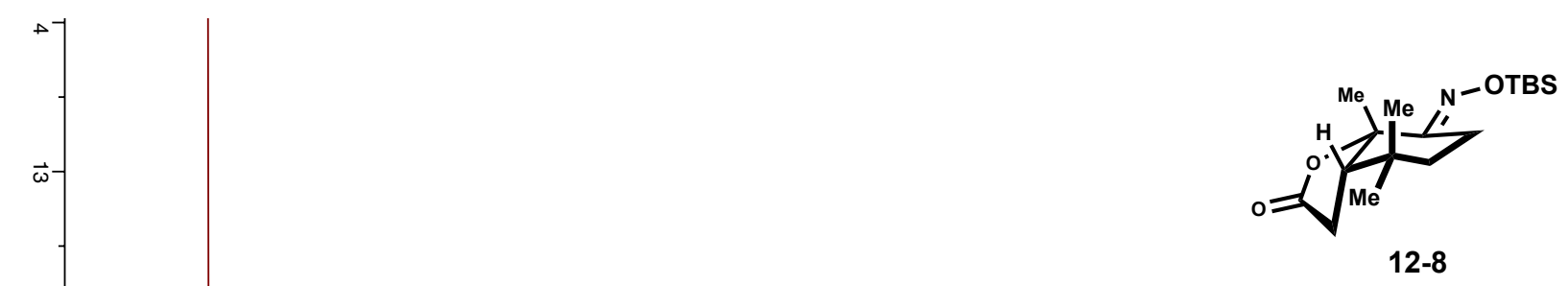

N-

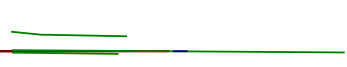
$-1.58$

1.57

1.57

1.56 


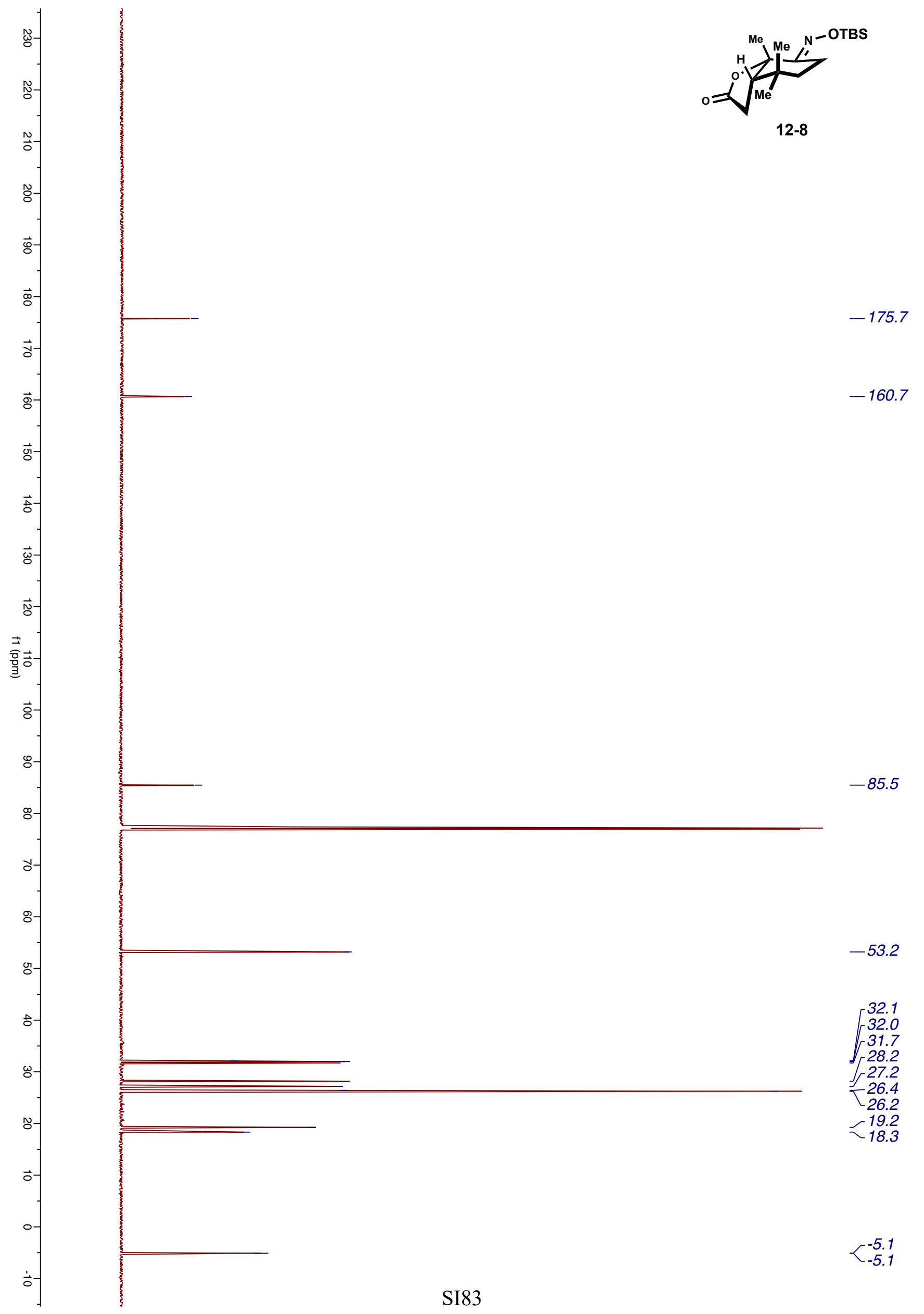


Synthesis of TBS-sulfone (10-6):

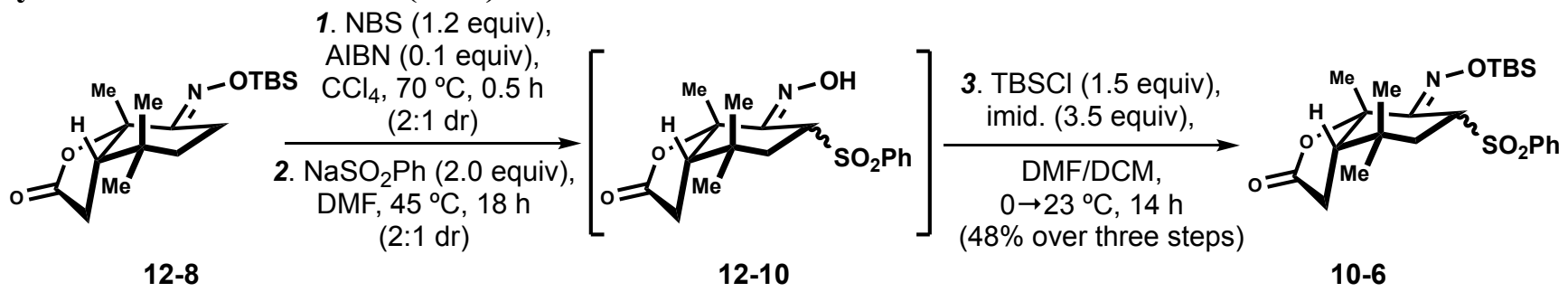

To a flame dried 20-mL microwave vial equipped with a magnetic stir bar was added oxime 12-8 $\left(1.14 \mathrm{~g}, 3.50 \mathrm{mmol}, 1.0\right.$ equiv) and $\mathrm{CCl}_{4}(7.0 \mathrm{~mL}, 0.5 \mathrm{M})$. To the reaction mixture was added $N$ bromosuccinimide (748 mg, $4.2 \mathrm{mmol}, 1.2$ equiv), and AIBN (57.5 mg, $0.350 \mathrm{mmol}, 0.1$ equiv). The microwave vial was sealed with a Teflon microwave cap and the reaction vessel was transferred to an oil bath, which was then heated to $70^{\circ} \mathrm{C}$.

After stirring at $70{ }^{\circ} \mathrm{C}$ for 30 minutes, the reaction vessel was removed from the oil bath and allowed to cool to room temperature. Once at room temperature, the reaction mixture was diluted with $\mathrm{Na}_{2} \mathrm{~S}_{2} \mathrm{O}_{3}(5 \mathrm{~mL})$, and water $(5 \mathrm{~mL})$. The layers were separated and the aqueous layer was extracted with $\mathrm{CH}_{2} \mathrm{Cl}_{2}(3 \times 10 \mathrm{~mL})$. The combined organic extracts were washed with brine $(15 \mathrm{~mL})$, dried over anhydrous $\mathrm{Na}_{2} \mathrm{SO}_{4}$, filtered and concentrated under reduced pressure by rotary evaporation to give the intermediate bromide as a yellow oil and a 2:1 mixture of diastereomers, which was used without further purification $(710 \mathrm{mg}, 54 \%)$.

To a flame-dried 20-mL microwave vial equipped with a magnetic stir bar was added crude bromide (710 mg, $1.88 \mathrm{mmol}, 1.0$ equiv), and benzenesulfinic acid sodium salt (619 mg, $3.77 \mathrm{mmol}, 2.0$ equiv). The microwave vial was sealed with a Teflon microwave cap, and DMF (3.7 mL, 0.5 M) was added to the reaction mixture. The reaction vessel was transferred to a $45^{\circ} \mathrm{C}$ pre-heated oil bath.

After stirring at $45^{\circ} \mathrm{C}$ for 18 hours, the reaction vessel was removed from the oil bath and cooled to room temperature. Once at room temperature, the reaction mixture was diluted with water $(20 \mathrm{~mL})$ and EtOAc $(10 \mathrm{~mL})$. The layers were separated and the aqueous layer was extracted with EtOAc $(3 \times 15 \mathrm{~mL})$. The combined organic extracts were washed with brine $(15 \mathrm{~mL})$, dried over anhydrous $\mathrm{Na}_{2} \mathrm{SO}_{4}$, filtered and concentrated under reduced pressure by rotary evaporation to give 12-10 as a yellow oil and a 2:1 mixture of diastereomers, which was used without further purification.

To a flame-dried 50-mL round-bottomed flask equipped with a magnetic stir bar was added crude oxime 12-10 as a solution in 1:2 DMF: $\mathrm{CH}_{2} \mathrm{Cl}_{2}(1.9 \mathrm{~mL}, 1.0 \mathrm{M})$. The reaction vessel was then moved to an ice-water cooled to $0^{\circ} \mathrm{C}$. To the reaction mixture was added imidazole ( $448 \mathrm{mg}, 6.58 \mathrm{mmol}, 3.5$ equiv) and TBSCl (425 mg, $2.82 \mathrm{mmol}, 1.5$ equiv), and the reaction vessel was removed from the ice-water bath and allowed to warm to room temperature.

After stirring at room temperature for 14 hours, the reaction mixture was diluted with sat. aq. $\mathrm{NaHCO}_{3}(15 \mathrm{~mL})$. The layers were separated and the aqueous layer was extracted with EtOAc $(3$ x 20 $\mathrm{mL})$. The combined organic extracts were washed with brine $(15 \mathrm{~mL})$, dried over anhydrous $\mathrm{Na}_{2} \mathrm{SO}_{4}$, filtered and concentrated under reduced pressure by rotary evaporation to give a yellow oil. Purification by flash column chromatography on silica gel (5\% EtOAc/hexanes to 20\% EtOAc/hexanes) afforded 106 (418 mg, 48\%, 3 steps) as a colorless foam.

\section{Rf: $0.27\left(50 \% \mathrm{Et}_{2} \mathrm{O} /\right.$ hexanes, $\left.\mathrm{KMnO}_{4}\right)$}

${ }^{1} \mathbf{H}$ NMR (600 MHz, $\left.\mathrm{CDCl}_{3}\right)$ : (major diastereomer) $\delta 7.94(\mathrm{~d}, J=7.3 \mathrm{~Hz}, 2 \mathrm{H}), 7.61(\mathrm{t}, J=7.8 \mathrm{~Hz}, 1 \mathrm{H})$, $7.49(\mathrm{t}, J=7.8 \mathrm{~Hz}, 2 \mathrm{H}), 5.22(\mathrm{dd}, J=10.1,8.6 \mathrm{~Hz}, 1 \mathrm{H}), 2.96(\mathrm{dd}, J=18.8,6.7 \mathrm{~Hz}, 1 \mathrm{H}), 2.78(\mathrm{dd}, J=$ $18.8,10.9 \mathrm{~Hz}, 1 \mathrm{H}), 2.47-2.30(\mathrm{~m}, 2 \mathrm{H}), 1.90$ (ddd, $J=14.7,10.2,2.1 \mathrm{~Hz}, 1 \mathrm{H}), 1.62(\mathrm{~s}, 3 \mathrm{H}), 1.02(\mathrm{~s}, 3 \mathrm{H})$, $0.86(\mathrm{~s}, 3 \mathrm{H}), 0.79(\mathrm{~s}, 9 \mathrm{H}),-0.1(\mathrm{~s}, 6 \mathrm{H})$ 
(minor diastereomer) $\delta 7.87(\mathrm{~d}, J=7.3 \mathrm{~Hz}, 2 \mathrm{H}), 7.67(\mathrm{t}, J=7.6 \mathrm{~Hz}, 1 \mathrm{H}), 7.55(\mathrm{t}, J=7.8 \mathrm{~Hz}, 2 \mathrm{H}), 5.28$ (dd, $J=10.2,8.8 \mathrm{~Hz}, 1 \mathrm{H}), 2.83(\mathrm{dd}, J=18.4,9.7 \mathrm{~Hz}, 1 \mathrm{H}), 2.61-2.57(\mathrm{~m}, 1 \mathrm{H}), 2.42-2.37(\mathrm{~m}, 2 \mathrm{H}), 2.00$ (dd, $J=14.3,10.2 \mathrm{~Hz}, 1 \mathrm{H}), 1.62(\mathrm{~s}, 3 \mathrm{H}), 1.02(\mathrm{~s}, 3 \mathrm{H}), 0.86(\mathrm{~s}, 3 \mathrm{H}), 0.81(\mathrm{~s}, 9 \mathrm{H}),-0.13$ (s, 6H)

${ }^{13}$ C NMR $\left(151 \mathrm{MHz}, \mathrm{CDCl}_{3}\right.$ ): (mixture of diastereomers) $\delta 175.3,175.2,152.1,151.7,139.2,138.3$, $134.1,133.8,129.8,129.2,129.1,128.8,85.2,84.2,56.2,55.9,52.1,50.7,35.4,32.6,31.7,31.2,30.3$, $29.5,29.1,29.0,28.6,28.1,27.0,26.2,26.1,25.8,19.8,18.3,18.2,5.2,5.2,5.4,5.5$

IR $\left(\mathrm{cm}^{-1}\right): 1778,1448,1309,1251,1234,1145,1085,947,896,838,687,604$

ESI-HRMS (m/z): [M+H] $]^{+}$calc'd for $\mathrm{C}_{23} \mathrm{H}_{36} \mathrm{NO}_{5} \mathrm{SSi}^{+}: 488.1897$; found: 488.1904

$[\boldsymbol{\alpha}]_{\boldsymbol{D}}^{\mathbf{2 0 . 0}}:-15.6^{\circ}\left(\mathrm{c} 1.0, \mathrm{CHCl}_{3}\right)$ 


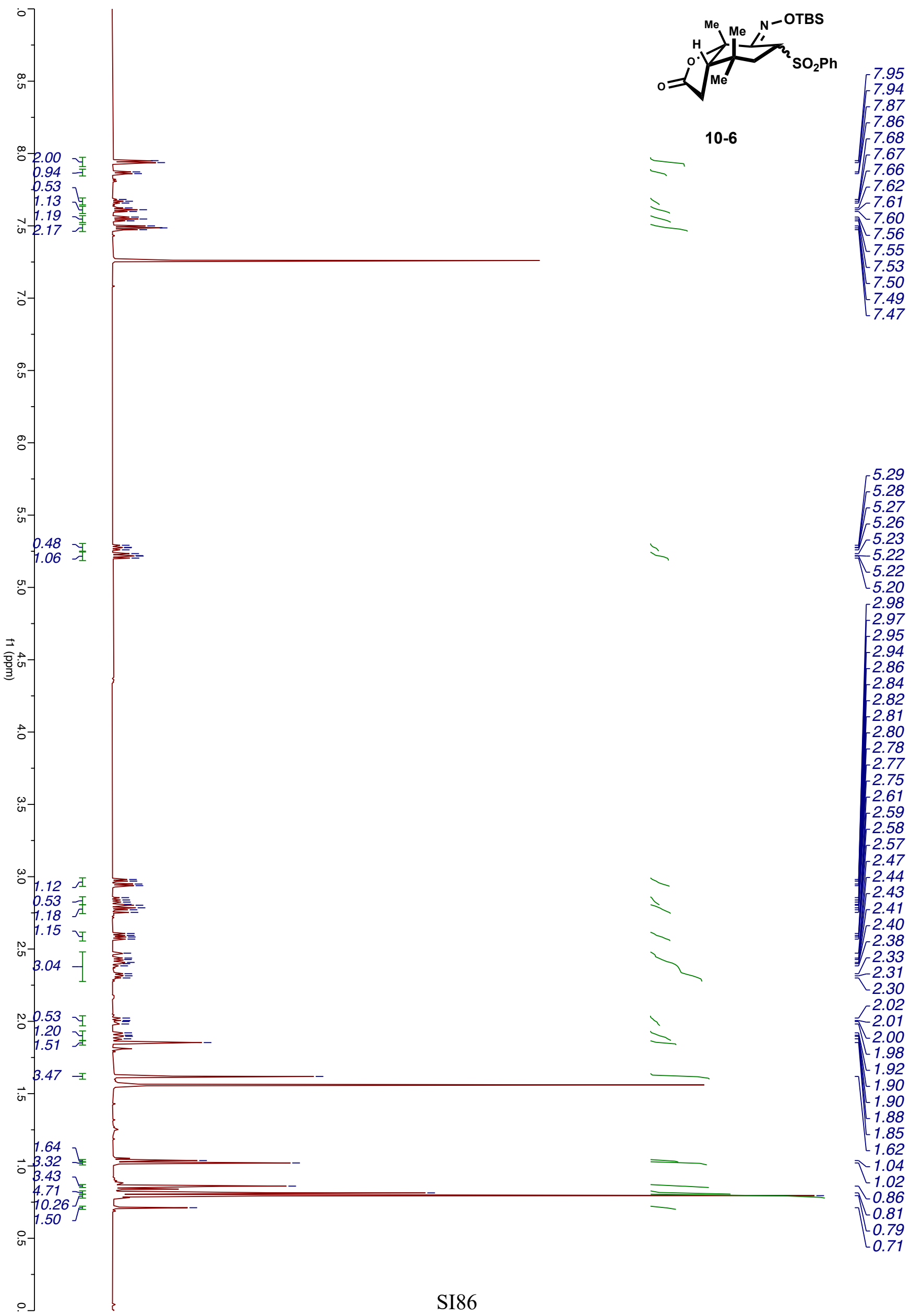




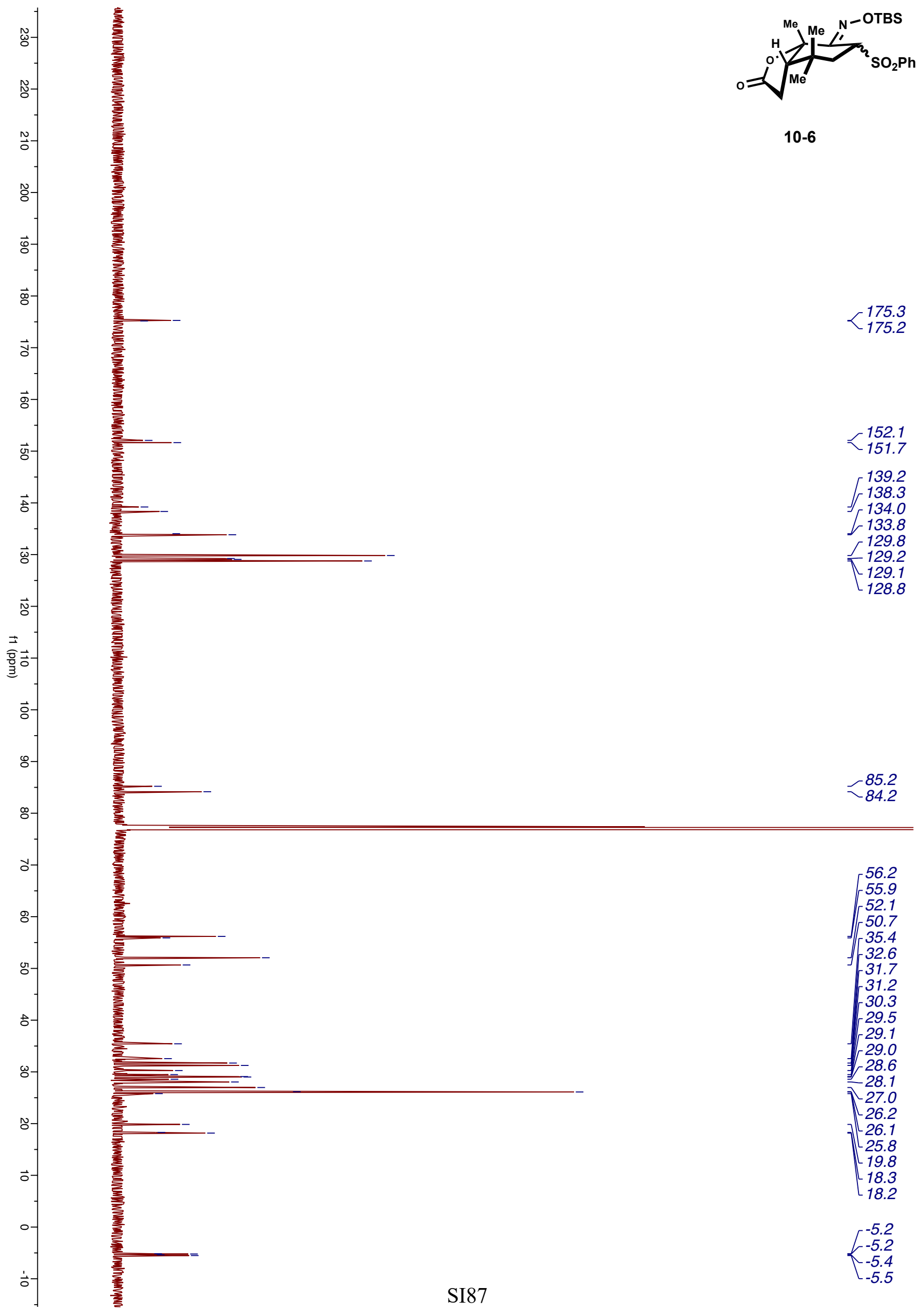


Synthesis of $\alpha, \beta$-unsaturated oxime (12-12):
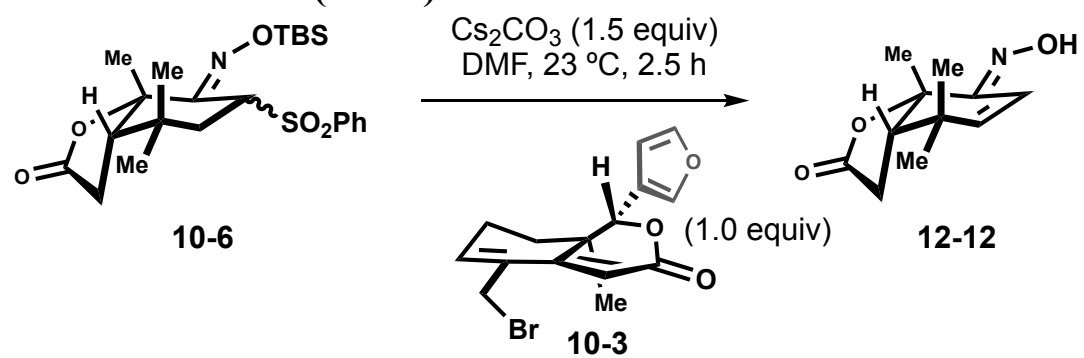

$(79 \%)$

To a flame-dried 5-mL microwave vial equipped with a magnetic stir bar was added sulfone 10-6 (15.1 mg, $0.04 \mathrm{mmol}, 1.0$ equiv), $\mathrm{Cs}_{2} \mathrm{CO}_{3}(19.5 \mathrm{mg}, 0.06 \mathrm{mmol}, 1.5$ equiv) and $\mathrm{DMF}(0.15 \mathrm{~mL}, 0.33 \mathrm{M})$. To the reaction mixture was added a solution of bromide 10-3 (13 mg, $0.04 \mathrm{mmol}, 1.0$ equiv) in DMF (80 $\mu \mathrm{L}, 0.5 \mathrm{M})$ at room temperature. After stirring at room temperature for 2.5 hours, the reaction mixture was diluted with water $(5 \mathrm{~mL})$, and the layers were separated.

The aqueous layer was extracted with EtOAc $(3 \times 5 \mathrm{~mL})$. The combined organic extracts were washed with brine $(5 \mathrm{~mL})$, dried over anhydrous $\mathrm{Na}_{2} \mathrm{SO}_{4}$, filtered and concentrated under reduced pressure by rotary evaporation to give a yellow oil. Purification by flash column chromatography on silica gel (10\% EtOAc/hexanes to 45\% EtOAc/hexanes) afforded 12-12 (6.6 mg, 79\%) as a colorless solid.

R. $0.61\left(65 \%\right.$ EtOAc/hexanes, $\left.\mathrm{KMnO}_{4}\right)$

${ }^{1}$ H NMR (600 MHz, $\left.\mathrm{CDCl}_{3}\right): \delta 7.93$ (brs, $\left.1 \mathrm{H}\right), 6.77$ (dd, $\left.J=10.3,1.6 \mathrm{~Hz}, 1 \mathrm{H}\right), 5.97(\mathrm{~d}, J=10.3 \mathrm{~Hz}, 1 \mathrm{H})$, 2.56-2.40 (m, 3H), $1.77(\mathrm{~s}, 3 \mathrm{H}), 1.23(\mathrm{~s}, 3 \mathrm{H}), 1.09(\mathrm{~s}, 3 \mathrm{H})$

${ }^{13}$ C NMR (151 MHz, $\left.\mathrm{CDCl}_{3}\right): \delta 174.4,152.4,144.4,113.8,110.2,83.5,52.6,35.1,33.7,30.0,27.9$

IR $\left(\mathrm{cm}^{-1}\right): 3234,1780,1378,1250,1088,952$

ESI-HRMS (m/z): [M+H $]^{+}$calc'd for $\mathrm{C}_{11} \mathrm{H}_{16} \mathrm{NO}_{3}{ }^{+}: 210.1125$; found: 210.1127

$[\boldsymbol{\alpha}]_{D}^{20.0}:-59.2^{\circ}\left(c 0.72, \mathrm{CHCl}_{3}\right)$ 


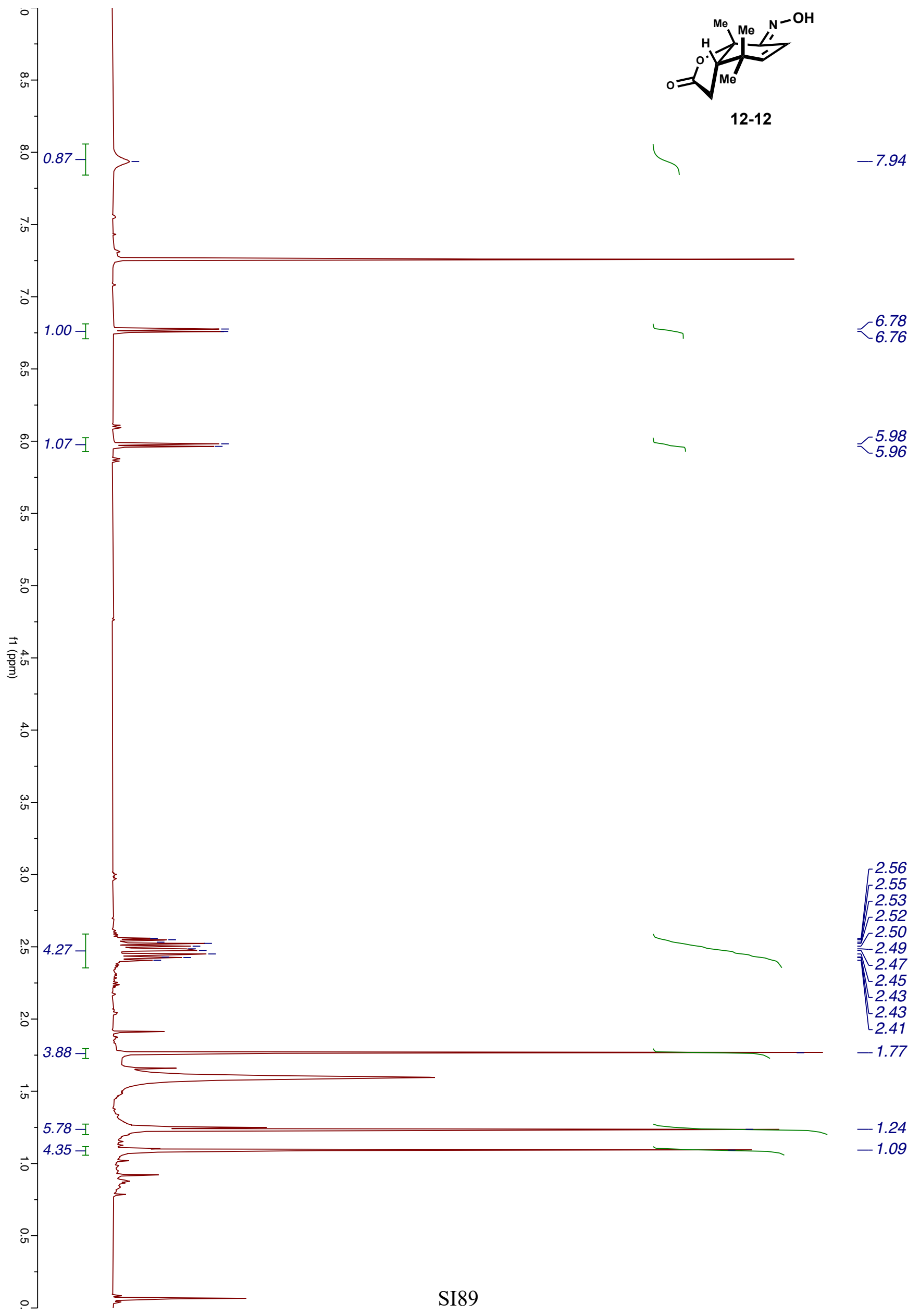




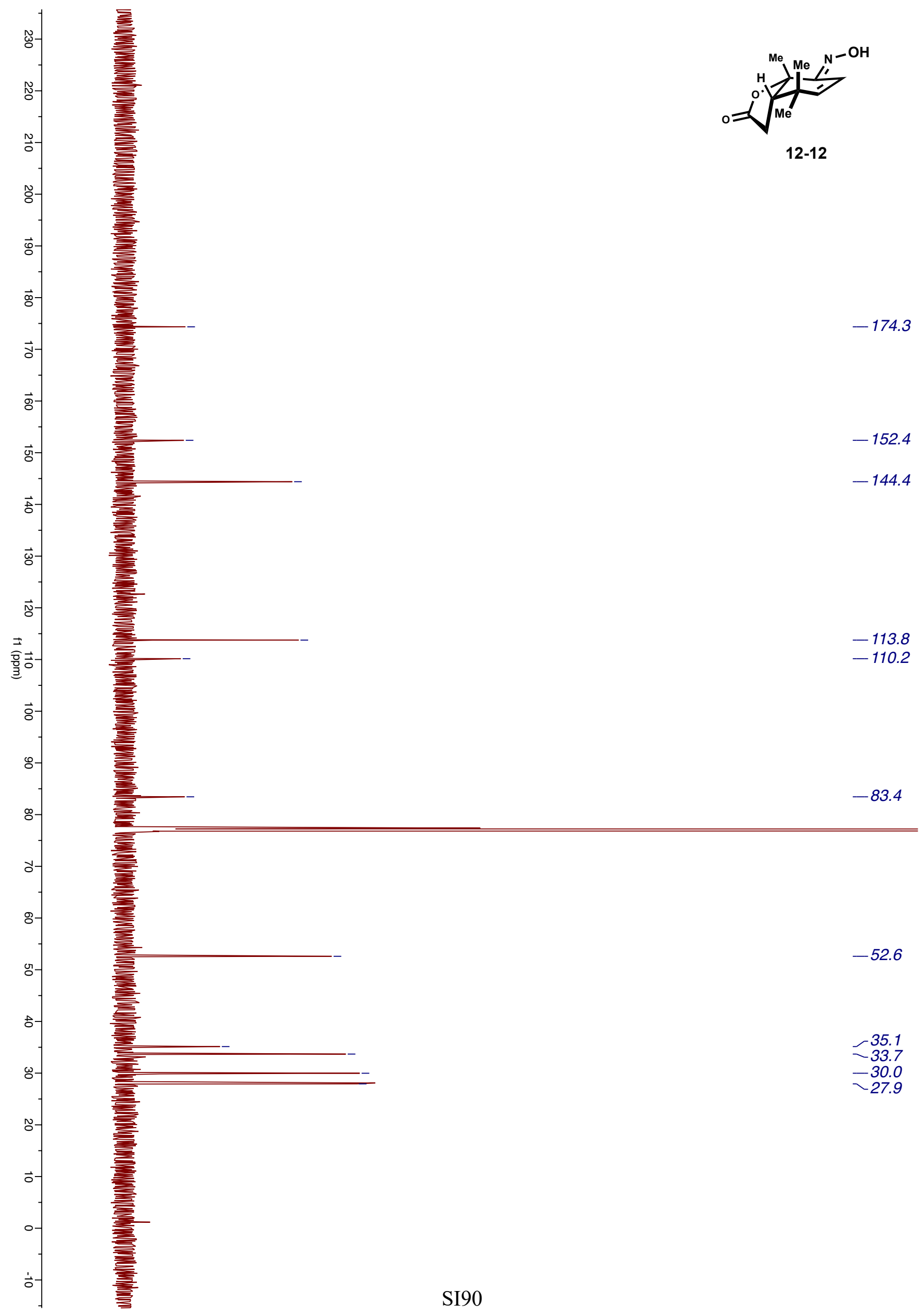




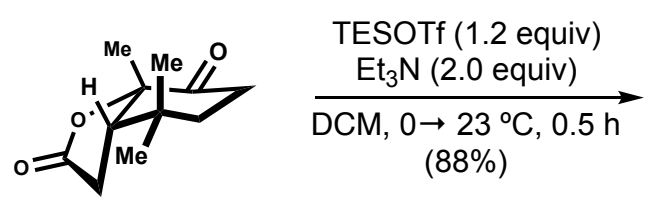

11-5

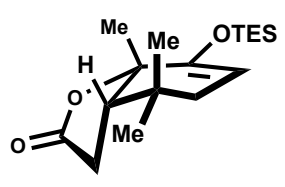

$10-8$

To a flame-dried 20 -mL microwave vial equipped with a magnetic stir bar was added ketone 115 (500.0 mg, $2.54 \mathrm{mmol}, 1.0$ equiv) and $\mathrm{CH}_{2} \mathrm{Cl}_{2}(8.5 \mathrm{~mL}, 0.3 \mathrm{M})$. The reaction vessel was then transferred to a $0{ }^{\circ} \mathrm{C}$ ice-water bath, and $\mathrm{Et}_{3} \mathrm{~N}(0.71 \mathrm{~mL}, 5.1 \mathrm{mmol}, 2.0$ equiv) was added. Following this, TESOTf $\left(690 \mu \mathrm{L}, 3.05 \mathrm{mmol}, 1.2\right.$ equiv) was added dropwise over one minute. After stirring at $0{ }^{\circ} \mathrm{C}$ for 15 minutes, the reaction vessel was removed from the ice-water bath and allowed to warm to room temperature.

After stirring at room temperature for 30 minutes, sat. aq. $\mathrm{NaHCO}_{3}(25 \mathrm{~mL})$ was added to the reaction mixture. The layers were separated and the aqueous layer was extracted with $\mathrm{CH}_{2} \mathrm{Cl}_{2}(3 \times 25$ $\mathrm{mL})$. The combined organic extracts were washed with brine $(30 \mathrm{~mL})$, dried over anhydrous $\mathrm{Na}_{2} \mathrm{SO}_{4}$, filtered and concentrated under reduced pressure by rotary evaporation to give a yellow oil. Purification by flash column chromatography on silica gel $\left(5 \% \mathrm{Et}_{2} \mathrm{O} /\right.$ hexanes to $15 \% \mathrm{Et}_{2} \mathrm{O} /$ hexanes) afforded 10-8 $(694 \mathrm{mg}, 88 \%)$ as a colorless oil.

Rf: $0.22\left(10 \% \mathrm{Et}_{2} \mathrm{O} /\right.$ hexanes, $\left._{\mathrm{KMnO}}\right)$

${ }^{1} \mathbf{H}$ NMR $\left(600 \mathrm{MHz}, \mathrm{CDCl}_{3}\right): \delta 4.83(\mathrm{dd}, J=5.2,3.3 \mathrm{~Hz}, 1 \mathrm{H}), 2.56(\mathrm{dd}, J=17.5,8.8 \mathrm{~Hz}, 1 \mathrm{H}), 2.41(\mathrm{dd}$, $J=17.6,9.7 \mathrm{~Hz}, 1 \mathrm{H}), 2.21$ (ddd, $J=9.7,8.7,0.9 \mathrm{~Hz}, 1 \mathrm{H}), 2.09$ (dd, $J=17.2,3.3 \mathrm{~Hz}, 1 \mathrm{H}), 1.85$ (ddd, $J$ $=17.3,5.3,1.0 \mathrm{~Hz}, 1 \mathrm{H}), 1.56(\mathrm{~s}, 3 \mathrm{H}), 1.05(\mathrm{~s}, 3 \mathrm{H}), 0.98(\mathrm{t}, J=7.9 \mathrm{~Hz}, 9 \mathrm{H}), 0.92(\mathrm{~s}, 3 \mathrm{H}), 0.69(\mathrm{qd}, J=$ $7.9,1.5 \mathrm{~Hz}, 6 \mathrm{H})$

${ }^{13} \mathrm{C}$ NMR (151 MHz, $\left.\mathrm{CDCl}_{3}\right): \delta 175.8,148.6,103.8,85.2,52.0,34.8,32.5,32.1,28.4,27.4,24.7,6.9$, 5.1

IR $\left(\mathrm{cm}^{-1}\right): 1775,1665,1458,1376,1236,121,1084,985,892,826,731$

ESI-HRMS (m/z): $[\mathrm{M}+\mathrm{H}]^{+}$calc'd for $\mathrm{C}_{17} \mathrm{H}_{31} \mathrm{O}_{3} \mathrm{Si}^{+}: 311.2037$; found: 311.2039

$$
[\boldsymbol{\alpha}]_{\boldsymbol{D}}^{\mathbf{2 0 . 0}}:-17.6^{\circ}\left(\mathrm{c} 1.0, \mathrm{CHCl}_{3}\right)
$$




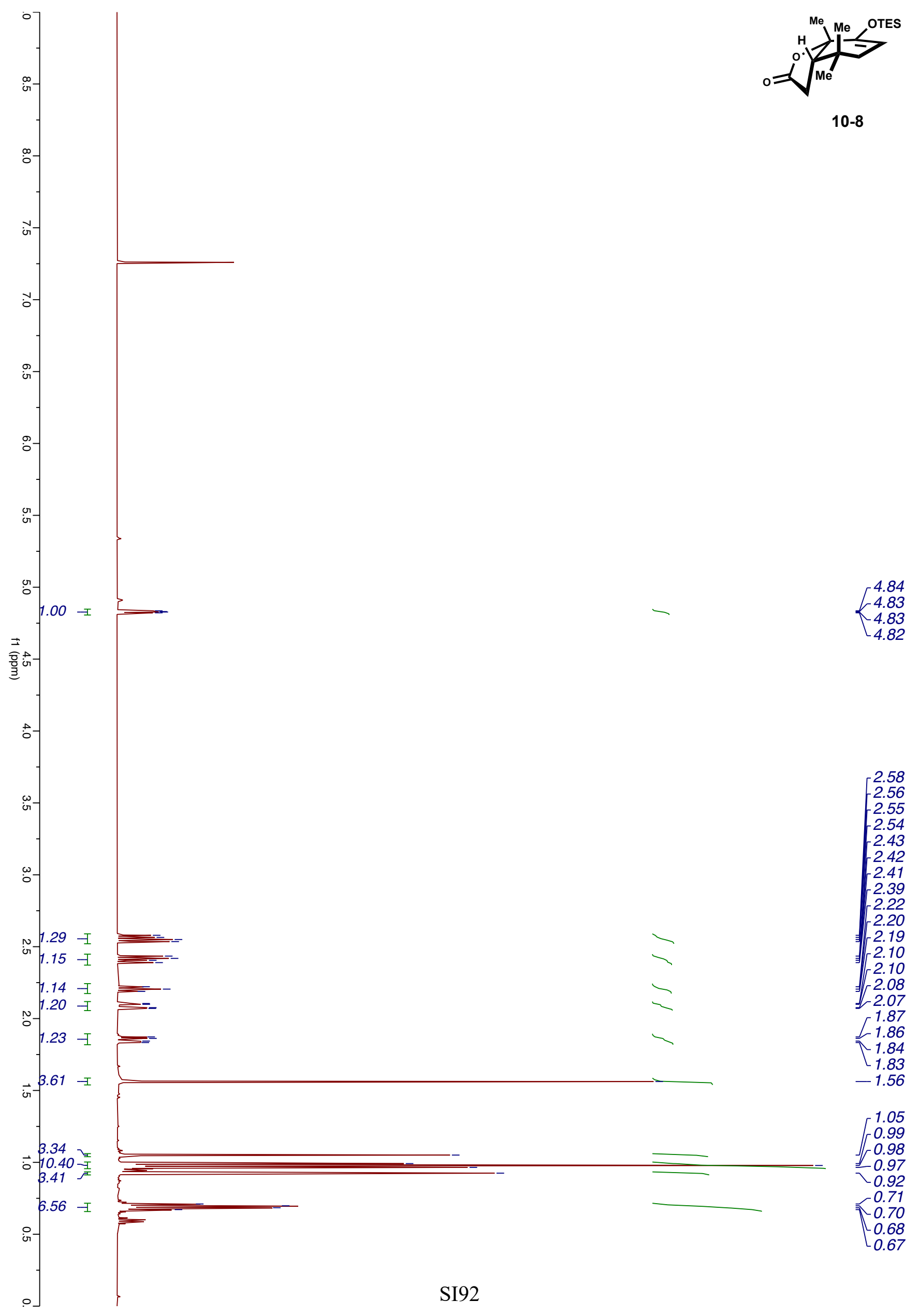




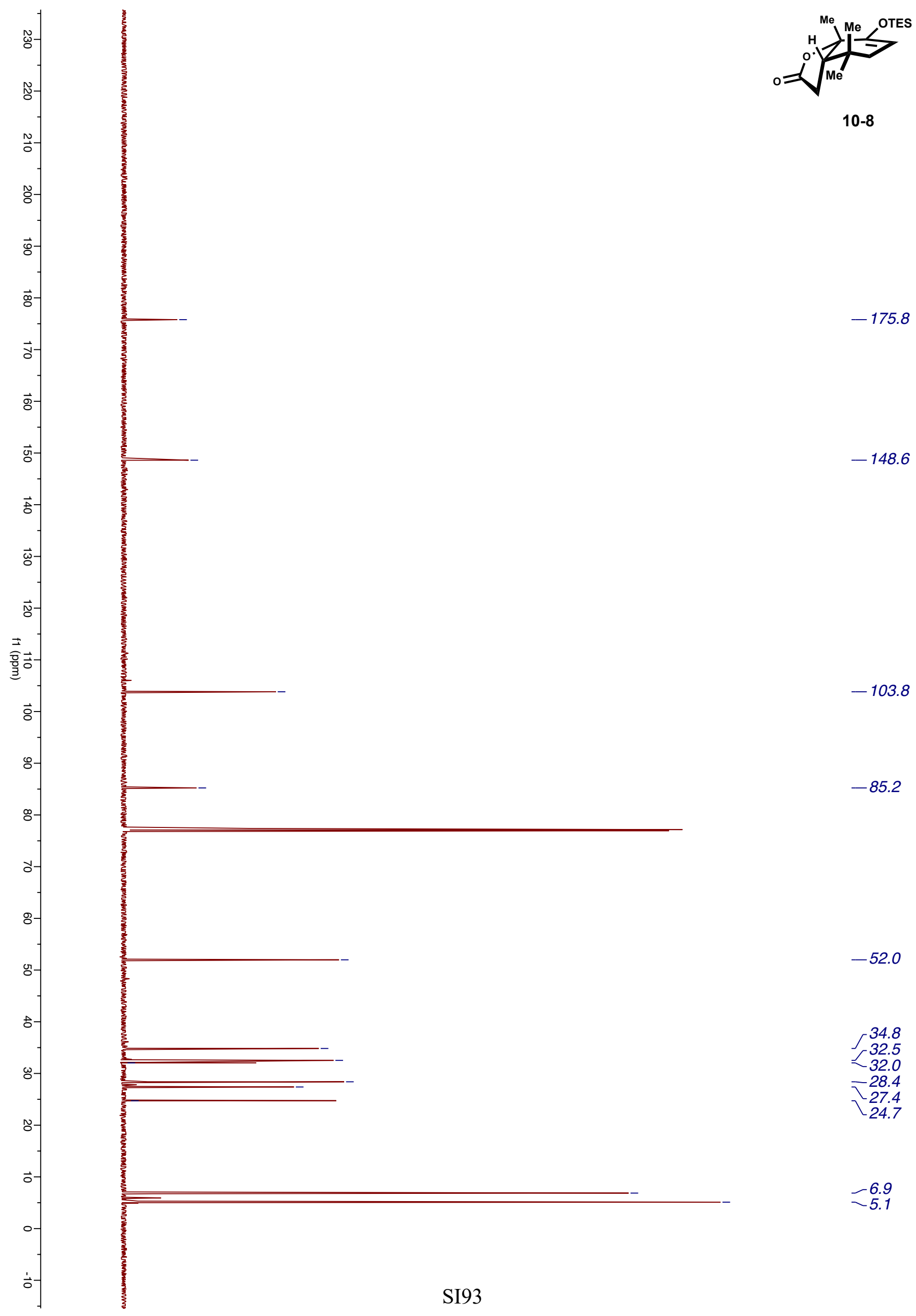


Synthesis of Mukaiyama aldol coupling product (13-1):

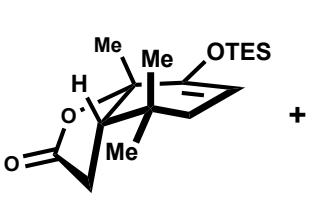

10-8

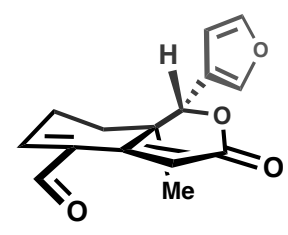

10-7

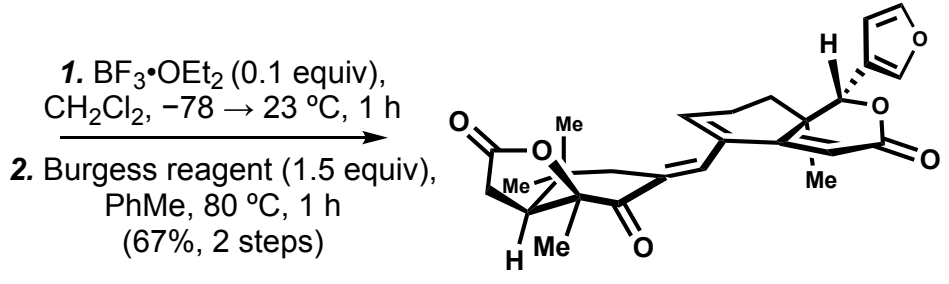

13-1

To a flame-dried $10-\mathrm{mL}$ microwave vial equipped with a magnetic stir bar was added aldehyde 10-7 ( $84 \mathrm{mg}, 0.32 \mathrm{mmol}, 1.0$ equiv). To the reaction vial was added a solution of enoxysilane 10-8 (100.0 $\mathrm{mg}, 0.32 \mathrm{mmol}, 1.0$ equiv) in $\mathrm{CH}_{2} \mathrm{Cl}_{2}(0.75 \mathrm{~mL}, 0.5 \mathrm{M})$. The reaction vial was then transferred to a saturated dry-ice acetone bath cooled to $-78^{\circ} \mathrm{C}$. After stirring at $-78{ }^{\circ} \mathrm{C}$ for 5 minutes, $\mathrm{BF}_{3} \cdot \mathrm{OEt}_{2}(5.0 \mu \mathrm{L}$, $0.032 \mathrm{mmol}, 0.1$ equiv) was added, which resulted in an orange reaction mixture. Once the reaction mixture had stirred at $-78^{\circ} \mathrm{C}$ for an additional 30 minutes, the dry-ice acetone bath was removed and the reaction mixture was allowed to gradually warm to room temperature.

After stirring at room temperature for 30 minutes, sat. aq. $\mathrm{NaHCO}_{3}(2 \mathrm{~mL})$ and water $(5 \mathrm{~mL})$ were added to the reaction mixture. The layers were separated and the aqueous layer was extracted with $\mathrm{CH}_{2} \mathrm{Cl}_{2}$ $(3 \times 5 \mathrm{~mL})$. The combined organic extracts were washed with brine $(5 \mathrm{~mL})$, dried over anhydrous $\mathrm{Na}_{2} \mathrm{SO}_{4}$, filtered and concentrated under reduced pressure by rotary evaporation to give a crude yellow oil.

To a flame-dried $10-\mathrm{mL}$ microwave vial equipped with a magnetic stir bar was added Burgess reagent (115 mg, $0.483 \mathrm{mmol}, 1.5$ equiv), and a solution of crude aldol intermediate in PhMe (1.5 mL, $0.25 \mathrm{M})$. The reaction vessel was sealed with a Teflon-coated silicon microwave and then transferred to an $80^{\circ} \mathrm{C}$ preheated oil bath.

After stirring at $80^{\circ} \mathrm{C}$ for 1 hour, the reaction vessel was removed from the oil bath and allowed to cool to room temperature. Once at room temperature, the reaction mixture was diluted with water $(5$ $\mathrm{mL})$ and EtOAc $(5 \mathrm{~mL})$. The layers were separated and the aqueous layer was extracted with EtOAc $(3 \mathrm{x}$ $5 \mathrm{~mL})$. The combined organic extracts were washed with brine $(30 \mathrm{~mL})$, dried over anhydrous $\mathrm{Na}_{2} \mathrm{SO}_{4}$, filtered and concentrated under reduced pressure by rotary evaporation to give a yellow oil. Purification by flash column chromatography on silica gel $\left(50 \% \mathrm{Et}_{2} \mathrm{O} /\right.$ hexanes to $\left.\mathrm{Et}_{2} \mathrm{O}\right)$ afforded 13-1 $(93.2 \mathrm{mg}, 67 \%$ over 2 steps) as a colorless oil.

\section{Rf: $0.23(65 \%$ EtOAc/hexanes, $p$-anisaldehyde $)$}

${ }^{1} \mathbf{H}$ NMR $\left(400 \mathrm{MHz}, \mathrm{CDCl}_{3}\right): \delta 7.50(\mathrm{~s}, 1 \mathrm{H}), 7.44(\mathrm{t}, J=1.6 \mathrm{~Hz}, 1 \mathrm{H}), 7.35(\mathrm{~s}, 1 \mathrm{H}), 6.46(\mathrm{~d}, J=1.2 \mathrm{~Hz}$, $1 \mathrm{H}), 6.25-6.24(\mathrm{~m}, 1 \mathrm{H}), 5.79(\mathrm{~s}, 1 \mathrm{H}), 5.16(\mathrm{~s}, 1 \mathrm{H}), 2.84(\mathrm{dd}, J=18.5,10.0 \mathrm{~Hz}, 1 \mathrm{H}), 2.57-2.34(\mathrm{~m}, 6 \mathrm{H})$, $1.59-1.53(\mathrm{~m}, 2 \mathrm{H}), 1.56(\mathrm{~s}, 3 \mathrm{H}), 1.08(\mathrm{~s}, 3 \mathrm{H}), 1.02(\mathrm{~s}, 3 \mathrm{H}), 0.84$ (s, 3H)

${ }^{13} \mathrm{C}$ NMR (101 MHz, $\left.\mathrm{CDCl}_{3}\right): \delta 195.3,174.5,165.2,157.2,143.3,141.3,139.8,136.2,134.3,130.0$, $120.0,112.6,110.1,85.6,80.7,51.8,39.7,37.3,32.1,30.9,29.5,28.9,26.4,22.7,22.4,16.2$

IR $\left(\mathrm{cm}^{-1}\right): 1779,1714,1462,1295,1266,1166,1054,702,613,572$

ESI-HRMS (m/z): $[\mathrm{M}+\mathrm{H}]^{+}$calc'd for $\mathrm{C}_{26} \mathrm{H}_{29} \mathrm{O}_{6}{ }^{+}: 437.1959$; found: 437.1958

$$
[\boldsymbol{\alpha}]_{\boldsymbol{D}}^{\mathbf{2 0 . 0}}:+104.2^{\circ}\left(c 1.0, \mathrm{CHCl}_{3}\right)
$$




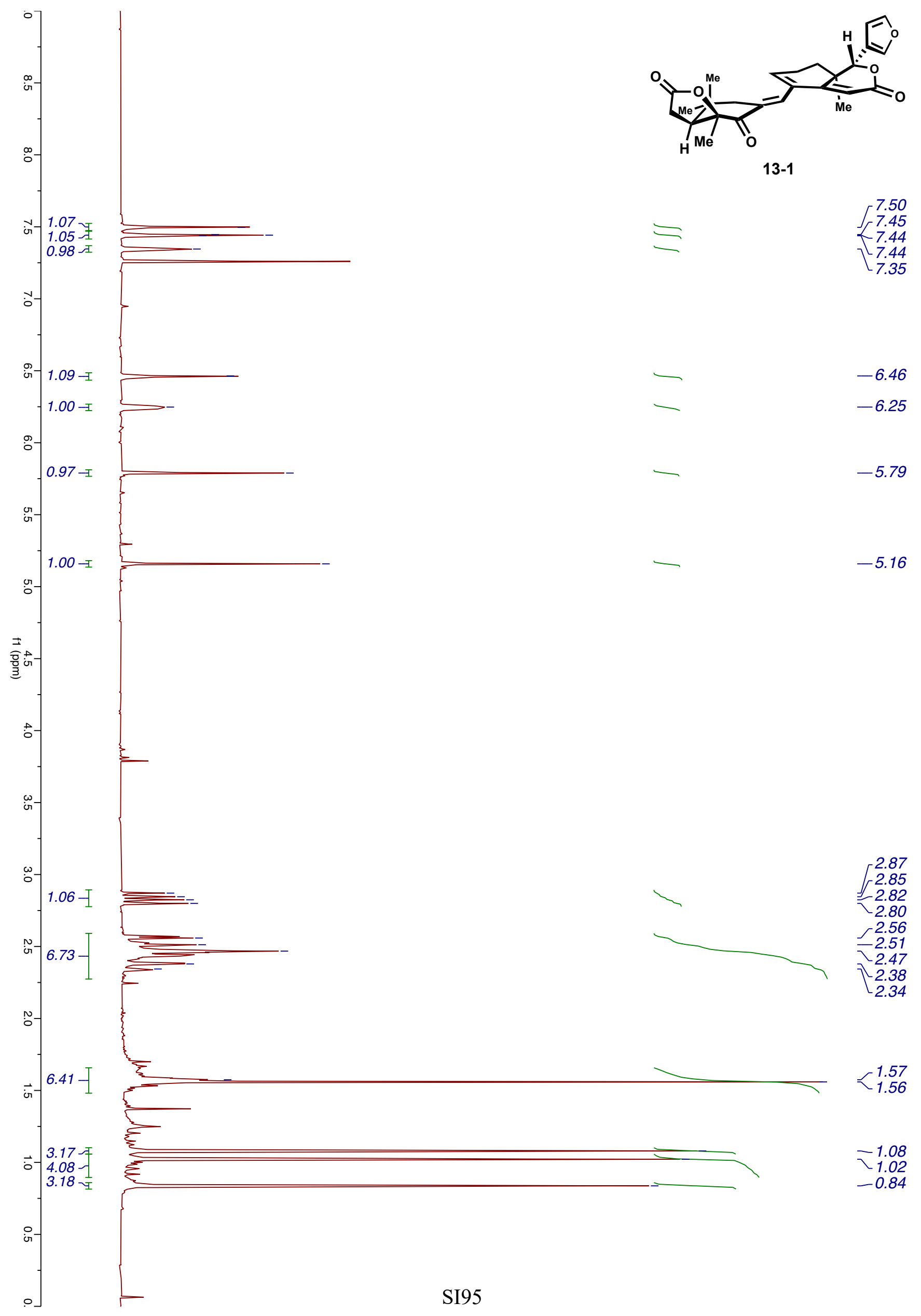




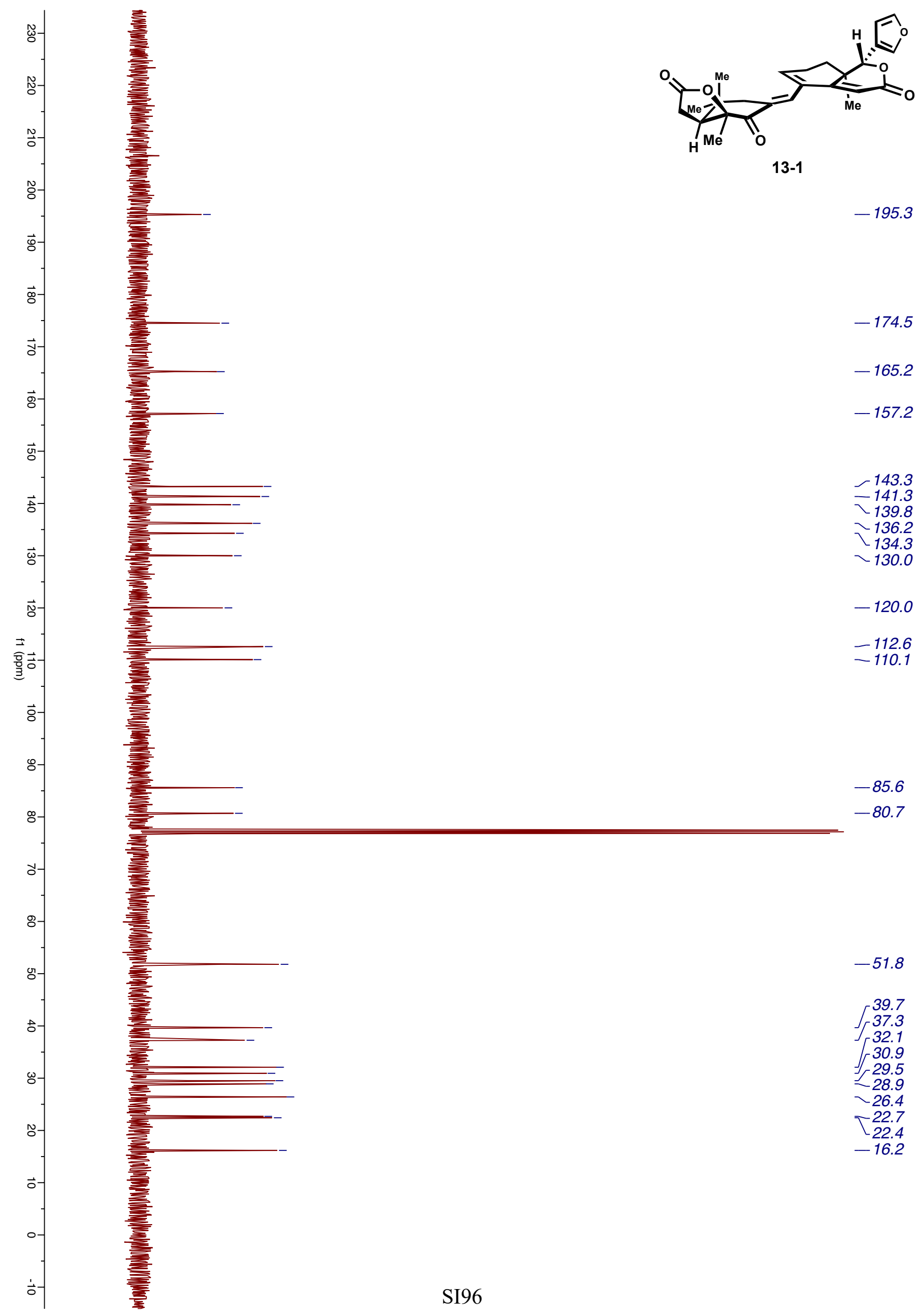




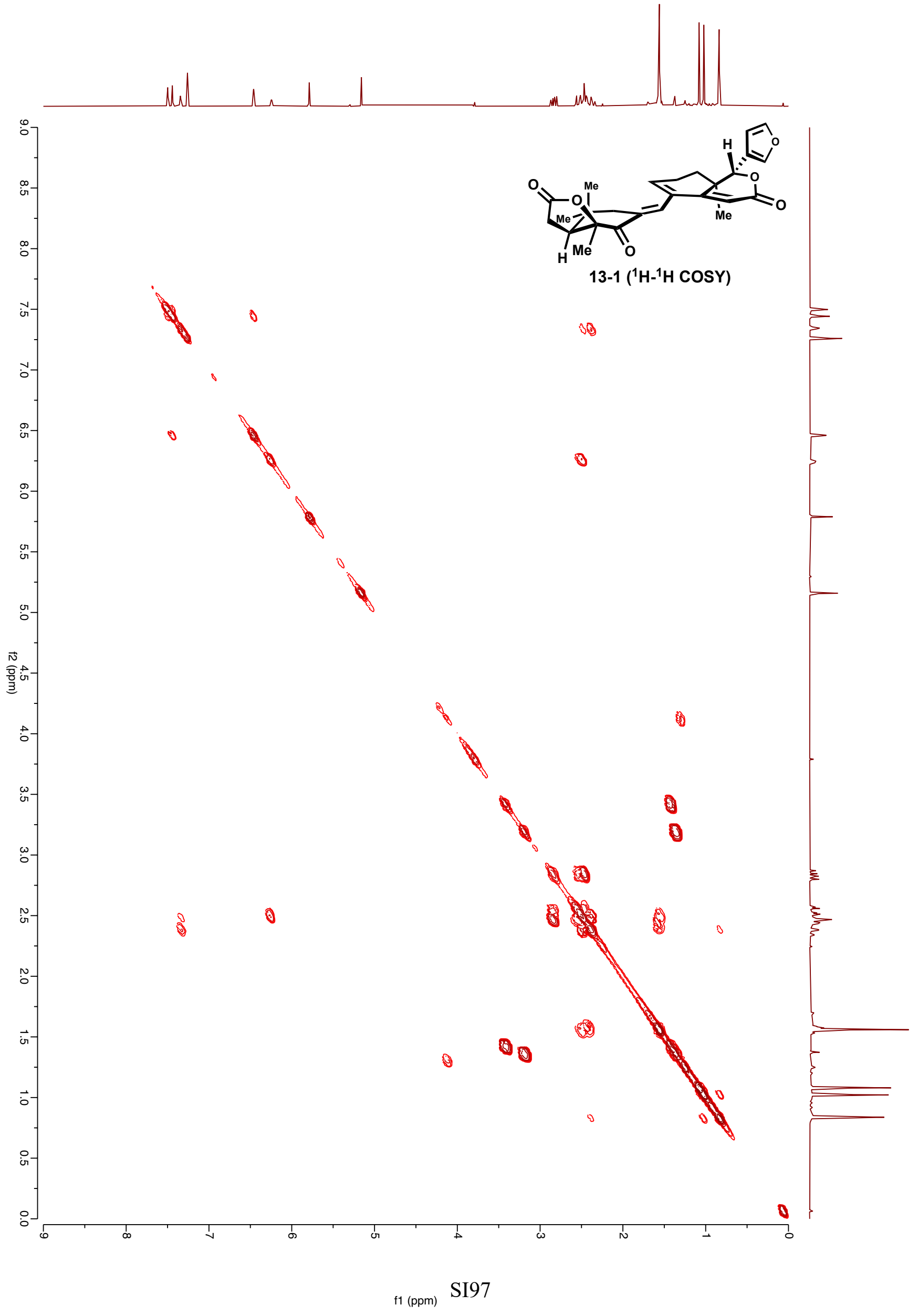




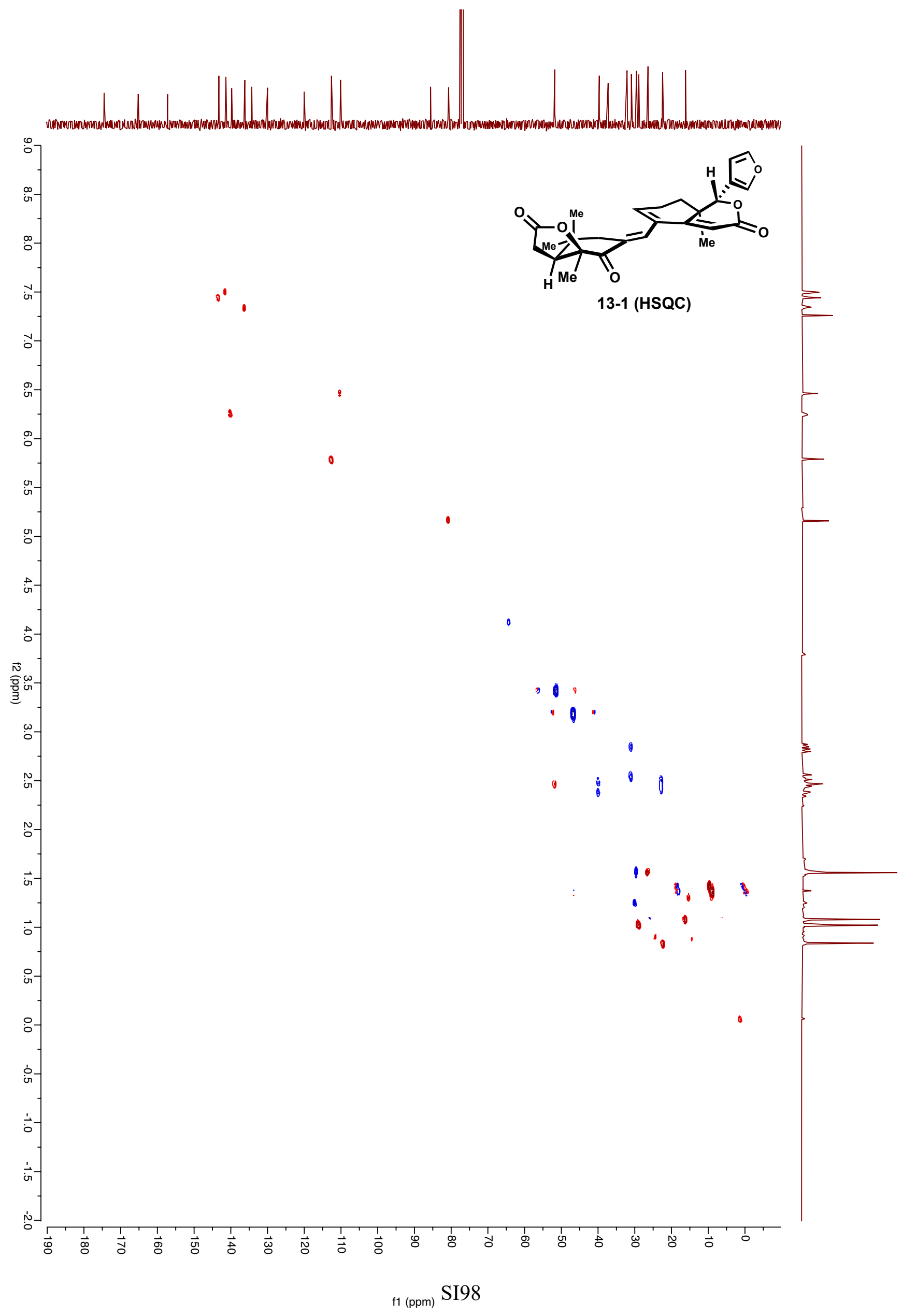




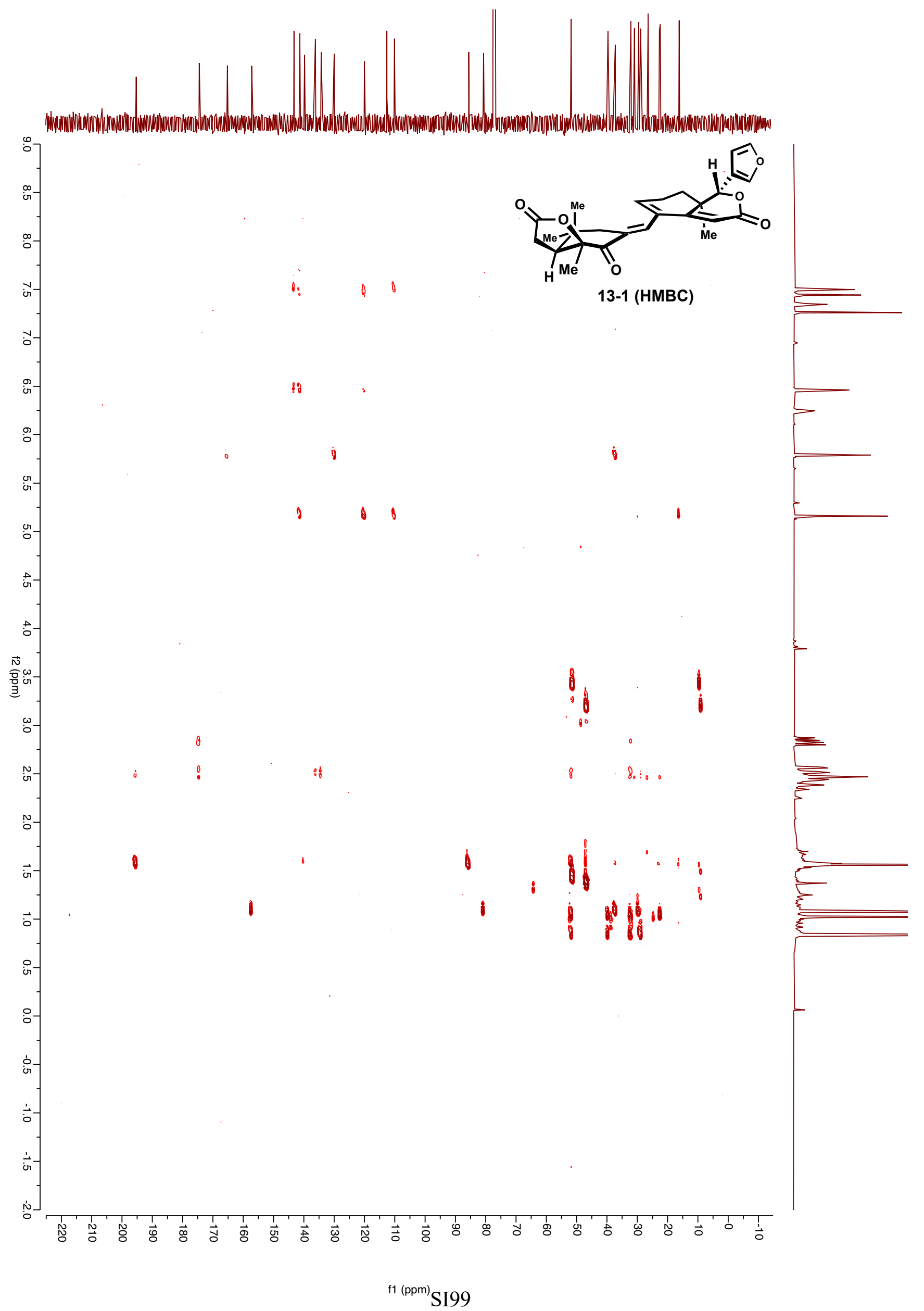




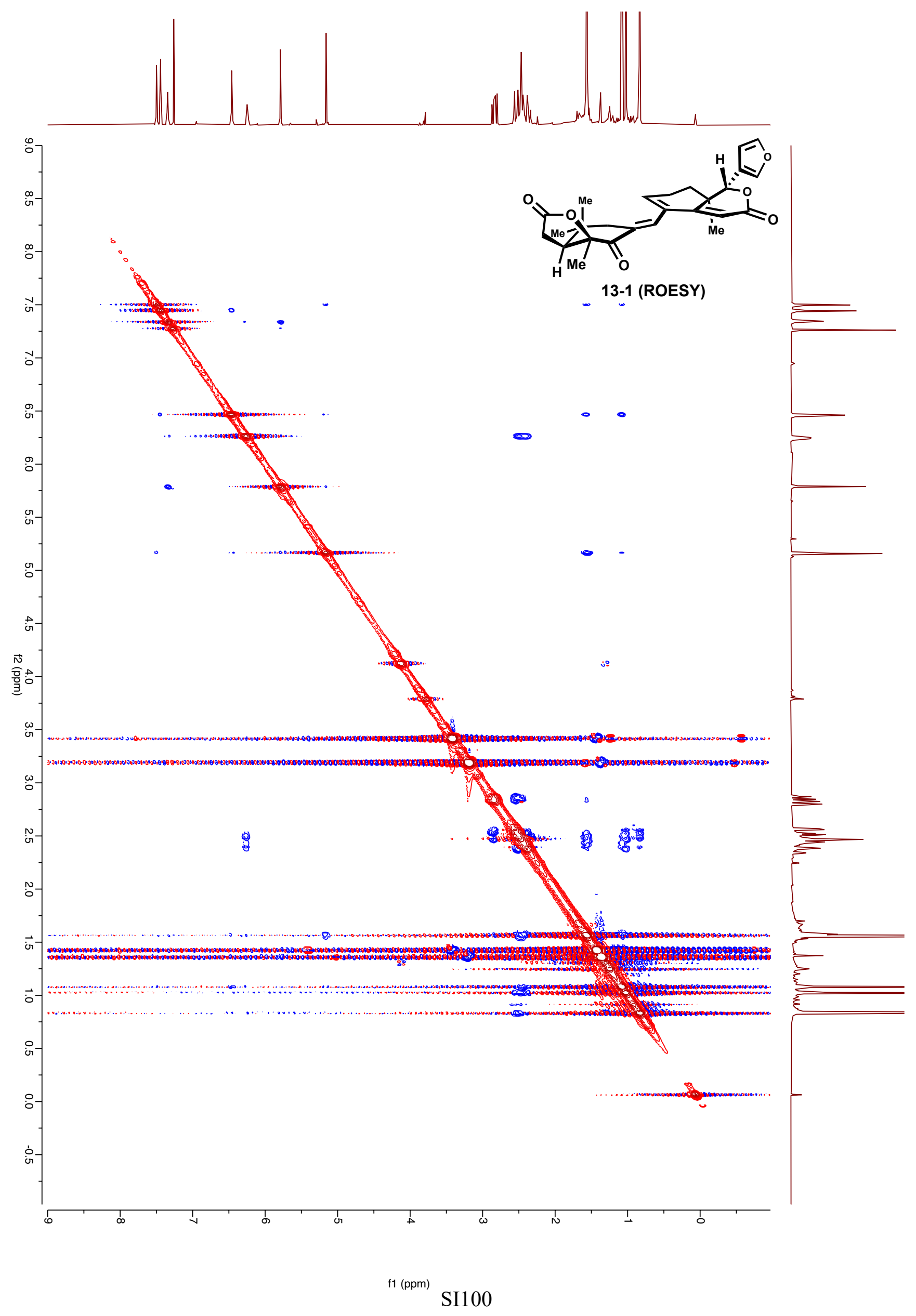


Synthesis of C3-deoxy-xylogranatin F (10-1):

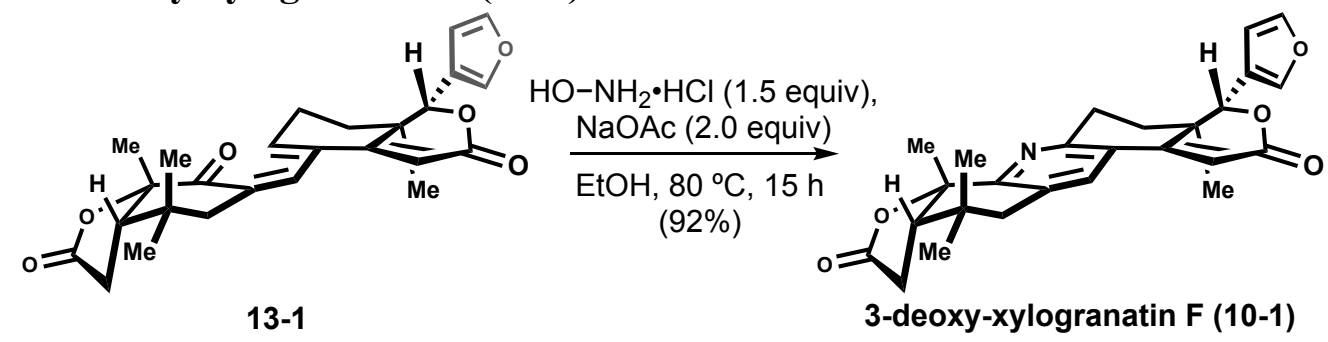

To a flame-dried 5-mL microwave vial equipped with a magnetic stir bar was added hydroxylamine hydrochloride $(3.6 \mathrm{mg}, 0.052 \mathrm{mmol}, 1.5$ equiv) and sodium acetate $(5.6 \mathrm{mg}, 0.068 \mathrm{mmol}$, 2.0 equiv). The reaction vessel was sealed with a Teflon-coated silicon microwave cap, and a solution of ketone 13-1 (15.0 mg, $0.034 \mathrm{mmol}, 1.0$ equiv) in ethanol $(0.34 \mathrm{~mL}, 0.1 \mathrm{M})$ was added to the reaction mixture. The reaction vessel was then transferred to an $80^{\circ} \mathrm{C}$ preheated oil bath.

After stirring at $80^{\circ} \mathrm{C}$ for 15 hours, the reaction vessel was removed from the oil bath and allowed to cool to room temperature. Once at room temperature, the reaction mixture was diluted with water (5 $\mathrm{mL})$ and EtOAc $(5 \mathrm{~mL})$. The layers were separated, and the aqueous layer was extracted with EtOAc (3 x $5 \mathrm{~mL}$ ). The combined organic extracts were washed with brine $(5 \mathrm{~mL})$, dried over anhydrous $\mathrm{Na}_{2} \mathrm{SO}_{4}$, filtered and concentrated under reduced pressure by rotary evaporation to give a yellow solid. Trituration of the yellow solid with $\mathrm{Et}_{2} \mathrm{O}(5 \mathrm{~mL})$ cooled to $0{ }^{\circ} \mathrm{C}$, resulted in the formation of a white solid, which was filtered and dried under vacuum to reveal 10-1 (13.6 $\mathrm{mg}, 92 \%)$ as a colorless solid.

$\mathbf{R}_{\mathbf{f}}: 0.26\left(85 \% \mathrm{Et}_{2} \mathrm{O} /\right.$ hexanes, $p$-anisaldehyde)

${ }^{1} \mathrm{H}$ NMR $\left(600 \mathrm{MHz}, \mathrm{CDCl}_{3}\right): \delta 7.77(\mathrm{~s}, 1 \mathrm{H}), 7.54(\mathrm{~s}, 1 \mathrm{H}), 7.47(\mathrm{~s}, 1 \mathrm{H}), 6.51(\mathrm{~s}, 1 \mathrm{H}), 6.50(\mathrm{~s}, 1 \mathrm{H}), 5.21(\mathrm{~s}$, 1H), 3.16 (dd, $J=17.7,4.7 \mathrm{~Hz}, 1 \mathrm{H}$ ), 3.06 (ddd, $J=18.3,13.0,5.4 \mathrm{~Hz}, 1 \mathrm{H}), 2.87$ (dd, $J=18.0,9.1 \mathrm{~Hz}$, $1 \mathrm{H}), 2.73(\mathrm{~d}, J=16.2 \mathrm{~Hz}, 1 \mathrm{H}), 2.65(\mathrm{~d}, J=16.1 \mathrm{~Hz}, 1 \mathrm{H}), 2.55(\mathrm{dd}, J=17.9,5.6 \mathrm{~Hz}, 1 \mathrm{H}), 2.49$ (dd, $J=$ 9.1, 5.6 Hz, 1H), 1.85 (ddd, $J=13.2,5.6,2.0 \mathrm{~Hz}, 1 \mathrm{H}), 1.83$ (s, $3 \mathrm{H}), 1.73$ (atd, $J=13.2,5.7 \mathrm{~Hz}, 1 \mathrm{H}$ ), $1.13(\mathrm{~s}, 3 \mathrm{H}), 1.12(\mathrm{~s}, 3 \mathrm{H}), 0.91(\mathrm{~s}, 3 \mathrm{H})$

${ }^{13} \mathrm{C}$ NMR $\left(151 \mathrm{MHz}, \mathrm{CDCl}_{3}\right): \delta 175.0,165.3,157.4,156.8,156.6,143.4,141.5,134.2,128.5,124.1$, 120.0, 111.0, 110.2, 84.7, 81.0, 51.4, 41.0, 37.8, 32.2, 32.0, 30.5, 30.1, 28.8, 28.4, 27.9, 23.8, 15.9

IR $\left(\mathrm{cm}^{-1}\right): 1770,1716,1441,1261,1238,1024,939,875,693$

ESI-HRMS (m/z): [M+H] $]^{+}$calc'd for $\mathrm{C}_{26} \mathrm{H}_{28} \mathrm{NO}_{5}{ }^{+}$: 434.1962; found: 434.1965

$[\boldsymbol{\alpha}]_{\boldsymbol{D}}^{\mathbf{2 0 . 0}}:+117.4^{\circ}\left(c 0.4, \mathrm{CHCl}_{3}\right)$ 


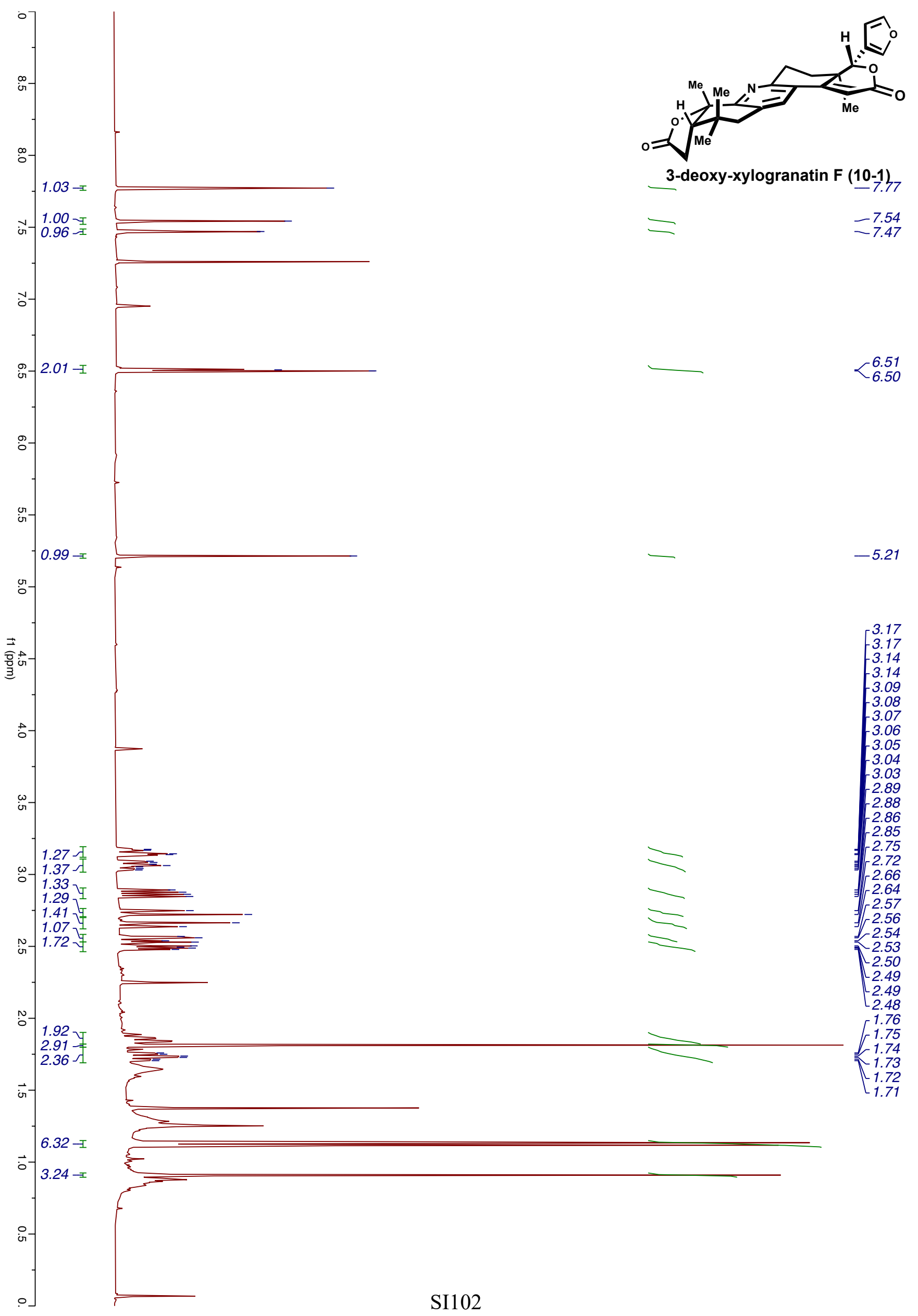




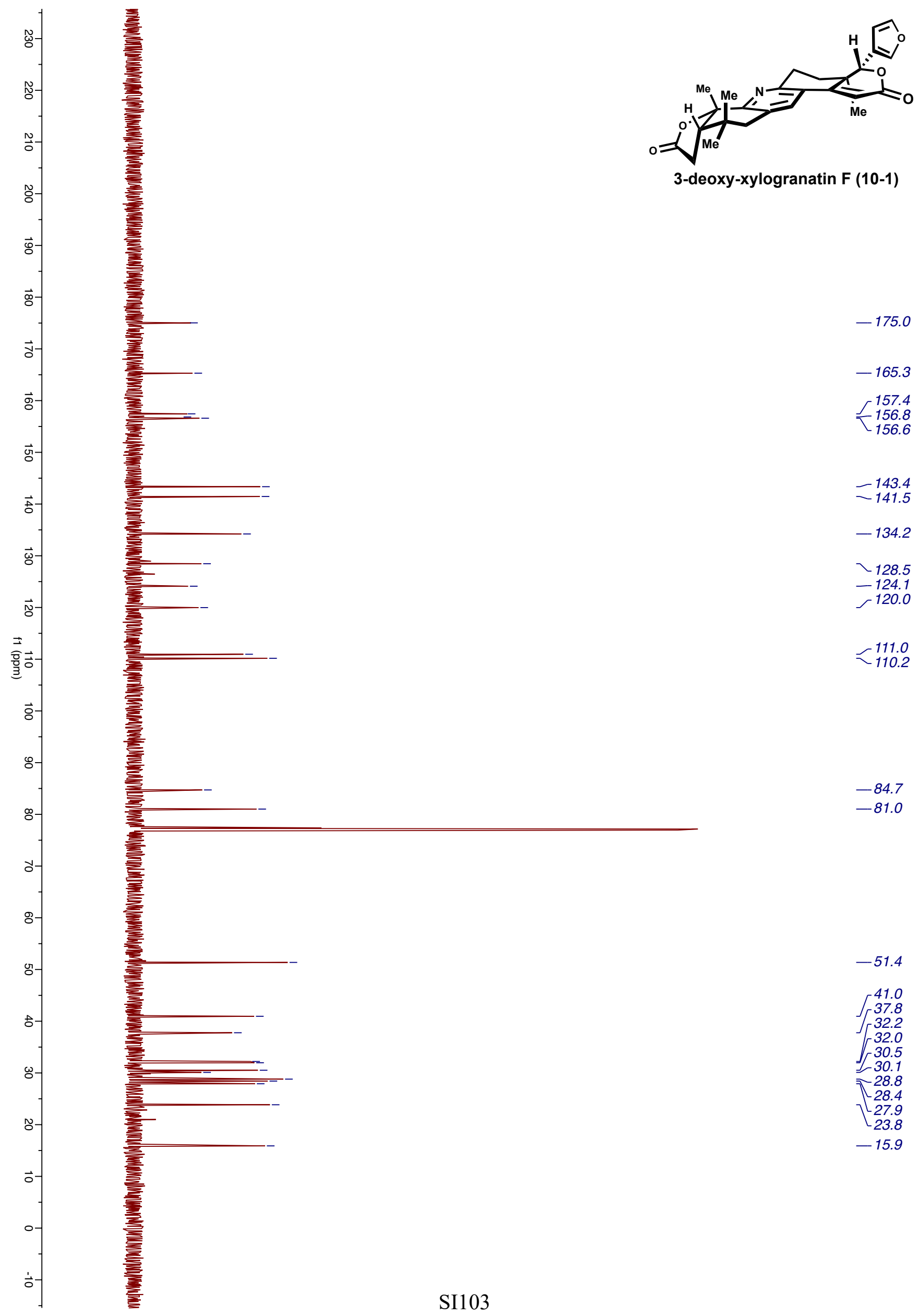




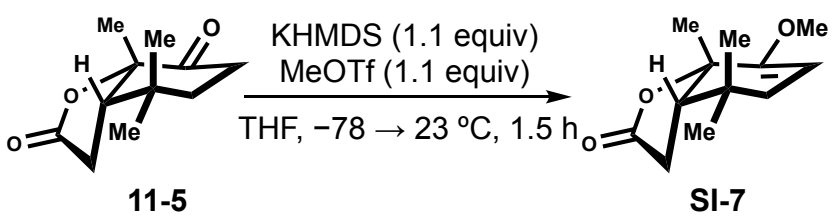

An evacuated flame-dried 100-mL round-bottomed flask equipped with a magnetic stir bar and a Schlenk adapter was brought into a glovebox. Once in the glovebox, the flask was filled with a nitrogen atmosphere. Solid KHMDS (2.79 g, $14.0 \mathrm{mmol}, 1.1$ equiv) was added and the flask was sealed. The flask was removed from the glovebox, and the flask was evacuated and backfilled with nitrogen three times using a dual manifold Schlenk line. The Schlenk adapter was replaced with a rubber septum and the flask was placed under a nitrogen atmosphere.

To this flask was added THF $(28 \mathrm{~mL}, 0.5 \mathrm{M})$ via cannula, and this mixture was allowed to stir at room temperature for 10 minutes to allow for complete dissolution of KHMDS solid. The reaction vessel was transferred to a $-78{ }^{\circ} \mathrm{C}$ saturated dry-ice acetone bath and stirred for 10 minutes before a solution of ketone 11-5 (2.5 g, $12.7 \mathrm{mmol}, 1.0$ equiv) in THF (13.0 mL, $1.0 \mathrm{M})$ was added over 5 minutes. After stirring at this temperature for 30 minutes, methyl trifluoromethanesulfonate $(1.5 \mathrm{~mL}, 14.0 \mathrm{mmol}, 1.1$ equiv) was added dropwise over two minutes. The reaction mixture was allowed to stir at this temperature for 15 minutes before the reaction vessel was removed from dry-ice acetone bath, and the reaction mixture was allowed to slowly warm up to room temperature over 1.5 hours.

The reaction mixture was then diluted with sat. aq. $\mathrm{NH}_{4} \mathrm{Cl}(30 \mathrm{~mL})$, and the layers were separated. The aqueous layer was extracted with EtOAc $(3 \times 25 \mathrm{~mL})$. The combined organic extracts were washed with brine $(50 \mathrm{~mL})$, dried over anhydrous $\mathrm{Na}_{2} \mathrm{SO}_{4}$, filtered, and concentrated under reduced pressure by rotary evaporation to provide SI-7 as a colorless solid. The compound was used without further purification. An analytically pure sample could be obtained through purification by flash column chromatography on silica gel (10\% EtOAc/hexanes to $25 \%$ EtOAc/hexanes).

\section{$\mathbf{R}_{\mathbf{f}}: 0.65\left(50 \%\right.$ EtOAc/hexanes, $\left.\mathrm{KMnO}_{4}\right)$}

${ }^{1}$ H NMR (500 MHz, $\left.\mathrm{CDCl}_{3}\right): \delta 4.65(\mathrm{dd}, J=5.2,3.3 \mathrm{~Hz}, 1 \mathrm{H}), 3.55(\mathrm{~s}, 3 \mathrm{H}), 2.57(\mathrm{dd}, J=17.5,8.8 \mathrm{~Hz}$, $1 \mathrm{H}), 2.42(\mathrm{dd}, J=17.5,9.6 \mathrm{~Hz}, 1 \mathrm{H}), 2.21(\mathrm{t}, J=9.2 \mathrm{~Hz}, 1 \mathrm{H}), 2.13$ (dd, $J=17.1,3.3 \mathrm{~Hz}, 1 \mathrm{H}), 1.91$ (dd, $J=17.1,5.2 \mathrm{~Hz}, 1 \mathrm{H}), 1.59(\mathrm{~s}, 3 \mathrm{H}), 1.04(\mathrm{~s}, 3 \mathrm{H}), 0.93(\mathrm{~s}, 3 \mathrm{H})$

${ }^{13} \mathrm{C}$ NMR $\left(126 \mathrm{MHz}, \mathrm{CDCl}_{3}\right): \delta 175.5,153.2,94.5,84.4,54.9,52.2,34.4,32.3,32.0,28.3,27.3,25.1$

IR $\left(\mathrm{cm}^{-1}\right): 1764,1668,1454,1370,1283,1233,1203,1164,1049,952,805,682$

ESI-HRMS (m/z): $[\mathrm{M}+\mathrm{H}]^{+}$calc' $d$ for $\mathrm{C}_{12} \mathrm{H}_{19} \mathrm{O}_{3}{ }^{+}: 211.1329$; found: 211.1330

$[\alpha]_{D}^{20.0}:-26.9^{\circ}\left(c 0.5, \mathrm{CHCl}_{3}\right)$ 


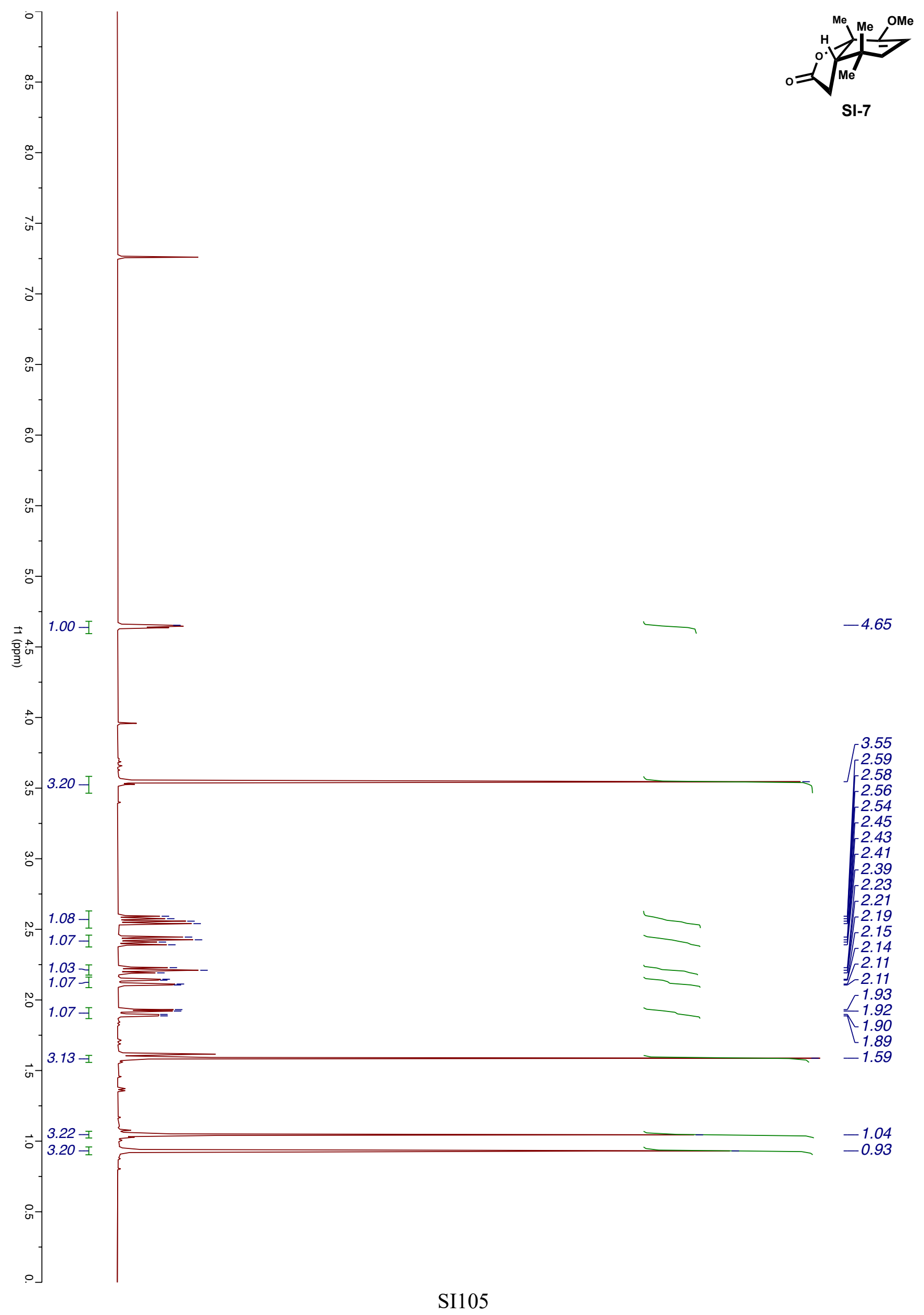




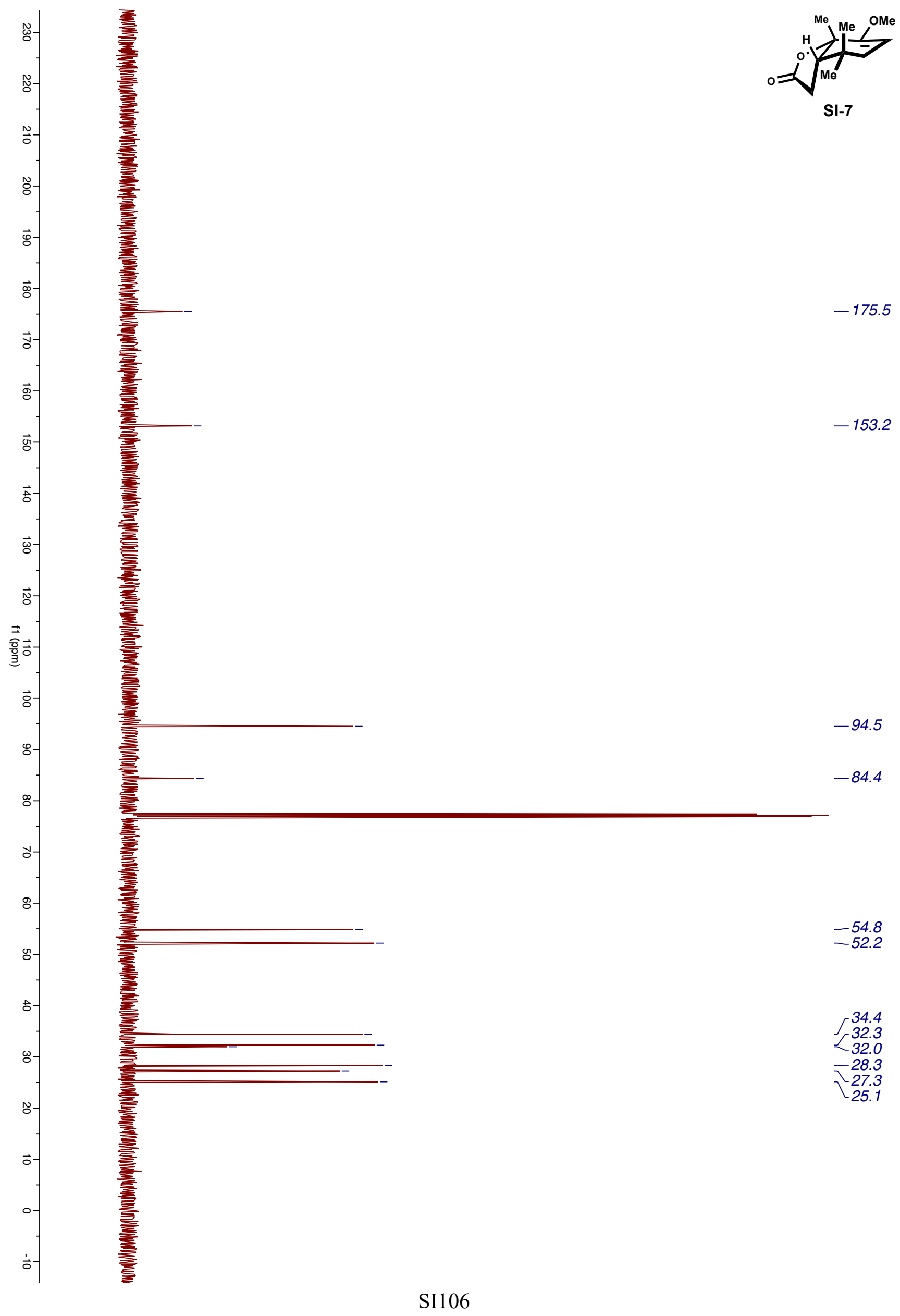




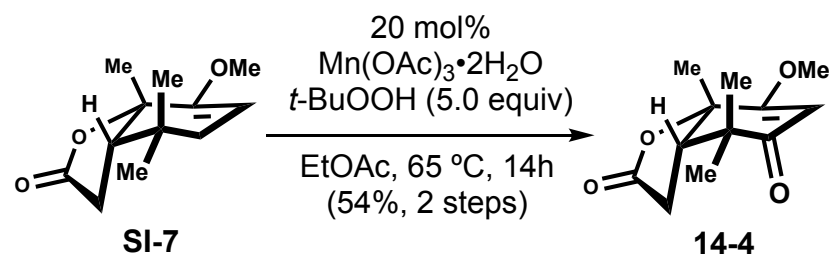

To a flame-dried 250-mL Teflon-sealed Schlenk flask equipped with a magnetic stir bar was added crude methy enol ether SI-7 as a solution in EtOAc $(64 \mathrm{~mL}, 0.2 \mathrm{M})$. To the reaction mixture was added $\mathrm{Mn}(\mathrm{OAc})_{3} \cdot 2 \mathrm{H}_{2} \mathrm{O}(681 \mathrm{mg}, 2.54 \mathrm{mmol}, 0.2$ equiv) and anhydrous TBHP $(12.7 \mathrm{~mL}, 63.5 \mathrm{mmol}, 5.0$ equiv, $5.5 \mathrm{M}$ in decane) at room temperature. The reaction vessel was then sealed, placed in a room temperature sonication bath for 5 minutes. Following this, the reaction flask was transferred to a $65{ }^{\circ} \mathrm{C}$ preheated oil bath.

After stirring at $65{ }^{\circ} \mathrm{C}$ for 14 hours, the reaction vessel was removed from the oil bath and cooled to room temperature. The reaction mixture was diluted with water $(150 \mathrm{~mL})$ and the layers were separated. The aqueous layer was extracted with EtOAc $(3 \times 50 \mathrm{~mL})$. The combined organic extracts were washed with brine $(150 \mathrm{~mL})$, dried over anhydrous $\mathrm{Na}_{2} \mathrm{SO}_{4}$, filtered, and concentrated under reduced pressure by rotary evaporation to provide a crude brown oil. Purification by flash column chromatography on silica gel (10\% EtOAc/hexanes to 35\% EtOAc/hexanes) afforded 14-4 (1.54 g, 54\% over 2 steps) as a colorless foam.

$\mathbf{R}_{\mathbf{f}}: 0.6\left(65 \% \mathrm{EtOAc} /\right.$ hexanes, $\left.\mathrm{KMnO}_{4}\right)$

${ }^{1} \mathbf{H}$ NMR $\left(600 \mathrm{MHz}_{\mathrm{CDCl}}\right): \delta 5.36(\mathrm{~s}, 1 \mathrm{H}), 3.76(\mathrm{~s}, 3 \mathrm{H}), 2.69-2.61(\mathrm{~m}, 2 \mathrm{H}), 2.35(\mathrm{dd}, J=16.3,10.5 \mathrm{~Hz}$, $1 \mathrm{H}), 1.79(\mathrm{~s}, 3 \mathrm{H}), 1.27(\mathrm{~s}, 3 \mathrm{H}), 1.14(\mathrm{~s}, 3 \mathrm{H})$

${ }^{13}$ C NMR (126 MHz, $\left.\mathrm{CDCl}_{3}\right): \delta 201.1,173.6,169.7,100.9,83.1,56.6,52.4,44.2,34.0,28.0,25.1,23.4$

IR $\left(\mathrm{cm}^{-1}\right): 1779,1666,1616,1362,1237,1191,1089,952,850$

ESI-HRMS (m/z): [M+H] $]^{+}$calc'd for $\mathrm{C}_{12} \mathrm{H}_{17} \mathrm{O}_{4}{ }^{+}: 225.1121$; found: 225.1129

$[\alpha]_{D}^{20.0}:-85.2^{\circ}\left(c 1.0, \mathrm{CHCl}_{3}\right)$ 


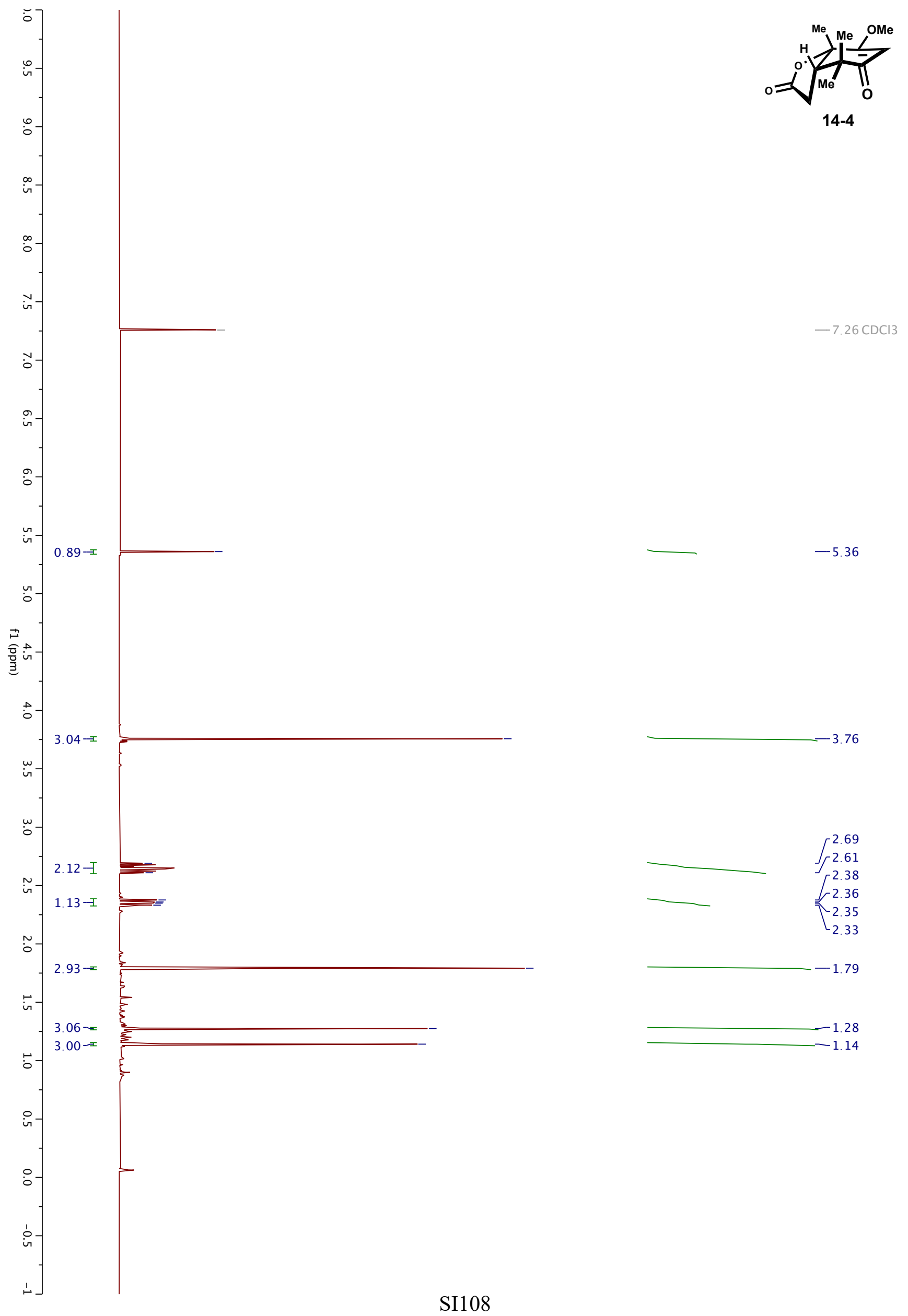




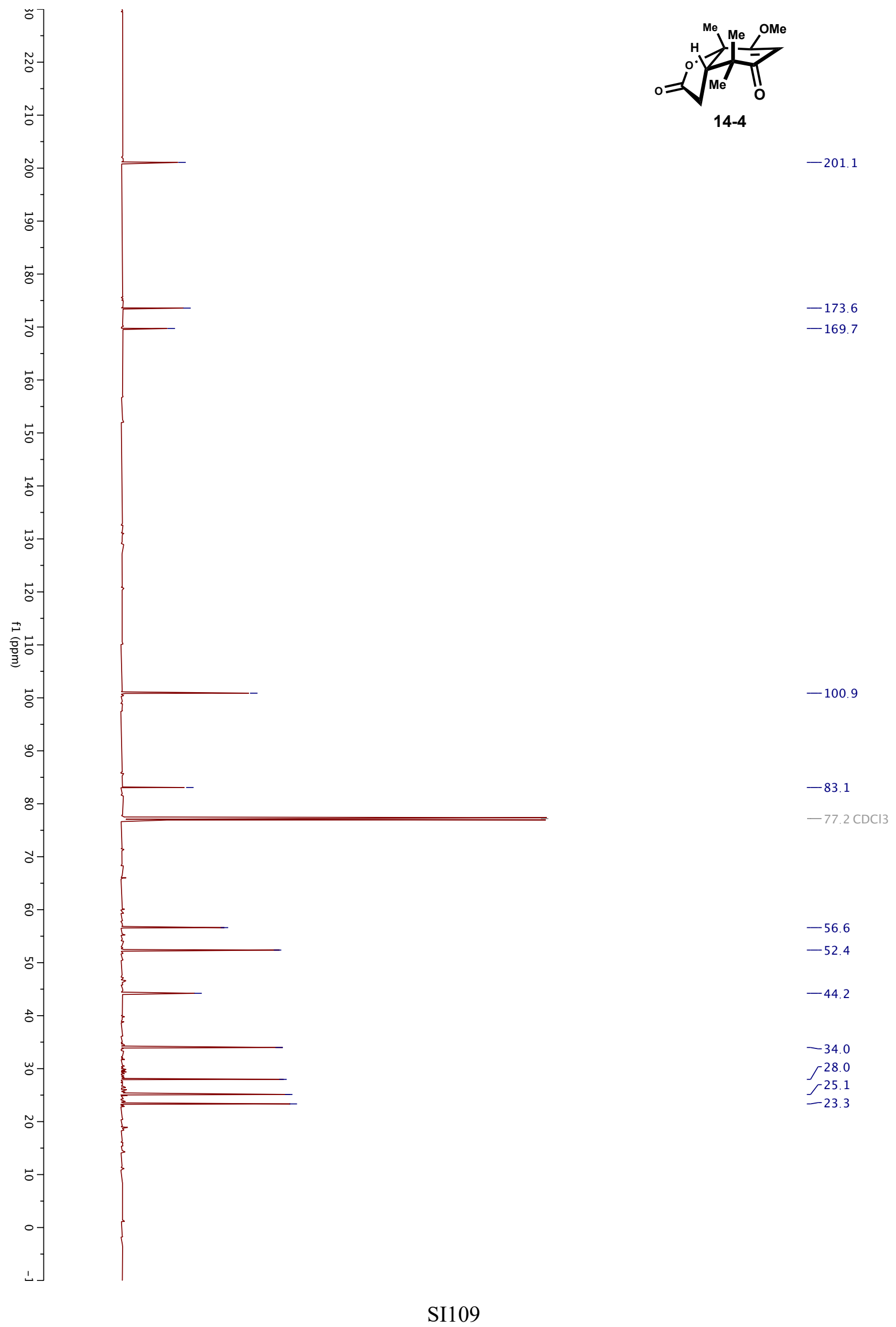


Synthesis of 1,3-diketone (10-9) from the vinylogous ester:

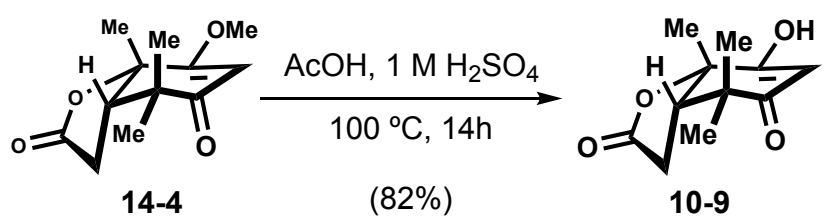

An evacuated flame-dried 50-mL round-bottomed flask equipped with a magnetic stir bar was added $\beta$-methoxy enone 14-4 (710 mg, $3.17 \mathrm{mmol}, 1.0$ equiv), glacial $\mathrm{AcOH}(6.0 \mathrm{~mL}, 0.5 \mathrm{M})$, and aq. 1 $\mathrm{M} \mathrm{H}_{2} \mathrm{SO}_{4}(6.0 \mathrm{~mL}, 0.5 \mathrm{M})$. The reaction vessel was fitted with an oven-dried reflux condenser and the reaction apparatus was moved to a $100^{\circ} \mathrm{C}$ preheated oil bath.

After stirring at $100^{\circ} \mathrm{C}$ for 14 hours, the reaction vessel was removed from the oil bath and allowed to cool to room temperature. Once at room temperature the reaction mixture was diluted with $\mathrm{CHCl}_{3}(50$ $\mathrm{mL})$ and the layers were separated. The aqueous layer was extracted with $\mathrm{CHCl}_{3}(3 \times 50 \mathrm{~mL})$. The combined organic extracts were washed with brine $(150 \mathrm{~mL}), \mathrm{NaHCO}_{3}(20 \mathrm{~mL})$, dried over anhydrous $\mathrm{Na}_{2} \mathrm{SO}_{4}$, filtered, and concentrated under reduced pressure by rotary evaporation to provide a crude orange oil. Purification by flash column chromatography on silica gel (65\% EtOAc/hexanes to $100 \%$ EtOAc) afforded 10-9 (546 $\mathrm{mg}, 82 \%)$ as a colorless foam.

The spectral data matched that which was previously reported. ${ }^{3}$ 


\section{Synthesis of pyran (15-5)}

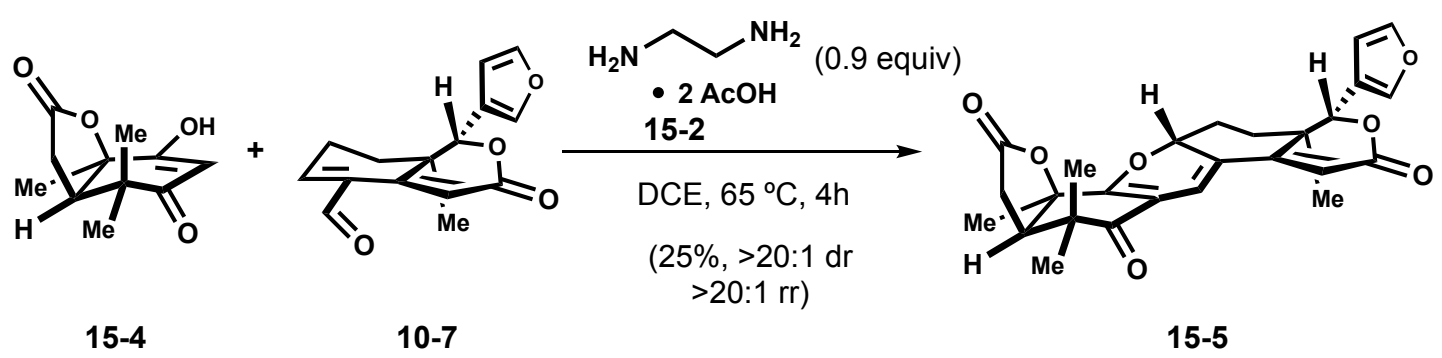

To a flame-dried 20-mL microwave vial equipped with a magnetic stir bar was added ethylenediammonium diacetate (201 mg, $1.1 \mathrm{mmol}, 0.9$ equiv), diketone 15-4 (260 mg, $1.2 \mathrm{mmol}, 1.0$ equiv), and aldehyde 10-7 (470 $\mathrm{mg}, 1.8 \mathrm{mmol}, 1.5$ equiv). The reaction vial was sealed with a Tefloncoated silicon microwave cap, and the reaction vial was evacuated and backfilled with nitrogen for three times. To the reaction mixture was added DCE $(6.2 \mathrm{~mL}, 0.2 \mathrm{M})$, and the reaction vessel was then transferred to a room temperature sonication bath for 5 minutes. Following this, the reaction vessel was moved to a $65^{\circ} \mathrm{C}$ preheated oil bath.

After the reaction mixture had stirred at $65^{\circ} \mathrm{C}$ for 4 hours, the reaction vessel was removed from the oil bath and allowed to cool to room temperature. Once at room temperature, the reaction mixture was diluted with EtOAc $(3 \mathrm{~mL})$ and concentrated under reduced pressure by rotary evaporation to provide the title compound yellow foam. Purification by flash column chromatography on silica gel (hexanes/EtOAc 1:1) afforded 15-5 (156 $\mathrm{mg}, 25 \%)$ as a yellow solid.

R: 0.49 (hexanes/EtOAc 1:2, p-anisaldehyde)

$[\boldsymbol{\alpha}]_{D}^{20.0}:+78^{\circ}\left(c 1.0, \mathrm{CHCl}_{3}\right)$

${ }^{1} \mathbf{H}$ NMR $\left(600 \mathrm{MHz}, \mathrm{CDCl}_{3}\right): \delta 7.50(\mathrm{~s}, 1 \mathrm{H}), 7.44(\mathrm{t}, J=1.8 \mathrm{~Hz}, 1 \mathrm{H}), 6.93(\mathrm{~d}, J=1.8 \mathrm{~Hz}, 1 \mathrm{H}), 6.45(\mathrm{~d}, J$ $=0.6 \mathrm{~Hz}, 1 \mathrm{H}), 6.26(\mathrm{~s}, 1 \mathrm{H}), 5.09(\mathrm{~s}, 1 \mathrm{H}), 5.05(\mathrm{ddd}, J=11.4,6.0,2.4 \mathrm{~Hz} 1 \mathrm{H}), 2.77(\mathrm{dd}, J=18,2.4 \mathrm{~Hz}$ $1 \mathrm{H}), 2.61(\mathrm{dd}, J=9.6,9.0 \mathrm{~Hz}, 1 \mathrm{H}), 2.44(\mathrm{dd}, J=5.4,3.6 \mathrm{~Hz} 1 \mathrm{H}), 2.41-2.37(\mathrm{~m}, 1 \mathrm{H}), 2.09-2.02(\mathrm{~m}$, $1 \mathrm{H}), 1.78(\mathrm{~s}, 3 \mathrm{H}), 1.68(\mathrm{dt}, J=14.4,3.0 \mathrm{~Hz} 1 \mathrm{H}), 1.50(\mathrm{td}, J=13.8,3.0 \mathrm{~Hz}, 1 \mathrm{H}), 1.26(\mathrm{~s}, 3 \mathrm{H}), 1.19$ (s, $3 \mathrm{H}), 1.15(\mathrm{~s}, 3 \mathrm{H})$

${ }^{13}$ C NMR (151 MHz, $\left.\mathrm{CDCl}_{3}\right): \delta$ 196.7, 173.5, 164.8, 159.3, 143.4, 141.4, 125.8, 119.9, 119.2, 113.3, $110.9,110.0,81.7,80.9,76.9,50.8,43.8,38.7,33.6,30.1,26.9,25.9,23.9,23.4,17.7$

IR $\left(\mathrm{cm}^{-1}\right): 2985,1780,1719,1257,1027,947,875$

ESI-HRMS (m/z): [M+H] $]^{+}$calc'd for $\mathrm{C}_{26} \mathrm{H}_{27} \mathrm{O}_{7}{ }^{+}: 451.1751$; found: 451.1745 

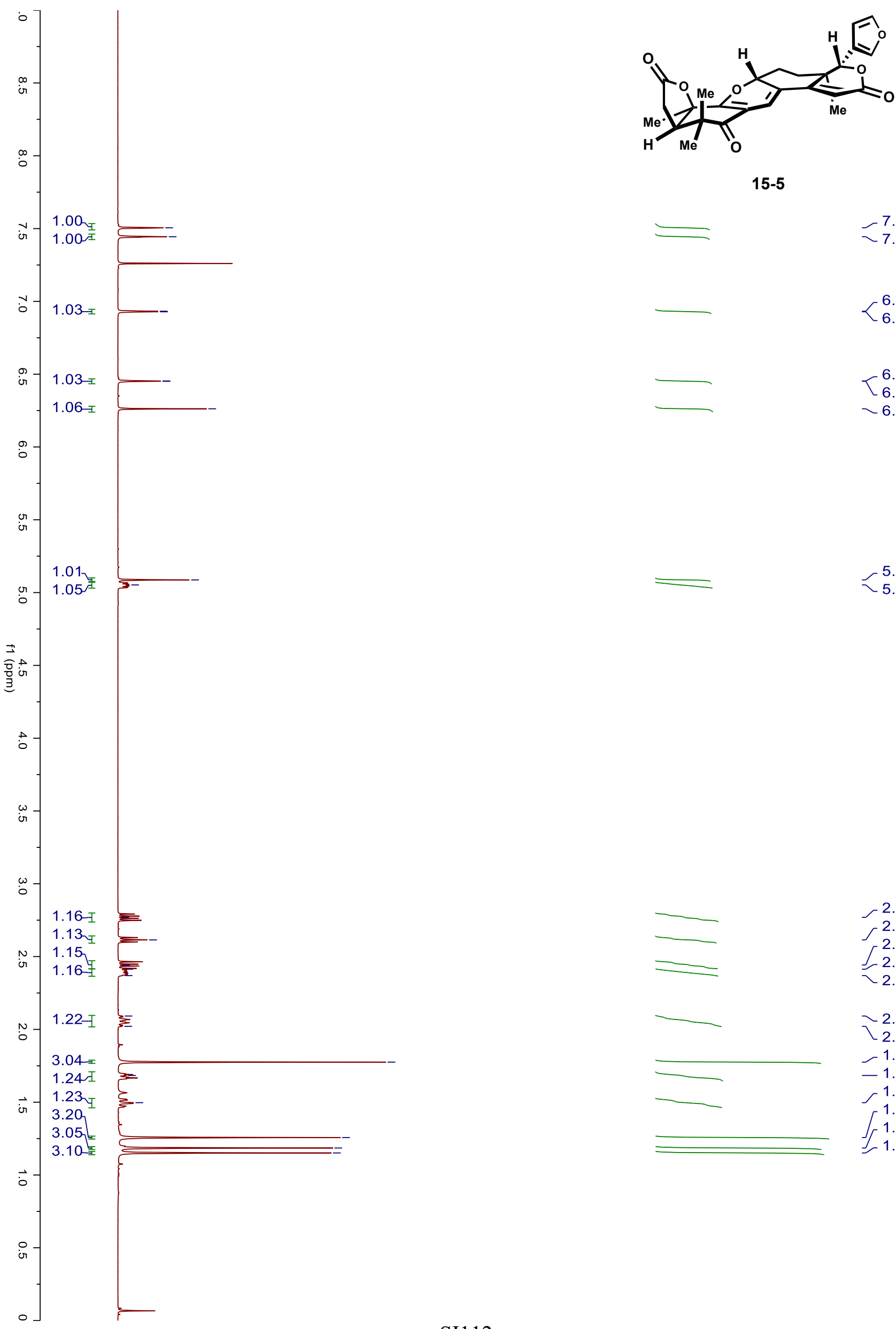

15-5
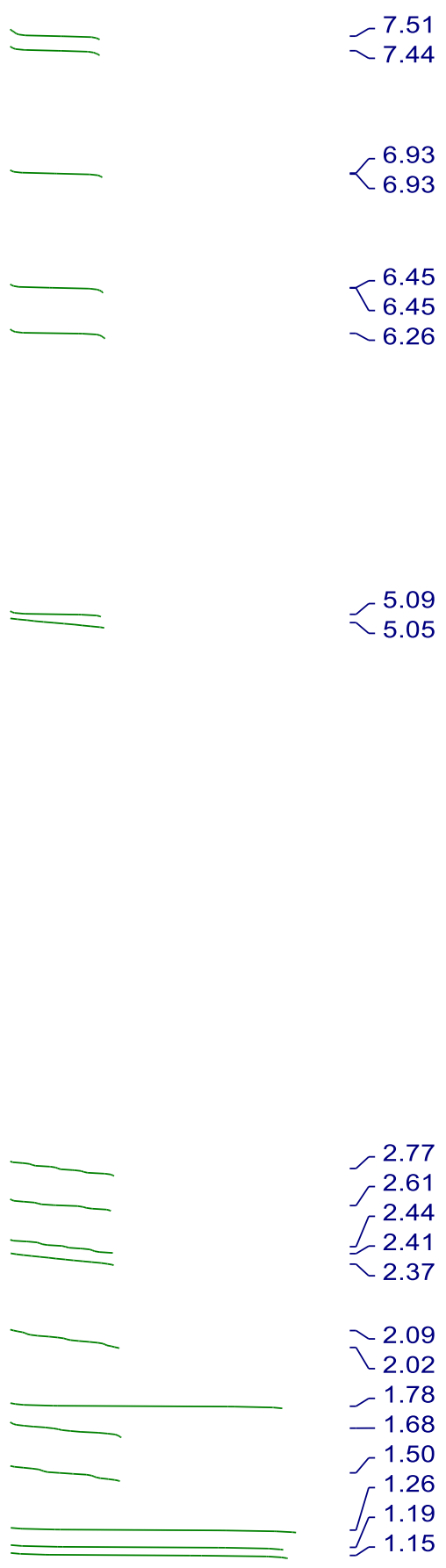


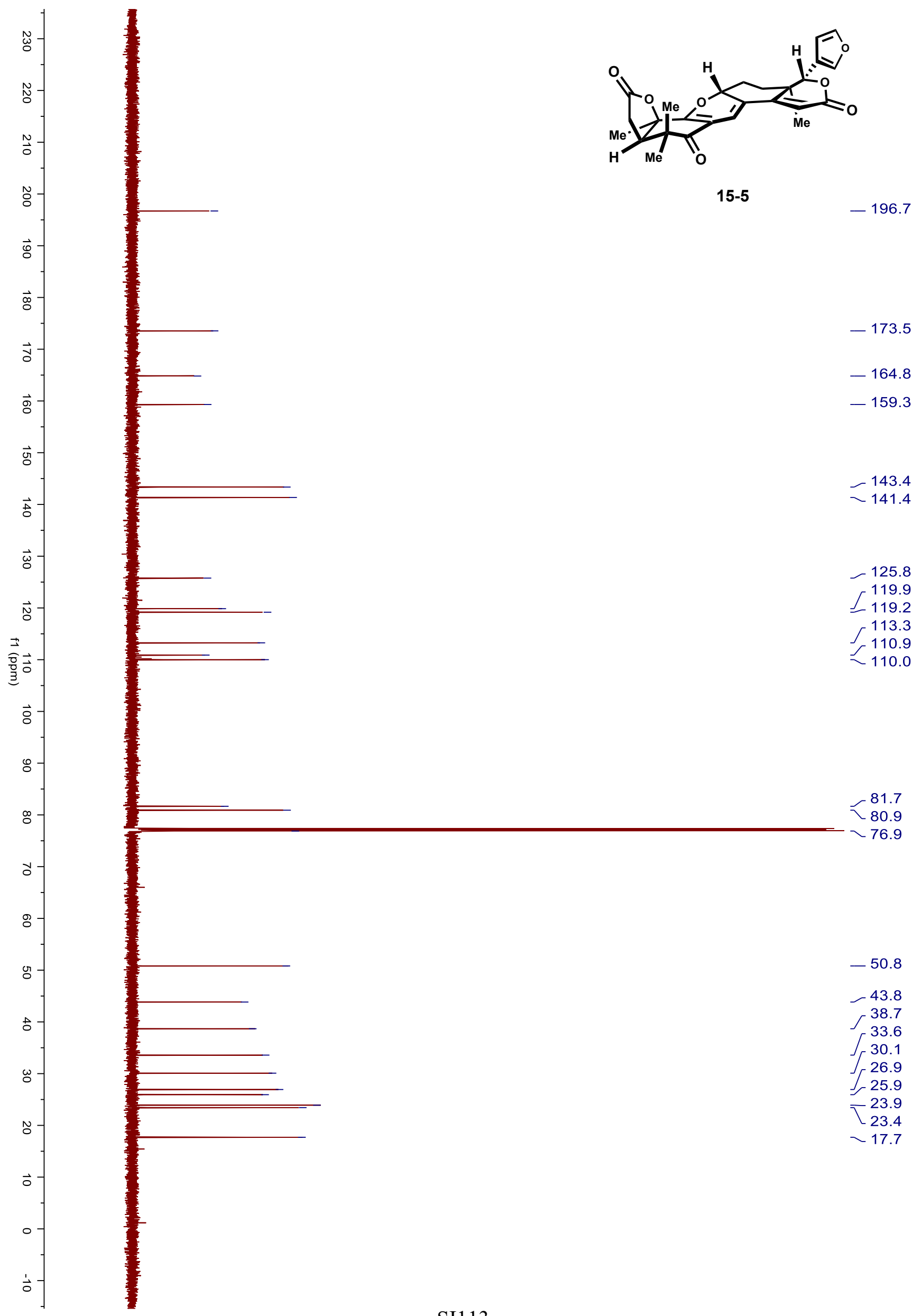




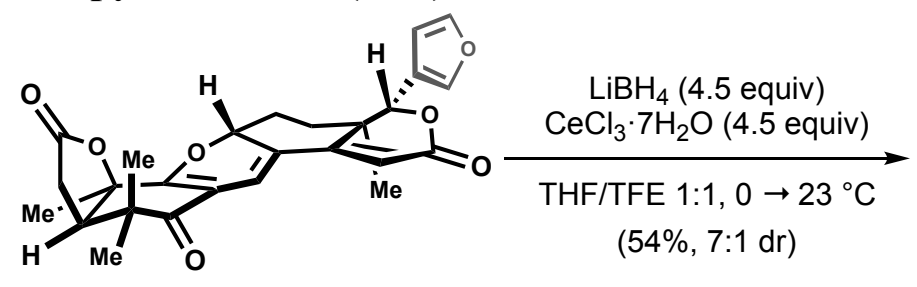

15-5

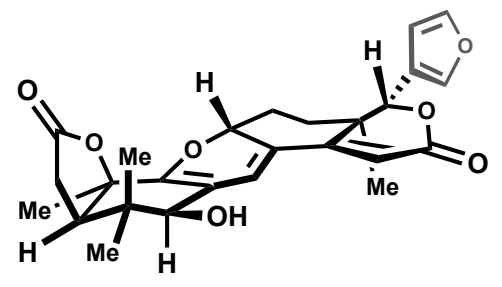

SI-8

To a flame-dried 50-mL round-bottomed flask equipped with a magnetic stir bar was added pyran 15-5 (129 mg, $0.25 \mathrm{mmol}, 1.0$ equiv) and $\mathrm{CeCl}_{3} \cdot 7 \mathrm{H}_{2} \mathrm{O}$ (416 mg, $1.1 \mathrm{mmol}, 4.5$ equiv). The reaction vial was evacuated and backfilled with nitrogen for three times. To this flask was added THF ( $5 \mathrm{~mL}, 0.05 \mathrm{M})$ and TFE $(5 \mathrm{~mL})$, and this mixture was transferred to a $0{ }^{\circ} \mathrm{C}$ ice bath and stirred for 30 minutes before $\mathrm{LiBH}_{4}(0.55 \mathrm{~mL}, 1.1 \mathrm{mmol}, 4.5$ equiv, $2.0 \mathrm{M}$ in THF) was added over 5 minutes, which resulted in a yellow solution. After stirring for 30 minutes at $0{ }^{\circ} \mathrm{C}$, the reaction vessel was allowed to warm to room temperature.

After the reaction mixture had stirred at room temperature for 3 hours, the reaction mixture was diluted with sat. aq. $\mathrm{NH}_{4} \mathrm{Cl}(5 \mathrm{~mL})$ and $\mathrm{H}_{2} \mathrm{O}(15 \mathrm{~mL})$, and the layers were separated. The aqueous layer was extracted with EtOAc $(3 \times 15 \mathrm{~mL})$. The combined organic extracts were washed with brine $(15 \mathrm{~mL})$, dried over anhydrous $\mathrm{Na}_{2} \mathrm{SO}_{4}$, filtered, and concentrated under reduced pressure by rotary evaporation to provide a crude yellow foam. Purification by flash column chromatography on silica gel (hexanes/EtOAc 1:1.2) afforded SI-8 (61 mg, 54\%, 7:1 dr) as a yellow solid.

\section{$\mathbf{R}_{\mathbf{f}}: 0.28$ (hexanes/EtOAc 1:2, $\mathrm{KMnO}_{4}$ )}

${ }^{1}$ H NMR (600 MHz, $\left.\mathrm{CDCl}_{3}\right): \delta 7.48(\mathrm{~s}, 1 \mathrm{H}), 7.42(\mathrm{~s}, 1 \mathrm{H}), 6.78(\mathrm{~d}, J=1.8 \mathrm{~Hz}, 1 \mathrm{H}), 6.44(\mathrm{~s}, 1 \mathrm{H}), 6.20$ (s, $1 \mathrm{H}), 5.04(\mathrm{~s}, 1 \mathrm{H}), 4.76(\mathrm{dd}, J=8.4,8.4 \mathrm{~Hz}), 4.04(\mathrm{~s}, 1 \mathrm{H}), 3.35-3.21($ br s, $1 \mathrm{H}), 3.01(\mathrm{dd}, J=12,5.4 \mathrm{~Hz}$, $1 \mathrm{H}), 2.74(\mathrm{dd}, J=18,9 \mathrm{~Hz}, 1 \mathrm{H}), 2.34-2.31(\mathrm{~m}, 1 \mathrm{~s}), 2.19(\mathrm{dd}, J=9,5.4 \mathrm{~Hz}), 1.99-1.92(\mathrm{~m}, 1 \mathrm{~s}), 1.58(\mathrm{~d}$, $13.8 \mathrm{~Hz}, 1 \mathrm{~s}), 1.52(\mathrm{~s}, 3 \mathrm{H}), 1.41(\mathrm{td}, J=14.4,3 \mathrm{~Hz}, 1 \mathrm{~s}), 1.13(\mathrm{~s}, 3 \mathrm{H}), 1.01(\mathrm{~s}, 3 \mathrm{H}), 0.96(\mathrm{~s}, 3 \mathrm{H})$

${ }^{13} \mathrm{C}$ NMR $\left(101 \mathrm{MHz}, \mathrm{CDCl}_{3}\right): \delta 175.7,166.0,160.1,151.8,143.2,141.4,125.9,124.9,119.9,114.3$, $110.9,110.1,82.2,81.1,74.5,74.4,49.4,38.2,36.7,31.9,29.5,26.5,24.8,24.0,17.7$

IR $\left(\mathrm{cm}^{-1}\right): 2953,1771,1707,1548,1256,1026,936,875,734$

ESI-HRMS (m/z): $[\mathrm{M}+\mathrm{H}]^{+}$calc'd for $\mathrm{C}_{26} \mathrm{H}_{29} \mathrm{O}_{7}{ }^{+}$: 453.1908 ; found: 453.1916 

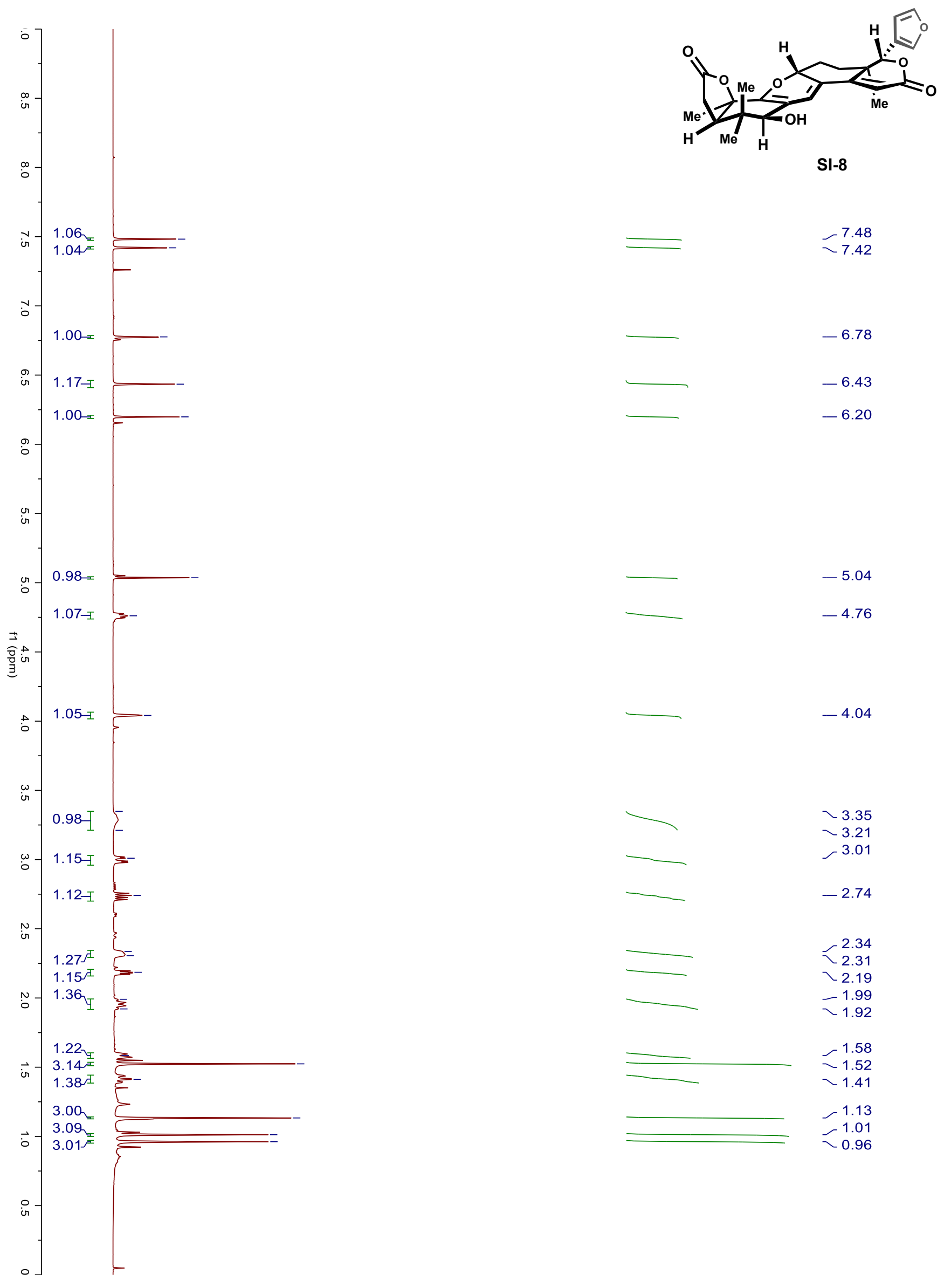

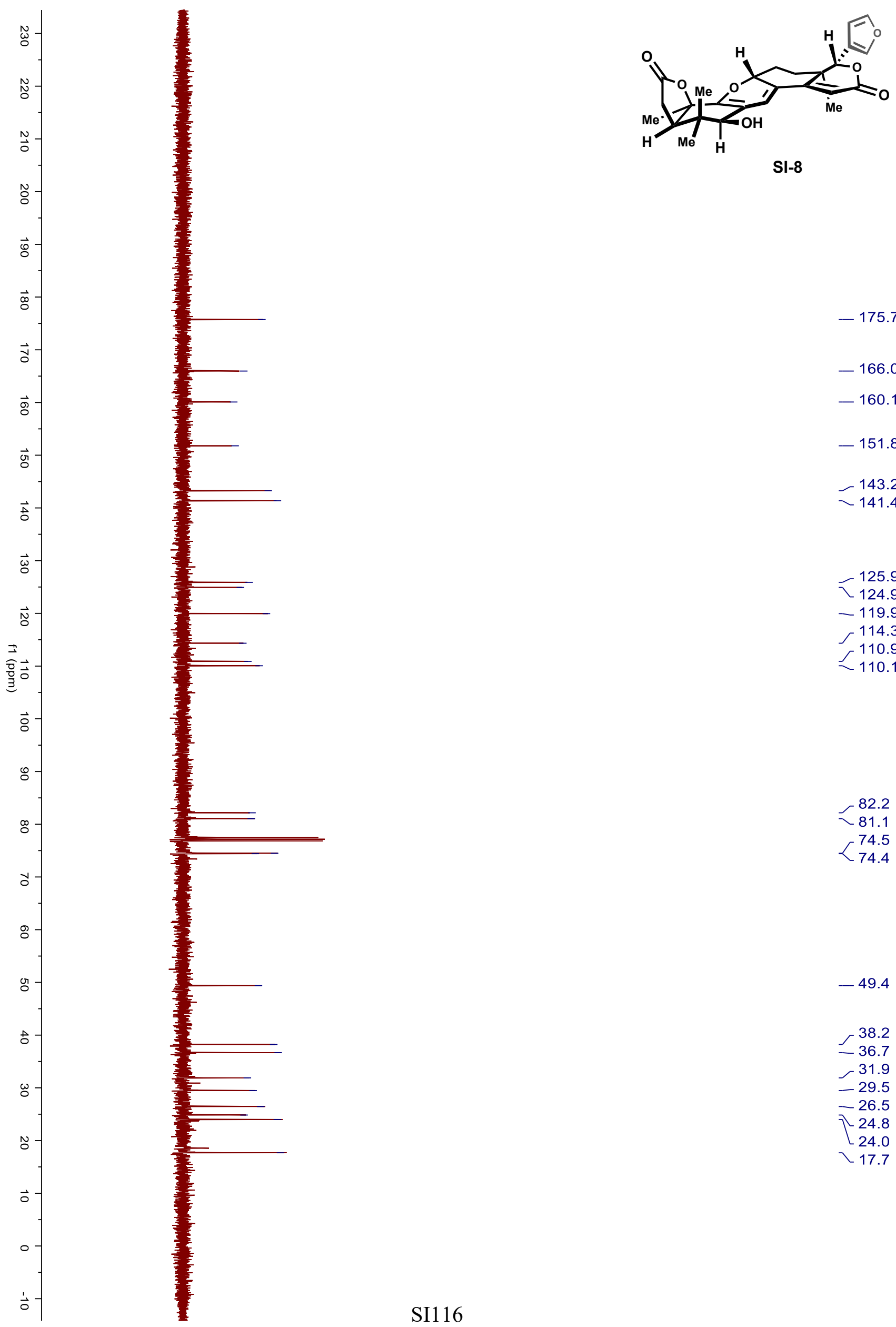

$-166.0$

$-160.1$

$-151.8$

$-143.2$

$\sim 141.4$

$-125.9$

$\backslash 124.9$

$-119.9$

114.3

110.9

$-110.1$

$-82.2$

81.1

74.5

$<74.4$

$-49.4$

38.2

$-36.7$

$-31.9$

$-29.5$

$-26.5$

ᄀ- 24.8

24.0

久 17.7 


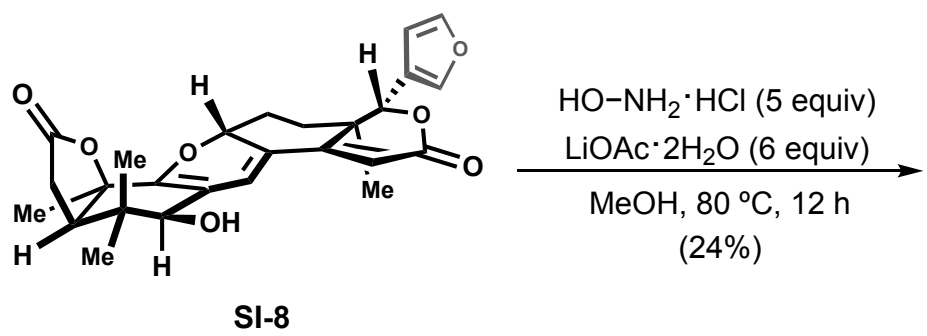

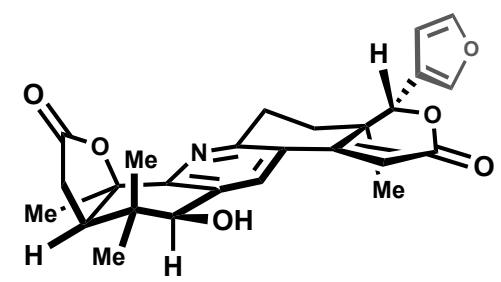

(+)-granatoine (1-4)

To a flame-dried 20-mL microwave vial equipped with a magnetic stir bar was added pyran alcohol SI-8 (61 mg, $0.14 \mathrm{mmol}, 1.0$ equiv), $\mathrm{HO}-\mathrm{NH}_{2} \cdot \mathrm{HCl}$ (46 mg, $0.67 \mathrm{mmol}, 5.0$ equiv) and $\mathrm{LiOAc} \cdot 2 \mathrm{H}_{2} \mathrm{O}(81 \mathrm{mg}, 0.81 \mathrm{mmol}, 6.0$ equiv). The reaction vial was evacuated and backfilled with nitrogen for three times. To this flask was added $\mathrm{MeOH}(2 \mathrm{~mL}, 0.07 \mathrm{M})$ at room temperature, and this mixture was transferred to a preheated $80{ }^{\circ} \mathrm{C}$ oil bath.

After stirring at $80{ }^{\circ} \mathrm{C}$ for 12 hours, the reaction mixture was diluted with sat. aq. $\mathrm{NH}_{4} \mathrm{Cl}(2 \mathrm{~mL})$, $\mathrm{H}_{2} \mathrm{O}(2 \mathrm{~mL})$ and EtOAc $(2 \mathrm{~mL})$, and the layers were separated. The aqueous layer was extracted with EtOAc $(3 \times 2 \mathrm{~mL})$. The combined organic extracts were washed with brine $(2 \mathrm{~mL})$, dried over anhydrous $\mathrm{Na}_{2} \mathrm{SO}_{4}$, filtered, and concentrated under reduced pressure by rotary evaporation to provide a crude yellow foam. Purification by flash column chromatography on silica gel (hexanes/EtOAc 1:2) afforded (+)granatoine (15 mg, 24\%) as a yellow solid.

Rf: 0.33 (hexanes/EtOAc 1:5, p-anisaldehyde)

$[\boldsymbol{\alpha}]_{\boldsymbol{D}}^{\mathbf{2 0 . 0}}:+145^{\circ}\left(c 1.0, \mathrm{CHCl}_{3}\right)$

${ }^{1} \mathbf{H}$ NMR $\left(600 \mathrm{MHz}, \mathrm{CDCl}_{3}\right): \delta 8.41(\mathrm{~s}, 1 \mathrm{H}), 7.55(\mathrm{~s}, 1 \mathrm{H}), 7.47(5, J=1.8 \mathrm{~Hz} 1 \mathrm{H}), 6.66(\mathrm{~s}, 1 \mathrm{H}), 6.51(\mathrm{~s}$, $1 \mathrm{H}), 5.24(\mathrm{~s}, 1 \mathrm{H}), 4.54(\mathrm{~d}, J=4.8 \mathrm{~Hz}, 1 \mathrm{H}), 3.42-3.33$ (br s, $1 \mathrm{H}), 3.22$ (dd, $J=18.6,3.6 \mathrm{~Hz}, 1 \mathrm{H}), 3.07-$ $3.01(\mathrm{~m}, 1 \mathrm{H}), 3.02(\mathrm{dd}, J=18,12.6 \mathrm{~Hz}, 1 \mathrm{H}), 2.73(\mathrm{dd}, J=18.0,1.2 \mathrm{~Hz}, 1 \mathrm{H}), 2.42(\mathrm{dd}, J=9,1.2 \mathrm{~Hz}$, 1H), 1.82 (ddd, $J=13.2,6.0,1.8 \mathrm{~Hz} 1 \mathrm{H}), 1.75$ (dd, $J=13.2,5.4 \mathrm{~Hz} 1 \mathrm{H}), 1.72$ (s, 3H), 1.15 (s, 3H), 1.14 $(\mathrm{s}, 3 \mathrm{H}), 0.67(\mathrm{~s}, 3 \mathrm{H})$

${ }^{13} \mathrm{C}$ NMR $\left(126 \mathrm{MHz}, \mathrm{CDCl}_{3}\right): \delta 175.3,166.0,157.9,156.9,155.7,143.4,141.6,131.9,131.7,124.2$, $119.9,111.0,110.1,83.3,81.1,74.4,49.1,37.8,37.6,31.3,30.3,28.6,27.7,25.2,16.0,14.3$

IR $\left(\mathrm{cm}^{-1}\right): 2930,1774,1715,1261,1233,1026,942,875$

ESI-HRMS (m/z): $[\mathrm{M}+\mathrm{H}]^{+}$calc'd for $\mathrm{C}_{26} \mathrm{H}_{28} \mathrm{NO}_{6}{ }^{+}$: 450.1911 ; found: 450.1919 


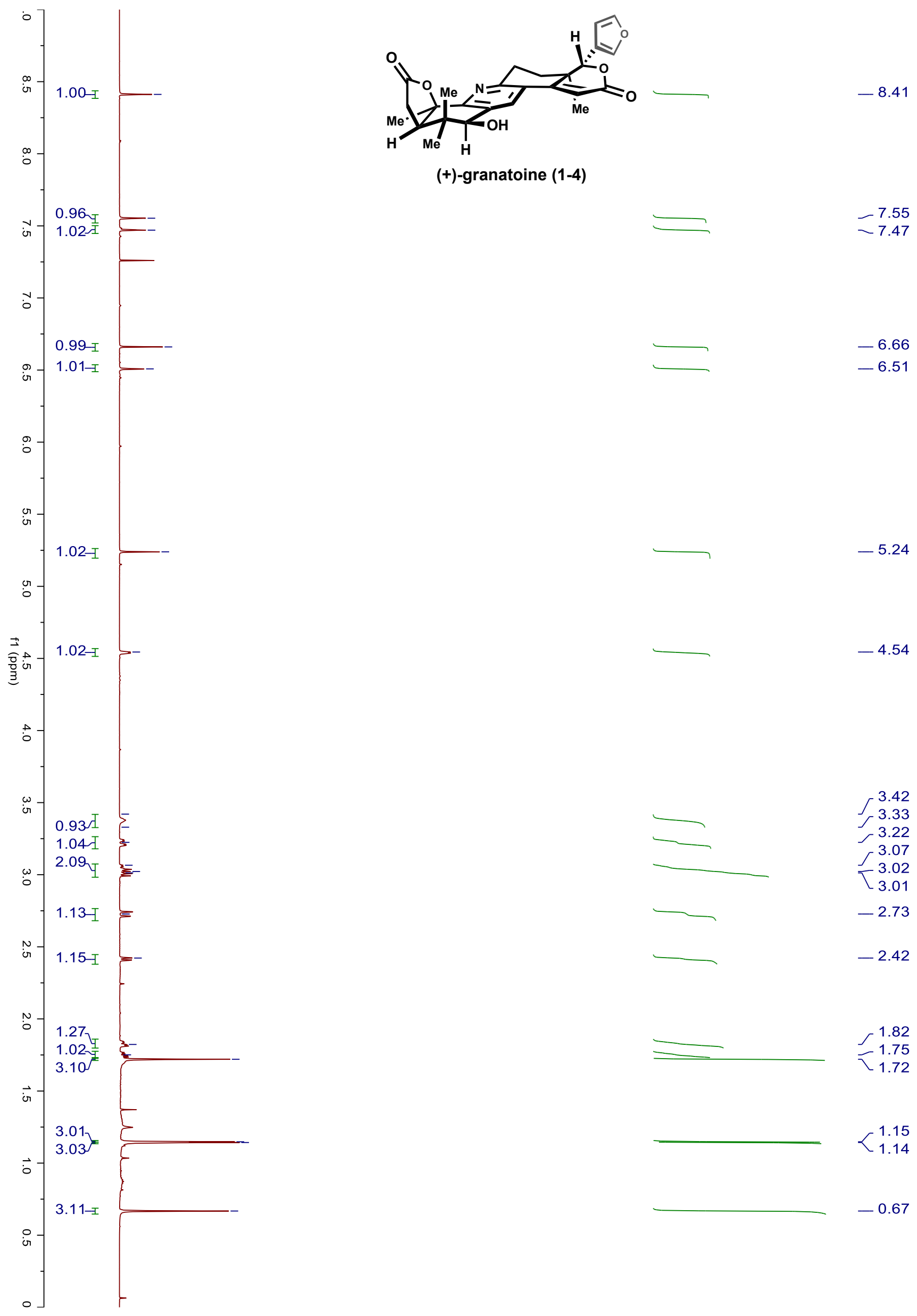



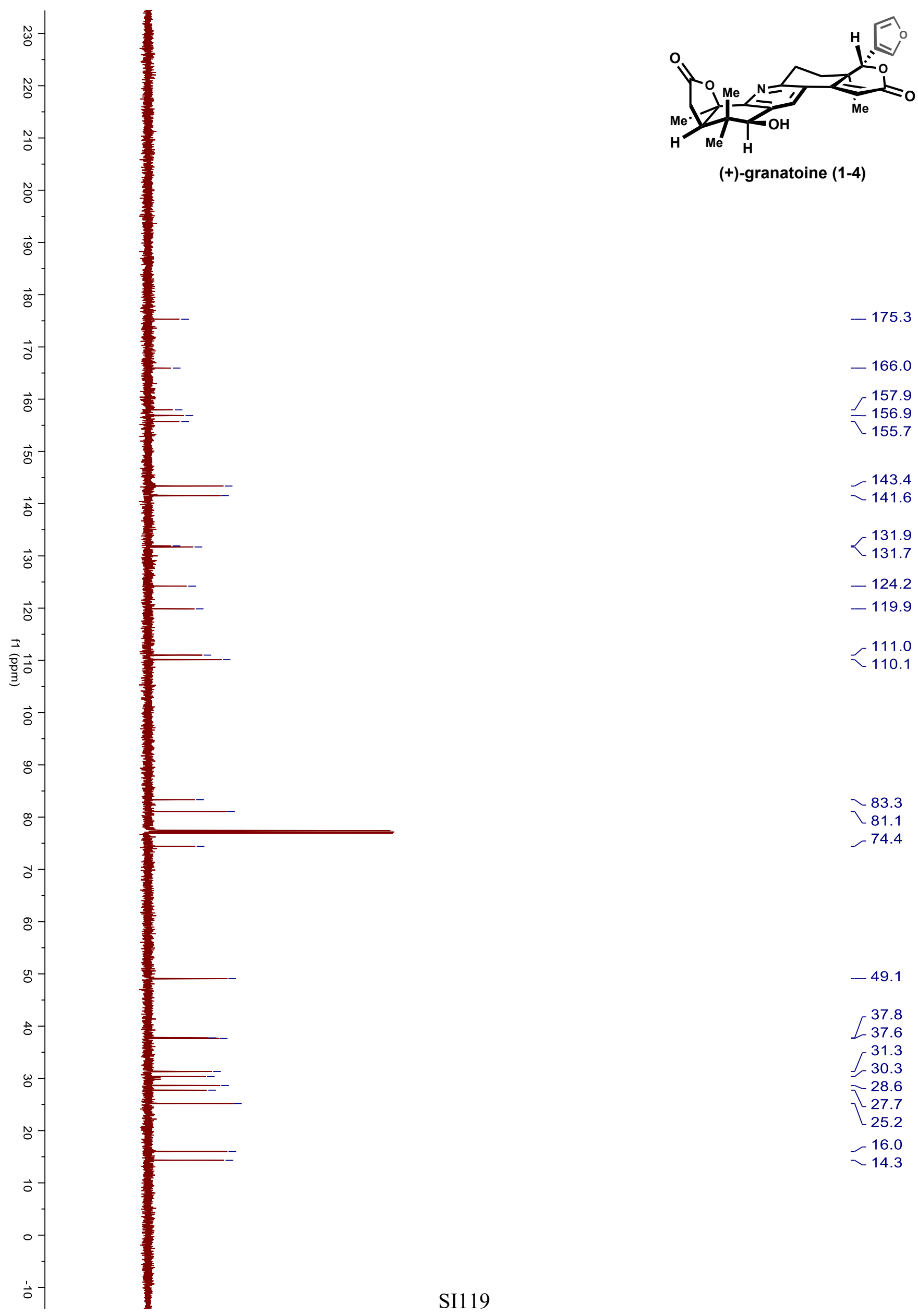

(+)-granatoine (1-4)

$-166.0$

157.9

$-156.9$

\} 1 5 5 . 7

$-143.4$

$-141.6$

$<131.9$

$<131.7$

$-124.2$

$-119.9$

$-111.0$

$\chi_{110.1}$

$\sim 83.3$

ไ 81.1

$-74.4$

$-49.1$

37.8
37.6

31.3

30.3

28.6

$-27.7$

25.2

$-16.0$

$\sim 14.3$ 


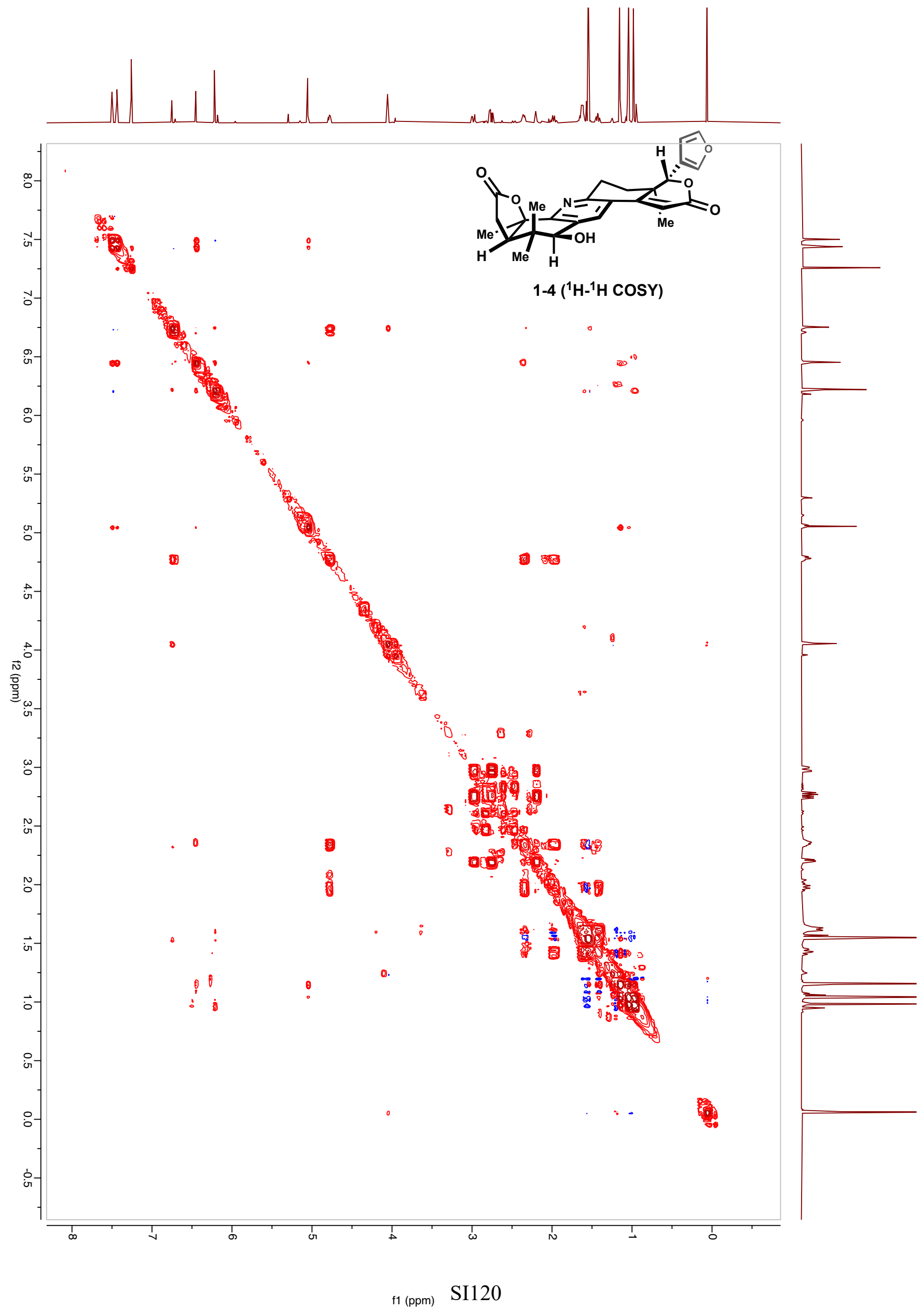




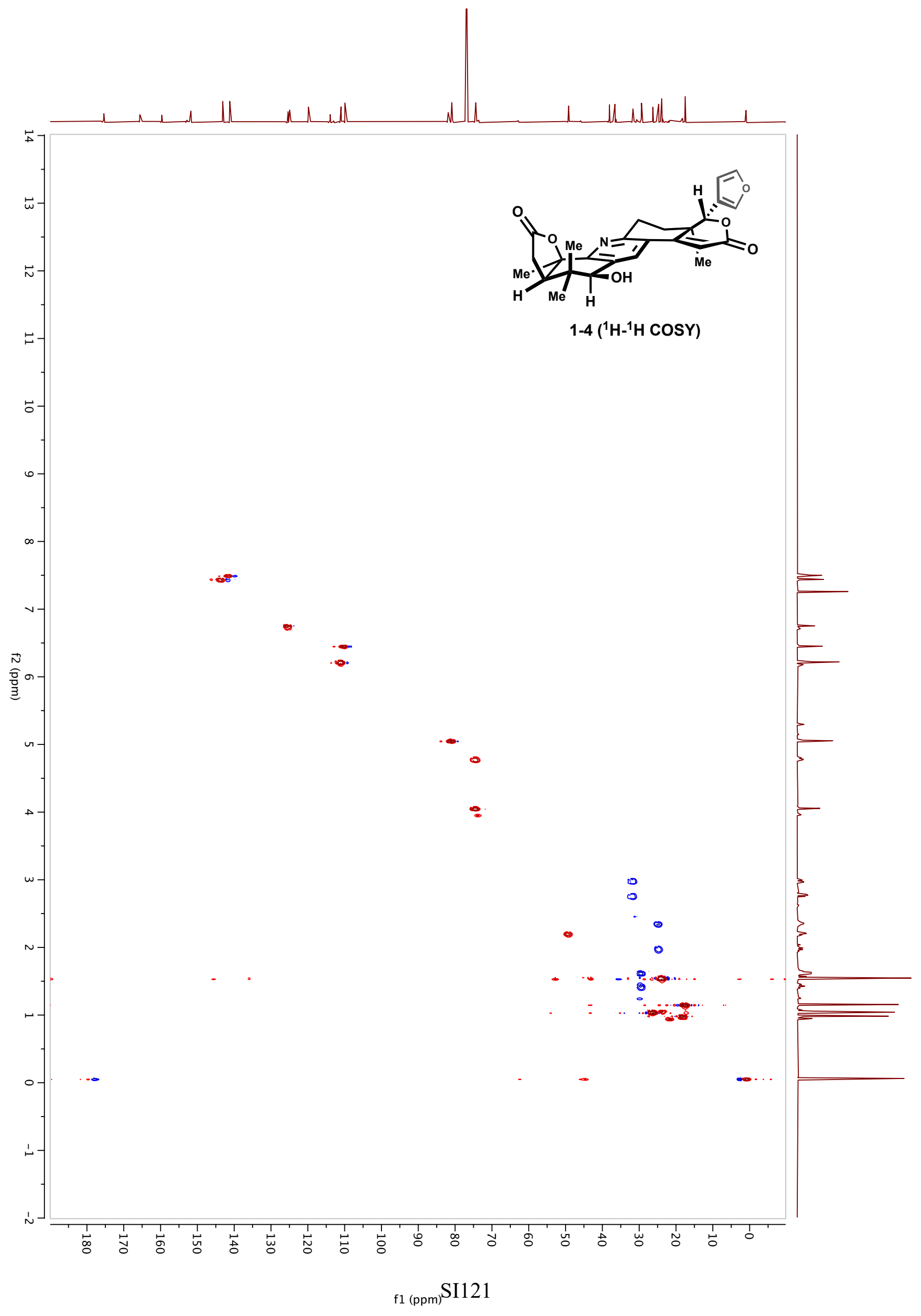




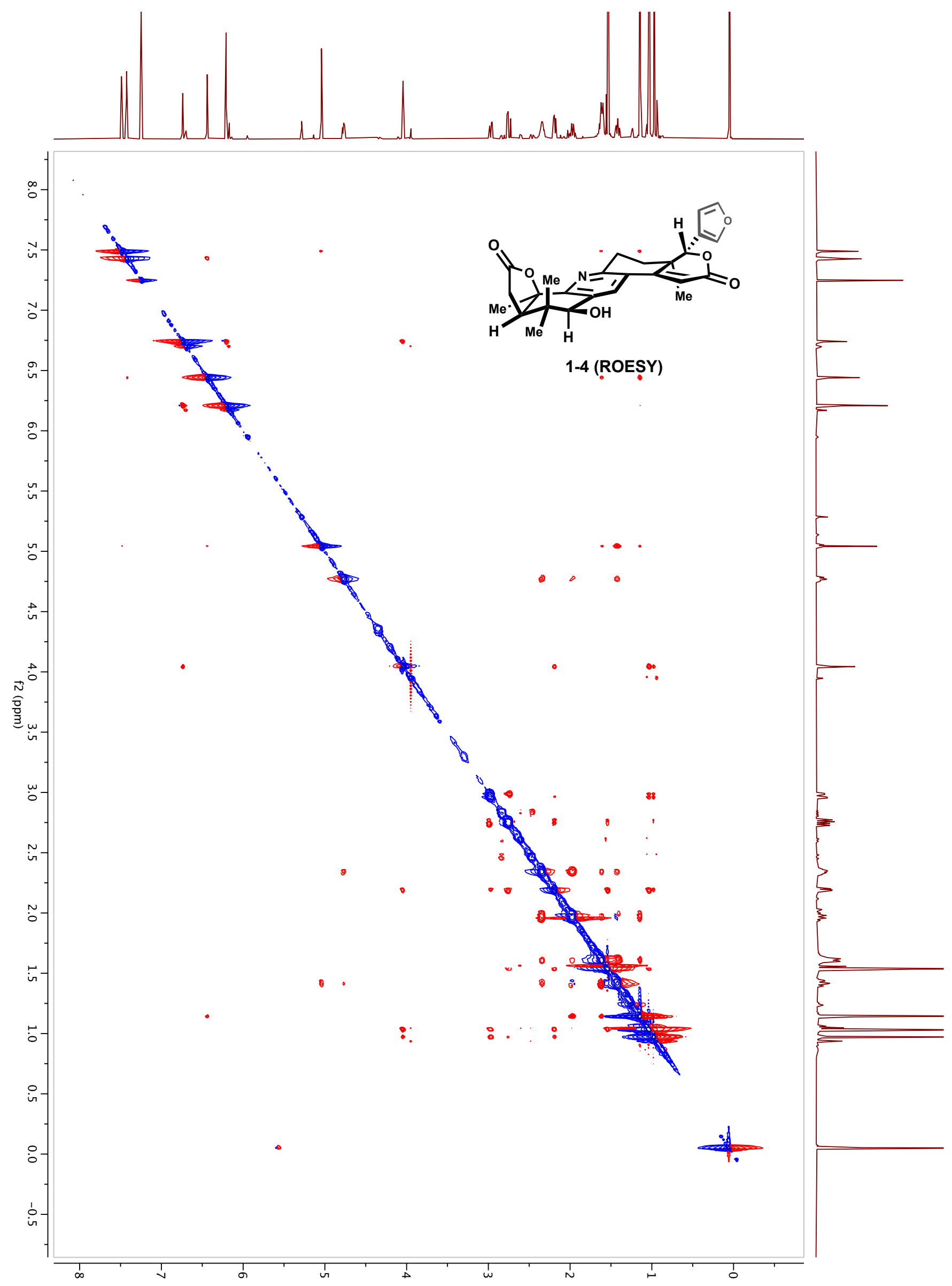

f1 (ppmSI1 22 


\section{$\underline{X-R a y}$ Experimental for sulfone $(+)-12-10$}

Low-temperature diffraction data ( $\omega$-scans) were collected on a Rigaku MicroMax-007HF diffractometer coupled to a Saturn994+ CCD detector with $\mathrm{Cu} \mathrm{K} \alpha(\lambda=1.54178 \AA)$ for the structure of 007a-18019. The diffraction images were processed and scaled using Rigaku Oxford Diffraction software (CrysAlisPro; Rigaku OD: The Woodlands, TX, 2015). The structure was solved with SHELXT and was refined against $\mathrm{F}^{2}$ on all data by full-matrix least squares with SHELXL (Sheldrick, G. M. Acta Cryst. 2008, A64, 112122). All non-hydrogen atoms were refined anisotropically. Hydrogen atoms were included in the model at geometrically calculated positions and refined using a riding model. The isotropic displacement parameters of all hydrogen atoms were fixed to 1.2 times the $U$ value of the atoms to which they are linked (1.5 times for methyl groups). The only exception is $\mathrm{H} 3$ which was found in the difference map and freely refined. The full numbering scheme of compound $(+)-\mathbf{1 2 - 1 0}$ can be found in the full details of the X-ray structure determination (CIF).

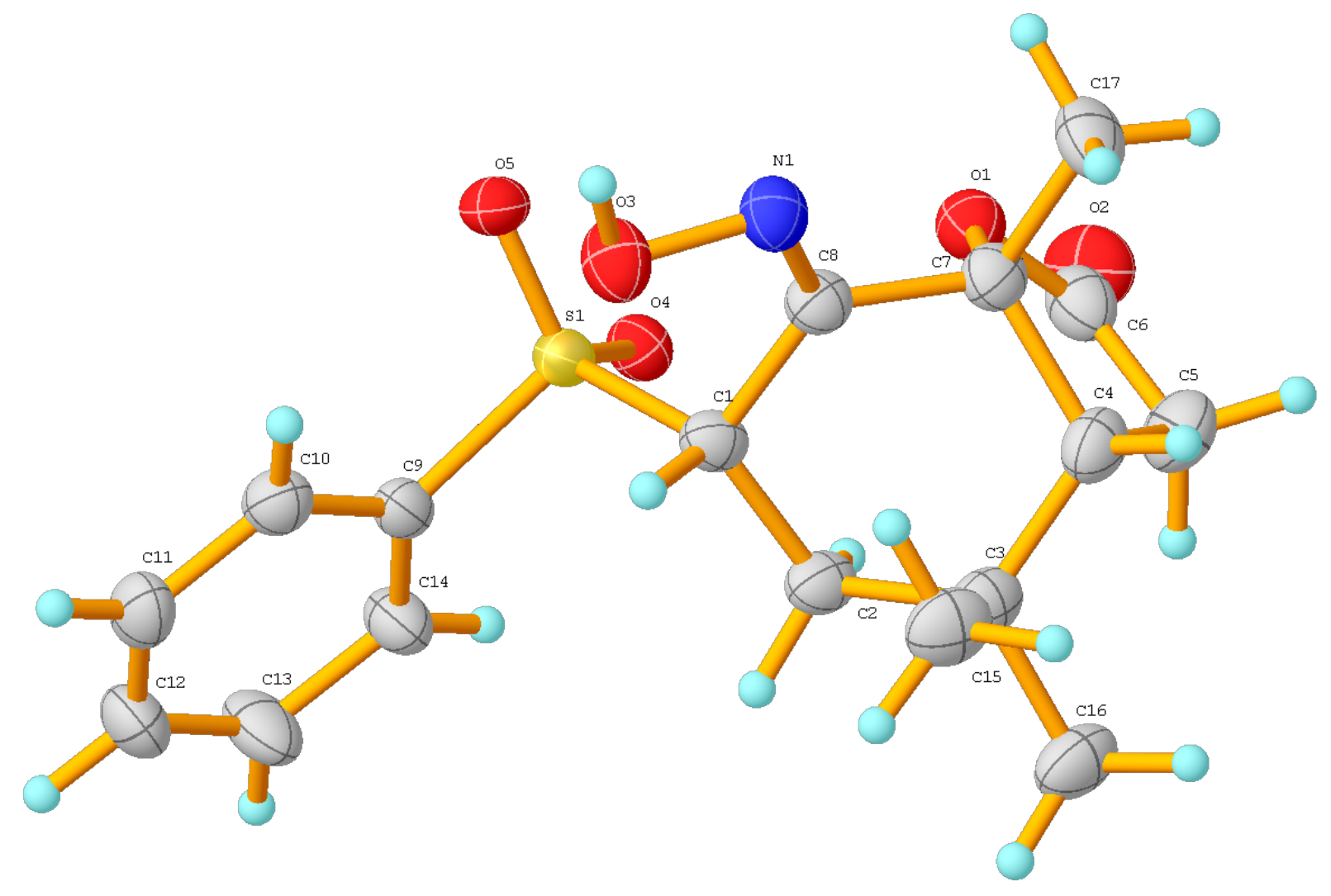

Figure SI-1. The complete numbering scheme of $(+)-\mathbf{1 2 - 1 0}$ with 50\% thermal ellipsoid probability levels. The hydrogen atoms are shown as circles for clarity. 
Table SI-1. Crystal data and structure refinement for 007a-18019.

Identification code

Empirical formula

Formula weight

Temperature

Wavelength

Crystal system

Space group

Unit cell dimensions

Volume

Z

Density (calculated)

Absorption coefficient

$\mathrm{F}(000)$

Crystal size

Crystal color and habit

Diffractometer

Theta range for data collection

Index ranges

Reflections collected

Independent reflections

Observed reflections (I $>2$ sigma(I))

Completeness to theta $=66.580^{\circ}$

Absorption correction

Max. and min. transmission

Solution method

Refinement method

Data / restraints / parameters

Goodness-of-fit on $\mathrm{F}^{2}$

Final $\mathrm{R}$ indices $[\mathrm{I}>2 \operatorname{sigma}(\mathrm{I})]$

$\mathrm{R}$ indices (all data)

Absolute structure parameter

Largest diff. peak and hole 007a-18019

C17 H21 N O5 S

351.41

93(2) K

$1.54184 \AA$

Orthorhombic

$\mathrm{P} 2{ }_{1} 2_{12}$

$\mathrm{a}=8.5606(2) \AA$

$\alpha=90^{\circ}$.

$\mathrm{b}=12.9936(3) \AA$

$\beta=90^{\circ}$.

$\mathrm{c}=15.5475(4) \AA$

$\gamma=90^{\circ}$

$1729.40(7) \AA^{3}$

4

$1.350 \mathrm{Mg} / \mathrm{m}^{3}$

$1.898 \mathrm{~mm}^{-1}$

744

$0.200 \times 0.200 \times 0.020 \mathrm{~mm}^{3}$

Colorless Plate

Rigaku Saturn 944+ CCD

4.435 to $66.580^{\circ}$.

$-10<=\mathrm{h}<=10,-15<=\mathrm{k}<=15,-18<=\mathrm{l}<=18$

64113

$3060[\mathrm{R}($ int $)=0.0710]$

2924

$100.0 \%$

Semi-empirical from equivalents

1.00000 and 0.75972

SHELXT-2014/5 (Sheldrick, 2014)

SHELXL-2014/7 (Sheldrick, 2014)

$3060 / 0 / 224$

1.101

$\mathrm{R} 1=0.0308, w \mathrm{R} 2=0.0770$

$\mathrm{R} 1=0.0328, w \mathrm{R} 2=0.0782$

$-0.006(5)$

0.127 and -0.333 e. $\AA^{-3}$ 
Table SI-2. Atomic coordinates (x 104) and equivalent isotropic displacement parameters $\left(\AA^{2} \times 10^{3}\right)$ for $007 \mathrm{a}-18019$. $\mathrm{U}(\mathrm{eq})$ is defined as one third of the trace of the orthogonalized $\mathrm{U}^{\mathrm{ij}}$ tensor.

\begin{tabular}{|c|c|c|c|c|}
\hline & $\mathrm{x}$ & $\mathrm{y}$ & $\mathrm{z}$ & $\mathrm{U}(\mathrm{eq})$ \\
\hline$S(1)$ & $6061(1)$ & $5243(1)$ & 2911(1) & $27(1)$ \\
\hline $\mathrm{O}(1)$ & $4006(2)$ & $5671(1)$ & 1062(1) & $34(1)$ \\
\hline $\mathrm{O}(2)$ & $4519(3)$ & $7191(2)$ & $461(1)$ & $49(1)$ \\
\hline $\mathrm{O}(3)$ & $3718(2)$ & $3155(2)$ & 2988(1) & $40(1)$ \\
\hline $\mathrm{O}(4)$ & $6549(2)$ & $6101(1)$ & 2384(1) & $30(1)$ \\
\hline $\mathrm{O}(5)$ & $6639(2)$ & $4238(1)$ & $2687(1)$ & $33(1)$ \\
\hline $\mathrm{N}(1)$ & $3206(3)$ & $3575(2)$ & $2212(2)$ & $35(1)$ \\
\hline $\mathrm{C}(1)$ & $3949(3)$ & $5181(2)$ & 2944(2) & $30(1)$ \\
\hline$C(2)$ & $3197(3)$ & $6257(2)$ & 2999(2) & $33(1)$ \\
\hline$C(3)$ & $1495(3)$ & $6216(2)$ & $2681(2)$ & $36(1)$ \\
\hline$C(4)$ & 1491(3) & $5983(2)$ & $1705(2)$ & $37(1)$ \\
\hline$C(5)$ & 1978(4) & $6878(2)$ & $1120(2)$ & $46(1)$ \\
\hline$C(6)$ & $3614(4)$ & $6647(2)$ & $832(2)$ & $38(1)$ \\
\hline$C(7)$ & $2673(3)$ & $5121(2)$ & $1433(2)$ & $32(1)$ \\
\hline$C(8)$ & $3338(3)$ & $4560(2)$ & $2199(2)$ & $30(1)$ \\
\hline$C(9)$ & $6615(3)$ & $5502(2)$ & $3980(2)$ & $28(1)$ \\
\hline$C(10)$ & $6755(3)$ & $4679(2)$ & $4547(2)$ & $34(1)$ \\
\hline $\mathrm{C}(11)$ & $7335(4)$ & $4865(3)$ & $5367(2)$ & $40(1)$ \\
\hline$C(12)$ & $7753(4)$ & $5852(3)$ & $5599(2)$ & $44(1)$ \\
\hline$C(13)$ & $7579(4)$ & $6658(3)$ & $5034(2)$ & $47(1)$ \\
\hline$C(14)$ & $7010(4)$ & $6495(2)$ & $4212(2)$ & $36(1)$ \\
\hline$C(15)$ & $564(3)$ & $5381(3)$ & $3166(2)$ & $44(1)$ \\
\hline$C(16)$ & $698(3)$ & $7251(2)$ & $2873(2)$ & $44(1)$ \\
\hline$C(17)$ & $2032(4)$ & $4414(2)$ & $741(2)$ & $43(1)$ \\
\hline
\end{tabular}

Table SI-3. Hydrogen bonds for $(+)-12-10\left[\AA\right.$ and $\left.{ }^{\circ}\right]$.

\begin{tabular}{lcccc}
\hline D-H...A & d(D-H) & d(H...A & $d(D \ldots A)$ & $<($ DHA $)$ \\
\hline $\mathrm{O}(3)-\mathrm{H}(3) \ldots \mathrm{O}(4) \# 1$ & $0.92(4)$ & $1.82(4)$ & $2.740(3)$ & $175(4)$ \\
\hline
\end{tabular}

Symmetry transformations used to generate equivalent atoms:

$\# 1-\mathrm{x}+1, \mathrm{y}-1 / 2,-\mathrm{z}+1 / 2$ 


\section{PTP1B Inhibition Assay}

PTP1B (amino acids 1-393) was overexpressed and purified as described previously. ${ }^{4}$ PTP1B kinetic assays were conducted at room temperature in kinetic buffer consisting of $100 \mathrm{mM}$ sodium acetate, $50 \mathrm{mM}$ Bis-Tris, and 50 $\mathrm{mM}$ Tris, $\mathrm{pH}=5.5$, and $1 \mathrm{mM}$ pNPP. Each ligand was dissolved in 80\%/20\% dimethylformamide/kinetic buffer then added to the kinetic assay to achieve $20 \mathrm{mM}$ and $40 \mathrm{mM}$ final ligand concentrations; the final concentration of DMF in the asaay was $4 \%$. The assay was initiated by the addition of $30 \mathrm{nM}$ PTP1B. Aliquots were removed after 10, 20, 30, 40,50, and 60 seconds from addition of PTP1B, quenched with $\mathrm{NaOH}$, and the absorbance measured at $405 \mathrm{nM}$, compared to a control that did not contain enzyme. In all cases the absorbance change over 60 seconds was linear. The slopes of the absorbance versus time were used to determine the initial reaction rate. Controls with only DMF without any ligands indicated no change in PTP1B activity with up to 5\% DMF. 


\section{Computational General Information}

DFT optimizations were performed using Gaussian $09^{5}$ on the Omega and Grace Clusters at Yale University, at levels of theory indicated in each section, using gas phase geometries at 298K. Optimized structures are listed with energies and geometric coordinates.

This work was supported by the HPC facilities operated by, and the staff of, the Yale Center for Research Computing. We gratefully acknowledge the National Science Foundation for financial support in the establishment of the Yale University High Performance Computing (HPC) Center (CNS 08-21132).

\section{Benzylic Oxidation Calculations}

Geometry optimization calculations were performed in the gas phase at 298K using UB3LYP/6$31+\mathrm{G}(\mathrm{d}, \mathrm{p}), \omega \mathrm{B} 97 \mathrm{x}-\mathrm{D} / 6-31+\mathrm{G}(\mathrm{d}, \mathrm{p})$, and M06-2X/6-31+G(d,p) levels of theory in Gaussian 09, followed by single point energy calculations at UB3LYP/6-311++G(d,p), $\omega B 97 x-D / 6-311++G(d, p)$, and M06-2X/6$311++\mathrm{G}(\mathrm{d}, \mathrm{p})$ levels of theory respectively in Gaussian 09.

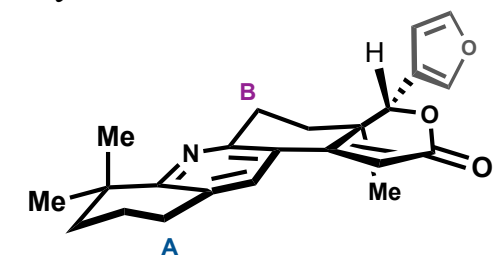

3-1

Table SI4. Summary of the calculation results of the benzylic oxidation of 3-1

\begin{tabular}{|c|c|c|c|c|}
\hline Level of theory & $3-1$ cation A & $3-1$ cation B & $3-1$ radical A & $3-1$ radical B \\
\hline $\begin{array}{c}\text { UB3LYP/6-311++G(d,p)// } \\
\text { UB3LYP/6-31+G(d,p) }\end{array}$ & 0.0 & 3.5 & 0.0 & 0.3 \\
\hline $\begin{array}{c}\omega \text { B97x-D/6-311++G(d,p)// } \\
\omega B 97 x-D / 6-31+\mathrm{G}(\mathrm{d}, \mathrm{p})\end{array}$ & 0.0 & 5.4 & 0.0 & 0.9 \\
\hline $\begin{array}{c}\text { M06-2X/6-311++G(d,p)// } \\
\text { M06-2X/6-31+G(d,p) }\end{array}$ & 0.0 & 5.5 & 0.0 & 0.9 \\
\hline
\end{tabular}

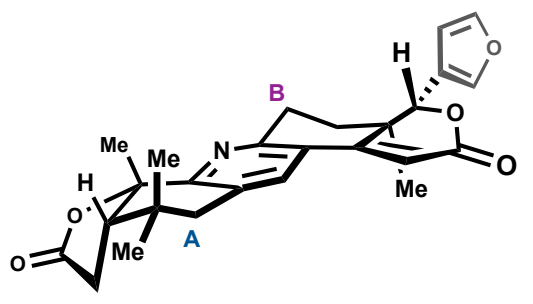

C3-deoxy-xylogranatin F (10-1)

Table SI5. Summary of the calculation results of the benzylic oxidation of 10-1

\begin{tabular}{|c|c|c|c|c|}
\hline Level of theory & $10-1$ cation A & $10-1$ cation B & $10-1$ radical A & $10-1$ radical B \\
\hline $\begin{array}{c}\text { UB3LYP/6-311++G(d,p)// } \\
\text { UB3LYP/6-31+G(d,p) }\end{array}$ & 0.0 & -0.7 & 0.0 & -2.6 \\
\hline $\begin{array}{c}\omega \mathrm{B} 97 \mathrm{x}-\mathrm{D} / 6-311++\mathrm{G}(\mathrm{d}, \mathrm{p}) / / \\
\omega \mathrm{B} 97 \mathrm{x}-\mathrm{D} / 6-31+\mathrm{G}(\mathrm{d}, \mathrm{p})\end{array}$ & 0.0 & -0.1 & 0.0 & -2.8 \\
\hline $\begin{array}{c}\mathrm{M} 06-2 \mathrm{X} / 6-311++\mathrm{G}(\mathrm{d}, \mathrm{p}) / / \\
\mathrm{M} 06-2 \mathrm{X} / 6-31+\mathrm{G}(\mathrm{d}, \mathrm{p})\end{array}$ & 0.0 & 0.1 & 0.0 & -2.6 \\
\hline
\end{tabular}


Calculations conducted with UB3LYP/6-311++G(d,p)//UB3LYP/6-31+G(d,p):

\author{
3-1 Cation $A$ \\ Zero-point correction $=$ \\ Thermal correction to Energy= \\ 0.420750 (Hartree/Particle) \\ Thermal correction to Enthalpy= \\ 0.443656 \\ Thermal correction to Gibbs Free Energy= \\ 0.444600 \\ Sum of electronic and zero-point Energies= \\ 0.370099 \\ Sum of electronic and thermal Energies= \\ $-1170.924193$ \\ Sum of electronic and thermal Enthalpies= \\ $-1170.901287$ \\ Sum of electronic and thermal Free Energies $=\quad-1170.974844$
}

11

C $\quad-1.77305800 \quad 1.42523100 \quad-0.00412700$

$\begin{array}{llll}\text { C } & -0.73653600 & 0.51680900 & -0.09159900\end{array}$

C $\quad-1.11448200 \quad-0.86868000 \quad-0.08119300$

$\mathrm{N} \quad-2.39402200 \quad-1.30327400 \quad-0.07787700$

$\mathrm{H} \quad-1.57630900 \quad 2.49009100 \quad 0.07775700$

C $\quad-0.07213300 \quad-1.93463700 \quad-0.02897600$

$\mathrm{H} \quad-0.42805300 \quad-2.79223900 \quad-0.60999500$

$\mathrm{H} \quad-0.05260600 \quad-2.29244100 \quad 1.01362400$

C $\quad 0.69181600 \quad 0.91395100 \quad-0.13239000$

$\begin{array}{llll}\mathrm{C} & 1.06622900 & 2.17826000 & -0.41145000\end{array}$

$\mathrm{H} \quad 0.37236800 \quad 2.96954600 \quad-0.67343200$

C $\quad 2.46431400 \quad 2.63928700 \quad-0.23751600$

$\begin{array}{llll}\mathrm{O} & 2.75025200 & 3.81189700 & -0.14716000\end{array}$

$\begin{array}{llll}\mathrm{C} & 1.75379300 & -0.14050100 & 0.17432100\end{array}$

C $\quad 1.31923900 \quad-1.47743800 \quad-0.47224300$

$\mathrm{H} \quad 1.32545700 \quad-1.37010200 \quad-1.56470800$

$\mathrm{H} \quad 2.04625900 \quad-2.25525200 \quad-0.22581900$

$\begin{array}{llll}\mathrm{O} & 3.40962000 & 1.67920600 & -0.09328900\end{array}$

C $\quad 3.07582300 \quad 0.33041200 \quad-0.50976800$

$\mathrm{H} \quad 2.88978900 \quad 0.35723700 \quad-1.59286400$

C $\quad 4.28680900 \quad-0.51112700 \quad-0.24477300$

$\begin{array}{llll}\text { C } & 5.26982800 & -0.26908000 & 0.67373500\end{array}$

$\begin{array}{llll}\text { C } & 4.67847800 & -1.71693600 & -0.93036200\end{array}$

$\begin{array}{llll}\mathrm{O} & 6.22362200 & -1.23586800 & 0.61089300\end{array}$

$\begin{array}{llll}\mathrm{H} & 5.44159300 & 0.52911700 & 1.37770700\end{array}$

C $\quad 5.85427100 \quad-2.11024100 \quad-0.36645000$

$\mathrm{H} \quad 4.17103900 \quad-2.20817700 \quad-1.74869900$

$\mathrm{H} \quad 6.52589100 \quad-2.93527400 \quad-0.54422400$

$\begin{array}{llll}\mathrm{C} & 1.92423700 & -0.28209300 & 1.70431800\end{array}$

$\mathrm{H} \quad 0.96966700 \quad-0.48015400 \quad 2.20186200$

$\mathrm{H} \quad 2.60885200 \quad-1.10216100 \quad 1.93681700$

$\begin{array}{llll}\mathrm{H} & 2.33381600 & 0.63532100 & 2.13496100\end{array}$

$\begin{array}{llll}\text { C } & -3.13241100 & 0.98431300 & -0.00964000\end{array}$

$\begin{array}{llll}\text { C } & -3.39659600 & -0.44206800 & -0.06945900\end{array}$

C $\quad-5.11888600 \quad-1.30810700 \quad 1.47393000$

SI128 


$\begin{array}{lrrr}\mathrm{H} & -4.43112100 & -2.07381700 & 1.84159000 \\ \mathrm{H} & -5.03443200 & -0.43467400 & 2.12919700 \\ \mathrm{H} & -6.13859300 & -1.69708100 & 1.55473500 \\ \mathrm{C} & -4.81697200 & -0.97907300 & -0.01820100 \\ \mathrm{C} & -4.95192500 & -2.26673400 & -0.85514900 \\ \mathrm{H} & -4.70425400 & -2.08715800 & -1.90615000 \\ \mathrm{H} & -4.29732100 & -3.05469100 & -0.48004900 \\ \mathrm{H} & -5.98579200 & -2.62181700 & -0.80587800 \\ \mathrm{C} & -5.59350900 & 1.48585800 & 0.03344100 \\ \mathrm{H} & -5.96946400 & 1.55280800 & 1.07248200 \\ \mathrm{H} & -6.16951100 & 2.25326600 & -0.50037200 \\ \mathrm{C} & -5.79697200 & 0.08754400 & -0.56316400 \\ \mathrm{H} & -6.82377700 & -0.24439900 & -0.38545600 \\ \mathrm{H} & -5.67605800 & 0.15821600 & -1.65144400 \\ \mathrm{C} & -4.17604300 & 1.88560400 & 0.08490400 \\ \mathrm{H} & -3.93911600 & 2.94155800 & 0.22079400\end{array}$

\section{3-1 Cation B}

Zero-point correction=

Thermal correction to Energy=

Thermal correction to Enthalpy=

Thermal correction to Gibbs Free Energy=

Sum of electronic and zero-point Energies $=$

Sum of electronic and thermal Energies=

Sum of electronic and thermal Enthalpies=

Sum of electronic and thermal Free Energies=
0.420705 (Hartree/Particle)

0.443551

0.444495

0.370024

$-1170.918655$

$-1170.895809$

$-1170.894864$

$-1170.969335$

11

$\begin{array}{llll}\mathrm{C} & -1.77585100 & 1.41984000 & -0.09232900\end{array}$

$\begin{array}{lllll}\mathrm{C} & & -0.70766300 & 0.51987900 & -0.14660200\end{array}$

$\begin{array}{llll}\mathrm{C} & -1.06376600 & -0.87415500 & -0.17400000\end{array}$

$\mathrm{N} \quad \begin{array}{llll}\mathrm{C} & -2.35948600 & -1.32364200 & -0.14004200\end{array}$

$\mathrm{H} \quad \begin{array}{llll}\mathrm{H} & -1.59274500 & 2.48821700 & -0.03903800\end{array}$

$\begin{array}{lllll}\mathrm{C} & -0.07353100 & -1.83422000 & -0.28374500\end{array}$

$\begin{array}{llll}\mathrm{H} & -0.39882800 & -2.87090400 & -0.35451200\end{array}$

$\begin{array}{llll}\text { C } & 0.70261400 & 0.91289400 & -0.16471400\end{array}$

$\begin{array}{llll}\mathrm{C} & 1.08801000 & 2.18247100 & -0.43346700\end{array}$

$\begin{array}{llll}\mathrm{H} & 0.39752200 & 2.97533100 & -0.69696900\end{array}$

$\begin{array}{llll}\mathrm{C} & 2.49239500 & 2.63125700 & -0.25972900\end{array}$

$\begin{array}{llll}\mathrm{O} & 2.78115800 & 3.80160300 & -0.16985400\end{array}$

$\begin{array}{llll}\mathrm{C} & 1.76636000 & -0.12994500 & 0.18481400\end{array}$

$\begin{array}{llll}\mathrm{C} & 1.36262100 & -1.51941400 & -0.37009400\end{array}$

$\mathrm{H} \quad 1.60810400 \quad-1.60412000 \quad-1.44751400$

$\mathrm{H} \quad \begin{array}{llll}\mathrm{H} & 1.95139500 & -2.31538400 & 0.10076100\end{array}$

$\begin{array}{llll}\mathrm{O} & 3.43129400 & 1.66486700 & -0.10847900\end{array}$

$\begin{array}{llll}\mathrm{C} & 3.09672800 & 0.31255900 & -0.50317800\end{array}$

$\begin{array}{llll}\mathrm{H} & 2.91762500 & 0.31892200 & -1.58829200\end{array}$

$\begin{array}{llll}\mathrm{C} & 4.29541700 & -0.53720400 & -0.21320300\end{array}$

$\begin{array}{llll}\mathrm{C} & 5.25542800 & -0.30923900 & 0.73367500\end{array}$

$\begin{array}{llll}\text { C } & 4.69599800 & -1.74121300 & -0.89770500\end{array}$

SI129 


$\begin{array}{lrrr}\mathrm{O} & 6.20181600 & -1.28184100 & 0.68715900 \\ \mathrm{H} & 5.41536200 & 0.48274300 & 1.44768500 \\ \mathrm{C} & 5.85357800 & -2.14682700 & -0.30540000 \\ \mathrm{H} & 4.21260500 & -2.22217100 & -1.73678200 \\ \mathrm{H} & 6.52504400 & -2.97426600 & -0.47230100 \\ \mathrm{C} & 1.90824800 & -0.20755400 & 1.72371500 \\ \mathrm{H} & 0.95974200 & -0.48201600 & 2.19584100 \\ \mathrm{H} & 2.65772300 & -0.95447900 & 1.99770900 \\ \mathrm{H} & 2.22218600 & 0.75557200 & 2.13375400 \\ \mathrm{C} & -3.09494700 & 0.96736000 & -0.07705500 \\ \mathrm{C} & -3.35252700 & -0.46591300 & -0.09229500 \\ \mathrm{C} & -4.94676300 & -1.58609400 & 1.44531000 \\ \mathrm{H} & -4.20333600 & -2.36040800 & 1.65435000 \\ \mathrm{H} & -4.84722700 & -0.80578600 & 2.20648000 \\ \mathrm{H} & -5.94218200 & -2.02970100 & 1.54588500 \\ \mathrm{C} & -4.76939700 & -1.03794300 & 0.00349100 \\ \mathrm{C} & -4.93966700 & -2.20042600 & -0.99830900 \\ \mathrm{H} & -4.77240000 & -1.86752300 & -2.02826400 \\ \mathrm{H} & -4.24892000 & -3.01824600 & -0.78414600 \\ \mathrm{H} & -5.96155400 & -2.58633900 & -0.93238400 \\ \mathrm{C} & -5.55604400 & 1.37810500 & 0.41348500 \\ \mathrm{H} & -5.53714800 & 1.24276400 & 1.50087500 \\ \mathrm{H} & -6.35409100 & 2.09625600 & 0.20396900 \\ \mathrm{C} & -5.82819500 & 0.05135200 & -0.29737900 \\ \mathrm{H} & -6.81185100 & -0.33878100 & -0.01677100 \\ \mathrm{H} & -5.86628300 & 0.22898100 & -1.38109300 \\ \mathrm{C} & -4.22087200 & 1.95987400 & -0.06330600 \\ \mathrm{H} & -3.92190000 & 2.84465900 & 0.51129300 \\ \mathrm{H} & -4.33563600 & 2.31244600 & -1.10273700\end{array}$

\section{3-1 Radical $A$}

Zero-point correction $=$

Thermal correction to Energy=

Thermal correction to Enthalpy=

Thermal correction to Gibbs Free Energy=

Sum of electronic and zero-point Energies=

Sum of electronic and thermal Energies=

Sum of electronic and thermal Enthalpies=

Sum of electronic and thermal Free Energies=
0.419664 (Hartree/Particle)

$$
0.442465
$$

0.443409

0.368612

$-1171.169641$

$-1171.146840$

$-1171.145896$

$-1171.220693$ 02

$\begin{array}{lrrr}\mathrm{C} & -1.79470500 & 1.41080800 & -0.08180700 \\ \mathrm{C} & -0.74369400 & 0.48897600 & -0.07638600 \\ \mathrm{C} & -1.09457800 & -0.88249700 & -0.03511800 \\ \mathrm{~N} & -2.37547900 & -1.30117700 & -0.02304400 \\ \mathrm{H} & -1.59263700 & 2.47729600 & -0.07541900 \\ \mathrm{C} & -0.04665000 & -1.96190500 & 0.02884400 \\ \mathrm{H} & -0.39022500 & -2.81637800 & -0.56317700 \\ \mathrm{H} & 0.01816700 & -2.32605800 & 1.06427300 \\ \mathrm{C} & 0.67671800 & 0.90764100 & -0.09498100\end{array}$




$\begin{array}{lrrr}\mathrm{C} & 1.05906000 & 2.18700600 & -0.31306000 \\ \mathrm{H} & 0.35719300 & 2.98675600 & -0.51549700 \\ \mathrm{C} & 2.44829300 & 2.64149000 & -0.15629500 \\ \mathrm{O} & 2.76551400 & 3.80994100 & -0.05174300 \\ \mathrm{C} & 1.75163700 & -0.14492200 & 0.18662000 \\ \mathrm{C} & 1.32476700 & -1.48701500 & -0.45254800 \\ \mathrm{H} & 1.29811200 & -1.36665200 & -1.54445700 \\ \mathrm{H} & 2.07725400 & -2.24960400 & -0.23120700 \\ \mathrm{O} & 3.40924200 & 1.67785600 & -0.06852700 \\ \mathrm{C} & 3.06074200 & 0.34133200 & -0.50214300 \\ \mathrm{H} & 2.85895200 & 0.38656700 & -1.58220200 \\ \mathrm{C} & 4.28251700 & -0.50100500 & -0.27353700 \\ \mathrm{C} & 5.29409900 & -0.25143000 & 0.60881100 \\ \mathrm{C} & 4.65747600 & -1.71012600 & -0.96272300 \\ \mathrm{O} & 6.25397100 & -1.21707900 & 0.52371200 \\ \mathrm{H} & 5.48093600 & 0.55031900 & 1.30429100 \\ \mathrm{C} & 5.85216700 & -2.09782100 & -0.43674300 \\ \mathrm{H} & 4.11665400 & -2.21137100 & -1.75287400 \\ \mathrm{H} & 6.51660300 & -2.92545700 & -0.62907900 \\ \mathrm{C} & 1.93981800 & -0.29035200 & 1.71479900 \\ \mathrm{H} & 0.98624000 & -0.48571100 & 2.21256400 \\ \mathrm{H} & 2.62222400 & -1.11550100 & 1.93983900 \\ \mathrm{H} & 2.35618100 & 0.62527900 & 2.14351500 \\ \mathrm{C} & -3.14582700 & 0.99090400 & -0.07564500 \\ \mathrm{C} & -3.37590400 & -0.43099900 & -0.05032700 \\ \mathrm{C} & -5.16219500 & -1.18460700 & 1.51455000 \\ \mathrm{H} & -4.49109100 & -1.92232700 & 1.96491300 \\ \mathrm{H} & -5.07859100 & -0.25874700 & 2.09246800 \\ \mathrm{H} & -6.19069200 & -1.55298000 & 1.60755600 \\ \mathrm{C} & -4.80323700 & -0.97714700 & 0.02006700 \\ \mathrm{C} & -4.91568800 & -2.32809200 & -0.71092700 \\ \mathrm{H} & -4.65172000 & -2.22726800 & -1.76933400 \\ \mathrm{H} & -4.24915900 & -3.07165800 & -0.26974500 \\ \mathrm{H} & -5.94584300 & -2.69737000 & -0.64988100 \\ \mathrm{C} & -5.64307700 & 1.46423500 & -0.09853800 \\ \mathrm{H} & -6.07533400 & 1.52911500 & 0.91451600 \\ \mathrm{H} & -6.24163800 & 2.15436900 & -0.70756300 \\ \mathrm{C} & -5.77398100 & 0.03316600 & -0.63993400 \\ \mathrm{H} & -6.80248900 & -0.32536700 & -0.51340200 \\ \mathrm{C} & -5.57579900 & 0.04779700 & -1.71987500 \\ -4.21654300 & 1.90972900 & -0.07198900 \\ \mathrm{H} & -3.99205300 & 2.97324900 & -0.03238400\end{array}$

\section{3-1 Radical B}

Zero-point correction=

Thermal correction to Energy=

Thermal correction to Enthalpy=

Thermal correction to Gibbs Free Energy=

Sum of electronic and zero-point Energies=
0.419655 (Hartree/Particle)

0.442428

0.443372

0.368639

$-1171.169223$

SI131 
$\begin{array}{ll}\text { Sum of electronic and thermal Energies }= & -1171.146450 \\ \text { Sum of electronic and thermal Enthalpies }= & -1171.145506 \\ \text { Sum of electronic and thermal Free Energies }= & -1171.220240\end{array}$

02

$\begin{array}{lrrr}\mathrm{C} & -1.77587900 & 1.39728500 & -0.12514000 \\ \mathrm{C} & -0.71515700 & 0.48908700 & -0.20492500 \\ \mathrm{C} & -1.06236200 & -0.90394300 & -0.22295900 \\ \mathrm{~N} & -2.36161600 & -1.31999300 & -0.15290300 \\ \mathrm{H} & -1.57177800 & 2.46308500 & -0.06770200 \\ \mathrm{C} & -0.06539700 & -1.88492700 & -0.33007300 \\ \mathrm{H} & -0.37297400 & -2.92526800 & -0.35752900 \\ \mathrm{C} & 0.69408400 & 0.89606300 & -0.22398200 \\ \mathrm{C} & 1.09191600 & 2.17130500 & -0.46197000 \\ \mathrm{H} & 0.39673500 & 2.96382800 & -0.71235600 \\ \mathrm{C} & 2.47180900 & 2.62637300 & -0.25280400 \\ \mathrm{O} & 2.79188500 & 3.79640700 & -0.17625100 \\ \mathrm{C} & 1.75194600 & -0.15647100 & 0.12191700 \\ \mathrm{C} & 1.37079200 & -1.52122500 & -0.50997200 \\ \mathrm{H} & 1.59028500 & -1.49234200 & -1.59292100 \\ \mathrm{H} & 2.01659400 & -2.30310500 & -0.09683700 \\ \mathrm{O} & 3.42131700 & 1.66135900 & -0.07054300 \\ \mathrm{C} & 3.09879500 & 0.31784100 & -0.49672700 \\ \mathrm{H} & 2.96052000 & 0.34217500 & -1.58765300 \\ \mathrm{C} & 4.30261600 & -0.52186400 & -0.18054300 \\ \mathrm{C} & 5.27590300 & -0.24088300 & 0.73458800 \\ \mathrm{C} & 4.69723800 & -1.76211000 & -0.79983200 \\ \mathrm{O} & 6.23095700 & -1.21517800 & 0.73309900 \\ \mathrm{H} & 5.43659500 & 0.58819700 & 1.40400200 \\ \mathrm{C} & 5.86468700 & -2.13382300 & -0.20548100 \\ \mathrm{H} & 4.18837300 & -2.29455500 & -1.59071900 \\ \mathrm{H} & 6.53018500 & -2.97305600 & -0.33297400 \\ \mathrm{C} & 1.84060300 & -0.28845400 & 1.66027700 \\ \mathrm{H} & 0.87056100 & -0.57161000 & 2.07820400 \\ \mathrm{H} & 2.57010000 & -1.05571100 & 1.93551100 \\ \mathrm{H} & 2.14689100 & 0.65663900 & 2.11697600 \\ \mathrm{C} & -3.10294900 & 0.97203200 & -0.08371800 \\ \mathrm{C} & -3.34719000 & -0.43474400 & -0.09582100 \\ \mathrm{C} & -4.91179600 & -1.65281800 & 1.42173100 \\ \mathrm{H} & -4.14375600 & -2.41614400 & 1.57422100 \\ \mathrm{H} & -4.81092800 & -0.90973200 & 2.21977900 \\ \mathrm{H} & -5.89615900 & -2.12511300 & 1.51994700 \\ \mathrm{C} & -4.76516800 & -1.01914500 & 0.01558400 \\ \mathrm{C} & -4.96460200 & -2.12239200 & -1.04538200 \\ \mathrm{H} & -4.83164100 & -1.72549400 & -2.05811600 \\ \mathrm{H} & -4.24929900 & -2.93522300 & -0.90361900 \\ \mathrm{H} & -5.98004400 & -2.52863700 & -0.97141400 \\ \mathrm{C} & -5.52390100 & 1.38640400 & 0.53340700 \\ \mathrm{H} & -5.42344300 & 1.21112200 & 1.61194300 \\ \mathrm{H} & -6.34570100 & 2.10048600 & 0.40787000 \\ \mathrm{C} & -5.83876300 & 0.07700100 & -0.19437100 \\ \mathrm{H} & -6.81039300 & -0.32052400 & 0.12309200 \\ & & & \\ & & & \end{array}$

SI132 


$\begin{array}{lrrr}\mathrm{H} & -5.92837700 & 0.28936900 & -1.26941000 \\ \mathrm{C} & -4.22708700 & 1.98386100 & -0.02098400 \\ \mathrm{H} & -3.90701600 & 2.85100700 & 0.56950500 \\ \mathrm{H} & -4.41810500 & 2.36313600 & -1.03683900\end{array}$

\section{0-1 Cation $A$}

Zero-point correction $=$

Thermal correction to Energy=

Thermal correction to Enthalpy=

Thermal correction to Gibbs Free Energy=

Sum of electronic and zero-point Energies $=$

Sum of electronic and thermal Energies $=$

Sum of electronic and thermal Enthalpies=

Sum of electronic and thermal Free Energies=
0.469682 (Hartree/Particle) 0.496681

0.497626

0.414472

$-1436.917117$

$-1436.890118$

$-1436.889174$

$-1436.972327$

11

C

$\mathrm{C}$

$\begin{array}{lll}-2.33114000 & -0.41346100 & -0.42979700\end{array}$

$\begin{array}{llll}-2.08095400 & 0.98703800 & -0.21959700\end{array}$

C $\quad-0.72317300 \quad 1.42362900 \quad-0.15642600$

C $\quad 0.31307100 \quad 0.51187100 \quad-0.25320800$

C $\quad-0.06728400 \quad-0.87025600 \quad-0.30772800$

$\mathrm{N} \quad-1.34588100 \quad-1.28655000 \quad-0.44808900$

$\begin{array}{llll}\mathrm{H} & -0.52278200 & 2.47761800 & 0.01151000\end{array}$

$\begin{array}{llll}\mathrm{C} & 0.95950000 & -1.94341800 & -0.17656900\end{array}$

$\mathrm{H} \quad 0.64336100 \quad-2.80094700 \quad-0.77943300$

$\mathrm{H} \quad 0.90105600 \quad-2.29740100 \quad 0.86617600$

C $\quad 1.74210000 \quad 0.90194200 \quad-0.21253200$

$\begin{array}{llll}\mathrm{C} & 2.13323100 & 2.16543300 & -0.47123000\end{array}$

$\mathrm{H} \quad 1.45479400 \quad 2.95611700 \quad-0.77340100$

$\begin{array}{llll}\mathrm{C} & 3.52087200 & 2.62319300 & -0.21931300\end{array}$

O $\quad 3.80296100 \quad 3.79547000 \quad-0.11355200$

$\begin{array}{llll}\text { C } & 2.78085800 & -0.15678200 & 0.15296600\end{array}$

C $\quad 2.38232800 \quad-1.49286500 \quad-0.51949500$

$\mathrm{H} \quad 2.46545900-1.38869100 \quad-1.60915800$

$\mathrm{H} \quad 3.08566800 \quad-2.27431900 \quad-0.22123900$

O $\quad 4.45309200 \quad 1.66104100 \quad-0.01993900$

C $\quad 4.14180200 \quad 0.31121800 \quad-0.45259000$

$\mathrm{H} \quad 4.02004700 \quad 0.33646500 \quad-1.54477400$

$\begin{array}{llll}\mathrm{C} & 5.33348100 & -0.53132300 & -0.11437500\end{array}$

$\begin{array}{llll}\text { C } & 6.25990600 & -0.28890800 & 0.86111400\end{array}$

C $\quad 5.76211900 \quad-1.74026000 \quad-0.77145800$

$\begin{array}{llll}\mathrm{O} & 7.21325300 & -1.25806400 & 0.85831700\end{array}$

$\begin{array}{llll}\mathrm{H} & 6.39046000 & 0.51064500 & 1.57233500\end{array}$

C $\quad 6.90085300 \quad-2.13469400 \quad-0.13668100$

$\mathrm{H} \quad 5.30324200 \quad-2.23332900-1.61688100$

$\mathrm{H} \quad 7.57934900 \quad-2.96231600 \quad-0.27095700$

$\begin{array}{llll}\mathrm{C} & 2.86018700 & -0.30164400 & 1.68983500\end{array}$

$\mathrm{H} \quad 1.87888000 \quad-0.50887400 \quad 2.12807400$

$\mathrm{H} \quad 3.53516500 \quad-1.11805300 \quad 1.95976300$

$\mathrm{H} \quad 3.23696500 \quad 0.61675000 \quad 2.14768900$

SI133 


$\begin{array}{lrrr}\mathrm{C} & -3.73986000 & -0.93819900 & -0.66638100 \\ \mathrm{C} & -5.39728500 & -1.68148900 & 0.79315500 \\ \mathrm{O} & -4.05730700 & -1.77781600 & 0.47708300 \\ \mathrm{C} & -3.75848700 & -1.79435000 & -1.94017400 \\ \mathrm{H} & -3.45079100 & -1.20525900 & -2.81032600 \\ \mathrm{H} & -3.07729200 & -2.63835300 & -1.82414800 \\ \mathrm{H} & -4.76489300 & -2.17871000 & -2.12504100 \\ \mathrm{O} & -5.89106200 & -2.33430700 & 1.66761900 \\ \mathrm{C} & -6.04470000 & -0.65048100 & -0.12186100 \\ \mathrm{H} & -6.57652300 & -1.18400500 & -0.91655900 \\ \mathrm{H} & -6.79399100 & -0.07430000 & 0.42133800 \\ \mathrm{C} & -4.85615200 & 0.15118600 & -0.67837800 \\ \mathrm{H} & -5.03207200 & 0.45332600 & -1.71536500 \\ \mathrm{C} & -3.13571000 & 1.86172100 & -0.01804600 \\ \mathrm{H} & -2.90014700 & 2.91426400 & 0.15077200 \\ \mathrm{C} & -4.55193400 & 1.46331800 & 0.11460000 \\ \mathrm{C} & -5.48391400 & 2.60166900 & -0.36375600 \\ \mathrm{H} & -5.30655300 & 3.52178100 & 0.20144600 \\ \mathrm{H} & -5.34204000 & 2.81494400 & -1.42753200 \\ \mathrm{H} & -6.52878900 & 2.31724700 & -0.21336200 \\ \mathrm{C} & -4.70010100 & 1.32669800 & 1.68187600 \\ \mathrm{H} & -5.75851300 & 1.18887300 & 1.91829800 \\ \mathrm{H} & -4.12961300 & 0.48605800 & 2.08107500 \\ \mathrm{H} & -4.37446500 & 2.24099600 & 2.18639800\end{array}$

\section{0-1 Cation B}

Zero-point correction $=$

Thermal correction to Energy=

Thermal correction to Enthalpy=

Thermal correction to Gibbs Free

Sum of electronic and zero-point Energies $=$

Sum of electronic and thermal Energies $=$

Sum of electronic and thermal Enthalpies=

Sum of electronic and thermal Free Energies=
0.469096 (Hartree/Particle) 0.496001

0.496946

0.414017

$-1436.918372$

$-1436.891467$

$-1436.890522$

$-1436.973451$

11

$\begin{array}{lrrr}\mathrm{C} & -2.32902300 & -0.37500500 & -0.61667000 \\ \mathrm{C} & -2.07232200 & 1.04288000 & -0.51005100 \\ \mathrm{C} & -0.75511100 & 1.48133700 & -0.39616700 \\ \mathrm{C} & 0.30249800 & 0.56326500 & -0.40180900 \\ \mathrm{C} & -0.06386600 & -0.82319700 & -0.52751700 \\ \mathrm{~N} & -1.36138800 & -1.25556700 & -0.63640900 \\ \mathrm{H} & -0.56565200 & 2.54186400 & -0.26820400 \\ \mathrm{C} & 0.91955400 & -1.79665800 & -0.58333800 \\ \mathrm{H} & 0.58652500 & -2.82371400 & -0.72572800 \\ \mathrm{C} & 1.71311500 & 0.93167000 & -0.27254900 \\ \mathrm{C} & 2.13712100 & 2.20512800 & -0.45004300 \\ \mathrm{H} & 1.48386500 & 3.02009200 & -0.73991200 \\ \mathrm{C} & 3.52644700 & 2.62251900 & -0.13193600 \\ \mathrm{O} & 3.81816500 & 3.78325500 & 0.03716300\end{array}$

SI134 


$\begin{array}{lrrr}\mathrm{C} & 2.72785200 & -0.14205800 & 0.12669300 \\ \mathrm{C} & 2.35954200 & -1.50176900 & -0.52008000 \\ \mathrm{H} & 2.69979800 & -1.54737500 & -1.57439700 \\ \mathrm{H} & 2.89310300 & -2.32656900 & -0.03326900 \\ \mathrm{O} & 4.43587200 & 1.63589900 & 0.05718200 \\ \mathrm{C} & 4.12026000 & 0.30576100 & -0.42142500 \\ \mathrm{H} & 4.03906800 & 0.35932500 & -1.51685000 \\ \mathrm{C} & 5.27694300 & -0.57483800 & -0.06185000 \\ \mathrm{C} & 6.14642500 & -0.40611000 & 0.98030700 \\ \mathrm{C} & 5.72581300 & -1.75225900 & -0.76236100 \\ \mathrm{O} & 7.08162800 & -1.39012900 & 0.97563900 \\ \mathrm{H} & 6.24753800 & 0.34901600 & 1.74333900 \\ \mathrm{C} & 6.81791800 & -2.20311300 & -0.08461900 \\ \mathrm{H} & 5.31819000 & -2.18626600 & -1.66492600 \\ \mathrm{H} & 7.49228400 & -3.03277300 & -0.22696900 \\ \mathrm{C} & 2.72893600 & -0.28498000 & 1.66731500 \\ \mathrm{H} & 1.73848400 & -0.56244300 & 2.04141400 \\ \mathrm{H} & 3.44069200 & -1.05514600 & 1.97517400 \\ \mathrm{H} & 3.01800000 & 0.65513200 & 2.14365200 \\ \mathrm{C} & -3.75404500 & -0.91902800 & -0.71683700 \\ \mathrm{C} & -5.13298400 & -1.82010700 & 0.93875900 \\ \mathrm{O} & -3.88398300 & -1.87842400 & 0.36467200 \\ \mathrm{C} & -3.92487000 & -1.65998900 & -2.05116700 \\ \mathrm{H} & -3.75651700 & -0.98555400 & -2.89771200 \\ \mathrm{H} & -3.21548100 & -2.48795500 & -2.10932300 \\ \mathrm{H} & -4.93876500 & -2.06161200 & -2.13163000 \\ \mathrm{H} & -5.45649300 & -2.55965000 & 1.82640200 \\ \mathrm{C} & -5.93685500 & -0.72244400 & 0.26240600 \\ \mathrm{H} & -6.64220900 & -1.19924800 & -0.42713600 \\ \mathrm{H} & -6.53474900 & -0.18546400 & 0.99981300 \\ \mathrm{H} & -4.89339400 & 0.12795100 & -0.48109300 \\ \mathrm{C} & -5.27643300 & 0.43799800 & -1.45923700 \\ \mathrm{H} & -4.45972200 & 1.42744400 & 0.26105900 \\ \mathrm{C} & -5.58995700 & 2.47063200 & 0.17102600 \\ \mathrm{H} & -5.29052200 & 3.40905500 & 0.64930400 \\ \mathrm{H} & -5.85386000 & 2.69036300 & -0.86944200 \\ \mathrm{H} & -6.49356200 & 2.12193200 & 0.67956300 \\ \mathrm{H} & -4.09361100 & 1.19977300 & 1.74421300 \\ \mathrm{H} & -36156300 & 0.87749200 & 2.32524100 \\ \mathrm{H} & -39700 & 0.44677400 & 1.88417200 \\ \mathrm{H} & 2.13509100 & 2.19116800 \\ \mathrm{H} & -3900 & 1.99114300 & -0.49574900 \\ \mathrm{H} & 2.95560400 & -0.07936700 \\ \mathrm{H} & 2.18804300 & -1.54143600\end{array}$

\section{0-1 Radical A}

Zero-point correction $=$

Thermal correction to Energy=

Thermal correction to Enthalpy=
0.468737 (Hartree/Particle)

0.495539

0.496483 


$\begin{array}{lc}\text { Thermal correction to Gibbs Free Energy= } & 0.413300 \\ \text { Sum of electronic and zero-point Energies }= & -1437.171300 \\ \text { Sum of electronic and thermal Energies }= & -1437.144499 \\ \text { Sum of electronic and thermal Enthalpies }= & -1437.143554 \\ \text { Sum of electronic and thermal Free Energies }= & -1437.226737\end{array}$

02

$\begin{array}{llll}\text { C } & -2.31229300 & -0.38972300 & -0.36974300\end{array}$

$\begin{array}{llll}\text { C } & -2.08303500 & 1.01754000 & -0.27058800\end{array}$

$\begin{array}{lllll}\mathrm{C} & -0.72841000 & 1.42829100 & -0.22539400\end{array}$

$\begin{array}{llll}\mathrm{C} & 0.31087500 & 0.49738900 & -0.21716900\end{array}$

$\begin{array}{llll}\mathrm{C} & -0.05133800 & -0.87597900 & -0.23118400\end{array}$

$\mathrm{N} \quad \quad-1.32788000 \quad-1.27899800 \quad-0.33960100$

$\mathrm{H} \quad-0.51841800 \quad 2.49077700 \quad-0.15465100$

C $\quad 0.98335400 \quad-1.96231100 \quad-0.11040700$

$\mathrm{H} \quad 0.67008600 \quad-2.81219700 \quad-0.72480200$

$\mathrm{H} \quad 0.97939400 \quad-2.32935000 \quad 0.92578300$

$\begin{array}{llll}\mathrm{C} & 1.73584100 & 0.90245300 & -0.16826600\end{array}$

C $\quad 2.13587500 \quad 2.17718700 \quad-0.37527400$

$\begin{array}{llll}\mathrm{H} & 1.45065400 & 2.97948700 & -0.62120800\end{array}$

C $\quad 3.51890400 \quad 2.62443300 \quad-0.14454900$

$\begin{array}{llll}\mathrm{O} & 3.83365700 & 3.79190000 & -0.02800000\end{array}$

$\begin{array}{llll}\text { C } & 2.78545800 & -0.15892600 & 0.16773200\end{array}$

C $\quad 2.38555200 \quad-1.49476600 \quad-0.50318300$

$\mathrm{H} \quad 2.42775800 \quad-1.36977200 \quad-1.59413500$

$\mathrm{H} \quad 3.11635700 \quad-2.26494300 \quad-0.23988500$

$\begin{array}{llll}\mathrm{O} & 4.46521000 & 1.65573800 & 0.00378600\end{array}$

C $\quad 4.13442900 \quad 0.31925700 \quad-0.44616000$

$\mathrm{H} \quad 3.99464200 \quad 0.36382300 \quad-1.53593100$

$\begin{array}{llll}\mathrm{C} & 5.33608100 & -0.52921400 & -0.14717500\end{array}$

$\begin{array}{llll}\mathrm{C} & 6.29541600 & -0.28594000 & 0.79346900\end{array}$

$\begin{array}{llll}\text { C } & 5.74340600 & -1.74011400 & -0.81427100\end{array}$

$\begin{array}{llll}\mathrm{O} & 7.25270100 & -1.25687800 & 0.76348400\end{array}$

$\begin{array}{llll}\mathrm{H} & 6.44582700 & 0.51422200 & 1.49952800\end{array}$

$\begin{array}{llll}\text { C } & 6.90287000 & -2.13503600 & -0.21934800\end{array}$

$\mathrm{H} \quad 5.24673900 \quad-2.23786300 \quad-1.63497800$

$\mathrm{H} \quad 7.57236100-2.96669700 \quad-0.37267900$

C $\quad 2.88595000 \quad-0.31380600 \quad 1.70295300$

$\mathrm{H} \quad 1.90602200 \quad-0.51279500 \quad 2.14506700$

$\mathrm{H} \quad 3.55447500 \quad-1.14048900 \quad 1.96070300$

$\begin{array}{llll}\mathrm{H} & 3.27703400 & 0.59890000 & 2.16086400\end{array}$

$\begin{array}{llll}\text { C } & -3.71388600 & -0.93088700 & -0.61089900\end{array}$

$\begin{array}{llll}\text { C } & -5.43509000 & -1.67467800 & 0.77143600\end{array}$

$\begin{array}{llll}\mathrm{O} & -4.09663300 & -1.76251700 & 0.53719000\end{array}$

C $\quad-3.70472200 \quad-1.83384500 \quad-1.85345100$

$\mathrm{H} \quad-3.38316100 \quad-1.26635700 \quad-2.73295000$

$\mathrm{H} \quad-3.00797700 \quad-2.65845700 \quad-1.69536100$

$\mathrm{H} \quad-4.70123000 \quad-2.24111800 \quad-2.04908100$

$\begin{array}{llll}\mathrm{O} & -5.98985800 & -2.33573700 & 1.61439600\end{array}$

C $\quad-6.04538300 \quad-0.65001400-0.17559700$

$\mathrm{H} \quad-6.55259600 \quad-1.19364300 \quad-0.98028500$

$\mathrm{H} \quad-6.80871100 \quad-0.06596100 \quad 0.33965400$

SI136 


$\begin{array}{lrrr}\mathrm{C} & -4.83683200 & 0.14731000 & -0.69398000 \\ \mathrm{H} & -4.96570500 & 0.42279200 & -1.74580100 \\ \mathrm{C} & -3.15657000 & 1.92842600 & -0.18438300 \\ \mathrm{H} & -2.93754900 & 2.99312500 & -0.13026900 \\ \mathrm{C} & -4.56646300 & 1.47644200 & 0.08450800 \\ \mathrm{C} & -5.56363300 & 2.55013500 & -0.40007900 \\ \mathrm{H} & -5.39148100 & 3.49764300 & 0.12222400 \\ \mathrm{H} & -5.45915800 & 2.73291700 & -1.47510900 \\ \mathrm{H} & -6.59870100 & 2.25046700 & -0.20480500 \\ \mathrm{C} & -4.70851200 & 1.32614200 & 1.62896300 \\ \mathrm{H} & -5.73372500 & 1.07516000 & 1.91936700 \\ \mathrm{H} & -4.03948900 & 0.55959800 & 2.02862200 \\ \mathrm{H} & -4.45596300 & 2.27508300 & 2.11272600\end{array}$

\section{0-1 Radical B}

Zero-point correction $=$

Thermal correction to Energy=

Thermal correction to Enthalpy=

Thermal correction to Gibbs Free Energy=

Sum of electronic and zero-point Energies=

Sum of electronic and thermal Energies=

Sum of electronic and thermal Enthalpies=

Sum of electronic and thermal Free Energies=
0.468364 (Hartree/Particle) 0.495178

0.496122

0.412956

$-1437.175482$

$-1437.148668$

$-1437.147724$

$-1437.230890$

02

$\begin{array}{lrrr}\mathrm{C} & -2.31406500 & -0.36517700 & -0.58602100 \\ \mathrm{C} & -2.07138400 & 1.02945700 & -0.48986800 \\ \mathrm{C} & -0.74330700 & 1.44354800 & -0.40242400 \\ \mathrm{C} & 0.30830100 & 0.52158800 & -0.43900800 \\ \mathrm{C} & -0.04683000 & -0.86597500 & -0.55680700 \\ \mathrm{~N} & -1.35047000 & -1.26950700 & -0.62433700 \\ \mathrm{H} & -0.53446600 & 2.50168700 & -0.27323600 \\ \mathrm{C} & 0.94651000 & -1.85404500 & -0.62619500 \\ \mathrm{H} & 0.63087100 & -2.88731700 & -0.72705400 \\ \mathrm{C} & 1.71975300 & 0.90822200 & -0.32109400 \\ \mathrm{C} & 2.14649500 & 2.18643700 & -0.47154300 \\ \mathrm{H} & 1.48275000 & 2.99766100 & -0.74641600 \\ \mathrm{C} & 3.50925200 & 2.61566700 & -0.12854300 \\ \mathrm{O} & 3.82873800 & 3.77786100 & 0.02456200 \\ \mathrm{C} & 2.73378700 & -0.17207200 & 0.06626100 \\ \mathrm{C} & 2.39640700 & -1.50310300 & -0.65676900 \\ \mathrm{H} & 2.71517200 & -1.43301200 & -1.71275600 \\ \mathrm{H} & 2.99142800 & -2.31238000 & -0.22080200 \\ \mathrm{O} & 4.42992700 & 1.63292000 & 0.09209800 \\ \mathrm{C} & 4.13327100 & 0.31109000 & -0.41485200 \\ \mathrm{H} & 4.08901700 & 0.38199400 & -1.51157400 \\ \mathrm{C} & 5.29823600 & -0.55501200 & -0.03209200 \\ \mathrm{C} & 6.19307300 & -0.32150300 & 0.97217100 \\ \mathrm{C} & 5.73139300 & -1.77611500 & -0.66348500 \\ \mathrm{O} & 7.13537500 & -1.30676900 & 1.01236800\end{array}$




$\begin{array}{lrrr}\mathrm{H} & 6.30478800 & 0.47924200 & 1.68465900 \\ \mathrm{C} & 6.84096900 & -2.18471500 & 0.01182700 \\ \mathrm{H} & 5.28658900 & -2.27232100 & -1.51428100 \\ \mathrm{H} & 7.50648000 & -3.02728700 & -0.09136700 \\ \mathrm{C} & 2.68831800 & -0.37363700 & 1.59871900 \\ \mathrm{H} & 1.68479200 & -0.66744600 & 1.91892100 \\ \mathrm{H} & 3.38790600 & -1.15885200 & 1.89917100 \\ \mathrm{H} & 2.95895900 & 0.54699200 & 2.12283200 \\ \mathrm{C} & -3.73896000 & -0.90843600 & -0.68010300 \\ \mathrm{C} & -5.18463000 & -1.78750300 & 0.92739800 \\ \mathrm{O} & -3.92105500 & -1.84793100 & 0.42972600 \\ \mathrm{C} & -3.90445300 & -1.69746600 & -1.98611400 \\ \mathrm{H} & -3.72319600 & -1.04804600 & -2.84927500 \\ \mathrm{H} & -3.18405600 & -2.51726100 & -2.00712900 \\ \mathrm{H} & -4.91602100 & -2.10767300 & -2.06833600 \\ \mathrm{O} & -5.57227500 & -2.52226600 & 1.80261200 \\ \mathrm{C} & -5.95823500 & -0.69307000 & 0.20832800 \\ \mathrm{H} & -6.63447800 & -1.17501700 & -0.50673700 \\ \mathrm{H} & -6.58409700 & -0.14873800 & 0.91711500 \\ \mathrm{C} & -4.87810200 & 0.14583100 & -0.49302800 \\ \mathrm{H} & -5.21674400 & 0.45851200 & -1.48744200 \\ \mathrm{C} & -4.46490300 & 1.44461500 & 0.26334400 \\ \mathrm{C} & -5.60161700 & 2.47942600 & 0.15259500 \\ \mathrm{H} & -5.31134400 & 3.42075600 & 0.63254300 \\ \mathrm{H} & -5.84324500 & 2.69738500 & -0.89440700 \\ \mathrm{H} & -6.51677800 & 2.13213000 & 0.64334200 \\ \mathrm{C} & -4.14433600 & 1.20800000 & 1.75543900 \\ \mathrm{H} & -5.02134300 & 0.85673100 & 2.30762300 \\ \mathrm{H} & -3.34359200 & 0.47883500 & 1.90497600 \\ \mathrm{H} & -3.82674500 & 2.14874200 & 2.21902700 \\ \mathrm{C} & -3.21804500 & 2.00661400 & -0.45741100 \\ \mathrm{H} & -2.89644000 & 2.93866000 & 0.02293200 \\ \mathrm{H} & -3.49998700 & 2.27606100 & -1.48725400\end{array}$

Calculations conducted with $\omega \mathrm{B} 97 \mathrm{x}-\mathrm{D} / 6-311++\mathrm{G}(\mathrm{d}, \mathrm{p}) / / \omega \mathrm{B} 97 \mathrm{x}-\mathrm{D} / 6-31+\mathrm{G}(\mathrm{d}, \mathrm{p})$ :

\section{3-1 Cation A}

Zero-point correction $=$

Thermal correction to Energy=

Thermal correction to Enthalpy=

Thermal correction to Gibbs Free Energy=

Sum of electronic and zero-point Energies=

Sum of electronic and thermal Energies=

Sum of electronic and thermal Enthalpies=

Sum of electronic and thermal Free Energies=
0.426360 (Hartree/Particle)

0.448900

0.449844

0.376011

$-1170.551751$

$-1170.529212$

$-1170.528267$

$-1170.602101$

11

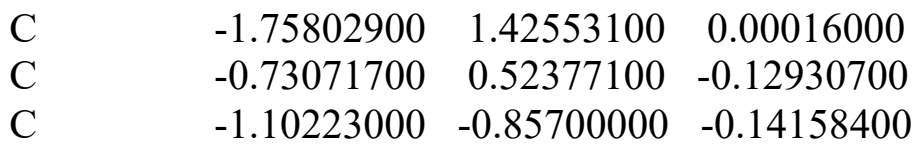

SI138 


\begin{tabular}{|c|c|c|c|}
\hline $\mathrm{N}$ & -2.37343500 & -1.29743100 & -0.12338700 \\
\hline $\mathrm{H}$ & -1.55947000 & 2.48814600 & 0.10786300 \\
\hline $\mathrm{C}$ & -0.05774900 & -1.91846300 & -0.12443900 \\
\hline $\mathrm{H}$ & -0.41376900 & -2.75869700 & -0.72754700 \\
\hline $\mathrm{H}$ & -0.03369700 & -2.29792700 & 0.90863900 \\
\hline $\mathrm{C}$ & 0.69552900 & 0.92467600 & -0.17711000 \\
\hline $\mathrm{C}$ & 1.06626700 & 2.18420100 & -0.44457100 \\
\hline $\mathrm{H}$ & 0.37660700 & 2.97954100 & -0.70454900 \\
\hline $\mathrm{C}$ & 2.46562100 & 2.63833300 & -0.24919500 \\
\hline $\mathrm{O}$ & 2.75021100 & 3.80366400 & -0.14214600 \\
\hline $\mathrm{C}$ & 1.74845700 & -0.12998100 & 0.11928700 \\
\hline $\mathrm{C}$ & 1.32431900 & -1.44533900 & -0.56014000 \\
\hline $\mathrm{H}$ & 1.32998500 & -1.30979500 & -1.64904500 \\
\hline $\mathrm{H}$ & 2.05531700 & -2.22456600 & -0.33113800 \\
\hline $\mathrm{O}$ & 3.39913800 & 1.68049800 & -0.10270200 \\
\hline $\mathrm{C}$ & 3.07187500 & 0.34990900 & -0.53253000 \\
\hline $\mathrm{H}$ & 2.91488500 & 0.37840900 & -1.62025200 \\
\hline $\mathrm{C}$ & 4.26053200 & -0.50345200 & -0.23206700 \\
\hline $\mathrm{C}$ & 5.20465200 & -0.27792800 & 0.72120600 \\
\hline $\mathrm{C}$ & 4.64798100 & -1.72186700 & -0.88733500 \\
\hline $\mathrm{O}$ & 6.13024500 & -1.26146600 & 0.70707600 \\
\hline $\mathrm{H}$ & 5.35817700 & 0.52136300 & 1.42799800 \\
\hline $\mathrm{C}$ & 5.78532400 & -2.13144400 & -0.26940100 \\
\hline $\mathrm{H}$ & 4.16369100 & -2.20911200 & -1.72148500 \\
\hline $\mathrm{H}$ & 6.44368900 & -2.97326300 & -0.41156500 \\
\hline $\mathrm{C}$ & 1.89451700 & -0.30180000 & 1.64094300 \\
\hline $\mathrm{H}$ & 0.92689700 & -0.47711700 & 2.12175700 \\
\hline $\mathrm{H}$ & 2.55121900 & -1.14552800 & 1.86773900 \\
\hline $\mathrm{H}$ & 2.32663200 & 0.59681000 & 2.08878500 \\
\hline $\mathrm{C}$ & -3.11395700 & 0.97973100 & 0.00783500 \\
\hline $\mathrm{C}$ & -3.37230200 & -0.43877700 & -0.07751100 \\
\hline $\mathrm{C}$ & -5.04533800 & -1.30666100 & 1.48884000 \\
\hline $\mathrm{H}$ & -4.35072400 & -2.07583800 & 1.83472300 \\
\hline $\mathrm{H}$ & -4.93688600 & -0.43437700 & 2.14179000 \\
\hline $\mathrm{H}$ & -6.06368700 & -1.69022000 & 1.59777000 \\
\hline $\mathrm{C}$ & -4.78402300 & -0.97783700 & -0.00243700 \\
\hline $\mathrm{C}$ & -4.92912300 & -2.25597800 & -0.83887500 \\
\hline $\mathrm{H}$ & -4.69598900 & -2.07050200 & -1.89156900 \\
\hline $\mathrm{H}$ & -4.26843900 & -3.04410700 & -0.47578000 \\
\hline $\mathrm{H}$ & -5.96155300 & -2.61107200 & -0.7754860 \\
\hline $\mathrm{C}$ & -5.56884600 & 1.46427500 & 0.10792200 \\
\hline $\mathrm{H}$ & -5.91757900 & 1.49716100 & 1.15591300 \\
\hline $\mathrm{H}$ & -6.15717400 & 2.24065300 & -0.3942560 \\
\hline $\mathrm{C}$ & -5.77094100 & 0.08572400 & -0.5187950 \\
\hline $\mathrm{H}$ & -6.79329300 & -0.25615200 & -0.33768500 \\
\hline $\mathrm{H}$ & -5.65866000 & 0.17910400 & -1.60578300 \\
\hline $\mathrm{C}$ & -4.15476100 & 1.86947500 & $0.1425130 \mathrm{C}$ \\
\hline $\mathrm{H}$ & -3.92122900 & 2.92294800 & 0.29861200 \\
\hline
\end{tabular}




\section{3-1 Cation B}

Zero-point correction $=$

Thermal correction to Energy=

0.426257 (Hartree/Particle)

Thermal correction to Enthalpy=

0.448761

Thermal correction to Gibbs Free Energy=

0.449705

Sum of electronic and zero-point Energies=

0.375868

Sum of electronic and thermal Energies $=$

$-1170.543183$

Sum of electronic and thermal Enthalpies=

$-1170.520679$

$-1170.519735$

Sum of electronic and thermal Free Energies $=\quad-1170.593573$

11

$\begin{array}{llll}\text { C } & -1.76376900 & 1.42392900 & -0.07470100\end{array}$

$\begin{array}{llll}\text { C } & -0.70249000 & 0.52672700 & -0.16838800\end{array}$

C $\quad-1.05280800 \quad-0.85820700 \quad-0.21852800$

$\mathrm{N} \quad-2.34279900 \quad-1.31345000 \quad-0.17774100$

$\mathrm{H} \quad-1.58124000 \quad 2.49081300 \quad 0.00346600$

C $\quad-0.06477700 \quad-1.81043300 \quad-0.35463500$

$\mathrm{H} \quad-0.38895700 \quad-2.84611500 \quad-0.44056600$

C $\quad 0.70842300 \quad 0.92219600 \quad-0.19749300$

$\begin{array}{llll}\mathrm{C} & 1.08769300 & 2.18520900 & -0.45654600\end{array}$

$\mathrm{H} \quad 0.39996300 \quad 2.98226100 \quad-0.71397300$

$\begin{array}{llll}\mathrm{C} & 2.49621900 & 2.62775300 & -0.27488000\end{array}$

$\begin{array}{llll}\mathrm{O} & 2.78604400 & 3.79041600 & -0.17679800\end{array}$

C $\quad 1.76399600 \quad-0.12125200 \quad 0.13852300$

$\begin{array}{llll}\mathrm{C} & 1.36614700 & -1.49126700 & -0.44592400\end{array}$

$\mathrm{H} \quad 1.59324400 \quad-1.54387700 \quad-1.52828200$

$\mathrm{H} \quad 1.96166300 \quad-2.29633000 \quad-0.00155700$

O $\quad 3.42366500 \quad 1.66288800 \quad-0.12642000$

C $\quad 3.09129900 \quad 0.32853300 \quad-0.52894900$

$\mathrm{H} \quad 2.93294600 \quad 0.33457600 \quad-1.61748500$

$\begin{array}{llll}\mathrm{C} & 4.26834000 & -0.53274000 & -0.20865500\end{array}$

$\begin{array}{llll}\text { C } & 5.21906000 & -0.29319800 & 0.73528400\end{array}$

C $\quad 4.63223300 \quad-1.77836400 \quad-0.82617800$

$\begin{array}{llll}\mathrm{O} & 6.12622800 & -1.29193100 & 0.74829700\end{array}$

$\begin{array}{llll}\mathrm{H} & 5.38788000 & 0.52462400 & 1.41711500\end{array}$

C $\quad 5.76496300 \quad-2.18653300 \quad-0.19828100$

$\mathrm{H} \quad 4.14478300 \quad-2.28424000 \quad-1.64757000$

$\mathrm{H} \quad 6.40999800 \quad-3.04226200 \quad-0.31677700$

$\begin{array}{llll}\mathrm{C} & 1.89607800 & -0.22627900 & 1.66897800\end{array}$

$\mathrm{H} \quad 0.93843500 \quad-0.48491500 \quad 2.13128500$

$\mathrm{H} \quad 2.62802400 \quad-0.99257300 \quad 1.93510700$

$\begin{array}{llll}\mathrm{H} & 2.23017000 & 0.72451100 & 2.09125200\end{array}$

C $\quad-3.07476100 \quad 0.96610600 \quad-0.04971300$

$\begin{array}{llll}\mathrm{C} & -3.33005600 & -0.46105300 & -0.09712500\end{array}$

$\begin{array}{llll}\text { C } & -4.89008200 & -1.60436300 & 1.43484300\end{array}$

$\mathrm{H} \quad-4.15066100 \quad-2.39028400 \quad 1.61087800$

$\mathrm{H} \quad-4.76191500 \quad-0.83931600 \quad 2.20672700$

$\mathrm{H} \quad \begin{array}{llll}\mathrm{H} & -5.88737200 & -2.03834500 & 1.55103100\end{array}$

$\begin{array}{llll}\text { C } & -4.73942900 & -1.03432800 & 0.00720200\end{array}$

$\begin{array}{llll}\text { C } & -4.91868400 & -2.17121500 & -1.01094200\end{array}$

$\mathrm{H} \quad-4.75770000 \quad-1.81734300 \quad-2.03429300$

$\mathrm{H} \quad-4.22755600 \quad-2.99346200 \quad-0.81677900$

SI140 


$\begin{array}{lrrr}\mathrm{H} & -5.94023400 & -2.55652300 & -0.94414700 \\ \mathrm{C} & -5.52040000 & 1.35588000 & 0.48676600 \\ \mathrm{H} & -5.48354100 & 1.18753100 & 1.56820600 \\ \mathrm{H} & -6.32288900 & 2.07618500 & 0.31071900 \\ \mathrm{C} & -5.79808800 & 0.05434700 & -0.25697300 \\ \mathrm{H} & -6.77790300 & -0.34492900 & 0.02157800 \\ \mathrm{H} & -5.84365400 & 0.26111700 & -1.33479500 \\ \mathrm{C} & -4.20032600 & 1.95283200 & 0.00541000 \\ \mathrm{H} & -3.89579900 & 2.81995500 & 0.60079900 \\ \mathrm{H} & -4.32828400 & 2.32642000 & -1.02294300\end{array}$

\section{3-1 Radical $A$}

Zero-point correction=

Thermal correction to Energy=

Thermal correction to Enthalpy=

Thermal correction to Gibbs Free Energy=

Sum of electronic and zero-point Energies=

Sum of electronic and thermal Energies $=$

Sum of electronic and thermal Enthalpies=

Sum of electronic and thermal Free Energies=
0.425004 (Hartree/Particle)

$$
0.447478
$$

0.448422

0.374183

$-1170.798768$

$-1170.776294$

$-1170.775350$

$-1170.849589$

02

$\begin{array}{lrrr}\mathrm{C} & -1.78568000 & 1.40945700 & -0.07969000 \\ \mathrm{C} & -0.73831900 & 0.49213600 & -0.11252700 \\ \mathrm{C} & -1.07890800 & -0.87410100 & -0.09172600 \\ \mathrm{~N} & -2.35234000 & -1.29936700 & -0.06241800 \\ \mathrm{H} & -1.58605400 & 2.47626700 & -0.05099600 \\ \mathrm{C} & -0.02854400 & -1.94844900 & -0.06477700 \\ \mathrm{H} & -0.37268000 & -2.78564800 & -0.67841000 \\ \mathrm{H} & 0.04338500 & -2.33594800 & 0.96020000 \\ \mathrm{C} & 0.67962600 & 0.91685600 & -0.13714800 \\ \mathrm{C} & 1.05642800 & 2.19091800 & -0.34599500 \\ \mathrm{H} & 0.35763800 & 2.99328200 & -0.54770200 \\ \mathrm{C} & 2.44681300 & 2.64055600 & -0.16343800 \\ \mathrm{O} & 2.75799200 & 3.80199800 & -0.03636700 \\ \mathrm{C} & 1.74762400 & -0.13376800 & 0.13355400 \\ \mathrm{C} & 1.33268900 & -1.45496800 & -0.53873700 \\ \mathrm{H} & 1.30353100 & -1.30587500 & -1.62663000 \\ \mathrm{H} & 2.08980300 & -2.21777600 & -0.33565500 \\ \mathrm{O} & 3.39735000 & 1.68238600 & -0.07424200 \\ \mathrm{C} & 3.05741600 & 0.36366700 & -0.52381000 \\ \mathrm{H} & 2.88283500 & 0.41293400 & -1.60836800 \\ \mathrm{C} & 4.25864100 & -0.48947100 & -0.26299100 \\ \mathrm{C} & 5.22488300 & -0.26919200 & 0.66722000 \\ \mathrm{C} & 4.63937300 & -1.69799500 & -0.93973000 \\ \mathrm{O} & 6.16123600 & -1.24725300 & 0.62198900 \\ \mathrm{H} & 5.38535600 & 0.52225500 & 1.38080900 \\ \mathrm{C} & 5.79415300 & -2.10820500 & -0.35642400 \\ \mathrm{H} & 4.12733600 & -2.18269100 & -1.75842900 \\ \mathrm{H} & 6.45031800 & -2.94752500 & -0.52197900\end{array}$

SI141 


$\begin{array}{lrrr}\mathrm{C} & 1.91251300 & -0.30927300 & 1.65338200 \\ \mathrm{H} & 0.94665100 & -0.48608700 & 2.13432700 \\ \mathrm{H} & 2.57049600 & -1.15547000 & 1.87121200 \\ \mathrm{H} & 2.34770400 & 0.58923100 & 2.09943200 \\ \mathrm{C} & -3.12892000 & 0.98333800 & -0.06045500 \\ \mathrm{C} & -3.35028100 & -0.43266200 & -0.05565600 \\ \mathrm{C} & -5.09556000 & -1.16446400 & 1.53825600 \\ \mathrm{H} & -4.42400500 & -1.90746400 & 1.97835500 \\ \mathrm{H} & -4.98143800 & -0.23386100 & 2.10299700 \\ \mathrm{H} & -6.12676500 & -1.51527300 & 1.65837600 \\ \mathrm{C} & -4.76915100 & -0.97816100 & 0.04166500 \\ \mathrm{C} & -4.89014800 & -2.32981800 & -0.67123400 \\ \mathrm{H} & -4.63690700 & -2.23788000 & -1.73243700 \\ \mathrm{H} & -4.21887700 & -3.06870500 & -0.22995600 \\ \mathrm{H} & -5.91963800 & -2.69622700 & -0.59379700 \\ \mathrm{C} & -5.62481300 & 1.44215600 & -0.05215300 \\ \mathrm{H} & -6.05218800 & 1.48989800 & 0.96202300 \\ \mathrm{H} & -6.22615000 & 2.13496500 & -0.65255100 \\ \mathrm{C} & -5.74473300 & 0.02237100 & -0.60910700 \\ \mathrm{H} & -6.76928100 & -0.34615800 & -0.48425300 \\ \mathrm{H} & -5.54526400 & 0.04814500 & -1.68813300 \\ \mathrm{C} & -4.20309100 & 1.89507700 & -0.02341500 \\ \mathrm{H} & -3.98412100 & 2.95810900 & 0.03706100 \\ & & & \end{array}$

\section{3-1 Radical B}

Zero-point correction=

Thermal correction to Energy=

Thermal correction to Enthalpy=

Thermal correction to Gibbs Free Energy=

Sum of electronic and zero-point Energies=

Sum of electronic and thermal Energies=

Sum of electronic and thermal Enthalpies=

Sum of electronic and thermal Free Energies=
0.424953 (Hartree/Particle) 0.447412

0.448357

0.374141

$-1170.797393$

$-1170.774933$

$-1170.773989$

$-1170.848205$

02

$\begin{array}{lrrr}\mathrm{C} & -1.76242400 & 1.39922600 & -0.10735500 \\ \mathrm{C} & -0.71107800 & 0.49427400 & -0.23202000 \\ \mathrm{C} & -1.05279400 & -0.88996100 & -0.26967600 \\ \mathrm{~N} & -2.34340300 & -1.30954900 & -0.19269900 \\ \mathrm{H} & -1.55644300 & 2.46314500 & -0.02338800 \\ \mathrm{C} & -0.05467400 & -1.86792700 & -0.39557600 \\ \mathrm{H} & -0.36085100 & -2.90764100 & -0.43470200 \\ \mathrm{C} & 0.69863300 & 0.90285600 & -0.26387800 \\ \mathrm{C} & 1.09107800 & 2.16960100 & -0.50488600 \\ \mathrm{H} & 0.39873800 & 2.96339800 & -0.75818500 \\ \mathrm{C} & 2.47306300 & 2.62046500 & -0.27831100 \\ \mathrm{O} & 2.78764300 & 3.78441500 & -0.18792200 \\ \mathrm{C} & 1.74894300 & -0.14644700 & 0.07821000 \\ \mathrm{C} & 1.37795500 & -1.49897200 & -0.56786400 \\ \mathrm{H} & 1.60080600 & -1.45896000 & -1.64842100\end{array}$

SI142 


$\begin{array}{lrrr}\mathrm{H} & 2.02218000 & -2.28217100 & -0.15569600 \\ \mathrm{O} & 3.41074000 & 1.66093400 & -0.09364600 \\ \mathrm{C} & 3.09271900 & 0.33140000 & -0.52163100 \\ \mathrm{H} & 2.97574600 & 0.35072600 & -1.61511000 \\ \mathrm{C} & 4.27487100 & -0.51692000 & -0.17294900 \\ \mathrm{C} & 5.22135000 & -0.24214000 & 0.76296500 \\ \mathrm{C} & 4.65335700 & -1.77688800 & -0.75042700 \\ \mathrm{O} & 6.14413000 & -1.23297100 & 0.81167500 \\ \mathrm{H} & 5.37416900 & 0.59598100 & 1.42280900 \\ \mathrm{C} & 5.78782200 & -2.15790400 & -0.11013200 \\ \mathrm{H} & 4.15529800 & -2.31494900 & -1.54390400 \\ \mathrm{H} & 6.43522400 & -3.01558600 & -0.19810300 \\ \mathrm{C} & 1.82421600 & -0.28974800 & 1.60851700 \\ \mathrm{H} & 0.84616500 & -0.56114200 & 2.01536500 \\ \mathrm{H} & 2.54123900 & -1.06876500 & 1.88201700 \\ \mathrm{H} & 2.14134400 & 0.64888100 & 2.07103100 \\ \mathrm{C} & -3.08381300 & 0.97110100 & -0.05166500 \\ \mathrm{C} & -3.32451300 & -0.42706300 & -0.09969500 \\ \mathrm{C} & -4.85370000 & -1.68744800 & 1.39543700 \\ \mathrm{H} & -4.08490100 & -2.45678600 & 1.50663500 \\ \mathrm{H} & -4.73133700 & -0.96850100 & 2.21182600 \\ \mathrm{H} & -5.83740700 & -2.15854400 & 1.49900400 \\ \mathrm{C} & -4.73341100 & -1.01490000 & 0.01353000 \\ \mathrm{C} & -4.94237200 & -2.07809600 & -1.07583100 \\ \mathrm{H} & -4.81049600 & -1.64804400 & -2.07443500 \\ \mathrm{H} & -4.23059700 & -2.89819200 & -0.96209900 \\ \mathrm{H} & -5.95943600 & -2.48033700 & -1.00916200 \\ \mathrm{C} & -5.48333500 & 1.35742200 & 0.62264100 \\ \mathrm{H} & -5.35791500 & 1.14060200 & 1.69014100 \\ \mathrm{H} & -6.30862600 & 2.07174400 & 0.54080200 \\ \mathrm{C} & -5.80698800 & 0.07983700 & -0.14583400 \\ \mathrm{H} & -6.77291100 & -0.33083800 & 0.16991800 \\ \mathrm{H} & -5.90834500 & 0.33028000 & -1.21115900 \\ \mathrm{C} & -4.20472000 & 1.97617200 & 0.06441500 \\ \mathrm{H} & -3.87505700 & 2.82089500 & 0.67934700 \\ \mathrm{H} & -4.41397000 & 2.38499100 & -0.93441800\end{array}$

\section{0-1 Cation $A$}

Zero-point correction $=$

Thermal correction to Energy=

Thermal correction to Enthalpy=

Thermal correction to Gibbs Free Energy=

Sum of electronic and zero-point Energies=

Sum of electronic and thermal Energies=

Sum of electronic and thermal Enthalpies=

Sum of electronic and thermal Free Energies=

11

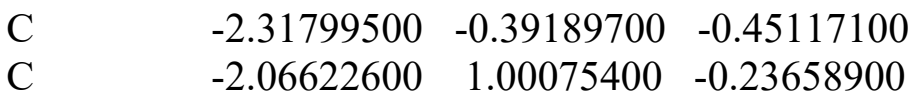

0.476147 (Hartree/Particle)

0.502689

0.503634

0.421317

$-1436.468484$

$-1436.441942$

$-1436.440997$

$-1436.523314$

\section{SI143}




\begin{tabular}{|c|c|c|c|}
\hline $\mathrm{C}$ & -0.71105700 & 1.43750400 & -0.18710500 \\
\hline $\mathrm{C}$ & 0.31408400 & 0.52753600 & -0.30715200 \\
\hline $\mathrm{C}$ & -0.06464100 & -0.84777000 & -0.36663700 \\
\hline $\mathrm{N}$ & -1.33950100 & -1.26565000 & -0.48754000 \\
\hline $\mathrm{H}$ & -0.50561900 & 2.48923200 & -0.00893200 \\
\hline $\mathrm{C}$ & 0.96209500 & -1.91994000 & -0.25772900 \\
\hline $\mathrm{H}$ & 0.64550700 & -2.76528900 & -0.87476300 \\
\hline $\mathrm{H}$ & 0.90450200 & -2.28488100 & 0.77953400 \\
\hline $\mathrm{C}$ & 1.74292400 & 0.91603300 & -0.27030800 \\
\hline $\mathrm{C}$ & 2.13620200 & 2.17125500 & -0.52472500 \\
\hline $\mathrm{H}$ & 1.46707100 & 2.96657800 & -0.83456900 \\
\hline $\mathrm{C}$ & 3.52414500 & 2.61842500 & -0.24606000 \\
\hline $\mathrm{O}$ & 3.80806000 & 3.78302000 & -0.12987900 \\
\hline $\mathrm{C}$ & 2.76671300 & -0.14387700 & 0.09930700 \\
\hline $\mathrm{C}$ & 2.37783200 & -1.46294900 & -0.59476000 \\
\hline $\mathrm{H}$ & 2.46390800 & -1.34055200 & -1.68183700 \\
\hline $\mathrm{H}$ & 3.08223800 & -2.24622900 & -0.30459600 \\
\hline $\mathrm{O}$ & 4.43926900 & 1.65599500 & -0.03318000 \\
\hline $\mathrm{C}$ & 4.13155700 & 0.32312300 & -0.47186400 \\
\hline $\mathrm{H}$ & 4.04313900 & 0.34390000 & -1.56747600 \\
\hline $\mathrm{C}$ & 5.29351700 & -0.53461500 & -0.09121600 \\
\hline $\mathrm{C}$ & 6.17969600 & -0.30666500 & 0.91566600 \\
\hline $\mathrm{C}$ & 5.70995800 & -1.76245700 & -0.71017100 \\
\hline $\mathrm{O}$ & 7.09638800 & -1.29713800 & 0.96685600 \\
\hline $\mathrm{H}$ & 6.29646700 & 0.49812200 & 1.62324700 \\
\hline $\mathrm{C}$ & 6.80426900 & -2.17425300 & -0.02039700 \\
\hline $\mathrm{H}$ & 5.27301300 & -2.25469100 & -1.56719400 \\
\hline $\mathrm{H}$ & 7.46286700 & -3.02268500 & -0.11383500 \\
\hline $\mathrm{C}$ & 2.81426000 & -0.30414700 & 1.62842400 \\
\hline $\mathrm{H}$ & 1.81750800 & -0.47579100 & 2.04709000 \\
\hline $\mathrm{H}$ & 3.45352000 & -1.14700300 & 1.90290800 \\
\hline $\mathrm{H}$ & 3.21826400 & 0.59706400 & 2.09687700 \\
\hline $\mathrm{C}$ & -3.72558600 & -0.91446600 & -0.67587100 \\
\hline $\mathrm{C}$ & -5.35217400 & -1.67793400 & 0.77330500 \\
\hline $\mathrm{O}$ & -4.02708300 & -1.76963600 & 0.43928300 \\
\hline $\mathrm{C}$ & -3.75211100 & -1.73109200 & -1.96839200 \\
\hline $\mathrm{H}$ & -3.44656500 & -1.11721300 & -2.82094200 \\
\hline $\mathrm{H}$ & -3.07357900 & -2.57998500 & -1.8776960 \\
\hline $\mathrm{H}$ & -4.76062900 & -2.10631700 & -2.15784300 \\
\hline $\mathrm{O}$ & -5.83301600 & -2.33692800 & 1.64447800 \\
\hline $\mathrm{C}$ & -6.01137900 & -0.63618300 & -0.11419400 \\
\hline $\mathrm{H}$ & -6.54480500 & -1.15610000 & -0.9153330 \\
\hline $\mathrm{H}$ & -6.75657300 & -0.07259600 & 0.4467940 \\
\hline $\mathrm{C}$ & -4.83098200 & 0.17344800 & -0.65478300 \\
\hline $\mathrm{H}$ & -5.01082600 & 0.51118900 & -1.67980500 \\
\hline $\mathrm{C}$ & -3.11342600 & 1.86146300 & 0.01707300 \\
\hline $\mathrm{H}$ & -2.88179400 & 2.91118800 & 0.20835100 \\
\hline $\mathrm{C}$ & -4.51652300 & 1.44089800 & 0.18576800 \\
\hline $\mathrm{C}$ & -5.47723200 & 2.58165400 & -0.19080400 \\
\hline $\mathrm{H}$ & -5.29309400 & 3.47071600 & 0.41912400 \\
\hline $\mathrm{H}$ & -5.37988800 & 2.85538700 & -1.24510600 \\
\hline
\end{tabular}




$\begin{array}{llll}\mathrm{H} & -6.51047900 & 2.27098100 & -0.01779600 \\ \mathrm{C} & -4.58451900 & 1.21189400 & 1.73729500 \\ \mathrm{H} & -5.62610600 & 1.03837200 & 2.01852700 \\ \mathrm{H} & -3.98131800 & 0.35914200 & 2.05562700 \\ \mathrm{H} & -4.24956300 & 2.10005400 & 2.28050900\end{array}$

\section{0-1 Cation B}

Zero-point correction=

Thermal correction to Energy=

Thermal correction to Enthalpy=

Thermal correction to Gibbs Free Energy=

Sum of electronic and zero-point Energies $=$

Sum of electronic and thermal Energies=

Sum of electronic and thermal Enthalpies=

Sum of electronic and thermal Free Energies=
0.475609 (Hartree/Particle)

0.502063

0.503007

0.420978

$-1436.468832$

$-1436.442378$

$-1436.441434$

$-1436.523464$

11

C

$\begin{array}{llll}\text { C } & -2.06210300 & 1.06007500 & -0.50405900\end{array}$

$\begin{array}{llll}\text { C } & -0.75114100 & 1.49971400 & -0.39925900\end{array}$

$\begin{array}{lllll}\mathrm{C} & 0.29952300 & 0.58219000 & -0.44371400\end{array}$

$\begin{array}{llll}\mathrm{C} & -0.06370900 & -0.79234200 & -0.59305800\end{array}$

$\mathrm{N} \quad-1.35709600 \quad-1.22597300 \quad-0.69823800$

$\mathrm{H} \quad \begin{array}{llll}\mathrm{H} & -0.56034500 & 2.55607200 & -0.24278800\end{array}$

$\begin{array}{llll}\mathrm{C} & 0.91709100 & -1.76147100 & -0.66771600\end{array}$

$\begin{array}{llll}\mathrm{H} & 0.58349100 & -2.78592100 & -0.82533100\end{array}$

$\begin{array}{llll}\mathrm{C} & 1.71271900 & 0.94792000 & -0.31889100\end{array}$

$\begin{array}{llll}\mathrm{C} & 2.13590100 & 2.21238600 & -0.48739200\end{array}$

$\begin{array}{llll}\mathrm{H} & 1.49006600 & 3.03285900 & -0.77793700\end{array}$

$\begin{array}{llll}\mathrm{C} & 3.52765900 & 2.61828000 & -0.15159100\end{array}$

$\begin{array}{llll}\mathrm{O} & 3.82384600 & 3.77017800 & 0.02310100\end{array}$

$\begin{array}{llll}\mathrm{C} & 2.71315200 & -0.12941400 & 0.07523300\end{array}$

$\begin{array}{llll}\mathrm{C} & 2.35295000 & -1.46829900 & -0.59934500\end{array}$

$\begin{array}{llll}\mathrm{H} & 2.68506000 & -1.48585000 & -1.65607000\end{array}$

$\mathrm{H} \quad 2.88763200 \quad-2.30278300 \quad-0.13227100$

$\begin{array}{llll}\mathrm{O} & 4.41970700 & 1.62974600 & 0.04562700\end{array}$

$\begin{array}{llll}\mathrm{C} & 4.10669800 & 0.31916700 & -0.44194900\end{array}$

$\begin{array}{llll}\mathrm{H} & 4.05500100 & 0.37159200 & -1.53955700\end{array}$

$\begin{array}{llll}\mathrm{C} & 5.23210900 & -0.57849200 & -0.04596700\end{array}$

$\begin{array}{llll}\mathrm{C} & 6.08749800 & -0.40108800 & 0.99780700\end{array}$

$\begin{array}{llll}\mathrm{C} & 5.63540700 & -1.80274800 & -0.68160400\end{array}$

$\begin{array}{llll}\mathrm{O} & 6.97222500 & -1.41796200 & 1.05388100\end{array}$

$\begin{array}{llll}\mathrm{H} & 6.20083500 & 0.38167700 & 1.73040200\end{array}$

$\begin{array}{llll}\mathrm{C} & 6.69259300 & -2.26217100 & 0.03611300\end{array}$

$\mathrm{H} \quad 5.22468600 \quad-2.26130200 \quad-1.57000400$

$\begin{array}{llll}\mathrm{H} & 7.33184700 & -3.12533300 & -0.05706200\end{array}$

$\begin{array}{llll}\mathrm{C} & 2.69237100 & -0.29700300 & 1.60564500\end{array}$

$\begin{array}{llll}\mathrm{H} & 1.69061300 & -0.55645200 & 1.96192200\end{array}$

$\mathrm{H} \quad 3.38345100 \quad-1.08658100 \quad 1.91013700$

$\begin{array}{llll}\mathrm{H} & 2.99737000 & 0.63009500 & 2.09700700\end{array}$

SI145 


$\begin{array}{lrrr}\mathrm{C} & -3.73971200 & -0.89360500 & -0.73295500 \\ \mathrm{C} & -5.06653100 & -1.82195000 & 0.92215300 \\ \mathrm{O} & -3.84414400 & -1.86939400 & 0.31738100 \\ \mathrm{C} & -3.93200000 & -1.59097900 & -2.07980000 \\ \mathrm{H} & -3.77695200 & -0.88839600 & -2.90471400 \\ \mathrm{H} & -3.22458100 & -2.41678400 & -2.17421700 \\ \mathrm{H} & -4.94744700 & -1.98883000 & -2.15381100 \\ \mathrm{O} & -5.36141100 & -2.56621600 & 1.81043300 \\ \mathrm{C} & -5.89247600 & -0.72646500 & 0.28002600 \\ \mathrm{H} & -6.59700800 & -1.19931300 & -0.41131200 \\ \mathrm{H} & -6.48578100 & -0.21038300 & 1.03484700 \\ \mathrm{C} & -4.86758300 & 0.14245300 & -0.45305200 \\ \mathrm{H} & -5.26534700 & 0.48609400 & -1.41387200 \\ \mathrm{C} & -4.41659500 & 1.40129400 & 0.32778200 \\ \mathrm{C} & -5.54680900 & 2.43821400 & 0.32675100 \\ \mathrm{H} & -5.23240700 & 3.35217100 & 0.84012600 \\ \mathrm{H} & -5.84459200 & 2.70615400 & -0.69241200 \\ \mathrm{H} & -6.43143100 & 2.06187300 & 0.84749300 \\ \mathrm{C} & -4.00104800 & 1.09836700 & 1.77778200 \\ \mathrm{H} & -4.85073400 & 0.75261600 & 2.37182500 \\ \mathrm{H} & -3.22270000 & 0.33138000 & 1.85098100 \\ \mathrm{H} & -3.62240000 & 2.00713200 & 2.25630300 \\ \mathrm{C} & -3.21710600 & 2.00058500 & -0.43795000 \\ \mathrm{H} & -2.90292700 & 2.95017900 & 0.00713100 \\ \mathrm{H} & -3.52675000 & 2.22708800 & -1.47013100\end{array}$

\section{0-1 Radical $A$}

Zero-point correction $=$

Thermal correction to Energy=

Thermal correction to Enthalpy=
0.474967 (Hartree/Particle)

0.501372

0.502316

Thermal correction to Gibbs Free Energy= $\quad 0.419869$

Sum of electronic and zero-point Energies $=\quad-1436.725100$

Sum of electronic and thermal Energies $=\quad-1436.698695$

Sum of electronic and thermal Enthalpies $=\quad-1436.697751$

Sum of electronic and thermal Free Energies $=\quad-1436.780198$ 02

$\begin{array}{lrrr}\mathrm{C} & -2.29832800 & -0.37259100 & -0.38405100 \\ \mathrm{C} & -2.07041500 & 1.02630900 & -0.27508900 \\ \mathrm{C} & -0.72183300 & 1.43847000 & -0.24188600 \\ \mathrm{C} & 0.31100900 & 0.50943900 & -0.26035700 \\ \mathrm{C} & -0.04627000 & -0.85744100 & -0.28281600 \\ \mathrm{~N} & -1.31794800 & -1.26145700 & -0.37541200 \\ \mathrm{H} & -0.51115800 & 2.50001700 & -0.15694700 \\ \mathrm{C} & 0.98928100 & -1.94147500 & -0.18636400 \\ \mathrm{H} & 0.67485100 & -2.77983500 & -0.81354100 \\ \mathrm{H} & 0.99114000 & -2.32043300 & 0.84408700 \\ \mathrm{C} & 1.73515000 & 0.91531400 & -0.21728300 \\ \mathrm{C} & 2.13462200 & 2.18189900 & -0.42367000 \\ \mathrm{H} & 1.45649300 & 2.98772600 & -0.67659800\end{array}$

SI146 


\begin{tabular}{|c|c|c|c|}
\hline $\mathrm{C}$ & 3.51858000 & 2.62065200 & -0.16803100 \\
\hline $\mathrm{O}$ & 3.83096600 & 3.78096000 & -0.03810400 \\
\hline $\mathrm{C}$ & 2.77339100 & -0.14566700 & 0.11757800 \\
\hline $\mathrm{C}$ & 2.38299400 & -1.46409900 & -0.57587000 \\
\hline $\mathrm{H}$ & 2.42369200 & -1.31902700 & -1.66393300 \\
\hline $\mathrm{H}$ & 3.11652300 & -2.23518600 & -0.32400100 \\
\hline $\mathrm{O}$ & 4.45008600 & 1.65446800 & -0.00953200 \\
\hline $\mathrm{C}$ & 4.12434600 & 0.33409500 & -0.46631400 \\
\hline $\mathrm{H}$ & 4.01380900 & 0.37558200 & -1.55956300 \\
\hline $\mathrm{C}$ & 5.29948600 & -0.52800900 & -0.12915600 \\
\hline $\mathrm{C}$ & 6.21235600 & -0.30982200 & 0.85416900 \\
\hline $\mathrm{C}$ & 5.70561900 & -1.74612400 & -0.77331700 \\
\hline $\mathrm{O}$ & 7.13868800 & -1.29766300 & 0.87063300 \\
\hline $\mathrm{H}$ & 6.33987400 & 0.48551900 & 1.57009100 \\
\hline $\mathrm{C}$ & 6.82001500 & -2.16309100 & -0.12038300 \\
\hline $\mathrm{H}$ & 5.23737700 & -2.23244300 & -1.61687000 \\
\hline $\mathrm{H}$ & 7.47555700 & -3.01057200 & -0.24059800 \\
\hline $\mathrm{C}$ & 2.84774700 & -0.31841600 & 1.64468800 \\
\hline $\mathrm{H}$ & 1.85448400 & -0.48553000 & 2.07024200 \\
\hline $\mathrm{H}$ & 3.48391400 & -1.16995200 & 1.90215700 \\
\hline $\mathrm{H}$ & 3.26476600 & 0.57720500 & 2.11330900 \\
\hline $\mathrm{C}$ & -3.69760300 & -0.91349300 & -0.61636400 \\
\hline $\mathrm{C}$ & -5.38956100 & -1.67177000 & 0.75784500 \\
\hline $\mathrm{O}$ & -4.06348100 & -1.75451700 & 0.50828000 \\
\hline $\mathrm{C}$ & -3.69405700 & -1.78411400 & -1.87460000 \\
\hline $\mathrm{H}$ & -3.37118400 & -1.19531400 & -2.73840600 \\
\hline $\mathrm{H}$ & -3.00104900 & -2.61494800 & -1.73564300 \\
\hline $\mathrm{H}$ & -4.69276600 & -2.18169000 & -2.07703700 \\
\hline $\mathrm{O}$ & -5.93153700 & -2.33780600 & 1.59885300 \\
\hline $\mathrm{C}$ & -6.01241500 & -0.64178200 & -0.16816500 \\
\hline $\mathrm{H}$ & -6.51931000 & -1.17695300 & -0.97721000 \\
\hline $\mathrm{H}$ & -6.77360300 & -0.06892900 & 0.36173100 \\
\hline $\mathrm{C}$ & -4.81327500 & 0.16278700 & -0.67441000 \\
\hline $\mathrm{H}$ & -4.94517200 & 0.46559700 & -1.71808200 \\
\hline $\mathrm{C}$ & -3.14411600 & 1.93205600 & -0.15982600 \\
\hline $\mathrm{H}$ & -2.93234300 & 2.99733600 & -0.09647900 \\
\hline $\mathrm{C}$ & -4.53504100 & 1.45580300 & 0.14180800 \\
\hline $\mathrm{C}$ & -5.55589300 & 2.53094200 & -0.25851500 \\
\hline $\mathrm{H}$ & -5.37404500 & 3.45663000 & 0.29727400 \\
\hline $\mathrm{H}$ & -5.49186500 & 2.75847100 & -1.32759700 \\
\hline $\mathrm{H}$ & -6.57904200 & 2.21048300 & -0.03800400 \\
\hline $\mathrm{C}$ & -4.61261200 & 1.23056600 & 1.67353900 \\
\hline $\mathrm{H}$ & -5.62045600 & 0.94483100 & $1.9908320 \mathrm{C}$ \\
\hline $\mathrm{H}$ & -3.91530200 & 0.45670900 & 2.00548400 \\
\hline $\mathrm{H}$ & -4.35640300 & 2.15872500 & 2.1931850 \\
\hline
\end{tabular}

\section{0-1 Radical B}

Zero-point correction=

Thermal correction to Energy=
0.474587 (Hartree/Particle)

0.500986

SI147 


$\begin{array}{lc}\text { Thermal correction to Enthalpy= } & 0.501930 \\ \text { Thermal correction to Gibbs Free Energy= } & 0.419556 \\ \text { Sum of electronic and zero-point Energies }= & -1436.729625 \\ \text { Sum of electronic and thermal Energies }= & -1436.703227 \\ \text { Sum of electronic and thermal Enthalpies }= & -1436.702283 \\ \text { Sum of electronic and thermal Free Energies }= & -1436.784656\end{array}$

02

$\begin{array}{llll}\text { C } & -2.30204000 & -0.33575700 & -0.61372400\end{array}$

$\begin{array}{llll}\text { C } & -2.06080700 & 1.04814200 & -0.47986700\end{array}$

$\begin{array}{llll}\text { C } & -0.73590800 & 1.46041400 & -0.40353700\end{array}$

$\begin{array}{llll}\mathrm{C} & 0.30635400 & 0.54009800 & -0.48662800\end{array}$

C $\quad-0.04637700 \quad-0.83632800 \quad-0.62657900$

$\mathrm{N} \quad-1.34371800 \quad-1.23845500 \quad-0.68963000$

$\mathrm{H} \quad-0.52306500 \quad 2.51365700 \quad-0.24285400$

C $\quad 0.94623200 \quad-1.82411100 \quad-0.71160100$

$\mathrm{H} \quad 0.62986600 \quad-2.85507100 \quad-0.82580300$

$\begin{array}{llll}\mathrm{C} & 1.72045800 & 0.92318800 & -0.37631700\end{array}$

C $\quad 2.14877300 \quad 2.19096500 \quad-0.53019000$

$\begin{array}{llll}\mathrm{H} & 1.49355300 & 3.00563500 & -0.81445300\end{array}$

$\begin{array}{llll}\mathrm{C} & 3.51101500 & 2.60947200 & -0.15939700\end{array}$

$\begin{array}{llll}\mathrm{O} & 3.82839400 & 3.76401700 & 0.00575900\end{array}$

$\begin{array}{llll}\text { C } & 2.71951900 & -0.15821300 & 0.01420700\end{array}$

C $\quad 2.39329100 \quad-1.47374100 \quad-0.72631400$

$\mathrm{H} \quad 2.72062300 \quad-1.39138400 \quad-1.77738500$

$\mathrm{H} \quad 2.98229100 \quad-2.28671000 \quad-0.29011900$

$\begin{array}{llll}\mathrm{O} & 4.41292800 & 1.62817700 & 0.07422200\end{array}$

C $\quad 4.12036400 \quad 0.32148100 \quad-0.43588500$

$\mathrm{H} \quad 4.10825400 \quad 0.38659100 \quad-1.53376400$

$\begin{array}{llll}\mathrm{C} & 5.25256800 & -0.55960200 & -0.01193600\end{array}$

$\begin{array}{llll}\mathrm{C} & 6.10717300 & -0.33932700 & 1.02172900\end{array}$

$\begin{array}{llll}\text { C } & 5.66809000 & -1.80160600 & -0.60259400\end{array}$

$\begin{array}{llll}\mathrm{O} & 7.00704500 & -1.34714600 & 1.11745100\end{array}$

$\begin{array}{llll}\mathrm{H} & 6.20634100 & 0.46833000 & 1.72819300\end{array}$

$\begin{array}{llll}\mathrm{C} & 6.72978900 & -2.22778500 & 0.12768200\end{array}$

$\mathrm{H} \quad 5.24257000 \quad-2.29863400 \quad-1.46228800$

$\begin{array}{llll}\mathrm{H} & 7.37088600 & -3.09250100 & 0.06698900\end{array}$

C $\quad 2.64726600 \quad-0.37130800 \quad 1.53651100$

$\begin{array}{llll}\mathrm{H} & 1.63218500 & -0.64473300 & 1.83767200\end{array}$

$\mathrm{H} \quad 3.32511700 \quad-1.17371800 \quad 1.84000900$

$\begin{array}{llll}\mathrm{H} & 2.93099300 & 0.54006800 & 2.06977700\end{array}$

C $\quad-3.72202000 \quad-0.87944100 \quad-0.69824500$

$\begin{array}{llll}\text { C } & -5.12077300 & -1.79509400 & 0.90057600\end{array}$

$\begin{array}{llll}\mathrm{O} & -3.87833100 & -1.84051100 & 0.37597900\end{array}$

C $\quad-3.90636900-1.61905200 \quad-2.02288400$

$\mathrm{H} \quad-3.73465600 \quad-0.93770400 \quad-2.86194500$

$\mathrm{H} \quad-3.18866000-2.43900300 \quad-2.08108300$

$\mathrm{H} \quad-4.92032100-2.02276500 \quad-2.10300800$

$\begin{array}{llll}\mathrm{O} & -5.48364300 & -2.54303800 & 1.76925200\end{array}$

C $\quad-5.91443800 \quad-0.69566800 \quad 0.22189800$

$\mathrm{H} \quad-6.59099600 \quad-1.16657800 \quad-0.49842200$

$\mathrm{H} \quad-6.53529000 \quad-0.17611700 \quad 0.95239000$ 


$\begin{array}{lrrr}\mathrm{C} & -4.85065000 & 0.16426000 & -0.46347000 \\ \mathrm{H} & -5.20123900 & 0.51613200 & -1.44030800 \\ \mathrm{C} & -4.42299500 & 1.41771400 & 0.34007500 \\ \mathrm{C} & -5.56020400 & 2.44731300 & 0.31914400 \\ \mathrm{H} & -5.25458000 & 3.36362000 & 0.83520100 \\ \mathrm{H} & -5.83685000 & 2.71434900 & -0.70695700 \\ \mathrm{H} & -6.45619700 & 2.07226300 & 0.82334700 \\ \mathrm{C} & -4.05717300 & 1.09895200 & 1.79969100 \\ \mathrm{H} & -4.91800200 & 0.71712100 & 2.35672700 \\ \mathrm{H} & -3.25541600 & 0.36006600 & 1.88093500 \\ \mathrm{H} & -3.72187000 & 2.01146900 & 2.30373600 \\ \mathrm{C} & -3.20528100 & 2.01792400 & -0.38367200 \\ \mathrm{H} & -2.87586200 & 2.92772000 & 0.13164300 \\ \mathrm{H} & -3.50993000 & 2.32774000 & -1.39416200\end{array}$

Calculations conducted with M06-2X/6-311++G(d,p)//M06-2X/6-31+G(d,p):

\section{3-1 Cation $A$}

Zero-point correction $=$

Thermal correction to Energy=

Thermal correction to Enthalpy=

Thermal correction to Gibbs Free Energy=

Sum of electronic and zero-point Energies $=$

Sum of electronic and thermal Energies=

Sum of electronic and thermal Enthalpies=

Sum of electronic and thermal Free Energies=
0.426403 (Hartree/Particle)

0.448953

0.449897

0.376063

$-1170.451842$

$-1170.429292$

$-1170.428348$

$-1170.502182$

11

$\begin{array}{llll}\mathrm{C} & -1.75941500 & 1.43030600 & -0.01864400\end{array}$

$\begin{array}{lllll}\mathrm{C} & & -0.73042600 & 0.52687100 & -0.13579900\end{array}$

$\begin{array}{llll}\mathrm{C} & -1.10141700 & -0.85648400 & -0.14181000\end{array}$

$\mathrm{N} \quad \quad-2.37316000 \quad-1.29995100 \quad-0.11606600$

$\mathrm{H} \quad \begin{array}{llll}\mathrm{H} & -1.56295100 & 2.49526200 & 0.07757000\end{array}$

$\begin{array}{llll}\mathrm{C} & -0.05515900 & -1.91723300 & -0.13152800\end{array}$

$\mathrm{H} \quad-0.42035200 \quad-2.75875400 \quad-0.72804300$

$\mathrm{H} \quad-\begin{array}{llll}\mathrm{H} & -0.01882700 & -2.29279800 & 0.90366200\end{array}$

$\begin{array}{llll}\mathrm{C} & 0.69670400 & 0.92782900 & -0.17872500\end{array}$

$\begin{array}{llll}\mathrm{C} & 1.06788000 & 2.19113300 & -0.43060100\end{array}$

$\begin{array}{llll}\mathrm{H} & 0.38089000 & 2.99281300 & -0.67968000\end{array}$

$\begin{array}{llll}\mathrm{C} & 2.47172700 & 2.63869600 & -0.22941000\end{array}$

$\begin{array}{llll}\mathrm{O} & 2.76223400 & 3.79971300 & -0.12515500\end{array}$

$\begin{array}{llll}\mathrm{C} & 1.74663900 & -0.13194500 & 0.10661000\end{array}$

$\begin{array}{llll}\mathrm{C} & 1.32079400 & -1.43948000 & -0.58268500\end{array}$

$\mathrm{H} \quad \begin{array}{llll}\mathrm{H} & 1.31300600 & -1.29130000 & -1.67061900\end{array}$

$\mathrm{H} \quad \begin{array}{llll}\mathrm{H} & 2.05732100 & -2.21792300 & -0.36637600\end{array}$

$\begin{array}{llll}\mathrm{O} & 3.39819700 & 1.67098900 & -0.07306600\end{array}$

$\begin{array}{llll}\mathrm{C} & 3.06970800 & 0.35276500 & -0.53472500\end{array}$

$\begin{array}{llll}\mathrm{H} & 2.91479800 & 0.40154100 & -1.62295200\end{array}$

$\begin{array}{llll}\mathrm{C} & 4.25426300 & -0.50787400 & -0.23750300\end{array}$

$\begin{array}{llll}\text { C } & 5.21266600 & -0.26079500 & 0.69723800\end{array}$ 


$\begin{array}{lrrr}\mathrm{C} & 4.62952400 & -1.74378300 & -0.86991400 \\ \mathrm{O} & 6.13369400 & -1.24839600 & 0.69361900 \\ \mathrm{H} & 5.37658300 & 0.55697800 & 1.38122700 \\ \mathrm{C} & 5.77503300 & -2.14096900 & -0.25671400 \\ \mathrm{H} & 4.13573200 & -2.24915500 & -1.68773300 \\ \mathrm{H} & 6.43016200 & -2.98760000 & -0.38670800 \\ \mathrm{C} & 1.89359900 & -0.31790400 & 1.62529600 \\ \mathrm{H} & 0.92232700 & -0.46818600 & 2.10789600 \\ \mathrm{H} & 2.52882100 & -1.18116900 & 1.84250200 \\ \mathrm{H} & 2.35307600 & 0.56767300 & 2.07337100 \\ \mathrm{C} & -3.11443800 & 0.98088200 & -0.00981900 \\ \mathrm{C} & -3.37167000 & -0.44062700 & -0.07816700 \\ \mathrm{C} & -5.04022000 & -1.27051900 & 1.50770100 \\ \mathrm{H} & -4.34452600 & -2.03332600 & 1.86579100 \\ \mathrm{H} & -4.92662000 & -0.38354800 & 2.13974300 \\ \mathrm{H} & -6.05933700 & -1.64990000 & 1.62631500 \\ \mathrm{C} & -4.78222600 & -0.97642100 & 0.01036500 \\ \mathrm{C} & -4.92693200 & -2.27280500 & -0.79440700 \\ \mathrm{H} & -4.69020100 & -2.11103100 & -1.85019500 \\ \mathrm{H} & -4.26699200 & -3.05097900 & -0.40933000 \\ \mathrm{H} & -5.96047300 & -2.62327100 & -0.72389400 \\ \mathrm{C} & -5.57320000 & 1.46058700 & 0.08507300 \\ \mathrm{H} & -5.92325000 & 1.50221500 & 1.13325200 \\ \mathrm{H} & -6.16212200 & 2.23160100 & -0.42514000 \\ \mathrm{C} & -5.76764000 & 0.07456900 & -0.52819400 \\ \mathrm{H} & -6.79007000 & -0.27008100 & -0.35012500 \\ \mathrm{H} & -5.64441600 & 0.15459700 & -1.61545900 \\ \mathrm{C} & -4.15889200 & 1.87021300 & 0.11770000 \\ \mathrm{H} & -3.92487000 & 2.92548900 & 0.26616800\end{array}$

\section{3-1 Cation $B$}

Zero-point correction $=$

Thermal correction to Energy=

Thermal correction to Enthalpy=

Thermal correction to Gibbs Free Energy=

Sum of electronic and zero-point Energies=

Sum of electronic and thermal Energies $=$

Sum of electronic and thermal Enthalpies=

Sum of electronic and thermal Free Energies=
0.426208 (Hartree/Particle) 0.448733

0.449678

0.375786

$-1170.442967$

$-1170.420442$

$-1170.419498$

$-1170.493389$

11

$\begin{array}{lrrr}\mathrm{C} & -1.76267400 & 1.42864200 & -0.07934700 \\ \mathrm{C} & -0.70310900 & 0.52744000 & -0.16905300 \\ \mathrm{C} & -1.05610000 & -0.85840600 & -0.21564600 \\ \mathrm{~N} & -2.34646600 & -1.31398600 & -0.17291000 \\ \mathrm{H} & -1.57786500 & 2.49608100 & -0.00441900 \\ \mathrm{C} & -0.06675500 & -1.81274500 & -0.35725100 \\ \mathrm{H} & -0.39540000 & -2.84807500 & -0.44226300 \\ \mathrm{C} & 0.70933700 & 0.92043800 & -0.19866800 \\ \mathrm{C} & 1.08753100 & 2.18665100 & -0.44938300\end{array}$

SI150 


$\begin{array}{lrrr}\mathrm{H} & 0.40025700 & 2.98769800 & -0.69809700 \\ \mathrm{C} & 2.50053600 & 2.62522500 & -0.26936900 \\ \mathrm{O} & 2.79570700 & 3.78451200 & -0.18362500 \\ \mathrm{C} & 1.76379300 & -0.12572000 & 0.12887200 \\ \mathrm{C} & 1.36503800 & -1.49269300 & -0.45789500 \\ \mathrm{H} & 1.58519000 & -1.54006000 & -1.54356500 \\ \mathrm{H} & 1.96450600 & -2.29847300 & -0.01789700 \\ \mathrm{O} & 3.42223700 & 1.65248600 & -0.10690000 \\ \mathrm{C} & 3.08867500 & 0.32743100 & -0.53405100 \\ \mathrm{H} & 2.93024500 & 0.34829800 & -1.62327100 \\ \mathrm{C} & 4.26302100 & -0.53810800 & -0.21403500 \\ \mathrm{C} & 5.24034200 & -0.26093800 & 0.69283900 \\ \mathrm{C} & 4.60261900 & -1.81481700 & -0.78368900 \\ \mathrm{O} & 6.13985000 & -1.26587700 & 0.72772900 \\ \mathrm{H} & 5.42967600 & 0.58780700 & 1.33118800 \\ \mathrm{C} & 5.75003300 & -2.20101400 & -0.16611600 \\ \mathrm{H} & 4.09447200 & -2.35525700 & -1.56989400 \\ \mathrm{H} & 6.38727100 & -3.06589200 & -0.26066500 \\ \mathrm{C} & 1.90316500 & -0.23546500 & 1.65710200 \\ \mathrm{H} & 0.94351100 & -0.47973900 & 2.12367300 \\ \mathrm{H} & 2.62594800 & -1.01356000 & 1.91524200 \\ \mathrm{H} & 2.25524600 & 0.71137700 & 2.07506100 \\ \mathrm{C} & -3.07511000 & 0.97091500 & -0.05237900 \\ \mathrm{C} & -3.33187700 & -0.45902800 & -0.09575900 \\ \mathrm{C} & -4.89083900 & -1.60575700 & 1.43105500 \\ \mathrm{H} & -4.14827100 & -2.39049100 & 1.59943500 \\ \mathrm{H} & -4.76338200 & -0.84447000 & 2.20655300 \\ \mathrm{H} & -5.88755500 & -2.04259700 & 1.54254200 \\ \mathrm{C} & -4.74105500 & -1.02943300 & 0.00782400 \\ \mathrm{C} & -4.91983200 & -2.16273600 & -1.01217900 \\ \mathrm{H} & -4.75303400 & -1.80613200 & -2.03354900 \\ \mathrm{H} & -4.23126500 & -2.98614800 & -0.81443800 \\ \mathrm{H} & -5.94342300 & -2.54322600 & -0.94862100 \\ \mathrm{C} & -5.51496400 & 1.35618100 & 0.50056400 \\ \mathrm{H} & -5.46160700 & 1.17807600 & 1.57980700 \\ \mathrm{H} & -6.32009500 & 2.07715400 & 0.34059900 \\ \mathrm{H} & -5.79729600 & 0.05993000 & -0.25142300 \\ \mathrm{H} & -6.77723200 & -0.34185700 & 0.02485300 \\ \mathrm{H} & -5.84032700 & 0.27356600 & -1.32856100 \\ -4.20150800 & 1.95666100 & 0.00419300 \\ -3.89050300 & 2.82887200 & 0.58887300 \\ \mathrm{H} & -4.34127800 & 2.32004200 & -1.02706300 \\ & & & \\ \mathrm{H} & & \end{array}$

\section{3-1 Radical A}

Zero-point correction=

Thermal correction to Energy=

Thermal correction to Enthalpy=

Thermal correction to Gibbs Free Energy=

Sum of electronic and zero-point Energies=
0.425513 (Hartree/Particle)

0.447911

0.448855

0.374845

$-1170.701079$

SI151 
Sum of electronic and thermal Energies $=$

Sum of electronic and thermal Enthalpies=

Sum of electronic and thermal Free Energies=
$-1170.678681$

$-1170.677737$

$-1170.751747$

02

C

$\begin{array}{llll}\mathrm{C} & -1.07743700 & -0.87580500 & -0.08952400\end{array}$

$\begin{array}{llll}-1.78791300 & 1.40967300 & -0.09181900\end{array}$

$\begin{array}{lll}-0.73921600 & 0.49156300 & -0.11683700\end{array}$

$\mathrm{N} \quad-2.35076000 \quad-1.30308700 \quad-0.05585500$

$\mathrm{H} \quad-1.58819500 \quad 2.47713100 \quad-0.07177200$

$\begin{array}{llll}\mathrm{C} & -0.02495900 & -1.94924600 & -0.06559300\end{array}$

$\mathrm{H} \quad-0.37727100 \quad-2.78920500 \quad-0.67091300$

$\begin{array}{llll}\mathrm{H} & 0.06033700 & -2.32990500 & 0.96137500\end{array}$

$\begin{array}{llll}\mathrm{C} & 0.67893200 & 0.91736500 & -0.13929700\end{array}$

$\begin{array}{llll}\mathrm{C} & 1.05479500 & 2.19435100 & -0.33392400\end{array}$

$\begin{array}{llll}\mathrm{H} & 0.35832800 & 3.00160400 & -0.52522500\end{array}$

$\begin{array}{llll}\mathrm{C} & 2.44935400 & 2.63908900 & -0.14607200\end{array}$

$\begin{array}{llll}\mathrm{O} & 2.76382400 & 3.79631600 & -0.01655700\end{array}$

$\begin{array}{llll}\mathrm{C} & 1.74556500 & -0.13640400 & 0.12101200\end{array}$

$\begin{array}{llll}\mathrm{C} & 1.32914100 & -1.45220700 & -0.55683300\end{array}$

$\mathrm{H} \quad 1.28528200 \quad-1.29400300 \quad-1.64357100$

$\mathrm{H} \quad 2.09231000 \quad-2.21249100 \quad-0.36484000$

$\begin{array}{llll}\mathrm{O} & 3.39564200 & 1.67297500 & -0.05347900\end{array}$

$\begin{array}{llll}\mathrm{C} & 3.05391800 & 0.36485000 & -0.52909900\end{array}$

$\begin{array}{llll}\mathrm{H} & 2.88026600 & 0.43050600 & -1.61379900\end{array}$

$\begin{array}{llll}\mathrm{C} & 4.25284400 & -0.49286800 & -0.27031500\end{array}$

$\begin{array}{llll}\mathrm{C} & 5.23281700 & -0.24595500 & 0.63991400\end{array}$

$\begin{array}{llll}\mathrm{C} & 4.62493300 & -1.72027800 & -0.92091800\end{array}$

$\begin{array}{llll}\mathrm{O} & 6.16725000 & -1.22602600 & 0.60771500\end{array}$

$\begin{array}{llll}\mathrm{H} & 5.40130400 & 0.56690000 & 1.32809500\end{array}$

$\begin{array}{llll}\mathrm{C} & 5.78885100 & -2.11338800 & -0.34182400\end{array}$

$\mathrm{H} \quad 4.10465200 \quad-2.22678700 \quad-1.72116000$

$\mathrm{H} \quad \begin{array}{llll}\mathrm{H} & 644406100 & -2.95639900 & -0.49301400\end{array}$

$\begin{array}{llll}\mathrm{C} & 1.91309000 & -0.32233200 & 1.63798700\end{array}$

$\begin{array}{llll}\mathrm{H} & 0.94420000 & -0.47827500 & 2.12077700\end{array}$

$\mathrm{H} \quad 2.55338900 \quad-1.18463600 \quad 1.84796600$

$\begin{array}{llll}\mathrm{H} & 2.37156200 & 0.56603400 & 2.08239900\end{array}$

$\begin{array}{llll}\mathrm{C} & -3.12894900 & 0.98131800 & -0.07096700\end{array}$

$\begin{array}{llll}\mathrm{C} & -3.34761200 & -0.43541400 & -0.05381900\end{array}$

$\begin{array}{llll}\mathrm{C} & -5.09797200 & -1.11092300 & 1.55230600\end{array}$

$\mathrm{H} \quad-4.43454300 \quad-1.84787800 \quad 2.01445600$

$\mathrm{H} \quad-4.97281700 \quad-0.16408400 \quad 2.08704100$

$\mathrm{H} \quad \begin{array}{llll}-6.13361100 & -1.44640900 & 1.67924200\end{array}$

$\begin{array}{llll}\text { C } & -4.76599700 & -0.97502600 & 0.05337500\end{array}$

$\begin{array}{llll}\mathrm{C} & -4.88503600 & -2.34696900 & -0.61506300\end{array}$

$\mathrm{H} \quad-4.62385100 \quad-2.28771500 \quad-1.67662900$

$\mathrm{H} \quad-4.21687400 \quad-3.07049000 \quad-0.14496200$

$\mathrm{H} \quad-5.91597200 \quad-2.70720700 \quad-0.53150700$

$\begin{array}{llll}\mathrm{C} & -5.63022400 & 1.43314700 & -0.08581900\end{array}$

$\begin{array}{llll}\mathrm{H} & -6.07296100 & 1.48546300 & 0.92160500\end{array}$

$\mathrm{H} \quad-6.22549100 \quad 2.11822500 \quad-0.70070000$

$\begin{array}{llll}\text { C } & -5.73398200 & 0.00732000 & -0.63076700\end{array}$

SI152 


$\begin{array}{lrrr}\mathrm{H} & -6.75841700 & -0.36654700 & -0.51975400 \\ \mathrm{H} & -5.51101500 & 0.02054200 & -1.70573900 \\ \mathrm{C} & -4.21003900 & 1.89102800 & -0.04328500 \\ \mathrm{H} & -3.99248600 & 2.95379100 & 0.01326800\end{array}$

\section{3-1 Radical B}

Zero-point correction= Thermal correction to Energy= Thermal correction to Enthalpy= Thermal correction to Gibbs Free Energy= Sum of electronic and zero-point Energies $=$ Sum of electronic and thermal Energies= Sum of electronic and thermal Enthalpies= Sum of electronic and thermal Free Energies=
0.425390 (Hartree/Particle) 0.447814 0.448759

0.374665 $-1170.699560$ $-1170.677136$ $-1170.676192$ $-1170.75028502$ $\begin{array}{rrr}-1.76428900 & 1.40280900 & -0.11998800 \\ -0.71263500 & 0.49537700 & -0.23509800 \\ -1.05457200 & -0.88823300 & -0.26057500 \\ -2.34270300 & -1.30883000 & -0.17999700 \\ -1.55651900 & 2.46763400 & -0.04410300 \\ -0.05181100 & -1.87067800 & -0.37966300 \\ -0.36013500 & -2.90948500 & -0.40402400 \\ 0.69815600 & 0.90424400 & -0.26530000 \\ 1.09019700 & 2.17308200 & -0.49735400 \\ 0.39998200 & 2.97079900 & -0.74526400 \\ 2.47601600 & 2.61989500 & -0.26657700 \\ 2.79475500 & 3.77986000 & -0.17916400 \\ 1.74750700 & -0.14708800 & 0.07133800 \\ 1.37650000 & -1.49683100 & -0.57621300 \\ 1.58307400 & -1.44638800 & -1.66059600 \\ 2.03210500 & -2.27713700 & -0.17570500 \\ 3.40857400 & 1.65258000 & -0.07324900 \\ 3.08879800 & 0.33228400 & -0.52467900 \\ 2.97028300 & 0.36620900 & -1.61842600 \\ 4.26818400 & -0.52183200 & -0.17985500 \\ 5.22969600 & -0.22587400 & 0.73523600 \\ 4.63495700 & -1.79782400 & -0.73320700 \\ 6.14881800 & -1.21912300 & 0.79430800 \\ 5.39242300 & 0.62981700 & 1.37072400 \\ 5.77864100 & -2.16547000 & -0.09940700 \\ 4.12711000 & -2.35352100 & -1.50832900 \\ 6.42343400 & -3.02649500 & -0.17502500 \\ 1.82657600 & -0.29497300 & 1.59940200 \\ 0.84353100 & -0.54556900 & 2.00849800 \\ 2.52880000 & -1.09006600 & 1.86627200 \\ 2.16634900 & 0.63761800 & 2.05902000 \\ -3.08605300 & 0.97522500 & -0.06221600 \\ -3.32439900 & -0.42466200 & -0.09716100 \\ -4.85193300 & -1.68727100 & 1.39429100 \\ -4.07742800 & -2.45121200 & 1.50314900\end{array}$

SI153 


$\begin{array}{lrrr}\mathrm{H} & -4.73637800 & -0.96889500 & 2.21194900 \\ \mathrm{H} & -5.83312000 & -2.16478600 & 1.49126900 \\ \mathrm{C} & -4.73141900 & -1.01285700 & 0.01546500 \\ \mathrm{C} & -4.93450900 & -2.07658900 & -1.07229700 \\ \mathrm{H} & -4.79527700 & -1.64687000 & -2.06991500 \\ \mathrm{H} & -4.22320100 & -2.89574800 & -0.95015500 \\ \mathrm{H} & -5.95274000 & -2.47623900 & -1.00992400 \\ \mathrm{C} & -5.47842400 & 1.35517700 & 0.62572400 \\ \mathrm{H} & -5.33470000 & 1.13252700 & 1.68977300 \\ \mathrm{H} & -6.30715400 & 2.06669700 & 0.55858600 \\ \mathrm{C} & -5.80432600 & 0.07921000 & -0.14522200 \\ \mathrm{H} & -6.77007100 & -0.33423100 & 0.16867000 \\ \mathrm{H} & -5.90197000 & 0.33165700 & -1.21094700 \\ \mathrm{C} & -4.20926800 & 1.97850200 & 0.05078900 \\ \mathrm{H} & -3.87535600 & 2.82930900 & 0.65478800 \\ \mathrm{H} & -4.43083400 & 2.37591800 & -0.95005800\end{array}$

\section{0-1 Cation $A$}

Zero-point correction $=$

Thermal correction to Energy=

Thermal correction to Enthalpy=

Thermal correction to Gibbs Free Energy=

Sum of electronic and zero-point Energies=

Sum of electronic and thermal Energies=

Sum of electronic and thermal Enthalpies=

Sum of electronic and thermal Free Energies=
0.476457 (Hartree/Particle)

0.502940

0.503884

0.421767

$-1436.358007$

$-1436.331524$

$-1436.330579$

$-1436.412697$

11

C $\quad-2.31502600 \quad-0.40366700 \quad-0.46144200$

$\begin{array}{llll}\text { C } & -2.06619200 & 0.99381400 & -0.26261000\end{array}$

C $\quad-0.71323900 \quad 1.43623100 \quad-0.20970000$

$\begin{array}{llll}\mathrm{C} & 0.31536500 & 0.52648600 & -0.31904400\end{array}$

C $\quad-0.05943300 \quad-0.85150100 \quad-0.38183800$

$\mathrm{N} \quad \quad \quad-1.33488900 \quad-1.27591600 \quad-0.49517500$

$\mathrm{H} \quad-0.51149100 \quad 2.49077900 \quad-0.03893300$

C $\quad 0.97272200 \quad-1.92133200 \quad-0.28971400$

$\mathrm{H} \quad 0.64937500 \quad-2.76217200 \quad-0.91010900$

$\begin{array}{llll}\mathrm{H} & 0.92783500 & -2.29337800 & 0.74661900\end{array}$

$\begin{array}{llll}\mathrm{C} & 1.74383300 & 0.91861400 & -0.27164000\end{array}$

$\begin{array}{llll}\text { C } & 2.13395400 & 2.18046700 & -0.50035200\end{array}$

$\mathrm{H} \quad \begin{array}{llll}\mathrm{H} & 1.46535000 & 2.98268300 & -0.79466700\end{array}$

$\begin{array}{llll}\text { C } & 3.52411800 & 2.62278300 & -0.20973500\end{array}$

$\begin{array}{llll}\mathrm{O} & 3.81104200 & 3.78302600 & -0.08852600\end{array}$

$\begin{array}{llll}\mathrm{C} & 2.76710600 & -0.14669800 & 0.08063900\end{array}$

C $\quad 2.38257700 \quad-1.45234200 \quad-0.63666100$

$\mathrm{H} \quad 2.45633400 \quad-1.30618100 \quad-1.72238200$

$\mathrm{H} \quad 3.09554300 \quad-2.23547800 \quad-0.36547700$

$\begin{array}{llll}\mathrm{O} & 4.43335600 & 1.65152200 & 0.00893100\end{array}$

C $\quad 4.13168100 \quad 0.33315700 \quad-0.47164900$

$\mathrm{H} \quad 4.04939100 \quad 0.38132700 \quad-1.56781500$ 


$\begin{array}{lrrr}\mathrm{C} & 5.29067300 & -0.53100200 & -0.09538600 \\ \mathrm{C} & 6.18752900 & -0.28457200 & 0.89881100 \\ \mathrm{C} & 5.69935700 & -1.77178300 & -0.69675200 \\ \mathrm{O} & 7.10145800 & -1.27667900 & 0.95901800 \\ \mathrm{H} & 6.31067700 & 0.53515900 & 1.58896300 \\ \mathrm{C} & 6.80063500 & -2.17177000 & -0.00877800 \\ \mathrm{H} & 5.25700400 & -2.27873400 & -1.54253600 \\ \mathrm{H} & 7.45799700 & -3.02255300 & -0.09191700 \\ \mathrm{C} & 2.81123400 & -0.33483800 & 1.60546600 \\ \mathrm{H} & 1.80968100 & -0.48718300 & 2.02092400 \\ \mathrm{H} & 3.43047100 & -1.19844500 & 1.86329000 \\ \mathrm{H} & 3.23922100 & 0.54983900 & 2.08541800 \\ \mathrm{C} & -3.72390800 & -0.93628700 & -0.65825800 \\ \mathrm{C} & -5.34976200 & -1.62944000 & 0.82611100 \\ \mathrm{O} & -4.02137000 & -1.73607500 & 0.49701000 \\ \mathrm{C} & -3.75704100 & -1.81343600 & -1.90848500 \\ \mathrm{H} & -3.45101100 & -1.24289100 & -2.79031800 \\ \mathrm{H} & -3.08029100 & -2.65784600 & -1.77407400 \\ \mathrm{H} & -4.76820500 & -2.19325100 & -2.07379900 \\ \mathrm{O} & -5.82746300 & -2.23342100 & 1.73465500 \\ \mathrm{C} & -6.01170000 & -0.64056000 & -0.12195900 \\ \mathrm{H} & -6.52655200 & -1.20611500 & -0.90418900 \\ \mathrm{H} & -6.76818500 & -0.05801900 & 0.40431700 \\ \mathrm{C} & -4.82773400 & 0.15178300 & -0.68093400 \\ \mathrm{H} & -4.99777500 & 0.46677800 & -1.71583500 \\ \mathrm{C} & -3.11979900 & 1.85508600 & -0.02127500 \\ \mathrm{H} & -2.89140400 & 2.90743400 & 0.16664300 \\ \mathrm{C} & -4.52048400 & 1.43015900 & 0.14132200 \\ \mathrm{C} & -5.48510900 & 2.56241300 & -0.24475000 \\ \mathrm{H} & -5.30029800 & 3.45739700 & 0.35617000 \\ \mathrm{H} & -5.38986700 & 2.82343000 & -1.30224000 \\ \mathrm{H} & -6.51642600 & 2.24869700 & -0.06496000 \\ \mathrm{C} & -4.59303400 & 1.21346200 & 1.69577600 \\ \mathrm{H} & -5.63594900 & 1.02772300 & 1.96740600 \\ \mathrm{H} & -3.97911500 & 0.37145900 & 2.02369100 \\ \mathrm{H} & -4.27421100 & 2.11262400 & 2.23035700\end{array}$

\section{0-1 Cation B}

Zero-point correction $=$

Thermal correction to Energy=

Thermal correction to Enthalpy=

Thermal correction to Gibbs Free Energy=

Sum of electronic and zero-point Energies=

Sum of electronic and thermal Energies $=$

Sum of electronic and thermal Enthalpies=

Sum of electronic and thermal Free Energies=
0.475732 (Hartree/Particle)

0.502146

0.503090

0.421142

$-1436.357983$

$-1436.331570$

$-1436.330626$

$-1436.412574$

11

$\begin{array}{llll}\text { C } & -2.31895300 & -0.34921700 & -0.65004300\end{array}$

C $\quad-2.06132800 \quad 1.06324200 \quad-0.50706900$

SI155 


\begin{tabular}{|c|c|c|c|}
\hline $\mathrm{C}$ & -0.74889800 & 1.50322100 & -0.40231100 \\
\hline $\mathrm{C}$ & 0.30026100 & 0.58238300 & -0.44858600 \\
\hline $\mathrm{C}$ & -0.06458300 & -0.79267100 & -0.60067400 \\
\hline $\mathrm{N}$ & -1.35860400 & -1.22736600 & -0.70497600 \\
\hline $\mathrm{H}$ & -0.55570000 & 2.55959200 & -0.24386400 \\
\hline $\mathrm{C}$ & 0.91854800 & -1.76275100 & -0.68274000 \\
\hline $\mathrm{H}$ & 0.58108400 & -2.78649000 & -0.84291600 \\
\hline $\mathrm{C}$ & 1.71480700 & 0.94621400 & -0.32328300 \\
\hline $\mathrm{C}$ & 2.13524900 & 2.21407200 & -0.48094200 \\
\hline $\mathrm{H}$ & 1.48826900 & 3.03803100 & -0.76135900 \\
\hline $\mathrm{C}$ & 3.53114500 & 2.61652900 & -0.14556600 \\
\hline $\mathrm{O}$ & 3.83338800 & 3.76553700 & 0.01738600 \\
\hline $\mathrm{C}$ & 2.71496900 & -0.13375900 & 0.06079500 \\
\hline $\mathrm{C}$ & 2.35610500 & -1.46770500 & -0.62072800 \\
\hline $\mathrm{H}$ & 2.68297600 & -1.47601400 & -1.68087600 \\
\hline $\mathrm{H}$ & 2.89510900 & -2.30382900 & -0.15943300 \\
\hline $\mathrm{O}$ & 4.41611900 & 1.61997600 & 0.06553700 \\
\hline $\mathrm{C}$ & 4.10650100 & 0.31986900 & -0.44797400 \\
\hline $\mathrm{H}$ & 4.05797000 & 0.38798000 & -1.54573100 \\
\hline $\mathrm{C}$ & 5.22862700 & -0.58147400 & -0.04987800 \\
\hline $\mathrm{C}$ & 6.11007600 & -0.36550200 & 0.96555200 \\
\hline $\mathrm{C}$ & 5.60602000 & -1.83763300 & -0.64098100 \\
\hline $\mathrm{O}$ & 6.98501800 & -1.38892400 & 1.04588700 \\
\hline $\mathrm{H}$ & 6.24468800 & 0.44912300 & 1.65981000 \\
\hline $\mathrm{C}$ & 6.67664300 & -2.27453000 & 0.07330200 \\
\hline $\mathrm{H}$ & 5.17485100 & -2.33150100 & -1.50041300 \\
\hline $\mathrm{H}$ & 7.30673300 & -3.14707700 & 0.00485800 \\
\hline $\mathrm{C}$ & 2.69851400 & -0.31040900 & 1.58904700 \\
\hline $\mathrm{H}$ & 1.69323800 & -0.55388200 & 1.94756400 \\
\hline $\mathrm{H}$ & 3.37845900 & -1.11379200 & 1.88336900 \\
\hline $\mathrm{H}$ & 3.02330400 & 0.61046600 & 2.08070500 \\
\hline $\mathrm{C}$ & -3.73957800 & -0.89665900 & -0.73092800 \\
\hline $\mathrm{C}$ & -5.07282500 & -1.78861000 & 0.93861000 \\
\hline $\mathrm{O}$ & -3.84414400 & -1.84728800 & 0.34063300 \\
\hline $\mathrm{C}$ & -3.92754300 & -1.62540900 & -2.06007800 \\
\hline $\mathrm{H}$ & -3.76956800 & -0.94325800 & -2.90127200 \\
\hline $\mathrm{H}$ & -3.21856900 & -2.45245800 & -2.12740400 \\
\hline $\mathrm{H}$ & -4.94332900 & -2.02473400 & -2.12403500 \\
\hline $\mathrm{O}$ & -5.36760600 & -2.50233100 & 1.84818300 \\
\hline $\mathrm{C}$ & -5.90185800 & -0.71784000 & 0.25465700 \\
\hline $\mathrm{H}$ & -6.58529000 & -1.21616400 & -0.44026600 \\
\hline $\mathrm{H}$ & -6.51330300 & -0.19145000 & 0.98813100 \\
\hline $\mathrm{C}$ & -4.86759900 & 0.14373600 & -0.47487700 \\
\hline $\mathrm{H}$ & -5.25154900 & 0.48996200 & -1.44152200 \\
\hline $\mathrm{C}$ & -4.41759200 & 1.39092600 & 0.31995100 \\
\hline $\mathrm{C}$ & -5.54427000 & 2.42879100 & 0.33535900 \\
\hline $\mathrm{H}$ & -5.22406300 & 3.33500400 & 0.85884100 \\
\hline $\mathrm{H}$ & -5.84243000 & 2.70849400 & -0.68049300 \\
\hline $\mathrm{H}$ & -6.42777200 & 2.04781100 & 0.85457000 \\
\hline $\mathrm{C}$ & -4.00262600 & 1.05924900 & 1.76231100 \\
\hline $\mathrm{H}$ & -4.85294400 & 0.69709100 & 2.34700600 \\
\hline
\end{tabular}




$\begin{array}{lrrr}\mathrm{H} & -3.22089000 & 0.29318600 & 1.81783400 \\ \mathrm{H} & -3.62836700 & 1.96001800 & 2.25954700 \\ \mathrm{C} & -3.21832600 & 2.00187500 & -0.43517500 \\ \mathrm{H} & -2.90520100 & 2.94722700 & 0.02109400 \\ \mathrm{H} & -3.52859700 & 2.23684300 & -1.46643200\end{array}$

\section{0-1 Radical $A$}

$\begin{array}{lc}\text { Zero-point correction }= & 0.475556 \text { (Hartree/Particle) } \\ \text { Thermal correction to Energy= } & 0.501850 \\ \text { Thermal correction to Enthalpy= } & 0.502794 \\ \text { Thermal correction to Gibbs Free Energy }= & 0.420621 \\ \text { Sum of electronic and zero-point Energies }= & -1436.616966 \\ \text { Sum of electronic and thermal Energies }= & -1436.590672 \\ \text { Sum of electronic and thermal Enthalpies }= & -1436.589728 \\ \text { Sum of electronic and thermal Free Energies }= & -1436.671901\end{array}$
02

$\begin{array}{lrrr}\mathrm{C} & -2.29590200 & -0.37436400 & -0.38800400 \\ \mathrm{C} & -2.06918500 & 1.02585900 & -0.29262300 \\ \mathrm{C} & -0.72284700 & 1.43965300 & -0.25825500 \\ \mathrm{C} & 0.31108900 & 0.50966700 & -0.26753800 \\ \mathrm{C} & -0.04439600 & -0.85835600 & -0.28463900 \\ \mathrm{~N} & -1.31614800 & -1.26420300 & -0.37359600 \\ \mathrm{H} & -0.51154900 & 2.50211300 & -0.17995800 \\ \mathrm{C} & 0.99372600 & -1.94168600 & -0.19300700 \\ \mathrm{H} & 0.67131500 & -2.78081700 & -0.81525400 \\ \mathrm{H} & 1.00820600 & -2.31701200 & 0.83906500 \\ \mathrm{C} & 1.73520800 & 0.91691500 & -0.21975800 \\ \mathrm{C} & 2.13296600 & 2.18695000 & -0.41017300 \\ \mathrm{H} & 1.45619700 & 2.99759200 & -0.65240800 \\ \mathrm{C} & 3.52038300 & 2.62077000 & -0.14737700 \\ \mathrm{O} & 3.83594900 & 3.77680200 & -0.01440500 \\ \mathrm{C} & 2.77220900 & -0.14772300 & 0.10427300 \\ \mathrm{C} & 2.38168700 & -1.45924900 & -0.59805200 \\ \mathrm{H} & 2.40856600 & -1.30234000 & -1.68553000 \\ \mathrm{H} & 3.12201000 & -2.22830900 & -0.35814800 \\ \mathrm{O} & 4.44693200 & 1.64645500 & 0.01570600 \\ \mathrm{C} & 4.12197300 & 0.33716300 & -0.46984600 \\ \mathrm{H} & 4.01365800 & 0.39676600 & -1.56334900 \\ \mathrm{C} & 5.29459900 & -0.52986300 & -0.13488400 \\ \mathrm{C} & 6.22071200 & -0.28755600 & 0.83138100 \\ \mathrm{C} & 5.69169600 & -1.76479700 & -0.75569500 \\ \mathrm{O} & 7.14488400 & -1.27680600 & 0.85964800 \\ \mathrm{H} & 6.35625200 & 0.52726200 & 1.52452400 \\ \mathrm{C} & 6.81488900 & -2.16604000 & -0.10597900 \\ \mathrm{H} & 5.21535700 & -2.27067600 & -1.58323400 \\ \mathrm{H} & 7.46918500 & -3.01645500 & -0.21307000 \\ \mathrm{C} & 2.84729200 & -0.33396300 & 1.62844900 \\ \mathrm{H} & 1.85057500 & -0.48079200 & 2.05424500 \\ \mathrm{H} & 3.46562000 & -1.20215000 & 1.87594200 \\ & & & \mathrm{~S} 1157 \\ & & & \\ & & & \\ \mathrm{H} & & & \\ \mathrm{H} & & & \end{array}$




$\begin{array}{lrrr}\mathrm{H} & 3.28725300 & 0.55024700 & 2.09907700 \\ \mathrm{C} & -3.69552900 & -0.92136100 & -0.60767500 \\ \mathrm{C} & -5.39282700 & -1.63753400 & 0.78115300 \\ \mathrm{O} & -4.06317400 & -1.72942000 & 0.53718900 \\ \mathrm{C} & -3.69200100 & -1.82607700 & -1.83992600 \\ \mathrm{H} & -3.36683800 & -1.26317200 & -2.71982900 \\ \mathrm{H} & -3.00061600 & -2.65278200 & -1.67204700 \\ \mathrm{H} & -4.69271200 & -2.22595800 & -2.02782400 \\ \mathrm{O} & -5.93646800 & -2.26906200 & 1.64357800 \\ \mathrm{C} & -6.01301800 & -0.63942000 & -0.18467900 \\ \mathrm{H} & -6.50512000 & -1.20285900 & -0.98355800 \\ \mathrm{H} & -6.78141700 & -0.05531200 & 0.32277000 \\ \mathrm{C} & -4.80851300 & 0.15462600 & -0.69511200 \\ \mathrm{H} & -4.92783900 & 0.45076600 & -1.74327300 \\ \mathrm{C} & -3.15094700 & 1.93235400 & -0.18895400 \\ \mathrm{H} & -2.94491900 & 2.99900600 & -0.14043000 \\ \mathrm{C} & -4.53490800 & 1.44526800 & 0.12186600 \\ \mathrm{C} & -5.56402300 & 2.51457300 & -0.26440000 \\ \mathrm{H} & -5.37755300 & 3.43919300 & 0.29147600 \\ \mathrm{H} & -5.51019000 & 2.74229400 & -1.33393500 \\ \mathrm{H} & -6.58290400 & 2.18918900 & -0.03271300 \\ \mathrm{C} & -4.60158200 & 1.20420400 & 1.65032400 \\ \mathrm{H} & -5.60159100 & 0.88985200 & 1.96705900 \\ \mathrm{H} & -3.88282300 & 0.44483500 & 1.97159200 \\ \mathrm{H} & -4.36657200 & 2.13513800 & 2.17502900\end{array}$

\section{0-1 Radical B}

Zero-point correction $=$

Thermal correction to Energy=

Thermal correction to Enthalpy=

Thermal correction to Gibbs Free Energy=

Sum of electronic and zero-point Energies=

Sum of electronic and thermal Energies=

Sum of electronic and thermal Enthalpies=

Sum of electronic and thermal Free Energies=
0.475111 (Hartree/Particle)

0.501447

0.502391

0.420143

$-1436.621124$

$-1436.594788$

$-1436.593843$

$-1436.676092$ 02

$\begin{array}{lrrr}\mathrm{C} & -2.29842600 & -0.34138500 & -0.61130500 \\ \mathrm{C} & -2.06112200 & 1.04586200 & -0.49092600 \\ \mathrm{C} & -0.73631800 & 1.45995200 & -0.41576900 \\ \mathrm{C} & 0.30731100 & 0.53856700 & -0.48940000 \\ \mathrm{C} & -0.04374500 & -0.83823700 & -0.61923000 \\ \mathrm{~N} & -1.33858100 & -1.24410200 & -0.67724900 \\ \mathrm{H} & -0.52289800 & 2.51487700 & -0.26288500 \\ \mathrm{C} & 0.95461600 & -1.82867400 & -0.70065500 \\ \mathrm{H} & 0.63667700 & -2.85986800 & -0.80129000 \\ \mathrm{C} & 1.72152400 & 0.92443200 & -0.37500100 \\ \mathrm{C} & 2.14613500 & 2.19548800 & -0.51367600 \\ \mathrm{H} & 1.49106900 & 3.01399000 & -0.78820200 \\ \mathrm{C} & 3.51065300 & 2.61089700 & -0.13569900\end{array}$

SI158 


\begin{tabular}{|c|c|c|c|}
\hline $\mathrm{O}$ & 3.82986200 & 3.76141300 & 0.03232600 \\
\hline $\mathrm{C}$ & 2.72226200 & -0.15823700 & 0.00583000 \\
\hline $\mathrm{C}$ & 2.39895700 & -1.46833700 & -0.74155500 \\
\hline $\mathrm{H}$ & 2.70800900 & -1.36908900 & -1.79775100 \\
\hline $\mathrm{H}$ & 3.00361100 & -2.27831500 & -0.32064000 \\
\hline $\mathrm{O}$ & 4.40855400 & 1.62236200 & 0.10150900 \\
\hline $\mathrm{C}$ & 4.11952400 & 0.32779400 & -0.43778000 \\
\hline $\mathrm{H}$ & 4.10670100 & 0.41244100 & -1.53512500 \\
\hline $\mathrm{C}$ & 5.25065900 & -0.55872500 & -0.02146500 \\
\hline $\mathrm{C}$ & 6.12033600 & -0.32087100 & 0.99679800 \\
\hline $\mathrm{C}$ & 5.65570800 & -1.81329200 & -0.59666700 \\
\hline $\mathrm{O}$ & 7.01747500 & -1.33018400 & 1.09795300 \\
\hline $\mathrm{H}$ & 6.22893500 & 0.50113400 & 1.68605400 \\
\hline $\mathrm{C}$ & 6.72696300 & -2.22806300 & 0.12822900 \\
\hline $\mathrm{H}$ & 5.22123200 & -2.32440100 & -1.44374700 \\
\hline $\mathrm{H}$ & 7.36617000 & -3.09493300 & 0.07545100 \\
\hline $\mathrm{C}$ & 2.65413900 & -0.38240900 & 1.52520900 \\
\hline $\mathrm{H}$ & 1.63428600 & -0.63670400 & 1.82832600 \\
\hline $\mathrm{H}$ & 3.31809400 & -1.20133300 & 1.81631300 \\
\hline $\mathrm{H}$ & 2.96063200 & 0.52054200 & 2.06112300 \\
\hline $\mathrm{C}$ & -3.71605900 & -0.89298500 & -0.68669200 \\
\hline $\mathrm{C}$ & -5.13008200 & -1.75497100 & 0.92693100 \\
\hline $\mathrm{O}$ & -3.87725100 & -1.81227000 & 0.42015700 \\
\hline $\mathrm{C}$ & -3.88829000 & -1.68202900 & -1.98276700 \\
\hline $\mathrm{H}$ & -3.71063300 & -1.03321100 & -2.84586900 \\
\hline $\mathrm{H}$ & -3.16794000 & -2.50137800 & -1.99916600 \\
\hline $\mathrm{H}$ & -4.90150700 & -2.08974700 & -2.05178600 \\
\hline $\mathrm{O}$ & -5.49835400 & -2.46339200 & 1.82229900 \\
\hline $\mathrm{C}$ & -5.92309700 & -0.69153900 & 0.18737900 \\
\hline $\mathrm{H}$ & -6.57268100 & -1.19883400 & -0.53317300 \\
\hline $\mathrm{H}$ & -6.56694400 & -0.15480300 & 0.88522300 \\
\hline $\mathrm{C}$ & -4.84747500 & 0.15500300 & -0.49721000 \\
\hline $\mathrm{H}$ & -5.17731200 & 0.49668100 & -1.48590300 \\
\hline $\mathrm{C}$ & -4.42984800 & 1.40739500 & 0.30859800 \\
\hline $\mathrm{C}$ & -5.56659200 & 2.43450500 & 0.28379900 \\
\hline $\mathrm{H}$ & -5.26094000 & 3.35069700 & 0.80006600 \\
\hline $\mathrm{H}$ & -5.83802100 & 2.69932200 & -0.74417400 \\
\hline $\mathrm{H}$ & -6.46352300 & 2.05925600 & 0.78584000 \\
\hline $\mathrm{C}$ & -4.07442200 & 1.07812800 & 1.76698800 \\
\hline $\mathrm{H}$ & -4.93920300 & 0.68757400 & 2.31301600 \\
\hline $\mathrm{H}$ & -3.26963100 & 0.34151900 & 1.84632200 \\
\hline $\mathrm{H}$ & -3.74831500 & 1.98918500 & 2.27997000 \\
\hline $\mathrm{C}$ & -3.20910900 & 2.01379700 & -0.40208000 \\
\hline $\mathrm{H}$ & -2.88474500 & 2.92155700 & 0.12120800 \\
\hline $\mathrm{H}$ & -3.50855000 & 2.32671200 & -1.4136960 \\
\hline
\end{tabular}




\section{Pyran Formation Calculations}

Geometry optimization and transition state calculations were performed in the gas phase at $298 \mathrm{~K}$ using the $\omega \mathrm{B} 97 \mathrm{x}-\mathrm{D} / 6-31+\mathrm{G}(\mathrm{d}, \mathrm{p})$ level of theory, followed by single point energy calculations at the levels of theory indicated in each section in Gaussian 09.

Scheme SI9. Computational Investigation of the Regioselective Pyran Formation

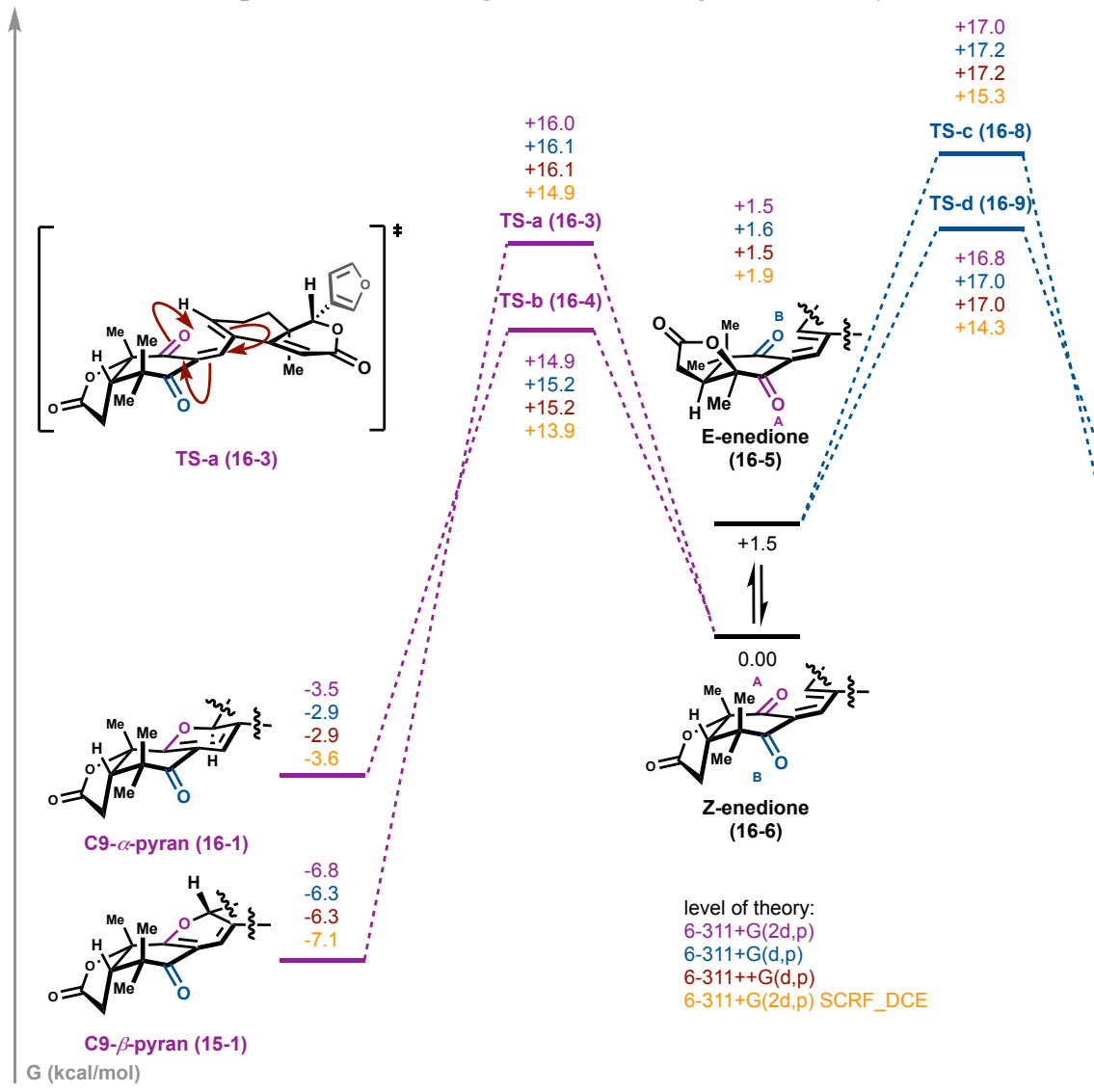

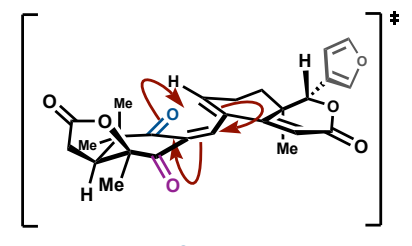

TS-c (16-8)

$-1.3$

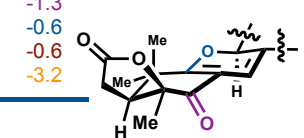

C9- $\alpha$-pyran-regioisomer (16-7)

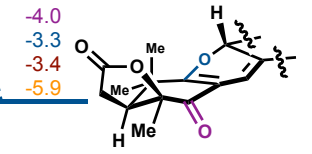

C9- $\beta$-pyran-regioisomer (16-2) 


\begin{tabular}{|c|c|c|c|c|}
\hline & $6-311+G(2 d, p)$ & $6-311+G(d, p)$ & $6-311++G(d, p)$ & $\begin{array}{c}\text { 6-311+G(2d,p) } \\
\text { SCRF_DCE }\end{array}$ \\
\hline Z-enedione (16-6) & 0.0 & 0.0 & 0.0 & 0.0 \\
\hline TS-a (16-3) & 16.0 & 16.1 & 16.1 & 14.9 \\
\hline C9-b-pyran (15-1) & -6.8 & -6.3 & -6.3 & -7.1 \\
\hline TS-b (16-4) & 14.9 & 15.2 & 15.2 & 13.9 \\
\hline C9-a-pyran (16-1) & -3.5 & -2.9 & -2.9 & -3.6 \\
\hline E-enedione (16-5) & 1.5 & 1.6 & 1.5 & 1.9 \\
\hline TS-c (16-8) & 17.0 & 17.2 & 17.2 & 15.3 \\
\hline $\begin{array}{c}\text { C9-b-pyran-regio } \\
(\mathbf{1 6 - 2})\end{array}$ & -4.0 & -3.3 & -3.4 & -5.9 \\
\hline TS-d (16-9) & 16.8 & 17.0 & 17.0 & 14.3 \\
\hline $\begin{array}{c}\text { C9-a-pyran-regio } \\
(\mathbf{1 6 - 7})\end{array}$ & -1.3 & -0.6 & -0.6 & -3.2 \\
\hline
\end{tabular}

Minimized structure coordinates and energies calculated with $6-311+G(2 d, p)$ basis set were already reported. ${ }^{6}$

Energies of minimized structures

Calculations conducted with $6-311+G(d, p)$ basis set:

\section{Z-enedione (16-6)}

Zero-point correction=

Thermal correction to Energy=

Thermal correction to Enthalpy=

Thermal correction to Gibbs Free Energy=

Sum of electronic and zero-point Energies=

Sum of electronic and thermal Energies $=$

Sum of electronic and thermal Enthalpies=

Sum of electronic and thermal Free Energies=
0.478146 (Hartree/Particle)

0.506777

0.507721

0.420115

$-1532.419631$

$-1532.391001$

$-1532.390057$

$-1532.477663$

\section{TS-a (16-3)}

Zero-point correction $=\quad 0.477850($ Hartree/Particle $)$ 
Thermal correction to Energy=

0.505493

Thermal correction to Enthalpy=

0.506438

Thermal correction to Gibbs Free Energy=

Sum of electronic and zero-point Energies=

Sum of electronic and thermal Energies=

0.421425

$-1532.395571$

$-1532.367928$

Sum of electronic and thermal Enthalpies=

$-1532.366984$

Sum of electronic and thermal Free Energies=

$-1532.451996$

\section{C9-b-pyran (15-1)}

Zero-point correction=

Thermal correction to Energy=

Thermal correction to Enthalpy=

Thermal correction to Gibbs Free Energy=

Sum of electronic and zero-point Energies $=$

Sum of electronic and thermal Energies=

Sum of electronic and thermal Enthalpies=

Sum of electronic and thermal Free Energies=
0.480796 (Hartree/Particle)

0.508455

0.509399

0.424426

$-1532.431262$

$-1532.403604$

$-1532.402659$

$-1532.487632$

\section{TS-b (16-4)}

Zero-point correction $=$

Thermal correction to Energy=

Thermal correction to Enthalpy=

Thermal correction to Gibbs Free Energy=

Sum of electronic and zero-point Energies $=$

Sum of electronic and thermal Energies=

Sum of electronic and thermal Enthalpies=

Sum of electronic and thermal Free Energies=
0.478317 (Hartree/Particle)

0.505792

0.506736

0.422266

$-1532.397355$

$-1532.369879$

$-1532.368935$

$-1532.453406$

\section{C9-a-pyran (16-1)}

Zero-point correction $=$

Thermal correction to Energy=

Thermal correction to Enthalpy=

Thermal correction to Gibbs Free Energy=

Sum of electronic and zero-point Energies $=$

Sum of electronic and thermal Energies=

Sum of electronic and thermal Enthalpies=

Sum of electronic and thermal Free Energies=
0.481218 (Hartree/Particle)

0.508723

0.509667

0.425182

$-1532.426212$

$-1532.398707$

$-1532.397763$

$-1532.482247$

\section{E-enedione (16-5)}

Zero-point correction $=$

Thermal correction to Energy=

Thermal correction to Enthalpy=

Thermal correction to Gibbs Free Energy=
0.478730 (Hartree/Particle)

0.507111

0.508055

0.421573 
Sum of electronic and zero-point Energies= Sum of electronic and thermal Energies=

Sum of electronic and thermal Enthalpies= Sum of electronic and thermal Free Energies=
$-1532.418021$

$-1532.389640$

$-1532.388696$

$-1532.475178$

\section{$T S-c$ (16-8)}

Zero-point correction $=$

Thermal correction to Energy=

Thermal correction to Enthalpy=

Thermal correction to Gibbs Free Energy=

Sum of electronic and zero-point Energies $=$

Sum of electronic and thermal Energies=

Sum of electronic and thermal Enthalpies=

Sum of electronic and thermal Free Energies=
0.478466 (Hartree/Particle)

0.505902

0.506846

0.422472

$-1532.394239$

$-1532.366803$

$-1532.365859$

$-1532.450233$

\section{C9-b-pyran-regio (16-2)}

Zero-point correction $=$

Thermal correction to Energy=

Thermal correction to Enthalpy=

Thermal correction to Gibbs Free Energy=

Sum of electronic and zero-point Energies $=$

Sum of electronic and thermal Energies=

Sum of electronic and thermal Enthalpies=

Sum of electronic and thermal Free Energies=

\author{
0.481089 (Hartree/Particle) \\ 0.508636 \\ 0.509580 \\ 0.424765 \\ $-1532.426644$ \\ $-1532.399096$ \\ $-1532.398152$ \\ $-1532.482967$
}

\section{TS-d (16-9)}

Zero-point correction $=$

Thermal correction to Energy=

Thermal correction to Enthalpy=

Thermal correction to Gibbs Free Energy=

Sum of electronic and zero-point Energies=

Sum of electronic and thermal Energies=

Sum of electronic and thermal Enthalpies=

Sum of electronic and thermal Free Energies=
0.478428 (Hartree/Particle)

0.505822

0.506766

0.422319

$-1532.394432$

$-1532.367038$

$-1532.366093$

$-1532.450541$

\section{C9-a-pyran-regio (16-7)}

Zero-point correction=

Thermal correction to Energy=

Thermal correction to Enthalpy=

Thermal correction to Gibbs Free Energy=

Sum of electronic and zero-point Energies $=$

Sum of electronic and thermal Energies=

Sum of electronic and thermal Enthalpies=
0.480723 (Hartree/Particle)

0.508258

0.509202

0.424463

$-1532.422386$

$-1532.394851$

$-1532.393907$

SI163 
Sum of electronic and thermal Free Energies $=\quad-1532.478646$

Calculations conducted with 6-311++G(d,p) basis set:

\section{Z-enedione (16-6)}

Zero-point correction $=$

Thermal correction to Energy=

Thermal correction to Enthalpy=

Thermal correction to Gibbs Free Energy=

Sum of electronic and zero-point Energies=

Sum of electronic and thermal Energies $=$

Sum of electronic and thermal Enthalpies=

Sum of electronic and thermal Free Energies=
0.478114 (Hartree/Particle)

0.506751

0.507695

0.420068

$-1532.420123$

$-1532.391487$

$-1532.390542$

$-1532.478169$

\section{TS-a (16-3)}

Zero-point correction=

Thermal correction to Energy=

Thermal correction to Enthalpy=

Thermal correction to Gibbs Free Energy=

Sum of electronic and zero-point Energies=

Sum of electronic and thermal Energies=

Sum of electronic and thermal Enthalpies=

Sum of electronic and thermal Free Energies=
0.477822 (Hartree/Particle)

0.505470

0.506414

0.421385

$-1532.396128$

$-1532.368479$

$-1532.367535$

$-1532.452564$

\section{C9-b-pyran (15-1)}

Zero-point correction=

Thermal correction to Energy=

Thermal correction to Enthalpy=

Thermal correction to Gibbs Free Energy=

Sum of electronic and zero-point Energies=

Sum of electronic and thermal Energies $=$

Sum of electronic and thermal Enthalpies=

Sum of electronic and thermal Free Energies=
0.480770 (Hartree/Particle)

0.508432

0.509376

0.424392

$-1532.431767$

$-1532.404105$

$-1532.403160$

$-1532.488145$

\section{TS-b (16-4)}

Zero-point correction=

Thermal correction to Energy=

Thermal correction to Enthalpy=

Thermal correction to Gibbs Free Energy=

Sum of electronic and zero-point Energies=

Sum of electronic and thermal Energies $=$

Sum of electronic and thermal Enthalpies=

Sum of electronic and thermal Free Energies=
0.478291 (Hartree/Particle)

0.505772

0.506716

0.422224

$-1532.397897$

$-1532.370415$

$-1532.369471$

$-1532.453963$ 
C9-a-pyran (16-1)

Zero-point correction=

Thermal correction to Energy=

Thermal correction to Enthalpy=

Thermal correction to Gibbs Free Energy=

Sum of electronic and zero-point Energies=

Sum of electronic and thermal Energies=

Sum of electronic and thermal Enthalpies=

Sum of electronic and thermal Free Energies=
0.481189 (Hartree/Particle)

0.508700

0.509644

0.425145

$-1532.426698$

$-1532.399187$

$-1532.398243$

$-1532.482742$

\section{E-enedione (16-5)}

Zero-point correction=

Thermal correction to Energy=

Thermal correction to Enthalpy=

Thermal correction to Gibbs Free Energy=

Sum of electronic and zero-point Energies=

Sum of electronic and thermal Energies=

Sum of electronic and thermal Enthalpies=

Sum of electronic and thermal Free Energies=
0.478697 (Hartree/Particle)

0.507085

0.508029

0.421523

$-1532.418602$

$-1532.390214$

$-1532.389270$

$-1532.475776$

\section{TS-c (16-8)}

Zero-point correction=

Thermal correction to Energy=

Thermal correction to Enthalpy=

Thermal correction to Gibbs Free Energy=

Sum of electronic and zero-point Energies=

Sum of electronic and thermal Energies=

Sum of electronic and thermal Enthalpies=

Sum of electronic and thermal Free Energies=
0.478437 (Hartree/Particle)

0.505877

0.506821

0.422434

$-1532.394768$

$-1532.367328$

$-1532.366383$

$-1532.450771$

\section{C9-b-pyran-regio (16-2)}

Zero-point correction=

Thermal correction to Energy=

Thermal correction to Enthalpy=

Thermal correction to Gibbs Free Energy=

Sum of electronic and zero-point Energies=

Sum of electronic and thermal Energies=

Sum of electronic and thermal Enthalpies=

Sum of electronic and thermal Free Energies=
0.481062 (Hartree/Particle)

0.508613

0.509558

0.424727

$-1532.427199$

$-1532.399647$

$-1532.398703$

$-1532.483533$ 
TS-d (16-9)

Zero-point correction=

Thermal correction to Energy=

0.478407 (Hartree/Particle)

Thermal correction to Enthalpy=

0.505804

0.506748

Thermal correction to Gibbs Free Energy $=\quad 0.422290$

Sum of electronic and zero-point Energies $=\quad-1532.394945$

Sum of electronic and thermal Energies $=\quad-1532.367547$

Sum of electronic and thermal Enthalpies $=\quad-1532.366603$

Sum of electronic and thermal Free Energies $=\quad-1532.451062$

\section{C9-a-pyran-regio (16-7)}

Zero-point correction $=$

Thermal correction to Energy=

Thermal correction to Enthalpy=

Thermal correction to Gibbs Free Energy=

Sum of electronic and zero-point Energies $=$

Sum of electronic and thermal Energies=

Sum of electronic and thermal Enthalpies=

Sum of electronic and thermal Free Energies=
0.480702 (Hartree/Particle)

0.508240

0.509184

0.424434

$-1532.422883$

$-1532.395345$

$-1532.394401$

$-1532.479151$

\section{Calculations conducted with $6-311+G(2 d, p)$ basis set with solvent correction (dichloroethane):}

\section{Z-enedione (16-6)}

Zero-point correction $=$

Thermal correction to Energy=

Thermal correction to Enthalpy=

Thermal correction to Gibbs Free Energy=

Sum of electronic and zero-point Energies $=$

Sum of electronic and thermal Energies=

Sum of electronic and thermal Enthalpies=

Sum of electronic and thermal Free Energies=
0.476885 (Hartree/Particle)

0.505387

0.506331

0.419347

$-1532.480884$

$-1532.452381$

$-1532.451437$

$-1532.538422$

\section{TS-a (16-3)}

Zero-point correction $=$

Thermal correction to Energy=

Thermal correction to Enthalpy=

Thermal correction to Gibbs Free Energy=

Sum of electronic and zero-point Energies=

Sum of electronic and thermal Energies=

Sum of electronic and thermal Enthalpies=

Sum of electronic and thermal Free Energies=
0.476814 (Hartree/Particle)

0.504298

0.505242

0.420845

$-1532.458727$

$-1532.431243$

$-1532.430299$

$-1532.514696$ 
Zero-point correction $=$

Thermal correction to Energy=

Thermal correction to Enthalpy=

Thermal correction to Gibbs Free Energy=

Sum of electronic and zero-point Energies=

Sum of electronic and thermal Energies $=$

Sum of electronic and thermal Enthalpies=

Sum of electronic and thermal Free Energies=
0.479880 (Hartree/Particle)

0.507326

0.508270

0.424176

$-1532.493998$

$-1532.466551$

$-1532.465607$

$-1532.549701$

\section{TS-b (16-4)}

Zero-point correction=

Thermal correction to Energy=

Thermal correction to Enthalpy=

Thermal correction to Gibbs Free Energy=

Sum of electronic and zero-point Energies=

Sum of electronic and thermal Energies=

Sum of electronic and thermal Enthalpies=

Sum of electronic and thermal Free Energies=
0.477151 (Hartree/Particle)

0.504478

0.505422

0.421700

$-1532.460874$

$-1532.433547$

$-1532.432603$

$-1532.516326$

\section{C9-a-pyran (16-1)}

Zero-point correction=

Thermal correction to Energy=

Thermal correction to Enthalpy=

Thermal correction to Gibbs Free

Sum of electronic and zero-point Energies=

Sum of electronic and thermal Energies $=$

Sum of electronic and thermal Enthalpies=

Sum of electronic and thermal Free Energies=
0.480115 (Hartree/Particle)

0.507465

0.508409

0.424639

$-1532.488678$

$-1532.461328$

$-1532.460384$

$-1532.544154$

\section{E-enedione (16-5)}

Zero-point correction=

Thermal correction to Energy=

Thermal correction to Enthalpy=

Thermal correction to Gibbs Free Energy=

Sum of electronic and zero-point Energies=

Sum of electronic and thermal Energies=

Sum of electronic and thermal Enthalpies=

Sum of electronic and thermal Free Energies=
0.477498 (Hartree/Particle)

0.505776

0.506721

0.420721

$-1532.478588$

$-1532.450310$

$-1532.449366$

$-1532.535366$

\section{TS-c (16-8)}

Zero-point correction=

Thermal correction to Energy=

Thermal correction to Enthalpy=
0.477268 (Hartree/Particle)

0.504608

0.505552 
Thermal correction to Gibbs Free Energy=

Sum of electronic and zero-point Energies $=$

Sum of electronic and thermal Energies=

Sum of electronic and thermal Enthalpies=

Sum of electronic and thermal Free Energies=
0.421599

$-1532.458387$

$-1532.431047$

$-1532.430102$

$-1532.514055$

\section{C9-b-pyran-regio (16-2)}

Zero-point correction=

Thermal correction to Energy=

Thermal correction to Enthalpy=

Thermal correction to Gibbs Free Energy=

Sum of electronic and zero-point Energies=

Sum of electronic and thermal Energies=

Sum of electronic and thermal Enthalpies=

Sum of electronic and thermal Free Energies=
0.479978 (Hartree/Particle)

0.507403

0.508347

0.424088

$-1532.491882$

$-1532.464457$

$-1532.463513$

$-1532.547772$

\section{TS-d (16-9)}

Zero-point correction=

Thermal correction to Energy=

Thermal correction to Enthalpy=

Thermal correction to Gibbs Free Energy=

Sum of electronic and zero-point Energies $=$

Sum of electronic and thermal Energies=

Sum of electronic and thermal Enthalpies=

Sum of electronic and thermal Free Energies=
0.477298 (Hartree/Particle)

0.504550

0.505494

0.421692

$-1532.460018$

$-1532.432766$

$-1532.431822$

$-1532.515624$

\section{C9-a-pyran-regio (16-7)}

Zero-point correction=

Thermal correction to Energy=

Thermal correction to Enthalpy=

Thermal correction to Gibbs Free Energy=

Sum of electronic and zero-point Energies=

Sum of electronic and thermal Energies=

Sum of electronic and thermal Enthalpies=

Sum of electronic and thermal Free Energies=
0.479685 (Hartree/Particle)

0.507060

0.508004

0.423998

$-1532.487841$

$-1532.460465$

$-1532.459521$

$-1532.543528$ 


\section{GIAO NMR Calculations}

The general workflow was performed as described by Hoye and co-workers. ${ }^{7}$ The calculations were performed on a Windows 10 system, therefore the file-sorting issue due to the script flaw was not encountered. ${ }^{8}$

\section{Conformational search:}

Molecular mechanics calculations using MacroModel (part of the Schrödinger suite) ${ }^{9}$ were performed in order to generate a library of conformers. For compounds 1-2, 1-3, and 17-1 to 17-8, 6-24 conformers with distinct energies were generated for each structure. The cut-off energy difference for structures subjected to Boltzmann-weighted averaging based on the calculated energies was $5.02 \mathrm{kcal} / \mathrm{mol}$.

\section{Geometry optimization and NMR calculations:}

All conformers were subjected to geometry optimization calculations using Gaussian 09. Geometry optimization calculations were performed in the gas phase using the B3LYP/6-31+G(d,p) level of theory. ${ }^{10}$

NMR single point calculations (GIAO) were performed using Gaussian 09 on all geometry optimized structures using mPW1PW91/6-311+G(2d,p) ${ }^{11}$ in chloroform with the SMD solvation method. ${ }^{12}$ Ultrafine grid size was used for both geometry optimization and NMR calculations.

The NMR and free energy data were assembled and Boltzmann-averaged using script D by Hoye and cowokers. ${ }^{2}$ The script provided by Williams and co-workers was also tested and it gave the exact same chemical shifts. ${ }^{3}$ All chemical shifts were scaled. ${ }^{13}$ The following equation was used to convert computed isotropic values to chemical shifts:

$$
\delta=\frac{\text { intercept }-\sigma}{- \text { slope }}
$$

The following intercepts and slopes were used:

\begin{tabular}{|c|c|c|}
\hline & Slope & Intercept \\
\hline${ }^{1} \mathrm{H}$ & -1.0936 & 31.8018 \\
\hline${ }^{13} \mathrm{C}$ & -1.0533 & 186.5242 \\
\hline
\end{tabular}

The NMR data, as well as maximum and average deviations between the scaled calculated and experimental chemical shifts, are shown in Tables SI7-SI10. For the computational ${ }^{1} \mathrm{H}$ NMR data, homotopic ${ }^{1} \mathrm{H}$ shifts were averaged (e.g. those of methyl groups). The scaled shifts were also subjected to statistical analysis using DP4. ${ }^{14}$ The Java applet on Goodman's website was used: http://wwwjmg.ch.cam.ac.uk/tools/nmr/DP4/ 
Table SI7. ${ }^{1} \mathrm{H}$ and ${ }^{13} \mathrm{C}$ NMR Chemical Shifts Calculated for Xylogranatin $\mathrm{G}^{\mathrm{a}}$

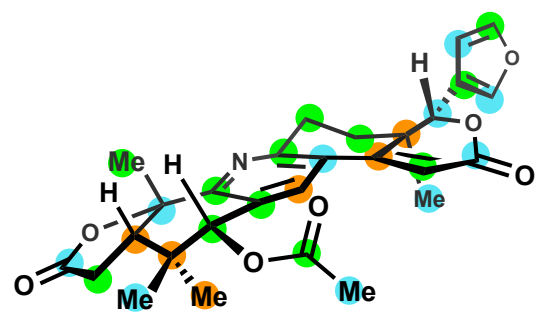

(+)-xylogranatin G (17-2)

[proposed structure]

\begin{tabular}{|c|c|c|c|c|c|c|c|c|c|c|}
\hline \multicolumn{5}{|c|}{ [proposed structure] } & \multicolumn{6}{|c|}{ [revised structure] } \\
\hline Position & $\begin{array}{l}\text { Wu et al. } \\
{ }^{1} \mathrm{H} \\
\delta[\mathrm{ppm}]^{13}\end{array}$ & $\begin{array}{c}\text { 17-2 } \\
{ }^{1} \mathrm{H} \\
\delta[\mathrm{ppm}]\end{array}$ & $\begin{array}{c}\mathbf{1 7 - 5} \\
{ }^{1} \mathrm{H} \\
\delta[\mathrm{ppm}]\end{array}$ & $\begin{array}{c}\Delta(\mathbf{1 7 - 2}- \\
{ }^{1} \mathrm{H} \\
\text { reported }) \\
{[\mathrm{ppm}]}\end{array}$ & $\begin{array}{c}\Delta(\mathbf{1 7 - 5}- \\
{ }^{1} \mathrm{H} \\
\text { reported }) \\
{[\mathrm{ppm}]}\end{array}$ & $\begin{array}{l}\text { Wu et } \\
\text { al. }{ }^{13} \mathrm{C} \\
\delta[\mathrm{ppm}]\end{array}$ & 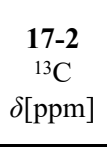 & $\begin{array}{c}\mathbf{1 7 - 5}{ }^{13} \mathrm{C} \\
\delta[\mathrm{ppm}]\end{array}$ & $\begin{array}{c}\Delta(\mathbf{1 7 - 2}- \\
{ }^{13} \mathrm{C} \\
\text { reported }) \\
{[\mathrm{ppm}]}\end{array}$ & $\begin{array}{c}\Delta(\mathbf{1 7 - 5}- \\
{ }^{13} \mathrm{C} \\
\text { reported }) \\
{[\mathrm{ppm}]}\end{array}$ \\
\hline 1 & & & & & & 156.9 & 155.6 & 156.4 & -1.3 & -0.5 \\
\hline 2 & & & & & & 126.8 & 127.8 & 126.3 & 1.0 & -0.5 \\
\hline 3 & 5.60 & 5.86 & 5.52 & 0.26 & -0.08 & 76.7 & 74.4 & 76.4 & -2.3 & -0.3 \\
\hline 4 & & & & & & 35.2 & 39.7 & 38.3 & 4.5 & 3.1 \\
\hline 5 & 2.93 & 2.54 & 2.79 & -0.39 & -0.14 & 45.5 & 49.7 & 46.8 & 4.2 & 1.3 \\
\hline $6 \alpha$ & 2.61 & 2.75 & 2.48 & 0.14 & -0.13 & 30.8 & 33.2 & 32.4 & 2.4 & 1.6 \\
\hline $6 \beta$ & 3.05 & 2.82 & 2.88 & -0.23 & -0.17 & & & & & \\
\hline 7 & & & & & & 174.8 & 175.7 & 176.2 & 0.9 & 1.4 \\
\hline 8 & & & & & & 124.3 & 123.5 & 123.5 & -0.8 & -0.8 \\
\hline 9 & & & & & & 158.7 & 157.6 & 158.6 & -1.1 & -0.1 \\
\hline 10 & & & & & & 83.6 & 83.9 & 84.1 & 0.3 & 0.5 \\
\hline $11 \alpha$ & 3.13 & 2.98 & 2.98 & -0.15 & -0.15 & 28.1 & 29.8 & 29.8 & 1.7 & 1.7 \\
\hline $11 \beta$ & 3.20 & 3.00 & 3.00 & -0.20 & -0.20 & & & & & \\
\hline $12 \alpha$ & 1.87 & 1.75 & 1.78 & -0.12 & -0.09 & 30.2 & 31.2 & 31.2 & 1.0 & 1.0 \\
\hline $12 \beta$ & 1.73 & 1.75 & 1.75 & 0.02 & 0.02 & & & & & \\
\hline 13 & & & & & & 37.6 & 41.5 & 41.6 & 3.9 & 4.0 \\
\hline 14 & & & & & & 156.5 & 159.7 & 159.5 & 3.2 & 3.0 \\
\hline 15 & 6.59 & 6.31 & 6.38 & -0.28 & -0.21 & 111.7 & 110.6 & 111.0 & -1.1 & -0.7 \\
\hline 16 & & & & & & 164.8 & 164.2 & 164.1 & -0.6 & -0.7 \\
\hline 17 & 5.21 & 5.07 & 5.05 & -0.14 & -0.16 & 80.9 & 80.2 & 80.1 & -0.7 & -0.8 \\
\hline $18^{\mathrm{b}}$ & 1.14 & 1.05 & 1.06 & -0.09 & -0.08 & 15.8 & 15.0 & 15.0 & -0.8 & -0.8 \\
\hline $19^{b}$ & 1.80 & 1.67 & 1.68 & -0.13 & -0.12 & 28.6 & 27.1 & 26.3 & -1.5 & -2.3 \\
\hline 20 & & & & & & 119.9 & 121.3 & 121.4 & 1.4 & 1.5 \\
\hline 21 & 7.55 & 7.30 & 7.31 & -0.25 & -0.24 & 141.4 & 141.0 & 141.0 & -0.4 & -0.4 \\
\hline 22 & 6.51 & 6.37 & 6.36 & -0.14 & 0.15 & 110.1 & 109.8 & 109.8 & -0.3 & -0.3 \\
\hline 23 & 7.48 & 7.26 & 7.26 & -0.22 & -0.22 & 143.3 & 141.6 & 141.6 & -1.7 & -1.7 \\
\hline $28^{\mathrm{b}}$ & 0.78 & 0.79 & 0.71 & 0.01 & -0.07 & 20.3 & 16.2 & 18.9 & -4.1 & -1.4 \\
\hline $29^{b}$ & 1.13 & 0.97 & 1.06 & -0.16 & -0.07 & 23.9 & 23.8 & 22.2 & -0.1 & -1.7 \\
\hline 30 & 8.14 & 7.90 & 8.14 & -0.24 & 0.00 & 135.7 & 131.4 & 135.8 & -4.3 & 0.1 \\
\hline $\begin{array}{c}\text { 3-OAc, } \\
1\end{array}$ & & & & & & 170.1 & 172.3 & 171.9 & 2.2 & 1.8 \\
\hline $\begin{array}{c}\text { 3-OAc } \\
2\end{array}$ & 2.06 & 2.21 & 1.99 & 0.15 & -0.07 & 20.9 & 21.0 & 21.0 & 0.1 & 0.1 \\
\hline MAE & & & & 0.17 & 0.12 & & & & 1.7 & 1.2 \\
\hline RMSD & & & & 0.19 & 0.14 & & & & 2.2 & 1.5 \\
\hline Max & & & & 0.39 & 0.24 & & & & 4.5 & 4.0 \\
\hline DP4 & & & & $0.0 \%$ & $100.0 \%$ & & & & $0.0 \%$ & $100.0 \%$ \\
\hline
\end{tabular}

${ }^{\mathrm{a}} \mathrm{Chemical}$ shifts with an absolute deviation greater than $0.20 \mathrm{ppm}\left({ }^{1} \mathrm{H}\right)$ and $3.0 \mathrm{ppm}\left({ }^{13} \mathrm{C}\right)$ are colored in red. ${ }^{\mathrm{b}}{ }^{1} \mathrm{H}$ shifts of homotopic protons were averaged.

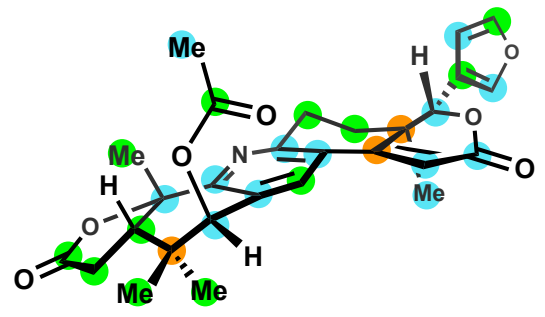

(+)-xylogranatin G (17-5)

[revised structure] 
Table SI8. ${ }^{1} \mathrm{H}$ and ${ }^{13} \mathrm{C}$ NMR Chemical Shifts Calculated for Xylogranatin $\mathbf{H}^{\mathrm{a}}$

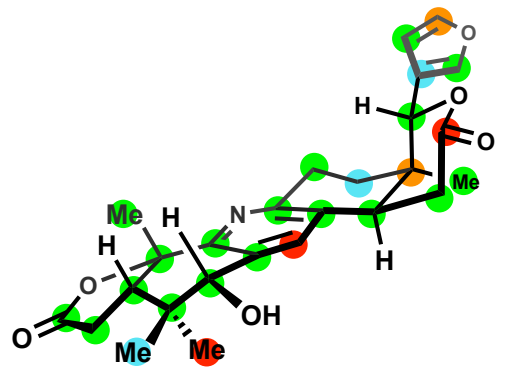

(+)-xylogranatin H (17-3) [proposed structure]

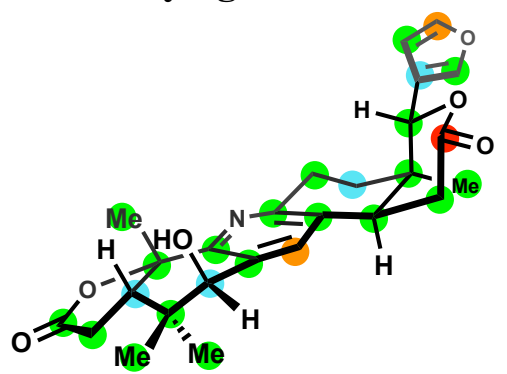

(+)-xylogranatin H (17-6) [revised structure]

\begin{tabular}{|c|c|c|c|c|c|c|c|c|c|c|}
\hline Position & $\begin{array}{l}\text { Wu et al. } \\
{ }^{1} \mathrm{H} \\
\delta[\mathrm{ppm}]^{13}\end{array}$ & $\begin{array}{c}\mathbf{1 7 - 3} \\
{ }^{1} \mathrm{H} \\
\delta[\mathrm{ppm}]\end{array}$ & $\begin{array}{c}\text { 17-6 } \\
{ }^{1} \mathrm{H} \\
\delta[\mathrm{ppm}]\end{array}$ & $\begin{array}{c}\Delta(\mathbf{1 7 - 3}- \\
\quad{ }^{1} \mathrm{H} \\
\text { reported }) \\
\quad[\mathrm{ppm}]\end{array}$ & $\begin{array}{c}\Delta(\mathbf{1 7 - 6}- \\
\quad{ }^{1} \mathrm{H} \\
\text { reported }) \\
{[\mathrm{ppm}]}\end{array}$ & $\begin{array}{l}\text { Wu et } \\
\text { al. }{ }^{13} \mathrm{C} \\
\delta[\mathrm{ppm}]\end{array}$ & $\begin{array}{c}\mathbf{1 7 - 3} \\
{ }^{13} \mathrm{C} \\
\delta[\mathrm{ppm}]\end{array}$ & $\begin{array}{c}\mathbf{1 7 - 6} \\
{ }^{13} \mathrm{C} \\
\delta[\mathrm{ppm}]\end{array}$ & $\begin{array}{c}\Delta(\mathbf{1 7 - 3}- \\
{ }^{13} \mathrm{C} \\
\text { reported }) \\
{[\mathrm{ppm}]}\end{array}$ & $\begin{array}{c}\Delta(\mathbf{1 7 - 6}- \\
{ }^{13} \mathrm{C} \\
\text { reported }) \\
\quad[\mathrm{ppm}]\end{array}$ \\
\hline 1 & & & & & & 153.2 & 150.3 & 151.7 & -2.9 & -1.5 \\
\hline 2 & & & & & & 132.5 & 130.1 & 129.7 & -2.4 & -2.8 \\
\hline 3 & 4.37 & 4.37 & 4.29 & 0.00 & -0.08 & 76.3 & 75.3 & 76.0 & -1.0 & -0.3 \\
\hline 4 & & & & & & 37.3 & 40.1 & 39.2 & 2.8 & 1.9 \\
\hline 5 & 2.94 & 2.38 & 2.86 & -0.56 & -0.08 & 47.0 & 49.7 & 46.6 & 2.7 & -0.4 \\
\hline $6 \alpha$ & 2.62 & 2.74 & 2.42 & 0.12 & -0.20 & 31.8 & 33.2 & 32.6 & 1.4 & 0.8 \\
\hline $6 \beta$ & 3.13 & 2.82 & 2.84 & -0.31 & -0.29 & & & & & \\
\hline 7 & & & & & & 174.5 & 176.2 & 176.5 & 1.7 & 2.0 \\
\hline 8 & & & & & & 134.7 & 132.4 & 132.2 & -2.3 & -2.5 \\
\hline 9 & & & & & & 158.2 & 156.1 & 157.0 & -2.1 & -1.2 \\
\hline 10 & & & & & & 86.0 & 83.6 & 84.5 & -2.4 & -1.5 \\
\hline $11 \alpha$ & 2.96 & 2.78 & 2.81 & -0.18 & -0.15 & 28.8 & 30.1 & 30.1 & 1.3 & 1.3 \\
\hline $11 \beta$ & 3.09 & 2.93 & 2.93 & -0.16 & -0.16 & & & & & \\
\hline $12 \alpha$ & 1.96 & 1.59 & 1.65 & -0.37 & -0.31 & 31.5 & 31.1 & 30.7 & -0.4 & -0.8 \\
\hline $12 \beta$ & 1.73 & 1.94 & 1.93 & 0.21 & 0.20 & & & & & \\
\hline 13 & & & & & & 37.6 & 40.7 & 40.6 & 3.1 & 3.0 \\
\hline 14 & 3.15 & 2.93 & 2.88 & -0.22 & -0.27 & 41.8 & 43.4 & 43.2 & 1.6 & 1.4 \\
\hline $15 \alpha$ & 3.02 & 2.54 & 2.54 & -0.48 & -0.48 & 36.8 & 38.7 & 38.7 & 1.9 & 1.9 \\
\hline $15 \beta$ & 2.88 & 2.57 & 2.61 & -0.31 & -0.27 & & & & & \\
\hline 16 & & & & & & 178.5 & 172.7 & 172.8 & -5.8 & -5.7 \\
\hline 17 & 5.44 & 5.13 & 5.08 & -0.31 & -0.36 & 81.0 & 79.5 & 79.9 & -1.5 & -1.1 \\
\hline $18^{\mathrm{b}}$ & 1.03 & 0.86 & 0.83 & -0.17 & -0.20 & 22.5 & 21.2 & 20.9 & -1.3 & -1.6 \\
\hline $19^{b}$ & 1.79 & 1.60 & 1.67 & -0.19 & -0.12 & 28.6 & 26.8 & 26.4 & -1.6 & -2.2 \\
\hline 20 & & & & & & 122.4 & 122.1 & 122.0 & -0.3 & -0.4 \\
\hline 21 & 7.66 & 7.29 & 7.30 & -0.37 & -0.36 & 142.6 & 140.2 & 140.2 & -2.4 & -2.4 \\
\hline 22 & 6.61 & 6.37 & 6.36 & -0.24 & -0.25 & 111.0 & 109.7 & 109.5 & -1.3 & -1.5 \\
\hline 23 & 7.59 & 7.27 & 7.26 & -0.32 & -0.33 & 144.7 & 141.7 & 141.7 & -3.0 & -3.0 \\
\hline $28^{b}$ & 0.72 & 0.68 & 0.66 & 0.04 & 0.06 & 21.4 & 14.0 & 19.5 & -7.4 & -1.9 \\
\hline $29^{b}$ & 1.15 & 1.01 & 1.07 & -0.14 & -0.08 & 24.1 & 23.5 & 21.9 & -0.6 & -2.2 \\
\hline 30 & 7.69 & 7.59 & 7.28 & -0.10 & -0.41 & 139.6 & 134.0 & 136.1 & -5.6 & -3.5 \\
\hline $3-\mathrm{OH}$ & 2.26 & 1.39 & 1.17 & -0.87 & -1.09 & & & & & \\
\hline MAE & & & & 0.27 & 0.27 & & & & 2.3 & 1.9 \\
\hline RMSD & & & & 0.33 & 0.36 & & & & 2.9 & 2.2 \\
\hline Max & & & & 0.87 & 1.08 & & & & 7.4 & 5.7 \\
\hline DP4 & & & & $4.2 \%$ & $95.8 \%$ & & & & $0.2 \%$ & $99.8 \%$ \\
\hline
\end{tabular}

${ }^{\mathrm{a}} \mathrm{Chemical}$ shifts with an absolute deviation greater than $0.20 \mathrm{ppm}\left({ }^{1} \mathrm{H}\right)$ and $3.0 \mathrm{ppm}\left({ }^{13} \mathrm{C}\right)$ are colored in red. ${ }^{\mathrm{b}}{ }^{1} \mathrm{H}$ shifts of homotopic protons were averaged. 
Table SI9. ${ }^{1} \mathrm{H}$ and ${ }^{13} \mathrm{C}$ NMR Chemical Shifts Calculated for Hainangranatumin $\mathbf{G}^{\text {a }}$

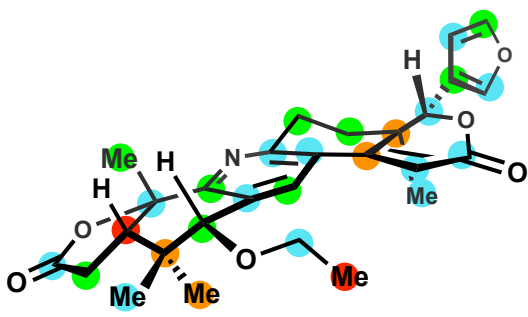

(+)-hainangranatumin $G(17-4)$ [proposed structure]

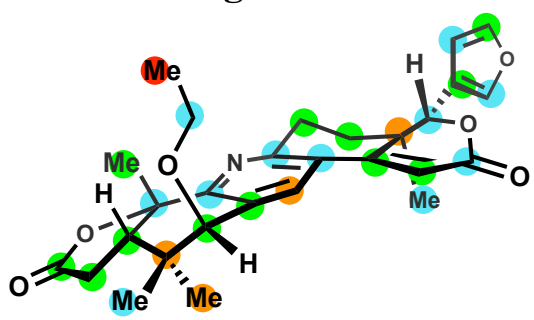

(+)-hainangranatumin G (17-7) [revised structure]

\begin{tabular}{|c|c|c|c|c|c|c|c|c|c|c|}
\hline Position & $\begin{array}{l}\text { Pan et al. } \\
{ }^{1} \mathrm{H} \\
\delta[\mathrm{ppm}]^{13}\end{array}$ & $\begin{array}{c}\mathbf{1 7 - 4} \\
{ }^{1} \mathrm{H} \\
\delta[\mathrm{ppm}]\end{array}$ & $\begin{array}{c}\mathbf{1 7 - 7} \\
{ }^{1} \mathrm{H} \\
\delta[\mathrm{ppm}]\end{array}$ & $\begin{array}{c}\Delta(\mathbf{1 7 - 4}- \\
{ }^{1} \mathrm{H} \\
\text { reported }) \\
{[\mathrm{ppm}]}\end{array}$ & $\begin{array}{c}\Delta(\mathbf{1 7 - 7}- \\
{ }^{1} \mathrm{H} \\
\text { reported }) \\
{[\mathrm{ppm}]}\end{array}$ & $\begin{array}{l}\text { Pan et } \\
\text { al. }{ }^{13} \mathrm{C} \\
\delta[\mathrm{ppm}]\end{array}$ & $\begin{array}{c}\mathbf{1 7 - 4} \\
{ }^{13} \mathrm{C} \\
\delta[\mathrm{ppm}]\end{array}$ & $\begin{array}{c}\mathbf{1 7 - 7 ^ { 1 3 } \mathrm { C }} \\
\delta[\mathrm{ppm}]\end{array}$ & $\begin{array}{c}\Delta(\mathbf{1 7 - 4}- \\
{ }^{13} \mathrm{C} \\
\text { reported }) \\
{[\mathrm{ppm}]}\end{array}$ & $\begin{array}{c}\Delta(\mathbf{1 7 - 7}- \\
{ }^{13} \mathrm{C} \\
\text { reported }) \\
{[\mathrm{ppm}]}\end{array}$ \\
\hline 1 & & & & & & 157.8 & 156.2 & 157.5 & -1.6 & -0.3 \\
\hline 2 & & & & & & 128.5 & 129.0 & 127.3 & 0.5 & -1.2 \\
\hline 3 & 3.82 & 3.89 & 3.77 & 0.07 & -0.05 & 83.8 & 82.0 & 82.7 & -1.8 & -1.1 \\
\hline 4 & & & & & & 36.1 & 40.4 & 39.3 & 4.4 & 3.2 \\
\hline 5 & 2.98 & 2.44 & 2.84 & -0.54 & -0.14 & 45.0 & 50.2 & 46.2 & 5.2 & 1.2 \\
\hline $6 \alpha$ & 2.55 & 2.93 & 2.43 & 0.38 & -0.11 & 30.6 & 33.5 & 32.3 & 2.9 & 1.7 \\
\hline $6 \beta$ & 2.98 & 2.73 & 2.86 & -0.25 & -0.12 & & & & & \\
\hline 7 & & & & & & 175.5 & 176.1 & 176.5 & 0.6 & 1.0 \\
\hline 8 & & & & & & 123.3 & 122.8 & 122.4 & -0.5 & -0.9 \\
\hline 9 & & & & & & 158.0 & 157.2 & 158.1 & -0.8 & 0.1 \\
\hline 10 & & & & & & 84.1 & 83.9 & 84.5 & -0.2 & 0.4 \\
\hline $11 \alpha$ & 3.12 & 2.98 & 3.00 & -0.14 & -0.12 & 27.9 & 29.7 & 29.7 & 1.8 & 1.8 \\
\hline $11 \beta$ & 3.19 & 2.99 & 3.00 & -0.20 & -0.19 & & & & & \\
\hline $12 \alpha$ & 1.87 & 1.77 & 1.79 & -0.10 & -0.08 & 30.2 & 31.4 & 31.2 & 1.2 & 1.0 \\
\hline $12 \beta$ & 1.77 & 1.76 & 1.77 & -0.01 & 0.00 & & & & & \\
\hline 13 & & & & & & 37.6 & 41.5 & 41.6 & 3.9 & 4.0 \\
\hline 14 & & & & & & 157.3 & 160.3 & 160.2 & 3.0 & 2.9 \\
\hline 15 & 6.52 & 6.38 & 6.38 & -0.21 & -0.14 & 111.0 & 110.1 & 110.0 & -0.9 & -1.0 \\
\hline 16 & & & & & & 165.1 & 164.3 & 164.3 & -0.8 & -0.8 \\
\hline 17 & 5.23 & 5.05 & 5.08 & -0.16 & -0.15 & 81.0 & 80.2 & 80.3 & -0.8 & -0.7 \\
\hline $18^{\mathrm{b}}$ & 1.17 & 1.06 & 1.07 & -0.08 & -0.10 & 15.8 & 15.0 & 15.0 & -0.8 & -0.8 \\
\hline $19^{\mathrm{b}}$ & 1.76 & 1.68 & 1.66 & -0.12 & -0.10 & 28.5 & 27.6 & 26.3 & -2.3 & -2.2 \\
\hline 20 & & & & & & 119.8 & 121.4 & 121.4 & 1.6 & 1.6 \\
\hline 21 & 7.55 & 7.31 & 7.32 & -0.24 & -0.23 & 141.4 & 141.0 & 141.0 & -0.4 & -0.4 \\
\hline 22 & 6.52 & 6.36 & 6.38 & 0.15 & -0.14 & 110.0 & 109.8 & 109.8 & -0.2 & -0.2 \\
\hline 23 & 7.48 & 7.26 & 7.27 & -0.22 & -0.21 & 143.3 & 141.6 & 141.6 & -1.7 & -1.7 \\
\hline $28^{\mathrm{b}}$ & 0.67 & 0.71 & 0.83 & -0.07 & 0.16 & 20.4 & 17.1 & 16.2 & -3.3 & -4.1 \\
\hline $29^{b}$ & 1.15 & 1.06 & 1.27 & -0.07 & 0.12 & 24.1 & 24.8 & 23.8 & 0.3 & -0.1 \\
\hline 30 & 7.79 & 8.14 & 7.92 & 0.00 & 0.13 & 133.7 & 132.0 & 131.4 & -1.7 & -4.3 \\
\hline $\begin{array}{c}3-\mathrm{OEt}^{\mathrm{b}}, \\
2\end{array}$ & 1.15 & 1.12 & 0.99 & -0.03 & -0.16 & 15.2 & 14.7 & 14.6 & 0.5 & -0.6 \\
\hline $\begin{array}{c}\text { 3-OEtb, } \\
1\end{array}$ & 3.40 & 1.99 & 3.49 & -0.07 & 0.09 & 54.5 & 66.3 & 63.0 & 11.8 & 8.5 \\
\hline MAE & & & & 0.17 & 0.12 & & & & 1.9 & 1.5 \\
\hline RMSD & & & & 0.21 & 0.13 & & & & 3.0 & 2.2 \\
\hline Max & & & & 0.54 & 0.23 & & & & 11.8 & 8.5 \\
\hline DP4 & & & & $0.0 \%$ & $100.0 \%$ & & & & $0.4 \%$ & $99.6 \%$ \\
\hline
\end{tabular}

${ }^{\mathrm{a}} \mathrm{Chemical}$ shifts with an absolute deviation greater than $0.20 \mathrm{ppm}\left({ }^{1} \mathrm{H}\right)$ and $3.0 \mathrm{ppm}\left({ }^{13} \mathrm{C}\right)$ are colored in red. ${ }^{\mathrm{b}}{ }^{1} \mathrm{H}$ shifts of homotopic protons were averaged. 
TABLE SI10. ${ }^{1} \mathrm{H}$ and ${ }^{13} \mathrm{C}$ NMR Chemical Shifts Calculated for Granatumine $\mathrm{A}^{\mathrm{a}}$

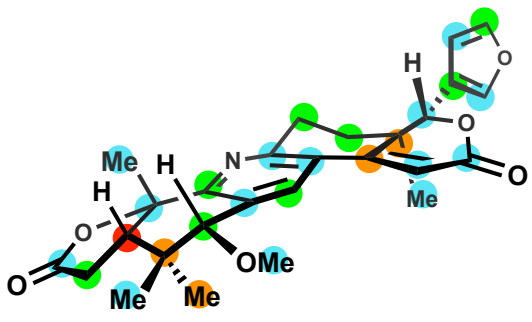

(+)-C3-epi-granatumine A (17-8)

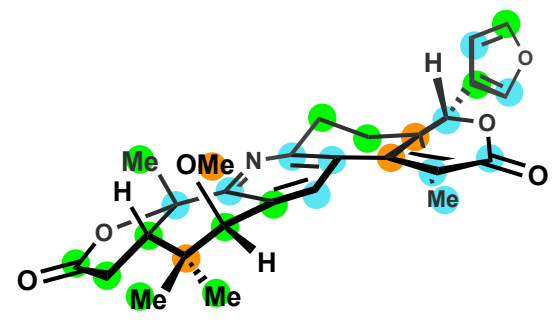

(+)-granatumine A (1-2)

[corroborated structure]

\begin{tabular}{|c|c|c|c|c|c|c|c|c|c|c|}
\hline Position & $\begin{array}{c}\text { Zhou et } \\
\text { al. }{ }^{1} \mathrm{H} \\
\delta[\mathrm{ppm}]^{13}\end{array}$ & $\begin{array}{l}\mathbf{1 7 - 8}^{1} \mathrm{H} \\
\delta[\mathrm{ppm}]\end{array}$ & $\begin{array}{l}\mathbf{1 - 2}{ }^{1} \mathrm{H} \\
\delta[\mathrm{ppm}]\end{array}$ & $\begin{array}{c}\Delta(\mathbf{1 7 - 8}- \\
{ }^{1} \mathrm{H} \\
\text { reported } \\
)[\mathrm{ppm}]\end{array}$ & $\begin{array}{c}\Delta(\mathbf{1 - 2}- \\
{ }^{1} \mathrm{H} \\
\text { reported } \\
)[\mathrm{ppm}]\end{array}$ & $\begin{array}{l}\text { Zhou et } \\
\text { al. }{ }^{13} \mathrm{C} \\
\delta[\mathrm{ppm}]\end{array}$ & $\begin{array}{c}\mathbf{1 7 - 8}{ }^{13} \mathrm{C} \\
\delta[\mathrm{ppm}]\end{array}$ & $\begin{array}{l}\mathbf{1 - 2}{ }^{13} \mathrm{C} \\
\delta[\mathrm{ppm}]\end{array}$ & $\begin{array}{c}\Delta(\mathbf{1 7 - 8}- \\
{ }^{13} \mathrm{C} \\
\text { reported }) \\
{[\mathrm{ppm}]}\end{array}$ & $\begin{array}{c}\Delta(\mathbf{1 - 2}- \\
{ }^{13} \mathrm{C} \\
\text { reported }) \\
{[\mathrm{ppm}]}\end{array}$ \\
\hline 1 & & & & & & 157.7 & 156.2 & 157.7 & -1.5 & 0.0 \\
\hline 2 & & & & & & 127.7 & 128.5 & 126.4 & 0.8 & -1.3 \\
\hline 3 & 3.70 & 3.80 & 3.65 & 0.10 & -0.05 & 85.7 & 83.4 & 83.9 & -2.3 & -1.8 \\
\hline 4 & & & & & & 36.1 & 40.6 & 39.4 & 4.5 & 3.3 \\
\hline 5 & 2.93 & 2.44 & 2.80 & -0.49 & -0.13 & 44.8 & 50.3 & 46.2 & 5.5 & 1.4 \\
\hline $6 \alpha$ & 2.98 & 2.90 & 2.42 & -0.08 & -0.56 & 30.6 & 33.5 & 32.2 & 2.9 & 1.6 \\
\hline $6 \beta$ & 2.54 & 2.72 & 2.86 & 0.18 & 0.32 & & & & & \\
\hline 7 & & & & & & 175.4 & 176.1 & 176.5 & 0.7 & 1.1 \\
\hline 8 & & & & & & 123.3 & 122.8 & 122.4 & -0.5 & -0.9 \\
\hline 9 & & & & & & 158.2 & 157.3 & 158.3 & -0.9 & 0.1 \\
\hline 10 & & & & & & 84.0 & 83.8 & 84.2 & -0.2 & 0.2 \\
\hline $11 \alpha$ & 3.20 & 2.98 & 3.00 & -0.22 & -0.20 & 27.9 & 29.8 & 29.8 & 1.9 & 1.9 \\
\hline $11 \beta$ & 3.13 & 3.00 & 3.00 & -0.13 & -0.13 & & & & & \\
\hline $12 \alpha$ & 1.88 & 1.76 & 1.77 & -0.10 & -0.11 & 30.1 & 31.3 & 31.1 & 1.2 & 1.0 \\
\hline $12 \beta$ & 1.78 & 1.77 & 1.76 & -0.01 & -0.02 & & & & & \\
\hline 13 & & & & & & 37.6 & 41.3 & 41.7 & 3.7 & 4.1 \\
\hline 14 & & & & & & 157.1 & 160.2 & 160.1 & 3.1 & 3.0 \\
\hline 15 & 6.55 & 6.37 & 6.34 & -0.18 & -0.21 & 110.0 & 110.2 & 110.1 & 0.2 & 0.1 \\
\hline 16 & & & & & & 165.1 & 164.3 & 164.3 & -0.8 & -0.8 \\
\hline 17 & 5.24 & 5.09 & 5.09 & -0.15 & -0.15 & 80.9 & 80.2 & 80.3 & -0.7 & -0.6 \\
\hline $18^{\mathrm{b}}$ & 1.15 & 1.07 & 1.07 & -0.08 & -0.08 & 15.7 & 15.0 & 15.0 & -0.7 & -0.7 \\
\hline $19^{\mathrm{b}}$ & 1.75 & 1.66 & 1.63 & -0.09 & -0.12 & 28.4 & 27.5 & 26.1 & -0.9 & -2.3 \\
\hline 20 & & & & & & 119.7 & 121.5 & 121.3 & 1.8 & 1.6 \\
\hline 21 & 7.55 & 7.31 & 7.32 & -0.24 & -0.23 & 141.3 & 141.0 & 141.0 & -0.3 & -0.3 \\
\hline 22 & 6.52 & 6.39 & 6.38 & -0.13 & -0.14 & 110.0 & 109.9 & 109.8 & -0.1 & -0.2 \\
\hline 23 & 7.47 & 7.27 & 7.27 & -0.20 & -0.20 & 143.2 & 141.6 & 141.6 & -1.6 & -1.6 \\
\hline $28^{\mathrm{b}}$ & 0.67 & 0.80 & 0.61 & 0.13 & -0.06 & 20.3 & 17.0 & 18.8 & -3.3 & -1.8 \\
\hline $29^{b}$ & 1.17 & 1.01 & 1.09 & -0.16 & -0.08 & 24.1 & 24.4 & 22.2 & 0.3 & -1.9 \\
\hline 30 & 7.81 & 7.96 & 7.71 & 0.15 & -0.10 & 134.0 & 131.9 & 134.1 & -2.1 & 0.1 \\
\hline $3-\mathrm{OMe}^{\mathrm{b}}$ & 3.27 & 3.35 & 3.07 & 0.08 & -0.20 & 56.8 & 56.9 & 53.7 & 0.1 & -3.1 \\
\hline MAE & & & & 0.15 & 0.12 & & & & 1.6 & 1.4 \\
\hline RMSD & & & & 0.18 & 0.20 & & & & 2.1 & 1.7 \\
\hline Max & & & & 0.49 & 0.56 & & & & 5.5 & 4.1 \\
\hline DP4 & & & & $2.3 \%$ & $97.7 \%$ & & & & $2.7 \%$ & $97.3 \%$ \\
\hline
\end{tabular}

${ }^{\mathrm{a}}$ Chemical shifts with an absolute deviation greater than $0.20 \mathrm{ppm}\left({ }^{1} \mathrm{H}\right)$ and $3.0 \mathrm{ppm}\left({ }^{13} \mathrm{C}\right)$ are colored in red. ${ }^{\mathrm{b}} \mathrm{H}_{\text {shifts of homotopic }}$ protons were averaged. 


\section{NMR calculations of xylogranatin G (17-2)}

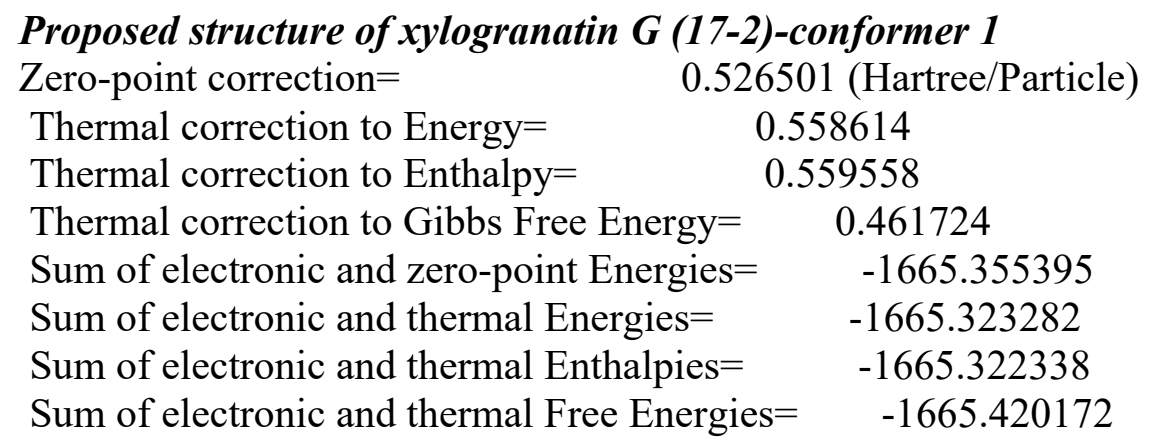

01

$\begin{array}{lrrr}\mathrm{N} & -0.82131700 & -1.84935500 & -0.53611500 \\ \mathrm{C} & -1.89565800 & -1.05750300 & -0.50914300 \\ \mathrm{C} & -1.80426300 & 0.33605600 & -0.35550200 \\ \mathrm{C} & -0.53290300 & 0.88145300 & -0.21656700 \\ \mathrm{C} & 0.61039300 & 0.06653500 & -0.24097000 \\ \mathrm{C} & 0.40041700 & -1.32271500 & -0.39680300 \\ \mathrm{C} & -3.23875000 & -1.75342000 & -0.68411700 \\ \mathrm{C} & -4.48882900 & -0.83650300 & -0.48779300 \\ \mathrm{C} & -4.24692100 & 0.46434900 & 0.34004400 \\ \mathrm{C} & -3.06109300 & 1.17985600 & -0.35571100 \\ \mathrm{C} & 1.97570600 & 0.61890200 & -0.09390900 \\ \mathrm{C} & 3.12877500 & -0.35572700 & 0.15066500 \\ \mathrm{C} & 2.89414700 & -1.63249700 & -0.69002700 \\ \mathrm{C} & 1.55010100 & -2.29837700 & -0.39179900 \\ \mathrm{C} & 2.23643100 & 1.94516000 & -0.13093800 \\ \mathrm{C} & 3.55801400 & 2.50730900 & 0.19429800 \\ \mathrm{O} & 4.60462600 & 1.63754400 & 0.24998900 \\ \mathrm{C} & 4.42575300 & 0.33387800 & -0.36130600 \\ \mathrm{O} & -3.34711300 & -2.76186900 & 0.37323100 \\ \mathrm{C} & -4.62078400 & -2.85650800 & 0.83914700 \\ \mathrm{C} & -5.48869600 & -1.81500500 & 0.15017300 \\ \mathrm{O} & -4.94877200 & -3.66814400 & 1.66920800 \\ \mathrm{C} & 5.70778900 & -0.41243900 & -0.14336000 \\ \mathrm{C} & 6.39017000 & -1.12822900 & -1.08498200 \\ \mathrm{O} & 7.51719100 & -1.67669500 & -0.55164700 \\ \mathrm{C} & 7.56439800 & -1.28891300 & 0.75807000 \\ \mathrm{C} & 6.48755000 & -0.51634100 & 1.06418600 \\ \mathrm{H} & -4.83783100 & -0.51966900 & -1.47697200 \\ \mathrm{O} & 3.73603000 & 3.67920300 & 0.46128900 \\ \mathrm{C} & 3.20340100 & -0.68651600 & 1.66000200 \\ \mathrm{C} & -3.27520400 & -2.48865300 & -2.03035400 \\ \mathrm{O} & -2.79019800 & 2.44241400 & 0.29862700 \\ \mathrm{O} & -3.21071300 & 3.61317400 & -1.60482900 \\ \mathrm{C} & -2.91623800 & 3.58878600 & -0.42912500 \\ \mathrm{C} & -2.64909500 & 4.79788500 & 0.43033300\end{array}$




$\begin{array}{lrrr}\mathrm{C} & -5.49987300 & 1.35718700 & 0.23837500 \\ \mathrm{C} & -3.93027100 & 0.19729800 & 1.82700100 \\ \mathrm{H} & -0.43935000 & 1.94837700 & -0.05712000 \\ \mathrm{H} & -3.34637500 & 1.41156400 & -1.38816400 \\ \mathrm{H} & 2.93228800 & -1.36550300 & -1.75521700 \\ \mathrm{H} & 3.71009800 & -2.33922600 & -0.51105500 \\ \mathrm{H} & 1.57444900 & -2.79387500 & 0.58824300 \\ \mathrm{H} & 1.33706800 & -3.08957800 & -1.11716500 \\ \mathrm{H} & 1.47264500 & 2.69414600 & -0.30118100 \\ \mathrm{H} & 4.29596000 & 0.49279800 & -1.44062900 \\ \mathrm{H} & -6.09609300 & -2.32846200 & -0.60347000 \\ \mathrm{H} & -6.18218000 & -1.37292400 & 0.86652100 \\ \mathrm{H} & 6.21609500 & -1.32764700 & -2.13141400 \\ \mathrm{H} & 8.41824900 & -1.63291100 & 1.32018700 \\ \mathrm{H} & 6.28054000 & -0.04801100 & 2.01474300 \\ \mathrm{H} & 3.49335300 & 0.19581600 & 2.23720700 \\ \mathrm{H} & 2.23431500 & -1.02373700 & 2.03768300 \\ \mathrm{H} & 3.93520500 & -1.47829900 & 1.84503900 \\ \mathrm{H} & -3.14511400 & -1.78107100 & -2.85600900 \\ \mathrm{H} & -2.46622000 & -3.22082600 & -2.06361400 \\ \mathrm{H} & -4.23045600 & -3.00595900 & -2.16462300 \\ \mathrm{H} & -2.61690900 & 5.68800500 & -0.19722500 \\ \mathrm{H} & -3.44717000 & 4.90255400 & 1.17273300 \\ \mathrm{H} & -1.70877800 & 4.68403600 & 0.97666600 \\ \mathrm{H} & -6.37720500 & 0.85332700 & 0.65505700 \\ \mathrm{H} & -5.72275600 & 1.62231100 & -0.80101900 \\ \mathrm{H} & -5.36148400 & 2.28378100 & 0.80279300 \\ \mathrm{H} & -4.78762800 & -0.25204200 & 2.33661700 \\ \mathrm{H} & -3.07484600 & -0.46877000 & 1.96507800 \\ \mathrm{H} & -3.70584500 & 1.14041300 & 2.33284400\end{array}$

\section{Proposed structure of xylogranatin G (17-2)-conformer 2}

Zero-point correction=

Thermal correction to Energy=

Thermal correction to Enthalpy=
0.526468 (Hartree/Particle)

0.558595

0.559540

0.461744

$-1665.355254$

$-1665.323126$

$-1665.322182$

$-1665.419978$
01

$\begin{array}{lrrr}\mathrm{N} & 0.83248100 & -1.85503900 & 0.52648100 \\ \mathrm{C} & 1.90374300 & -1.05897300 & 0.50187600 \\ \mathrm{C} & 1.80655200 & 0.33515100 & 0.35690100 \\ \mathrm{C} & 0.53272700 & 0.87667300 & 0.22598100 \\ \mathrm{C} & -0.60757100 & 0.05734700 & 0.24868100 \\ \mathrm{C} & -0.39143200 & -1.33182500 & 0.39376100 \\ \mathrm{C} & 3.24989600 & -1.75057300 & 0.67010000 \\ \mathrm{C} & 4.49590400 & -0.82784000 & 0.47489300\end{array}$

SI175 


\begin{tabular}{|c|c|c|c|}
\hline $\mathrm{C}$ & 4.24649400 & 0.47613200 & -0.34568100 \\
\hline $\mathrm{C}$ & 3.06020700 & 1.18370100 & 0.35745000 \\
\hline $\mathrm{C}$ & -1.97550400 & 0.60539600 & 0.11006800 \\
\hline $\mathrm{C}$ & -3.12927700 & -0.36989500 & -0.13164300 \\
\hline $\mathrm{C}$ & -2.88316100 & -1.65398100 & 0.69503700 \\
\hline $\mathrm{C}$ & -1.53743700 & -2.31087200 & 0.38343600 \\
\hline $\mathrm{C}$ & -2.23748800 & 1.93127900 & 0.15319200 \\
\hline $\mathrm{C}$ & -3.56008300 & 2.49152800 & -0.16641100 \\
\hline $\mathrm{O}$ & -4.60443900 & 1.61892900 & -0.22168800 \\
\hline $\mathrm{C}$ & -4.42657200 & 0.31721600 & 0.38864900 \\
\hline $\mathrm{O}$ & 3.35942600 & -2.75383400 & -0.39187700 \\
\hline $\mathrm{C}$ & 4.63219200 & -2.84124500 & -0.86177400 \\
\hline $\mathrm{C}$ & 5.49780500 & -1.79924600 & -0.17067800 \\
\hline $\mathrm{O}$ & 4.96113100 & -3.64795800 & -1.69621800 \\
\hline $\mathrm{C}$ & -5.70856700 & -0.42887100 & 0.15817900 \\
\hline $\mathrm{C}$ & -6.62250900 & -0.19873600 & -0.82979900 \\
\hline $\mathrm{O}$ & -7.67869700 & -1.05368200 & -0.71366600 \\
\hline $\mathrm{C}$ & -7.43943700 & -1.84184900 & 0.37296700 \\
\hline $\mathrm{C}$ & -6.25309300 & -1.50347000 & 0.94939200 \\
\hline $\mathrm{H}$ & 4.84644800 & -0.51461200 & 1.46467400 \\
\hline $\mathrm{O}$ & -3.74344000 & 3.66304100 & -0.43104500 \\
\hline $\mathrm{C}$ & -3.22508400 & -0.68792400 & -1.64194800 \\
\hline $\mathrm{C}$ & 3.29253100 & -2.49164600 & 2.01299400 \\
\hline $\mathrm{O}$ & 2.78249000 & 2.44844000 & -0.28976700 \\
\hline $\mathrm{O}$ & 3.20406800 & 3.61134200 & 1.61827900 \\
\hline $\mathrm{C}$ & 2.90648300 & 3.59170400 & 0.44327100 \\
\hline $\mathrm{C}$ & 2.63296800 & 4.80405000 & -0.40956500 \\
\hline $\mathrm{C}$ & 5.49631700 & 1.37330400 & -0.24357800 \\
\hline $\mathrm{C}$ & 3.92612500 & 0.21518100 & -1.83292300 \\
\hline $\mathrm{H}$ & 0.43512600 & 1.94427900 & 0.07403400 \\
\hline $\mathrm{H}$ & 3.34794500 & 1.41134900 & 1.39012200 \\
\hline $\mathrm{H}$ & -2.91867700 & -1.39976100 & 1.76350000 \\
\hline $\mathrm{H}$ & -3.69147900 & -2.36666600 & 0.50767900 \\
\hline $\mathrm{H}$ & -1.56524600 & -2.79530300 & -0.60198700 \\
\hline $\mathrm{H}$ & -1.31850600 & -3.10942700 & 1.09891900 \\
\hline $\mathrm{H}$ & -1.47411900 & 2.68086600 & 0.32197700 \\
\hline $\mathrm{H}$ & -4.29728400 & 0.47480400 & 1.46917700 \\
\hline $\mathrm{H}$ & 6.10974100 & -2.31361200 & 0.57866100 \\
\hline $\mathrm{H}$ & 6.18716600 & -1.35096700 & -0.88716000 \\
\hline $\mathrm{H}$ & -6.67582300 & 0.52386800 & -1.62753100 \\
\hline $\mathrm{H}$ & -8.19653700 & -2.57474000 & 0.60333000 \\
\hline $\mathrm{H}$ & -5.82539000 & -1.95016200 & 1.83572800 \\
\hline $\mathrm{H}$ & -3.51340900 & 0.20179200 & -2.20835400 \\
\hline $\mathrm{H}$ & -2.26542300 & -1.03466800 & -2.03473100 \\
\hline $\mathrm{H}$ & -3.97252800 & -1.46612500 & -1.82243200 \\
\hline $\mathrm{H}$ & 3.16183900 & -1.78827800 & 2.84214600 \\
\hline $\mathrm{H}$ & 2.48647100 & -3.22710300 & 2.04500900 \\
\hline $\mathrm{H}$ & 4.25009200 & -3.00588000 & 2.14254200 \\
\hline $\mathrm{H}$ & 2.59641900 & 5.69060400 & 0.22279000 \\
\hline $\mathrm{H}$ & 3.43059400 & 4.91681800 & -1.15127900 \\
\hline $\mathrm{H}$ & 1.69331300 & 4.68841500 & -0.95662500 \\
\hline
\end{tabular}




$\begin{array}{lrrr}\mathrm{H} & 6.37423600 & 0.87495900 & -0.66560700 \\ \mathrm{H} & 5.72155700 & 1.63411900 & 0.79639600 \\ \mathrm{H} & 5.35250100 & 2.30214000 & -0.80292500 \\ \mathrm{H} & 4.78366300 & -0.22815000 & -2.34746900 \\ \mathrm{H} & 3.07297100 & -0.45365800 & -1.97165500 \\ \mathrm{H} & 3.69627700 & 1.15985100 & -2.33339100\end{array}$

\section{Proposed structure of xylogranatin G (17-2)-conformer 3}

$\begin{array}{lc}\text { Zero-point correction }= & 0.526755 \text { (Hartree/Particle) } \\ \text { Thermal correction to Energy= } & 0.558847 \\ \text { Thermal correction to Enthalpy= } & 0.559792 \\ \text { Thermal correction to Gibbs Free Energy= } & 0.462098 \\ \text { Sum of electronic and zero-point Energies }= & -1665.354732 \\ \text { Sum of electronic and thermal Energies }= & -1665.322639 \\ \text { Sum of electronic and thermal Enthalpies }= & -1665.321695 \\ \text { Sum of electronic and thermal Free Energies }= & -1665.419388\end{array}$
01

$\begin{array}{lrrr}\mathrm{N} & -0.83092300 & -1.89609200 & -0.20322400 \\ \mathrm{C} & -1.91864200 & -1.13447200 & -0.36343600 \\ \mathrm{C} & -1.83435100 & 0.25954000 & -0.51732000 \\ \mathrm{C} & -0.56429300 & 0.83688500 & -0.49809700 \\ \mathrm{C} & 0.58486700 & 0.05423800 & -0.31770000 \\ \mathrm{C} & 0.38275800 & -1.33824900 & -0.16271400 \\ \mathrm{C} & -3.24701400 & -1.89587300 & -0.38520700 \\ \mathrm{C} & -4.50488300 & -0.97092200 & -0.48899700 \\ \mathrm{C} & -4.28302000 & 0.37282300 & -1.23989400 \\ \mathrm{C} & -3.05787700 & 1.13479900 & -0.68737200 \\ \mathrm{C} & 1.94607000 & 0.63722400 & -0.28489900 \\ \mathrm{C} & 3.10594800 & -0.25636800 & 0.15938400 \\ \mathrm{C} & 2.87787200 & -1.68850600 & -0.37602600 \\ \mathrm{C} & 1.53882100 & -2.27790200 & 0.06893000 \\ \mathrm{C} & 2.19640500 & 1.93040600 & -0.59053300 \\ \mathrm{C} & 3.51938800 & 2.55177800 & -0.40414100 \\ \mathrm{O} & 4.57222400 & 1.71554100 & -0.17976000 \\ \mathrm{C} & 4.39585200 & 0.31205400 & -0.49801000 \\ \mathrm{O} & -3.37425600 & -2.56650500 & 0.91100200 \\ \mathrm{C} & -4.35564300 & -2.03462500 & 1.68557400 \\ \mathrm{C} & -5.00052100 & -0.86817400 & 0.96623800 \\ \mathrm{O} & -4.61282500 & -2.46639800 & 2.78302500 \\ \mathrm{C} & 5.68287400 & -0.36655300 & -0.13510400 \\ \mathrm{C} & 6.36253500 & -1.26534200 & -0.90635400 \\ \mathrm{O} & 7.49557400 & -1.68332600 & -0.27607100 \\ \mathrm{C} & 7.54923500 & -1.02374500 & 0.91981500 \\ \mathrm{C} & 6.47085500 & -0.20684000 & 1.06094700 \\ \mathrm{H} & -5.25838200 & -1.52700800 & -1.05960500 \\ \mathrm{O} & 3.69667700 & 3.75303800 & -0.39275000 \\ \mathrm{C} & 3.18996400 & -0.24594100 & 1.70433500 \\ \mathrm{C} & -3.21789300 & -3.01805000 & -1.42534000 \\ \mathrm{O} & -3.39136100 & 1.73360900 & 0.60961900\end{array}$




$\begin{array}{lrrr}\mathrm{O} & -2.24111000 & 3.62268300 & 0.10017600 \\ \mathrm{C} & -2.92532500 & 2.98308900 & 0.87273100 \\ \mathrm{C} & -3.36330500 & 3.44651500 & 2.23849300 \\ \mathrm{C} & -4.00860300 & 0.11140300 & -2.74155000 \\ \mathrm{C} & -5.55152000 & 1.24335700 & -1.14523500 \\ \mathrm{H} & -0.48951100 & 1.91362500 & -0.60669000 \\ \mathrm{H} & -2.81953500 & 1.96560600 & -1.35620900 \\ \mathrm{H} & 2.91108400 & -1.66546500 & -1.47415000 \\ \mathrm{H} & 3.69850300 & -2.33351200 & -0.04787000 \\ \mathrm{H} & 1.56538500 & -2.53140500 & 1.13741200 \\ \mathrm{H} & 1.33130700 & -3.21722500 & -0.45252700 \\ \mathrm{H} & 1.42624100 & 2.62763000 & -0.89819200 \\ \mathrm{H} & 4.25813400 & 0.23588100 & -1.58547900 \\ \mathrm{H} & -6.08601500 & -0.92634300 & 1.07025900 \\ \mathrm{H} & -4.67003700 & 0.04715100 & 1.46341400 \\ \mathrm{H} & 6.18284600 & -1.68483500 & -1.88452400 \\ \mathrm{H} & 8.40827800 & -1.23650700 & 1.53638000 \\ \mathrm{H} & 6.26779400 & 0.45402700 & 1.89026100 \\ \mathrm{H} & 3.47843000 & 0.74299600 & 2.07086800 \\ \mathrm{H} & 2.22455100 & -0.49483800 & 2.15331900 \\ \mathrm{H} & 3.92653000 & -0.97487900 & 2.05495400 \\ \mathrm{H} & -3.12500000 & -2.61606100 & -2.43776000 \\ \mathrm{H} & -2.36819600 & -3.67422100 & -1.22958500 \\ \mathrm{H} & -4.14259800 & -3.59935900 & -1.36263300 \\ \mathrm{H} & -2.93621800 & 2.79204600 & 3.00497700 \\ \mathrm{H} & -3.02540600 & 4.47002100 & 2.39806400 \\ \mathrm{H} & -4.45199500 & 3.39082100 & 2.32949200 \\ \mathrm{H} & -4.81407400 & -0.48922500 & -3.17643900 \\ \mathrm{H} & -3.06515100 & -0.41160500 & -2.91768800 \\ \mathrm{H} & -3.96640800 & 1.05878000 & -3.28945300 \\ \mathrm{H} & -6.39810800 & 0.72468100 & -1.60845700 \\ \mathrm{H} & -5.81928200 & 1.47787400 & -0.11331900 \\ \mathrm{H} & -5.40944000 & 2.18955500 & -1.67927900 \\ & & & \\ & & & \end{array}$

Proposed structure of xylogranatin G (17-2)-conformer 4

Zero-point correction=

Thermal correction to Energy=

Thermal correction to Enthalpy=

Thermal correction to Gibbs Free Energy=

Sum of electronic and zero-point Energies $=$

Sum of electronic and thermal Energies=

Sum of electronic and thermal Enthalpies=

Sum of electronic and thermal Free Energies=

01

$\begin{array}{lrrr}\mathrm{N} & -0.84218700 & -1.89946500 & -0.19480300 \\ \mathrm{C} & -1.92700200 & -1.13418000 & -0.35714500 \\ \mathrm{C} & -1.83704100 & 0.25877000 & -0.51752600 \\ \mathrm{C} & -0.56458600 & 0.83086400 & -0.50329500 \\ \mathrm{C} & 0.58173000 & 0.04440200 & -0.32064500\end{array}$
0.526751 (Hartree/Particle)

0.558844

0.559788

0.462231

$-1665.354581$

$-1665.322488$

$-1665.321544$

$-1665.419101$ 


\begin{tabular}{|c|c|c|c|}
\hline $\mathrm{C}$ & 0.37365600 & -1.34610400 & -0.15855100 \\
\hline $\mathrm{C}$ & -3.25851800 & -1.89016700 & -0.37437900 \\
\hline $\mathrm{C}$ & -4.51262200 & -0.96032300 & -0.47962200 \\
\hline $\mathrm{C}$ & -4.28654700 & 0.37948700 & -1.23624400 \\
\hline $\mathrm{C}$ & -3.05717900 & 1.13850600 & -0.68908700 \\
\hline $\mathrm{C}$ & 1.94543900 & 0.62177200 & -0.29240600 \\
\hline $\mathrm{C}$ & 3.10658600 & -0.27464300 & 0.14468600 \\
\hline $\mathrm{C}$ & 2.86660300 & -1.70923800 & -0.37944900 \\
\hline $\mathrm{C}$ & 1.52631400 & -2.28820900 & 0.07629600 \\
\hline $\mathrm{C}$ & 2.19673900 & 1.91497900 & -0.59740800 \\
\hline $\mathrm{C}$ & 3.52102800 & 2.53220200 & -0.41463300 \\
\hline $\mathrm{O}$ & 4.57206700 & 1.69185900 & -0.19704000 \\
\hline $\mathrm{C}$ & 4.39564800 & 0.29189200 & -0.52040900 \\
\hline $\mathrm{O}$ & -3.38687000 & -2.55590800 & 0.92415700 \\
\hline $\mathrm{C}$ & -4.36475600 & -2.01693600 & 1.69838800 \\
\hline $\mathrm{C}$ & -5.00507600 & -0.84978700 & 0.97611800 \\
\hline $\mathrm{O}$ & -4.62250600 & -2.44408300 & 2.79747900 \\
\hline $\mathrm{C}$ & 5.68338700 & -0.38573300 & -0.15125400 \\
\hline $\mathrm{C}$ & 6.60484100 & 0.04903700 & 0.75774700 \\
\hline $\mathrm{O}$ & 7.66459900 & -0.80772300 & 0.81266600 \\
\hline $\mathrm{C}$ & 7.42001900 & -1.80647300 & -0.08282800 \\
\hline $\mathrm{C}$ & 6.22678000 & -1.60014400 & -0.70556300 \\
\hline $\mathrm{H}$ & -5.26951600 & -1.51552700 & -1.04659700 \\
\hline $\mathrm{O}$ & 3.70367200 & 3.73252900 & -0.39892900 \\
\hline $\mathrm{C}$ & 3.21397100 & -0.25670700 & 1.68756200 \\
\hline $\mathrm{C}$ & -3.23540400 & -3.01597600 & -1.41076000 \\
\hline $\mathrm{O}$ & -3.38580500 & 1.74399400 & 0.60599800 \\
\hline $\mathrm{O}$ & -2.22605500 & 3.62482300 & 0.08781900 \\
\hline $\mathrm{C}$ & -2.91262800 & 2.99192300 & 0.86380500 \\
\hline $\mathrm{C}$ & -3.34586900 & 3.46274800 & 2.22851500 \\
\hline $\mathrm{C}$ & -4.01610000 & 0.11112100 & -2.73740700 \\
\hline $\mathrm{C}$ & -5.55119900 & 1.25571900 & -1.14258800 \\
\hline $\mathrm{H}$ & -0.48602800 & 1.90667400 & -0.61768000 \\
\hline $\mathrm{H}$ & -2.81654900 & 1.96550200 & -1.36182500 \\
\hline $\mathrm{H}$ & 2.89593800 & -1.69619100 & -1.47791600 \\
\hline $\mathrm{H}$ & 3.68008800 & -2.35914900 & -0.04456800 \\
\hline $\mathrm{H}$ & 1.55718200 & -2.53214700 & 1.14683900 \\
\hline $\mathrm{H}$ & 1.31269200 & -3.23126600 & -0.43587300 \\
\hline $\mathrm{H}$ & 1.42685100 & 2.61478700 & -0.89946700 \\
\hline $\mathrm{H}$ & 4.25612600 & 0.21881900 & -1.60880200 \\
\hline $\mathrm{H}$ & -6.09065000 & -0.90205000 & 1.08236000 \\
\hline $\mathrm{H}$ & -4.66899300 & 0.06565200 & 1.46933900 \\
\hline $\mathrm{H}$ & 6.66150000 & 0.92289300 & 1.38588000 \\
\hline $\mathrm{H}$ & 8.17896300 & -2.56877900 & -0.1622100 \\
\hline $\mathrm{H}$ & 5.79355100 & -2.22390600 & -1.4745410 \\
\hline $\mathrm{H}$ & 3.49980000 & 0.73612300 & 2.04520800 \\
\hline $\mathrm{H}$ & 2.25908900 & -0.51449500 & 2.15370000 \\
\hline $\mathrm{H}$ & 3.96752200 & -0.97361500 & 2.02698400 \\
\hline $\mathrm{H}$ & -3.14234900 & -2.61785900 & -2.4246860 \\
\hline $\mathrm{H}$ & -2.38809800 & -3.67491900 & -1.2139160 \\
\hline $\mathrm{H}$ & -4.16235000 & -3.59333000 & -1.3447270 \\
\hline
\end{tabular}




$\begin{array}{lrrc}\mathrm{H} & -3.00442300 & 4.48589800 & 2.38272700 \\ \mathrm{H} & -4.43445200 & 3.41061700 & 2.32266200 \\ \mathrm{H} & -2.91858600 & 2.81044300 & 2.99675300 \\ \mathrm{H} & -4.82462000 & -0.48826700 & -3.16832600 \\ \mathrm{H} & -3.07489800 & -0.41598500 & -2.91341900 \\ \mathrm{H} & -3.97157900 & 1.05618000 & -3.28910800 \\ \mathrm{H} & -6.40083800 & 0.73880300 & -1.60217900 \\ \mathrm{H} & -5.81599100 & 1.49540100 & -0.11109700 \\ \mathrm{H} & -5.40615500 & 2.19921100 & -1.68060400\end{array}$

Proposed structure of xylogranatin G (17-2)-conformer 5

Zero-point correction=

Thermal correction to Energy=

Thermal correction to Enthalpy=

Thermal correction to Gibbs Free Energy=

Sum of electronic and zero-point Energies=

Sum of electronic and thermal Energies=

Sum of electronic and thermal Enthalpies=

Sum of electronic and thermal Free Energies=
0.526358 (Hartree/Particle)

0.558426

0.559370

0.461739

$-1665.351109$

$-1665.319041$

$-1665.318097$

$-1665.415728$

01

$\begin{array}{lrrr}\mathrm{N} & -0.78611700 & -1.73352900 & -0.82667700 \\ \mathrm{C} & -1.87616500 & -0.97287200 & -0.64700200 \\ \mathrm{C} & -1.81048200 & 0.39444900 & -0.33750800 \\ \mathrm{C} & -0.54430900 & 0.96615800 & -0.19570800 \\ \mathrm{C} & 0.59687500 & 0.17884800 & -0.36367400 \\ \mathrm{C} & 0.41916500 & -1.18413900 & -0.68308600 \\ \mathrm{C} & -3.21002400 & -1.68520700 & -0.82631100 \\ \mathrm{C} & -4.47009700 & -0.83499500 & -0.46478900 \\ \mathrm{C} & -4.21613500 & 0.37306700 & 0.48984800 \\ \mathrm{C} & -3.08625700 & 1.19458300 & -0.18064200 \\ \mathrm{C} & 1.97514800 & 0.69282600 & -0.28731400 \\ \mathrm{C} & 3.05009300 & -0.19731100 & 0.34995300 \\ \mathrm{C} & 2.67009700 & -1.70648200 & 0.23580500 \\ \mathrm{C} & 1.65233600 & -2.02739200 & -0.87224100 \\ \mathrm{C} & 2.31751500 & 1.90019000 & -0.78309100 \\ \mathrm{C} & 3.69240900 & 2.42175500 & -0.69645300 \\ \mathrm{O} & 4.67227400 & 1.52337900 & -0.39456900 \\ \mathrm{C} & 4.36694000 & 0.10100500 & -0.42813100 \\ \mathrm{O} & -3.23452700 & -2.80543000 & 0.11896800 \\ \mathrm{C} & -4.47778000 & -2.99007300 & 0.63630600 \\ \mathrm{C} & -5.40864000 & -1.90847600 & 0.11048900 \\ \mathrm{O} & -4.73910500 & -3.89611500 & 1.38894600 \\ \mathrm{C} & 5.60725800 & -0.59423200 & 0.04778400 \\ \mathrm{C} & 6.21685100 & -1.65309300 & -0.56260300 \\ \mathrm{O} & 7.32610200 & -2.03631900 & 0.12818900 \\ \mathrm{C} & 7.43739000 & -1.19220400 & 1.19719100 \\ \mathrm{C} & 6.41813600 & -0.29160600 & 1.20016600 \\ \mathrm{H} & -4.88032500 & -0.42174900 & -1.39298100 \\ \mathrm{O} & 3.98175200 & 3.59041800 & -0.85450100\end{array}$

SI180 


$\begin{array}{lrrr}\mathrm{C} & 3.17472600 & 0.17871400 & 1.84681400 \\ \mathrm{C} & -3.30477200 & -2.27213700 & -2.24085200 \\ \mathrm{O} & -2.81125700 & 2.38556700 & 0.59560300 \\ \mathrm{O} & -3.36209000 & 3.74428800 & -1.14258500 \\ \mathrm{C} & -3.00216600 & 3.59993800 & 0.00594100 \\ \mathrm{C} & -2.71093500 & 4.71565100 & 0.97689300 \\ \mathrm{C} & -5.49372200 & 1.23411400 & 0.55151100 \\ \mathrm{C} & -3.81457800 & -0.04637300 & 1.91998600 \\ \mathrm{H} & -0.44871000 & 2.01167600 & 0.07571000 \\ \mathrm{H} & -3.43117200 & 1.53005300 & -1.16523200 \\ \mathrm{H} & 3.57898500 & -2.30036300 & 0.10219700 \\ \mathrm{H} & 2.23602200 & -2.02614300 & 1.18933900 \\ \mathrm{H} & 1.37362200 & -3.08393100 & -0.85241000 \\ \mathrm{H} & 2.08474400 & -1.82575300 & -1.86333900 \\ \mathrm{H} & 1.59665400 & 2.56674900 & -1.24443100 \\ \mathrm{H} & 4.19627300 & -0.17562100 & -1.47785400 \\ \mathrm{H} & -6.04127200 & -2.35615200 & -0.66401000 \\ \mathrm{H} & -6.07459400 & -1.56932100 & 0.90487200 \\ \mathrm{H} & 6.00073100 & -2.21422800 & -1.45912800 \\ \mathrm{H} & 8.28685600 & -1.35769800 & 1.84092300 \\ \mathrm{H} & 6.27143900 & 0.51069000 & 1.90751800 \\ \mathrm{H} & 3.54742700 & 1.19774100 & 1.98062500 \\ \mathrm{H} & 2.19599200 & 0.10626500 & 2.33127400 \\ \mathrm{H} & 3.85399500 & -0.51093600 & 2.35660500 \\ \mathrm{H} & -3.23996500 & -1.47574500 & -2.98973300 \\ \mathrm{H} & -2.48066800 & -2.97044200 & -2.39812500 \\ \mathrm{H} & -4.25262600 & -2.80182900 & -2.37934300 \\ \mathrm{H} & -3.44369700 & 4.69681800 & 1.79012400 \\ \mathrm{H} & -1.72217700 & 4.58567300 & 1.42584700 \\ \mathrm{H} & -2.76580200 & 5.67140600 & 0.45666000 \\ \mathrm{H} & -6.33510500 & 0.66154100 & 0.95340400 \\ \mathrm{H} & -5.77831600 & 1.60497700 & -0.43933200 \\ \mathrm{H} & -5.34762700 & 2.09691300 & 1.20769700 \\ \mathrm{H} & -4.63240300 & -0.57476600 & 2.41860700 \\ \mathrm{H} & -2.93706600 & -0.69748200 & 1.93925700 \\ \mathrm{H} & -3.58686400 & 0.84179600 & 2.51589900\end{array}$

\section{Proposed structure of xylogranatin G (17-2)-conformer 6}

Zero-point correction $=$

Thermal correction to Energy=

Thermal correction to Enthalpy=

Thermal correction to Gibbs Free Energy=

Sum of electronic and zero-point Energies=

Sum of electronic and thermal Energies=

Sum of electronic and thermal Enthalpies=

Sum of electronic and thermal Free Energies=
0.526280 (Hartree/Particle)

$$
0.558371
$$

0.559315

\subsection{7}

$-1665.350699$

$-1665.318608$

$-1665.317664$

$-1665.415402$

01

$\begin{array}{llll}\mathrm{N} & -0.79023400 & -1.73567200 & -0.81378200 \\ \mathrm{C} & -1.87909700 & -0.97188200 & -0.64085800\end{array}$

$\begin{array}{llll}\text { C } & -1.87909700 & -0.97188200 & -0.64085800\end{array}$ 


\begin{tabular}{|c|c|c|c|}
\hline $\mathrm{C}$ & -1.81119900 & 0.39566900 & -0.33267900 \\
\hline $\mathrm{C}$ & -0.54421900 & 0.96456500 & -0.18782600 \\
\hline $\mathrm{C}$ & 0.59594000 & 0.17445700 & -0.35051200 \\
\hline $\mathrm{C}$ & 0.41589400 & -1.18922500 & -0.66606500 \\
\hline $\mathrm{C}$ & -3.21397500 & -1.68072700 & -0.82601500 \\
\hline $\mathrm{C}$ & -4.47332900 & -0.82709700 & -0.46991300 \\
\hline $\mathrm{C}$ & -4.22000700 & 0.38037600 & 0.48558500 \\
\hline $\mathrm{C}$ & -3.08548900 & 1.19904100 & -0.18060400 \\
\hline $\mathrm{C}$ & 1.97464600 & 0.68754000 & -0.27566400 \\
\hline $\mathrm{C}$ & 3.05397800 & -0.20169500 & 0.35597000 \\
\hline $\mathrm{C}$ & 2.65574000 & -1.70742800 & 0.27228200 \\
\hline $\mathrm{C}$ & 1.64701800 & -2.03896500 & -0.84070200 \\
\hline $\mathrm{C}$ & 2.31647400 & 1.89315000 & -0.77630500 \\
\hline $\mathrm{C}$ & 3.69322800 & 2.40950300 & -0.69743300 \\
\hline $\mathrm{O}$ & 4.67195500 & 1.50564800 & -0.40632400 \\
\hline $\mathrm{C}$ & 4.36244800 & 0.08550900 & -0.44305600 \\
\hline $\mathrm{O}$ & -3.24569100 & -2.80112100 & 0.11872000 \\
\hline $\mathrm{C}$ & -4.49164500 & -2.98238700 & 0.63077100 \\
\hline $\mathrm{C}$ & -5.41719500 & -1.89796200 & 0.10148400 \\
\hline $\mathrm{O}$ & -4.75869800 & -3.88800700 & 1.38191000 \\
\hline $\mathrm{C}$ & 5.60410500 & -0.61718800 & 0.02445800 \\
\hline $\mathrm{C}$ & 6.53382100 & -0.14695000 & 0.90751200 \\
\hline $\mathrm{O}$ & 7.54127500 & -1.05098200 & 1.06920500 \\
\hline $\mathrm{C}$ & 7.25554600 & -2.11861100 & 0.27043000 \\
\hline $\mathrm{C}$ & 6.08729400 & -1.90800100 & -0.39655500 \\
\hline $\mathrm{H}$ & -4.87851300 & -0.41286400 & -1.39988100 \\
\hline $\mathrm{O}$ & 3.98780700 & 3.57713100 & -0.85283400 \\
\hline $\mathrm{C}$ & 3.21538500 & 0.19045200 & 1.84454500 \\
\hline $\mathrm{C}$ & -3.30398200 & -2.26700400 & -2.24116200 \\
\hline $\mathrm{O}$ & -2.81033900 & 2.38916500 & 0.59693300 \\
\hline $\mathrm{O}$ & -3.34995400 & 3.74974300 & -1.14336400 \\
\hline $\mathrm{C}$ & -2.99547400 & 3.60421400 & 0.00670300 \\
\hline $\mathrm{C}$ & -2.70581200 & 4.71884600 & 0.97934900 \\
\hline $\mathrm{C}$ & -5.49557900 & 1.24475700 & 0.54228600 \\
\hline $\mathrm{C}$ & -3.82506700 & -0.04001300 & 1.91729300 \\
\hline $\mathrm{H}$ & -0.44713100 & 2.01041800 & 0.08172600 \\
\hline $\mathrm{H}$ & -3.42585700 & 1.53552500 & -1.16642300 \\
\hline $\mathrm{H}$ & 3.55414400 & -2.32142200 & 0.17136000 \\
\hline $\mathrm{H}$ & 2.20199400 & -1.99495500 & 1.22709100 \\
\hline $\mathrm{H}$ & 1.36332600 & -3.09396000 & -0.81037300 \\
\hline $\mathrm{H}$ & 2.08690100 & -1.85042200 & -1.83106000 \\
\hline $\mathrm{H}$ & 1.59535900 & 2.56037700 & -1.23613900 \\
\hline $\mathrm{H}$ & 4.17917800 & -0.18695000 & -1.49216400 \\
\hline $\mathrm{H}$ & -6.04812700 & -2.34366600 & -0.67553300 \\
\hline $\mathrm{H}$ & -6.08527300 & -1.55699200 & 0.89330900 \\
\hline $\mathrm{H}$ & 6.63358800 & 0.78132200 & 1.44603800 \\
\hline $\mathrm{H}$ & 7.97094300 & -2.92566000 & 0.28319400 \\
\hline $\mathrm{H}$ & 5.63398900 & -2.57807900 & -1.11377900 \\
\hline $\mathrm{H}$ & 3.58608200 & 1.21237200 & 1.95891900 \\
\hline $\mathrm{H}$ & 2.25087300 & 0.11644200 & 2.35636000 \\
\hline $\mathrm{H}$ & 3.91623300 & -0.48833600 & 2.33988000 \\
\hline
\end{tabular}




$\begin{array}{lrrr}\mathrm{H} & -3.23377400 & -1.47062000 & -2.98956000 \\ \mathrm{H} & -2.48106000 & -2.96748700 & -2.39498300 \\ \mathrm{H} & -4.25260400 & -2.79416800 & -2.38396300 \\ \mathrm{H} & -3.44423900 & 4.70332900 & 1.78753100 \\ \mathrm{H} & -1.72079800 & 4.58462900 & 1.43519400 \\ \mathrm{H} & -2.75313700 & 5.67474500 & 0.45864900 \\ \mathrm{H} & -6.33996600 & 0.67447300 & 0.94110900 \\ \mathrm{H} & -5.77546600 & 1.61619200 & -0.44968300 \\ \mathrm{H} & -5.34968800 & 2.10727100 & 1.19888000 \\ \mathrm{H} & -4.64621500 & -0.56621200 & 2.41276700 \\ \mathrm{H} & -2.94935400 & -0.69342700 & 1.94005900 \\ \mathrm{H} & -3.59730800 & 0.84756500 & 2.51405600\end{array}$

\section{Proposed structure of xylogranatin G (17-2)-conformer 7}

Zero-point correction $=$

Thermal correction to Energy=

Thermal correction to Enthalpy=

Thermal correction to Gibbs Free Energy=

Sum of electronic and zero-point Energies=

Sum of electronic and thermal Energies=

Sum of electronic and thermal Enthalpies=

Sum of electronic and thermal Free Energies=
0.526580 (Hartree/Particle)

0.558646

0.559590

0.462033

$-1665.350669$

$-1665.318603$

$-1665.317659$

$-1665.415216$

01

$\begin{array}{lrrr}\mathrm{N} & -0.80656200 & -1.79748600 & -0.61875500 \\ \mathrm{C} & -1.90736100 & -1.02747600 & -0.57656700 \\ \mathrm{C} & -1.84268400 & 0.37136600 & -0.48288800 \\ \mathrm{C} & -0.57543100 & 0.96770700 & -0.43531300 \\ \mathrm{C} & 0.56938400 & 0.17207900 & -0.46011500 \\ \mathrm{C} & 0.39397200 & -1.22730400 & -0.54792500 \\ \mathrm{C} & -3.22988100 & -1.79561600 & -0.65365500 \\ \mathrm{C} & -4.49950100 & -0.89080200 & -0.51876700 \\ \mathrm{C} & -4.33270900 & 0.56919000 & -1.02712600 \\ \mathrm{C} & -3.08118400 & 1.23942300 & -0.41840500 \\ \mathrm{C} & 1.94782700 & 0.69310600 & -0.47392400 \\ \mathrm{C} & 3.02132200 & -0.07160400 & 0.31109300 \\ \mathrm{C} & 2.63668200 & -1.57531000 & 0.46744700 \\ \mathrm{C} & 1.62988700 & -2.08732100 & -0.57677100 \\ \mathrm{C} & 2.29080100 & 1.79233000 & -1.17671700 \\ \mathrm{C} & 3.66879000 & 2.31369000 & -1.19464800 \\ \mathrm{O} & 4.64662700 & 1.48184700 & -0.73407000 \\ \mathrm{C} & 4.33805300 & 0.07829300 & -0.50850600 \\ \mathrm{O} & -3.27278500 & -2.68656000 & 0.50910300 \\ \mathrm{C} & -4.21092000 & -2.31981500 & 1.42020000 \\ \mathrm{C} & -4.91065600 & -1.05920300 & 0.95658200 \\ \mathrm{O} & -4.39667700 & -2.94241100 & 2.43768200 \\ \mathrm{C} & 5.57699400 & -0.52208100 & 0.08567100 \\ \mathrm{C} & 6.18345900 & -1.67610900 & -0.32149200 \\ \mathrm{O} & 7.29221600 & -1.92994700 & 0.42742100 \\ \mathrm{C} & 7.40630800 & -0.90528000 & 1.32458000\end{array}$

SI183 


$\begin{array}{lrrr}\mathrm{C} & 6.38943600 & -0.01652600 & 1.16337300 \\ \mathrm{H} & -5.28029700 & -1.34970800 & -1.13707400 \\ \mathrm{O} & 3.96365300 & 3.42903500 & -1.57212500 \\ \mathrm{C} & 3.14861000 & 0.56523800 & 1.71652000 \\ \mathrm{C} & -3.25735000 & -2.71672400 & -1.87564100 \\ \mathrm{O} & -3.33784600 & 1.58484500 & 0.98452600 \\ \mathrm{O} & -2.26729800 & 3.57392900 & 0.75939900 \\ \mathrm{C} & -2.88425300 & 2.78149800 & 1.44152800 \\ \mathrm{C} & -3.24520300 & 2.97601200 & 2.89237600 \\ \mathrm{C} & -4.14836500 & 0.58645800 & -2.56469700 \\ \mathrm{C} & -5.59840900 & 1.38706600 & -0.70301900 \\ \mathrm{H} & -0.49566900 & 2.04844500 & -0.35694200 \\ \mathrm{H} & -2.88993600 & 2.18282800 & -0.93596800 \\ \mathrm{H} & 3.54442800 & -2.18555800 & 0.45333600 \\ \mathrm{H} & 2.19091300 & -1.71695400 & 1.45800400 \\ \mathrm{H} & 1.35152300 & -3.12511300 & -0.37729500 \\ \mathrm{H} & 2.07081000 & -2.05887400 & -1.58416300 \\ \mathrm{H} & 1.56911700 & 2.37074800 & -1.74353700 \\ \mathrm{H} & 4.16639800 & -0.38420400 & -1.49053300 \\ \mathrm{H} & -5.98750000 & -1.15919100 & 1.10814000 \\ \mathrm{H} & -4.56287300 & -0.23974700 & 1.59020500 \\ \mathrm{H} & 5.96546000 & -2.39071000 & -1.10070300 \\ \mathrm{H} & 8.25573900 & -0.95286800 & 1.98758400 \\ \mathrm{H} & 6.24498000 & 0.90172900 & 1.71244900 \\ \mathrm{H} & 3.52432300 & 1.59056100 & 1.66554900 \\ \mathrm{H} & 2.17003600 & 0.58442700 & 2.20630400 \\ \mathrm{H} & 3.82597000 & -0.02449600 & 2.34130100 \\ \mathrm{H} & -3.23007600 & -2.14090700 & -2.80460100 \\ \mathrm{H} & -2.39285200 & -3.38214400 & -1.85068300 \\ \mathrm{H} & -4.17256900 & -3.31599400 & -1.86179900 \\ \mathrm{H} & -4.32865800 & 2.90432700 & 3.02672600 \\ \mathrm{H} & -2.78743300 & 2.18790700 & 3.49832500 \\ \mathrm{H} & -2.89208800 & 3.95169600 & 3.22491100 \\ \mathrm{H} & -4.97694300 & 0.06309200 & -3.05278300 \\ \mathrm{H} & -3.21586000 & 0.11640900 & -2.88709300 \\ \mathrm{H} & -4.14188200 & 1.61748300 & -2.93413300 \\ \mathrm{H} & -6.46855700 & 0.94497900 & -1.20070800 \\ \mathrm{H} & -5.80409800 & 1.42895900 & 0.36822400 \\ & -5.49531100 & 2.41565600 & -1.06641500\end{array}$

\footnotetext{
Proposed structure of xylogranatin G (17-2)-conformer 8

Zero-point correction $=$

Thermal correction to Energy=

Thermal correction to Enthalpy=

Thermal correction to Gibbs Free Energy=

Sum of electronic and zero-point Energies=

Sum of electronic and thermal Energies=

Sum of electronic and thermal Enthalpies=

Sum of electronic and thermal Free Energies=

0.526523 (Hartree/Particle)

0.558599

0.559543

0.462004

$-1665.350171$

$-1665.318096$

$-1665.317152$

$-1665.414690$

SI184
} 
01

$\begin{array}{lll}-0.80816700 & -1.79337800 & -0.61330800 \\ -1.90841600 & -1.02248500 & -0.57590600\end{array}$

$\begin{array}{llll}\text { C } & -1.84282700 & 0.37587900 & -0.47542900\end{array}$

$\begin{array}{llll}\text { C } & -0.57534800 & 0.97057900 & -0.41834600\end{array}$

$\begin{array}{llll}\mathrm{C} & 0.56917900 & 0.17413300 & -0.44021800\end{array}$

C $\quad 0.39257900 \quad-1.22491200 \quad-0.53261600$

C $\quad-3.23111400 \quad-1.78886000 \quad-0.66564500$

C $\quad-4.50070800 \quad-0.88359300 \quad-0.53413800$

$\begin{array}{llll}\text { C } & -4.32930100 & 0.57895200 & -1.03358400\end{array}$

$\begin{array}{llll}\text { C } & -3.08092500 & 1.24471000 & -0.41357400\end{array}$

$\begin{array}{llll}\text { C } & 1.94755200 & 0.69553200 & -0.45094900\end{array}$

$\begin{array}{llll}\text { C } & 3.02678600 & -0.07401800 & 0.32194600\end{array}$

$\begin{array}{llll}\mathrm{C} & 2.62383900 & -1.56957100 & 0.50009200\end{array}$

$\begin{array}{llll}\mathrm{C} & 1.62670500 & -2.08822000 & -0.54980100\end{array}$

$\begin{array}{llll}\mathrm{C} & 2.28884800 & 1.79760400 & -1.15034000\end{array}$

$\begin{array}{llll}\text { C } & 3.66837600 & 2.31318200 & -1.17216700\end{array}$

O $\quad 4.64585600 \quad 1.47014900 \quad-0.73018800$

C $\quad 4.33318200 \quad 0.06668500 \quad-0.51844800$

$\begin{array}{llll}\mathrm{O} & -3.28250000 & -2.68620500 & 0.49174700\end{array}$

$\begin{array}{llll}\text { C } & -4.22639800 & -2.32360200 & 1.39865700\end{array}$

C $\quad-4.92150900 \quad-1.05952400 \quad 0.93760100$

$\begin{array}{llll}\mathrm{O} & -4.41968800 & -2.95190100 & 2.41120300\end{array}$

$\begin{array}{llll}\mathrm{C} & 5.57462600 & -0.54784600 & 0.06061700\end{array}$

$\begin{array}{llll}\mathrm{C} & 6.51035500 & 0.06685400 & 0.84281400\end{array}$

$\begin{array}{llll}\mathrm{O} & 7.51521400 & -0.79899000 & 1.15763800\end{array}$

C $\quad 7.22164100 \quad-1.98965800 \quad 0.56137900$

C $\quad 6.05092300 \quad-1.89497200 \quad-0.12749100$

$\mathrm{H} \quad-5.27795300 \quad-1.33840000 \quad-1.15990100$

$\mathrm{O} \quad 3.96768500 \quad 3.43128000 \quad-1.53754200$

$\begin{array}{llll}\text { C } & 3.19430100 & 0.56845200 & 1.71992600\end{array}$

C $\quad-3.25145600 \quad-2.70319700 \quad-1.89287700$

$\begin{array}{llll}\mathrm{O} & -3.34565700 & 1.58253100 & 0.98960200\end{array}$

$\begin{array}{llll}\mathrm{O} & -2.26871200 & 3.57010800 & 0.78250600\end{array}$

$\begin{array}{llll}\text { C } & -2.89208000 & 2.77558500 & 1.45628300\end{array}$

$\begin{array}{llll}\text { C } & -3.26315400 & 2.96348300 & 2.90541400\end{array}$

C $\quad-4.13553500 \quad 0.60427200 \quad-2.56989700$

C $\quad-5.59614000 \quad 1.39643000 \quad-0.71292200$

$\mathrm{H} \quad-0.49513600 \quad 2.05090100 \quad-0.33517800$

$\mathrm{H} \quad-2.88572800 \quad 2.19069600 \quad-0.92491400$

$\mathrm{H} \quad 3.52082000 \quad-2.19353200 \quad 0.51979400$

$\mathrm{H} \quad 2.15777700 \quad-1.68368000 \quad 1.48506500$

$\mathrm{H} \quad 1.34348800 \quad-3.12375800 \quad-0.34530100$

$\mathrm{H} \quad 2.07523700 \quad-2.06774400 \quad-1.55399000$

$\mathrm{H} \quad \begin{array}{llll}\mathrm{H} & 1.56629700 & 2.38057600 & -1.71123300\end{array}$

$\mathrm{H} \quad 4.14617900 \quad-0.38365100 \quad-1.50376500$

$\mathrm{H} \quad-5.99942100 \quad-1.15883400 \quad 1.08179500$

$\mathrm{H} \quad-4.57661800 \quad-0.24404300 \quad 1.57792500$

$\begin{array}{llll}\mathrm{H} & 6.61615100 & 1.07520900 & 1.20846200\end{array}$

$\begin{array}{llll}\mathrm{H} & 7.93407000 & -2.78497900 & 0.71369400\end{array}$

$\mathrm{H} \quad 5.59161200 \quad-2.67923000 \quad-0.71304200$

SI185 


$\begin{array}{lrrr}\mathrm{H} & 3.57071800 & 1.59252100 & 1.65509700 \\ \mathrm{H} & 2.23070700 & 0.59035200 & 2.23830300 \\ \mathrm{H} & 3.89248300 & -0.01877200 & 2.32413400 \\ \mathrm{H} & -3.21769800 & -2.12238600 & -2.81849900 \\ \mathrm{H} & -2.38774200 & -3.36958400 & -1.86599200 \\ \mathrm{H} & -4.16723000 & -3.30176500 & -1.88824200 \\ \mathrm{H} & -2.90004000 & 3.93171700 & 3.24877200 \\ \mathrm{H} & -4.34886200 & 2.90645000 & 3.02869500 \\ \mathrm{H} & -2.82264900 & 2.16429100 & 3.50950600 \\ \mathrm{H} & -4.96162400 & 0.08438800 & -3.06584300 \\ \mathrm{H} & -3.20155000 & 0.13502300 & -2.88917500 \\ \mathrm{H} & -4.12578600 & 1.63723800 & -2.93379800 \\ \mathrm{H} & -6.46366300 & 0.95796800 & -1.21833900 \\ \mathrm{H} & -5.80841600 & 1.43282800 & 0.35723900 \\ \mathrm{H} & -5.48972000 & 2.42683900 & -1.07014700\end{array}$

Revised structure of xylogranatin G (17-5)-conformer 1

$\begin{array}{lc}\text { Zero-point correction= } & 0.526601 \text { (Hartree/Particle) } \\ \text { Thermal correction to Energy= } & 0.558686 \\ \text { Thermal correction to Enthalpy= } & 0.559630 \\ \text { Thermal correction to Gibbs Free Energy= } & 0.462291 \\ \text { Sum of electronic and zero-point Energies }= & -1665.357237 \\ \text { Sum of electronic and thermal Energies }= & -1665.325152 \\ \text { Sum of electronic and thermal Enthalpies }= & -1665.324208 \\ \text { Sum of electronic and thermal Free Energies }= & -1665.421547\end{array}$
01

$\begin{array}{lrrr}\mathrm{N} & 0.87344200 & -1.57503400 & 0.71269200 \\ \mathrm{C} & 1.92756100 & -0.81068000 & 0.41636000 \\ \mathrm{C} & 1.79152400 & 0.48434400 & -0.10742100 \\ \mathrm{C} & 0.50362000 & 0.96165700 & -0.33400200 \\ \mathrm{C} & -0.61790500 & 0.17272300 & -0.03283100 \\ \mathrm{C} & -0.36474600 & -1.11642900 & 0.49284600 \\ \mathrm{C} & 3.29469800 & -1.42561500 & 0.69258600 \\ \mathrm{C} & 4.51875400 & -0.57885800 & 0.21674200 \\ \mathrm{C} & 4.20564400 & 0.47155500 & -0.89174700 \\ \mathrm{C} & 3.00783400 & 1.32223400 & -0.41927800 \\ \mathrm{C} & -2.00215200 & 0.64588900 & -0.26160200 \\ \mathrm{C} & -3.14076300 & -0.37055100 & -0.15905500 \\ \mathrm{C} & -2.83357300 & -1.35709700 & 0.99122900 \\ \mathrm{C} & -1.48990200 & -2.06607500 & 0.81809500 \\ \mathrm{C} & -2.29221300 & 1.92483500 & -0.59144200 \\ \mathrm{C} & -3.64367800 & 2.35660900 & -0.98889400 \\ \mathrm{O} & -4.66983300 & 1.49574800 & -0.73549200 \\ \mathrm{C} & -4.42735500 & 0.42252200 & 0.20855200 \\ \mathrm{O} & 3.37278800 & -2.66291000 & -0.09136500 \\ \mathrm{C} & 4.62536300 & -2.86077300 & -0.58219800 \\ \mathrm{C} & 5.50549900 & -1.67791500 & -0.20950000 \\ \mathrm{O} & 4.92774200 & -3.84819400 & -1.20625100 \\ \mathrm{C} & -5.69915900 & -0.36849500 & 0.28259500 \\ & & & \mathrm{~S} 1186 \\ & & & \end{array}$




$\begin{array}{lrrr}\mathrm{C} & -6.31348900 & -0.79689700 & 1.42435600 \\ \mathrm{O} & -7.45189500 & -1.48540300 & 1.13133600 \\ \mathrm{C} & -7.57616300 & -1.48315200 & -0.22979600 \\ \mathrm{C} & -6.53692200 & -0.81687200 & -0.80094600 \\ \mathrm{H} & 4.90264900 & -0.02272900 & 1.07595400 \\ \mathrm{O} & -3.86757700 & 3.40048800 & -1.56764800 \\ \mathrm{C} & -3.28231900 & -1.11338500 & -1.50862500 \\ \mathrm{C} & 3.40731900 & -1.80730100 & 2.17398600 \\ \mathrm{O} & 3.41553800 & 2.03985500 & 0.79338400 \\ \mathrm{O} & 2.03768700 & 3.76694500 & 0.28391200 \\ \mathrm{C} & 2.84950400 & 3.25103500 & 1.02507300 \\ \mathrm{C} & 3.35182100 & 3.84843500 & 2.31552100 \\ \mathrm{C} & 5.43129000 & 1.38291100 & -1.10408500 \\ \mathrm{C} & 3.82514000 & -0.16444800 & -2.24945300 \\ \mathrm{H} & 0.38831600 & 1.95434800 & -0.75482900 \\ \mathrm{H} & 2.76001000 & 2.07493500 & -1.17163400 \\ \mathrm{H} & -2.82567100 & -0.80232300 & 1.93972000 \\ \mathrm{H} & -3.63919700 & -2.09411900 & 1.06211900 \\ \mathrm{H} & -1.54902500 & -2.81355800 & 0.01535200 \\ \mathrm{H} & -1.22237400 & -2.62369600 & 1.72091200 \\ \mathrm{H} & -1.53981500 & 2.69907100 & -0.68346200 \\ \mathrm{H} & -4.24712400 & 0.88205400 & 1.19021400 \\ \mathrm{H} & 6.15344100 & -1.98959500 & 0.61747200 \\ \mathrm{H} & 6.16078300 & -1.42094300 & -1.04290200 \\ \mathrm{H} & -6.08104500 & -0.69107000 & 2.47309100 \\ \mathrm{H} & -8.44850200 & -1.98059300 & -0.62344000 \\ \mathrm{H} & -6.39112000 & -0.63302500 & -1.85483500 \\ \mathrm{H} & -3.62247400 & -0.43184600 & -2.29312800 \\ \mathrm{H} & -2.32506000 & -1.53333700 & -1.82938800 \\ \mathrm{H} & -4.00231700 & -1.93271200 & -1.42406800 \\ \mathrm{H} & 3.30735400 & -0.91676900 & 2.80295600 \\ \mathrm{H} & 2.61321900 & -2.51161600 & 2.42867100 \\ \mathrm{H} & 4.37647200 & -2.27188800 & 2.38143600 \\ \mathrm{H} & 3.00201800 & 4.87728000 & 2.39728700 \\ \mathrm{H} & 2.96903300 & 3.26578900 & 3.16007000 \\ \mathrm{H} & 4.44372800 & 3.81320500 & 2.35879900 \\ \mathrm{H} & 5.20337200 & 2.16903900 & -1.83278400 \\ \mathrm{H} & 5.27994100 & 0.81341500 & -1.49522800 \\ \mathrm{H} & 2.978460000 & -0.85112600 & -2.17871900 \\ \mathrm{H} & & 1.86299100 & -0.17301800 \\ \mathrm{H} & -5618300 & -0.71807900 & -2.67188000\end{array}$

\footnotetext{
Revised structure of xylogranatin G (17-5)-conformer 2

Zero-point correction $=$ Thermal correction to Energy= Thermal correction to Enthalpy= Thermal correction to Gibbs Free Energy= Sum of electronic and zero-point Energies=

0.526577 (Hartree/Particle)

$$
\begin{gathered}
0.558670 \\
0.559614
\end{gathered}
$$

0.462336 $-1665.357141$

SI187
} 
$\begin{array}{ll}\text { Sum of electronic and thermal Energies }= & -1665.325048 \\ \text { Sum of electronic and thermal Enthalpies }= & -1665.324104 \\ \text { Sum of electronic and thermal Free Energies }= & -1665.421382\end{array}$ 01

$\begin{array}{lrrr}\mathrm{N} & 0.88281300 & -1.58602000 & 0.69514800 \\ \mathrm{C} & 1.93403700 & -0.81520600 & 0.40532200 \\ \mathrm{C} & 1.79286200 & 0.48585300 & -0.10191500 \\ \mathrm{C} & 0.50303500 & 0.96291600 & -0.31759100 \\ \mathrm{C} & -0.61562100 & 0.16746700 & -0.02256700 \\ \mathrm{C} & -0.35708200 & -1.12756300 & 0.48496000 \\ \mathrm{C} & 3.30368900 & -1.42958200 & 0.67004300 \\ \mathrm{C} & 4.52384000 & -0.57387000 & 0.20022500 \\ \mathrm{C} & 4.20419900 & 0.48851700 & -0.89487000 \\ \mathrm{C} & 3.00594000 & 1.33052800 & -0.40820600 \\ \mathrm{C} & -2.00185500 & 0.64005300 & -0.24025400 \\ \mathrm{C} & -3.14106700 & -0.37673600 & -0.14082000 \\ \mathrm{C} & -2.82344100 & -1.38053800 & 0.99191000 \\ \mathrm{C} & -1.47894200 & -2.08368000 & 0.79990000 \\ \mathrm{C} & -2.29274600 & 1.92202900 & -0.55758600 \\ \mathrm{C} & -3.64480500 & 2.35557800 & -0.94724400 \\ \mathrm{O} & -4.66873000 & 1.49103500 & -0.69726500 \\ \mathrm{C} & -4.42751200 & 0.41427100 & 0.23962200 \\ \mathrm{O} & 3.38273600 & -2.65751500 & -0.12824900 \\ \mathrm{C} & 4.63437200 & -2.84623900 & -0.62517600 \\ \mathrm{C} & 5.51228000 & -1.66507000 & -0.24200700 \\ \mathrm{O} & 4.93760700 & -3.82575700 & -1.26111000 \\ \mathrm{C} & -5.69991300 & -0.38028400 & 0.29745600 \\ \mathrm{C} & -6.66839100 & -0.44462600 & -0.66285100 \\ \mathrm{O} & -7.69520500 & -1.24427500 & -0.25477200 \\ \mathrm{C} & -7.38108400 & -1.69520600 & 0.99312100 \\ \mathrm{C} & -6.17608200 & -1.19695200 & 1.38542600 \\ \mathrm{H} & 4.90896300 & -0.02674800 & 1.06465200 \\ \mathrm{O} & -3.87365200 & 3.40264800 & -1.51807600 \\ \mathrm{C} & -3.30370500 & -1.10030000 & -1.49782200 \\ \mathrm{C} & 3.42202000 & -1.82793000 & 2.14662300 \\ \mathrm{O} & 3.41625800 & 2.03502400 & 0.81126400 \\ \mathrm{O} & 2.03010100 & 3.76306100 & 0.32834700 \\ \mathrm{C} & 2.84707300 & 3.24136800 & 1.05974700 \\ \mathrm{C} & 3.35323700 & 3.82537000 & 2.35481100 \\ \mathrm{C} & 5.42677000 & 1.40543600 & -1.10091300 \\ \mathrm{C} & 3.82053500 & -0.13270400 & -2.25850800 \\ \mathrm{H} & 0.38433400 & 1.96068800 & -0.72510100 \\ \mathrm{H} & 2.75345900 & 2.09131500 & -1.15082600 \\ \mathrm{H} & -2.81270100 & -0.84251900 & 1.95004600 \\ \mathrm{H} & -3.62186400 & -2.12577600 & 1.05150000 \\ \mathrm{H} & -1.54176100 & -2.81744500 & -0.01507200 \\ \mathrm{H} & -1.20624900 & -2.65611300 & 1.69183700 \\ \mathrm{H} & -1.54088000 & 2.69699200 & -0.64657700 \\ \mathrm{H} & -4.24779100 & 0.86757100 & 1.22530800 \\ \mathrm{H} & 6.16407400 & -1.98425100 & 0.57905200 \\ \mathrm{H} & 6.16386100 & -1.39662700 & -1.07469600 \\ & & & 5 \\ & & & \mathrm{n} \\ \mathrm{H} & & & \end{array}$




$\begin{array}{rrrr}\mathrm{H} & -6.78060900 & 0.02618100 & -1.62572900 \\ \mathrm{H} & -8.10654500 & -2.34250100 & 1.46016100 \\ \mathrm{H} & -5.69261800 & -1.37399800 & 2.33569700 \\ \mathrm{H} & -3.64153200 & -0.40439400 & -2.27050000 \\ \mathrm{H} & -2.35623600 & -1.53185600 & -1.83193000 \\ \mathrm{H} & -4.03943600 & -1.90595300 & -1.41655600 \\ \mathrm{H} & 3.32156800 & -0.94497800 & 2.78611500 \\ \mathrm{H} & 2.63073000 & -2.53742000 & 2.39566000 \\ \mathrm{H} & 4.39311700 & -2.29214400 & 2.34566400 \\ \mathrm{H} & 2.99848900 & 4.85124400 & 2.45124200 \\ \mathrm{H} & 2.97836500 & 3.23021500 & 3.19416000 \\ \mathrm{H} & 4.44555500 & 3.79552800 & 2.39158400 \\ \mathrm{H} & 5.19415100 & 2.19956800 & -1.81937400 \\ \mathrm{H} & 6.27533800 & 0.84277500 & -1.50199000 \\ \mathrm{H} & 5.74147200 & 1.87523200 & -0.16539500 \\ \mathrm{H} & 2.97587500 & -0.82235900 & -2.19280700 \\ \mathrm{H} & 3.55273800 & 0.65800100 & -2.96804700 \\ \mathrm{H} & 4.66365500 & -0.67924700 & -2.69022800\end{array}$

\section{Revised structure of xylogranatin G (17-5)-conformer 3}

Zero-point correction $=$

Thermal correction to Energy=

Thermal correction to Enthalpy=

Thermal correction to Gibbs Free Energy=

Sum of electronic and zero-point Energies $=$

Sum of electronic and thermal Energies=

Sum of electronic and thermal Enthalpies=

Sum of electronic and thermal Free Energies=
0.526532 (Hartree/Particle)

0.558708

0.559653

0.461390

$-1665.354312$

$-1665.322135$

$-1665.321191$

$-1665.419454$

01

$\begin{array}{lrrr}\mathrm{N} & -0.79718900 & -1.95028500 & -0.44077600 \\ \mathrm{C} & -1.90535800 & -1.20824400 & -0.35097000 \\ \mathrm{C} & -1.86135000 & 0.18290600 & -0.14506200 \\ \mathrm{C} & -0.60461500 & 0.77169300 & -0.03195500 \\ \mathrm{C} & 0.56819700 & 0.00804800 & -0.12376400 \\ \mathrm{C} & 0.40638700 & -1.38307900 & -0.31926800 \\ \mathrm{C} & -3.22008400 & -1.98092100 & -0.48084700 \\ \mathrm{C} & -4.48862600 & -1.08054600 & -0.32405300 \\ \mathrm{C} & -4.32322700 & 0.39757000 & -0.78063600 \\ \mathrm{C} & -3.13065800 & 0.99935900 & -0.00039900 \\ \mathrm{C} & 1.91575300 & 0.61140300 & -0.01671100 \\ \mathrm{C} & 3.11423800 & -0.32220500 & 0.15864700 \\ \mathrm{C} & 2.89845800 & -1.58538000 & -0.70764700 \\ \mathrm{C} & 1.59257100 & -2.31180400 & -0.38211000 \\ \mathrm{C} & 2.12226600 & 1.94741900 & -0.03417100 \\ \mathrm{C} & 3.43348500 & 2.55698100 & 0.24454100 \\ \mathrm{O} & 4.51374500 & 1.72744400 & 0.24839700 \\ \mathrm{C} & 4.36387400 & 0.42978100 & -0.38281200 \\ \mathrm{O} & -3.27900700 & -2.91687800 & 0.64715900 \\ \mathrm{C} & -4.21963500 & -2.57768300 & 1.56542500\end{array}$

SI189 


\begin{tabular}{|c|c|c|c|}
\hline $\mathrm{C}$ & -4.90412300 & -1.29083400 & 1.14454200 \\
\hline $\mathrm{O}$ & -4.42369600 & -3.23742300 & 2.55460900 \\
\hline $\mathrm{C}$ & 5.68119000 & -0.26893300 & -0.22569000 \\
\hline $\mathrm{C}$ & 6.35672300 & -0.93911800 & -1.20508000 \\
\hline $\mathrm{O}$ & 7.52281400 & -1.45215200 & -0.72299300 \\
\hline $\mathrm{C}$ & 7.60189000 & -1.08747800 & 0.59186700 \\
\hline $\mathrm{C}$ & 6.50739000 & -0.36429600 & 0.95126800 \\
\hline $\mathrm{H}$ & -5.26878000 & -1.51727200 & -0.95860500 \\
\hline $\mathrm{O}$ & 3.57729600 & 3.73237800 & 0.51605100 \\
\hline $\mathrm{C}$ & 3.25772400 & -0.68765700 & 1.65488800 \\
\hline $\mathrm{C}$ & -3.23117800 & -2.85385900 & -1.73670100 \\
\hline $\mathrm{O}$ & -2.87901900 & 2.35370800 & -0.45647500 \\
\hline $\mathrm{O}$ & -3.40449800 & 3.21777900 & 1.58026500 \\
\hline $\mathrm{C}$ & -3.06770800 & 3.37604700 & 0.42663600 \\
\hline $\mathrm{C}$ & -2.81144000 & 4.70667600 & -0.23356200 \\
\hline $\mathrm{C}$ & -4.07775000 & 0.47977900 & -2.30291500 \\
\hline $\mathrm{C}$ & -5.61547000 & 1.17487900 & -0.45730400 \\
\hline $\mathrm{H}$ & -0.54481900 & 1.83980300 & 0.13723300 \\
\hline $\mathrm{H}$ & -3.38995600 & 1.07683500 & 1.05947500 \\
\hline $\mathrm{H}$ & 2.88846100 & -1.28968700 & -1.76590600 \\
\hline $\mathrm{H}$ & 3.74689000 & -2.26375700 & -0.57631800 \\
\hline $\mathrm{H}$ & 1.67095700 & -2.83037500 & 0.58306300 \\
\hline $\mathrm{H}$ & 1.38480400 & -3.09199800 & -1.12077300 \\
\hline $\mathrm{H}$ & 1.32259200 & 2.66814400 & -0.15427100 \\
\hline $\mathrm{H}$ & 4.18958000 & 0.60471500 & -1.45341800 \\
\hline $\mathrm{H}$ & -5.98190800 & -1.38009700 & 1.29348300 \\
\hline $\mathrm{H}$ & -4.55667500 & -0.50123000 & 1.82000400 \\
\hline $\mathrm{H}$ & 6.15304000 & -1.12569500 & -2.24853300 \\
\hline $\mathrm{H}$ & 8.48812600 & -1.40783000 & 1.11658000 \\
\hline $\mathrm{H}$ & 6.31639300 & 0.07725800 & 1.91785100 \\
\hline $\mathrm{H}$ & 3.53354300 & 0.19099400 & 2.24447900 \\
\hline $\mathrm{H}$ & 2.31746600 & -1.07299900 & 2.05848300 \\
\hline $\mathrm{H}$ & 4.02665300 & -1.45350800 & 1.79216500 \\
\hline $\mathrm{H}$ & -3.19776200 & -2.24198400 & -2.64187900 \\
\hline $\mathrm{H}$ & -2.36315400 & -3.51496200 & -1.7282730 \\
\hline $\mathrm{H}$ & -4.14294200 & -3.45808200 & -1.7547950 \\
\hline $\mathrm{H}$ & -2.79998700 & 5.48976000 & 0.52400100 \\
\hline $\mathrm{H}$ & -1.86540500 & 4.69234200 & -0.78124500 \\
\hline $\mathrm{H}$ & -3.60624300 & 4.91308200 & -0.95815400 \\
\hline $\mathrm{H}$ & -4.04851400 & 1.52388200 & -2.6251470 \\
\hline $\mathrm{H}$ & -4.88897300 & -0.01918400 & -2.8439140 \\
\hline $\mathrm{H}$ & -3.13432200 & 0.01839000 & -2.6054440 \\
\hline $\mathrm{H}$ & -5.81912500 & 1.21632100 & $0.6164650 \mathrm{C}$ \\
\hline $\mathrm{H}$ & -5.55087400 & 2.20338300 & -0.8244050 \\
\hline $\mathrm{H}$ & -6.47339400 & 0.70387400 & -0.9498200 \\
\hline
\end{tabular}

Revised structure of xylogranatin G (17-5)-conformer 4

Zero-point correction $=$

Thermal correction to Energy=
0.526492 (Hartree/Particle)

0.558683

SI190 


$\begin{array}{lc}\text { Thermal correction to Enthalpy= } & 0.559628 \\ \text { Thermal correction to Gibbs Free Energy= } & 0.461404 \\ \text { Sum of electronic and zero-point Energies }= & -1665.354154 \\ \text { Sum of electronic and thermal Energies }= & -1665.321962 \\ \text { Sum of electronic and thermal Enthalpies= } & -1665.321018 \\ \text { Sum of electronic and thermal Free Energies }= & -1665.419242\end{array}$

01

N

C

C

C

C

C

C

C

C

C

C

C

C

C

C

C

$\mathrm{O}$

C

$\mathrm{O}$

C

C

$\mathrm{O}$

C

C

$\mathrm{O}$

C

C

$\mathrm{H}$

O

C

C

$\mathrm{O}$

$\mathrm{O}$

C

C

C

C

$\mathrm{H}$

$\mathrm{H}$

$\mathrm{H}$

$\mathrm{H}$

$\mathrm{H}$

$\mathrm{H}$

$\mathrm{H}$ $\begin{array}{rrr}-0.80769000 & -1.95637400 & -0.42675800 \\ -1.91294600 & -1.20956900 & -0.34085200 \\ -1.86322900 & 0.18299700 & -0.14587800 \\ -0.60413000 & 0.76810000 & -0.04083100 \\ 0.56583700 & -0.00054200 & -0.12893800 \\ 0.39803300 & -1.39233400 & -0.31215500 \\ -3.23081600 & -1.97820000 & -0.46273800 \\ -4.49562300 & -1.07197000 & -0.30958000 \\ -4.32587100 & 0.40223100 & -0.77706200 \\ -3.12922000 & 1.00509000 & -0.00392600 \\ 1.91594400 & 0.59855800 & -0.03012100 \\ 3.11513800 & -0.33569600 & 0.14184600 \\ 2.88810600 & -1.60759100 & -0.70908500 \\ 1.58073400 & -2.32494300 & -0.36854900 \\ 2.12369700 & 1.93437300 & -0.05281900 \\ 3.43604700 & 2.54174800 & 0.21975000 \\ 4.51412400 & 1.70924000 & 0.22128400 \\ 4.36423700 & 0.41392000 & -0.40946400 \\ -3.29112500 & -2.90629100 & 0.67156400 \\ -4.22866400 & -2.55721100 & 1.58941400 \\ -4.90838000 & -1.27019000 & 1.16146100 \\ -4.43366900 & -3.20978200 & 2.58310600 \\ 5.68211500 & -0.28504900 & -0.24234300 \\ 6.62199900 & -0.03979500 & 0.71728800 \\ 7.70585400 & -0.84908400 & 0.54376700 \\ 7.45801200 & -1.62271200 & -0.55129000 \\ 6.23894100 & -1.31977300 & -1.07695400 \\ -5.27889200 & -1.51034900 & -0.93913900 \\ 3.58544300 & 3.71670900 & 0.48970300 \\ 3.28065500 & -0.68661900 & 1.63871500 \\ -3.24765000 & -2.85955700 & -1.71267400 \\ -2.87370100 & 2.35533300 & -0.46976100 \\ -3.39536500 & 3.23531800 & 1.56116300 \\ -3.05873700 & 3.38448300 & 0.40630400 \\ -2.79900700 & 4.70966500 & -0.26339900 \\ -4.08373800 & 0.47287000 & -2.30044800 \\ -5.61448100 & 1.18652000 & -0.45611200 \\ -0.54070100 & 1.83737200 & 0.11905500 \\ -3.38566000 & 1.09068300 & 1.05602200 \\ 2.87544000 & -1.32564200 & -1.77112800 \\ 3.72937600 & -2.29245700 & -0.56905400 \\ 1.66260500 & -2.83112100 & 0.60285000 \\ 1.36745400 & -3.11394200 & -1.09620300 \\ 1.32461100 & 2.65597300 & -0.17053300\end{array}$

SI191 


$\begin{array}{rrrr}\mathrm{H} & 4.18886600 & 0.58802500 & -1.48099400 \\ \mathrm{H} & -5.98616900 & -1.35339400 & 1.31378600 \\ \mathrm{H} & -4.55543300 & -0.47757700 & 1.83054400 \\ \mathrm{H} & 6.67619200 & 0.66683500 & 1.52916200 \\ \mathrm{H} & 8.23428100 & -2.31966500 & -0.82525900 \\ \mathrm{H} & 5.79687800 & -1.76419000 & -1.95737000 \\ \mathrm{H} & 3.55538900 & 0.19981300 & 2.21688400 \\ \mathrm{H} & 2.35090000 & -1.08058800 & 2.05800000 \\ \mathrm{H} & 4.06413400 & -1.43860800 & 1.77092900 \\ \mathrm{H} & -3.21366200 & -2.25401200 & -2.62207000 \\ \mathrm{H} & -2.38215900 & -3.52394600 & -1.70139500 \\ \mathrm{H} & -4.16173500 & -3.46040900 & -1.72490800 \\ \mathrm{H} & -2.78162500 & 5.49757900 & 0.48903300 \\ \mathrm{H} & -1.85512100 & 4.68782400 & -0.81449200 \\ \mathrm{H} & -3.59570300 & 4.91480900 & -0.98629300 \\ \mathrm{H} & -4.05137500 & 1.51458000 & -2.63004700 \\ \mathrm{H} & -4.89809400 & -0.02680700 & -2.83605500 \\ \mathrm{H} & -3.14275700 & 0.00585200 & -2.60195700 \\ \mathrm{H} & -5.81518800 & 1.23653500 & 0.61784000 \\ \mathrm{H} & -5.54717800 & 2.21207600 & -0.83089300 \\ \mathrm{H} & -6.47534300 & 0.71502000 & -0.94299500\end{array}$

\section{Revised structure of xylogranatin G (17-5)-conformer 5}

Zero-point correction=

Thermal correction to Energy=

Thermal correction to Enthalpy=

Thermal correction to Gibbs Free Energy=

Sum of electronic and zero-point Energies=

Sum of electronic and thermal Energies $=$

Sum of electronic and thermal Enthalpies=

Sum of electronic and thermal Free Energies=
0.526435 (Hartree/Particle)

0.558483

0.559427

0.462267

$-1665.353102$

$-1665.321054$

$-1665.320110$

$-1665.417270$

01

$\begin{array}{lrrr}\mathrm{N} & -0.82546700 & -1.40255800 & -0.98071000 \\ \mathrm{C} & -1.89533700 & -0.72952900 & -0.53048800 \\ \mathrm{C} & -1.78990000 & 0.48589800 & 0.16059600 \\ \mathrm{C} & -0.51107700 & 0.99535400 & 0.40506400 \\ \mathrm{C} & 0.60921600 & 0.29296200 & -0.04371800 \\ \mathrm{C} & 0.39245100 & -0.91502600 & -0.74300500 \\ \mathrm{C} & -3.24662500 & -1.36986300 & -0.82628600 \\ \mathrm{C} & -4.48269400 & -0.65510800 & -0.19234400 \\ \mathrm{C} & -4.16408700 & 0.25492100 & 1.03225600 \\ \mathrm{C} & -3.02593800 & 1.21548200 & 0.62911100 \\ \mathrm{C} & 1.99827700 & 0.76141200 & 0.10616800 \\ \mathrm{C} & 3.09103300 & -0.27760400 & 0.38949300 \\ \mathrm{C} & 2.67792800 & -1.68608700 & -0.13850100 \\ \mathrm{C} & 1.60153800 & -1.66449300 & -1.23707200 \\ \mathrm{C} & 2.33243100 & 2.06191000 & -0.02741400 \\ \mathrm{C} & 3.72074800 & 2.53306800 & 0.11980700 \\ \mathrm{O} & 4.69971800 & 1.58354300 & 0.08436100\end{array}$

SI192 


\begin{tabular}{|c|c|c|c|}
\hline $\mathrm{C}$ & 4.36679300 & 0.23421500 & -0.34420900 \\
\hline $\mathrm{O}$ & -3.23210400 & -2.70077400 & -0.20773100 \\
\hline $\mathrm{C}$ & -4.44997000 & -3.02328400 & 0.30315900 \\
\hline $\mathrm{C}$ & -5.39883800 & -1.84838000 & 0.12409900 \\
\hline $\mathrm{O}$ & -4.67825500 & -4.09666300 & 0.80511000 \\
\hline $\mathrm{C}$ & 5.61903100 & -0.57136300 & -0.16635000 \\
\hline $\mathrm{C}$ & 6.17293900 & -1.40783000 & -1.09306600 \\
\hline $\mathrm{O}$ & 7.31260300 & -1.97681200 & -0.61110200 \\
\hline $\mathrm{C}$ & 7.50026800 & -1.48005100 & 0.64821500 \\
\hline $\mathrm{C}$ & 6.49985600 & -0.61787700 & 0.97340500 \\
\hline $\mathrm{H}$ & -4.93064200 & -0.01093500 & -0.95340600 \\
\hline $\mathrm{O}$ & 4.02539200 & 3.69607400 & 0.28726700 \\
\hline $\mathrm{C}$ & 3.30716100 & -0.35739000 & 1.92056800 \\
\hline $\mathrm{C}$ & -3.41574600 & -1.56423700 & -2.33850300 \\
\hline $\mathrm{O}$ & -3.51865800 & 2.06445900 & -0.46087600 \\
\hline $\mathrm{O}$ & -2.20113600 & 3.77889500 & 0.22149100 \\
\hline $\mathrm{C}$ & -3.01955900 & 3.32298200 & -0.55104300 \\
\hline $\mathrm{C}$ & -3.60375400 & 4.05650700 & -1.73218800 \\
\hline $\mathrm{C}$ & -5.41616000 & 1.07110900 & 1.41184300 \\
\hline $\mathrm{C}$ & -3.69604500 & -0.53389000 & 2.27779700 \\
\hline $\mathrm{H}$ & -0.39934900 & 1.92864300 & 0.94901500 \\
\hline $\mathrm{H}$ & -2.77610900 & 1.87500200 & 1.46372800 \\
\hline $\mathrm{H}$ & 3.56761800 & -2.21876900 & -0.48688800 \\
\hline $\mathrm{H}$ & 2.28490300 & -2.26875300 & 0.70173400 \\
\hline $\mathrm{H}$ & 1.30719700 & -2.67903000 & -1.51701000 \\
\hline $\mathrm{H}$ & 1.98696100 & -1.17722000 & -2.14486400 \\
\hline $\mathrm{H}$ & 1.59739200 & 2.83616000 & -0.22049800 \\
\hline $\mathrm{H}$ & 4.13214000 & 0.27630800 & -1.41705000 \\
\hline $\mathrm{H}$ & -6.06897800 & -2.08274900 & -0.71068100 \\
\hline $\mathrm{H}$ & -6.02639700 & -1.73467700 & 1.00912300 \\
\hline $\mathrm{H}$ & 5.89577600 & -1.68368100 & -2.09925800 \\
\hline $\mathrm{H}$ & 8.38179400 & -1.82663800 & 1.16412900 \\
\hline $\mathrm{H}$ & 6.40838900 & -0.05556300 & 1.89045600 \\
\hline $\mathrm{H}$ & 3.70510800 & 0.57730000 & 2.32437500 \\
\hline $\mathrm{H}$ & 2.35612800 & -0.56736600 & 2.41991900 \\
\hline $\mathrm{H}$ & 4.00124500 & -1.16699600 & 2.16508400 \\
\hline $\mathrm{H}$ & -3.38669800 & -0.59670200 & -2.84998600 \\
\hline $\mathrm{H}$ & -2.60493700 & -2.18906100 & -2.7174060 \\
\hline $\mathrm{H}$ & -4.37250900 & -2.04656500 & -2.5623270 \\
\hline $\mathrm{H}$ & -4.69349000 & 3.96859100 & -1.74190300 \\
\hline $\mathrm{H}$ & -3.30788800 & 5.10443300 & -1.68872100 \\
\hline $\mathrm{H}$ & -3.22839600 & 3.61095700 & -2.6594870 \\
\hline $\mathrm{H}$ & -5.18896700 & 1.76496300 & 2.22913800 \\
\hline $\mathrm{H}$ & -6.22156500 & 0.41524800 & $1.7565150 \mathrm{C}$ \\
\hline $\mathrm{H}$ & -5.79024100 & 1.65365300 & 0.5658850 \\
\hline $\mathrm{H}$ & -2.82576500 & -1.16467500 & 2.08281800 \\
\hline $\mathrm{H}$ & -3.43325200 & 0.16051600 & 3.0835480 \\
\hline $\mathrm{H}$ & -4.49531000 & -1.17711300 & 2.6564680 \\
\hline
\end{tabular}




\section{Revised structure of xylogranatin G (17-5)-conformer 6}

Zero-point correction=

Thermal correction to Energy=

Thermal correction to Enthalpy=

Thermal correction to Gibbs Free Energy=

Sum of electronic and zero-point Energies $=$

Sum of electronic and thermal Energies=

Sum of electronic and thermal Enthalpies=

Sum of electronic and thermal Free Energies=
0.526362 (Hartree/Particle)

0.558428

0.559373

0.462140

$-1665.352695$

$-1665.320628$

$-1665.319684$

$-1665.416916$

01

$\mathrm{N}$

C

C

C

C

C

C

C

C

C

C

C

C

C

C

C

$\mathrm{O}$

C

$\mathrm{O}$

C

C

$\mathrm{O}$

C

C

$\mathrm{O}$

C

C

$\mathrm{H}$

$\mathrm{O}$

C

C

O

$\mathrm{O}$

C

C

C

C

$\mathrm{H}$

$\mathrm{H}$

$\mathrm{H}$

$\mathrm{H}$

$\begin{array}{rrr}-0.82916900 & -1.41357300 & -0.95871400 \\ -1.89846400 & -0.73270600 & -0.51930000 \\ -1.79128300 & 0.48722300 & 0.16358200 \\ -0.51168400 & 0.99354200 & 0.40977200 \\ 0.60818900 & 0.28396100 & -0.02914200 \\ 0.38964700 & -0.92923400 & -0.71904500 \\ -3.25093000 & -1.36950700 & -0.81731900 \\ -4.48699500 & -0.64572800 & -0.19361500 \\ -4.17013000 & 0.27149700 & 1.02607900 \\ -3.02664300 & 1.22490900 & 0.62110800 \\ 1.99749900 & 0.75254900 & 0.11832700 \\ 3.09465500 & -0.28261100 & 0.40036500 \\ 2.66426600 & -1.69916600 & -0.08817500 \\ 1.59742900 & -1.69224600 & -1.19594800 \\ 2.33091000 & 2.05227600 & -0.02537600 \\ 3.72069400 & 2.52091100 & 0.11043200 \\ 4.69758500 & 1.56913300 & 0.06417800 \\ 4.35942800 & 0.22123900 & -0.36054500 \\ -3.24459900 & -2.69650400 & -0.19050100 \\ -4.46595400 & -3.01087500 & 0.31719800 \\ -5.40920900 & -1.83324800 & 0.12689200 \\ -4.70073800 & -4.08024900 & 0.82464000 \\ 5.61260100 & -0.58852000 & -0.19259500 \\ 6.60239200 & -0.39305500 & 0.72792000 \\ 7.59982000 & -1.30728100 & 0.56050700 \\ 7.24600600 & -2.10035300 & -0.49081500 \\ 6.04438700 & -1.70518000 & -0.99485700 \\ -4.92915200 & -0.00506600 & -0.96098800 \\ 4.03100600 & 3.68253800 & 0.27657000 \\ 3.34994700 & -0.33698500 & 1.92592300 \\ -3.41382700 & -1.57254100 & -2.32908600 \\ -3.51139900 & 2.06745600 & -0.47741000 \\ -2.18811900 & 3.78101600 & 0.19589000 \\ -3.00601500 & 3.32285600 & -0.57586700 \\ -3.58256200 & 4.04967800 & -1.76488100 \\ -5.42070400 & 1.09499700 & 1.39465000 \\ -3.71037100 & -0.51049000 & 2.27898100 \\ -0.39894700 & 1.93051300 & 0.94709400 \\ -2.77812100 & 1.88968600 & 1.45194100 \\ 3.54460700 & -2.26340000 & -0.40595100 \\ 2.25080600 & -2.24550500 & 0.76677400 \\ & & \end{array}$

SI194 


$\begin{array}{lrrr}\mathrm{H} & 1.29847500 & -2.70982400 & -1.45961100 \\ \mathrm{H} & 1.99088900 & -1.22300500 & -2.10974700 \\ \mathrm{H} & 1.59589900 & 2.82612300 & -0.21987200 \\ \mathrm{H} & 4.11019500 & 0.26300800 & -1.43053300 \\ \mathrm{H} & -6.07705300 & -2.07027000 & -0.70898500 \\ \mathrm{H} & -6.03974400 & -1.71129100 & 1.00869400 \\ \mathrm{H} & 6.75221800 & 0.34143000 & 1.50235100 \\ \mathrm{H} & 7.94484900 & -2.87842200 & -0.75448000 \\ \mathrm{H} & 5.53607000 & -2.14055900 & -1.84396100 \\ \mathrm{H} & 3.74721800 & 0.60741400 & 2.30660000 \\ \mathrm{H} & 2.41525000 & -0.55223800 & 2.45295800 \\ \mathrm{H} & 4.06406200 & -1.13203100 & 2.16119400 \\ \mathrm{H} & -3.37866200 & -0.60827800 & -2.84633700 \\ \mathrm{H} & -2.60374400 & -2.20284800 & -2.70041700 \\ \mathrm{H} & -4.37143400 & -2.05253000 & -2.55434700 \\ \mathrm{H} & -3.28245300 & 5.09666400 & -1.72832700 \\ \mathrm{H} & -3.20542000 & 3.59547300 & -2.68724800 \\ \mathrm{H} & -4.67260600 & 3.96624700 & -1.77820800 \\ \mathrm{H} & -5.19447500 & 1.79340500 & 2.20832600 \\ \mathrm{H} & -6.23013700 & 0.44451600 & 1.74008400 \\ \mathrm{H} & -5.78879900 & 1.67331700 & 0.54318500 \\ \mathrm{H} & -2.84191700 & -1.14621900 & 2.09202400 \\ \mathrm{H} & -3.44797000 & 0.18842600 & 3.08094600 \\ \mathrm{H} & -4.51382900 & -1.14775200 & 2.65885700\end{array}$

\section{NMR calculations of xylogranatin H (17-3)}

Proposed structure of xylogranatin H (17-3)-conformer 1

Zero-point correction $=$

Thermal correction to Energy=

Thermal correction to Enthalpy=

Thermal correction to Gibbs Free Energy=

Sum of electronic and zero-point Energies=

Sum of electronic and thermal Energies=

Sum of electronic and thermal Enthalpies=

Sum of electronic and thermal Free Energies=
0.512599 (Hartree/Particle)

0.541308

0.542252

0.454249

$-1513.911909$

$-1513.883200$

$-1513.882256$

$-1513.970260$

01

$\begin{array}{lrrr}\mathrm{N} & -1.26232800 & -1.34848600 & -0.64525800 \\ \mathrm{C} & -2.25035700 & -0.45578200 & -0.55110700 \\ \mathrm{C} & -2.01760000 & 0.90220500 & -0.28989000 \\ \mathrm{C} & -0.69406200 & 1.30313700 & -0.11243800 \\ \mathrm{C} & 0.35316900 & 0.37953600 & -0.20184700 \\ \mathrm{C} & 0.00762100 & -0.95824900 & -0.46622600 \\ \mathrm{C} & -3.65721400 & -0.99423000 & -0.77527600 \\ \mathrm{C} & -4.80665700 & 0.03067800 & -0.50802400 \\ \mathrm{C} & -4.43294300 & 1.23024100 & 0.41514300 \\ \mathrm{C} & -3.16902300 & 1.88144900 & -0.21594800 \\ \mathrm{C} & 1.78660200 & 0.84439100 & 0.03062800 \\ \mathrm{C} & 2.84073000 & -0.30825800 & 0.11809400\end{array}$

SI195 


\begin{tabular}{|c|c|c|c|}
\hline $\mathrm{C}$ & 2.44565800 & -1.46598000 & -0.82944900 \\
\hline $\mathrm{C}$ & 1.05883500 & -2.03767400 & -0.53718700 \\
\hline $\mathrm{C}$ & 2.23238500 & 1.92633400 & -0.98445500 \\
\hline $\mathrm{C}$ & 3.52735400 & 2.53402400 & -0.48412000 \\
\hline $\mathrm{O}$ & 4.43725900 & 1.62810700 & -0.03022800 \\
\hline $\mathrm{C}$ & 4.22116300 & 0.23728500 & -0.39700700 \\
\hline $\mathrm{O}$ & -3.88067500 & -2.06372300 & 0.20360700 \\
\hline $\mathrm{C}$ & -5.15957200 & -2.06024800 & 0.65897500 \\
\hline $\mathrm{C}$ & -5.90874500 & -0.88283100 & 0.05368700 \\
\hline $\mathrm{O}$ & -5.58048100 & -2.89490300 & 1.42264100 \\
\hline $\mathrm{C}$ & 5.44001700 & -0.51135300 & 0.05490300 \\
\hline $\mathrm{C}$ & 6.08386400 & -1.49763000 & -0.63595900 \\
\hline $\mathrm{O}$ & 7.15279300 & -1.96254300 & 0.07041700 \\
\hline $\mathrm{C}$ & 7.20089300 & -1.24487600 & 1.23234600 \\
\hline $\mathrm{C}$ & 6.18151700 & -0.34570000 & 1.27885000 \\
\hline $\mathrm{H}$ & -5.11333400 & 0.45529100 & -1.47120400 \\
\hline $\mathrm{O}$ & -2.71829300 & 3.03936300 & 0.48976900 \\
\hline $\mathrm{O}$ & 3.75722100 & 3.71765700 & -0.39714300 \\
\hline $\mathrm{H}$ & 1.78462700 & 1.34534400 & 1.00858200 \\
\hline $\mathrm{C}$ & 2.91917000 & -0.79300000 & 1.57777100 \\
\hline $\mathrm{C}$ & -3.76497600 & -1.62246100 & -2.17074400 \\
\hline $\mathrm{C}$ & -5.58589900 & 2.25456800 & 0.38669800 \\
\hline $\mathrm{C}$ & -4.15474800 & 0.82244300 & 1.87681800 \\
\hline $\mathrm{H}$ & -0.49572600 & 2.34442400 & 0.12068900 \\
\hline $\mathrm{H}$ & -3.43470400 & 2.18006000 & -1.24504800 \\
\hline $\mathrm{H}$ & 2.45939900 & -1.09952600 & -1.86598500 \\
\hline $\mathrm{H}$ & 3.19952700 & -2.25931100 & -0.76780200 \\
\hline $\mathrm{H}$ & 0.76633300 & -2.76027100 & -1.30548200 \\
\hline $\mathrm{H}$ & 1.05925300 & -2.59362900 & 0.40994400 \\
\hline $\mathrm{H}$ & 2.36920000 & 1.49168300 & -1.98314900 \\
\hline $\mathrm{H}$ & 1.50414300 & 2.73264000 & -1.07695000 \\
\hline $\mathrm{H}$ & 4.19714100 & 0.19625700 & -1.49254800 \\
\hline $\mathrm{H}$ & -6.56331500 & -1.27065400 & -0.73487500 \\
\hline $\mathrm{H}$ & -6.55481300 & -0.42711800 & 0.80521800 \\
\hline $\mathrm{H}$ & 5.91925400 & -1.95537600 & -1.59942700 \\
\hline $\mathrm{H}$ & 8.01180700 & -1.48630700 & 1.90130900 \\
\hline $\mathrm{H}$ & 5.98720300 & 0.36967800 & 2.06389000 \\
\hline $\mathrm{H}$ & -3.30994300 & 3.77662600 & 0.29677700 \\
\hline $\mathrm{H}$ & 3.54501300 & -1.68423800 & 1.67593700 \\
\hline $\mathrm{H}$ & 3.33497100 & -0.01338600 & 2.22429100 \\
\hline $\mathrm{H}$ & 1.92185000 & -1.03372000 & 1.95868900 \\
\hline $\mathrm{H}$ & -3.55880400 & -0.87357300 & -2.94292600 \\
\hline $\mathrm{H}$ & -3.03379100 & -2.42817200 & -2.25976100 \\
\hline $\mathrm{H}$ & -4.76712600 & -2.02921700 & -2.34054000 \\
\hline $\mathrm{H}$ & -5.37505800 & 3.10258600 & 1.04701700 \\
\hline $\mathrm{H}$ & -6.52301700 & 1.81150800 & 0.73714000 \\
\hline $\mathrm{H}$ & -5.76026600 & 2.63815200 & -0.62677700 \\
\hline $\mathrm{H}$ & -3.39557000 & 0.04082500 & 1.95795800 \\
\hline $\mathrm{H}$ & -3.80023600 & 1.69112700 & 2.43843200 \\
\hline $\mathrm{H}$ & -5.06341800 & 0.45792900 & 2.36550600 \\
\hline
\end{tabular}

SI196 
Proposed structure of xylogranatin H (17-3)-conformer 2

Zero-point correction $=$

Thermal correction to Energy=

Thermal correction to Enthalpy=

Thermal correction to Gibbs Free Energy=

Sum of electronic and zero-point Energies $=$

Sum of electronic and thermal Energies=

Sum of electronic and thermal Enthalpies=

Sum of electronic and thermal Free Energies=
0.512779 (Hartree/Particle)

0.541407

0.542351
0.454509

$-1513.911411$

$-1513.882782$

$-1513.881838$

$-1513.969681$

01

$\mathrm{N}$

C

C

C

C

C

C

C

C

C

C

C

C

C

C

C

O

C

O

C

C

O

C

C

O

C

C

$\mathrm{H}$

O

O

$\mathrm{H}$

C

C

C

C

$\mathrm{H}$

$\mathrm{H}$

$\mathrm{H}$

$\mathrm{H}$ \begin{tabular}{rrr}
-1.25542900 & -1.35638500 & -0.58874200 \\
-2.24332100 & -0.46127900 & -0.51163600 \\
-2.01245100 & 0.89952900 & -0.25792100 \\
-0.68476700 & 1.30018500 & -0.10177900 \\
0.36329600 & 0.37655900 & -0.17987300 \\
0.01472400 & -0.96665500 & -0.41253700 \\
-3.64568900 & -0.99434000 & -0.76680900 \\
-4.79124000 & 0.04372800 & -0.55463500 \\
-4.45446500 & 1.23747400 & 0.39104300 \\
-3.15991000 & 1.89370200 & -0.17021100 \\
1.79929800 & 0.84614600 & 0.02638000 \\
2.85366100 & -0.30506400 & 0.13340200 \\
2.44883200 & -1.48737000 & -0.77882200 \\
1.06393900 & -2.04907400 & -0.45912700 \\
2.23642700 & 1.90219900 & -1.01950200 \\
3.53551300 & 2.52081900 & -0.54292300 \\
4.44944100 & 1.62472000 & -0.07745100 \\
4.22904400 & 0.22616600 & -0.40953300 \\
-3.91422400 & -2.04433000 & 0.22235900 \\
-5.21614100 & -2.03102800 & 0.61104600 \\
-5.92837300 & -0.86116700 & -0.05178500 \\
-5.67632100 & -2.85055800 & 1.36835500 \\
5.45175200 & -0.51317500 & 0.04716200 \\
6.08661300 & -1.51701000 & -0.62661500 \\
7.16257800 & -1.96607400 & 0.07903100 \\
7.22470000 & -1.22043900 & 1.22245000 \\
6.20717300 & -0.31865600 & 1.25828900 \\
-5.04471500 & 0.47749100 & -1.52872500 \\
-2.78302900 & 3.07993600 & 0.52702300 \\
3.76474200 & 3.70592700 & -0.48147900 \\
1.80813400 & 1.37142800 & 0.99154500 \\
2.94704900 & -0.75094900 & 1.60454900 \\
-3.71206500 & -1.64391300 & -2.15564900 \\
-5.59736400 & 2.26990800 & 0.32008000 \\
-4.25106400 & 0.80720200 & 1.86064400 \\
-0.47764200 & 2.34901300 & 0.09279600 \\
-3.38995100 & 2.25748100 & -1.18118600 \\
2.45379300 & -1.14956500 & -1.82506100 \\
3.20228000 & -2.27967200 & -0.70204700 \\
& & \\
\hline
\end{tabular}

SI197 


$\begin{array}{lrrr}\mathrm{H} & 0.76447300 & -2.79351500 & -1.20332600 \\ \mathrm{H} & 1.07128800 & -2.57656200 & 0.50418000 \\ \mathrm{H} & 2.36519100 & 1.44257700 & -2.00790100 \\ \mathrm{H} & 1.50825800 & 2.70680400 & -1.12693600 \\ \mathrm{H} & 4.19314400 & 0.15909400 & -1.50342800 \\ \mathrm{H} & -6.53202400 & -1.25715000 & -0.87605100 \\ \mathrm{H} & -6.62087200 & -0.39561600 & 0.65058000 \\ \mathrm{H} & 5.91101000 & -1.99759900 & -1.57693800 \\ \mathrm{H} & 8.04290700 & -1.44657300 & 1.88786600 \\ \mathrm{H} & 6.02316500 & 0.41638600 & 2.02748900 \\ \mathrm{H} & -2.54198000 & 2.84858800 & 1.43504800 \\ \mathrm{H} & 3.57357800 & -1.63958200 & 1.71980800 \\ \mathrm{H} & 3.37015900 & 0.04517600 & 2.22574800 \\ \mathrm{H} & 1.95372300 & -0.98134400 & 2.00218000 \\ \mathrm{H} & -3.47292400 & -0.90921700 & -2.93181300 \\ \mathrm{H} & -2.98605700 & -2.45740300 & -2.20743300 \\ \mathrm{H} & -4.71133400 & -2.04433800 & -2.35360400 \\ \mathrm{H} & -5.34874700 & 3.15753300 & 0.90725900 \\ \mathrm{H} & -6.53328100 & 1.85826600 & 0.71086600 \\ \mathrm{H} & -5.77639100 & 2.59352900 & -0.71200700 \\ \mathrm{H} & -3.43244600 & 0.09349000 & 1.98617300 \\ \mathrm{H} & -4.04539400 & 1.68014400 & 2.49069900 \\ \mathrm{H} & -5.15586600 & 0.34788300 & 2.26857400\end{array}$

Proposed structure of xylogranatin H (17-3)-conformer 3

Zero-point correction $=$

Thermal correction to Energy=

Thermal correction to Enthalpy=

Thermal correction to Gibbs Free Energy=

Sum of electronic and zero-point Energies $=$

Sum of electronic and thermal Energies $=$

Sum of electronic and thermal Enthalpies $=$

Sum of electronic and thermal Free Energies=
0.512747 (Hartree/Particle)

0.541388

0.542332

0.454521

$-1513.911391$

$-1513.882750$

$-1513.881806$

$-1513.969617$

01

$\begin{array}{lrrr}\mathrm{N} & -1.26854300 & -1.35629800 & -0.60367100 \\ \mathrm{C} & -2.25071300 & -0.45602300 & -0.51440100 \\ \mathrm{C} & -2.01041500 & 0.90170100 & -0.25270400 \\ \mathrm{C} & -0.67947600 & 1.29390900 & -0.10300000 \\ \mathrm{C} & 0.36257500 & 0.36471800 & -0.19437100 \\ \mathrm{C} & 0.00475000 & -0.97451500 & -0.43298300 \\ \mathrm{C} & -3.65767900 & -0.97913800 & -0.76472300 \\ \mathrm{C} & -4.79587900 & 0.06385500 & -0.53757200 \\ \mathrm{C} & -4.44629700 & 1.24870200 & 0.41457700 \\ \mathrm{C} & -3.15161100 & 1.90169000 & -0.15020400 \\ \mathrm{C} & 1.80271600 & 0.82476600 & 0.00178500 \\ \mathrm{C} & 2.85279500 & -0.33163900 & 0.10246100 \\ \mathrm{C} & 2.43609500 & -1.50806900 & -0.81281700 \\ \mathrm{C} & 1.04787200 & -2.06141700 & -0.49056300 \\ \mathrm{C} & 2.23660100 & 1.87677200 & -1.04948800\end{array}$

SI198 


\begin{tabular}{|c|c|c|c|}
\hline $\mathrm{C}$ & 3.53520800 & 2.49586600 & -0.57520100 \\
\hline $\mathrm{O}$ & 4.44350900 & 1.59970500 & -0.09935300 \\
\hline $\mathrm{C}$ & 4.23289800 & 0.20219200 & -0.43345100 \\
\hline $\mathrm{O}$ & -3.92607800 & -2.03509300 & 0.21802100 \\
\hline $\mathrm{C}$ & -5.22543400 & -2.01726100 & 0.61508800 \\
\hline $\mathrm{C}$ & -5.93500900 & -0.83824900 & -0.03419900 \\
\hline $\mathrm{O}$ & -5.68557400 & -2.84001100 & 1.36890500 \\
\hline $\mathrm{C}$ & 5.45365600 & -0.52746700 & 0.04707800 \\
\hline $\mathrm{C}$ & 6.35749600 & -0.08645300 & 0.96984700 \\
\hline $\mathrm{O}$ & 7.34831700 & -1.00777100 & 1.14770400 \\
\hline $\mathrm{C}$ & 7.07579300 & -2.05438700 & 0.31878600 \\
\hline $\mathrm{C}$ & 5.93304200 & -1.81667100 & -0.38308600 \\
\hline $\mathrm{H}$ & -5.05301800 & 0.50620700 & -1.50683200 \\
\hline $\mathrm{O}$ & -2.76339000 & 3.08052600 & 0.55326000 \\
\hline $\mathrm{O}$ & 3.76911200 & 3.68019500 & -0.51988300 \\
\hline $\mathrm{H}$ & 1.82178300 & 1.35074900 & 0.96633100 \\
\hline $\mathrm{C}$ & 2.95350300 & -0.77907700 & 1.57245700 \\
\hline $\mathrm{C}$ & -3.73646700 & -1.61764300 & -2.15805200 \\
\hline $\mathrm{C}$ & -5.58368800 & 2.28809900 & 0.35834700 \\
\hline $\mathrm{C}$ & -4.23603400 & 0.80661900 & 1.87969900 \\
\hline $\mathrm{H}$ & -0.46494100 & 2.34025200 & 0.09700800 \\
\hline $\mathrm{H}$ & -3.38607200 & 2.27423100 & -1.15696800 \\
\hline $\mathrm{H}$ & 2.44431700 & -1.16906600 & -1.85852500 \\
\hline $\mathrm{H}$ & 3.17671900 & -2.31111400 & -0.73789700 \\
\hline $\mathrm{H}$ & 0.74122400 & -2.80083800 & -1.23688000 \\
\hline $\mathrm{H}$ & 1.05710400 & -2.59318800 & 0.47042700 \\
\hline $\mathrm{H}$ & 2.36408100 & 1.41349600 & -2.03626800 \\
\hline $\mathrm{H}$ & 1.50820300 & 2.68093400 & -1.15875900 \\
\hline $\mathrm{H}$ & 4.20942100 & 0.13424300 & -1.52888800 \\
\hline $\mathrm{H}$ & -6.54628100 & -1.22443800 & -0.85750000 \\
\hline $\mathrm{H}$ & -6.62023500 & -0.37405300 & 0.67614500 \\
\hline $\mathrm{H}$ & 6.44280400 & 0.82584200 & 1.53690500 \\
\hline $\mathrm{H}$ & 7.77993000 & -2.87127900 & 0.33788600 \\
\hline $\mathrm{H}$ & 5.49683900 & -2.47000700 & -1.12506100 \\
\hline $\mathrm{H}$ & -2.51770700 & 2.84110800 & 1.45795000 \\
\hline $\mathrm{H}$ & 3.56630000 & -1.67823500 & 1.68108400 \\
\hline $\mathrm{H}$ & 3.40233600 & 0.00905500 & 2.18591500 \\
\hline $\mathrm{H}$ & 1.96089900 & -0.99126000 & 1.98213100 \\
\hline $\mathrm{H}$ & -3.49780400 & -0.87845300 & -2.93008400 \\
\hline $\mathrm{H}$ & -3.01565500 & -2.43499800 & -2.22058700 \\
\hline $\mathrm{H}$ & -4.73931300 & -2.01063400 & -2.35278300 \\
\hline $\mathrm{H}$ & -5.32623200 & 3.17005100 & 0.95024600 \\
\hline $\mathrm{H}$ & -6.51943200 & 1.87900100 & 0.75219800 \\
\hline $\mathrm{H}$ & -5.76745800 & 2.62014500 & -0.67022400 \\
\hline $\mathrm{H}$ & -3.42078000 & 0.08732800 & 1.99485900 \\
\hline $\mathrm{H}$ & -4.02130000 & 1.67375800 & 2.51470800 \\
\hline $\mathrm{H}$ & -5.14087300 & 0.34956500 & 2.2900820 \\
\hline
\end{tabular}

Proposed structure of xylogranatin H (17-3)-conformer 4 SI199 


\begin{tabular}{|c|c|c|c|c|}
\hline \multicolumn{5}{|c|}{0.512603 (Hartree/Particle) } \\
\hline \multicolumn{3}{|c|}{ Thermal correction to Energy= } & 0.5 & 1309 \\
\hline \multicolumn{3}{|c|}{ Thermal correction to Enthalpy $=$} & 0.5 & 42253 \\
\hline \multicolumn{4}{|c|}{ Thermal correction to Gibbs Free Energy= } & 0.453454 \\
\hline \multicolumn{4}{|c|}{ Sum of electronic and zero-point Energies $=$} & -1513.910998 \\
\hline \multicolumn{4}{|c|}{ Sum of electronic and thermal Energies $=$} & -1513.882292 \\
\hline \multicolumn{4}{|c|}{ Sum of electronic and thermal Enthalpies $=$} & -1513.881348 \\
\hline \multirow{2}{*}{\multicolumn{4}{|c|}{ Sum of electronic and thermal Free Energies $=$}} & -1513.970148 \\
\hline & & & & \\
\hline $\mathrm{N}$ & -1.11385000 & -1.17344800 & -0.64 & 98700 \\
\hline $\mathrm{C}$ & -2.16320500 & -0.34847300 & -0.53 & 96900 \\
\hline $\mathrm{C}$ & -2.03770500 & 0.99076700 & -0.14 & 12700 \\
\hline $\mathrm{C}$ & -0.75375100 & 1.46262400 & 0.138 & 34300 \\
\hline $\mathrm{C}$ & 0.34956600 & 0.61532300 & 0.028 & 54000 \\
\hline $\mathrm{C}$ & 0.10934600 & -0.71535500 & -0.356 & 48700 \\
\hline $\mathrm{C}$ & -3.51483800 & -0.95022700 & -0.89 & 41300 \\
\hline $\mathrm{C}$ & -4.74447100 & -0.02817200 & -0.61 & 89300 \\
\hline $\mathrm{C}$ & -4.50635700 & 1.09931000 & 0.434 & 15400 \\
\hline $\mathrm{C}$ & -3.25578300 & 1.88442500 & -0.05 & 51300 \\
\hline $\mathrm{C}$ & 1.75818200 & 1.14278500 & 0.249 & 14000 \\
\hline $\mathrm{C}$ & 2.83748300 & 0.06760200 & 0.688 & 99000 \\
\hline $\mathrm{C}$ & 2.22055500 & -1.35106700 & 0.773 & 14600 \\
\hline $\mathrm{C}$ & 1.26101900 & -1.68737600 & -0.37 & 36300 \\
\hline $\mathrm{C}$ & 2.19786000 & 1.92739100 & -1.020 & 53700 \\
\hline $\mathrm{C}$ & 3.63106100 & 2.39151600 & -0.907 & 12700 \\
\hline $\mathrm{O}$ & 4.50864700 & 1.42366300 & -0.536 & 88200 \\
\hline $\mathrm{C}$ & 3.99640600 & 0.07311000 & -0.366 & 91000 \\
\hline $\mathrm{O}$ & -3.72232900 & -2.11834700 & -0.03 & 36100 \\
\hline $\mathrm{C}$ & -5.02304400 & -2.23694900 & 0.33 & 61000 \\
\hline $\mathrm{C}$ & -5.81341800 & -1.05688400 & -0.21 & 03000 \\
\hline $\mathrm{O}$ & -5.43054000 & -3.16385100 & 0.99 & 75700 \\
\hline $\mathrm{C}$ & 5.19269100 & -0.78197000 & -0.05 & 53400 \\
\hline $\mathrm{C}$ & 6.36356800 & -0.38163200 & 0.517 & 79900 \\
\hline $\mathrm{O}$ & 7.23590300 & -1.42613100 & 0.606 & 29500 \\
\hline $\mathrm{C}$ & 6.61474100 & -2.51481200 & 0.069 & 77000 \\
\hline $\mathrm{C}$ & 5.36627200 & -2.18096000 & -0.35 & 28800 \\
\hline $\mathrm{H}$ & -5.02233900 & 0.46560800 & -1.55 & 50600 \\
\hline $\mathrm{O}$ & -2.92417000 & 2.99552700 & 0.78 & 30200 \\
\hline $\mathrm{O}$ & 4.02027500 & 3.52169300 & -1.093 & 22300 \\
\hline $\mathrm{H}$ & 1.69872700 & 1.88584700 & 1.052 & 59900 \\
\hline $\mathrm{C}$ & 3.38622700 & 0.45127000 & 2.076 & 27500 \\
\hline $\mathrm{C}$ & -3.49818300 & -1.45139800 & -2.34 & 50000 \\
\hline $\mathrm{C}$ & -5.72239000 & 2.04831200 & 0.426 & 35400 \\
\hline $\mathrm{C}$ & -4.28498900 & 0.57300900 & 1.867 & 39800 \\
\hline $\mathrm{H}$ & -0.63280600 & 2.49284700 & 0.458 & 92300 \\
\hline $\mathrm{H}$ & -3.48292300 & 2.26362600 & -1.06 & 12900 \\
\hline $\mathrm{H}$ & 3.02096900 & -2.09313700 & 0.846 & 00800 \\
\hline $\mathrm{H}$ & 1.65667400 & -1.42146300 & 1.711 & 41500 \\
\hline $\mathrm{H}$ & 1.77733400 & -1.65113400 & -1.34 & 86900 \\
\hline $\mathrm{H}$ & 0.86323700 & -2.70091900 & -0.27 & 83500 \\
\hline $\mathrm{H}$ & 2.09776000 & 1.29158900 & -1.905 & 83500 \\
\hline
\end{tabular}




$\begin{array}{lrrr}\mathrm{H} & 1.56772900 & 2.80405800 & -1.17635200 \\ \mathrm{H} & 3.59182500 & -0.25708000 & -1.33186700 \\ \mathrm{H} & -6.39246200 & -1.40887200 & -1.07211500 \\ \mathrm{H} & -6.53219700 & -0.71464000 & 0.53470100 \\ \mathrm{H} & 6.72111900 & 0.57184800 & 0.87065400 \\ \mathrm{H} & 7.18436000 & -3.43067100 & 0.06217400 \\ \mathrm{H} & 4.66095000 & -2.84314700 & -0.84162500 \\ \mathrm{H} & -3.55547900 & 3.70779700 & 0.62296700 \\ \mathrm{H} & 4.08159300 & -0.30530900 & 2.45063200 \\ \mathrm{H} & 3.91126700 & 1.41155000 & 2.05303600 \\ \mathrm{H} & 2.55996700 & 0.53365900 & 2.79031000 \\ \mathrm{H} & -3.30065500 & -0.62217200 & -3.03721300 \\ \mathrm{H} & -2.70889900 & -2.19697900 & -2.46342200 \\ \mathrm{H} & -4.45798800 & -1.90417200 & -2.61851400 \\ \mathrm{H} & -5.60681100 & 2.84190400 & 1.17236800 \\ \mathrm{H} & -6.64565800 & 1.51708800 & 0.67654600 \\ \mathrm{H} & -5.86501000 & 2.51396800 & -0.55723700 \\ \mathrm{H} & -3.47910800 & -0.16252900 & 1.92533100 \\ \mathrm{H} & -4.02489200 & 1.40525500 & 2.52724900 \\ \mathrm{H} & -5.19268700 & 0.10626400 & 2.26184000\end{array}$

\section{Proposed structure of xylogranatin H (17-3)-conformer 5}

$\begin{array}{lc}\text { Zero-point correction }= & 0.512779 \text { (Hartree/Particle) } \\ \text { Thermal correction to Energy= } & 0.541394 \\ \text { Thermal correction to Enthalpy= } & 0.542338 \\ \text { Thermal correction to Gibbs Free Energy= } & 0.454141 \\ \text { Sum of electronic and zero-point Energies }= & -1513.910895 \\ \text { Sum of electronic and thermal Energies }= & -1513.882280 \\ \text { Sum of electronic and thermal Enthalpies }= & -1513.881336 \\ \text { Sum of electronic and thermal Free Energies }= & -1513.969533\end{array}$
01

$\begin{array}{lrrr}\mathrm{N} & -1.13453100 & -1.15451800 & -0.69591600 \\ \mathrm{C} & -2.17846200 & -0.32959300 & -0.53679300 \\ \mathrm{C} & -2.03936800 & 0.99438400 & -0.09713600 \\ \mathrm{C} & -0.74061100 & 1.45794900 & 0.14223800 \\ \mathrm{C} & 0.35562500 & 0.61428600 & -0.03341000 \\ \mathrm{C} & 0.09743800 & -0.70740200 & -0.43901200 \\ \mathrm{C} & -3.53757800 & -0.90480900 & -0.90582600 \\ \mathrm{C} & -4.75076900 & 0.02507700 & -0.59362700 \\ \mathrm{C} & -4.51317800 & 1.09311000 & 0.51766600 \\ \mathrm{C} & -3.24901800 & 1.89610600 & 0.09578000 \\ \mathrm{C} & 1.77789700 & 1.12041700 & 0.12642500 \\ \mathrm{C} & 2.83057300 & 0.04025100 & 0.61500700 \\ \mathrm{C} & 2.22440700 & -1.38826200 & 0.63103800 \\ \mathrm{C} & 1.25143900 & -1.67198500 & -0.52373700 \\ \mathrm{C} & 2.21867300 & 1.81329400 & -1.19388100 \\ \mathrm{C} & 3.63836300 & 2.31974200 & -1.07764900 \\ \mathrm{O} & 4.52257000 & 1.41095300 & -0.59010200 \\ \mathrm{C} & 4.04587400 & 0.05290400 & -0.37313200 \\ & & & \mathrm{SI} 201\end{array}$




\begin{tabular}{|c|c|c|c|}
\hline $\mathrm{O}$ & -3.76455000 & -2.09447000 & -0.07721700 \\
\hline $\mathrm{C}$ & -5.07435500 & -2.21140000 & 0.26475200 \\
\hline $\mathrm{C}$ & -5.84150400 & -1.00572700 & -0.25783400 \\
\hline $\mathrm{O}$ & -5.50133300 & -3.15253100 & 0.88837800 \\
\hline $\mathrm{C}$ & 5.25345400 & -0.74167700 & 0.03083500 \\
\hline $\mathrm{C}$ & 5.60152700 & -1.97452600 & -0.44284700 \\
\hline $\mathrm{O}$ & 6.76388600 & -2.40029200 & 0.12528600 \\
\hline $\mathrm{C}$ & 7.17739600 & -1.40860800 & 0.96981600 \\
\hline $\mathrm{C}$ & 6.29692200 & -0.37220300 & 0.95357000 \\
\hline $\mathrm{H}$ & -5.00582400 & 0.57403500 & -1.50732200 \\
\hline $\mathrm{O}$ & -2.96127300 & 2.98880500 & 0.96756300 \\
\hline $\mathrm{O}$ & 4.00615600 & 3.44076500 & -1.34318300 \\
\hline $\mathrm{H}$ & 1.75509000 & 1.91418800 & 0.88204000 \\
\hline $\mathrm{C}$ & 3.28124400 & 0.40621400 & 2.04223300 \\
\hline $\mathrm{C}$ & -3.52837800 & -1.36106800 & -2.37130600 \\
\hline $\mathrm{C}$ & -5.71627000 & 2.05678100 & 0.55177100 \\
\hline $\mathrm{C}$ & -4.32009300 & 0.47510300 & 1.92025400 \\
\hline $\mathrm{H}$ & -0.59790900 & 2.48592800 & 0.46544500 \\
\hline $\mathrm{H}$ & -3.47800500 & 2.38892800 & -0.85918500 \\
\hline $\mathrm{H}$ & 3.03557800 & -2.12351800 & 0.64454200 \\
\hline $\mathrm{H}$ & 1.67661500 & -1.52135800 & 1.57167200 \\
\hline $\mathrm{H}$ & 1.75700200 & -1.58059100 & -1.49641500 \\
\hline $\mathrm{H}$ & 0.86223900 & -2.69233400 & -0.47053100 \\
\hline $\mathrm{H}$ & 2.14862300 & 1.11276300 & -2.03591000 \\
\hline $\mathrm{H}$ & 1.57352200 & 2.66263700 & -1.42341800 \\
\hline $\mathrm{H}$ & 3.70266200 & -0.33935100 & -1.33815700 \\
\hline $\mathrm{H}$ & -6.39696800 & -1.31952600 & -1.14866000 \\
\hline $\mathrm{H}$ & -6.58026300 & -0.68262700 & 0.47661200 \\
\hline $\mathrm{H}$ & 5.15277000 & -2.64595400 & -1.15914800 \\
\hline $\mathrm{H}$ & 8.10447800 & -1.58999400 & 1.49036300 \\
\hline $\mathrm{H}$ & 6.38295100 & 0.55464800 & 1.50044200 \\
\hline $\mathrm{H}$ & -2.72195400 & 2.64132000 & 1.83823400 \\
\hline $\mathrm{H}$ & 3.93196100 & -0.36414900 & 2.46526000 \\
\hline $\mathrm{H}$ & 3.82017000 & 1.35916000 & 2.06299600 \\
\hline $\mathrm{H}$ & 2.40525100 & 0.49910100 & 2.69332300 \\
\hline $\mathrm{H}$ & -3.31801700 & -0.51398400 & -3.03279100 \\
\hline $\mathrm{H}$ & -2.75093200 & -2.11489400 & -2.50894900 \\
\hline $\mathrm{H}$ & -4.49474500 & -1.79006600 & -2.65439400 \\
\hline $\mathrm{H}$ & -5.53660300 & 2.86826500 & 1.26152500 \\
\hline $\mathrm{H}$ & -6.63346800 & 1.54144000 & 0.85384000 \\
\hline $\mathrm{H}$ & -5.89154500 & 2.50797200 & -0.43193700 \\
\hline $\mathrm{H}$ & -3.46052300 & -0.19830900 & 1.97459700 \\
\hline $\mathrm{H}$ & -4.18819900 & 1.26271200 & 2.67091700 \\
\hline $\mathrm{H}$ & -5.20338100 & -0.09081600 & 2.2294450 \\
\hline
\end{tabular}

\section{Proposed structure of xylogranatin H (17-3)-conformer 6}

Zero-point correction=

Thermal correction to Energy=

Thermal correction to Enthalpy=
0.512791 (Hartree/Particle)

0.541409

0.542353 


$\begin{array}{lc}\text { Thermal correction to Gibbs Free Energy= } & 0.453857 \\ \text { Sum of electronic and zero-point Energies }= & -1513.910536 \\ \text { Sum of electronic and thermal Energies }= & -1513.881918 \\ \text { Sum of electronic and thermal Enthalpies= } & -1513.880974 \\ \text { Sum of electronic and thermal Free Energies }= & -1513.969471\end{array}$

01

\begin{tabular}{|c|c|c|c|}
\hline $\mathrm{N}$ & -1.10580900 & -1.18133900 & -0.58484800 \\
\hline $\mathrm{C}$ & -2.15545500 & -0.35423100 & -0.49962800 \\
\hline $\mathrm{C}$ & -2.03328100 & 0.98808300 & -0.11291300 \\
\hline $\mathrm{C}$ & -0.74435500 & 1.46410400 & 0.14928200 \\
\hline $\mathrm{C}$ & 0.36054900 & 0.61796600 & 0.04762400 \\
\hline $\mathrm{C}$ & 0.11734400 & -0.72164300 & -0.30490000 \\
\hline $\mathrm{C}$ & -3.50036800 & -0.94857800 & -0.88985700 \\
\hline $\mathrm{C}$ & -4.72475700 & -0.00976000 & -0.65794200 \\
\hline $\mathrm{C}$ & -4.52609200 & 1.10489600 & 0.41455800 \\
\hline $\mathrm{C}$ & -3.25008000 & 1.89351800 & 0.00112800 \\
\hline $\mathrm{C}$ & 1.77123900 & 1.15146100 & 0.23780600 \\
\hline $\mathrm{C}$ & 2.85467200 & 0.08757500 & 0.69405500 \\
\hline $\mathrm{C}$ & 2.23719100 & -1.32708200 & 0.82682700 \\
\hline $\mathrm{C}$ & 1.26684100 & -1.69630900 & -0.30404200 \\
\hline $\mathrm{C}$ & 2.19690400 & 1.90084600 & -1.05776500 \\
\hline $\mathrm{C}$ & 3.63214100 & 2.36571900 & -0.97219600 \\
\hline $\mathrm{O}$ & 4.51273100 & 1.40641400 & -0.58639900 \\
\hline $\mathrm{C}$ & 4.00092300 & 0.06201900 & -0.37450700 \\
\hline $\mathrm{O}$ & -3.75345900 & -2.10307900 & -0.02027600 \\
\hline $\mathrm{C}$ & -5.07389700 & -2.20936300 & 0.28203600 \\
\hline $\mathrm{C}$ & -5.82471900 & -1.02850800 & -0.31553300 \\
\hline $\mathrm{O}$ & -5.52033100 & -3.12512700 & 0.92933900 \\
\hline $\mathrm{C}$ & 5.19901000 & -0.78706300 & -0.05791700 \\
\hline $\mathrm{C}$ & 6.37739000 & -0.37376200 & 0.49459100 \\
\hline $\mathrm{O}$ & 7.24854300 & -1.41738400 & 0.60101800 \\
\hline $\mathrm{C}$ & 6.61919800 & -2.51882000 & 0.10146300 \\
\hline $\mathrm{C}$ & 5.36635500 & -2.19402600 & -0.32178500 \\
\hline $\mathrm{H}$ & -4.94978600 & 0.49941100 & -1.60205100 \\
\hline $\mathrm{O}$ & -2.99334700 & 3.02312200 & 0.83463900 \\
\hline $\mathrm{O}$ & 4.02020700 & 3.48999000 & -1.19150200 \\
\hline $\mathrm{H}$ & 1.72175400 & 1.91649600 & 1.02120000 \\
\hline $\mathrm{C}$ & 3.42054700 & 0.50962200 & 2.06409300 \\
\hline $\mathrm{C}$ & -3.44073200 & -1.46591600 & -2.33370900 \\
\hline $\mathrm{C}$ & -5.73142600 & 2.06523500 & 0.36829400 \\
\hline $\mathrm{C}$ & -4.37815500 & 0.54716900 & 1.84755600 \\
\hline $\mathrm{H}$ & -0.61516000 & 2.50531900 & 0.43354900 \\
\hline $\mathrm{H}$ & -3.44804900 & 2.34443400 & -0.98108400 \\
\hline $\mathrm{H}$ & 3.03763500 & -2.06752700 & 0.91376800 \\
\hline $\mathrm{H}$ & 1.68251300 & -1.36927700 & 1.77235900 \\
\hline $\mathrm{H}$ & 1.77422000 & -1.69167800 & -1.27980800 \\
\hline $\mathrm{H}$ & 0.86772000 & -2.70534800 & -0.16833400 \\
\hline $\mathrm{H}$ & 2.08615700 & 1.24157400 & -1.92842600 \\
\hline $\mathrm{H}$ & 1.56639400 & 2.77412900 & -1.23035500 \\
\hline $\mathrm{H}$ & 3.58440300 & -0.29336700 & -1.32531600 \\
\hline $\mathrm{H}$ & -6.35019500 & -1.38062700 & -1.21022600 \\
\hline
\end{tabular}




$\begin{array}{lrrr}\mathrm{H} & -6.58762800 & -0.67684200 & 0.38009600 \\ \mathrm{H} & 6.74112900 & 0.58819200 & 0.81683800 \\ \mathrm{H} & 7.18713700 & -3.43569400 & 0.11168800 \\ \mathrm{H} & 4.65447700 & -2.86748200 & -0.77821200 \\ \mathrm{H} & -2.78348100 & 2.71373100 & 1.72702800 \\ \mathrm{H} & 4.12055000 & -0.23640100 & 2.45065100 \\ \mathrm{H} & 3.94521200 & 1.46869500 & 2.00773800 \\ \mathrm{H} & 2.60334200 & 0.61175600 & 2.78611300 \\ \mathrm{H} & -3.21016400 & -0.64665200 & -3.02292700 \\ \mathrm{H} & -2.65735700 & -2.22201400 & -2.41317300 \\ \mathrm{H} & -4.39598200 & -1.91011200 & -2.63077700 \\ \mathrm{H} & -5.57700200 & 2.90618400 & 1.04908400 \\ \mathrm{H} & -6.65724600 & 1.56001100 & 0.66095900 \\ \mathrm{H} & -5.87466000 & 2.47448500 & -0.63866700 \\ \mathrm{H} & -3.51884200 & -0.11955800 & 1.95866000 \\ \mathrm{H} & -4.27351300 & 1.36616700 & 2.56833600 \\ \mathrm{H} & -5.26957400 & -0.00903600 & 2.15097100\end{array}$

\section{Proposed structure of xylogranatin H (17-3)-conformer 7}

Zero-point correction $=$

Thermal correction to Energy=

Thermal correction to Enthalpy=

Thermal correction to Gibbs Free Energy=

Sum of electronic and zero-point Energies=

Sum of electronic and thermal Energies=

Sum of electronic and thermal Enthalpies=

Sum of electronic and thermal Free Energies=
0.512804 (Hartree/Particle)

0.541468

0.542412

0.454362

$-1513.909660$

$-1513.880997$

$-1513.880053$

$-1513.968103$

01

$\begin{array}{lrrr}\mathrm{N} & 1.26491800 & -1.33953200 & 0.73588200 \\ \mathrm{C} & 2.28803000 & -0.52191100 & 0.46074800 \\ \mathrm{C} & 2.09115500 & 0.77984800 & -0.02195000 \\ \mathrm{C} & 0.77269700 & 1.19343000 & -0.22630000 \\ \mathrm{C} & -0.30528700 & 0.34974600 & 0.04436600 \\ \mathrm{C} & 0.00643800 & -0.93692800 & 0.52712500 \\ \mathrm{C} & 3.67832200 & -1.11057900 & 0.71230600 \\ \mathrm{C} & 4.83557500 & -0.17916300 & 0.23075600 \\ \mathrm{C} & 4.55626900 & 1.34421600 & 0.34901600 \\ \mathrm{C} & 3.22569600 & 1.72553800 & -0.35730300 \\ \mathrm{C} & -1.72888700 & 0.82511300 & -0.22255800 \\ \mathrm{C} & -2.82250700 & -0.28496500 & -0.08454700 \\ \mathrm{C} & -2.43548900 & -1.27753500 & 1.03773300 \\ \mathrm{C} & -1.07904900 & -1.94458400 & 0.81238500 \\ \mathrm{C} & -2.10518700 & 2.07654900 & 0.60903600 \\ \mathrm{C} & -3.39290100 & 2.64219400 & 0.04434300 \\ \mathrm{O} & -4.34708700 & 1.70987100 & -0.22586200 \\ \mathrm{C} & -4.16731300 & 0.39240200 & 0.36496400 \\ \mathrm{O} & 3.79960800 & -2.31155100 & -0.11970700 \\ \mathrm{C} & 4.62233700 & -2.12687900 & -1.18542700 \\ \mathrm{C} & 5.14096100 & -0.70442200 & -1.18540900\end{array}$




\begin{tabular}{|c|c|c|c|}
\hline $\mathrm{O}$ & 4.85260600 & -3.00647300 & -1.97975900 \\
\hline $\mathrm{C}$ & -5.42415200 & -0.37364900 & 0.07647000 \\
\hline $\mathrm{C}$ & -6.08067300 & -1.20121000 & 0.94179300 \\
\hline $\mathrm{O}$ & -7.18549300 & -1.73777100 & 0.35131400 \\
\hline $\mathrm{C}$ & -7.24373600 & -1.22809900 & -0.91526900 \\
\hline $\mathrm{C}$ & -6.19581000 & -0.39073500 & -1.13989900 \\
\hline $\mathrm{H}$ & 5.70380100 & -0.39700200 & 0.86594700 \\
\hline $\mathrm{O}$ & 3.30673200 & 1.75937000 & -1.79639500 \\
\hline $\mathrm{O}$ & -3.58165100 & 3.80241800 & -0.23832100 \\
\hline $\mathrm{H}$ & -1.74429800 & 1.15449300 & -1.27070000 \\
\hline $\mathrm{C}$ & -2.96266600 & -1.00806300 & -1.43699300 \\
\hline $\mathrm{C}$ & 3.81923400 & -1.60581900 & 2.15270300 \\
\hline $\mathrm{C}$ & 4.43230300 & 1.76604800 & 1.83247200 \\
\hline $\mathrm{C}$ & 5.73373600 & 2.13299600 & -0.25831800 \\
\hline $\mathrm{H}$ & 0.59490200 & 2.19111500 & -0.62278300 \\
\hline $\mathrm{H}$ & 2.94509800 & 2.73210700 & -0.01016700 \\
\hline $\mathrm{H}$ & -2.40359800 & -0.73886400 & 1.99573100 \\
\hline $\mathrm{H}$ & -3.21698400 & -2.04006700 & 1.13367300 \\
\hline $\mathrm{H}$ & -0.78567700 & -2.53615600 & 1.68516600 \\
\hline $\mathrm{H}$ & -1.12822100 & -2.65325000 & -0.02508000 \\
\hline $\mathrm{H}$ & -2.22652800 & 1.81862900 & 1.66904400 \\
\hline $\mathrm{H}$ & -1.34799800 & 2.85898300 & 0.54897200 \\
\hline $\mathrm{H}$ & -4.11110200 & 0.53525100 & 1.45068100 \\
\hline $\mathrm{H}$ & 6.20058400 & -0.69662500 & -1.44875000 \\
\hline $\mathrm{H}$ & 4.59708500 & -0.15139400 & -1.95746900 \\
\hline $\mathrm{H}$ & -5.90304300 & -1.49353500 & 1.96547400 \\
\hline $\mathrm{H}$ & -8.08211600 & -1.54857100 & -1.51342200 \\
\hline $\mathrm{H}$ & -6.00071100 & 0.17135500 & -2.04089700 \\
\hline $\mathrm{H}$ & 3.81412700 & 2.53763100 & -2.06282800 \\
\hline $\mathrm{H}$ & -3.62053400 & -1.87838700 & -1.36473800 \\
\hline $\mathrm{H}$ & -3.37275600 & -0.33493300 & -2.19682400 \\
\hline $\mathrm{H}$ & -1.98664100 & -1.34797200 & -1.79673700 \\
\hline $\mathrm{H}$ & 3.73738900 & -0.78258200 & 2.86672500 \\
\hline $\mathrm{H}$ & 3.02997800 & -2.32999600 & 2.36311000 \\
\hline $\mathrm{H}$ & 4.79238600 & -2.08868500 & 2.28275800 \\
\hline $\mathrm{H}$ & 4.37941400 & 2.85759900 & 1.91301000 \\
\hline $\mathrm{H}$ & 5.30503000 & 1.43348300 & 2.40427100 \\
\hline $\mathrm{H}$ & 3.53872400 & 1.36005900 & 2.31357800 \\
\hline $\mathrm{H}$ & 5.91687700 & 1.87612200 & -1.30501900 \\
\hline $\mathrm{H}$ & 5.55291800 & 3.21353400 & -0.19464600 \\
\hline $\mathrm{H}$ & 6.65517400 & 1.92622500 & 0.29712700 \\
\hline
\end{tabular}

\section{Proposed structure of xylogranatin H (17-3)-conformer 8}

Zero-point correction $=$

Thermal correction to Energy=

Thermal correction to Enthalpy=

Thermal correction to Gibbs Free Energy=

Sum of electronic and zero-point Energies=

Sum of electronic and thermal Energies=
0.512763 (Hartree/Particle)

0.541444

0.542388

0.454328

$-1513.909624$

$-1513.880943$

SI205 
$\begin{array}{lc}\text { Sum of electronic and thermal Enthalpies }= & -1513.879999 \\ \text { Sum of electronic and thermal Free Energies }= & -1513.968059\end{array}$

01

\begin{tabular}{|c|c|c|c|}
\hline $\mathrm{N}$ & 1.27808200 & -1.34106000 & 0.74434500 \\
\hline $\mathrm{C}$ & 2.29524400 & -0.51914800 & 0.46010300 \\
\hline $\mathrm{C}$ & 2.08869400 & 0.78076700 & -0.02376400 \\
\hline $\mathrm{C}$ & 0.76682500 & 1.18842200 & -0.21763700 \\
\hline $\mathrm{C}$ & -0.30499300 & 0.34028800 & 0.06340800 \\
\hline $\mathrm{C}$ & 0.01638500 & -0.94406900 & 0.54456700 \\
\hline $\mathrm{C}$ & 3.69014400 & -1.10047100 & 0.70332400 \\
\hline $\mathrm{C}$ & 4.83935200 & -0.16536800 & 0.20981600 \\
\hline $\mathrm{C}$ & 4.55425400 & 1.35711500 & 0.32557000 \\
\hline $\mathrm{C}$ & 3.21636800 & 1.73036000 & -0.37115300 \\
\hline $\mathrm{C}$ & -1.73288200 & 0.80992400 & -0.18836600 \\
\hline $\mathrm{C}$ & -2.82207700 & -0.30508700 & -0.04959700 \\
\hline $\mathrm{C}$ & -2.42279300 & -1.29758300 & 1.06914500 \\
\hline $\mathrm{C}$ & -1.06277000 & -1.95578500 & 0.83611300 \\
\hline $\mathrm{C}$ & -2.10565900 & 2.05290200 & 0.65730700 \\
\hline $\mathrm{C}$ & -3.39268900 & 2.62319000 & 0.09837900 \\
\hline $\mathrm{O}$ & -4.34160800 & 1.69057000 & -0.18802900 \\
\hline $\mathrm{C}$ & -4.17197600 & 0.37104400 & 0.39608700 \\
\hline $\mathrm{O}$ & 3.81112800 & -2.30387500 & -0.12506200 \\
\hline $\mathrm{C}$ & 4.62472400 & -2.11900200 & -1.19776900 \\
\hline $\mathrm{C}$ & 5.13580100 & -0.69383800 & -1.20704700 \\
\hline $\mathrm{O}$ & 4.85361200 & -3.00046300 & -1.99040200 \\
\hline $\mathrm{C}$ & -5.42688300 & -0.38783800 & 0.07584700 \\
\hline $\mathrm{C}$ & -6.33484700 & -0.08940700 & -0.89852000 \\
\hline $\mathrm{O}$ & -7.36004600 & -0.99002200 & -0.88945800 \\
\hline $\mathrm{C}$ & -7.10528500 & -1.87710900 & 0.11298100 \\
\hline $\mathrm{C}$ & -5.94028500 & -1.55799000 & 0.74218200 \\
\hline $\mathrm{H}$ & 5.71353900 & -0.37741500 & 0.83877900 \\
\hline $\mathrm{O}$ & 3.28558300 & 1.75973300 & -1.81093100 \\
\hline $\mathrm{O}$ & -3.58581500 & 3.78574500 & -0.17077900 \\
\hline $\mathrm{H}$ & -1.75889000 & 1.14703300 & -1.23376500 \\
\hline $\mathrm{C}$ & -2.96923900 & -1.02172000 & -1.40451900 \\
\hline $\mathrm{C}$ & 3.84385800 & -1.58973600 & 2.14448500 \\
\hline $\mathrm{C}$ & 4.44036900 & 1.78318600 & 1.80861800 \\
\hline $\mathrm{C}$ & 5.72323800 & 2.14914800 & -0.29381000 \\
\hline $\mathrm{H}$ & 0.58116400 & 2.18480000 & -0.61389300 \\
\hline $\mathrm{H}$ & 2.93416200 & 2.73681700 & -0.02501200 \\
\hline $\mathrm{H}$ & -2.39411100 & -0.76264300 & 2.02919200 \\
\hline $\mathrm{H}$ & -3.19170600 & -2.07131300 & 1.16502900 \\
\hline $\mathrm{H}$ & -0.76195200 & -2.54684100 & 1.70674100 \\
\hline $\mathrm{H}$ & -1.11385500 & -2.66370000 & -0.00194300 \\
\hline $\mathrm{H}$ & -2.22604100 & 1.78414100 & 1.71466200 \\
\hline $\mathrm{H}$ & -1.34804100 & 2.83544600 & 0.60431000 \\
\hline $\mathrm{H}$ & -4.12893200 & 0.50659900 & 1.48462100 \\
\hline $\mathrm{H}$ & 6.19314300 & -0.68136700 & -1.47920900 \\
\hline $\mathrm{H}$ & 4.58254800 & -0.14633100 & -1.97637500 \\
\hline $\mathrm{H}$ & -6.40078400 & 0.70592800 & -1.62252600 \\
\hline $\mathrm{H}$ & -7.83671900 & -2.65718700 & 0.25429600 \\
\hline
\end{tabular}




$\begin{array}{lrrr}\mathrm{H} & -5.51025400 & -2.08115500 & 1.58419700 \\ \mathrm{H} & 3.78710800 & 2.53945700 & -2.08414500 \\ \mathrm{H} & -3.61313200 & -1.90232500 & -1.32884400 \\ \mathrm{H} & -3.40564100 & -0.34995200 & -2.15092500 \\ \mathrm{H} & -1.99347200 & -1.34350500 & -1.78152200 \\ \mathrm{H} & 3.76312600 & -0.76433800 & 2.85612200 \\ \mathrm{H} & 3.05969300 & -2.31700400 & 2.36314100 \\ \mathrm{H} & 4.82026400 & -2.06739100 & 2.26924400 \\ \mathrm{H} & 4.38370800 & 2.87476500 & 1.88607600 \\ \mathrm{H} & 5.31895500 & 1.45599500 & 2.37451600 \\ \mathrm{H} & 3.55227900 & 1.37516600 & 2.29809700 \\ \mathrm{H} & 5.89889000 & 1.88981400 & -1.34118300 \\ \mathrm{H} & 5.53817500 & 3.22907200 & -0.23197700 \\ \mathrm{H} & 6.65011900 & 1.94817000 & 0.25466500\end{array}$

Proposed structure of xylogranatin H (17-3)-conformer 9

Zero-point correction=

Thermal correction to Energy=

Thermal correction to Enthalpy=

Thermal correction to Gibbs Free Energy=

Sum of electronic and zero-point Energies=

Sum of electronic and thermal Energies=

Sum of electronic and thermal Enthalpies=

Sum of electronic and thermal Free Energies=
0.512537 (Hartree/Particle)

0.541312

0.542256

0.454081

$-1513.910146$

$-1513.881371$

$-1513.880427$

$-1513.968602$

01

$\begin{array}{lrrr}\mathrm{N} & 1.38193800 & -1.62463500 & 0.07928700 \\ \mathrm{C} & 2.18611100 & -0.59787200 & 0.37233900 \\ \mathrm{C} & 1.70080000 & 0.68251200 & 0.67269500 \\ \mathrm{C} & 0.31684400 & 0.86573300 & 0.64871000 \\ \mathrm{C} & -0.53291900 & -0.19715100 & 0.33877000 \\ \mathrm{C} & 0.05553500 & -1.44313100 & 0.05172000 \\ \mathrm{C} & 3.67716100 & -0.90774800 & 0.38657800 \\ \mathrm{C} & 4.60818400 & 0.33289400 & 0.57822500 \\ \mathrm{C} & 3.97480100 & 1.70877000 & 0.20834200 \\ \mathrm{C} & 2.65266100 & 1.80573700 & 1.02165700 \\ \mathrm{C} & -2.04202700 & -0.03167700 & 0.37252000 \\ \mathrm{C} & -2.75437100 & -1.02154200 & -0.57842500 \\ \mathrm{C} & -2.29204300 & -2.46082700 & -0.23684400 \\ \mathrm{C} & -0.76865800 & -2.64350200 & -0.36986700 \\ \mathrm{C} & -2.53592800 & -0.20274200 & 1.83094700 \\ \mathrm{C} & -3.98492300 & -0.60081400 & 2.05017400 \\ \mathrm{O} & -4.67717000 & -1.13939200 & 1.01536600 \\ \mathrm{C} & -4.29214000 & -0.90588400 & -0.36665300 \\ \mathrm{O} & 4.03034800 & -1.43265300 & -0.93756100 \\ \mathrm{C} & 5.25984100 & -1.00945300 & -1.32697000 \\ \mathrm{C} & 5.82186200 & -0.05825000 & -0.28139000 \\ \mathrm{O} & 5.77728500 & -1.37220800 & -2.35553400 \\ \mathrm{C} & -4.95225400 & 0.37479500 & -0.82256100 \\ \mathrm{C} & -5.43149600 & 1.37881500 & -0.02813100\end{array}$




$\begin{array}{lrrr}\mathrm{O} & -6.01378100 & 2.35525100 & -0.78216100 \\ \mathrm{C} & -5.91962900 & 1.96299100 & -2.08432800 \\ \mathrm{C} & -5.28798400 & 0.76093600 & -2.17174100 \\ \mathrm{H} & 4.88825800 & 0.38680900 & 1.63684600 \\ \mathrm{O} & 1.96272300 & 3.04339800 & 0.83262500 \\ \mathrm{O} & -4.51102600 & -0.54007500 & 3.13953500 \\ \mathrm{H} & -2.28771600 & 0.98683500 & 0.04759700 \\ \mathrm{C} & -2.41866100 & -0.70210200 & -2.04846000 \\ \mathrm{C} & 3.97682800 & -2.01056400 & 1.41000900 \\ \mathrm{C} & 4.92609700 & 2.83159100 & 0.67074100 \\ \mathrm{C} & 3.69225000 & 1.87444300 & -1.29923900 \\ \mathrm{H} & -0.08740900 & 1.85113600 & 0.85872200 \\ \mathrm{H} & 2.91848100 & 1.71340500 & 2.08916800 \\ \mathrm{H} & -2.60662800 & -2.71726900 & 0.77975100 \\ \mathrm{H} & -2.80201200 & -3.17352200 & -0.89652600 \\ \mathrm{H} & -0.43808700 & -3.51395500 & 0.20712600 \\ \mathrm{H} & -0.49861300 & -2.86923600 & -1.40940500 \\ \mathrm{H} & -1.95944400 & -0.99114300 & 2.33093300 \\ \mathrm{H} & -2.35535400 & 0.70346000 & 2.41541800 \\ \mathrm{H} & -4.76093200 & -1.74031400 & -0.90045900 \\ \mathrm{H} & 6.57675000 & -0.60264200 & 0.29697100 \\ \mathrm{H} & 6.33521500 & 0.77093000 & -0.77007600 \\ \mathrm{H} & -5.48171100 & 1.51973300 & 1.03984600 \\ \mathrm{H} & -6.34517100 & 2.63418300 & -2.81373000 \\ \mathrm{H} & -5.09163000 & 0.21125500 & -3.08072400 \\ \mathrm{H} & 2.42857000 & 3.73888900 & 1.31240900 \\ \mathrm{H} & -2.98048900 & -1.35454800 & -2.72752200 \\ \mathrm{H} & -2.65241200 & 0.33544600 & -2.29819000 \\ \mathrm{H} & -1.35684700 & -0.85533600 & -2.25250000 \\ \mathrm{H} & 3.68713700 & -1.68651400 & 2.41530900 \\ \mathrm{H} & 3.40644400 & -2.90498000 & 1.15240000 \\ \mathrm{H} & 5.04337800 & -2.25749300 & 1.41874500 \\ \mathrm{H} & 4.53078600 & 3.81747800 & 0.40328300 \\ \mathrm{H} & 5.90607400 & 2.74795500 & 0.19122100 \\ \mathrm{H} & 5.08581700 & 2.80391700 & 1.75625900 \\ \mathrm{H} & 3.07986100 & 1.06479900 & -1.70330400 \\ \mathrm{H} & 3.15901900 & 2.81352200 & -1.47109100 \\ & 4.62241300 & 1.90934100 & -1.87454600\end{array}$

Proposed structure of xylogranatin H (17-3)-conformer 10

Zero-point correction $=$

Thermal correction to Energy=

Thermal correction to Enthalpy=

Thermal correction to Gibbs Free Energy=

Sum of electronic and zero-point Energies=

Sum of electronic and thermal Energies=

Sum of electronic and thermal Enthalpies=

Sum of electronic and thermal Free Energies= 01
0.512515 (Hartree/Particle)

0.541324

0.542268

0.453999

$-1513.910131$

$-1513.881322$

$-1513.880378$

$-1513.968647$ 


\begin{tabular}{|c|c|c|c|}
\hline $\mathrm{N}$ & 1.37085800 & -1.60970000 & 0.01808600 \\
\hline $\mathrm{C}$ & 2.18490800 & -0.59305700 & 0.32075900 \\
\hline $\mathrm{C}$ & 1.71258900 & 0.69196000 & 0.62672900 \\
\hline $\mathrm{C}$ & 0.32710400 & 0.87490600 & 0.63168000 \\
\hline $\mathrm{C}$ & -0.53429400 & -0.17854800 & 0.32179600 \\
\hline $\mathrm{C}$ & 0.04573000 & -1.42019100 & -0.00003000 \\
\hline $\mathrm{C}$ & 3.66987200 & -0.92263900 & 0.36255900 \\
\hline $\mathrm{C}$ & 4.60761400 & 0.30139000 & 0.60105100 \\
\hline $\mathrm{C}$ & 4.02034400 & 1.68995200 & 0.20171300 \\
\hline $\mathrm{C}$ & 2.66585500 & 1.83027500 & 0.95453900 \\
\hline $\mathrm{C}$ & -2.04223000 & -0.00641900 & 0.39251300 \\
\hline $\mathrm{C}$ & -2.78506200 & -0.98294100 & -0.54994100 \\
\hline $\mathrm{C}$ & -2.30596300 & -2.42585100 & -0.24728200 \\
\hline $\mathrm{C}$ & -0.78998100 & -2.60417900 & -0.44060200 \\
\hline $\mathrm{C}$ & -2.50526000 & -0.18256300 & 1.86149000 \\
\hline $\mathrm{C}$ & -3.95133500 & -0.57959700 & 2.11788800 \\
\hline $\mathrm{O}$ & -4.66963000 & -1.11457200 & 1.10071700 \\
\hline $\mathrm{C}$ & -4.31515300 & -0.88527700 & -0.29451300 \\
\hline $\mathrm{O}$ & 4.05644400 & -1.42786500 & -0.96005800 \\
\hline $\mathrm{C}$ & 5.31315400 & -1.02988300 & -1.28896700 \\
\hline $\mathrm{C}$ & 5.85259700 & -0.11288000 & -0.20108700 \\
\hline $\mathrm{O}$ & 5.86230200 & -1.38459000 & -2.30370800 \\
\hline $\mathrm{C}$ & -5.00485400 & 0.37091100 & -0.75886100 \\
\hline $\mathrm{C}$ & -5.86521600 & 0.45160900 & -1.81567200 \\
\hline $\mathrm{O}$ & -6.33349500 & 1.72210300 & -1.96683300 \\
\hline $\mathrm{C}$ & -5.77296800 & 2.47030200 & -0.97301400 \\
\hline $\mathrm{C}$ & -4.95448600 & 1.70190000 & -0.20385400 \\
\hline $\mathrm{H}$ & 4.83692500 & 0.35362600 & 1.67152600 \\
\hline $\mathrm{O}$ & 2.05093600 & 3.10541100 & 0.77073300 \\
\hline $\mathrm{O}$ & -4.44090300 & -0.52720800 & 3.22370500 \\
\hline $\mathrm{H}$ & -2.27985900 & 1.01645000 & 0.07683700 \\
\hline $\mathrm{C}$ & -2.51224500 & -0.63403300 & -2.02639700 \\
\hline $\mathrm{C}$ & 3.92596100 & -2.04600500 & 1.37631800 \\
\hline $\mathrm{C}$ & 4.97239800 & 2.79730100 & 0.69629300 \\
\hline C & 3.81228400 & 1.84437400 & -1.32121400 \\
\hline $\mathrm{H}$ & -0.07512300 & 1.85398700 & 0.87890700 \\
\hline $\mathrm{H}$ & 2.88575400 & 1.80884900 & 2.03083800 \\
\hline $\mathrm{H}$ & -2.58102900 & -2.69685400 & 0.77730800 \\
\hline $\mathrm{H}$ & -2.83963300 & -3.12985800 & -0.8973030 \\
\hline $\mathrm{H}$ & -0.43902200 & -3.49592600 & 0.0895200 \\
\hline $\mathrm{H}$ & -0.55770500 & -2.78751300 & -1.49770900 \\
\hline $\mathrm{H}$ & -1.91983600 & -0.97574500 & 2.3428120 \\
\hline $\mathrm{H}$ & -2.30570800 & 0.71842400 & 2.4482580 \\
\hline $\mathrm{H}$ & -4.78419000 & -1.72939100 & -0.8098670 \\
\hline $\mathrm{H}$ & 6.55850200 & -0.68960400 & 0.4069010 \\
\hline $\mathrm{H}$ & 6.41707400 & 0.70743400 & -0.64614200 \\
\hline $\mathrm{H}$ & -6.23127300 & -0.27566700 & -2.5242470 \\
\hline $\mathrm{H}$ & -6.06148200 & 3.50920900 & -0.9432490 \\
\hline $\mathrm{H}$ & -4.41433700 & 2.03888300 & 0.6690480 \\
\hline $\mathrm{H}$ & 1.79952700 & 3.20049200 & -0.1586960 \\
\hline $\mathrm{H}$ & -3.07804100 & -1.29566300 & -2.6927460 \\
\hline
\end{tabular}




$\begin{array}{lrrr}\mathrm{H} & -2.80088700 & 0.39550800 & -2.25316700 \\ \mathrm{H} & -1.45345400 & -0.74532000 & -2.27173200 \\ \mathrm{H} & 3.61102900 & -1.73463200 & 2.37790700 \\ \mathrm{H} & 3.35272500 & -2.92891100 & 1.08753900 \\ \mathrm{H} & 4.98837200 & -2.30676300 & 1.41246400 \\ \mathrm{H} & 4.54259400 & 3.78425200 & 0.50718400 \\ \mathrm{H} & 5.94105500 & 2.74848200 & 0.18895400 \\ \mathrm{H} & 5.15219200 & 2.71381200 & 1.77456300 \\ \mathrm{H} & 3.12009500 & 1.10540400 & -1.73364100 \\ \mathrm{H} & 3.42848800 & 2.84382300 & -1.55597900 \\ \mathrm{H} & 4.75783300 & 1.74998000 & -1.86249200\end{array}$

\section{Proposed structure of xylogranatin H (17-3)-conformer 11}

$\begin{array}{lc}\text { Zero-point correction }= & 0.512864 \text { (Hartree/Particle) } \\ \text { Thermal correction to Energy= } & 0.541494 \\ \text { Thermal correction to Enthalpy= } & 0.542438 \\ \text { Thermal correction to Gibbs Free Energy= } & 0.454218 \\ \text { Sum of electronic and zero-point Energies }= & -1513.909109 \\ \text { Sum of electronic and thermal Energies }= & -1513.880479 \\ \text { Sum of electronic and thermal Enthalpies }= & -1513.879534 \\ \text { Sum of electronic and thermal Free Energies }= & -1513.967755\end{array}$
01

$\begin{array}{lrrr}\mathrm{N} & 1.15309000 & -1.08992600 & 0.89576200 \\ \mathrm{C} & 2.22981100 & -0.38273800 & 0.51519100 \\ \mathrm{C} & 2.12163400 & 0.81823600 & -0.19783500 \\ \mathrm{C} & 0.83330900 & 1.26857200 & -0.51379500 \\ \mathrm{C} & -0.28897800 & 0.54420300 & -0.12714700 \\ \mathrm{C} & -0.06625800 & -0.65293900 & 0.58056300 \\ \mathrm{C} & 3.57626200 & -0.99291300 & 0.91081300 \\ \mathrm{C} & 4.79677700 & -0.23359400 & 0.30170800 \\ \mathrm{C} & 4.61092300 & 1.29944400 & 0.13730800 \\ \mathrm{C} & 3.31807000 & 1.62297100 & -0.66173000 \\ \mathrm{C} & -1.69596600 & 1.05279700 & -0.37987300 \\ \mathrm{C} & -2.79000300 & -0.07331600 & -0.59761400 \\ \mathrm{C} & -2.24146900 & -1.48480100 & -0.25448700 \\ \mathrm{C} & -1.25723500 & -1.50831300 & 0.92593200 \\ \mathrm{C} & -2.09173900 & 2.04246700 & 0.75151100 \\ \mathrm{C} & -3.48785000 & 2.57356500 & 0.51862500 \\ \mathrm{O} & -4.41383100 & 1.61994800 & 0.24120200 \\ \mathrm{C} & -4.00239100 & 0.22706300 & 0.34771000 \\ \mathrm{O} & 3.64046300 & -2.33155100 & 0.31568200 \\ \mathrm{C} & 4.48754900 & -2.39006600 & -0.74517500 \\ \mathrm{C} & 5.08974800 & -1.02257300 & -0.98910700 \\ \mathrm{O} & 4.67645900 & -3.41094200 & -1.36154800 \\ \mathrm{C} & -5.24735700 & -0.58159200 & 0.12715300 \\ \mathrm{C} & -5.65586100 & -1.65039400 & 0.87294000 \\ \mathrm{O} & -6.83754200 & -2.14180900 & 0.40687900 \\ \mathrm{C} & -7.20143100 & -1.35791100 & -0.65182100 \\ \mathrm{C} & -6.27107100 & -0.39001900 & -0.86888000\end{array}$




$\begin{array}{lrrr}\mathrm{H} & 5.63984000 & -0.38423300 & 0.98825000 \\ \mathrm{O} & 3.42576700 & 1.39773700 & -2.08180400 \\ \mathrm{O} & -3.80217200 & 3.74164300 & 0.52284500 \\ \mathrm{H} & -1.66258600 & 1.65178200 & -1.29736400 \\ \mathrm{C} & -3.22473700 & -0.05277800 & -2.07545200 \\ \mathrm{C} & 3.65868500 & -1.22271900 & 2.42093700 \\ \mathrm{C} & 4.48923700 & 1.98945500 & 1.51682800 \\ \mathrm{C} & 5.84479500 & 1.89569000 & -0.56953500 \\ \mathrm{H} & 0.71838500 & 2.19416600 & -1.07505900 \\ \mathrm{H} & 3.09247700 & 2.68926600 & -0.50448600 \\ \mathrm{H} & -3.08139200 & -2.16326100 & -0.07242300 \\ \mathrm{H} & -1.71845200 & -1.87752700 & -1.13442900 \\ \mathrm{H} & -1.73745100 & -1.14503200 & 1.84657100 \\ \mathrm{H} & -0.91259500 & -2.52490300 & 1.13282800 \\ \mathrm{H} & -2.04550600 & 1.54687200 & 1.72963600 \\ \mathrm{H} & -1.40788000 & 2.89193500 & 0.78505600 \\ \mathrm{H} & -3.67714900 & 0.05357700 & 1.38076300 \\ \mathrm{H} & 6.15136600 & -1.12178400 & -1.22428400 \\ \mathrm{H} & 4.58990400 & -0.58854200 & -1.86063800 \\ \mathrm{H} & -5.24071500 & -2.15542200 & 1.73193900 \\ \mathrm{H} & -8.13580300 & -1.61254800 & -1.12664100 \\ \mathrm{H} & -6.31074400 & 0.38464100 & -1.61975800 \\ \mathrm{H} & 3.98942500 & 2.08306100 & -2.46487500 \\ \mathrm{H} & -3.90245600 & -0.88003400 & -2.30375300 \\ \mathrm{H} & -3.72858600 & 0.88442300 & -2.33428100 \\ \mathrm{H} & -2.34473000 & -0.15282300 & -2.71986300 \\ \mathrm{H} & 3.61474200 & -0.27921500 & 2.97052000 \\ \mathrm{H} & 2.82216500 & -1.84936300 & 2.73606400 \\ \mathrm{H} & 4.59711900 & -1.72905100 & 2.66599300 \\ \mathrm{H} & 4.50546700 & 3.07872300 & 1.39855400 \\ \mathrm{H} & 5.32869500 & 1.71385700 & 2.16377500 \\ \mathrm{H} & 3.56316400 & 1.73200700 & 2.03717000 \\ \mathrm{H} & 6.02972200 & 1.44275900 & -1.54720700 \\ \mathrm{H} & 5.72998300 & 2.97845400 & -0.70671200 \\ \mathrm{H} & 6.74208400 & 1.74070000 & 0.03967600\end{array}$

\section{Proposed structure of xylogranatin H (17-3)-conformer 12}

Zero-point correction=

Thermal correction to Energy=

Thermal correction to Enthalpy=
0.542414

Thermal correction to Gibbs Free Energy $=0.453567$

Sum of electronic and zero-point Energies $=\quad-1513.908756$

Sum of electronic and thermal Energies $=\quad-1513.880100$

Sum of electronic and thermal Enthalpies $=\quad-1513.879156$

Sum of electronic and thermal Free Energies $=\quad-1513.968002$
01

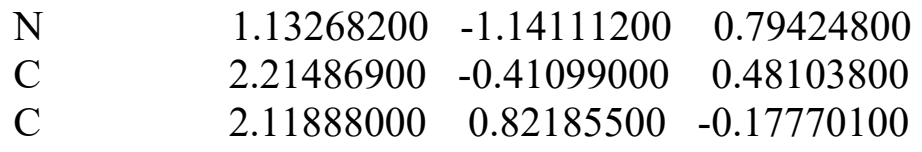




\begin{tabular}{|c|c|c|c|}
\hline $\mathrm{C}$ & 0.83718200 & 1.27934200 & -0.50729000 \\
\hline $\mathrm{C}$ & -0.29243300 & 0.53275300 & -0.18723800 \\
\hline $\mathrm{C}$ & -0.08121800 & -0.69734400 & 0.46529900 \\
\hline $\mathrm{C}$ & 3.55354200 & -1.03072800 & 0.88825400 \\
\hline $\mathrm{C}$ & 4.78583200 & -0.23719900 & 0.35058100 \\
\hline $\mathrm{C}$ & 4.59410900 & 1.30071400 & 0.25035400 \\
\hline $\mathrm{C}$ & 3.32263000 & 1.65309200 & -0.57046200 \\
\hline $\mathrm{C}$ & -1.69108700 & 1.05952000 & -0.45888800 \\
\hline $\mathrm{C}$ & -2.80946500 & -0.04471600 & -0.67034200 \\
\hline $\mathrm{C}$ & -2.24720000 & -1.47211500 & -0.44675600 \\
\hline $\mathrm{C}$ & -1.26995200 & -1.58397100 & 0.73307700 \\
\hline $\mathrm{C}$ & -2.07188100 & 2.07031700 & 0.66012900 \\
\hline $\mathrm{C}$ & -3.48153000 & 2.57870700 & 0.46601400 \\
\hline $\mathrm{O}$ & -4.40678300 & 1.60654700 & 0.26189200 \\
\hline $\mathrm{C}$ & -3.96685100 & 0.22277800 & 0.35222600 \\
\hline $\mathrm{O}$ & 3.64520400 & -2.34071300 & 0.23590500 \\
\hline $\mathrm{C}$ & 4.52404900 & -2.34636200 & -0.80044800 \\
\hline $\mathrm{C}$ & 5.12236700 & -0.96539200 & -0.96519700 \\
\hline $\mathrm{O}$ & 4.73933400 & -3.33753700 & -1.45540800 \\
\hline $\mathrm{C}$ & -5.20722100 & -0.61080400 & 0.19921500 \\
\hline $\mathrm{C}$ & -6.35202800 & -0.26804100 & -0.46154600 \\
\hline $\mathrm{O}$ & -7.28009400 & -1.26173000 & -0.35917000 \\
\hline $\mathrm{C}$ & -6.72215300 & -2.25743200 & 0.38656400 \\
\hline $\mathrm{C}$ & -5.45885900 & -1.91386600 & 0.76115400 \\
\hline $\mathrm{H}$ & 5.60946500 & -0.41396000 & 1.05427800 \\
\hline $\mathrm{O}$ & 3.47225800 & 1.49222300 & -1.99539000 \\
\hline $\mathrm{O}$ & -3.81169700 & 3.74236100 & 0.45041900 \\
\hline $\mathrm{H}$ & -1.63898100 & 1.64584300 & -1.38353400 \\
\hline $\mathrm{C}$ & -3.34110300 & 0.05772900 & -2.11295800 \\
\hline $\mathrm{C}$ & 3.59295600 & -1.32796500 & 2.38834200 \\
\hline $\mathrm{C}$ & 4.42807200 & 1.92673900 & 1.65550000 \\
\hline $\mathrm{C}$ & 5.84364500 & 1.93528700 & -0.39269400 \\
\hline $\mathrm{H}$ & 0.73258100 & 2.22978700 & -1.02762100 \\
\hline $\mathrm{H}$ & 3.08568100 & 2.71005100 & -0.37224900 \\
\hline $\mathrm{H}$ & -3.07580500 & -2.17770500 & -0.33700100 \\
\hline $\mathrm{H}$ & -1.71185800 & -1.77502400 & -1.35479400 \\
\hline $\mathrm{H}$ & -1.75576500 & -1.30089600 & 1.67840600 \\
\hline $\mathrm{H}$ & -0.91754400 & -2.61123500 & 0.85915200 \\
\hline $\mathrm{H}$ & -1.99113800 & 1.59428900 & 1.64582700 \\
\hline $\mathrm{H}$ & -1.39859300 & 2.92869400 & 0.65833000 \\
\hline $\mathrm{H}$ & -3.58053200 & 0.05896400 & 1.36606700 \\
\hline $\mathrm{H}$ & 6.19110000 & -1.04703300 & -1.17334600 \\
\hline $\mathrm{H}$ & 4.64456100 & -0.49621600 & -1.83088700 \\
\hline $\mathrm{H}$ & -6.65529500 & 0.61660600 & -0.99719400 \\
\hline $\mathrm{H}$ & -7.34157100 & -3.12261000 & 0.56286400 \\
\hline $\mathrm{H}$ & -4.79363100 & -2.50648400 & 1.37341800 \\
\hline $\mathrm{H}$ & 4.04228000 & 2.19681500 & -2.33122600 \\
\hline $\mathrm{H}$ & -4.05513600 & -0.74148600 & -2.33038700 \\
\hline $\mathrm{H}$ & -3.83986400 & 1.01566900 & -2.29265300 \\
\hline $\mathrm{H}$ & -2.50972800 & -0.03036600 & -2.82039000 \\
\hline $\mathrm{H}$ & 3.52559300 & -0.41051900 & 2.97816200 \\
\hline
\end{tabular}




$\begin{array}{rrrr}\mathrm{H} & 2.75221300 & -1.97341900 & 2.64974300 \\ \mathrm{H} & 4.52751900 & -1.83897300 & 2.63843600 \\ \mathrm{H} & 4.44003800 & 3.02031200 & 1.58695800 \\ \mathrm{H} & 5.25055700 & 1.62696400 & 2.31340400 \\ \mathrm{H} & 3.48932400 & 1.64062500 & 2.13671100 \\ \mathrm{H} & 6.05936200 & 1.52834000 & -1.38411500 \\ \mathrm{H} & 5.72546600 & 3.02252900 & -0.48385800 \\ \mathrm{H} & 6.72423300 & 1.75755300 & 0.23441700\end{array}$

Proposed structure of xylogranatin H (17-3)-conformer 13

Zero-point correction $=$

Thermal correction to Energy=

Thermal correction to Enthalpy=

Thermal correction to Gibbs Free Energy=

Sum of electronic and zero-point Energies=

Sum of electronic and thermal Energies $=$

Sum of electronic and thermal Enthalpies=

Sum of electronic and thermal Free Energies=
0.512562 (Hartree/Particle)

0.541285

0.542230

\author{
0.454244
}

$-1513.911882$

$-1513.883159$

$-1513.882215$

$-1513.970201$

01

$\begin{array}{lrrr}\mathrm{N} & -1.27568100 & -1.34832600 & -0.65943900 \\ \mathrm{C} & -2.25795400 & -0.45064500 & -0.55347100 \\ \mathrm{C} & -2.01580700 & 0.90446900 & -0.28556100 \\ \mathrm{C} & -0.68887300 & 1.29714600 & -0.11521900 \\ \mathrm{C} & 0.35236700 & 0.36808100 & -0.21737800 \\ \mathrm{C} & -0.00252200 & -0.96572900 & -0.48673100 \\ \mathrm{C} & -3.66934600 & -0.97971000 & -0.77174700 \\ \mathrm{C} & -4.81112900 & 0.04996000 & -0.48990100 \\ \mathrm{C} & -4.42442400 & 1.24147900 & 0.43828600 \\ \mathrm{C} & -3.16127700 & 1.88964100 & -0.19749000 \\ \mathrm{C} & 1.79011200 & 0.82360800 & 0.00454400 \\ \mathrm{C} & 2.83982800 & -0.33417700 & 0.08631000 \\ \mathrm{C} & 2.43278000 & -1.48631100 & -0.86375500 \\ \mathrm{C} & 1.04254200 & -2.04948400 & -0.56852100 \\ \mathrm{C} & 2.23289700 & 1.90092600 & -1.01665900 \\ \mathrm{C} & 3.52750800 & 2.50925300 & -0.51900500 \\ \mathrm{O} & 4.43137500 & 1.60329100 & -0.05388000 \\ \mathrm{C} & 4.22506300 & 0.21332800 & -0.42169100 \\ \mathrm{O} & -3.89224900 & -2.05449900 & 0.20107800 \\ \mathrm{C} & -5.16802100 & -2.04694800 & 0.66536700 \\ \mathrm{C} & -5.91451100 & -0.86105800 & 0.07345300 \\ \mathrm{O} & -5.58831500 & -2.88451700 & 1.42610800 \\ \mathrm{C} & 5.44159400 & -0.52590000 & 0.05507300 \\ \mathrm{C} & 6.33583500 & -0.10455000 & 0.99613300 \\ \mathrm{O} & 7.32568700 & -1.02899900 & 1.16399400 \\ \mathrm{C} & 7.06203300 & -2.05763900 & 0.31002000 \\ \mathrm{C} & 5.92621600 & -1.80527500 & -0.39795200 \\ \mathrm{H} & -5.12205000 & 0.48239600 & -1.44822500 \\ \mathrm{O} & -2.69914400 & 3.04058500 & 0.51220700 \\ \mathrm{O} & 3.76229100 & 3.69227200 & -0.43904000\end{array}$

SI213 


$\begin{array}{lrrr}\mathrm{H} & 1.79838300 & 1.32589400 & 0.98170900 \\ \mathrm{C} & 2.92530900 & -0.81969000 & 1.54514500 \\ \mathrm{C} & -3.78992900 & -1.59756200 & -2.17082600 \\ \mathrm{C} & -5.57171200 & 2.27241500 & 0.42417800 \\ \mathrm{C} & -4.13851000 & 0.82295700 & 1.89544100 \\ \mathrm{H} & -0.48310100 & 2.33598600 & 0.12242400 \\ \mathrm{H} & -3.43246800 & 2.19617700 & -1.22280000 \\ \mathrm{H} & 2.44980000 & -1.11910500 & -1.89986000 \\ \mathrm{H} & 3.17378700 & -2.29038500 & -0.80414500 \\ \mathrm{H} & 0.74281500 & -2.76706600 & -1.33878700 \\ \mathrm{H} & 1.04470800 & -2.60955600 & 0.37623400 \\ \mathrm{H} & 2.36839000 & 1.46204800 & -2.01362800 \\ \mathrm{H} & 1.50458900 & 2.70691200 & -1.11150000 \\ \mathrm{H} & 4.21367900 & 0.17073200 & -1.51864300 \\ \mathrm{H} & -6.57689500 & -1.23968600 & -0.71304500 \\ \mathrm{H} & -6.55259800 & -0.40680700 & 0.83263800 \\ \mathrm{H} & 6.41427100 & 0.79499200 & 1.58414700 \\ \mathrm{H} & 7.76628700 & -2.87461200 & 0.31873400 \\ \mathrm{H} & 5.49746500 & -2.44292600 & -1.15769100 \\ \mathrm{H} & -3.28804200 & 3.78233000 & 0.32814200 \\ \mathrm{H} & 3.53717500 & -1.72143400 & 1.63683000 \\ \mathrm{H} & 3.36717700 & -0.04762400 & 2.18354500 \\ \mathrm{H} & 1.92845000 & -1.04194500 & 1.93857300 \\ \mathrm{H} & -3.58472400 & -0.84445500 & -2.93914700 \\ \mathrm{H} & -3.06393100 & -2.40673600 & -2.27032900 \\ \mathrm{H} & -4.79548200 & -1.99751100 & -2.33666800 \\ \mathrm{H} & -5.35129500 & 3.11517900 & 1.08807700 \\ \mathrm{H} & -6.50884700 & 1.83255600 & 0.77857600 \\ \mathrm{H} & -5.75103400 & 2.66313200 & -0.58569900 \\ \mathrm{H} & -3.38329600 & 0.03653800 & 1.96652800 \\ \mathrm{H} & -3.77516000 & 1.68608800 & 2.45995000 \\ \mathrm{H} & -5.04587200 & 0.46059700 & 2.38814400 \\ & & & \\ & & & \\ & & & \end{array}$

\section{Proposed structure of xylogranatin H (17-3)-conformer 14}

Zero-point correction=

Thermal correction to Energy=

Thermal correction to Enthalpy=

Thermal correction to Gibbs Free Energy=

Sum of electronic and zero-point Energies=

Sum of electronic and thermal Energies $=$

Sum of electronic and thermal Enthalpies=

Sum of electronic and thermal Free Energies=
0.512668 (Hartree/Particle)

0.541384

0.542328

\author{
0.454211
}

$-1513.909756$

$-1513.881040$

$-1513.880095$

$-1513.968213$

01

$\begin{array}{lrrr}\mathrm{N} & 1.37380500 & -1.61175200 & -0.00954200 \\ \mathrm{C} & 2.17789200 & -0.59564400 & 0.32091900 \\ \mathrm{C} & 1.69397200 & 0.67956900 & 0.64881700 \\ \mathrm{C} & 0.30716000 & 0.85360400 & 0.64398200 \\ \mathrm{C} & -0.54343900 & -0.19901600 & 0.30375800 \\ \mathrm{C} & 0.04776000 & -1.43080000 & -0.03628200 \\ & & & \text { SI } 214\end{array}$




\begin{tabular}{|c|c|c|c|}
\hline $\mathrm{C}$ & 3.66484000 & -0.91561100 & 0.36773800 \\
\hline $\mathrm{C}$ & 4.59216900 & 0.30970800 & 0.63817300 \\
\hline $\mathrm{C}$ & 3.99781100 & 1.70222100 & 0.26397100 \\
\hline $\mathrm{C}$ & 2.63678600 & 1.81665400 & 1.00943100 \\
\hline $\mathrm{C}$ & -2.05275300 & -0.04407500 & 0.36236800 \\
\hline $\mathrm{C}$ & -2.76982600 & -0.99293700 & -0.62622300 \\
\hline $\mathrm{C}$ & -2.29764400 & -2.44423700 & -0.35578600 \\
\hline $\mathrm{C}$ & -0.77454100 & -2.61315800 & -0.50868000 \\
\hline $\mathrm{C}$ & -2.52927700 & -0.28648300 & 1.81650200 \\
\hline $\mathrm{C}$ & -3.97391300 & -0.70328300 & 2.03155600 \\
\hline $\mathrm{O}$ & -4.67496700 & -1.19501800 & 0.97908700 \\
\hline $\mathrm{C}$ & -4.30587000 & -0.89430100 & -0.39378600 \\
\hline $\mathrm{O}$ & 4.06471600 & -1.39102300 & -0.96211300 \\
\hline $\mathrm{C}$ & 5.32059000 & -0.97710800 & -1.27387100 \\
\hline $\mathrm{C}$ & 5.84569300 & -0.07896500 & -0.16353600 \\
\hline $\mathrm{O}$ & 5.87933100 & -1.30677100 & -2.29186400 \\
\hline $\mathrm{C}$ & -4.97508900 & 0.40384800 & -0.78187900 \\
\hline $\mathrm{C}$ & -5.44863700 & 1.36795400 & 0.06389700 \\
\hline $\mathrm{O}$ & -6.04266700 & 2.37600200 & -0.63731600 \\
\hline $\mathrm{C}$ & -5.96242600 & 2.04517200 & -1.95725800 \\
\hline $\mathrm{C}$ & -5.32752400 & 0.85103000 & -2.10775500 \\
\hline $\mathrm{H}$ & 4.81373900 & 0.34112200 & 1.71108700 \\
\hline $\mathrm{O}$ & 2.01493300 & 3.09148600 & 0.85017500 \\
\hline $\mathrm{O}$ & -4.48796000 & -0.69829300 & 3.12793900 \\
\hline $\mathrm{H}$ & -2.30876400 & 0.98684800 & 0.08828100 \\
\hline $\mathrm{C}$ & -2.45026100 & -0.60499600 & -2.08325400 \\
\hline $\mathrm{C}$ & 3.92140400 & -2.05770900 & 1.36017200 \\
\hline $\mathrm{C}$ & 4.93807700 & 2.80552900 & 0.78911200 \\
\hline $\mathrm{C}$ & 3.79981300 & 1.88771900 & -1.25680600 \\
\hline $\mathrm{H}$ & -0.10495400 & 1.82424900 & 0.90750900 \\
\hline $\mathrm{H}$ & 2.84894900 & 1.77208500 & 2.08658700 \\
\hline $\mathrm{H}$ & -2.60283500 & -2.74965900 & 0.64999900 \\
\hline $\mathrm{H}$ & -2.80940300 & -3.12788900 & -1.04409600 \\
\hline $\mathrm{H}$ & -0.43521700 & -3.50860300 & 0.02293200 \\
\hline $\mathrm{H}$ & -0.51155600 & -2.78724800 & -1.56000100 \\
\hline $\mathrm{H}$ & -1.94290500 & -1.09380400 & 2.27274300 \\
\hline $\mathrm{H}$ & -2.34775200 & 0.59228800 & 2.44118400 \\
\hline $\mathrm{H}$ & -4.77675900 & -1.70436800 & -0.96214200 \\
\hline $\mathrm{H}$ & 6.55155200 & -0.66311300 & 0.43739600 \\
\hline $\mathrm{H}$ & 6.40727000 & 0.75440200 & -0.58752000 \\
\hline $\mathrm{H}$ & -5.48778900 & 1.45871000 & 1.13780000 \\
\hline $\mathrm{H}$ & -6.39965300 & 2.74741300 & -2.64958700 \\
\hline $\mathrm{H}$ & -5.14085300 & 0.34444400 & -3.04345700 \\
\hline $\mathrm{H}$ & 1.76558100 & 3.20486800 & -0.07773700 \\
\hline $\mathrm{H}$ & -3.01594600 & -1.22835700 & -2.78591300 \\
\hline $\mathrm{H}$ & -2.69176200 & 0.44160500 & -2.28321500 \\
\hline $\mathrm{H}$ & -1.38988900 & -0.74428800 & -2.30465000 \\
\hline $\mathrm{H}$ & 3.59680200 & -1.76908300 & 2.36548400 \\
\hline $\mathrm{H}$ & 3.35662000 & -2.93849800 & 1.04912200 \\
\hline $\mathrm{H}$ & 4.98534700 & -2.31174700 & 1.39909800 \\
\hline $\mathrm{H}$ & 4.50230000 & 3.79311800 & 0.61793300 \\
\hline
\end{tabular}




$\begin{array}{lrrr}\mathrm{H} & 5.91074000 & 2.77453400 & 0.28803900 \\ \mathrm{H} & 5.11060700 & 2.70034300 & 1.86666800 \\ \mathrm{H} & 3.11680000 & 1.15218500 & -1.69015100 \\ \mathrm{H} & 3.40932000 & 2.88881000 & -1.47271600 \\ \mathrm{H} & 4.75008300 & 1.81271700 & -1.79282900\end{array}$

Proposed structure of xylogranatin H (17-3)-conformer 15

Zero-point correction=

Thermal correction to Energy=

Thermal correction to Enthalpy=

Thermal correction to Gibbs Free Energy=

Sum of electronic and zero-point Energies=

Sum of electronic and thermal Energies=

Sum of electronic and thermal Enthalpies=

Sum of electronic and thermal Free Energies=
0.512602 (Hartree/Particle)

0.541296

0.542240

0.453896

$-1513.911364$

$-1513.882670$

$-1513.881725$

$-1513.970070$

01

$\mathrm{N}$

C

C

C

$\begin{array}{lll}-1.14303000 & -1.14003300 & -0.75751000\end{array}$

$\begin{array}{lll}-2.18677700 & -0.31953900 & -0.57937900\end{array}$

$\begin{array}{lll}-2.04500200 & 1.00026100 & -0.13095600\end{array}$

$\begin{array}{lll}-0.75067700 & 1.45927400 & 0.13148900\end{array}$

$\begin{array}{llll}0.34430200 & 0.61615300 & -0.05501600\end{array}$

$\begin{array}{llll}\text { C } & 0.08895300 & -0.69417000 & -0.49608500\end{array}$

$\begin{array}{llll}\mathrm{C} & -3.55148100 & -0.90441900 & -0.91665400\end{array}$

$\begin{array}{llll}C & -4.76880700 & 0.00403400 & -0.54878600\end{array}$

$\begin{array}{llll}\mathrm{C} & -4.49162300 & 1.08373900 & 0.54103100\end{array}$

$\begin{array}{llll}\mathrm{C} & -3.25752000 & 1.88926500 & 0.04379400\end{array}$

$\begin{array}{llll}\mathrm{C} & 1.76518800 & 1.11529300 & 0.13612900\end{array}$

$\begin{array}{llll}\mathrm{C} & 2.81180100 & 0.02081100 & 0.60512000\end{array}$

$\begin{array}{llll}\mathrm{C} & 2.20693600 & -1.40801800 & 0.56806600\end{array}$

$\begin{array}{llll}\mathrm{C} & 1.24512100 & -1.65392700 & -0.60488000\end{array}$

$\begin{array}{llll}\mathrm{C} & 2.22213300 & 1.84636600 & -1.15775000\end{array}$

$\begin{array}{llll}\mathrm{C} & 3.63940400 & 2.35018000 & -1.00934500\end{array}$

$\begin{array}{llll}\mathrm{O} & 4.51835400 & 1.42861200 & -0.53724400\end{array}$

$\begin{array}{lllll}\mathrm{C} & 4.04033600 & 0.06419300 & -0.36551100\end{array}$

$\begin{array}{llll}\mathrm{O} & -3.72981300 & -2.10965500 & -0.09908800\end{array}$

$\begin{array}{llll}\mathrm{C} & -5.01660500 & -2.24449200 & 0.31159300\end{array}$

$\begin{array}{llll}\text { C } & -5.82417300 & -1.04170800 & -0.15210200\end{array}$

$\begin{array}{llll}\mathrm{O} & -5.40176600 & -3.19929900 & 0.94174200\end{array}$

$\begin{array}{llll}\mathrm{C} & 5.24402500 & -0.73982300 & 0.03145300\end{array}$

$\begin{array}{llll}\mathrm{C} & 5.60149600 & -1.95750300 & -0.47328500\end{array}$

$\begin{array}{llll}\mathrm{O} & 6.75693600 & -2.39778900 & 0.09824100\end{array}$

$\begin{array}{llll}\mathrm{C} & 7.15612600 & -1.43063400 & 0.97749300\end{array}$

$\begin{array}{llll}\mathrm{C} & 6.27361500 & -0.39585700 & 0.97929600\end{array}$

$\mathrm{H} \quad \begin{array}{llll}\mathrm{C} & -5.07916600 & 0.53903900 & -1.45404300\end{array}$

$\begin{array}{llll}\mathrm{O} & -2.89530000 & 2.96229300 & 0.91569500\end{array}$

$\begin{array}{llll}\mathrm{O} & 4.00961600 & 3.47882400 & -1.23818300\end{array}$

$\begin{array}{llll}\mathrm{H} & 1.73324400 & 1.88626000 & 0.91455500\end{array}$

$\begin{array}{llll}\text { C } & 3.24232000 & 0.34227500 & 2.04920000\end{array}$

$\begin{array}{llll}\text { C } & -3.58784800 & -1.34095600 & -2.38708900\end{array}$

SI216 


$\begin{array}{lrrr}\mathrm{C} & -5.70540200 & 2.03254300 & 0.61806000 \\ \mathrm{C} & -4.22079100 & 0.49442100 & 1.94080700 \\ \mathrm{H} & -0.61553500 & 2.47391600 & 0.49333300 \\ \mathrm{H} & -3.51931200 & 2.31277400 & -0.94154300 \\ \mathrm{H} & 3.01858700 & -2.14296100 & 0.56550100 \\ \mathrm{H} & 1.64977100 & -1.57220200 & 1.49810900 \\ \mathrm{H} & 1.75979800 & -1.52863200 & -1.56905600 \\ \mathrm{H} & 0.85721900 & -2.67601400 & -0.58921100 \\ \mathrm{H} & 2.16327200 & 1.17046600 & -2.02054100 \\ \mathrm{H} & 1.57882500 & 2.70144100 & -1.37043300 \\ \mathrm{H} & 3.71089400 & -0.30035800 & -1.34609000 \\ \mathrm{H} & -6.43371500 & -1.35546800 & -1.00690000 \\ \mathrm{H} & -6.51575000 & -0.73294500 & 0.63291400 \\ \mathrm{H} & 5.16389400 & -2.60863400 & -1.21476400 \\ \mathrm{H} & 8.07600500 & -1.62571900 & 1.50580900 \\ \mathrm{H} & 6.34923400 & 0.51434100 & 1.55491300 \\ \mathrm{H} & -3.53001400 & 3.68128700 & 0.81028800 \\ \mathrm{H} & 3.88765500 & -0.44075100 & 2.45710800 \\ \mathrm{H} & 3.78014200 & 1.29435700 & 2.10709300 \\ \mathrm{H} & 2.35718700 & 0.41490300 & 2.69024100 \\ \mathrm{H} & -3.41329300 & -0.48221400 & -3.04410000 \\ \mathrm{H} & -2.80481600 & -2.08122000 & -2.56221400 \\ \mathrm{H} & -4.55772500 & -1.78072700 & -2.64109400 \\ \mathrm{H} & -5.56227100 & 2.79219700 & 1.39402200 \\ \mathrm{H} & -6.62031300 & 1.49097100 & 0.87669300 \\ \mathrm{H} & -5.88154300 & 2.54134000 & -0.33835900 \\ \mathrm{H} & -3.41584900 & -0.24444600 & 1.93731200 \\ \mathrm{H} & -3.93442500 & 1.29640300 & 2.62676800 \\ \mathrm{H} & -5.11530400 & 0.01237100 & 2.34678500\end{array}$

\section{Proposed structure of xylogranatin H (17-3)-conformer 16}

Zero-point correction=

Thermal correction to Energy=

Thermal correction to Enthalpy=

Thermal correction to Gibbs Free Energy=

Sum of electronic and zero-point Energies=

Sum of electronic and thermal Energies=

Sum of electronic and thermal Enthalpies=

Sum of electronic and thermal Free Energies=
0.512678 (Hartree/Particle)

$$
0.541467
$$

0.542411

0.453890

$-1513.910500$

$-1513.881712$

$-1513.880768$

$-1513.969289$

$\begin{array}{lrrr}\mathrm{N} & 1.25559900 & -1.33883400 & 0.69402100 \\ \mathrm{C} & 2.27534300 & -0.52061500 & 0.41724000 \\ \mathrm{C} & 2.07328400 & 0.77474200 & -0.08680800 \\ \mathrm{C} & 0.75278000 & 1.19028000 & -0.27095400 \\ \mathrm{C} & -0.32434100 & 0.34309900 & 0.00527200 \\ \mathrm{C} & -0.00629100 & -0.94377700 & 0.47894500 \\ \mathrm{C} & 3.66884600 & -1.08238200 & 0.71422200 \\ \mathrm{C} & 4.84367800 & -0.11932700 & 0.32879200 \\ \mathrm{C} & 4.50106200 & 1.39972600 & 0.35006400\end{array}$




\begin{tabular}{|c|c|c|c|}
\hline $\mathrm{C}$ & 3.21932300 & 1.69181400 & -0.46287700 \\
\hline $\mathrm{C}$ & -1.75117200 & 0.82009500 & -0.23941500 \\
\hline $\mathrm{C}$ & -2.84195300 & -0.29310900 & -0.10359700 \\
\hline $\mathrm{C}$ & -2.44295000 & -1.29822700 & 1.00312700 \\
\hline $\mathrm{C}$ & -1.08623000 & -1.95844700 & 0.75933600 \\
\hline $\mathrm{C}$ & -2.12027500 & 2.06076000 & 0.61170400 \\
\hline $\mathrm{C}$ & -3.41255000 & 2.63161100 & 0.06223400 \\
\hline $\mathrm{O}$ & -4.36864500 & 1.70159900 & -0.20877300 \\
\hline $\mathrm{C}$ & -4.18314100 & 0.37799100 & 0.36630400 \\
\hline $\mathrm{O}$ & 3.84391200 & -2.26153000 & -0.13555000 \\
\hline $\mathrm{C}$ & 4.80050000 & -2.09097800 & -1.08659300 \\
\hline $\mathrm{C}$ & 5.35909100 & -0.68696600 & -1.00837300 \\
\hline $\mathrm{O}$ & 5.09665700 & -2.97018200 & -1.85951700 \\
\hline $\mathrm{C}$ & -5.44182300 & -0.38609200 & 0.08108900 \\
\hline $\mathrm{C}$ & -6.08895000 & -1.22425300 & 0.94336800 \\
\hline $\mathrm{O}$ & -7.19861300 & -1.75531700 & 0.35746500 \\
\hline $\mathrm{C}$ & -7.26985400 & -1.23157900 & -0.90260000 \\
\hline $\mathrm{C}$ & -6.22510400 & -0.39042500 & -1.12796900 \\
\hline $\mathrm{H}$ & 5.62891000 & -0.26815800 & 1.07976600 \\
\hline $\mathrm{O}$ & 3.51748200 & 1.57696300 & -1.86926500 \\
\hline $\mathrm{O}$ & -3.60208400 & 3.79393100 & -0.21043900 \\
\hline $\mathrm{H}$ & -1.78008300 & 1.16268300 & -1.28318700 \\
\hline $\mathrm{C}$ & -2.99451100 & -1.00080700 & -1.46280100 \\
\hline $\mathrm{C}$ & 3.75117900 & -1.59687600 & 2.15371800 \\
\hline $\mathrm{C}$ & 4.25434900 & 1.87110000 & 1.80273200 \\
\hline $\mathrm{C}$ & 5.68548400 & 2.21226800 & -0.21028500 \\
\hline $\mathrm{H}$ & 0.56419500 & 2.19743900 & -0.64222600 \\
\hline $\mathrm{H}$ & 2.91825300 & 2.73157300 & -0.26054300 \\
\hline $\mathrm{H}$ & -2.40492600 & -0.77166300 & 1.96751000 \\
\hline $\mathrm{H}$ & -3.22146900 & -2.06412500 & 1.09560300 \\
\hline $\mathrm{H}$ & -0.78438700 & -2.55938400 & 1.62262700 \\
\hline $\mathrm{H}$ & -1.13971800 & -2.65712300 & -0.08633200 \\
\hline $\mathrm{H}$ & -2.23308300 & 1.78901300 & 1.66905300 \\
\hline $\mathrm{H}$ & -1.36434300 & 2.84482600 & 0.55611900 \\
\hline $\mathrm{H}$ & -4.11674700 & 0.50890000 & 1.45289600 \\
\hline $\mathrm{H}$ & 6.44807100 & -0.71961500 & -1.08483400 \\
\hline $\mathrm{H}$ & 4.97963000 & -0.13368600 & -1.87086400 \\
\hline $\mathrm{H}$ & -5.90138500 & -1.52767300 & 1.96204800 \\
\hline $\mathrm{H}$ & -8.11378500 & -1.54618400 & -1.49604100 \\
\hline $\mathrm{H}$ & -6.03991600 & 0.18241700 & -2.02428000 \\
\hline $\mathrm{H}$ & 2.69445800 & 1.64819300 & -2.37045400 \\
\hline $\mathrm{H}$ & -3.65183400 & -1.87174800 & -1.39430900 \\
\hline $\mathrm{H}$ & -3.41178000 & -0.31940900 & -2.21131300 \\
\hline $\mathrm{H}$ & -2.02192600 & -1.33753400 & -1.83495500 \\
\hline $\mathrm{H}$ & 3.63681800 & -0.77880900 & 2.87053000 \\
\hline $\mathrm{H}$ & 2.96042800 & -2.32876800 & 2.32721700 \\
\hline $\mathrm{H}$ & 4.72287500 & -2.07216100 & 2.31782900 \\
\hline $\mathrm{H}$ & 4.09900200 & 2.95527800 & 1.82987400 \\
\hline $\mathrm{H}$ & 5.12393100 & 1.64557500 & 2.42877200 \\
\hline $\mathrm{H}$ & 3.37920900 & 1.40232500 & 2.26071900 \\
\hline $\mathrm{H}$ & 5.90513700 & 1.96202900 & -1.24903800 \\
\hline
\end{tabular}




$\begin{array}{lrrr}\mathrm{H} & 5.46670100 & 3.28520300 & -0.16715400 \\ \mathrm{H} & 6.58426000 & 2.03095700 & 0.39019200\end{array}$

Proposed structure of xylogranatin H (17-3)-conformer 17

Zero-point correction=

Thermal correction to Energy=

Thermal correction to Enthalpy=

Thermal correction to Gibbs Free Energy=

Sum of electronic and zero-point Energies=

Sum of electronic and thermal Energies=

Sum of electronic and thermal Enthalpies=

Sum of electronic and thermal Free Energies=
0.512654 (Hartree/Particle)

0.541452

0.542396

0.453903

$-1513.910463$

$-1513.881665$

$-1513.880721$

$-1513.969213$

01

$\begin{array}{lrrr}\mathrm{N} & 1.26841900 & -1.34040000 & 0.70264900 \\ \mathrm{C} & 2.28227400 & -0.51791400 & 0.41699000 \\ \mathrm{C} & 2.07055700 & 0.77532500 & -0.08873800 \\ \mathrm{C} & 0.74684500 & 1.18490800 & -0.26296500 \\ \mathrm{C} & -0.32412700 & 0.33336500 & 0.02358500 \\ \mathrm{C} & 0.00337400 & -0.95107300 & 0.49600600 \\ \mathrm{C} & 3.68042900 & -1.07206000 & 0.70636300 \\ \mathrm{C} & 4.84795700 & -0.10528000 & 0.30847400 \\ \mathrm{C} & 4.49898400 & 1.41234400 & 0.32714500 \\ \mathrm{C} & 3.20966000 & 1.69611800 & -0.47671900 \\ \mathrm{C} & -1.75498500 & 0.80447100 & -0.20647100 \\ \mathrm{C} & -2.84153900 & -0.31343600 & -0.06940200 \\ \mathrm{C} & -2.43044000 & -1.31822000 & 1.03387400 \\ \mathrm{C} & -1.07031700 & -1.96970600 & 0.78256600 \\ \mathrm{C} & -2.12031900 & 2.03717600 & 0.65773400 \\ \mathrm{C} & -3.41193900 & 2.61233200 & 0.11392500 \\ \mathrm{O} & -4.36304200 & 1.68205100 & -0.17255200 \\ \mathrm{C} & -4.18757800 & 0.35680900 & 0.39668200 \\ \mathrm{O} & 3.85518900 & -2.25408900 & -0.13934000 \\ \mathrm{C} & 4.80373800 & -2.08283500 & -1.09835200 \\ \mathrm{C} & 5.35526300 & -0.67548600 & -1.03068700 \\ \mathrm{O} & 5.09883900 & -2.96405200 & -1.86935700 \\ \mathrm{C} & -5.44470000 & -0.39998800 & 0.08062100 \\ \mathrm{C} & -6.36193700 & -0.09327600 & -0.88249500 \\ \mathrm{O} & -7.38591100 & -0.99497400 & -0.87234400 \\ \mathrm{C} & -7.12106000 & -1.89131700 & 0.11915700 \\ \mathrm{C} & -5.95058500 & -1.57700200 & 0.74058000 \\ \mathrm{H} & 5.63970800 & -0.24816100 & 1.05375200 \\ \mathrm{O} & 3.49735700 & 1.57770900 & -1.88494800 \\ \mathrm{O} & -3.60571800 & 3.77672500 & -0.14590900 \\ \mathrm{H} & -1.79430000 & 1.15404800 & -1.24749900 \\ \mathrm{C} & -3.00148900 & -1.01503800 & -1.43071900 \\ \mathrm{C} & 3.77506200 & -1.57983900 & 2.14752100 \\ \mathrm{C} & 4.26159300 & 1.88786800 & 1.78001100 \\ \mathrm{C} & 5.67550600 & 2.22786100 & -0.24539700 \\ \mathrm{H} & 0.55073300 & 2.19059800 & -0.63439100 \\ & & & \\ & & & 5\end{array}$

SI219 


$\begin{array}{lrrr}\mathrm{H} & 2.90564100 & 2.73523500 & -0.27551000 \\ \mathrm{H} & -2.39549000 & -0.79523700 & 2.00018600 \\ \mathrm{H} & -3.19648800 & -2.09513900 & 1.12617000 \\ \mathrm{H} & -0.76115700 & -2.57013900 & 1.64364500 \\ \mathrm{H} & -1.12585000 & -2.66759400 & -0.06369100 \\ \mathrm{H} & -2.23200700 & 1.75536900 & 1.71249300 \\ \mathrm{H} & -1.36386700 & 2.82117700 & 0.60851000 \\ \mathrm{H} & -4.13403300 & 0.48105300 & 1.48604500 \\ \mathrm{H} & 6.44371200 & -0.70242600 & -1.11625300 \\ \mathrm{H} & 4.96541800 & -0.12775000 & -1.89210400 \\ \mathrm{H} & -6.43589300 & 0.70916100 & -1.59785900 \\ \mathrm{H} & -7.85054100 & -2.67331600 & 0.25988500 \\ \mathrm{H} & -5.51254400 & -2.10738300 & 1.57391700 \\ \mathrm{H} & 2.67030700 & 1.64465800 & -2.38008400 \\ \mathrm{H} & -3.64499500 & -1.89613600 & -1.35867900 \\ \mathrm{H} & -3.44482100 & -0.33526800 & -2.16575800 \\ \mathrm{H} & -2.02941300 & -1.33384100 & -1.81992300 \\ \mathrm{H} & 3.66158700 & -0.75926400 & 2.86158900 \\ \mathrm{H} & 2.98907000 & -2.31480400 & 2.32951000 \\ \mathrm{H} & 4.75012400 & -2.04974800 & 2.30705900 \\ \mathrm{H} & 4.10232800 & 2.97153700 & 1.80455100 \\ \mathrm{H} & 5.13675300 & 1.66784200 & 2.40020600 \\ \mathrm{H} & 3.39172700 & 1.41741300 & 2.24625900 \\ \mathrm{H} & 5.88816500 & 1.97465200 & -1.28488700 \\ \mathrm{H} & 5.45243300 & 3.29999900 & -0.20457000 \\ \mathrm{H} & 6.57968700 & 2.05266200 & 0.34874900\end{array}$

\section{Proposed structure of xylogranatin H (17-3)-conformer 18}

Zero-point correction $=$

Thermal correction to Energy=

Thermal correction to Enthalpy=

Thermal correction to Gibbs Free Energy=

Sum of electronic and zero-point Energies $=$

Sum of electronic and thermal Energies=

Sum of electronic and thermal Enthalpies=

Sum of electronic and thermal Free Energies=
0.512596 (Hartree/Particle)

$$
0.541417
$$

0.542361

0.454020

$-1513.908195$

$-1513.879374$

$-1513.878430$

$-1513.966771$

01

$\begin{array}{lrrr}\mathrm{N} & -1.38552600 & -1.45282700 & -0.78014500 \\ \mathrm{C} & -2.23886300 & -0.47362200 & -0.45131100 \\ \mathrm{C} & -1.80021700 & 0.79569800 & -0.04937300 \\ \mathrm{C} & -0.41871200 & 1.00463600 & 0.01307900 \\ \mathrm{C} & 0.47837200 & -0.00816700 & -0.31507800 \\ \mathrm{C} & -0.06701700 & -1.24646200 & -0.71047000 \\ \mathrm{C} & -3.72047800 & -0.84641500 & -0.54416200 \\ \mathrm{C} & -4.66951700 & 0.26923500 & -0.00294600 \\ \mathrm{C} & -4.17514600 & 1.72535500 & -0.22098000 \\ \mathrm{C} & -2.73895600 & 1.91820800 & 0.34018400 \\ \mathrm{C} & 1.97872700 & 0.23014300 & -0.30922300 \\ \mathrm{C} & 2.77346600 & -1.07627200 & -0.07258300\end{array}$

SI220 


\begin{tabular}{|c|c|c|c|}
\hline $\mathrm{C}$ & 2.31393500 & -2.13068800 & -1.11182400 \\
\hline $\mathrm{C}$ & 0.80975100 & -2.44200000 & -1.02143100 \\
\hline $\mathrm{C}$ & 2.39367600 & 0.90457400 & -1.64142500 \\
\hline $\mathrm{C}$ & 3.83990500 & 0.77276800 & -2.09464000 \\
\hline $\mathrm{O}$ & 4.60346200 & -0.20724100 & -1.55462100 \\
\hline $\mathrm{C}$ & 4.29154500 & -0.79990100 & -0.25885200 \\
\hline $\mathrm{O}$ & -3.93917000 & -1.98511800 & 0.35363100 \\
\hline $\mathrm{C}$ & -4.61273600 & -1.63829800 & 1.48138700 \\
\hline $\mathrm{C}$ & -4.90854000 & -0.15352600 & 1.45951000 \\
\hline $\mathrm{O}$ & -4.89147600 & -2.44315700 & 2.33722900 \\
\hline $\mathrm{C}$ & 4.97330500 & 0.01384200 & 0.80970300 \\
\hline $\mathrm{C}$ & 5.87128100 & -0.47233200 & 1.71566600 \\
\hline $\mathrm{O}$ & 6.32002400 & 0.51807600 & 2.53658000 \\
\hline $\mathrm{C}$ & 5.70787900 & 1.66995800 & 2.13671100 \\
\hline $\mathrm{C}$ & 4.87599600 & 1.42637400 & 1.08764800 \\
\hline $\mathrm{H}$ & -5.61954600 & 0.16790400 & -0.54320800 \\
\hline $\mathrm{O}$ & -2.67125500 & 2.01767200 & 1.77727100 \\
\hline $\mathrm{O}$ & 4.29102000 & 1.44791600 & -2.99275700 \\
\hline $\mathrm{H}$ & 2.20671600 & 0.91939700 & 0.51258100 \\
\hline $\mathrm{C}$ & 2.54401500 & -1.60641000 & 1.35658000 \\
\hline $\mathrm{C}$ & -4.07731800 & -1.36235900 & -1.93914100 \\
\hline $\mathrm{C}$ & -4.13527600 & 2.07195800 & -1.72839800 \\
\hline $\mathrm{C}$ & -5.15369300 & 2.70843000 & 0.45259900 \\
\hline $\mathrm{H}$ & -0.04460100 & 1.97508200 & 0.33450300 \\
\hline $\mathrm{H}$ & -2.34376700 & 2.85522700 & -0.08239400 \\
\hline $\mathrm{H}$ & 2.55905500 & -1.78289000 & -2.12076500 \\
\hline $\mathrm{H}$ & 2.88446800 & -3.05609500 & -0.96687600 \\
\hline $\mathrm{H}$ & 0.45711400 & -2.90106000 & -1.95123200 \\
\hline $\mathrm{H}$ & 0.61904100 & -3.18963300 & -0.24090500 \\
\hline $\mathrm{H}$ & 1.81266900 & 0.47962000 & -2.46935100 \\
\hline $\mathrm{H}$ & 2.15050600 & 1.97078400 & -1.63636600 \\
\hline $\mathrm{H}$ & 4.79408400 & -1.77113800 & -0.30520900 \\
\hline $\mathrm{H}$ & -5.92352300 & 0.02704200 & 1.81932300 \\
\hline $\mathrm{H}$ & -4.21373300 & 0.33464900 & 2.14992400 \\
\hline $\mathrm{H}$ & 6.27725700 & -1.45629800 & 1.89450100 \\
\hline $\mathrm{H}$ & 5.97402300 & 2.56104600 & 2.68312200 \\
\hline $\mathrm{H}$ & 4.29588100 & 2.16983600 & 0.56045200 \\
\hline $\mathrm{H}$ & -3.03986500 & 2.86894400 & 2.04865500 \\
\hline $\mathrm{H}$ & 3.14535700 & -2.50491300 & 1.53821100 \\
\hline $\mathrm{H}$ & 2.81903200 & -0.86175400 & 2.10781200 \\
\hline $\mathrm{H}$ & 1.49676800 & -1.87108400 & 1.51944300 \\
\hline $\mathrm{H}$ & -3.94391800 & -0.58631200 & -2.69686300 \\
\hline $\mathrm{H}$ & -3.43121900 & -2.20657600 & -2.18704800 \\
\hline $\mathrm{H}$ & -5.12018400 & -1.69296800 & -1.95416600 \\
\hline $\mathrm{H}$ & -3.92579700 & 3.13862200 & -1.86665800 \\
\hline $\mathrm{H}$ & -5.10030100 & 1.85993100 & -2.20057200 \\
\hline $\mathrm{H}$ & -3.36531100 & 1.51587900 & -2.26927000 \\
\hline $\mathrm{H}$ & -5.27126500 & 2.51876200 & 1.52285600 \\
\hline $\mathrm{H}$ & -4.81776500 & 3.74479300 & 0.32023500 \\
\hline $\mathrm{H}$ & -6.14563000 & 2.62944800 & -0.00576200 \\
\hline
\end{tabular}


Proposed structure of xylogranatin H (17-3)-conformer 19

Zero-point correction=

Thermal correction to Energy=

Thermal correction to Enthalpy=

Thermal correction to Gibbs Free Energy=

Sum of electronic and zero-point Energies=

Sum of electronic and thermal Energies=

Sum of electronic and thermal Enthalpies=

Sum of electronic and thermal Free Energies=
0.512804 (Hartree/Particle)

0.541513

0.542457

0.454399

$-1513.907891$

$-1513.879182$

$-1513.878238$

$-1513.966297$

01

$\mathrm{N}$

C

C

C

C

C

C

C

C

C

C

C

C

C

C

C

O

C

O

C

C

O

C

C

O

C

C

$\mathrm{H}$

$\mathrm{O}$

O

$\mathrm{H}$

C

C

C

C

$\mathrm{H}$

$\mathrm{H}$

$\mathrm{H}$

$\mathrm{H}$ \begin{tabular}{rrr}
-1.39025200 & -1.48246800 & -0.72269600 \\
-2.23296000 & -0.48003200 & -0.43859400 \\
-1.78072600 & 0.79853200 & -0.08406300 \\
-0.39694900 & 0.99303600 & -0.02108200 \\
0.48850000 & -0.04322400 & -0.30335000 \\
-0.06982500 & -1.28980000 & -0.65291200 \\
-3.71859500 & -0.83746400 & -0.52703200 \\
-4.65689500 & 0.31046000 & -0.03715100 \\
-4.14237000 & 1.75052900 & -0.30871200 \\
-2.70762300 & 1.94703400 & 0.25480600 \\
1.99119000 & 0.17204100 & -0.30328200 \\
2.76007000 & -1.13175800 & 0.01429500 \\
2.30626400 & -2.23226100 & -0.97835500 \\
0.79271900 & -2.50952400 & -0.90984300 \\
2.41988100 & 0.75376700 & -1.67340500 \\
3.86521200 & 0.57081300 & -2.10238400 \\
4.61090100 & -0.38245900 & -1.49022000 \\
4.28472900 & -0.87170200 & -0.16058000 \\
-3.95781800 & -1.93693700 & 0.41356900 \\
-4.63388300 & -1.53715800 & 1.52207500 \\
-4.91107200 & -0.05100600 & 1.43912900 \\
-4.92768200 & -2.30379200 & 2.40753900 \\
4.94405500 & 0.04438700 & 0.84430500 \\
5.38341100 & 1.32025700 & 0.62446600 \\
5.98034900 & 1.82488900 & 1.74245300 \\
5.93707000 & 0.84852800 & 2.69285700 \\
5.32299400 & -0.26230400 & 2.20245800 \\
-5.60449300 & 0.19972700 & -0.57982100 \\
-2.64866200 & 2.10152500 & 1.68742000 \\
4.34164700 & 1.18149000 & -3.03357000 \\
2.23821100 & 0.90803000 & 0.47185500 \\
2.48361900 & -1.58904000 & 1.46007400 \\
-4.07282100 & -1.40378900 & -1.90303500 \\
-4.08819700 & 2.03706900 & -1.82824500 \\
-5.11252700 & 2.77171700 & 0.31869300 \\
-0.01166700 & 1.97049900 & 0.26360000 \\
-2.29745000 & 2.86175200 & -0.20093600 \\
2.58323600 & -1.94607400 & -1.99789500 \\
2.85409100 & -3.15911800 & -0.76900400 \\
& & \\
\hline
\end{tabular}

SI222 


$\begin{array}{lrrr}\mathrm{H} & 0.45089500 & -2.99009100 & -1.83286200 \\ \mathrm{H} & 0.56980800 & -3.22978100 & -0.11247000 \\ \mathrm{H} & 1.83669100 & 0.28675900 & -2.47694500 \\ \mathrm{H} & 2.19553600 & 1.82209600 & -1.73493100 \\ \mathrm{H} & 4.79039000 & -1.84312800 & -0.12127400 \\ \mathrm{H} & -5.92614100 & 0.15609200 & 1.78413200 \\ \mathrm{H} & -4.21499500 & 0.45596500 & 2.11454300 \\ \mathrm{H} & 5.39532300 & 1.96151700 & -0.24249000 \\ \mathrm{H} & 6.38018400 & 1.09381000 & 3.64527500 \\ \mathrm{H} & 5.16583700 & -1.18843900 & 2.73578300 \\ \mathrm{H} & -3.00256300 & 2.96970600 & 1.92232600 \\ \mathrm{H} & 3.08692500 & -2.46914100 & 1.71257700 \\ \mathrm{H} & 2.70837100 & -0.80039700 & 2.18185200 \\ \mathrm{H} & 1.43502500 & -1.86319100 & 1.59371300 \\ \mathrm{H} & -3.92400700 & -0.66025000 & -2.68995900 \\ \mathrm{H} & -3.43624100 & -2.26545600 & -2.11258300 \\ \mathrm{H} & -5.11983500 & -1.72124600 & -1.91261900 \\ \mathrm{H} & -3.86368000 & 3.09466900 & -2.00668900 \\ \mathrm{H} & -5.05294500 & 1.81929600 & -2.29839300 \\ \mathrm{H} & -3.32223500 & 1.45030600 & -2.34168500 \\ \mathrm{H} & -5.23928200 & 2.62609400 & 1.39475400 \\ \mathrm{H} & -4.76232800 & 3.79767200 & 0.14784500 \\ \mathrm{H} & -6.10240100 & 2.68722600 & -0.14315900\end{array}$

Proposed structure of xylogranatin H (17-3)-conformer 20

Zero-point correction=

Thermal correction to Energy=

Thermal correction to Enthalpy=

Thermal correction to Gibbs Free Energy=

Sum of electronic and zero-point Energies=

Sum of electronic and thermal Energies=

Sum of electronic and thermal Enthalpies $=$

Sum of electronic and thermal Free Energies=

01

$\begin{array}{lrrr}\mathrm{N} & -1.11622900 & -1.15721200 & -0.71559900 \\ \mathrm{C} & -2.19698200 & -0.42074700 & -0.42210100 \\ \mathrm{C} & -2.10125600 & 0.81199700 & 0.24174200 \\ \mathrm{C} & -0.81882300 & 1.27712100 & 0.55605000 \\ \mathrm{C} & 0.31294100 & 0.52310900 & 0.24950700 \\ \mathrm{C} & 0.09880700 & -0.71884400 & -0.37626100 \\ \mathrm{C} & -3.53404500 & -1.01051600 & -0.87931900 \\ \mathrm{C} & -4.78424800 & -0.16908800 & -0.45101400 \\ \mathrm{C} & -4.53541300 & 1.35703300 & -0.26750200 \\ \mathrm{C} & -3.31940200 & 1.61504700 & 0.65095100 \\ \mathrm{C} & 1.71198900 & 1.06053900 & 0.49861600 \\ \mathrm{C} & 2.83923800 & -0.03474500 & 0.70917900 \\ \mathrm{C} & 2.27386100 & -1.46805300 & 0.54238200 \\ \mathrm{C} & 1.28168400 & -1.62033900 & -0.61954900 \\ \mathrm{C} & 2.07253100 & 2.05898500 & -0.63865800\end{array}$

SI223 


\begin{tabular}{|c|c|c|c|}
\hline $\mathrm{C}$ & 3.48816500 & 2.56445700 & -0.48238200 \\
\hline $\mathrm{O}$ & 4.41551500 & 1.59087600 & -0.29544200 \\
\hline $\mathrm{C}$ & 3.96735400 & 0.20821600 & -0.35158000 \\
\hline $\mathrm{O}$ & -3.68971800 & -2.29943700 & -0.20284900 \\
\hline $\mathrm{C}$ & -4.70136200 & -2.30058900 & 0.70551100 \\
\hline $\mathrm{C}$ & -5.33110700 & -0.92652800 & 0.77496400 \\
\hline $\mathrm{O}$ & -4.98802100 & -3.28647000 & 1.34112400 \\
\hline $\mathrm{C}$ & 5.20711500 & -0.62974700 & -0.22041000 \\
\hline $\mathrm{C}$ & 6.37381000 & -0.28126000 & 0.39781300 \\
\hline $\mathrm{O}$ & 7.29245700 & -1.28243900 & 0.28595000 \\
\hline $\mathrm{C}$ & 6.70618200 & -2.28888800 & -0.42259800 \\
\hline $\mathrm{C}$ & 5.43376700 & -1.94493800 & -0.76450000 \\
\hline $\mathrm{H}$ & -5.51897100 & -0.26706000 & -1.25937400 \\
\hline $\mathrm{O}$ & -3.68574900 & 1.31793200 & 2.01403600 \\
\hline $\mathrm{O}$ & 3.82148600 & 3.72708200 & -0.48397400 \\
\hline $\mathrm{H}$ & 1.66901600 & 1.65844600 & 1.41646100 \\
\hline $\mathrm{C}$ & 3.41187300 & 0.10872100 & 2.13260800 \\
\hline $\mathrm{C}$ & -3.49860900 & -1.33452600 & -2.37529900 \\
\hline $\mathrm{C}$ & -4.24030800 & 2.01914400 & -1.63427500 \\
\hline $\mathrm{C}$ & -5.79607300 & 2.02737400 & 0.31424700 \\
\hline $\mathrm{H}$ & -0.70682500 & 2.24736400 & 1.04055400 \\
\hline $\mathrm{H}$ & -3.06963300 & 2.68587300 & 0.58996300 \\
\hline $\mathrm{H}$ & 3.10103500 & -2.17721500 & 0.44619000 \\
\hline $\mathrm{H}$ & 1.75083900 & -1.73869200 & 1.46782500 \\
\hline $\mathrm{H}$ & 1.75634200 & -1.37870100 & -1.58178200 \\
\hline $\mathrm{H}$ & 0.92319000 & -2.65009000 & -0.70119400 \\
\hline $\mathrm{H}$ & 1.96909100 & 1.57220400 & -1.61690200 \\
\hline $\mathrm{H}$ & 1.40255800 & 2.91992300 & -0.63250100 \\
\hline $\mathrm{H}$ & 3.55098300 & 0.03004900 & -1.35094800 \\
\hline $\mathrm{H}$ & -6.41908400 & -1.02034300 & 0.78860100 \\
\hline $\mathrm{H}$ & -5.02276500 & -0.47004500 & 1.71877900 \\
\hline $\mathrm{H}$ & 6.69865600 & 0.61179200 & 0.90618800 \\
\hline $\mathrm{H}$ & 7.31506800 & -3.16102400 & -0.60128000 \\
\hline $\mathrm{H}$ & 4.74667600 & -2.54520400 & -1.34432600 \\
\hline $\mathrm{H}$ & -2.89453900 & 1.36245500 & 2.56694500 \\
\hline $\mathrm{H}$ & 4.13850200 & -0.67932700 & 2.34882000 \\
\hline $\mathrm{H}$ & 3.90793400 & 1.07439500 & 2.27369400 \\
\hline $\mathrm{H}$ & 2.60259600 & 0.03183100 & 2.86663600 \\
\hline $\mathrm{H}$ & -3.39064900 & -0.42484800 & $-2.9725650 c$ \\
\hline $\mathrm{H}$ & -2.65634800 & -1.99564400 & -2.58698300 \\
\hline $\mathrm{H}$ & -4.42806400 & -1.83422700 & -2.6640970 \\
\hline $\mathrm{H}$ & -4.15702400 & 3.10561500 & -1.52055500 \\
\hline $\mathrm{H}$ & -5.05617200 & 1.82162500 & -2.3373260 \\
\hline $\mathrm{H}$ & -3.31115100 & 1.66440500 & -2.08835100 \\
\hline $\mathrm{H}$ & -6.05551300 & 1.63747600 & 1.29937600 \\
\hline $\mathrm{H}$ & -5.64179600 & 3.10757900 & 0.41555200 \\
\hline $\mathrm{H}$ & -6.64823500 & 1.87393800 & -0.35771300 \\
\hline
\end{tabular}




$\begin{array}{lc}\text { Zero-point correction }= & 0.512350 \text { (Hartree/Particle) } \\ \text { Thermal correction to Energy= } & 0.541230 \\ \text { Thermal correction to Enthalpy= } & 0.542174 \\ \text { Thermal correction to Gibbs Free Energy= } & 0.453797 \\ \text { Sum of electronic and zero-point Energies }= & -1513.910544 \\ \text { Sum of electronic and thermal Energies }= & -1513.881664 \\ \text { Sum of electronic and thermal Enthalpies }= & -1513.880720 \\ \text { Sum of electronic and thermal Free Energies }= & -1513.969098\end{array}$

01

\begin{tabular}{lrrr}
$\mathrm{N}$ & 1.37926200 & -1.62083200 & 0.11577000 \\
$\mathrm{C}$ & 2.19418000 & -0.59397100 & 0.37604800 \\
$\mathrm{C}$ & 1.72158000 & 0.69708400 & 0.65023300 \\
$\mathrm{C}$ & 0.33902600 & 0.89008700 & 0.63554600 \\
$\mathrm{C}$ & -0.52245900 & -0.17317500 & 0.36010000 \\
$\mathrm{C}$ & 0.05393800 & -1.42969500 & 0.09685600 \\
$\mathrm{C}$ & 3.68287800 & -0.91511000 & 0.38348600 \\
$\mathrm{C}$ & 4.62513400 & 0.32256100 & 0.53570000 \\
$\mathrm{C}$ & 3.99841800 & 1.69387600 & 0.13832100 \\
$\mathrm{C}$ & 2.68549500 & 1.82080100 & 0.96240000 \\
$\mathrm{C}$ & -2.03019200 & 0.01087700 & 0.40429900 \\
$\mathrm{C}$ & -2.76963800 & -1.00898800 & -0.49389500 \\
$\mathrm{C}$ & -2.30078500 & -2.43649100 & -0.11305700 \\
$\mathrm{C}$ & -0.78454200 & -2.63175300 & -0.28642600 \\
$\mathrm{C}$ & -2.51007000 & -0.08517600 & 1.87510200 \\
$\mathrm{C}$ & -3.96176600 & -0.45609400 & 2.13664200 \\
$\mathrm{O}$ & -4.67252000 & -1.04175300 & 1.14286600 \\
$\mathrm{C}$ & -4.30171400 & -0.89214200 & -0.25962700 \\
$\mathrm{O}$ & 4.01903200 & -1.47496100 & -0.93067800 \\
$\mathrm{C}$ & 5.24794300 & -1.07127800 & -1.34202800 \\
$\mathrm{C}$ & 5.82726000 & -0.09890400 & -0.32574300 \\
$\mathrm{O}$ & 5.75280900 & -1.46348700 & -2.36598700 \\
$\mathrm{C}$ & -4.98284200 & 0.33759700 & -0.80065900 \\
$\mathrm{C}$ & -5.84200400 & 0.35775100 & -1.86126600 \\
$\mathrm{O}$ & -6.30233900 & 1.61925600 & -2.09176500 \\
$\mathrm{C}$ & -5.73746800 & 2.42430800 & -1.14587100 \\
$\mathrm{C}$ & -4.92444900 & 1.70014500 & -0.32954900 \\
$\mathrm{H}$ & 4.91596600 & 0.40014700 & 1.58993800 \\
$\mathrm{O}$ & 2.00297100 & 3.05915300 & 0.75114500 \\
$\mathrm{O}$ & -4.46349800 & -0.33862200 & 3.23235100 \\
$\mathrm{H}$ & -2.25642600 & 1.01740400 & 0.03292000 \\
$\mathrm{C}$ & -2.48111900 & -0.73744800 & -1.98371600 \\
$\mathrm{C}$ & 3.98410900 & -1.99492400 & 1.43071800 \\
$\mathrm{C}$ & 4.96282400 & 2.82023100 & 0.56354500 \\
$\mathrm{C}$ & 3.70186100 & 1.82464800 & -1.36997100 \\
$\mathrm{H}$ & -0.05486500 & 1.88371300 & 0.82578800 \\
$\mathrm{H}$ & 2.96163900 & 1.75197600 & 2.02905800 \\
$\mathrm{H}$ & -2.58456900 & -2.65208900 & 0.92237400 \\
$\mathrm{H}$ & -2.83376600 & -3.17076200 & -0.72937800 \\
$\mathrm{H}$ & -0.44192400 & -3.49592900 & 0.29283000 \\
& -1.934626100 & -2.87194900 & -1.33062500 \\
$\mathrm{H}$ & & -0.85760800 & 2.40249700 \\
\hline
\end{tabular}




$\begin{array}{lrrr}\mathrm{H} & -2.30816200 & 0.84320400 & 2.41656200 \\ \mathrm{H} & -4.76885700 & -1.76228600 & -0.73157800 \\ \mathrm{H} & 6.58383800 & -0.63457600 & 0.25851200 \\ \mathrm{H} & 6.34187600 & 0.71398200 & -0.83982000 \\ \mathrm{H} & -6.21150900 & -0.40994600 & -2.52392000 \\ \mathrm{H} & -6.01809500 & 3.46515400 & -1.18217200 \\ \mathrm{H} & -4.38068400 & 2.08764400 & 0.51976200 \\ \mathrm{H} & 2.48207000 & 3.76261900 & 1.20557900 \\ \mathrm{H} & -3.04301700 & -1.43075600 & -2.62060200 \\ \mathrm{H} & -2.76313900 & 0.28007000 & -2.26591500 \\ \mathrm{H} & -1.42041500 & -0.86389600 & -2.21239000 \\ \mathrm{H} & 3.70658300 & -1.64430000 & 2.43051600 \\ \mathrm{H} & 3.40459800 & -2.89091600 & 1.20040500 \\ \mathrm{H} & 5.04881000 & -2.24978500 & 1.43534700 \\ \mathrm{H} & 4.57301400 & 3.80233200 & 0.27484400 \\ \mathrm{H} & 5.93755900 & 2.71655100 & 0.07734900 \\ \mathrm{H} & 5.13249000 & 2.81855900 & 1.64790400 \\ \mathrm{H} & 3.08011300 & 1.00965000 & -1.74809900 \\ \mathrm{H} & 3.17324100 & 2.76293100 & -1.55959900 \\ \mathrm{H} & 4.62642400 & 1.83908700 & -1.95507700\end{array}$

\section{Proposed structure of xylogranatin H (17-3)-conformer 22}

$\begin{array}{lcc}\text { Zero-point correction }= & 0.512626 \text { (Hartree/Particle) } \\ \text { Thermal correction to Energy= } & 0.541264 \\ \text { Thermal correction to Enthalpy= } & 0.542208 \\ \text { Thermal correction to Gibbs Free Energy= } & 0.453977 \\ \text { Sum of electronic and zero-point Energies }= & -1513.903858 \\ \text { Sum of electronic and thermal Energies }= & -1513.875220 \\ \text { Sum of electronic and thermal Enthalpies }= & -1513.874276 \\ \text { Sum of electronic and thermal Free Energies }= & -1513.962508\end{array}$
01

$\begin{array}{lrrr}\mathrm{N} & 1.09940200 & -1.37339600 & 0.28884200 \\ \mathrm{C} & 2.03848400 & -0.42548100 & 0.34298500 \\ \mathrm{C} & 1.79667100 & 0.89763400 & -0.05041500 \\ \mathrm{C} & 0.51544700 & 1.20820900 & -0.50550600 \\ \mathrm{C} & -0.48259100 & 0.23074500 & -0.55790900 \\ \mathrm{C} & -0.12581400 & -1.06900500 & -0.15743100 \\ \mathrm{C} & 3.39215400 & -0.86075300 & 0.88712300 \\ \mathrm{C} & 4.51685600 & 0.22050600 & 0.79923700 \\ \mathrm{C} & 4.28722100 & 1.33979600 & -0.26171300 \\ \mathrm{C} & 2.88666300 & 1.94294700 & 0.04363300 \\ \mathrm{C} & -1.88204300 & 0.59686400 & -1.05867700 \\ \mathrm{C} & -2.92258900 & -0.56915500 & -1.07734400 \\ \mathrm{C} & -2.19514300 & -1.91984200 & -1.28473100 \\ \mathrm{C} & -1.12067300 & -2.19923100 & -0.23216200 \\ \mathrm{C} & -2.46523400 & 1.77971900 & -0.25597600 \\ \mathrm{C} & -2.66781400 & 1.37616300 & 1.18857900 \\ \mathrm{O} & -3.10825000 & 0.10670100 & 1.38186600 \\ \mathrm{C} & -3.72434400 & -0.64500000 & 0.29276500 \\ & & & \mathrm{SI} 226\end{array}$




$\begin{array}{lrrr}\mathrm{O} & 3.87409000 & -1.96297300 & 0.04581900 \\ \mathrm{C} & 5.21816100 & -1.90122400 & -0.12925500 \\ \mathrm{C} & 5.75922200 & -0.64924700 & 0.54450000 \\ \mathrm{O} & 5.83543500 & -2.74480900 & -0.73367700 \\ \mathrm{C} & -5.20290100 & -0.34920000 & 0.26816900 \\ \mathrm{C} & -6.17321100 & -1.30186500 & 0.39540700 \\ \mathrm{O} & -7.41549100 & -0.74354700 & 0.36294700 \\ \mathrm{C} & -7.23710600 & 0.60261900 & 0.22970000 \\ \mathrm{C} & -5.91182700 & 0.90341300 & 0.16642500 \\ \mathrm{H} & 4.58771300 & 0.71662700 & 1.77428000 \\ \mathrm{O} & 2.53985800 & 3.02540900 & -0.82497300 \\ \mathrm{O} & -2.40810000 & 2.07358900 & 2.14235000 \\ \mathrm{H} & -1.76324100 & 0.93569700 & -2.09623100 \\ \mathrm{C} & -3.87544300 & -0.35701600 & -2.27166300 \\ \mathrm{C} & 3.23382700 & -1.40754000 & 2.31162400 \\ \mathrm{C} & 5.35356800 & 2.43654800 & -0.06368300 \\ \mathrm{C} & 4.34763700 & 0.83300400 & -1.71765000 \\ \mathrm{H} & 0.31921200 & 2.22481900 & -0.82896300 \\ \mathrm{H} & 2.91049100 & 2.32125200 & 1.08001500 \\ \mathrm{H} & -2.93531900 & -2.73001100 & -1.30152300 \\ \mathrm{H} & -1.72454900 & -1.91061900 & -2.27657900 \\ \mathrm{H} & -1.56843600 & -2.34950100 & 0.76033300 \\ \mathrm{H} & -0.57903000 & -3.12162800 & -0.46194900 \\ \mathrm{H} & -1.81912900 & 2.65808500 & -0.26397500 \\ \mathrm{H} & -3.42235400 & 2.08431300 & -0.69375300 \\ \mathrm{H} & -3.63627400 & -1.67111300 & 0.65528200 \\ \mathrm{H} & 6.24598100 & -0.95360600 & 1.47784700 \\ \mathrm{H} & 6.52899200 & -0.19357300 & -0.07977500 \\ \mathrm{H} & -6.13859700 & -2.37375400 & 0.51914800 \\ \mathrm{H} & -8.13577700 & 1.19867500 & 0.20452500 \\ \mathrm{H} & -5.50090300 & 1.89875200 & 0.08527900 \\ \mathrm{H} & 3.01750100 & 3.81589000 & -0.54619700 \\ \mathrm{H} & -4.64815100 & -1.13024300 & -2.30801600 \\ \mathrm{H} & -4.38540700 & 0.60998500 & -2.23609700 \\ \mathrm{H} & -3.30658800 & -0.40528600 & -3.20614600 \\ \mathrm{H} & 2.82872000 & -0.63484500 & 2.97346900 \\ \mathrm{H} & 2.54273600 & -2.25244500 & 2.29771300 \\ \mathrm{H} & 5.19679600 & -1.73984700 & 2.71283100 \\ \mathrm{H} & & & \\ \mathrm{H} & 5.365268000 & 2.03710100 & -0.18315200 \\ \mathrm{H} & 2.8380000 & 0.00360800 & -1.90222500 \\ \mathrm{H} & & 0.49663000 & -1.97814300\end{array}$

\section{Proposed structure of xylogranatin H (17-3)-conformer 23}

Zero-point correction=

Thermal correction to Energy=

Thermal correction to Enthalpy=
0.512679 (Hartree/Particle)

0.541451

0.542396 


$\begin{array}{lc}\text { Thermal correction to Gibbs Free Energy= } & 0.453589 \\ \text { Sum of electronic and zero-point Energies }= & -1513.909937 \\ \text { Sum of electronic and thermal Energies }= & -1513.881165 \\ \text { Sum of electronic and thermal Enthalpies }= & -1513.880221 \\ \text { Sum of electronic and thermal Free Energies }= & -1513.969027\end{array}$

01

\begin{tabular}{|c|c|c|c|}
\hline $\mathrm{N}$ & 1.13960900 & -1.10637900 & 0.82867200 \\
\hline $\mathrm{C}$ & 2.21415900 & -0.39325800 & 0.46042600 \\
\hline $\mathrm{C}$ & 2.10338500 & 0.80413500 & -0.26255700 \\
\hline $\mathrm{C}$ & 0.81367600 & 1.26109800 & -0.56176300 \\
\hline $\mathrm{C}$ & -0.30956900 & 0.52998200 & -0.18125200 \\
\hline $\mathrm{C}$ & -0.08225300 & -0.67680600 & 0.50572200 \\
\hline $\mathrm{C}$ & 3.56226800 & -0.96857900 & 0.90317800 \\
\hline $\mathrm{C}$ & 4.80253000 & -0.15723300 & 0.39546400 \\
\hline $\mathrm{C}$ & 4.55498500 & 1.35917500 & 0.14289700 \\
\hline $\mathrm{C}$ & 3.31198600 & 1.57796500 & -0.74918300 \\
\hline $\mathrm{C}$ & -1.71749700 & 1.04771900 & -0.40932300 \\
\hline $\mathrm{C}$ & -2.81925200 & -0.07079900 & -0.62887400 \\
\hline $\mathrm{C}$ & -2.26606200 & -1.49030200 & -0.33097000 \\
\hline $\mathrm{C}$ & -1.26781200 & -1.54562600 & 0.83592700 \\
\hline $\mathrm{C}$ & -2.09342700 & 2.02184400 & 0.74246400 \\
\hline $\mathrm{C}$ & -3.49377600 & 2.55563300 & 0.54213600 \\
\hline $\mathrm{O}$ & -4.42515200 & 1.60507400 & 0.27234300 \\
\hline $\mathrm{C}$ & -4.01058700 & 0.21131800 & 0.34844000 \\
\hline $\mathrm{O}$ & 3.68924400 & -2.28971800 & 0.28531600 \\
\hline $\mathrm{C}$ & 4.67315100 & -2.34253600 & -0.65157600 \\
\hline $\mathrm{C}$ & 5.30848500 & -0.97816000 & -0.80696000 \\
\hline $\mathrm{O}$ & 4.93473300 & -3.36022100 & -1.24660600 \\
\hline $\mathrm{C}$ & -5.25881500 & -0.59590600 & 0.14216600 \\
\hline $\mathrm{C}$ & -5.64798900 & -1.67842500 & 0.87859900 \\
\hline $\mathrm{O}$ & -6.83894900 & -2.16424400 & 0.43126900 \\
\hline $\mathrm{C}$ & -7.22868000 & -1.36320500 & -0.60505900 \\
\hline $\mathrm{C}$ & -6.30544500 & -0.38950300 & -0.82671700 \\
\hline $\mathrm{H}$ & 5.56110900 & -0.21883400 & 1.18513000 \\
\hline $\mathrm{O}$ & 3.63447900 & 1.21046300 & -2.10626200 \\
\hline $\mathrm{O}$ & -3.80715300 & 3.72349300 & 0.56566700 \\
\hline $\mathrm{H}$ & -1.69455100 & 1.66064900 & -1.31804200 \\
\hline $\mathrm{C}$ & -3.28695200 & -0.01559100 & -2.09576400 \\
\hline $\mathrm{C}$ & 3.57362900 & -1.21931300 & 2.41354400 \\
\hline $\mathrm{C}$ & 4.30626100 & 2.09102100 & 1.48298500 \\
\hline $\mathrm{C}$ & 5.79979800 & 1.99167900 & -0.51105300 \\
\hline $\mathrm{H}$ & 0.69032000 & 2.20582900 & -1.09172900 \\
\hline $\mathrm{H}$ & 3.06912900 & 2.65199400 & -0.73469700 \\
\hline $\mathrm{H}$ & -3.10359500 & -2.17370900 & -0.15715300 \\
\hline $\mathrm{H}$ & -1.75414600 & -1.85853900 & -1.22802700 \\
\hline $\mathrm{H}$ & -1.73757500 & -1.21288100 & 1.77328200 \\
\hline $\mathrm{H}$ & -0.91801400 & -2.56689500 & 1.00857400 \\
\hline $\mathrm{H}$ & -2.02996200 & 1.51220500 & 1.71229900 \\
\hline $\mathrm{H}$ & -1.40931100 & 2.87109600 & 0.77646200 \\
\hline $\mathrm{H}$ & -3.66238200 & 0.02169100 & 1.37104500 \\
\hline $\mathrm{H}$ & 6.39504000 & -1.08035700 & -0.84780400 \\
\hline
\end{tabular}




$\begin{array}{lrrr}\mathrm{H} & 4.97504900 & -0.56648600 & -1.76276700 \\ \mathrm{H} & -5.21246300 & -2.19707100 & 1.71921600 \\ \mathrm{H} & -8.17345900 & -1.61153500 & -1.06229500 \\ \mathrm{H} & -6.36446000 & 0.39828000 & -1.56253000 \\ \mathrm{H} & 2.82704800 & 1.23395700 & -2.63648600 \\ \mathrm{H} & -3.97329700 & -0.83483900 & -2.32687500 \\ \mathrm{H} & -3.79238000 & 0.92895400 & -2.32262400 \\ \mathrm{H} & -2.42237500 & -0.10541300 & -2.76240100 \\ \mathrm{H} & 3.48958000 & -0.28091300 & 2.96883100 \\ \mathrm{H} & 2.73547000 & -1.86379300 & 2.68438700 \\ \mathrm{H} & 4.50954700 & -1.71028000 & 2.69638900 \\ \mathrm{H} & 4.22340600 & 3.17078900 & 1.31715000 \\ \mathrm{H} & 5.14353900 & 1.92488500 & 2.16876300 \\ \mathrm{H} & 3.39090300 & 1.76450800 & 1.98380700 \\ \mathrm{H} & 6.02668100 & 1.55097400 & -1.48273900 \\ \mathrm{H} & 5.64723000 & 3.06629900 & -0.66216300 \\ \mathrm{H} & 6.67186300 & 1.86734800 & 0.14108500\end{array}$

\section{Proposed structure of xylogranatin H (17-3)-conformer 24}

Zero-point correction $=$

Thermal correction to Energy=

Thermal correction to Enthalpy=

Thermal correction to Gibbs Free Energy=

Sum of electronic and zero-point Energies=

Sum of electronic and thermal Energies=

Sum of electronic and thermal Enthalpies=

Sum of electronic and thermal Free Energies=
0.512715 (Hartree/Particle)

0.541263

0.542207

0.454340

$-1513.903826$

$-1513.875277$

$-1513.874333$

$-1513.962201$

01

$\begin{array}{lrrr}\mathrm{N} & 1.11659300 & -1.35173300 & 0.39250500 \\ \mathrm{C} & 2.04291600 & -0.38979600 & 0.37245000 \\ \mathrm{C} & 1.78063700 & 0.89974000 & -0.10998100 \\ \mathrm{C} & 0.49144200 & 1.16198100 & -0.57307600 \\ \mathrm{C} & -0.49312700 & 0.17030000 & -0.54703200 \\ \mathrm{C} & -0.11637400 & -1.09434100 & -0.06166000 \\ \mathrm{C} & 3.40660600 & -0.76879700 & 0.93342100 \\ \mathrm{C} & 4.51663600 & 0.31712900 & 0.75861200 \\ \mathrm{C} & 4.26336600 & 1.35603300 & -0.37610400 \\ \mathrm{C} & 2.85802700 & 1.96203900 & -0.09969000 \\ \mathrm{C} & -1.90480200 & 0.49021100 & -1.04348900 \\ \mathrm{C} & -2.91343200 & -0.70785900 & -1.04804200 \\ \mathrm{C} & -2.14771500 & -2.04799200 & -1.15904300 \\ \mathrm{C} & -1.09805100 & -2.23822200 & -0.06205900 \\ \mathrm{C} & -2.51146800 & 1.66191600 & -0.23924500 \\ \mathrm{C} & -2.67306000 & 1.24672500 & 1.20469100 \\ \mathrm{O} & -3.11952700 & -0.02510600 & 1.38987500 \\ \mathrm{C} & -3.76629500 & -0.73055700 & 0.29536000 \\ \mathrm{O} & 3.89564400 & -1.92215300 & 0.16823400 \\ \mathrm{C} & 5.23717500 & -1.85645800 & -0.02374200 \\ \mathrm{C} & 5.76781100 & -0.55315200 & 0.55401100\end{array}$




$\begin{array}{lrrr}\mathrm{O} & 5.86011000 & -2.73317900 & -0.57268900 \\ \mathrm{C} & -5.21760200 & -0.30860200 & 0.23446800 \\ \mathrm{C} & -5.79278000 & 0.79607200 & 0.79624500 \\ \mathrm{O} & -7.14461300 & 0.78700900 & 0.60764500 \\ \mathrm{C} & -7.44410000 & -0.35454300 & -0.07366600 \\ \mathrm{C} & -6.31179600 & -1.06639600 & -0.32294800 \\ \mathrm{H} & 4.58967500 & 0.88170600 & 1.69553000 \\ \mathrm{O} & 2.48921500 & 2.97719600 & -1.03772000 \\ \mathrm{O} & -2.39190700 & 1.92778600 & 2.16405600 \\ \mathrm{H} & -1.80188100 & 0.82945600 & -2.08194800 \\ \mathrm{C} & -3.81727700 & -0.56764400 & -2.28887200 \\ \mathrm{C} & 3.26725000 & -1.21450200 & 2.39462900 \\ \mathrm{C} & 5.31746000 & 2.47675100 & -0.26590600 \\ \mathrm{C} & 4.31722100 & 0.74878900 & -1.79335500 \\ \mathrm{H} & 0.27663400 & 2.15083800 & -0.96468800 \\ \mathrm{H} & 2.88666900 & 2.41176800 & 0.90766300 \\ \mathrm{H} & -2.86731200 & -2.87649900 & -1.14920100 \\ \mathrm{H} & -1.64744200 & -2.08324200 & -2.13573600 \\ \mathrm{H} & -1.57125200 & -2.31195800 & 0.92695000 \\ \mathrm{H} & -0.54309100 & -3.16970100 & -0.20723500 \\ \mathrm{H} & -1.88845300 & 2.55660000 & -0.26119200 \\ \mathrm{H} & -3.49030600 & 1.93157600 & -0.65323300 \\ \mathrm{H} & -3.76502900 & -1.76325400 & 0.65555700 \\ \mathrm{H} & 6.26687200 & -0.78429200 & 1.50174600 \\ \mathrm{H} & 6.52596100 & -0.13358300 & -0.10863400 \\ \mathrm{H} & -5.40925200 & 1.61952400 & 1.37752600 \\ \mathrm{H} & -8.48732500 & -0.51433300 & -0.29676700 \\ \mathrm{H} & -6.26059400 & -2.01918400 & -0.83035700 \\ \mathrm{H} & 2.96429800 & 3.78898900 & -0.82317600 \\ \mathrm{H} & -4.53623800 & -1.38773700 & -2.36396400 \\ \mathrm{H} & -4.38491300 & 0.36754000 & -2.28685600 \\ \mathrm{H} & -3.19917300 & -0.59089200 & -3.19233100 \\ \mathrm{H} & 2.85722900 & -0.40181900 & 3.00340800 \\ \mathrm{H} & 2.58745600 & -2.06700700 & 2.44741500 \\ \mathrm{H} & 4.23791800 & -1.50489500 & 2.80957900 \\ \mathrm{H} & 5.18853000 & 3.21693600 & -1.06288200 \\ \mathrm{H} & 6.33301600 & 2.08201500 & -0.36687200 \\ \mathrm{H} & 5.25783900 & 2.99303200 & 0.70078200 \\ \mathrm{H} & 3.64022900 & -0.10059600 & -1.91215700 \\ \mathrm{H} & 5.32755100 & 0.40827600 & -2.03981900\end{array}$

\section{Revised structure of xylogranatin H (17-6)-conformer 1}

Zero-point correction $=$ Thermal correction to Energy= Thermal correction to Enthalpy= Thermal correction to Gibbs Free Energy= Sum of electronic and zero-point Energies $=$ Sum of electronic and thermal Energies $=$
0.512692 (Hartree/Particle)

0.541389

0.542333

0.454331

$-1513.911744$

$-1513.883047$

SI230 


$\begin{array}{lc}\text { Sum of electronic and thermal Enthalpies }= & -1513.882102 \\ \text { Sum of electronic and thermal Free Energies }= & -1513.970104\end{array}$

01

\begin{tabular}{|c|c|c|c|}
\hline $\mathrm{N}$ & -1.24442200 & -1.28487500 & -0.65429300 \\
\hline $\mathrm{C}$ & -2.23443700 & -0.40646700 & -0.47308400 \\
\hline $\mathrm{C}$ & -1.99875700 & 0.91931600 & -0.08716000 \\
\hline $\mathrm{C}$ & -0.67408200 & 1.30613200 & 0.10632000 \\
\hline $\mathrm{C}$ & 0.37668300 & 0.40296800 & -0.07868200 \\
\hline $\mathrm{C}$ & 0.02616600 & -0.90766400 & -0.45546900 \\
\hline $\mathrm{C}$ & -3.64287900 & -0.92324800 & -0.73631000 \\
\hline $\mathrm{C}$ & -4.79329800 & 0.08088300 & -0.41123000 \\
\hline $\mathrm{C}$ & -4.42170100 & 1.20679100 & 0.59912500 \\
\hline $\mathrm{C}$ & -3.13325300 & 1.90012800 & 0.08157400 \\
\hline $\mathrm{C}$ & 1.81269500 & 0.85047900 & 0.16899000 \\
\hline $\mathrm{C}$ & 2.87136800 & -0.30098600 & 0.13243800 \\
\hline $\mathrm{C}$ & 2.45875500 & -1.37229300 & -0.90489700 \\
\hline $\mathrm{C}$ & 1.07918100 & -1.97246500 & -0.63587100 \\
\hline $\mathrm{C}$ & 2.23738300 & 2.02131600 & -0.75268600 \\
\hline $\mathrm{C}$ & 3.53714300 & 2.58628600 & -0.21638600 \\
\hline $\mathrm{O}$ & 4.45960500 & 1.64644900 & 0.12981800 \\
\hline $\mathrm{C}$ & 4.23895000 & 0.29491100 & -0.36080600 \\
\hline $\mathrm{O}$ & -3.87068600 & -2.05169700 & 0.17673600 \\
\hline $\mathrm{C}$ & -5.15436500 & -2.07774100 & 0.61866400 \\
\hline $\mathrm{C}$ & -5.90044900 & -0.86892500 & 0.07402200 \\
\hline $\mathrm{O}$ & -5.57843600 & -2.95551500 & 1.33123000 \\
\hline $\mathrm{C}$ & 5.46891400 & -0.48773000 & -0.00772500 \\
\hline $\mathrm{C}$ & 6.09936900 & -1.40150900 & -0.80282900 \\
\hline $\mathrm{O}$ & 7.18468500 & -1.92637600 & -0.16726500 \\
\hline $\mathrm{C}$ & 7.25734700 & -1.32153900 & 1.05591700 \\
\hline $\mathrm{C}$ & 6.23736600 & -0.43506800 & 1.20969900 \\
\hline $\mathrm{H}$ & -5.07921100 & 0.57831600 & -1.34162300 \\
\hline $\mathrm{O}$ & -3.31185400 & 2.52949800 & -1.20225000 \\
\hline $\mathrm{O}$ & 3.76040500 & 3.75698100 & -0.01349900 \\
\hline $\mathrm{H}$ & 1.82899000 & 1.26062400 & 1.18840300 \\
\hline $\mathrm{C}$ & 2.98287600 & -0.91197600 & 1.54170900 \\
\hline $\mathrm{C}$ & -3.74489600 & -1.45903100 & -2.16962100 \\
\hline $\mathrm{C}$ & -5.56787500 & 2.23756800 & 0.66128400 \\
\hline $\mathrm{C}$ & -4.15541500 & 0.69039800 & 2.03135000 \\
\hline $\mathrm{H}$ & -0.46450800 & 2.32826800 & 0.41616600 \\
\hline $\mathrm{H}$ & -2.83374500 & 2.66491900 & 0.81407600 \\
\hline $\mathrm{H}$ & 2.45043400 & -0.91664300 & -1.90540800 \\
\hline $\mathrm{H}$ & 3.21491800 & -2.16539800 & -0.92823300 \\
\hline $\mathrm{H}$ & 0.77328300 & -2.62865600 & -1.45656800 \\
\hline $\mathrm{H}$ & 1.09867200 & -2.60593000 & 0.26105600 \\
\hline $\mathrm{H}$ & 2.35991700 & 1.67788100 & -1.78783800 \\
\hline $\mathrm{H}$ & 1.50529000 & 2.82933900 & -0.76369500 \\
\hline $\mathrm{H}$ & 4.19040300 & 0.35586100 & -1.45454800 \\
\hline $\mathrm{H}$ & -6.53736200 & -1.21113100 & -0.74954500 \\
\hline $\mathrm{H}$ & -6.56493100 & -0.46393400 & 0.83875600 \\
\hline $\mathrm{H}$ & 5.91425400 & -1.76680100 & -1.80143800 \\
\hline $\mathrm{H}$ & 8.08365800 & -1.62150700 & 1.68090700 \\
\hline
\end{tabular}




$\begin{array}{lrrr}\mathrm{H} & 6.05956900 & 0.20229600 & 2.06290400 \\ \mathrm{H} & -3.85889400 & 3.31843400 & -1.09112500 \\ \mathrm{H} & 3.61290700 & -1.80559700 & 1.54724400 \\ \mathrm{H} & 3.41124200 & -0.19058200 & 2.24516100 \\ \mathrm{H} & 1.99491600 & -1.19009800 & 1.92170300 \\ \mathrm{H} & -3.53794000 & -0.65742800 & -2.88571200 \\ \mathrm{H} & -3.01431600 & -2.25774500 & -2.31064900 \\ \mathrm{H} & -4.74687500 & -1.85317100 & -2.36729000 \\ \mathrm{H} & -5.28552300 & 3.09410700 & 1.28593400 \\ \mathrm{H} & -6.46868100 & 1.80240400 & 1.10476400 \\ \mathrm{H} & -5.84439800 & 2.60795800 & -0.33188400 \\ \mathrm{H} & -3.36853400 & -0.06627800 & 2.07037300 \\ \mathrm{H} & -3.85141700 & 1.52129900 & 2.67861900 \\ \mathrm{H} & -5.05764700 & 0.25537400 & 2.47135500\end{array}$

Revised structure of xylogranatin H (17-6)-conformer 2

Zero-point correction=

Thermal correction to Energy=

Thermal correction to Enthalpy=

Thermal correction to Gibbs Free Energy=

Sum of electronic and zero-point Energies=

Sum of electronic and thermal Energies=

Sum of electronic and thermal Enthalpies=

Sum of electronic and thermal Free Energies=
0.512662 (Hartree/Particle)

0.541371

0.542315

0.454373

$-1513.911728$

$-1513.883019$

$-1513.882075$

$-1513.970017$

01

$\begin{array}{lrrr}\mathrm{N} & -1.25715900 & -1.28481700 & -0.66791600 \\ \mathrm{C} & -2.24141500 & -0.40238200 & -0.47512900 \\ \mathrm{C} & -1.99635300 & 0.92014000 & -0.08366000 \\ \mathrm{C} & -0.66838300 & 1.29982800 & 0.10104600 \\ \mathrm{C} & 0.37632500 & 0.39238400 & -0.09672900 \\ \mathrm{C} & 0.01652000 & -0.91437300 & -0.47642100 \\ \mathrm{C} & -3.65427800 & -0.91052900 & -0.73141300 \\ \mathrm{C} & -4.79734800 & 0.09710600 & -0.39143300 \\ \mathrm{C} & -4.41257600 & 1.21487500 & 0.62297600 \\ \mathrm{C} & -3.12483600 & 1.90526000 & 0.09972700 \\ \mathrm{C} & 1.81646600 & 0.83224700 & 0.13816700 \\ \mathrm{C} & 2.87061000 & -0.32383500 & 0.09791800 \\ \mathrm{C} & 2.44634000 & -1.39099900 & -0.93970600 \\ \mathrm{C} & 1.06341100 & -1.98270400 & -0.66625900 \\ \mathrm{C} & 2.23777100 & 1.99682900 & -0.79292000 \\ \mathrm{C} & 3.53684200 & 2.56440300 & -0.26038900 \\ \mathrm{O} & 4.45371200 & 1.62450100 & 0.09967300 \\ \mathrm{C} & 4.24345800 & 0.27262600 & -0.38853600 \\ \mathrm{O} & -3.88101700 & -2.04391200 & 0.17570100 \\ \mathrm{C} & -5.16146300 & -2.06648900 & 0.62709800 \\ \mathrm{C} & -5.90549700 & -0.85033100 & 0.09619800 \\ \mathrm{O} & -5.58463000 & -2.94697800 & 1.33683500 \\ \mathrm{C} & 5.47137000 & -0.50163300 & -0.00622500 \\ \mathrm{C} & 6.38474900 & -0.16338700 & 0.94993300\end{array}$

SI232 


$\begin{array}{lrrr}\mathrm{O} & 7.37995400 & -1.09505300 & 1.01222900 \\ \mathrm{C} & 7.10034000 & -2.04324900 & 0.07437200 \\ \mathrm{C} & 5.94892100 & -1.73274000 & -0.58348400 \\ \mathrm{H} & -5.08781900 & 0.60168300 & -1.31655000 \\ \mathrm{O} & -3.31029000 & 2.54327400 & -1.17886300 \\ \mathrm{O} & 3.76462000 & 3.73575500 & -0.06752700 \\ \mathrm{H} & 1.84321200 & 1.24624200 & 1.15572300 \\ \mathrm{C} & 2.98830000 & -0.93333300 & 1.50713400 \\ \mathrm{C} & -3.76921100 & -1.43629200 & -2.16748100 \\ \mathrm{C} & -5.55317200 & 2.25079200 & 0.70032300 \\ \mathrm{C} & -4.13786600 & 0.68823400 & 2.04985600 \\ \mathrm{H} & -0.45125700 & 2.31944600 & 0.41407300 \\ \mathrm{H} & -2.81609400 & 2.66413000 & 0.83453500 \\ \mathrm{H} & 2.44150200 & -0.93609900 & -1.94045200 \\ \mathrm{H} & 3.18965100 & -2.19470000 & -0.96431900 \\ \mathrm{H} & 0.75040300 & -2.63516300 & -1.48729000 \\ \mathrm{H} & 1.08471700 & -2.61856300 & 0.22899200 \\ \mathrm{H} & 2.35933700 & 1.64636100 & -1.82576000 \\ \mathrm{H} & 1.50523500 & 2.80440200 & -0.80851100 \\ \mathrm{H} & 4.20857100 & 0.32922600 & -1.48429500 \\ \mathrm{H} & -6.55054300 & -1.18388500 & -0.72458600 \\ \mathrm{H} & -6.56193400 & -0.44703900 & 0.86873800 \\ \mathrm{H} & 6.47417200 & 0.67977600 & 1.61489200 \\ \mathrm{H} & 7.80656900 & -2.85458300 & -0.00605200 \\ \mathrm{H} & 5.50555100 & -2.30063100 & -1.38880700 \\ \mathrm{H} & -3.85149600 & 3.33488400 & -1.05853700 \\ \mathrm{H} & 3.60459200 & -1.83667400 & 1.50738800 \\ \mathrm{H} & 3.44170200 & -0.21751000 & 2.20065900 \\ \mathrm{H} & 2.00081400 & -1.19402500 & 1.90078800 \\ \mathrm{H} & -3.56356700 & -0.63096600 & -2.87976200 \\ \mathrm{H} & -3.04358300 & -2.23759300 & -2.31906900 \\ \mathrm{H} & -4.77449900 & -1.82429900 & -2.36045800 \\ \mathrm{H} & -5.26182400 & 3.10202300 & 1.32808900 \\ \mathrm{H} & -6.45267500 & 1.81727900 & 1.14803600 \\ \mathrm{H} & -5.83541000 & 2.62870300 & -0.28838900 \\ \mathrm{H} & -3.35453900 & -0.07259800 & 2.07818900 \\ \mathrm{H} & -3.82474700 & 1.51353400 & 2.69993200 \\ & -5.03888300 & 0.25497200 & 2.49406600\end{array}$

\section{Revised structure of xylogranatin H (17-6)-conformer 3}

Zero-point correction=

Thermal correction to Energy=

Thermal correction to Enthalpy=

Thermal correction to Gibbs Free Energy=

Sum of electronic and zero-point Energies=

Sum of electronic and thermal Energies=

Sum of electronic and thermal Enthalpies=

Sum of electronic and thermal Free Energies= 01
0.512621 (Hartree/Particle)

0.541333

0.542277

0.453840

$-1513.911154$

$-1513.882443$

$-1513.881499$

$-1513.969935$ 


\begin{tabular}{|c|c|c|c|}
\hline $\mathrm{N}$ & -1.12851900 & -1.06526600 & -0.76721900 \\
\hline $\mathrm{C}$ & -2.17376900 & -0.27222200 & -0.49197600 \\
\hline $\mathrm{C}$ & -2.02739600 & 0.98747100 & 0.09967300 \\
\hline $\mathrm{C}$ & -0.73101700 & 1.42219100 & 0.38799700 \\
\hline $\mathrm{C}$ & 0.36668000 & 0.61512400 & 0.09685400 \\
\hline $\mathrm{C}$ & 0.10482900 & -0.64340700 & -0.47601100 \\
\hline $\mathrm{C}$ & -3.54109700 & -0.81902100 & -0.87956900 \\
\hline $\mathrm{C}$ & -4.75785500 & 0.05641000 & -0.44405300 \\
\hline $\mathrm{C}$ & -4.48058400 & 1.02721300 & 0.74192500 \\
\hline $\mathrm{C}$ & -3.22336700 & 1.86346300 & 0.38391500 \\
\hline $\mathrm{C}$ & 1.78888100 & 1.09983300 & 0.31119100 \\
\hline $\mathrm{C}$ & 2.84833100 & -0.03200400 & 0.64224200 \\
\hline $\mathrm{C}$ & 2.24656600 & -1.45198600 & 0.46933200 \\
\hline $\mathrm{C}$ & 1.26249200 & -1.58037200 & -0.70363400 \\
\hline $\mathrm{C}$ & 2.21686000 & 1.96523100 & -0.90767500 \\
\hline $\mathrm{C}$ & 3.63444700 & 2.45913600 & -0.73108100 \\
\hline $\mathrm{O}$ & 4.52608000 & 1.49700600 & -0.37768700 \\
\hline $\mathrm{C}$ & 4.05618100 & 0.11962500 & -0.34343600 \\
\hline $\mathrm{O}$ & -3.72466400 & -2.08726000 & -0.16051700 \\
\hline $\mathrm{C}$ & -5.01583700 & -2.25337900 & 0.22544800 \\
\hline $\mathrm{C}$ & -5.81857800 & -1.01743200 & -0.15210900 \\
\hline $\mathrm{O}$ & -5.40508400 & -3.25399000 & 0.77806600 \\
\hline $\mathrm{C}$ & 5.26978600 & -0.71631700 & -0.05870000 \\
\hline $\mathrm{C}$ & 5.61914600 & -1.87249800 & -0.69633300 \\
\hline $\mathrm{O}$ & 6.78757300 & -2.36498600 & -0.19880800 \\
\hline $\mathrm{C}$ & 7.20348600 & -1.49387200 & 0.76856600 \\
\hline $\mathrm{C}$ & 6.31875100 & -0.46911500 & 0.89803500 \\
\hline $\mathrm{H}$ & -5.04829000 & 0.67786800 & -1.29507700 \\
\hline $\mathrm{O}$ & -3.40773000 & 2.67981600 & -0.78894800 \\
\hline $\mathrm{O}$ & 3.99532500 & 3.60831900 & -0.84072100 \\
\hline $\mathrm{H}$ & 1.77074900 & 1.78478700 & 1.16698300 \\
\hline $\mathrm{C}$ & 3.30826300 & 0.13929200 & 2.10278300 \\
\hline $\mathrm{C}$ & -3.57310500 & -1.12926200 & -2.38131100 \\
\hline $\mathrm{C}$ & -5.68752300 & 1.97067200 & 0.92473800 \\
\hline $\mathrm{C}$ & -4.22085200 & 0.30662800 & 2.08440500 \\
\hline $\mathrm{H}$ & -0.58426600 & 2.40091100 & 0.84203300 \\
\hline $\mathrm{H}$ & -2.98798200 & 2.51643000 & 1.23804900 \\
\hline $\mathrm{H}$ & 3.06007400 & -2.17868600 & 0.37466100 \\
\hline $\mathrm{H}$ & 1.70892900 & -1.71455700 & 1.38829300 \\
\hline $\mathrm{H}$ & 1.75664900 & -1.35252100 & -1.65961900 \\
\hline $\mathrm{H}$ & 0.87830700 & -2.60051700 & -0.78692900 \\
\hline $\mathrm{H}$ & 2.14464400 & 1.38282900 & -1.83508200 \\
\hline $\mathrm{H}$ & 1.56556300 & 2.83329300 & -1.01923800 \\
\hline $\mathrm{H}$ & 3.70734700 & -0.14013100 & -1.35026700 \\
\hline $\mathrm{H}$ & -6.41103700 & -1.26102100 & -1.04131100 \\
\hline $\mathrm{H}$ & -6.52672900 & -0.77454600 & 0.64154200 \\
\hline $\mathrm{H}$ & 5.16754100 & -2.44377600 & -1.49318000 \\
\hline $\mathrm{H}$ & 8.13519200 & -1.73905800 & 1.25350300 \\
\hline $\mathrm{H}$ & 6.40499900 & 0.37615400 & 1.56405700 \\
\hline $\mathrm{H}$ & -4.00230800 & 3.41025300 & -0.57227600 \\
\hline $\mathrm{H}$ & 3.96367200 & -0.67909100 & 2.41355100 \\
\hline
\end{tabular}




$\begin{array}{lrrr}\mathrm{H} & 3.84527900 & 1.08239900 & 2.24846300 \\ \mathrm{H} & 2.43656100 & 0.14041000 & 2.76611800 \\ \mathrm{H} & -3.39811400 & -0.21513800 & -2.95745300 \\ \mathrm{H} & -2.79128700 & -1.85314700 & -2.61883400 \\ \mathrm{H} & -4.54328100 & -1.54444800 & -2.67241300 \\ \mathrm{H} & -5.47258500 & 2.73229900 & 1.68459700 \\ \mathrm{H} & -6.57154000 & 1.42220900 & 1.26405100 \\ \mathrm{H} & -5.96067900 & 2.47720200 & -0.00735600 \\ \mathrm{H} & -3.39043900 & -0.40115900 & 2.03268100 \\ \mathrm{H} & -3.98567000 & 1.04064500 & 2.86396100 \\ \mathrm{H} & -5.10597100 & -0.24270400 & 2.41865800\end{array}$

\section{Revised structure of xylogranatin H (17-6)-conformer 4}

$\begin{array}{lc}\text { Zero-point correction }= & 0.512639 \\ \text { Thermal correction to Energy }= & 0.541395 \\ \text { Thermal correction to Enthalpy=/Particle) } & 0.542339 \\ \text { Thermal correction to Gibbs Free Energy= } & 0.454241 \\ \text { Sum of electronic and zero-point Energies }= & -1513.912912 \\ \text { Sum of electronic and thermal Energies }= & -1513.884157 \\ \text { Sum of electronic and thermal Enthalpies }= & -1513.883213 \\ \text { Sum of electronic and thermal Free Energies }= & -1513.971311\end{array}$
01

$\begin{array}{lrrr}\mathrm{N} & -1.25007900 & -1.26519400 & -0.70768200 \\ \mathrm{C} & -2.24092100 & -0.39346600 & -0.51240900 \\ \mathrm{C} & -2.00647100 & 0.93339000 & -0.11954900 \\ \mathrm{C} & -0.68247400 & 1.31640100 & 0.08831700 \\ \mathrm{C} & 0.37109800 & 0.41569900 & -0.10926300 \\ \mathrm{C} & 0.02216600 & -0.88710300 & -0.50995600 \\ \mathrm{C} & -3.65402400 & -0.91809200 & -0.74107200 \\ \mathrm{C} & -4.80571800 & 0.07226800 & -0.37209300 \\ \mathrm{C} & -4.41190700 & 1.21537700 & 0.61330800 \\ \mathrm{C} & -3.15215700 & 1.90550200 & 0.04316500 \\ \mathrm{C} & 1.80544000 & 0.85563300 & 0.16055700 \\ \mathrm{C} & 2.86142900 & -0.29782200 & 0.11303900 \\ \mathrm{C} & 2.45800500 & -1.34493300 & -0.95224000 \\ \mathrm{C} & 1.07487800 & -1.94831500 & -0.71114100 \\ \mathrm{C} & 2.24358900 & 2.04173800 & -0.73442800 \\ \mathrm{C} & 3.53940100 & 2.59382000 & -0.17444100 \\ \mathrm{O} & 4.45434700 & 1.64598700 & 0.16677600 \\ \mathrm{C} & 4.23697700 & 0.30354200 & -0.35099500 \\ \mathrm{O} & -3.83560600 & -2.05518100 & 0.17020600 \\ \mathrm{C} & -5.09830000 & -2.09270400 & 0.67112200 \\ \mathrm{C} & -5.87769900 & -0.88936800 & 0.16566900 \\ \mathrm{O} & -5.48020400 & -2.97830100 & 1.39753500 \\ \mathrm{C} & 5.46026300 & -0.48841100 & 0.00378600 \\ \mathrm{C} & 6.10047600 & -1.38668500 & -0.80121400 \\ \mathrm{O} & 7.17531700 & -1.92687800 & -0.16120000 \\ \mathrm{C} & 7.23156300 & -1.34792000 & 1.07526900 \\ \mathrm{C} & 6.21115300 & -0.46264700 & 1.23297200\end{array}$




$\begin{array}{lrrr}\mathrm{H} & -5.14054200 & 0.55812900 & -1.29122400 \\ \mathrm{O} & -3.50520400 & 2.48459800 & -1.22939800 \\ \mathrm{O} & 3.76229700 & 3.76086800 & 0.04846300 \\ \mathrm{H} & 1.81197400 & 1.24670400 & 1.18758800 \\ \mathrm{C} & 2.95309000 & -0.93896400 & 1.51025200 \\ \mathrm{C} & -3.79534300 & -1.44580700 & -2.17379600 \\ \mathrm{C} & -5.55906300 & 2.24308800 & 0.69298000 \\ \mathrm{C} & -4.09472300 & 0.71462900 & 2.04020100 \\ \mathrm{H} & -0.47237100 & 2.32917200 & 0.43049300 \\ \mathrm{H} & -2.84988000 & 2.71056800 & 0.73011200 \\ \mathrm{H} & 2.46146600 & -0.86697200 & -1.94238200 \\ \mathrm{H} & 3.21293500 & -2.13878000 & -0.98548300 \\ \mathrm{H} & 0.77455200 & -2.58151600 & -1.55181400 \\ \mathrm{H} & 1.08444500 & -2.60620600 & 0.16809200 \\ \mathrm{H} & 2.37648400 & 1.71727300 & -1.77448000 \\ \mathrm{H} & 1.51517700 & 2.85332500 & -0.73652300 \\ \mathrm{H} & 4.20335900 & 0.38479900 & -1.44399400 \\ \mathrm{H} & -6.55132700 & -1.23590900 & -0.62639800 \\ \mathrm{H} & -6.50782900 & -0.48958000 & 0.96142000 \\ \mathrm{H} & 5.92919700 & -1.73062600 & -1.80983700 \\ \mathrm{H} & 8.04822300 & -1.66268200 & 1.70563100 \\ \mathrm{H} & 6.02247700 & 0.15702500 & 2.09680500 \\ \mathrm{H} & -2.70794300 & 2.84653700 & -1.63745500 \\ \mathrm{H} & 3.58077400 & -1.83415800 & 1.50464100 \\ \mathrm{H} & 3.37422400 & -0.23410600 & 2.23447400 \\ \mathrm{H} & 1.95973500 & -1.22253300 & 1.87161200 \\ \mathrm{H} & -3.62549300 & -0.63656600 & -2.89119600 \\ \mathrm{H} & -3.05995700 & -2.23421000 & -2.34568700 \\ \mathrm{H} & -4.79840900 & -1.85139600 & -2.33986000 \\ \mathrm{H} & -5.27886700 & 3.07751900 & 1.34622500 \\ \mathrm{H} & -6.46349000 & 1.79065700 & 1.11242000 \\ \mathrm{H} & -5.79902100 & 2.65185300 & -0.29122500 \\ \mathrm{H} & -3.31544400 & -0.05118000 & 2.06274300 \\ \mathrm{H} & -3.75995900 & 1.55081900 & 2.66468400 \\ \mathrm{H} & -4.98587700 & 0.29655200 & 2.51709500\end{array}$

Revised structure of xylogranatin H (17-6)-conformer 5

Zero-point correction=

Thermal correction to Energy=

Thermal correction to Enthalpy=
0.512648 (Hartree/Particle)

0.541438

0.542382

Thermal correction to Gibbs Free Energy $=\quad 0.453891$

Sum of electronic and zero-point Energies $=\quad-1513.910999$

Sum of electronic and thermal Energies $=\quad-1513.882209$

Sum of electronic and thermal Enthalpies $=\quad-1513.881265$

Sum of electronic and thermal Free Energies $=\quad-1513.969756$

01

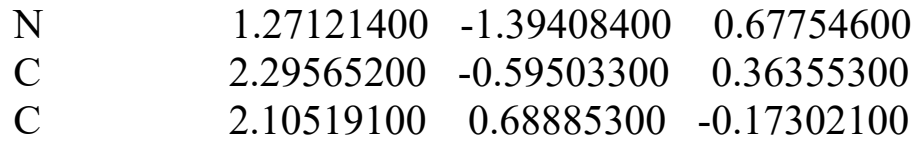

SI236 


\begin{tabular}{|c|c|c|c|}
\hline $\mathrm{C}$ & 0.78930000 & 1.10958600 & -0.37368100 \\
\hline $\mathrm{C}$ & -0.29073100 & 0.28186100 & -0.05528800 \\
\hline $\mathrm{C}$ & 0.01233000 & -0.98878200 & 0.46805300 \\
\hline $\mathrm{C}$ & 3.68502300 & -1.17764700 & 0.63183600 \\
\hline $\mathrm{C}$ & 4.85248800 & -0.21858900 & 0.22672700 \\
\hline $\mathrm{C}$ & 4.52866000 & 1.30040700 & 0.31044100 \\
\hline $\mathrm{C}$ & 3.26956600 & 1.58270300 & -0.55246900 \\
\hline $\mathrm{C}$ & -1.71345300 & 0.76393500 & -0.31685100 \\
\hline $\mathrm{C}$ & -2.81920200 & -0.32384500 & -0.11075100 \\
\hline $\mathrm{C}$ & -2.42067500 & -1.28022500 & 1.03832300 \\
\hline $\mathrm{C}$ & -1.07848100 & -1.97371500 & 0.80717800 \\
\hline $\mathrm{C}$ & -2.05616300 & 2.05786400 & 0.46332400 \\
\hline $\mathrm{C}$ & -3.34936900 & 2.61294800 & -0.09882200 \\
\hline $\mathrm{O}$ & -4.32185000 & 1.68120700 & -0.30261400 \\
\hline $\mathrm{C}$ & -4.14304400 & 0.39033900 & 0.34259300 \\
\hline $\mathrm{O}$ & 3.83856100 & -2.34927700 & -0.24275700 \\
\hline $\mathrm{C}$ & 4.73552200 & -2.15147600 & -1.23770700 \\
\hline $\mathrm{C}$ & 5.29043400 & -0.74141300 & -1.15489800 \\
\hline $\mathrm{O}$ & 5.00309200 & -3.00365800 & -2.05040800 \\
\hline $\mathrm{C}$ & -5.41617900 & -0.37138100 & 0.12028200 \\
\hline $\mathrm{C}$ & -6.05742900 & -1.15672700 & 1.03494500 \\
\hline $\mathrm{O}$ & -7.18443100 & -1.70231300 & 0.49647100 \\
\hline $\mathrm{C}$ & -7.27227700 & -1.24146300 & -0.78698200 \\
\hline $\mathrm{C}$ & -6.22178300 & -0.42621800 & -1.07275300 \\
\hline $\mathrm{H}$ & 5.67435700 & -0.40462100 & 0.92860600 \\
\hline $\mathrm{O}$ & 2.83040000 & 2.94354800 & -0.46021200 \\
\hline $\mathrm{O}$ & -3.53235200 & 3.76019800 & -0.43288800 \\
\hline $\mathrm{H}$ & -1.74439900 & 1.04691500 & -1.37817800 \\
\hline $\mathrm{C}$ & -3.00277100 & -1.09508000 & -1.43115900 \\
\hline $\mathrm{C}$ & 3.79956100 & -1.71937600 & 2.05720100 \\
\hline $\mathrm{C}$ & 4.28310100 & 1.73316100 & 1.77126700 \\
\hline $\mathrm{C}$ & 5.72876100 & 2.10429900 & -0.23198000 \\
\hline $\mathrm{H}$ & 0.62240500 & 2.10134300 & -0.78213900 \\
\hline $\mathrm{H}$ & 3.52193100 & 1.37976000 & -1.60469600 \\
\hline $\mathrm{H}$ & -2.35941200 & -0.70758600 & 1.97489200 \\
\hline $\mathrm{H}$ & -3.21004900 & -2.02754200 & 1.17914900 \\
\hline $\mathrm{H}$ & -0.77486000 & -2.53950500 & 1.69351900 \\
\hline $\mathrm{H}$ & -1.15603900 & -2.70939900 & -0.00454000 \\
\hline $\mathrm{H}$ & -2.15718700 & 1.85110500 & 1.53658600 \\
\hline $\mathrm{H}$ & -1.29016900 & 2.82569000 & 0.35093900 \\
\hline $\mathrm{H}$ & -4.05656200 & 0.58011300 & 1.41912700 \\
\hline $\mathrm{H}$ & 6.37229900 & -0.76178100 & -1.30121000 \\
\hline $\mathrm{H}$ & 4.86816900 & -0.17900100 & -1.99490200 \\
\hline $\mathrm{H}$ & -5.85480200 & -1.41115200 & 2.06407800 \\
\hline $\mathrm{H}$ & -8.13066200 & -1.57444200 & -1.34884600 \\
\hline $\mathrm{H}$ & -6.04560600 & 0.09864900 & -1.99972600 \\
\hline $\mathrm{H}$ & 3.39736000 & 3.49576400 & -1.01236000 \\
\hline $\mathrm{H}$ & -3.67082500 & -1.95225700 & -1.31054100 \\
\hline $\mathrm{H}$ & -3.42193000 & -0.44467500 & -2.20576200 \\
\hline $\mathrm{H}$ & -2.04059100 & -1.46298300 & -1.80079400 \\
\hline $\mathrm{H}$ & 3.71224200 & -0.91341300 & 2.79053500 \\
\hline
\end{tabular}




$\begin{array}{lrrr}\mathrm{H} & 3.00298300 & -2.44322400 & 2.23631600 \\ \mathrm{H} & 4.76865100 & -2.21005700 & 2.18831900 \\ \mathrm{H} & 4.11401400 & 2.81176400 & 1.82102300 \\ \mathrm{H} & 5.15438800 & 1.49240300 & 2.39032300 \\ \mathrm{H} & 3.40875200 & 1.24792200 & 2.21161800 \\ \mathrm{H} & 5.91684000 & 1.90818900 & -1.29329700 \\ \mathrm{H} & 5.56732200 & 3.18048500 & -0.10744400 \\ \mathrm{H} & 6.64131100 & 1.85256800 & 0.31968800\end{array}$

\section{Revised structure of xylogranatin H (17-6)-conformer 6 \\ Zero-point correction= \\ Thermal correction to Energy= \\ Thermal correction to Enthalpy= \\ Thermal correction to Gibbs Free Energy= \\ Sum of electronic and zero-point Energies= \\ Sum of electronic and thermal Energies= \\ Sum of electronic and thermal Enthalpies $=$ \\ Sum of electronic and thermal Free Energies= \\ 0.512616 (Hartree/Particle) \\ 0.541382 \\ 0.542326 \\ 0.454284 \\ $-1513.912877$ \\ $-1513.884111$ \\ $-1513.883167$ \\ $-1513.971209$}

01

$\begin{array}{lrrr}\mathrm{N} & -1.26297600 & -1.26472200 & -0.72081300 \\ \mathrm{C} & -2.24801400 & -0.38902200 & -0.51422600 \\ \mathrm{C} & -2.00416600 & 0.93477900 & -0.11654600 \\ \mathrm{C} & -0.67677800 & 1.31081700 & 0.08211800 \\ \mathrm{C} & 0.37070300 & 0.40587900 & -0.12807300 \\ \mathrm{C} & 0.01236900 & -0.89317900 & -0.53091100 \\ \mathrm{C} & -3.66535300 & -0.90550500 & -0.73522600 \\ \mathrm{C} & -4.80945700 & 0.08786000 & -0.35090500 \\ \mathrm{C} & -4.40212300 & 1.22335100 & 0.63774600 \\ \mathrm{C} & -3.14414000 & 1.91107300 & 0.06078500 \\ \mathrm{C} & 1.80938800 & 0.83836000 & 0.12845100 \\ \mathrm{C} & 2.86069400 & -0.31980000 & 0.07751800 \\ \mathrm{C} & 2.44535200 & -1.36312600 & -0.98759600 \\ \mathrm{C} & 1.05883200 & -1.95789100 & -0.74143900 \\ \mathrm{C} & 2.24430400 & 2.01781500 & -0.77681700 \\ \mathrm{C} & 3.53969300 & 2.57262800 & -0.22114800 \\ \mathrm{O} & 4.44886400 & 1.62459300 & 0.13407200 \\ \mathrm{C} & 4.24150000 & 0.28149400 & -0.38014200 \\ \mathrm{O} & -3.84523100 & -2.04775500 & 0.16984600 \\ \mathrm{C} & -5.10393000 & -2.08246000 & 0.68088100 \\ \mathrm{C} & -5.88151300 & -0.87194900 & 0.19000000 \\ \mathrm{O} & -5.48428500 & -2.97116200 & 1.40430200 \\ \mathrm{C} & 5.46212600 & -0.50263700 & 0.00486100 \\ \mathrm{C} & 6.36314000 & -0.18421300 & 0.97943400 \\ \mathrm{O} & 7.35474300 & -1.11962700 & 1.03835900 \\ \mathrm{C} & 7.08558600 & -2.05009300 & 0.07999600 \\ \mathrm{C} & 5.94416500 & -1.72455100 & -0.58794500 \\ \mathrm{H} & -5.14962000 & 0.58062200 & -1.26437400 \\ \mathrm{O} & -3.50524800 & 2.49835500 & -1.20574900 \\ \mathrm{O} & 3.76743500 & 3.74054700 & -0.00880100\end{array}$

SI238 


$\begin{array}{lrrr}\mathrm{H} & 1.82659900 & 1.23381800 & 1.15360400 \\ \mathrm{C} & 2.95868100 & -0.95872100 & 1.47512100 \\ \mathrm{C} & -3.82014800 & -1.42305200 & -2.17027900 \\ \mathrm{C} & -5.54381100 & 2.25579900 & 0.73318800 \\ \mathrm{C} & -4.07519700 & 0.71279400 & 2.05894200 \\ \mathrm{H} & -0.45892500 & 2.32107400 & 0.42696600 \\ \mathrm{H} & -2.83261000 & 2.71114600 & 0.74942000 \\ \mathrm{H} & 2.45214800 & -0.88629600 & -1.97813200 \\ \mathrm{H} & 3.18738200 & -2.16755500 & -1.02238600 \\ \mathrm{H} & 0.75117500 & -2.58758100 & -1.58213900 \\ \mathrm{H} & 1.07024900 & -2.61780600 & 0.13631300 \\ \mathrm{H} & 2.37589000 & 1.68569300 & -1.81454700 \\ \mathrm{H} & 1.51568800 & 2.82920500 & -0.78381500 \\ \mathrm{H} & 4.22155600 & 0.35756100 & -1.47511400 \\ \mathrm{H} & -6.56376500 & -1.20996900 & -0.59835800 \\ \mathrm{H} & -6.50265700 & -0.47419000 & 0.99379100 \\ \mathrm{H} & 6.44573600 & 0.64650300 & 1.66076400 \\ \mathrm{H} & 7.79070500 & -2.86188700 & -0.00524400 \\ \mathrm{H} & 5.51053700 & -2.27670500 & -1.40936000 \\ \mathrm{H} & -2.71009000 & 2.86027700 & -1.61791600 \\ \mathrm{H} & 3.57248600 & -1.86361400 & 1.46423500 \\ \mathrm{H} & 3.40530000 & -0.25897300 & 2.18910500 \\ \mathrm{H} & 1.96569700 & -1.22473500 & 1.85089300 \\ \mathrm{H} & -3.65209700 & -0.60982600 & -2.88358600 \\ \mathrm{H} & -3.08979700 & -2.21369100 & -2.35307200 \\ \mathrm{H} & -4.82633700 & -1.82293600 & -2.33124500 \\ \mathrm{H} & -5.25413800 & 3.08517800 & 1.38872700 \\ \mathrm{H} & -6.44663300 & 1.80509500 & 1.15791100 \\ \mathrm{H} & -5.79042100 & 2.67129600 & -0.24654400 \\ \mathrm{H} & -3.29952900 & -0.05691700 & 2.07046300 \\ \mathrm{H} & -3.73103900 & 1.54369300 & 2.68537200 \\ \mathrm{H} & -4.96429800 & 0.29627300 & 2.54099800\end{array}$

\section{Revised structure of xylogranatin H (17-6)-confromer 7 \\ Zero-point correction= \\ Thermal correction to Energy= \\ Thermal correction to Enthalpy= \\ Thermal correction to Gibbs Free Energy= \\ Sum of electronic and zero-point Energies= \\ Sum of electronic and thermal Energies $=$ \\ Sum of electronic and thermal Enthalpies $=$ \\ Sum of electronic and thermal Free Energies= \\ 0.512872 (Hartree/Particle) \\ 0.541552 \\ 0.542496 \\ 0.454304 \\ $-1513.910790$ \\ $-1513.882110$ \\ $-1513.881165$ \\ $-1513.969358$}

01

$\begin{array}{lrrr}\mathrm{N} & 1.27690900 & -1.36409300 & 0.73805000 \\ \mathrm{C} & 2.30312300 & -0.57562500 & 0.40249500 \\ \mathrm{C} & 2.11707100 & 0.70494700 & -0.14516000 \\ \mathrm{C} & 0.79917400 & 1.11952100 & -0.35769700 \\ \mathrm{C} & -0.28322700 & 0.30045900 & -0.02530800 \\ \mathrm{C} & 0.01861600 & -0.95838400 & 0.52841200\end{array}$

SI239 


\begin{tabular}{|c|c|c|c|}
\hline $\mathrm{C}$ & 3.69136000 & -1.17180300 & 0.64375000 \\
\hline $\mathrm{C}$ & 4.84715400 & -0.24791600 & 0.14481900 \\
\hline $\mathrm{C}$ & 4.57993700 & 1.28010400 & 0.24532600 \\
\hline $\mathrm{C}$ & 3.27730100 & 1.61262700 & -0.53244800 \\
\hline $\mathrm{C}$ & -1.70538200 & 0.77277900 & -0.30785600 \\
\hline $\mathrm{C}$ & -2.80850500 & -0.31447000 & -0.08645700 \\
\hline $\mathrm{C}$ & -2.41839400 & -1.23771000 & 1.09224700 \\
\hline $\mathrm{C}$ & -1.07264500 & -1.93364400 & 0.89274000 \\
\hline $\mathrm{C}$ & -2.05969500 & 2.08083400 & 0.44219600 \\
\hline $\mathrm{C}$ & -3.35082900 & 2.62086800 & -0.14044100 \\
\hline $\mathrm{O}$ & -4.31585000 & 1.68142500 & -0.33991100 \\
\hline $\mathrm{C}$ & -4.14109100 & 0.40426300 & 0.33379200 \\
\hline $\mathrm{O}$ & 3.79446100 & -2.37734000 & -0.18995100 \\
\hline $\mathrm{C}$ & 4.60384100 & -2.20303100 & -1.26368500 \\
\hline $\mathrm{C}$ & 5.14840900 & -0.78679300 & -1.26639100 \\
\hline $\mathrm{O}$ & 4.81198000 & -3.07915400 & -2.06765300 \\
\hline $\mathrm{C}$ & -5.40840200 & -0.36655700 & 0.11079400 \\
\hline $\mathrm{C}$ & -6.06111300 & -1.13076400 & 1.03528100 \\
\hline $\mathrm{O}$ & -7.17822900 & -1.69303800 & 0.49393600 \\
\hline $\mathrm{C}$ & -7.24822400 & -1.26471100 & -0.80183000 \\
\hline $\mathrm{C}$ & -6.19590100 & -0.45352300 & -1.09234600 \\
\hline $\mathrm{H}$ & 5.72021700 & -0.46101400 & 0.77402500 \\
\hline $\mathrm{O}$ & 2.91960300 & 2.99422700 & -0.44646000 \\
\hline $\mathrm{O}$ & -3.53500200 & 3.76275300 & -0.49121400 \\
\hline $\mathrm{H}$ & -1.72879200 & 1.03293200 & -1.37516600 \\
\hline $\mathrm{C}$ & -2.97250700 & -1.12090800 & -1.38823900 \\
\hline $\mathrm{C}$ & 3.85145400 & -1.66436000 & 2.08213400 \\
\hline $\mathrm{C}$ & 4.45111900 & 1.71252500 & 1.72366000 \\
\hline $\mathrm{C}$ & 5.76243200 & 2.05015300 & -0.37616900 \\
\hline $\mathrm{H}$ & 0.63092100 & 2.09753100 & -0.80091900 \\
\hline $\mathrm{H}$ & 3.47669900 & 1.48217000 & -1.60276600 \\
\hline $\mathrm{H}$ & -2.36789600 & -0.63928800 & 2.01325200 \\
\hline $\mathrm{H}$ & -3.20710100 & -1.98302800 & 1.24632700 \\
\hline $\mathrm{H}$ & -0.77328400 & -2.47022800 & 1.79855900 \\
\hline $\mathrm{H}$ & -1.14148600 & -2.69530700 & 0.10468000 \\
\hline $\mathrm{H}$ & -2.16829300 & 1.89656100 & 1.51889600 \\
\hline $\mathrm{H}$ & -1.29709100 & 2.85033700 & 0.31799800 \\
\hline $\mathrm{H}$ & -4.06994300 & 0.61689700 & 1.40719600 \\
\hline $\mathrm{H}$ & 6.20904500 & -0.79775900 & -1.52411800 \\
\hline $\mathrm{H}$ & 4.63230000 & -0.24112000 & -2.06428400 \\
\hline $\mathrm{H}$ & -5.87318700 & -1.35860900 & 2.07340500 \\
\hline $\mathrm{H}$ & -8.09722300 & -1.61425400 & -1.36786100 \\
\hline $\mathrm{H}$ & -6.00769700 & 0.04839800 & -2.02961100 \\
\hline $\mathrm{H}$ & 2.66898200 & 3.19810500 & 0.46542200 \\
\hline $\mathrm{H}$ & -3.63861400 & -1.97735800 & -1.25313600 \\
\hline $\mathrm{H}$ & -3.38461500 & -0.49302800 & -2.18482100 \\
\hline $\mathrm{H}$ & -2.00452700 & -1.49444800 & -1.73643000 \\
\hline $\mathrm{H}$ & 3.79210900 & -0.83610500 & 2.79264800 \\
\hline $\mathrm{H}$ & 3.05677900 & -2.37682200 & 2.31016300 \\
\hline $\mathrm{H}$ & 4.82076000 & -2.15825000 & 2.19778700 \\
\hline $\mathrm{H}$ & 4.44139000 & 2.80448500 & 1.80766500 \\
\hline
\end{tabular}




$\begin{array}{lrrr}\mathrm{H} & 5.31113900 & 1.35783800 & 2.30121800 \\ \mathrm{H} & 3.54592400 & 1.32770200 & 2.20303600 \\ \mathrm{H} & 5.90967300 & 1.79466100 & -1.43023800 \\ \mathrm{H} & 5.58679800 & 3.12770600 & -0.31956000 \\ \mathrm{H} & 6.69248600 & 1.82570900 & 0.15859000\end{array}$

Revised structure of xylogranatin H (17-6)-conformer 8

Zero-point correction $=$

Thermal correction to Energy=

Thermal correction to Enthalpy=

Thermal correction to Gibbs Free Energy=

Sum of electronic and zero-point Energies=

Sum of electronic and thermal Energies=

Sum of electronic and thermal Enthalpies=

Sum of electronic and thermal Free Energies=
0.512830 (Hartree/Particle)

0.541528

0.542472

0.454270

$-1513.910755$

$-1513.882057$

$-1513.881113$

$-1513.969315$

01

C

$1.28951600-1.36807500$

0.74146800

$2.30999700-0.57462500$

0.40010100

C

2.11468600

0.70591400

$-0.14458500$

C

0.79360500

1.11580100

$-0.34615300$

C

$-0.28279700 \quad 0.29173300$

$-0.00674600$

C

$0.02828600-0.96673700$

0.54146500

$3.70239300-1.16500900$

0.63140600

$4.85062600-0.23627800$

0.12427200

C

4.57816400

1.29064500

0.22759000

$\begin{array}{lll}3.26833200 & 1.61846800 & -0.53999400\end{array}$

C

$-1.70894700$

0.76008300

$-0.27360500$

$\begin{array}{lll}-2.80826300 & -0.33209700 & -0.05344000\end{array}$

C

$-2.40601700-1.25935600$

1.11866500

$-1.05690700-1.94673400$

0.90859100

C

$\begin{array}{ll}-2.05945100 & 2.05968700\end{array}$

0.49278000

C

$\begin{array}{ll}-3.34992200 & 2.60561600\end{array}$

$-0.08330300$

$\mathrm{O}$

$-4.31020400$

1.66525200

$-0.29965900$

$-4.14523600$

0.38476100

0.36582000

$\begin{array}{lll}3.80494500 & -2.37020500 & -0.20274300\end{array}$

$\begin{array}{lll}4.60541700 & -2.19216600 & -1.28262400\end{array}$

C

$\begin{array}{lll}5.14317800 & -0.77336000 & -1.28943500\end{array}$

$\mathrm{O}$

$\begin{array}{rrr}4.81182500 & -3.06748500 & -2.08788100\end{array}$

$\begin{array}{lll}-5.41145100 & -0.38037300 & 0.11143200\end{array}$

C

$-6.32848300-0.1$

$-0.13711200$

$-0.86979100$

$\begin{array}{lll}-7.36236000 & -1.02404700 & -0.78913400\end{array}$

$\mathrm{O}$

$-7.10397300-1.84588000$

0.26655100

C

$-5.92808900-1.49852100$

0.85955900

$\mathrm{H}$

5.72933400

0.74662600

2.90585700

$-0.44629500$

$-0.45020000$

$\mathrm{O}$

$-3.53818900$

2.99857500

$-0.41921000$

$\mathrm{H}$

$-1.74232700$

3.75112700

$-1.33815400$

C

$-2.98055000-1.1$

1.02992400

$-1.36011000$

C

$3.87454700-1.65677800$

2.06869300 


$\begin{array}{lrrr}\mathrm{C} & 4.45885900 & 1.72196100 & 1.70704200 \\ \mathrm{C} & 5.75279400 & 2.06569100 & -0.40256200 \\ \mathrm{H} & 0.61795700 & 2.09396300 & -0.78621300 \\ \mathrm{H} & 3.46001900 & 1.48948700 & -1.61189800 \\ \mathrm{H} & -2.35847300 & -0.66741400 & 2.04386400 \\ \mathrm{H} & -3.18247100 & -2.01625700 & 1.27092600 \\ \mathrm{H} & -0.75040200 & -2.48628400 & 1.81027100 \\ \mathrm{H} & -1.12782600 & -2.70485500 & 0.11723100 \\ \mathrm{H} & -2.16673600 & 1.86312600 & 1.56735100 \\ \mathrm{H} & -1.29635800 & 2.82991000 & 0.37623600 \\ \mathrm{H} & -4.08585200 & 0.58899500 & 1.44284300 \\ \mathrm{H} & 6.20174300 & -0.77916100 & -1.55568600 \\ \mathrm{H} & 4.61799800 & -0.23003100 & -2.08300800 \\ \mathrm{H} & -6.39579500 & 0.60973400 & -1.64361700 \\ \mathrm{H} & -7.84142700 & -2.60691300 & 0.46773700 \\ \mathrm{H} & -5.49305700 & -1.96940600 & 1.72941300 \\ \mathrm{H} & 2.66195900 & 3.20096500 & 0.46381900 \\ \mathrm{H} & -3.63316800 & -1.99510900 & -1.22304700 \\ \mathrm{H} & -3.41889400 & -0.49838000 & -2.14093800 \\ \mathrm{H} & -2.01329200 & -1.48457700 & -1.72829500 \\ \mathrm{H} & 3.81636500 & -0.82885500 & 2.77966800 \\ \mathrm{H} & 3.08464700 & -2.37281000 & 2.30212400 \\ \mathrm{H} & 4.84678900 & -2.14639200 & 2.17771200 \\ \mathrm{H} & 4.44616200 & 2.81384300 & 1.79168000 \\ \mathrm{H} & 5.32424100 & 1.36981800 & 2.27810200 \\ \mathrm{H} & 3.55844400 & 1.33397400 & 2.19285200 \\ \mathrm{H} & 5.89289000 & 1.81133600 & -1.45787300 \\ \mathrm{H} & 5.57334000 & 3.14251200 & -0.34400500 \\ \mathrm{H} & 6.68782400 & 1.84465600 & 0.12488600\end{array}$

Revised structure of xylogranatin H (17-6)-conformer 9

Zero-point correction=

Thermal correction to Energy=

Thermal correction to Enthalpy=

Thermal correction to Gibbs Free Energy=

Sum of electronic and zero-point Energies=

Sum of electronic and thermal Energies $=$

Sum of electronic and thermal Enthalpies $=$

Sum of electronic and thermal Free Energies=
0.512334 (Hartree/Particle)

0.541231

0.542176

0.453646

$-1513.910168$

$-1513.881271$

$-1513.880327$

$-1513.968856$

$\begin{array}{lrrr}\mathrm{N} & 1.35090900 & -1.55072500 & 0.30326100 \\ \mathrm{C} & 2.17058800 & -0.49587600 & 0.36863000 \\ \mathrm{C} & 1.69898700 & 0.82201000 & 0.40810500 \\ \mathrm{C} & 0.31660800 & 1.01040300 & 0.38456500 \\ \mathrm{C} & -0.55192300 & -0.07869400 & 0.31830600 \\ \mathrm{C} & 0.02582500 & -1.36247300 & 0.26989400 \\ \mathrm{C} & 3.65954100 & -0.81280700 & 0.42008900 \\ \mathrm{C} & 4.60741500 & 0.42688100 & 0.37998700 \\ \mathrm{C} & 3.98304900 & 1.71584300 & -0.23245900\end{array}$

SI242 


\begin{tabular}{|c|c|c|c|}
\hline $\mathrm{C}$ & 2.64701100 & 1.99183500 & 0.50743300 \\
\hline $\mathrm{C}$ & -2.05880900 & 0.10982000 & 0.35826900 \\
\hline $\mathrm{C}$ & -2.80920000 & -1.04854000 & -0.34069900 \\
\hline $\mathrm{C}$ & -2.33134900 & -2.38970400 & 0.27226900 \\
\hline $\mathrm{C}$ & -0.81686400 & -2.61182200 & 0.11540400 \\
\hline $\mathrm{C}$ & -2.51310500 & 0.26411400 & 1.83219000 \\
\hline $\mathrm{C}$ & -3.96120600 & -0.05162600 & 2.17418000 \\
\hline $\mathrm{O}$ & -4.68568300 & -0.80035500 & 1.30685900 \\
\hline $\mathrm{C}$ & -4.33769800 & -0.89204300 & -0.10570500 \\
\hline $\mathrm{O}$ & 3.98768100 & -1.56539300 & -0.79895600 \\
\hline $\mathrm{C}$ & 5.21957100 & -1.23652600 & -1.26542100 \\
\hline $\mathrm{C}$ & 5.80789100 & -0.13081500 & -0.40173500 \\
\hline $\mathrm{O}$ & 5.71747700 & -1.77759200 & -2.22333700 \\
\hline $\mathrm{C}$ & -5.02816200 & 0.22951300 & -0.83709000 \\
\hline $\mathrm{C}$ & -5.89056700 & 0.07385000 & -1.88374300 \\
\hline $\mathrm{O}$ & -6.35845500 & 1.27937900 & -2.31316500 \\
\hline $\mathrm{C}$ & -5.79552400 & 2.22938700 & -1.51181300 \\
\hline $\mathrm{C}$ & -4.97601500 & 1.65056500 & -0.59237600 \\
\hline $\mathrm{H}$ & 4.88490500 & 0.67234900 & 1.40836700 \\
\hline $\mathrm{O}$ & 2.82606000 & 2.24306000 & 1.91471700 \\
\hline $\mathrm{O}$ & -4.44838400 & 0.25640700 & 3.23864100 \\
\hline $\mathrm{H}$ & -2.29667200 & 1.03823900 & -0.17485900 \\
\hline $\mathrm{C}$ & -2.54362000 & -1.03706400 & -1.85913600 \\
\hline $\mathrm{C}$ & 3.96053500 & -1.71968300 & 1.61961600 \\
\hline $\mathrm{C}$ & 4.94370300 & 2.90337400 & -0.01512600 \\
\hline $\mathrm{C}$ & 3.68757600 & 1.60230600 & -1.74532300 \\
\hline $\mathrm{H}$ & -0.08477500 & 2.02211200 & 0.41555700 \\
\hline $\mathrm{H}$ & 2.17234400 & 2.87165100 & 0.04675800 \\
\hline $\mathrm{H}$ & -2.60166000 & -2.42553100 & 1.33271400 \\
\hline $\mathrm{H}$ & -2.87012700 & -3.21861700 & -0.20270300 \\
\hline $\mathrm{H}$ & -0.46376200 & -3.36038600 & 0.83271300 \\
\hline $\mathrm{H}$ & -0.59119900 & -3.03180300 & -0.87326600 \\
\hline $\mathrm{H}$ & -1.93126000 & -0.41046900 & 2.47241800 \\
\hline $\mathrm{H}$ & -2.30087100 & 1.26902400 & 2.20751000 \\
\hline $\mathrm{H}$ & -4.81054200 & -1.82916100 & -0.41608400 \\
\hline $\mathrm{H}$ & 6.55414200 & -0.58370100 & 0.26080000 \\
\hline $\mathrm{H}$ & 6.33736900 & 0.59001600 & -1.02657900 \\
\hline $\mathrm{H}$ & -6.25820000 & -0.79248100 & -2.41224000 \\
\hline $\mathrm{H}$ & -6.08356800 & 3.24910500 & -1.71348200 \\
\hline $\mathrm{H}$ & -4.43425900 & 2.17242000 & 0.18315100 \\
\hline $\mathrm{H}$ & 3.24129900 & 3.10833900 & 2.02844100 \\
\hline $\mathrm{H}$ & -3.11555800 & -1.82748200 & -2.35919900 \\
\hline $\mathrm{H}$ & -2.82962700 & -0.08222900 & -2.30765500 \\
\hline $\mathrm{H}$ & -1.48671100 & -1.20488100 & -2.07873800 \\
\hline $\mathrm{H}$ & 3.68983700 & -1.21249600 & 2.55108000 \\
\hline $\mathrm{H}$ & 3.37767100 & -2.63868200 & 1.53433100 \\
\hline $\mathrm{H}$ & 5.02445900 & -1.97463200 & 1.65775000 \\
\hline $\mathrm{H}$ & 4.48003900 & 3.84216200 & -0.34279300 \\
\hline $\mathrm{H}$ & 5.86258500 & 2.78137000 & -0.59670600 \\
\hline $\mathrm{H}$ & 5.23901300 & 3.00942000 & 1.03446500 \\
\hline $\mathrm{H}$ & 3.02732100 & 0.76640700 & -1.98728200 \\
\hline
\end{tabular}




$\begin{array}{llll}\mathrm{H} & 3.20767700 & 2.52077000 & -2.10305500 \\ \mathrm{H} & 4.60864800 & 1.47683200 & -2.32217800\end{array}$

\section{Revised structure of xylogranatin H (17-6)-conformer 10}

Zero-point correction $=$

Thermal correction to Energy=

Thermal correction to Enthalpy=

Thermal correction to Gibbs Free Energy=

Sum of electronic and zero-point Energies=

Sum of electronic and thermal Energies=

Sum of electronic and thermal Enthalpies=

Sum of electronic and thermal Free Energies=
0.512518 (Hartree/Particle)

$$
0.541313
$$

$$
0.542257
$$

0.454025

$-1513.909858$

$-1513.881062$

$-1513.880118$

$-1513.968350$

01

$\begin{array}{lrrr}\mathrm{N} & -1.35410600 & -1.56301200 & -0.24451200 \\ \mathrm{C} & -2.16372500 & -0.50436900 & -0.35892300 \\ \mathrm{C} & -1.68021500 & 0.80667800 & -0.44822600 \\ \mathrm{C} & -0.29633000 & 0.98443400 & -0.42027300 \\ \mathrm{C} & 0.56129000 & -0.10860000 & -0.30203900 \\ \mathrm{C} & -0.02787000 & -1.38495000 & -0.20791500 \\ \mathrm{C} & -3.65502300 & -0.81031800 & -0.40834400 \\ \mathrm{C} & -4.59239400 & 0.43783000 & -0.42545100 \\ \mathrm{C} & -3.96084500 & 1.74574000 & 0.13738400 \\ \mathrm{C} & -2.61729100 & 1.97927100 & -0.60357800 \\ \mathrm{C} & 2.06964700 & 0.05936500 & -0.33741500 \\ \mathrm{C} & 2.79428800 & -1.06679300 & 0.43625800 \\ \mathrm{C} & 2.32343400 & -2.43484400 & -0.11939100 \\ \mathrm{C} & 0.80148800 & -2.63596400 & 0.00438000 \\ \mathrm{C} & 2.53742700 & 0.11511900 & -1.81317300 \\ \mathrm{C} & 3.98423900 & -0.23540800 & -2.11261700 \\ \mathrm{O} & 4.69099700 & -0.93203400 & -1.18673300 \\ \mathrm{C} & 4.32879500 & -0.91875500 & 0.22053000 \\ \mathrm{O} & -3.99770500 & -1.50974600 & 0.83835100 \\ \mathrm{C} & -5.22932800 & -1.15118800 & 1.28294300 \\ \mathrm{C} & -5.80255400 & -0.07712800 & 0.37055400 \\ \mathrm{O} & -5.73780100 & -1.64778700 & 2.25926700 \\ \mathrm{C} & 4.99823100 & 0.27514400 & 0.86116400 \\ \mathrm{C} & 5.47034600 & 1.38953100 & 0.22528800 \\ \mathrm{O} & 6.06549500 & 2.23681400 & 1.11358800 \\ \mathrm{C} & 5.98749300 & 1.64764200 & 2.34044000 \\ \mathrm{C} & 5.35321400 & 0.44723600 & 2.24919700 \\ \mathrm{H} & -4.86138000 & 0.64292000 & -1.46487000 \\ \mathrm{O} & -2.78462300 & 2.17238400 & -2.02141400 \\ \mathrm{O} & 4.49631900 & 0.00280900 & -3.18378000 \\ \mathrm{H} & 2.32587700 & 1.01488900 & 0.13711900 \\ \mathrm{C} & 2.48165100 & -0.98199000 & 1.94311600 \\ \mathrm{C} & -3.95608500 & -1.76309600 & -1.57167900 \\ \mathrm{C} & -4.90942000 & 2.93134800 & -0.13621700 \\ \mathrm{C} & -3.67687300 & 1.69279500 & 1.65575600 \\ \mathrm{H} & 0.11495300 & 1.99025000 & -0.48883900\end{array}$

SI244 


$\begin{array}{lrrr}\mathrm{H} & -2.13819800 & 2.87365600 & -0.17693600 \\ \mathrm{H} & 2.62406300 & -2.52961700 & -1.16752000 \\ \mathrm{H} & 2.84036300 & -3.24176000 & 0.41422900 \\ \mathrm{H} & 0.45997100 & -3.40261900 & -0.69941800 \\ \mathrm{H} & 0.54497900 & -3.02498100 & 0.99804200 \\ \mathrm{H} & 1.95461400 & -0.59179000 & -2.41683400 \\ \mathrm{H} & 2.34270800 & 1.09776000 & -2.25106500 \\ \mathrm{H} & 4.80434500 & -1.82624800 & 0.60949900 \\ \mathrm{H} & -6.54844200 & -0.55077400 & -0.27773700 \\ \mathrm{H} & -6.32983600 & 0.67323700 & 0.96158600 \\ \mathrm{H} & 5.50782000 & 1.69352100 & -0.80873500 \\ \mathrm{H} & 6.42561400 & 2.19684400 & 3.15902200 \\ \mathrm{H} & 5.16809300 & -0.23675800 & 3.06458800 \\ \mathrm{H} & -3.18856700 & 3.03692500 & -2.17461300 \\ \mathrm{H} & 3.05337800 & -1.73179500 & 2.50282800 \\ \mathrm{H} & 2.72038000 & 0.00386600 & 2.34900500 \\ \mathrm{H} & 1.42307800 & -1.16773600 & 2.13693900 \\ \mathrm{H} & -3.67490200 & -1.29681100 & -2.52122300 \\ \mathrm{H} & -3.38183500 & -2.68270300 & -1.44473900 \\ \mathrm{H} & -5.02193500 & -2.01035500 & -1.60664400 \\ \mathrm{H} & -4.43998800 & 3.87890100 & 0.15605200 \\ \mathrm{H} & -5.83374400 & 2.84127000 & 0.44258600 \\ \mathrm{H} & -5.19566900 & 2.99643900 & -1.19162300 \\ \mathrm{H} & -3.02690900 & 0.86120400 & 1.93718800 \\ \mathrm{H} & -3.19000100 & 2.62061500 & 1.97815800 \\ \mathrm{H} & -4.60308800 & 1.60084400 & 2.23068800\end{array}$

\section{Revised structure of xylogranatin H (17-6)-conformer 11}

Zero-point correction $=$

Thermal correction to Energy=

Thermal correction to Enthalpy=

Thermal correction to Gibbs Free Energy=

Sum of electronic and zero-point Energies=

Sum of electronic and thermal Energies=

Sum of electronic and thermal Enthalpies=

Sum of electronic and thermal Free Energies=
0.512872 (Hartree/Particle)

$$
0.541551
$$

0.542495

0.453597

$-1513.909946$

$-1513.881268$

$-1513.880324$

$-1513.969222$

01

$\begin{array}{lrrr}\mathrm{N} & 1.13586900 & -1.20628900 & 0.73403800 \\ \mathrm{C} & 2.22323900 & -0.49466500 & 0.40294700 \\ \mathrm{C} & 2.14237300 & 0.72994900 & -0.27904400 \\ \mathrm{C} & 0.86357800 & 1.19238600 & -0.61589300 \\ \mathrm{C} & -0.27306100 & 0.46182700 & -0.27454500 \\ \mathrm{C} & -0.07610900 & -0.75556900 & 0.40291400 \\ \mathrm{C} & 3.55822600 & -1.12666500 & 0.80099800 \\ \mathrm{C} & 4.79261800 & -0.31905500 & 0.28977900 \\ \mathrm{C} & 4.60579500 & 1.22213400 & 0.21331100 \\ \mathrm{C} & 3.37363100 & 1.53255800 & -0.67971100 \\ \mathrm{C} & -1.66522300 & 1.00216100 & -0.55753600 \\ \mathrm{C} & -2.80843000 & -0.08612100 & -0.70903900 \\ & & & \text { SI245 }\end{array}$




$\begin{array}{lrrr}\mathrm{C} & -2.26396700 & -1.51725200 & -0.46995100 \\ \mathrm{C} & -1.27191700 & -1.62405100 & 0.69747100 \\ \mathrm{C} & -2.01283900 & 2.06888300 & 0.52012700 \\ \mathrm{C} & -3.42327300 & 2.58136200 & 0.34200100 \\ \mathrm{O} & -4.36255400 & 1.61004600 & 0.21043800 \\ \mathrm{C} & -3.93034900 & 0.22724900 & 0.33961700 \\ \mathrm{O} & 3.65017100 & -2.41994900 & 0.10930200 \\ \mathrm{C} & 4.53227600 & -2.40045100 & -0.92003000 \\ \mathrm{C} & 5.15027300 & -1.01952000 & -1.03467000 \\ \mathrm{O} & 4.74315600 & -3.36722200 & -1.61159300 \\ \mathrm{C} & -5.18070900 & -0.60124200 & 0.25706000 \\ \mathrm{C} & -6.34449100 & -0.27300900 & -0.37743900 \\ \mathrm{O} & -7.27522600 & -1.25509700 & -0.20907200 \\ \mathrm{C} & -6.69960900 & -2.22812800 & 0.55291400 \\ \mathrm{C} & -5.42233100 & -1.88145800 & 0.87331500 \\ \mathrm{H} & 5.61151900 & -0.50675900 & 0.99527800 \\ \mathrm{O} & 3.08929800 & 2.93138700 & -0.76185900 \\ \mathrm{O} & -3.74413200 & 3.74616700 & 0.28566700 \\ \mathrm{H} & -1.61057400 & 1.54623300 & -1.50740500 \\ \mathrm{C} & -3.38270300 & -0.00795700 & -2.13698900 \\ \mathrm{C} & 3.59674800 & -1.46655500 & 2.29124500 \\ \mathrm{C} & 4.41148800 & 1.81676600 & 1.62666100 \\ \mathrm{C} & 5.86522700 & 1.86196700 & -0.40480300 \\ \mathrm{H} & 0.77145400 & 2.13470400 & -1.15027500 \\ \mathrm{H} & 3.62997800 & 1.27819700 & -1.71512800 \\ \mathrm{H} & -3.10121000 & -2.20848300 & -0.33694100 \\ \mathrm{H} & -1.74618600 & -1.84224500 & -1.38067900 \\ \mathrm{H} & -1.74137300 & -1.32353600 & 1.64562300 \\ \mathrm{H} & -0.93020500 & -2.65385200 & 0.83257100 \\ \mathrm{H} & -1.91169300 & 1.63863400 & 1.52492700 \\ \mathrm{H} & -1.33350300 & 2.92039100 & 0.46131100 \\ \mathrm{H} & -3.51310200 & 0.09832200 & 1.34620400 \\ \mathrm{H} & 6.22247200 & -1.10691100 & -1.21961000 \\ \mathrm{H} & 4.71248700 & -0.53946600 & -1.91711100 \\ \mathrm{H} & -6.65939600 & 0.59451100 & -0.93400000 \\ \mathrm{H} & -7.31865700 & -3.08159400 & 0.78023800 \\ \mathrm{H} & -4.74100100 & -2.45729500 & 1.48391200 \\ \mathrm{H} & 2.80064500 & 3.24541400 & 0.10645300 \\ \mathrm{H} & -4.12192300 & -0.79490600 & -2.31063300 \\ \mathrm{H} & -3.86410600 & 0.95666200 & -2.32725700 \\ \mathrm{H} & -2.57655800 & -0.13484100 & -2.86736200 \\ \mathrm{H} & 3.53751500 & -0.56400000 & 2.90457700 \\ \mathrm{H} & 2.75059300 & -2.11085700 & 2.53657900 \\ \mathrm{H} & 4.52730900 & -1.99136200 & 2.52681000 \\ \mathrm{H} & 4.45677300 & 2.91065100 & 1.59561300 \\ \mathrm{H} & 5.21408700 & 1.48536100 & 2.29375800 \\ \mathrm{H} & 3.45912700 & 1.52985400 & 2.08255800 \\ \mathrm{H} & 6.06096800 & 1.48908600 & -1.41503600 \\ \mathrm{H} & 5.74783700 & 2.94688200 & -0.47081500 \\ \mathrm{H} & 6.74717000 & 1.64931700 & 0.21024200\end{array}$

SI246 
Revised structure of xylogranatin H (17-6)-conformer 12

Zero-point correction=

Thermal correction to Energy=

Thermal correction to Enthalpy=

Thermal correction to Gibbs Free Energy=

Sum of electronic and zero-point Energies=

Sum of electronic and thermal Energies=

Sum of electronic and thermal Enthalpies=

Sum of electronic and thermal Free Energies=
0.512331 (Hartree/Particle)

0.541279

0.542223

0.453611

$-1513.911430$

$-1513.882483$

$-1513.881539$

$-1513.970151$

01

$\mathrm{N}$

$\mathrm{C}$

C

$\mathrm{C}$

C

$\mathrm{C}$

C

$\mathrm{C}$

C

$\mathrm{C}$

$\mathrm{C}$

$\mathrm{C}$

C

C

$\mathrm{C}$

C

$\mathrm{O}$

C

O

C

C

O

C

C

O

C

C

$\mathrm{H}$

O

$\mathrm{O}$

$\mathrm{H}$

C

C

C

C

$\mathrm{H}$

$\mathrm{H}$

$\mathrm{H}$

$\mathrm{H}$

$$
\begin{array}{rrr}
-1.35537600 & -1.54762400 & -0.35793900 \\
-2.17714400 & -0.49580500 & -0.40813800 \\
-1.70748900 & 0.82574400 & -0.44406700 \\
-0.32547400 & 1.01668600 & -0.40505000 \\
0.54649500 & -0.07307200 & -0.35076900 \\
-0.02875800 & -1.35741100 & -0.32752000 \\
-3.66888900 & -0.81050300 & -0.41998800 \\
-4.61769400 & 0.42889000 & -0.33899800 \\
-3.97214600 & 1.72642000 & 0.23769100 \\
-2.66899000 & 1.98640600 & -0.55111100 \\
2.05330600 & 0.11980100 & -0.36954600 \\
2.79906900 & -1.05220600 & 0.31166800 \\
2.33011700 & -2.38027900 & -0.33555800 \\
0.81475700 & -2.60873900 & -0.19770900 \\
2.52424600 & 0.30815800 & -1.83423800 \\
3.97613100 & -0.00003800 & -2.16896300 \\
4.69260600 & -0.76471300 & -1.31070900 \\
4.32973100 & -0.88757300 & 0.09635500 \\
-3.94984000 & -1.57281800 & 0.80385700 \\
-5.15812200 & -1.23990100 & 1.32884200 \\
-5.77995000 & -0.12842300 & 0.49873400 \\
-5.61231700 & -1.78632700 & 2.30511600 \\
5.01036500 & 0.21874800 & 0.85908400 \\
5.86437500 & 0.04081600 & 1.90913400 \\
6.32467500 & 1.23707500 & 2.37072600 \\
5.76589700 & 2.20423000 & 1.58742500 \\
4.95589900 & 1.64504100 & 0.64758600 \\
-4.94500600 & 0.67053700 & -1.35261800 \\
-3.02670300 & 2.21900300 & -1.92851500 \\
4.47086700 & 0.33047200 & -3.22321300 \\
2.28277000 & 1.03656100 & 0.18701200 \\
2.51803200 & -1.07431900 & 1.82726500 \\
-4.00914400 & -1.71024800 & -1.61403900 \\
-4.93376500 & 2.91434200 & 0.03098500 \\
-3.62487200 & 1.62519600 & 1.73985700 \\
0.07624300 & 2.02982600 & -0.40325400 \\
-2.18917300 & 2.89223100 & -0.14981200 \\
2.61072000 & -2.39231000 & -1.39392100 \\
2.86606500 & -3.21844300 & 0.12597200
\end{array}
$$




$\begin{array}{lrrr}\mathrm{H} & 0.46944600 & -3.33937600 & -0.93709900 \\ \mathrm{H} & 0.58034300 & -3.05430000 & 0.77749600 \\ \mathrm{H} & 1.94999500 & -0.35155600 & -2.49645300 \\ \mathrm{H} & 2.31851300 & 1.32244200 & -2.18776600 \\ \mathrm{H} & 4.80110400 & -1.83046100 & 0.39074900 \\ \mathrm{H} & -6.55925700 & -0.57556100 & -0.12894500 \\ \mathrm{H} & -6.27594400 & 0.59323500 & 1.14935400 \\ \mathrm{H} & 6.23006400 & -0.83669900 & 2.42025100 \\ \mathrm{H} & 6.04898600 & 3.21969300 & 1.81578700 \\ \mathrm{H} & 4.41940800 & 2.18400600 & -0.11985600 \\ \mathrm{H} & -2.21855100 & 2.26755700 & -2.45550000 \\ \mathrm{H} & 3.08628300 & -1.87466500 & 2.31543700 \\ \mathrm{H} & 2.79819200 & -0.12922600 & 2.29939100 \\ \mathrm{H} & 1.45937400 & -1.24852500 & 2.03299300 \\ \mathrm{H} & -3.77640900 & -1.19554000 & -2.55173600 \\ \mathrm{H} & -3.42164500 & -2.62865400 & -1.55716400 \\ \mathrm{H} & -5.07316500 & -1.96721800 & -1.61465500 \\ \mathrm{H} & -4.47496700 & 3.84323900 & 0.38910500 \\ \mathrm{H} & -5.86172300 & 2.77128100 & 0.59404100 \\ \mathrm{H} & -5.18425100 & 3.04747500 & -1.02394200 \\ \mathrm{H} & -2.97516000 & 0.77814700 & 1.97350700 \\ \mathrm{H} & -3.11532100 & 2.53825300 & 2.06853200 \\ \mathrm{H} & -4.52947300 & 1.52809700 & 2.34698300\end{array}$

Revised structure of xylogranatin H (17-6)-conformer 13

Zero-point correction $=$

Thermal correction to Energy=

Thermal correction to Enthalpy=

Thermal correction to Gibbs Free Energy=

Sum of electronic and zero-point Energies $=$

Sum of electronic and thermal Energies=

Sum of electronic and thermal Enthalpies=

Sum of electronic and thermal Free Energies=
0.512355 (Hartree/Particle)

0.541332

0.542276

0.453279

$-1513.909583$

$-1513.880606$

$-1513.879662$

$-1513.968659$

01

$\begin{array}{lrrr}\mathrm{N} & -1.39728900 & -1.38074600 & -0.92585200 \\ \mathrm{C} & -2.24926600 & -0.48161500 & -0.41919400 \\ \mathrm{C} & -1.81236800 & 0.69468400 & 0.21082500 \\ \mathrm{C} & -0.43260400 & 0.90505300 & 0.28711900 \\ \mathrm{C} & 0.46213500 & -0.02768900 & -0.23583700 \\ \mathrm{C} & -0.07767300 & -1.18115800 & -0.83544000 \\ \mathrm{C} & -3.73128300 & -0.83000500 & -0.57462700 \\ \mathrm{C} & -4.69214600 & 0.23117300 & 0.05573600 \\ \mathrm{C} & -4.15184500 & 1.68948900 & 0.08200700 \\ \mathrm{C} & -2.78259200 & 1.69133900 & 0.81312300 \\ \mathrm{C} & 1.95983400 & 0.22639000 & -0.21813100 \\ \mathrm{C} & 2.77362700 & -1.08926000 & -0.23325800 \\ \mathrm{C} & 2.30068800 & -1.95139400 & -1.43164500 \\ \mathrm{C} & 0.80215000 & -2.29480500 & -1.36525100 \\ \mathrm{C} & 2.33600600 & 1.13296000 & -1.41779800\end{array}$




\begin{tabular}{|c|c|c|c|}
\hline $\mathrm{C}$ & 3.77097000 & 1.10117000 & -1.92131600 \\
\hline $\mathrm{O}$ & 4.55822100 & 0.05252600 & -1.57799500 \\
\hline $\mathrm{C}$ & 4.28380900 & -0.76214300 & -0.40049000 \\
\hline $\mathrm{O}$ & -3.96995300 & -2.05943700 & 0.19594300 \\
\hline $\mathrm{C}$ & -4.71860500 & -1.85099400 & 1.30437500 \\
\hline $\mathrm{C}$ & -5.06084300 & -0.37727100 & 1.42247000 \\
\hline $\mathrm{O}$ & -5.02533200 & -2.74265900 & 2.05898900 \\
\hline $\mathrm{C}$ & 4.98093900 & -0.13805100 & 0.78016500 \\
\hline $\mathrm{C}$ & 5.90356100 & -0.76218800 & 1.56925700 \\
\hline $\mathrm{O}$ & 6.36026700 & 0.07612400 & 2.54149200 \\
\hline $\mathrm{C}$ & 5.72754700 & 1.27149900 & 2.36096700 \\
\hline $\mathrm{C}$ & 4.87538300 & 1.20294600 & 1.30218600 \\
\hline $\mathrm{H}$ & -5.60006900 & 0.24270900 & -0.55925600 \\
\hline $\mathrm{O}$ & -2.15328500 & 2.97908600 & 0.80758800 \\
\hline $\mathrm{O}$ & 4.19362400 & 1.92699700 & -2.69915200 \\
\hline $\mathrm{H}$ & 2.19920000 & 0.76297600 & 0.70764100 \\
\hline $\mathrm{C}$ & 2.58440300 & -1.86657000 & 1.08442500 \\
\hline $\mathrm{C}$ & -4.07327300 & -1.18679500 & -2.02170300 \\
\hline $\mathrm{C}$ & -3.99514000 & 2.24681200 & -1.34846100 \\
\hline $\mathrm{C}$ & -5.15413700 & 2.58611800 & 0.83872200 \\
\hline $\mathrm{H}$ & -0.06693400 & 1.81509700 & 0.75310300 \\
\hline $\mathrm{H}$ & -2.95342200 & 1.40453300 & 1.86238500 \\
\hline $\mathrm{H}$ & 2.51786900 & -1.42802000 & -2.36860300 \\
\hline $\mathrm{H}$ & 2.88417000 & -2.87958300 & -1.46428100 \\
\hline $\mathrm{H}$ & 0.43373400 & -2.59124800 & -2.35321400 \\
\hline $\mathrm{H}$ & 0.63793700 & -3.16892700 & -0.72197100 \\
\hline $\mathrm{H}$ & 1.73739200 & 0.85604400 & -2.29447800 \\
\hline $\mathrm{H}$ & 2.08330200 & 2.17763500 & -1.21647500 \\
\hline $\mathrm{H}$ & 4.79594600 & -1.70272800 & -0.62674900 \\
\hline $\mathrm{H}$ & -6.11291500 & -0.26353900 & 1.69168400 \\
\hline $\mathrm{H}$ & -4.47550600 & 0.02354800 & 2.25726200 \\
\hline $\mathrm{H}$ & 6.32374900 & -1.75638400 & 1.56520500 \\
\hline $\mathrm{H}$ & 5.99677100 & 2.05750000 & 3.04884200 \\
\hline $\mathrm{H}$ & 4.27626200 & 2.01862100 & 0.92405900 \\
\hline $\mathrm{H}$ & -2.59137800 & 3.54443400 & 1.45552900 \\
\hline $\mathrm{H}$ & 3.19985800 & -2.77385000 & 1.09180300 \\
\hline $\mathrm{H}$ & 2.86926200 & -1.26184800 & 1.94915700 \\
\hline $\mathrm{H}$ & 1.54421900 & -2.17169500 & 1.21993200 \\
\hline $\mathrm{H}$ & -3.94211300 & -0.32337700 & -2.67921700 \\
\hline $\mathrm{H}$ & -3.41773200 & -1.98933700 & -2.36340200 \\
\hline $\mathrm{H}$ & -5.11350100 & -1.52029400 & -2.0833330 \\
\hline $\mathrm{H}$ & -3.66948800 & 3.28950700 & -1.31303900 \\
\hline $\mathrm{H}$ & -4.95210100 & 2.20330500 & -1.8801010 \\
\hline $\mathrm{H}$ & -3.25515700 & 1.69687000 & -1.93477100 \\
\hline $\mathrm{H}$ & -5.25805800 & 2.30014400 & 1.89120800 \\
\hline $\mathrm{H}$ & -4.84764000 & 3.63706500 & 0.79934200 \\
\hline $\mathrm{H}$ & -6.14662400 & 2.52680500 & 0.37842600 \\
\hline
\end{tabular}




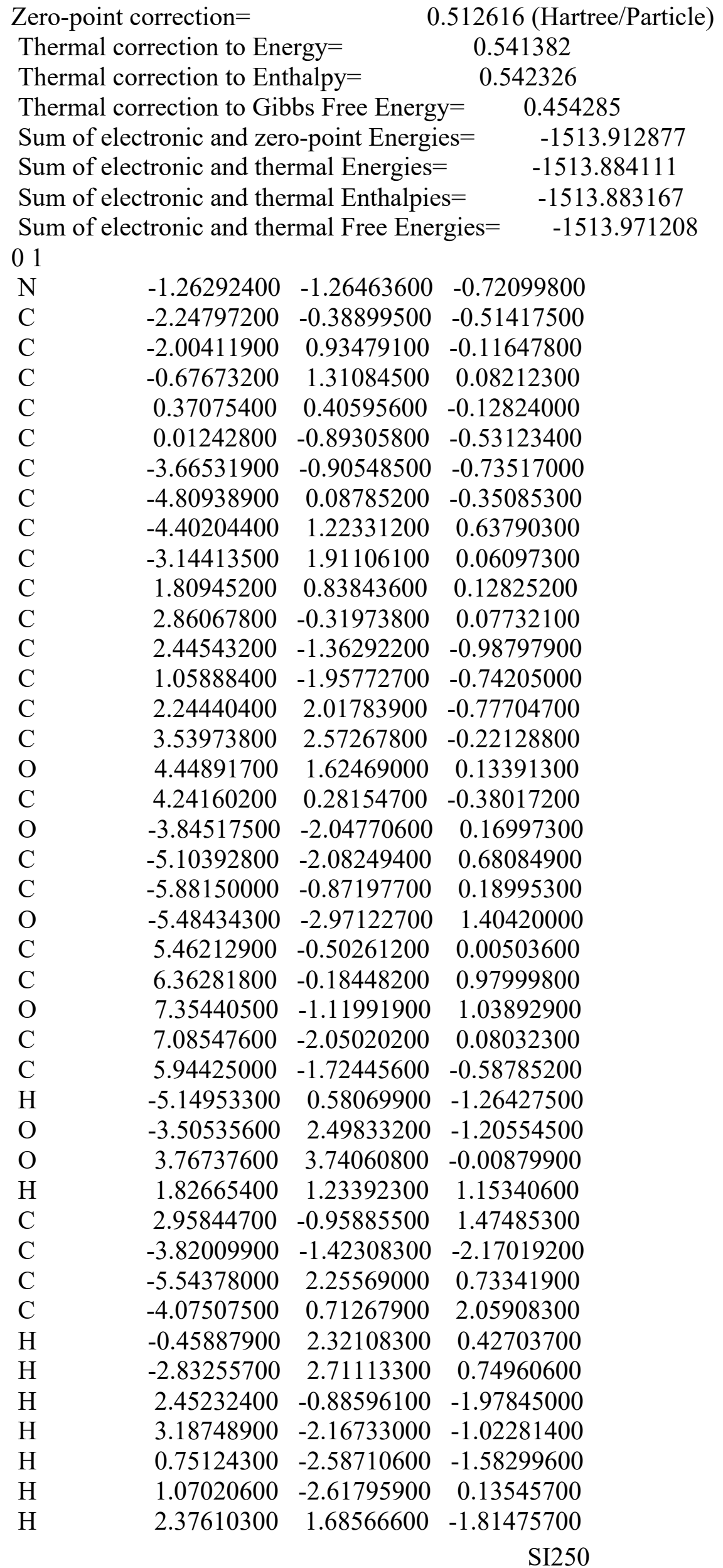




$\begin{array}{lrrr}\mathrm{H} & 1.51577000 & 2.82920600 & -0.78415800 \\ \mathrm{H} & 4.22177600 & 0.35751700 & -1.47515300 \\ \mathrm{H} & -6.56367800 & -1.20995800 & -0.59848800 \\ \mathrm{H} & -6.50271100 & -0.47424000 & 0.99370000 \\ \mathrm{H} & 6.44529500 & 0.64612300 & 1.66148200 \\ \mathrm{H} & 7.79057200 & -2.86202500 & -0.00486900 \\ \mathrm{H} & 5.51082500 & -2.27639900 & -1.40951500 \\ \mathrm{H} & -2.71028300 & 2.86070000 & -1.61750400 \\ \mathrm{H} & 3.57216500 & -1.86379900 & 1.46390700 \\ \mathrm{H} & 3.40504800 & -0.25924600 & 2.18898400 \\ \mathrm{H} & 1.96538700 & -1.22481000 & 1.85046200 \\ \mathrm{H} & -3.65206800 & -0.60984500 & -2.88349100 \\ \mathrm{H} & -3.08972200 & -2.21369700 & -2.35295900 \\ \mathrm{H} & -4.82628000 & -1.82298700 & -2.33116700 \\ \mathrm{H} & -5.25413100 & 3.08509300 & 1.38894600 \\ \mathrm{H} & -6.44654200 & 1.80492400 & 1.15820300 \\ \mathrm{H} & -5.79048800 & 2.67122400 & -0.24626900 \\ \mathrm{H} & -3.29937200 & -0.05699000 & 2.07052900 \\ \mathrm{H} & -3.73095700 & 1.54358600 & 2.68552100 \\ \mathrm{H} & -4.96416500 & 0.29611100 & 2.54110700\end{array}$

\section{Revised structure of xylogranatin H (17-6)-conformer 15}

$\begin{array}{lc}\text { Zero-point correction }= & 0.512536 \\ \text { Thermal correction to Energy }= & 0.541371 \\ \text { Thermal correction to Enthalpy= } & 0.542315 \\ \text { Thermal correction to Gibbs Free Energy }= & 0.454078 \\ \text { Sum of electronic and zero-point Energies }= & -1513.911124 \\ \text { Sum of electronic and thermal Energies }= & -1513.882289 \\ \text { Sum of electronic and thermal Enthalpies }= & -1513.881345 \\ \text { Sum of electronic and thermal Free Energies }= & -1513.969583\end{array}$
01

$\begin{array}{lrrr}\mathrm{N} & -1.35847700 & -1.56505200 & -0.27863700 \\ \mathrm{C} & -2.16968000 & -0.50958000 & -0.39103700 \\ \mathrm{C} & -1.68739900 & 0.80397800 & -0.49135300 \\ \mathrm{C} & -0.30388000 & 0.98467600 & -0.44972300 \\ \mathrm{C} & 0.55657500 & -0.10877300 & -0.33074600 \\ \mathrm{C} & -0.03060400 & -1.38542800 & -0.24626700 \\ \mathrm{C} & -3.66410000 & -0.81120700 & -0.40039900 \\ \mathrm{C} & -4.60205900 & 0.43888400 & -0.39262100 \\ \mathrm{C} & -3.94959400 & 1.75895600 & 0.12149100 \\ \mathrm{C} & -2.63726800 & 1.96584400 & -0.66789300 \\ \mathrm{C} & 2.06488000 & 0.06294200 & -0.34799800 \\ \mathrm{C} & 2.78376300 & -1.06836000 & 0.42374800 \\ \mathrm{C} & 2.32174200 & -2.43243500 & -0.14872000 \\ \mathrm{C} & 0.79890400 & -2.63761700 & -0.04299100 \\ \mathrm{C} & 2.54942800 & 0.13229600 & -1.81775400 \\ \mathrm{C} & 3.99945100 & -0.21642900 & -2.10580500 \\ \mathrm{O} & 4.69706800 & -0.91817400 & -1.17843200 \\ \mathrm{C} & 4.32014800 & -0.91497900 & 0.22546900\end{array}$




\begin{tabular}{|c|c|c|c|}
\hline $\mathrm{O}$ & -3.96263700 & -1.50634300 & 0.85894000 \\
\hline $\mathrm{C}$ & -5.17199500 & -1.13560700 & 1.35518300 \\
\hline $\mathrm{C}$ & -5.77653900 & -0.06378800 & 0.46257700 \\
\hline $\mathrm{O}$ & -5.63922700 & -1.62593900 & 2.35485400 \\
\hline $\mathrm{C}$ & 4.98020200 & 0.27647300 & 0.88005800 \\
\hline $\mathrm{C}$ & 5.46213800 & 1.39254300 & 0.25438100 \\
\hline $\mathrm{O}$ & 6.04445900 & 2.23672000 & 1.15376900 \\
\hline $\mathrm{C}$ & 5.94849400 & 1.64393100 & 2.37754600 \\
\hline $\mathrm{C}$ & 5.31499500 & 0.44414200 & 2.27366500 \\
\hline $\mathrm{H}$ & -4.91858000 & 0.63022000 & -1.42030300 \\
\hline $\mathrm{O}$ & -2.98097100 & 2.12851000 & -2.05886300 \\
\hline $\mathrm{O}$ & 4.51952000 & 0.02932900 & -3.17146400 \\
\hline $\mathrm{H}$ & 2.31369100 & 1.01485200 & 0.13770200 \\
\hline $\mathrm{C}$ & 2.45505000 & -0.99713800 & 1.92789500 \\
\hline $\mathrm{C}$ & -4.00226000 & -1.76880400 & -1.54915200 \\
\hline $\mathrm{C}$ & -4.89836800 & 2.94289200 & -0.15548600 \\
\hline $\mathrm{C}$ & -3.61621100 & 1.73330300 & 1.62999200 \\
\hline $\mathrm{H}$ & 0.10808600 & 1.99251400 & -0.49722900 \\
\hline $\mathrm{H}$ & -2.15260000 & 2.88729300 & -0.31052000 \\
\hline $\mathrm{H}$ & 2.63409100 & -2.51807400 & -1.19425100 \\
\hline $\mathrm{H}$ & 2.83436800 & -3.24282400 & 0.38358300 \\
\hline $\mathrm{H}$ & 0.46611600 & -3.39517100 & -0.76084100 \\
\hline $\mathrm{H}$ & 0.53212600 & -3.04078200 & 0.94212700 \\
\hline $\mathrm{H}$ & 1.97351400 & -0.56905900 & -2.43439600 \\
\hline $\mathrm{H}$ & 2.36228400 & 1.11991500 & -2.24801300 \\
\hline $\mathrm{H}$ & 4.79369000 & -1.82407300 & 0.61296500 \\
\hline $\mathrm{H}$ & -6.55436300 & -0.53650900 & -0.14796900 \\
\hline $\mathrm{H}$ & -6.27166100 & 0.69512800 & 1.07002400 \\
\hline $\mathrm{H}$ & 5.51585900 & 1.69915300 & -0.77815100 \\
\hline $\mathrm{H}$ & 6.37483000 & 2.19053800 & 3.20404000 \\
\hline $\mathrm{H}$ & 5.11812600 & -0.24205800 & 3.08438000 \\
\hline $\mathrm{H}$ & -2.16764400 & 2.14521500 & -2.57985700 \\
\hline $\mathrm{H}$ & 3.02383000 & -1.74946400 & 2.48707000 \\
\hline $\mathrm{H}$ & 2.68578400 & -0.01388400 & 2.34447000 \\
\hline $\mathrm{H}$ & 1.39534000 & -1.18858900 & 2.10952200 \\
\hline $\mathrm{H}$ & -3.75651500 & -1.30541900 & -2.51001300 \\
\hline $\mathrm{H}$ & -3.42375100 & -2.68812000 & -1.43937300 \\
\hline $\mathrm{H}$ & -5.06855800 & -2.01616600 & -1.5463770 \\
\hline $\mathrm{H}$ & -4.43401300 & 3.88515500 & 0.15772200 \\
\hline $\mathrm{H}$ & -5.83238100 & 2.83764100 & 0.40591900 \\
\hline $\mathrm{H}$ & -5.13857100 & 3.02299300 & -1.21813100 \\
\hline $\mathrm{H}$ & -2.97745200 & 0.89319800 & 1.91364700 \\
\hline $\mathrm{H}$ & -3.09992700 & 2.65724100 & 1.91479700 \\
\hline $\mathrm{H}$ & -4.52695200 & 1.67738600 & 2.23311800 \\
\hline
\end{tabular}

\section{Revised structure of xylogranatin H (17-6)-conformer 16}

Zero-point correction $=$

Thermal correction to Energy=

Thermal correction to Enthalpy=
0.512499 (Hartree/Particle)

0.541383

0.542327 


$\begin{array}{lc}\text { Thermal correction to Gibbs Free Energy }= & 0.453536 \\ \text { Sum of electronic and zero-point Energies }= & -1513.909239 \\ \text { Sum of electronic and thermal Energies }= & -1513.880355 \\ \text { Sum of electronic and thermal Enthalpies }= & -1513.879411 \\ \text { Sum of electronic and thermal Free Energies }= & -1513.968202\end{array}$

01

$\mathrm{N} \quad-1.40350400 \quad-1.37861000 \quad-0.92901300$

C $\quad-2.24550500 \quad-0.46884000 \quad-0.42420600$

$\begin{array}{llll}\text { C } & -1.79580100 & 0.70229400 & 0.20629200\end{array}$

$\begin{array}{llll}\text { C } & -0.41359500 & 0.89567400 & 0.28673600\end{array}$

C $\quad 0.47032100 \quad-0.04850900-0.23345000$

C $\quad-0.08190400 \quad-1.19506000 \quad-0.83567800$

C $\quad-3.73128100 \quad-0.79984500 \quad-0.58167100$

$\begin{array}{llll}\text { C } & -4.68055000 & 0.27351800 & 0.04558300\end{array}$

$\begin{array}{llll}\text { C } & -4.12287900 & 1.72525900 & 0.07074600\end{array}$

$\begin{array}{llll}\mathrm{C} & -2.75508200 & 1.71200600 & 0.80453500\end{array}$

$\begin{array}{llll}\text { C } & 1.97067300 & 0.18291100 & -0.21641300\end{array}$

C $\quad 2.75996600 \quad-1.14695700 \quad-0.20690700$

C $\quad 2.29302900 \quad-2.01235200 \quad-1.40499100$

C $\quad 0.78452300 \quad-2.32082300 \quad-1.36478500$

$\begin{array}{llll}\mathrm{C} & 2.36050300 & 1.05683800 & -1.43466600\end{array}$

C $\quad 3.79633700 \quad 0.99265100 \quad-1.92446000$

O $\quad 4.56677700 \quad-0.05989900 \quad-1.54995800$

$\begin{array}{llll}\mathrm{C} & 4.27742000 & -0.83283300 & -0.35378000\end{array}$

$\begin{array}{llll}\mathrm{O} & -3.98547400 & -2.02521900 & 0.19062200\end{array}$

$\begin{array}{llll}\mathrm{C} & -4.73269500 & -1.80606700 & 1.29791400\end{array}$

$\begin{array}{llll}\text { C } & -5.05866500 & -0.32842700 & 1.41261800\end{array}$

$\begin{array}{llll}\mathrm{O} & -5.04994500 & -2.69272900 & 2.05415000\end{array}$

$\begin{array}{llll}\mathrm{C} & 4.95224400 & -0.15109500 & 0.81400800\end{array}$

$\begin{array}{llll}\mathrm{C} & 5.36432600 & 1.15087900 & 0.87718800\end{array}$

$\begin{array}{llll}\mathrm{O} & 5.98620500 & 1.40357800 & 2.06485500\end{array}$

$\begin{array}{llll}\mathrm{C} & 5.98673100 & 0.23741300 & 2.77085800\end{array}$

$\begin{array}{llll}\text { C } & 5.37601000 & -0.74752200 & 2.05770500\end{array}$

$\mathrm{H} \quad-5.58725100 \quad 0.29496300 \quad-0.57094700$

$\begin{array}{llll}\mathrm{O} & -2.11035100 & 2.99194100 & 0.79694500\end{array}$

$\mathrm{O} \quad 4.24505300 \quad 1.79666600 \quad-2.71117800$

$\begin{array}{llll}\mathrm{H} & 2.22797900 & 0.73625400 & 0.69519300\end{array}$

$\begin{array}{llll}\mathrm{C} & 2.52388400 & -1.91181600 & 1.11027800\end{array}$

C $\quad-4.07538900 \quad-1.15500500 \quad-2.02861400$

C $\quad-3.95663700 \quad 2.27849900 \quad-1.36022500$

$\begin{array}{llll}\text { C } & -5.11574100 & 2.63511800 & 0.82405100\end{array}$

$\begin{array}{llll}\mathrm{H} & -0.03715900 & 1.80106300 & 0.75314300\end{array}$

$\mathrm{H} \quad-2.93131200 \quad 1.42968300 \quad 1.85411100$

$\mathrm{H} \quad 2.54088200-1.50634200 \quad-2.34340000$

$\mathrm{H} \quad 2.85567000 \quad-2.95387300 \quad-1.41517400$

$\mathrm{H} \quad 0.42585600 \quad-2.59807400 \quad-2.36194000$

$\mathrm{H} \quad 0.58934200 \quad-3.19848700 \quad-0.73534900$

$\mathrm{H} \quad \begin{array}{llll}1.76211400 & 0.76904300 & -2.30815400\end{array}$

$\mathrm{H} \quad 2.12319300 \quad 2.10887900 \quad-1.25542500$

$\mathrm{H} \quad 4.79293400 \quad-1.78202300 \quad-0.53909300$

$\mathrm{H} \quad-6.10995500 \quad-0.20252100 \quad 1.67951200$ 


$\begin{array}{lrrr}\mathrm{H} & -4.47068700 & 0.06741500 & 2.24792000 \\ \mathrm{H} & 5.33922100 & 1.97149800 & 0.17794100 \\ \mathrm{H} & 6.45470000 & 0.27129300 & 3.74219100 \\ \mathrm{H} & 5.24950100 & -1.77351700 & 2.37123800 \\ \mathrm{H} & -2.53835600 & 3.56246400 & 1.44705200 \\ \mathrm{H} & 3.14007800 & -2.81794100 & 1.15104700 \\ \mathrm{H} & 2.76151900 & -1.29642700 & 1.98114800 \\ \mathrm{H} & 1.48101000 & -2.22203800 & 1.20446300 \\ \mathrm{H} & -3.93328300 & -0.29422300 & -2.68730600 \\ \mathrm{H} & -3.42876100 & -1.96564800 & -2.36817600 \\ \mathrm{H} & -5.11934800 & -1.47645700 & -2.09120900 \\ \mathrm{H} & -3.61845900 & 3.31721000 & -1.32555300 \\ \mathrm{H} & -4.91298600 & 2.24573400 & -1.89375400 \\ \mathrm{H} & -3.22213600 & 1.71882200 & -1.94421000 \\ \mathrm{H} & -5.22554300 & 2.35180500 & 1.87666800 \\ \mathrm{H} & -4.79597000 & 3.68205700 & 0.78410900 \\ \mathrm{H} & -6.10785100 & 2.58749200 & 0.36157200\end{array}$

\section{Revised structure of xylogranatin H (17-6)-conformer 17}

Zero-point correction=

Thermal correction to Energy=

Thermal correction to Enthalpy=

Thermal correction to Gibbs Free Energy=

Sum of electronic and zero-point Energies=

Sum of electronic and thermal Energies=

Sum of electronic and thermal Enthalpies=

Sum of electronic and thermal Free Energies=
0.512615 (Hartree/Particle)

0.541370

0.542314

0.453816

$-1513.912279$

$-1513.883523$

$-1513.882579$

$-1513.971078$

01

$\begin{array}{lrrr}\mathrm{N} & -1.13775100 & -1.03409400 & -0.82762400 \\ \mathrm{C} & -2.18238200 & -0.25021700 & -0.53261700 \\ \mathrm{C} & -2.03527100 & 1.00437700 & 0.07569100 \\ \mathrm{C} & -0.73884400 & 1.42835700 & 0.38120400 \\ \mathrm{C} & 0.36012300 & 0.62656900 & 0.07115500 \\ \mathrm{C} & 0.09781200 & -0.61556800 & -0.53382200 \\ \mathrm{C} & -3.55604000 & -0.80551200 & -0.89037400 \\ \mathrm{C} & -4.77279700 & 0.04694900 & -0.40486500 \\ \mathrm{C} & -4.47076500 & 1.03083100 & 0.76680900 \\ \mathrm{C} & -3.24020100 & 1.87217200 & 0.35938300 \\ \mathrm{C} & 1.78280200 & 1.09877600 & 0.30735000 \\ \mathrm{C} & 2.83281200 & -0.04614400 & 0.62397200 \\ \mathrm{C} & 2.23016800 & -1.45881700 & 0.39935000 \\ \mathrm{C} & 1.25521100 & -1.54653200 & -0.78530200 \\ \mathrm{C} & 2.22796700 & 1.98592800 & -0.88925400 \\ \mathrm{C} & 3.64379900 & 2.47470600 & -0.68363400 \\ \mathrm{O} & 4.52823400 & 1.50598200 & -0.33369200 \\ \mathrm{C} & 4.05769600 & 0.12776500 & -0.33695200 \\ \mathrm{O} & -3.69343000 & -2.08523100 & -0.18314700 \\ \mathrm{C} & -4.96384500 & -2.27256900 & 0.26129700 \\ \mathrm{C} & -5.79972900 & -1.04639000 & -0.06831000 \\ & & & \mathrm{SI} 254 \\ & & & \end{array}$




$\begin{array}{lrrr}\mathrm{O} & -5.31103600 & -3.28470900 & 0.82065800 \\ \mathrm{C} & 5.26615800 & -0.71464900 & -0.05047800 \\ \mathrm{C} & 5.62846500 & -1.85305400 & -0.71257800 \\ \mathrm{O} & 6.78704700 & -2.35872300 & -0.20613500 \\ \mathrm{C} & 7.18383000 & -1.51432900 & 0.79244100 \\ \mathrm{C} & 6.29624100 & -0.49348600 & 0.93275500 \\ \mathrm{H} & -5.11240000 & 0.65922800 & -1.24313200 \\ \mathrm{O} & -3.59716300 & 2.63605900 & -0.81027800 \\ \mathrm{O} & 4.00531800 & 3.62583900 & -0.76799900 \\ \mathrm{H} & 1.76143700 & 1.76612000 & 1.17697600 \\ \mathrm{C} & 3.26706700 & 0.08251200 & 2.09663400 \\ \mathrm{C} & -3.63029900 & -1.09751100 & -2.39400500 \\ \mathrm{C} & -5.67748400 & 1.96838100 & 0.97519600 \\ \mathrm{C} & -4.15965200 & 0.31915400 & 2.10252300 \\ \mathrm{H} & -0.58974900 & 2.38896400 & 0.87399300 \\ \mathrm{H} & -3.00115400 & 2.56644000 & 1.17937600 \\ \mathrm{H} & 3.04328800 & -2.18336900 & 0.28681400 \\ \mathrm{H} & 1.68477900 & -1.75143300 & 1.30443100 \\ \mathrm{H} & 1.75769900 & -1.28830600 & -1.72914900 \\ \mathrm{H} & 0.86965200 & -2.56247200 & -0.90466400 \\ \mathrm{H} & 2.16693100 & 1.42178400 & -1.82860000 \\ \mathrm{H} & 1.58127100 & 2.85868400 & -0.99162900 \\ \mathrm{H} & 3.72625900 & -0.10949000 & -1.35519300 \\ \mathrm{H} & -6.43137600 & -1.29366100 & -0.92919300 \\ \mathrm{H} & -6.47238200 & -0.81744500 & 0.75948800 \\ \mathrm{H} & 5.19260800 & -2.40233000 & -1.53332700 \\ \mathrm{H} & 8.10611100 & -1.77263400 & 1.28843700 \\ \mathrm{H} & 6.36953300 & 0.33302600 & 1.62341900 \\ \mathrm{H} & -2.81254300 & 3.09978100 & -1.13041300 \\ \mathrm{H} & 3.91322800 & -0.74722800 & 2.39612700 \\ \mathrm{H} & 3.80540300 & 1.01865400 & 2.27807300 \\ \mathrm{H} & 2.38363100 & 0.06928400 & 2.74410300 \\ \mathrm{H} & -3.49209700 & -0.17318200 & -2.96398500 \\ \mathrm{H} & -2.84505000 & -1.80514600 & -2.66718200 \\ \mathrm{H} & -4.60274600 & -1.52525000 & -2.65784400 \\ \mathrm{H} & -5.46191700 & 2.69780700 & 1.76450400 \\ \mathrm{H} & -6.56353100 & 1.40516600 & 1.28546800 \\ \mathrm{H} & -5.91781400 & 2.52010000 & 0.06351800 \\ \mathrm{H} & -3.33769500 & -0.39683700 & 2.02562300 \\ \mathrm{H} & -3.88980100 & 1.05765200 & 2.86614200 \\ \mathrm{H} & & -0.21917000 & 2.47452500\end{array}$

\section{Revised structure of xylogranatin H (17-6)-conformer 18}

Zero-point correction $=$

Thermal correction to Energy=

Thermal correction to Enthalpy=

Thermal correction to Gibbs Free Energy=

Sum of electronic and zero-point Energies=

Sum of electronic and thermal Energies=
0.512596 (Hartree/Particle)

0.541358

0.542302

0.453520

$-1513.911918$

$-1513.883157$

SI255 


$$
\begin{array}{lc}
\text { Sum of electronic and thermal Enthalpies }= & -1513.882213 \\
\text { Sum of electronic and thermal Free Energies }= & -1513.970995
\end{array}
$$

\begin{tabular}{|c|c|c|c|}
\hline $\mathrm{N}$ & -1.11627000 & -1.07885300 & -0.72253000 \\
\hline $\mathrm{C}$ & -2.16559600 & -0.27898900 & -0.49945300 \\
\hline $\mathrm{C}$ & -2.03114900 & 1.00345200 & 0.05152300 \\
\hline $\mathrm{C}$ & -0.74252800 & 1.43759400 & 0.37259700 \\
\hline $\mathrm{C}$ & 0.36356400 & 0.61978800 & 0.13412500 \\
\hline $\mathrm{C}$ & 0.11301900 & -0.65129500 & -0.41290100 \\
\hline $\mathrm{C}$ & -3.53019600 & -0.84671500 & -0.87196000 \\
\hline $\mathrm{C}$ & -4.75702300 & 0.03138500 & -0.46386000 \\
\hline $\mathrm{C}$ & -4.48544300 & 1.06831800 & 0.66888900 \\
\hline $\mathrm{C}$ & -3.24041600 & 1.88667000 & 0.25859900 \\
\hline $\mathrm{C}$ & 1.77706200 & 1.11364500 & 0.39242800 \\
\hline $\mathrm{C}$ & 2.85370700 & -0.01007100 & 0.69792300 \\
\hline $\mathrm{C}$ & 2.23740100 & -1.42825400 & 0.59525700 \\
\hline $\mathrm{C}$ & 1.26634200 & -1.60652900 & -0.58106900 \\
\hline $\mathrm{C}$ & 2.20858300 & 2.02975100 & -0.78835800 \\
\hline $\mathrm{C}$ & 3.63843000 & 2.48910600 & -0.62029500 \\
\hline $\mathrm{O}$ & 4.52075600 & 1.49366200 & -0.35040900 \\
\hline $\mathrm{C}$ & 4.01958100 & 0.12800100 & -0.34078100 \\
\hline $\mathrm{O}$ & -3.69449200 & -2.09144300 & -0.11008800 \\
\hline $\mathrm{C}$ & -4.97849700 & -2.25376600 & 0.30400000 \\
\hline $\mathrm{C}$ & -5.79853800 & -1.04165600 & -0.10734400 \\
\hline $\mathrm{O}$ & -5.34698500 & -3.23764400 & 0.89903600 \\
\hline $\mathrm{C}$ & 5.22127900 & -0.74718200 & -0.12555200 \\
\hline $\mathrm{C}$ & 6.38252900 & -0.40862600 & 0.50824200 \\
\hline $\mathrm{O}$ & 7.26423000 & -1.44816400 & 0.47962200 \\
\hline $\mathrm{C}$ & 6.65960400 & -2.46993900 & -0.19054700 \\
\hline $\mathrm{C}$ & 5.41195200 & -2.09818800 & -0.58978000 \\
\hline $\mathrm{H}$ & -5.06862900 & 0.60469400 & -1.33973600 \\
\hline $\mathrm{O}$ & -3.56022900 & 2.59523400 & -0.95588000 \\
\hline $\mathrm{O}$ & 4.01745900 & 3.63621100 & -0.67962100 \\
\hline $\mathrm{H}$ & 1.73345300 & 1.76498800 & 1.27316200 \\
\hline $\mathrm{C}$ & 3.39202600 & 0.19359200 & 2.12745500 \\
\hline $\mathrm{C}$ & -3.56041400 & -1.20885100 & -2.36180700 \\
\hline $\mathrm{C}$ & -5.69413900 & 2.01748200 & 0.79807600 \\
\hline $\mathrm{C}$ & -4.21594500 & 0.41917600 & 2.04491000 \\
\hline $\mathrm{H}$ & -0.60453500 & 2.42051600 & 0.82285100 \\
\hline $\mathrm{H}$ & -3.02280400 & 2.61834900 & 1.05156200 \\
\hline $\mathrm{H}$ & 3.03837300 & -2.17221800 & 0.55801600 \\
\hline $\mathrm{H}$ & 1.68311300 & -1.62774400 & 1.52049100 \\
\hline $\mathrm{H}$ & 1.77172300 & -1.43318400 & -1.54240900 \\
\hline $\mathrm{H}$ & 0.87180700 & -2.62556900 & -0.61678300 \\
\hline $\mathrm{H}$ & 2.11196100 & 1.49165900 & -1.74006400 \\
\hline $\mathrm{H}$ & 1.57416800 & 2.91511700 & -0.85019800 \\
\hline $\mathrm{H}$ & 3.62421900 & -0.09199100 & -1.34036900 \\
\hline $\mathrm{H}$ & -6.40558400 & -1.32692400 & -0.97414200 \\
\hline $\mathrm{H}$ & -6.49431300 & -0.77202900 & 0.68846100 \\
\hline $\mathrm{H}$ & 6.72736500 & 0.49863800 & 0.97673200 \\
\hline $\mathrm{H}$ & 7.23884400 & -3.37284300 & -0.30252100 \\
\hline
\end{tabular}

01 


$\begin{array}{lrrr}\mathrm{H} & 4.71881200 & -2.70360800 & -1.15690900 \\ \mathrm{H} & -2.76512000 & 3.04242200 & -1.27364400 \\ \mathrm{H} & 4.08076600 & -0.60756900 & 2.40956700 \\ \mathrm{H} & 3.92172200 & 1.14635500 & 2.22839500 \\ \mathrm{H} & 2.56030100 & 0.19010800 & 2.84002800 \\ \mathrm{H} & -3.40092500 & -0.31282500 & -2.97014000 \\ \mathrm{H} & -2.77047000 & -1.93099800 & -2.57750100 \\ \mathrm{H} & -4.52635900 & -1.64551000 & -2.63474300 \\ \mathrm{H} & -5.49829700 & 2.78316800 & 1.55762300 \\ \mathrm{H} & -6.59062200 & 1.47174400 & 1.10957700 \\ \mathrm{H} & -5.90657300 & 2.52571800 & -0.14524300 \\ \mathrm{H} & -3.39511800 & -0.30200100 & 2.02586800 \\ \mathrm{H} & -3.96539200 & 1.19195200 & 2.78067700 \\ \mathrm{H} & -5.10508500 & -0.09866400 & 2.41592100\end{array}$

Revised structure of xylogranatin H (17-6)-conformer 19

Zero-point correction=

Thermal correction to Energy=

Thermal correction to Enthalpy=

Thermal correction to Gibbs Free Energy=

Sum of electronic and zero-point Energies=

Sum of electronic and thermal Energies=

Sum of electronic and thermal Enthalpies=

Sum of electronic and thermal Free Energies=
0.512826 (Hartree/Particle) 0.541583

0.542527

0.454174

$-1513.909248$

$-1513.880491$

$-1513.879547$

$-1513.967900$

01

$\begin{array}{lrrr}\mathrm{N} & -1.40876400 & -1.29981800 & -1.03807200 \\ \mathrm{C} & -2.25280300 & -0.42624000 & -0.47518200 \\ \mathrm{C} & -1.80780800 & 0.71477900 & 0.21279100 \\ \mathrm{C} & -0.42364300 & 0.89630900 & 0.31368200 \\ \mathrm{C} & 0.46343500 & -0.01414900 & -0.25830500 \\ \mathrm{C} & -0.08778400 & -1.11781100 & -0.93818000 \\ \mathrm{C} & -3.73663500 & -0.77062100 & -0.61834300 \\ \mathrm{C} & -4.67053700 & 0.22641200 & 0.13787300 \\ \mathrm{C} & -4.17093300 & 1.69672300 & 0.20747200 \\ \mathrm{C} & -2.75963500 & 1.71472500 & 0.85558000 \\ \mathrm{C} & 1.96453300 & 0.20902900 & -0.21108400 \\ \mathrm{C} & 2.74936000 & -1.12117400 & -0.29062100 \\ \mathrm{C} & 2.28919100 & -1.89652600 & -1.55129000 \\ \mathrm{C} & 0.77993000 & -2.20331000 & -1.54330300 \\ \mathrm{C} & 2.36888100 & 1.16658400 & -1.35987700 \\ \mathrm{C} & 3.80678600 & 1.12714600 & -1.84763300 \\ \mathrm{O} & 4.57022500 & 0.04897500 & -1.54136500 \\ \mathrm{C} & 4.26901200 & -0.80284900 & -0.40258100 \\ \mathrm{O} & -3.94734600 & -2.05949100 & 0.05638100 \\ \mathrm{C} & -4.60121600 & -1.93100900 & 1.23677500 \\ \mathrm{C} & -4.90869400 & -0.46737600 & 1.49230500 \\ \mathrm{O} & -4.86173900 & -2.87709600 & 1.94018300 \\ \mathrm{C} & 4.93560800 & -0.20423300 & 0.81427000 \\ \mathrm{C} & 5.35609300 & 1.08781000 & 0.96622000\end{array}$




$\begin{array}{lrrr}\mathrm{O} & 5.96663300 & 1.25793800 & 2.17399900 \\ \mathrm{C} & 5.95154300 & 0.04854000 & 2.80269500 \\ \mathrm{C} & 5.34199200 & -0.88349200 & 2.02079500 \\ \mathrm{H} & -5.62637800 & 0.23925400 & -0.40037800 \\ \mathrm{O} & -2.19193300 & 3.02655300 & 0.90605000 \\ \mathrm{O} & 4.26080900 & 1.98071400 & -2.57706400 \\ \mathrm{H} & 2.21530500 & 0.69410500 & 0.74031100 \\ \mathrm{C} & 2.50040400 & -1.97714800 & 0.96680400 \\ \mathrm{C} & -4.12129500 & -1.01466900 & -2.07759000 \\ \mathrm{C} & -4.12411400 & 2.32222100 & -1.20510400 \\ \mathrm{C} & -5.14358800 & 2.52981900 & 1.06623200 \\ \mathrm{H} & -0.04518300 & 1.76302700 & 0.84986300 \\ \mathrm{H} & -2.86805300 & 1.45885900 & 1.91635900 \\ \mathrm{H} & 2.54479500 & -1.32501600 & -2.44913600 \\ \mathrm{H} & 2.84970900 & -2.83635200 & -1.62552200 \\ \mathrm{H} & 0.42680100 & -2.40558400 & -2.56033400 \\ \mathrm{H} & 0.57814300 & -3.12413900 & -0.98151600 \\ \mathrm{H} & 1.77305100 & 0.94934500 & -2.25521600 \\ \mathrm{H} & 2.14157500 & 2.20499300 & -1.10389000 \\ \mathrm{H} & 4.78333000 & -1.73876700 & -0.64844100 \\ \mathrm{H} & -5.92544400 & -0.36346300 & 1.87567900 \\ \mathrm{H} & -4.23308100 & -0.12674000 & 2.28488700 \\ \mathrm{H} & 5.34488200 & 1.95237200 & 0.32169800 \\ \mathrm{H} & 6.40858400 & 0.01590600 & 3.77925100 \\ \mathrm{H} & 5.20530000 & -1.92664200 & 2.26590200 \\ \mathrm{H} & -2.00098500 & 3.32069800 & 0.00441300 \\ \mathrm{H} & 3.11409200 & -2.88562000 & 0.94772100 \\ \mathrm{H} & 2.73241600 & -1.42610200 & 1.88114700 \\ \mathrm{H} & 1.45621500 & -2.29064200 & 1.03083000 \\ \mathrm{H} & -4.00352800 & -0.10691000 & -2.67460800 \\ \mathrm{H} & -3.47912800 & -1.79199200 & -2.49531100 \\ \mathrm{H} & -5.16397600 & -1.34075400 & -2.13542600 \\ \mathrm{H} & -3.94294300 & 3.40064700 & -1.14435900 \\ \mathrm{H} & -5.08528500 & 2.19015700 & -1.71273600 \\ \mathrm{H} & -3.34860100 & 1.88364000 & -1.84014800 \\ \mathrm{H} & -5.22273700 & 2.14414400 & 2.08751400 \\ \mathrm{H} & -4.80211800 & 3.56638900 & 1.13060500 \\ & -6.14710100 & 2.52623100 & 0.62547600\end{array}$

Revised structure of xylogranatin H (17-6)-conformer 20

Zero-point correction=

Thermal correction to Energy=

Thermal correction to Enthalpy=

Thermal correction to Gibbs Free Energy=

Sum of electronic and zero-point Energies $=$

Sum of electronic and thermal Energies=

Sum of electronic and thermal Enthalpies=

Sum of electronic and thermal Free Energies= 01
0.512623 (Hartree/Particle)

0.541424

0.542368

0.453912

$-1513.910971$

$-1513.882170$

$-1513.881226$

$-1513.969682$ 


\begin{tabular}{|c|c|c|c|}
\hline $\mathrm{N}$ & 1.28382400 & -1.39778400 & 0.68133300 \\
\hline $\mathrm{C}$ & 2.30256000 & -0.59383500 & 0.36138700 \\
\hline $\mathrm{C}$ & 2.10281700 & 0.68956800 & -0.17320400 \\
\hline $\mathrm{C}$ & 0.78379100 & 1.10521800 & -0.36350000 \\
\hline $\mathrm{C}$ & -0.29026600 & 0.27253200 & -0.03784500 \\
\hline $\mathrm{C}$ & 0.02195800 & -0.99726700 & 0.48078900 \\
\hline $\mathrm{C}$ & 3.69626700 & -1.17010300 & 0.62099400 \\
\hline $\mathrm{C}$ & 4.85670900 & -0.20610900 & 0.20762900 \\
\hline $\mathrm{C}$ & 4.52702000 & 1.31150200 & 0.29323800 \\
\hline $\mathrm{C}$ & 3.26074100 & 1.58826400 & -0.56086000 \\
\hline $\mathrm{C}$ & -1.71687900 & 0.75009400 & -0.28422500 \\
\hline $\mathrm{C}$ & -2.81881300 & -0.34254200 & -0.07892500 \\
\hline $\mathrm{C}$ & -2.40832000 & -1.30206400 & 1.06397800 \\
\hline $\mathrm{C}$ & -1.06277900 & -1.98680500 & 0.82306700 \\
\hline $\mathrm{C}$ & -2.05582400 & 2.03569100 & 0.51116200 \\
\hline $\mathrm{C}$ & -3.34822600 & 2.59621700 & -0.04484200 \\
\hline $\mathrm{O}$ & -4.31600000 & 1.66358300 & -0.26528700 \\
\hline $\mathrm{C}$ & -4.14713200 & 0.37002100 & 0.37279300 \\
\hline $\mathrm{O}$ & 3.84965800 & -2.34173200 & -0.25334700 \\
\hline $\mathrm{C}$ & 4.73907000 & -2.14052900 & -1.25449300 \\
\hline $\mathrm{C}$ & 5.28724400 & -0.72754600 & -1.17683500 \\
\hline $\mathrm{O}$ & 5.00558900 & -2.99232000 & -2.06790100 \\
\hline $\mathrm{C}$ & -5.41971000 & -0.38539800 & 0.12017200 \\
\hline $\mathrm{C}$ & -6.34948800 & -0.11830700 & -0.84263800 \\
\hline $\mathrm{O}$ & -7.38587200 & -1.00296800 & -0.76612500 \\
\hline $\mathrm{C}$ & -7.11591800 & -1.84754500 & 0.26859600 \\
\hline $\mathrm{C}$ & -5.93042700 & -1.51699800 & 0.85199100 \\
\hline $\mathrm{H}$ & 5.68423400 & -0.38846800 & 0.90381900 \\
\hline $\mathrm{O}$ & 2.81656900 & 2.94733700 & -0.46571200 \\
\hline $\mathrm{O}$ & -3.53519200 & 3.74674600 & -0.36452700 \\
\hline $\mathrm{H}$ & -1.75764200 & 1.04200500 & -1.34272000 \\
\hline $\mathrm{C}$ & -3.01042700 & -1.10449300 & -1.40336200 \\
\hline $\mathrm{C}$ & 3.82221100 & -1.70997800 & 2.04614100 \\
\hline $\mathrm{C}$ & 4.28986100 & 1.74364600 & 1.75563400 \\
\hline $\mathrm{C}$ & 5.71984900 & 2.12030300 & -0.25782000 \\
\hline $\mathrm{H}$ & 0.60966300 & 2.09680000 & -0.76941300 \\
\hline $\mathrm{H}$ & 3.50651900 & 1.38622800 & -1.61480700 \\
\hline $\mathrm{H}$ & -2.35011300 & -0.73542000 & 2.00424800 \\
\hline $\mathrm{H}$ & -3.18544800 & -2.06093400 & 1.20282200 \\
\hline $\mathrm{H}$ & -0.75210000 & -2.55487500 & 1.70552400 \\
\hline $\mathrm{H}$ & -1.14236800 & -2.71938500 & 0.00867100 \\
\hline $\mathrm{H}$ & -2.15586600 & 1.81739200 & 1.58216900 \\
\hline $\mathrm{H}$ & -1.28925900 & 2.80400200 & 0.40610700 \\
\hline $\mathrm{H}$ & -4.07245200 & 0.55224800 & 1.45278400 \\
\hline $\mathrm{H}$ & 6.36807700 & -0.74232600 & -1.33114800 \\
\hline $\mathrm{H}$ & 4.85572500 & -0.16794300 & -2.01401400 \\
\hline $\mathrm{H}$ & -6.42456700 & 0.64483800 & -1.59963600 \\
\hline $\mathrm{H}$ & -7.85351900 & -2.60986500 & 0.46432300 \\
\hline $\mathrm{H}$ & -5.48503700 & -2.00739400 & 1.70565700 \\
\hline $\mathrm{H}$ & 3.37642100 & 3.50155700 & -1.02307600 \\
\hline $\mathrm{H}$ & -3.66526900 & -1.97170700 & -1.28073400 \\
\hline
\end{tabular}




$\begin{array}{lrrr}\mathrm{H} & -3.45517800 & -0.45267700 & -2.16248900 \\ \mathrm{H} & -2.04909100 & -1.45497500 & -1.79193000 \\ \mathrm{H} & 3.73566000 & -0.90385000 & 2.77937300 \\ \mathrm{H} & 3.03016200 & -2.43741600 & 2.23076800 \\ \mathrm{H} & 4.79436300 & -2.19604300 & 2.17165400 \\ \mathrm{H} & 4.11692500 & 2.82159400 & 1.80630500 \\ \mathrm{H} & 5.16631100 & 1.50643700 & 2.36873700 \\ \mathrm{H} & 3.42043900 & 1.25513400 & 2.20208700 \\ \mathrm{H} & 5.90139300 & 1.92455100 & -1.32034000 \\ \mathrm{H} & 5.55461100 & 3.19582900 & -0.13260300 \\ \mathrm{H} & 6.63729100 & 1.87275400 & 0.28759600\end{array}$

\section{Revised structure of xylogranatin H (17-6)-conformer 21}

Zero-point correction $=$

Thermal correction to Energy=

Thermal correction to Enthalpy=

Thermal correction to Gibbs Free Energy=

Sum of electronic and zero-point Energies $=$

Sum of electronic and thermal Energies=

Sum of electronic and thermal Enthalpies=

Sum of electronic and thermal Free Energies=
0.512624 (Hartree/Particle)

0.541334

0.542278

0.453566

$-1513.910747$

$-1513.882037$

$-1513.881093$

$-1513.969806$

01

$\begin{array}{lrrr}\mathrm{N} & -1.10103200 & -1.11157100 & -0.64017700 \\ \mathrm{C} & -2.15201900 & -0.30269200 & -0.45122100 \\ \mathrm{C} & -2.02196100 & 0.98861200 & 0.07273500 \\ \mathrm{C} & -0.73516900 & 1.43563000 & 0.38081500 \\ \mathrm{C} & 0.37135300 & 0.61262400 & 0.17535600 \\ \mathrm{C} & 0.12412600 & -0.67779600 & -0.32896800 \\ \mathrm{C} & -3.50648400 & -0.86778200 & -0.85724900 \\ \mathrm{C} & -4.73483400 & 0.03210400 & -0.51361800 \\ \mathrm{C} & -4.49560000 & 1.06725900 & 0.62531300 \\ \mathrm{C} & -3.22417400 & 1.88085900 & 0.26497400 \\ \mathrm{C} & 1.78238800 & 1.12320900 & 0.41749400 \\ \mathrm{C} & 2.87253700 & 0.01557100 & 0.73077300 \\ \mathrm{C} & 2.25877600 & -1.40645000 & 0.69876800 \\ \mathrm{C} & 1.27698200 & -1.63994300 & -0.45816700 \\ \mathrm{C} & 2.19493700 & 2.02735900 & -0.77988400 \\ \mathrm{C} & 3.62953300 & 2.48245100 & -0.64839800 \\ \mathrm{O} & 4.51568800 & 1.48477500 & -0.39550700 \\ \mathrm{C} & 4.00723200 & 0.12324700 & -0.34516200 \\ \mathrm{O} & -3.71981700 & -2.09503900 & -0.07789400 \\ \mathrm{C} & -5.02402300 & -2.23726800 & 0.27199100 \\ \mathrm{C} & -5.80872100 & -1.02222600 & -0.19963600 \\ \mathrm{O} & -5.43585000 & -3.20561000 & 0.86429600 \\ \mathrm{C} & 5.20941700 & -0.75549400 & -0.14780700 \\ \mathrm{C} & 6.39382700 & -0.40991900 & 0.43732900 \\ \mathrm{O} & 7.26694400 & -1.45694600 & 0.40624200 \\ \mathrm{C} & 6.63249500 & -2.49085100 & -0.21616200 \\ \mathrm{C} & 5.37462600 & -2.11966000 & -0.58245700 \\ & & & \\ & & & \mathrm{~S} 1260\end{array}$

SI260 


$\begin{array}{lrrr}\mathrm{H} & -4.99349500 & 0.60549600 & -1.40754300 \\ \mathrm{O} & -3.36464700 & 2.62953200 & -0.95794000 \\ \mathrm{O} & 4.01340300 & 3.62694000 & -0.72529200 \\ \mathrm{H} & 1.73801000 & 1.78579500 & 1.28968600 \\ \mathrm{C} & 3.45303800 & 0.27104900 & 2.13548000 \\ \mathrm{C} & -3.48579900 & -1.25879500 & -2.34019100 \\ \mathrm{C} & -5.70525300 & 2.02077800 & 0.71350400 \\ \mathrm{C} & -4.28456600 & 0.42217400 & 2.01395300 \\ \mathrm{H} & -0.60183200 & 2.43824900 & 0.78406700 \\ \mathrm{H} & -3.01668200 & 2.58083800 & 1.08857900 \\ \mathrm{H} & 3.06118600 & -2.14980400 & 0.68791400 \\ \mathrm{H} & 1.71407800 & -1.56338000 & 1.63796800 \\ \mathrm{H} & 1.77296500 & -1.51396300 & -1.43165200 \\ \mathrm{H} & 0.88238800 & -2.65959400 & -0.44164200 \\ \mathrm{H} & 2.07784100 & 1.47949700 & -1.72371400 \\ \mathrm{H} & 1.56050200 & 2.91263200 & -0.84008200 \\ \mathrm{H} & 3.58082500 & -0.11363900 & -1.32792600 \\ \mathrm{H} & -6.37183300 & -1.31304200 & -1.09369900 \\ \mathrm{H} & -6.54231100 & -0.73499300 & 0.55515900 \\ \mathrm{H} & 6.76053900 & 0.50654300 & 0.86988300 \\ \mathrm{H} & 7.20106600 & -3.40104300 & -0.32383100 \\ \mathrm{H} & 4.65788400 & -2.73401600 & -1.10920500 \\ \mathrm{H} & -3.96878400 & 3.36843100 & -0.80589900 \\ \mathrm{H} & 4.15951500 & -0.51345800 & 2.42089500 \\ \mathrm{H} & 3.97464500 & 1.23192800 & 2.18972500 \\ \mathrm{H} & 2.64400700 & 0.28169500 & 2.87364100 \\ \mathrm{H} & -3.28690000 & -0.37749000 & -2.95817500 \\ \mathrm{H} & -2.69866900 & -1.99591400 & -2.50988900 \\ \mathrm{H} & -4.44645100 & -1.68746200 & -2.64315800 \\ \mathrm{H} & -5.51437200 & 2.82345500 & 1.43661600 \\ \mathrm{H} & -6.60203700 & 1.49301800 & 1.05216300 \\ \mathrm{H} & -5.94490900 & 2.47470000 & -0.25426800 \\ \mathrm{H} & -3.45620700 & -0.28974300 & 2.03010200 \\ \mathrm{H} & -4.07243400 & 1.19789000 & 2.75898000 \\ \mathrm{H} & -5.18306100 & -0.10515500 & 2.34791800\end{array}$

Revised structure of xylogranatin H (17-6)-conformer 22

Zero-point correction=

Thermal correction to Energy=

Thermal correction to Enthalpy=

Thermal correction to Gibbs Free Energy=

Sum of electronic and zero-point Energies $=$

Sum of electronic and thermal Energies=

Sum of electronic and thermal Enthalpies=

Sum of electronic and thermal Free Energies=
0.512639 (Hartree/Particle)

0.541424

0.542369

$-1513.910376$

$-1513.881590$

$-1513.880646$

$-1513.969628$

01

$\begin{array}{lrrr}\mathrm{N} & 1.14861800 & -1.19410800 & 0.77924000 \\ \mathrm{C} & 2.22920600 & -0.49507600 & 0.40147900 \\ \mathrm{C} & 2.13290800 & 0.70534300 & -0.31878700\end{array}$

SI261 


\begin{tabular}{|c|c|c|c|}
\hline $\mathrm{C}$ & 0.84985600 & 1.17372600 & -0.62558100 \\
\hline $\mathrm{C}$ & -0.27783000 & 0.45733100 & -0.23113200 \\
\hline $\mathrm{C}$ & -0.06885300 & -0.74509900 & 0.46762100 \\
\hline $\mathrm{C}$ & 3.57131600 & -1.10673300 & 0.80826900 \\
\hline $\mathrm{C}$ & 4.80713100 & -0.28535000 & 0.31459800 \\
\hline $\mathrm{C}$ & 4.57456200 & 1.24486300 & 0.16295100 \\
\hline $\mathrm{C}$ & 3.36132200 & 1.46555700 & -0.77974600 \\
\hline $\mathrm{C}$ & -1.67788300 & 0.99416700 & -0.46855700 \\
\hline $\mathrm{C}$ & -2.80447600 & -0.10618500 & -0.64964000 \\
\hline $\mathrm{C}$ & -2.27353100 & -1.53126600 & -0.33973400 \\
\hline $\mathrm{C}$ & -1.26593900 & -1.58971400 & 0.81872300 \\
\hline $\mathrm{C}$ & -2.02566900 & 2.01118500 & 0.65505000 \\
\hline $\mathrm{C}$ & -3.42149900 & 2.55771100 & 0.46115900 \\
\hline $\mathrm{O}$ & -4.37103300 & 1.61186700 & 0.23821300 \\
\hline $\mathrm{C}$ & -3.97265700 & 0.21574900 & 0.34281600 \\
\hline $\mathrm{O}$ & 3.68318100 & -2.40341500 & 0.12432200 \\
\hline $\mathrm{C}$ & 4.62003300 & -2.40519800 & -0.85318200 \\
\hline $\mathrm{C}$ & 5.25415800 & -1.03047500 & -0.95776400 \\
\hline $\mathrm{O}$ & 4.86172700 & -3.38248800 & -1.52017700 \\
\hline $\mathrm{C}$ & -5.23543000 & -0.57931700 & 0.18097600 \\
\hline $\mathrm{C}$ & -5.62399500 & -1.63935100 & 0.94953300 \\
\hline $\mathrm{O}$ & -6.83048100 & -2.11905200 & 0.53746000 \\
\hline $\mathrm{C}$ & -7.23024800 & -1.33625800 & -0.50905600 \\
\hline $\mathrm{C}$ & -6.29875400 & -0.38064800 & -0.77119200 \\
\hline $\mathrm{H}$ & 5.59410500 & -0.41174300 & 1.06788800 \\
\hline $\mathrm{O}$ & 3.00354700 & 2.84745600 & -0.90564000 \\
\hline $\mathrm{O}$ & -3.72144400 & 3.72939800 & 0.45512700 \\
\hline $\mathrm{H}$ & -1.64577700 & 1.57884400 & -1.39511900 \\
\hline $\mathrm{C}$ & -3.29856000 & -0.06599200 & -2.10858100 \\
\hline $\mathrm{C}$ & 3.60568600 & -1.43400700 & 2.30182200 \\
\hline $\mathrm{C}$ & 4.31246100 & 1.90296700 & 1.53399700 \\
\hline $\mathrm{C}$ & 5.83748700 & 1.89047100 & -0.44474200 \\
\hline $\mathrm{H}$ & 0.74966500 & 2.11185500 & -1.16312600 \\
\hline $\mathrm{H}$ & 3.63172000 & 1.09464900 & -1.78049000 \\
\hline $\mathrm{H}$ & -3.12119700 & -2.19809100 & -0.15083200 \\
\hline $\mathrm{H}$ & -1.77557300 & -1.91782400 & -1.23699900 \\
\hline $\mathrm{H}$ & -1.72209000 & -1.23766900 & 1.75581900 \\
\hline $\mathrm{H}$ & -0.93296200 & -2.61513200 & 1.00044900 \\
\hline $\mathrm{H}$ & -1.95517600 & 1.53212500 & 1.64010200 \\
\hline $\mathrm{H}$ & -1.32833700 & 2.85016200 & 0.65137700 \\
\hline $\mathrm{H}$ & -3.60714600 & 0.04750300 & 1.36312700 \\
\hline $\mathrm{H}$ & 6.33675400 & -1.13029800 & -1.05891600 \\
\hline $\mathrm{H}$ & 4.88974000 & -0.57746200 & -1.88631200 \\
\hline $\mathrm{H}$ & -5.17820500 & -2.14490700 & 1.79271300 \\
\hline $\mathrm{H}$ & -8.18732700 & -1.58176300 & -0.94159200 \\
\hline $\mathrm{H}$ & -6.36160100 & 0.39114600 & -1.52344700 \\
\hline $\mathrm{H}$ & 3.62981600 & 3.28146700 & -1.49781800 \\
\hline $\mathrm{H}$ & -4.00577800 & -0.87467700 & -2.31309700 \\
\hline $\mathrm{H}$ & -3.78849200 & 0.88497300 & -2.34240400 \\
\hline $\mathrm{H}$ & -2.44839100 & -0.18444700 & -2.78899900 \\
\hline $\mathrm{H}$ & 3.54420800 & -0.52366000 & 2.90384700 \\
\hline
\end{tabular}




$\begin{array}{lrrr}\mathrm{H} & 2.76081100 & -2.07728200 & 2.55294200 \\ \mathrm{H} & 4.53784800 & -1.95301300 & 2.54425900 \\ \mathrm{H} & 4.20952300 & 2.98492200 & 1.41893900 \\ \mathrm{H} & 5.14789500 & 1.70736500 & 2.21524100 \\ \mathrm{H} & 3.39651700 & 1.53941200 & 2.00586800 \\ \mathrm{H} & 6.04426400 & 1.52959000 & -1.45825700 \\ \mathrm{H} & 5.73996000 & 2.98078300 & -0.48417900 \\ \mathrm{H} & 6.71610200 & 1.67139500 & 0.17208600\end{array}$

\section{Revised structure of xylogranatin H (17-6)-conformer 23}

Zero-point correction=

Thermal correction to Energy=

Thermal correction to Enthalpy=

Thermal correction to Gibbs Free Energy=

Sum of electronic and zero-point Energies=

Sum of electronic and thermal Energies=

Sum of electronic and thermal Enthalpies=

Sum of electronic and thermal Free Energies=
0.512629 (Hartree/Particle)

0.541422

0.542366

0.453123

$-1513.910054$

$-1513.881261$

$-1513.880317$

$-1513.969560$

01

$\begin{array}{lrrr}\mathrm{N} & 1.11719300 & -1.24941200 & 0.63798600 \\ \mathrm{C} & 2.20582200 & -0.52210000 & 0.35148500 \\ \mathrm{C} & 2.12854700 & 0.71872100 & -0.29989200 \\ \mathrm{C} & 0.85525100 & 1.19534000 & -0.62956400 \\ \mathrm{C} & -0.28366800 & 0.45083900 & -0.32594000 \\ \mathrm{C} & -0.09201200 & -0.79262700 & 0.30243200 \\ \mathrm{C} & 3.53527000 & -1.14730200 & 0.77881600 \\ \mathrm{C} & 4.78271600 & -0.29242300 & 0.38069300 \\ \mathrm{C} & 4.54539000 & 1.24289200 & 0.30836600 \\ \mathrm{C} & 3.36768100 & 1.51230300 & -0.66621300 \\ \mathrm{C} & -1.67153500 & 1.00939400 & -0.59820300 \\ \mathrm{C} & -2.82855000 & -0.06221300 & -0.75670600 \\ \mathrm{C} & -2.28726900 & -1.50513300 & -0.60123700 \\ \mathrm{C} & -1.28607400 & -1.67877100 & 0.54925900 \\ \mathrm{C} & -2.00115600 & 2.06916500 & 0.49283300 \\ \mathrm{C} & -3.41840500 & 2.57459000 & 0.35735500 \\ \mathrm{O} & -4.35749700 & 1.59841400 & 0.25616800 \\ \mathrm{C} & -3.91157700 & 0.21701700 & 0.34100800 \\ \mathrm{O} & 3.68606100 & -2.40381600 & 0.03061700 \\ \mathrm{C} & 4.65867800 & -2.34431400 & -0.90949700 \\ \mathrm{C} & 5.28211600 & -0.96078900 & -0.91458100 \\ \mathrm{O} & 4.93506700 & -3.28154200 & -1.61910800 \\ \mathrm{C} & -5.15803700 & -0.61960700 & 0.28718100 \\ \mathrm{C} & -6.34996000 & -0.28428100 & -0.28850100 \\ \mathrm{O} & -7.26544600 & -1.27900000 & -0.10888500 \\ \mathrm{C} & -6.65048000 & -2.26758100 & 0.60065900 \\ \mathrm{C} & -5.36350000 & -1.91866600 & 0.87657900 \\ \mathrm{H} & 5.54188600 & -0.45834600 & 1.15463000 \\ \mathrm{O} & 3.00375200 & 2.89710600 & -0.72392700 \\ \mathrm{O} & -3.74892900 & 3.73736200 & 0.31451000\end{array}$

SI263 


$\begin{array}{lrrr}\mathrm{H} & -1.61376700 & 1.56204700 & -1.54293400 \\ \mathrm{C} & -3.45267100 & 0.08104600 & -2.15881900 \\ \mathrm{C} & 3.51144700 & -1.55573900 & 2.25239900 \\ \mathrm{C} & 4.22667000 & 1.81974400 & 1.70378600 \\ \mathrm{C} & 5.82627700 & 1.92809100 & -0.21215600 \\ \mathrm{H} & 0.76987200 & 2.16290500 & -1.11499000 \\ \mathrm{H} & 3.67961600 & 1.20319400 & -1.67584100 \\ \mathrm{H} & -3.12594400 & -2.20003700 & -0.49932100 \\ \mathrm{H} & -1.77834000 & -1.77958400 & -1.53351300 \\ \mathrm{H} & -1.74812300 & -1.43819500 & 1.51788300 \\ \mathrm{H} & -0.94212900 & -2.71444800 & 0.61967000 \\ \mathrm{H} & -1.87440500 & 1.63181700 & 1.49171600 \\ \mathrm{H} & -1.32618600 & 2.92338100 & 0.42598400 \\ \mathrm{H} & -3.45556600 & 0.07010500 & 1.32805200 \\ \mathrm{H} & 6.36854400 & -1.04567800 & -0.98253500 \\ \mathrm{H} & 4.94557000 & -0.45908200 & -1.82851700 \\ \mathrm{H} & -6.69450500 & 0.59565700 & -0.80664700 \\ \mathrm{H} & -7.25265600 & -3.13262800 & 0.82958700 \\ \mathrm{H} & -4.65198700 & -2.50533800 & 1.44065800 \\ \mathrm{H} & 3.64863700 & 3.36924800 & -1.26475300 \\ \mathrm{H} & -4.21321000 & -0.68511900 & -2.33400900 \\ \mathrm{H} & -3.92167300 & 1.06055000 & -2.29587700 \\ \mathrm{H} & -2.67608800 & -0.03322600 & -2.92253700 \\ \mathrm{H} & 3.41757100 & -0.68030700 & 2.90022600 \\ \mathrm{H} & 2.66249800 & -2.21722500 & 2.43269200 \\ \mathrm{H} & 4.43721900 & -2.08154000 & 2.50446300 \\ \mathrm{H} & 4.12316600 & 2.90627800 & 1.64757400 \\ \mathrm{H} & 5.03575000 & 1.58709800 & 2.40490400 \\ \mathrm{H} & 3.29467600 & 1.42732400 & 2.11754700 \\ \mathrm{H} & 6.07452400 & 1.62632300 & -1.23568200 \\ \mathrm{H} & 5.72286500 & 3.01843500 & -0.19359100 \\ \mathrm{H} & 6.68195400 & 1.67849600 & 0.42499600 \\ & & & \\ & & & \\ & & & \end{array}$

\section{Revised structure of xylogranatin H (17-6)-conformer 24}

Zero-point correction=

Thermal correction to Energy=

Thermal correction to Enthalpy=

Thermal correction to Gibbs Free Energy=

Sum of electronic and zero-point Energies=

Sum of electronic and thermal Energies=

Sum of electronic and thermal Enthalpies $=$

Sum of electronic and thermal Free Energies=
0.512584 (Hartree/Particle)

0.541238

0.542182

0.453907

$-1513.902320$

$-1513.873667$

$-1513.872723$

$-1513.960998$

01

$\begin{array}{rrrr}\mathrm{N} & 1.10429500 & -1.28626700 & 0.46439600 \\ \mathrm{C} & 2.04894700 & -0.35144300 & 0.32450500 \\ \mathrm{C} & 1.80214200 & 0.87439700 & -0.30482900 \\ \mathrm{C} & 0.50947300 & 1.10846800 & -0.77239300 \\ \mathrm{C} & -0.49615000 & 0.15004400 & -0.62423800 \\ \mathrm{C} & -0.12899400 & -1.05869400 & -0.00374100 \\ & & & \text { SI264 }\end{array}$




\begin{tabular}{|c|c|c|c|}
\hline $\mathrm{C}$ & 3.41414500 & -0.68985000 & 0.90788300 \\
\hline $\mathrm{C}$ & 4.53813800 & 0.35445900 & 0.62088100 \\
\hline $\mathrm{C}$ & 4.28710500 & 1.27045500 & -0.61372600 \\
\hline $\mathrm{C}$ & 2.88571100 & 1.91631800 & -0.44399800 \\
\hline $\mathrm{C}$ & -1.90475400 & 0.42491900 & -1.15676600 \\
\hline $\mathrm{C}$ & -2.93655800 & -0.73770400 & -0.98332300 \\
\hline $\mathrm{C}$ & -2.19849000 & -2.09805100 & -0.95173700 \\
\hline $\mathrm{C}$ & -1.12630000 & -2.18014200 & 0.13669700 \\
\hline $\mathrm{C}$ & -2.48873700 & 1.71810600 & -0.54876500 \\
\hline $\mathrm{C}$ & -2.70999800 & 1.55225600 & 0.94000500 \\
\hline $\mathrm{O}$ & -3.13780200 & 0.32402900 & 1.33157700 \\
\hline $\mathrm{C}$ & -3.74998600 & -0.58961600 & 0.37353500 \\
\hline $\mathrm{O}$ & 3.87884800 & -1.91960100 & 0.24968100 \\
\hline $\mathrm{C}$ & 5.22014700 & -1.89327000 & 0.04520200 \\
\hline $\mathrm{C}$ & 5.77428100 & -0.55134700 & 0.49975200 \\
\hline $\mathrm{O}$ & 5.82415000 & -2.82627400 & -0.42785900 \\
\hline $\mathrm{C}$ & -5.22724600 & -0.29709800 & 0.28905700 \\
\hline $\mathrm{C}$ & -6.20186200 & -1.21495700 & 0.55925400 \\
\hline $\mathrm{O}$ & -7.44185100 & -0.66643100 & 0.42778900 \\
\hline $\mathrm{C}$ & -7.25792300 & 0.64055100 & 0.08205400 \\
\hline $\mathrm{C}$ & -5.93117600 & 0.92460600 & -0.01770000 \\
\hline $\mathrm{H}$ & 4.61459800 & 1.01451400 & 1.48868800 \\
\hline $\mathrm{O}$ & 2.79312800 & 2.75040100 & 0.72539000 \\
\hline $\mathrm{O}$ & -2.47950500 & 2.40186000 & 1.76842900 \\
\hline $\mathrm{H}$ & -1.79871700 & 0.59592800 & -2.23617900 \\
\hline $\mathrm{C}$ & -3.88183200 & -0.73886200 & -2.20220800 \\
\hline $\mathrm{C}$ & 3.28168100 & -0.98698600 & 2.40639100 \\
\hline $\mathrm{C}$ & 5.35915700 & 2.37909000 & -0.65531400 \\
\hline $\mathrm{C}$ & 4.31851500 & 0.51537400 & -1.96184100 \\
\hline $\mathrm{H}$ & 0.29579300 & 2.05595900 & -1.26285500 \\
\hline $\mathrm{H}$ & 2.67649000 & 2.52702000 & -1.33575000 \\
\hline $\mathrm{H}$ & -2.93310000 & -2.90398200 & -0.82873800 \\
\hline $\mathrm{H}$ & -1.72361900 & -2.25914000 & -1.92844600 \\
\hline $\mathrm{H}$ & -1.57526000 & -2.13874800 & 1.13895200 \\
\hline $\mathrm{H}$ & -0.58630200 & -3.13004500 & 0.08460800 \\
\hline $\mathrm{H}$ & -1.83888500 & 2.58323900 & -0.68650100 \\
\hline $\mathrm{H}$ & -3.44029400 & 1.95499000 & -1.03792700 \\
\hline $\mathrm{H}$ & -3.67015300 & -1.54512700 & 0.89590500 \\
\hline $\mathrm{H}$ & 6.26792300 & -0.70248400 & 1.46645700 \\
\hline $\mathrm{H}$ & 6.54164400 & -0.20842400 & -0.19593800 \\
\hline $\mathrm{H}$ & -6.17189000 & -2.25316000 & 0.85371700 \\
\hline $\mathrm{H}$ & -8.15431400 & 1.22694100 & -0.04505400 \\
\hline $\mathrm{H}$ & -5.51691200 & 1.89373600 & -0.25273000 \\
\hline $\mathrm{H}$ & 3.29141300 & 3.56408800 & 0.57241000 \\
\hline $\mathrm{H}$ & -4.64910900 & -1.51306000 & -2.11187100 \\
\hline $\mathrm{H}$ & -4.39851500 & 0.21638100 & -2.33306500 \\
\hline $\mathrm{H}$ & -3.30605500 & -0.94021900 & -3.11174700 \\
\hline $\mathrm{H}$ & 2.89436200 & -0.10771700 & 2.93058100 \\
\hline $\mathrm{H}$ & 2.58883100 & -1.81805500 & 2.55109400 \\
\hline $\mathrm{H}$ & 4.25223400 & -1.25220000 & 2.83794000 \\
\hline $\mathrm{H}$ & 5.14114300 & 3.09912200 & -1.45397100 \\
\hline
\end{tabular}




$\begin{array}{lrrr}\mathrm{H} & 6.35072700 & 1.96448900 & -0.86140600 \\ \mathrm{H} & 5.42740300 & 2.92274800 & 0.29316600 \\ \mathrm{H} & 3.60010500 & -0.30633500 & -2.00521000 \\ \mathrm{H} & 4.08711100 & 1.20474300 & -2.78236500 \\ \mathrm{H} & 5.31091500 & 0.10065900 & -2.16242500\end{array}$

NMR calculations of hainangranatumin G (17-4)

$\begin{array}{lc}\text { Proposed structure of hainangranatumin } & \text { (17-4)-conformer } 1 \\ \text { Zero-point correction= } & 0.545122 \text { (Hartree/Particle) } \\ \text { Thermal correction to Energy }= & 0.576586 \\ \text { Thermal correction to Enthalpy= } & 0.577531 \\ \text { Thermal correction to Gibbs Free Energy= } & 0.482181 \\ \text { Sum of electronic and zero-point Energies }= & -1591.291197 \\ \text { Sum of electronic and thermal Energies }= & -1591.259733 \\ \text { Sum of electronic and thermal Enthalpies }= & -1591.258789 \\ \text { Sum of electronic and thermal Free Energies }= & -1591.354138\end{array}$

01

\begin{tabular}{|c|c|c|c|}
\hline $\mathrm{N}$ & -0.94658200 & -1.75888700 & -0.54930500 \\
\hline $\mathrm{C}$ & -2.00198400 & -0.94037700 & -0.54761600 \\
\hline $\mathrm{C}$ & -1.87978300 & 0.45367400 & -0.42884100 \\
\hline $\mathrm{C}$ & -0.59871000 & 0.97113500 & -0.27463200 \\
\hline $\mathrm{C}$ & 0.52596600 & 0.12965100 & -0.27260200 \\
\hline $\mathrm{C}$ & 0.28568900 & -1.25674900 & -0.41205800 \\
\hline $\mathrm{C}$ & -3.36201600 & -1.60971500 & -0.69224700 \\
\hline $\mathrm{C}$ & -4.58882400 & -0.65891200 & -0.50649200 \\
\hline $\mathrm{C}$ & -4.30917600 & 0.66476600 & 0.26939000 \\
\hline $\mathrm{C}$ & -3.11167700 & 1.34429200 & -0.45087100 \\
\hline $\mathrm{C}$ & 1.90195000 & 0.65185000 & -0.11681200 \\
\hline $\mathrm{C}$ & 3.03084800 & -0.34587100 & 0.14716000 \\
\hline $\mathrm{C}$ & 2.77397600 & -1.62714600 & -0.67990600 \\
\hline $\mathrm{C}$ & 1.41287400 & -2.25830600 & -0.38445500 \\
\hline $\mathrm{C}$ & 2.19312200 & 1.97181600 & -0.16295500 \\
\hline $\mathrm{C}$ & 3.52570300 & 2.50777900 & 0.15862300 \\
\hline $\mathrm{O}$ & 4.55194300 & 1.61433800 & 0.23340500 \\
\hline $\mathrm{C}$ & 4.34723000 & 0.30757300 & -0.36215100 \\
\hline $\mathrm{O}$ & -3.48077700 & -2.58747600 & 0.39280000 \\
\hline $\mathrm{C}$ & -4.74830700 & -2.63640100 & 0.88090900 \\
\hline $\mathrm{C}$ & -5.60125700 & -1.59307600 & 0.17673600 \\
\hline $\mathrm{O}$ & -5.08329500 & -3.41761100 & 1.73733300 \\
\hline $\mathrm{C}$ & 5.61003100 & -0.46526200 & -0.12410100 \\
\hline $\mathrm{C}$ & 6.28244800 & -1.21063900 & -1.04972400 \\
\hline $\mathrm{O}$ & 7.39255200 & -1.77733700 & -0.49979300 \\
\hline $\mathrm{C}$ & 7.43893600 & -1.37133300 & 0.80448900 \\
\hline $\mathrm{C}$ & 6.37820600 & -0.56945000 & 1.09080800 \\
\hline $\mathrm{H}$ & -4.94594200 & -0.36985200 & -1.50182000 \\
\hline $\mathrm{O}$ & 3.73250500 & 3.67976500 & 0.40415500 \\
\hline C & 3.08602800 & -0.65986500 & 1.66099400 \\
\hline $\mathrm{C}$ & -3.43033700 & -2.38170100 & -2.01648800 \\
\hline
\end{tabular}




$\begin{array}{lrrr}\mathrm{O} & -2.82273400 & 2.61387500 & 0.12586500 \\ \mathrm{C} & -2.49869900 & 4.98125100 & -0.00184700 \\ \mathrm{C} & -2.82631400 & 3.71986000 & -0.78178400 \\ \mathrm{C} & -5.54198900 & 1.58198900 & 0.15092200 \\ \mathrm{C} & -3.98166400 & 0.45121000 & 1.76238600 \\ \mathrm{H} & -0.49385600 & 2.03744600 & -0.11651700 \\ \mathrm{H} & -3.41025500 & 1.49540300 & -1.50155500 \\ \mathrm{H} & 2.82653400 & -1.37388400 & -1.74793600 \\ \mathrm{H} & 3.57229200 & -2.34997400 & -0.48603700 \\ \mathrm{H} & 1.41822400 & -2.74132500 & 0.60204600 \\ \mathrm{H} & 1.18809700 & -3.05416400 & -1.10122200 \\ \mathrm{H} & 1.44571400 & 2.73545100 & -0.34020900 \\ \mathrm{H} & 4.23000800 & 0.45528200 & -1.44460400 \\ \mathrm{H} & -6.23569600 & -2.11348300 & -0.54954600 \\ \mathrm{H} & -6.26913700 & -1.11172300 & 0.89218400 \\ \mathrm{H} & 6.11133000 & -1.42180100 & -2.09432500 \\ \mathrm{H} & 8.28018100 & -1.72690000 & 1.37829600 \\ \mathrm{H} & 6.17470900 & -0.08255600 & 2.03275600 \\ \mathrm{H} & 3.39193600 & 0.22259300 & 2.22969300 \\ \mathrm{H} & 2.10628800 & -0.96933800 & 2.03474300 \\ \mathrm{H} & 3.79755700 & -1.46626100 & 1.86156400 \\ \mathrm{H} & -2.63762400 & -3.13202100 & -2.03809300 \\ \mathrm{H} & -4.39806600 & -2.88160500 & -2.12599100 \\ \mathrm{H} & -3.29422400 & -1.70070200 & -2.86347200 \\ \mathrm{H} & -2.49671000 & 5.84688600 & -0.67232700 \\ \mathrm{H} & -3.24026200 & 5.15320300 & 0.78406400 \\ \mathrm{H} & -1.51313300 & 4.90674700 & 0.46749000 \\ \mathrm{H} & -2.08575600 & 3.55330900 & -1.57976800 \\ \mathrm{H} & -3.81411700 & 3.80585800 & -1.25890600 \\ \mathrm{H} & -5.35236600 & 2.53745900 & 0.64714100 \\ \mathrm{H} & -6.42003700 & 1.13172500 & 0.62441600 \\ \mathrm{H} & -5.79513000 & 1.78290300 & -0.89735200 \\ \mathrm{H} & -3.14641000 & -0.23639200 & 1.91825400 \\ \mathrm{H} & -3.71748700 & 1.40950100 & 2.21775700 \\ \mathrm{H} & -4.84577000 & 0.05372800 & 2.30328200\end{array}$

Proposed structure of hainangranatumin G (17-4)-conformer 2

Zero-point correction $=$

Thermal correction to Energy=

Thermal correction to Enthalpy=

Thermal correction to Gibbs Free Energy=

Sum of electronic and zero-point Energies=

Sum of electronic and thermal Energies=

Sum of electronic and thermal Enthalpies=

Sum of electronic and thermal Free Energies=
0.545091 (Hartree/Particle)

0.576568

0.577512

0.482218

$-1591.291055$

$-1591.259577$

$-1591.258633$

$-1591.353927$

01

$\begin{array}{llll}\mathrm{N} & -0.95735600 & -1.76452800 & -0.53973000 \\ \mathrm{C} & -2.00971600 & -0.94212300 & -0.54068700 \\ \mathrm{C} & -1.88188900 & 0.45217500 & -0.43083600\end{array}$

SI267 


\begin{tabular}{|c|c|c|c|}
\hline $\mathrm{C}$ & -0.59845600 & 0.96591600 & -0.28437500 \\
\hline $\mathrm{C}$ & 0.52324600 & 0.12032600 & -0.28015500 \\
\hline $\mathrm{C}$ & 0.27696000 & -1.26575600 & -0.40894300 \\
\hline $\mathrm{C}$ & -3.37262000 & -1.60706000 & -0.67828600 \\
\hline $\mathrm{C}$ & -4.59527400 & -0.65055000 & -0.49424100 \\
\hline $\mathrm{C}$ & -4.30828100 & 0.67613100 & 0.27373900 \\
\hline $\mathrm{C}$ & -3.11050200 & 1.34732300 & -0.45391700 \\
\hline $\mathrm{C}$ & 1.90169600 & 0.63829900 & -0.13218900 \\
\hline $\mathrm{C}$ & 3.03147900 & -0.35997900 & 0.12881300 \\
\hline $\mathrm{C}$ & 2.76313100 & -1.64804600 & -0.68444000 \\
\hline $\mathrm{C}$ & 1.40054600 & -2.27032100 & -0.37593200 \\
\hline $\mathrm{C}$ & 2.19390700 & 1.95789200 & -0.18382800 \\
\hline $\mathrm{C}$ & 3.52734000 & 2.49194900 & 0.13261100 \\
\hline $\mathrm{O}$ & 4.55147900 & 1.59594500 & 0.20627000 \\
\hline $\mathrm{C}$ & 4.34799800 & 0.29129100 & -0.38879300 \\
\hline $\mathrm{O}$ & -3.49227400 & -2.57892200 & 0.41181100 \\
\hline $\mathrm{C}$ & -4.75870000 & -2.62046500 & 0.90358100 \\
\hline $\mathrm{C}$ & -5.60941800 & -1.57715400 & 0.19670100 \\
\hline $\mathrm{O}$ & -5.09444500 & -3.39626700 & 1.76458000 \\
\hline $\mathrm{C}$ & 5.61095700 & -0.48090100 & -0.13906700 \\
\hline $\mathrm{C}$ & 6.52298100 & -0.25823100 & 0.85231800 \\
\hline $\mathrm{O}$ & 7.56027500 & -1.13859100 & 0.75560000 \\
\hline $\mathrm{C}$ & 7.31049500 & -1.93598600 & -0.32190600 \\
\hline $\mathrm{C}$ & 6.13628100 & -1.57848600 & -0.91150700 \\
\hline $\mathrm{H}$ & -4.95405300 & -0.36542500 & -1.49010700 \\
\hline $\mathrm{O}$ & 3.73915900 & 3.66325300 & 0.37669000 \\
\hline $\mathrm{C}$ & 3.10818600 & -0.66194600 & 1.64357300 \\
\hline $\mathrm{C}$ & -3.44730400 & -2.38534900 & -1.99851900 \\
\hline $\mathrm{O}$ & -2.81458900 & 2.61877100 & 0.11511000 \\
\hline $\mathrm{C}$ & -2.48466000 & 4.98459800 & -0.02527200 \\
\hline $\mathrm{C}$ & -2.82051000 & 3.72065000 & -0.79752800 \\
\hline $\mathrm{C}$ & -5.53799700 & 1.59737200 & 0.15430000 \\
\hline $\mathrm{C}$ & -3.97693300 & 0.46917800 & 1.76681900 \\
\hline $\mathrm{H}$ & -0.48972300 & 2.03288000 & -0.13379700 \\
\hline $\mathrm{H}$ & -3.41176200 & 1.49399400 & -1.50446100 \\
\hline $\mathrm{H}$ & 2.81286000 & -1.40740000 & -1.75558200 \\
\hline $\mathrm{H}$ & 3.55371100 & -2.37644400 & -0.48217400 \\
\hline $\mathrm{H}$ & 1.40954600 & -2.74239400 & 0.61578200 \\
\hline $\mathrm{H}$ & 1.16987500 & -3.07323200 & -1.08289600 \\
\hline $\mathrm{H}$ & 1.44682100 & 2.72206100 & -0.35945100 \\
\hline $\mathrm{H}$ & 4.23090700 & 0.43805900 & -1.47234000 \\
\hline $\mathrm{H}$ & -6.24819400 & -2.09857300 & -0.52503500 \\
\hline $\mathrm{H}$ & -6.27315400 & -1.08950700 & 0.91174400 \\
\hline $\mathrm{H}$ & 6.58697800 & 0.47368500 & 1.64070600 \\
\hline $\mathrm{H}$ & 8.05201200 & -2.68930300 & -0.53655400 \\
\hline $\mathrm{H}$ & 5.70424600 & -2.02780600 & -1.79440500 \\
\hline $\mathrm{H}$ & 3.41296900 & 0.22762100 & 2.20151500 \\
\hline $\mathrm{H}$ & 2.13747600 & -0.98081300 & 2.03265700 \\
\hline $\mathrm{H}$ & 3.83549400 & -1.45542200 & 1.83939700 \\
\hline $\mathrm{H}$ & -2.65748400 & -3.13876600 & -2.01848600 \\
\hline $\mathrm{H}$ & -4.41718000 & -2.88217200 & -2.10295700 \\
\hline
\end{tabular}




$\begin{array}{lrrr}\mathrm{H} & -3.31092600 & -1.70909300 & -2.84925100 \\ \mathrm{H} & -2.48418400 & 5.84718300 & -0.69967300 \\ \mathrm{H} & -3.22103500 & 5.16224700 & 0.76423600 \\ \mathrm{H} & -1.49655400 & 4.90938000 & 0.43857700 \\ \mathrm{H} & -2.08519100 & 3.54832200 & -1.59913200 \\ \mathrm{H} & -3.81087000 & 3.80735500 & -1.26915700 \\ \mathrm{H} & -5.34310600 & 2.55480600 & 0.64466400 \\ \mathrm{H} & -6.41614900 & 1.15309000 & 0.63321300 \\ \mathrm{H} & -5.79390600 & 1.79350300 & -0.89420700 \\ \mathrm{H} & -3.14383600 & -0.22077600 & 1.92381900 \\ \mathrm{H} & -3.70771500 & 1.42881600 & 2.21635600 \\ \mathrm{H} & -4.84088000 & 0.07783200 & 2.31242500\end{array}$

\section{Proposed structure of hainangranatumin G (17-4)-conformer 3}

Zero-point correction $=$

Thermal correction to Energy=

Thermal correction to Enthalpy=

Thermal correction to Gibbs Free Energy=

Sum of electronic and zero-point Energies=

Sum of electronic and thermal Energies=

Sum of electronic and thermal Enthalpies=

Sum of electronic and thermal Free Energies=
0.545428 (Hartree/Particle)

0.576833

0.577777

0.482486

$-1591.290758$

$-1591.259352$

$-1591.258408$

$-1591.353699$

01

$\begin{array}{lrrr}\mathrm{N} & -0.91593400 & -1.75307100 & -0.17706300 \\ \mathrm{C} & -1.98240200 & -0.96578200 & -0.34736700 \\ \mathrm{C} & -1.86510600 & 0.42829000 & -0.49855300 \\ \mathrm{C} & -0.58020200 & 0.96390600 & -0.50656500 \\ \mathrm{C} & 0.55215100 & 0.15390700 & -0.32412300 \\ \mathrm{C} & 0.31305800 & -1.22645800 & -0.13618900 \\ \mathrm{C} & -3.32959900 & -1.69327200 & -0.40032500 \\ \mathrm{C} & -4.56824400 & -0.75959900 & -0.64199800 \\ \mathrm{C} & -4.25396800 & 0.60058300 & -1.33390000 \\ \mathrm{C} & -3.08475200 & 1.32387300 & -0.62265300 \\ \mathrm{C} & 1.92774700 & 0.69917300 & -0.31808400 \\ \mathrm{C} & 3.06298100 & -0.20632100 & 0.16275700 \\ \mathrm{C} & 2.79992800 & -1.64931300 & -0.32709200 \\ \mathrm{C} & 1.44281400 & -2.18978800 & 0.12639200 \\ \mathrm{C} & 2.21378100 & 1.97038400 & -0.68017600 \\ \mathrm{C} & 3.54894800 & 2.56767000 & -0.51108200 \\ \mathrm{O} & 4.57850600 & 1.71754500 & -0.24111500 \\ \mathrm{C} & 4.37031900 & 0.30633800 & -0.50638200 \\ \mathrm{O} & -3.53603400 & -2.28606400 & 0.92116800 \\ \mathrm{C} & -4.62099900 & -1.78124300 & 1.56659500 \\ \mathrm{C} & -5.25466200 & -0.68646400 & 0.73644500 \\ \mathrm{O} & -4.96103700 & -2.18280600 & 2.65328600 \\ \mathrm{C} & 5.63847300 & -0.38793600 & -0.10917100 \\ \mathrm{C} & 6.30184400 & -1.32978500 & -0.84235800 \\ \mathrm{O} & 7.42024400 & -1.75098400 & -0.18882300 \\ \mathrm{C} & 7.48147000 & -1.05007300 & 0.98289500\end{array}$




$\begin{array}{lrrr}\mathrm{C} & 6.42182500 & -0.20355300 & 1.08636600 \\ \mathrm{H} & -5.23758100 & -1.29957600 & -1.32179300 \\ \mathrm{O} & 3.75330700 & 3.76473800 & -0.55003500 \\ \mathrm{C} & 3.13914100 & -0.14649100 & 1.70688200 \\ \mathrm{C} & -3.27236900 & -2.86665000 & -1.38255800 \\ \mathrm{O} & -3.52788700 & 1.77241000 & 0.66521700 \\ \mathrm{C} & -3.44761000 & 3.25197600 & 2.54053700 \\ \mathrm{C} & -2.72502900 & 2.77299300 & 1.29227700 \\ \mathrm{C} & -3.84341100 & 0.36229800 & -2.80670700 \\ \mathrm{C} & -5.51106700 & 1.49207400 & -1.34141000 \\ \mathrm{H} & -0.46476200 & 2.03397000 & -0.64870200 \\ \mathrm{H} & -2.81261200 & 2.21140800 & -1.21833200 \\ \mathrm{H} & 2.84070400 & -1.66268100 & -1.42508900 \\ \mathrm{H} & 3.60160400 & -2.30408500 & 0.02764500 \\ \mathrm{H} & 1.45786700 & -2.41421000 & 1.20168000 \\ \mathrm{H} & 1.21332900 & -3.13733900 & -0.37026700 \\ \mathrm{H} & 1.46330300 & 2.67124700 & -1.02559600 \\ \mathrm{H} & 4.23761700 & 0.19262100 & -1.59108800 \\ \mathrm{H} & -6.33592600 & -0.83747700 & 0.69786600 \\ \mathrm{H} & -5.06630200 & 0.25830100 & 1.25007100 \\ \mathrm{H} & 6.11868200 & -1.78035000 & -1.80596100 \\ \mathrm{H} & 8.33094900 & -1.26060000 & 1.61331400 \\ \mathrm{H} & 6.22879700 & 0.49105100 & 1.89010900 \\ \mathrm{H} & 3.44984500 & 0.84679200 & 2.04240100 \\ \mathrm{H} & 2.16573300 & -0.35762000 & 2.15783500 \\ \mathrm{H} & 3.85613300 & -0.88079500 & 2.08552500 \\ \mathrm{H} & -2.44774000 & -3.53069900 & -1.11959400 \\ \mathrm{H} & -4.21252600 & -3.42457000 & -1.33872700 \\ \mathrm{H} & -3.12584400 & -2.51074000 & -2.40682400 \\ \mathrm{H} & -2.85199800 & 4.01967300 & 3.04540300 \\ \mathrm{H} & -4.42193700 & 3.68067300 & 2.28720600 \\ \mathrm{H} & -3.60359000 & 2.42406000 & 3.23865400 \\ \mathrm{H} & -1.73988300 & 2.36332800 & 1.55621500 \\ \mathrm{H} & -2.56644100 & 3.60628700 & 0.58847100 \\ \mathrm{H} & -3.66967200 & 1.31770700 & -3.31427100 \\ \mathrm{H} & -4.64517100 & -0.15599600 & -3.34307400 \\ \mathrm{H} & -2.93256600 & -0.23351600 & -2.90796900 \\ \mathrm{H} & -5.84721900 & 1.74264500 & -0.33455800 \\ & -5.30860600 & 2.43153700 & -1.86867800 \\ & -6.32981500 & 0.98731100 & -1.86673100\end{array}$

\section{Proposed structure of hainangranatumin G (17-4)-conformer 4}

Zero-point correction $=$

Thermal correction to Energy=

Thermal correction to Enthalpy=

Thermal correction to Gibbs Free Energy=

Sum of electronic and zero-point Energies=

Sum of electronic and thermal Energies $=$

Sum of electronic and thermal Enthalpies=
0.545412 (Hartree/Particle)

0.576825

0.577769

0.482554

$-1591.290654$

$-1591.259241$

$-1591.258297$

SI270 
Sum of electronic and thermal Free Energies= $\quad-1591.353512$

01

\begin{tabular}{|c|c|c|c|}
\hline $\mathrm{N}$ & -0.92645900 & -1.75612700 & -0.17026600 \\
\hline $\mathrm{C}$ & -1.99006600 & -0.96534100 & -0.34222900 \\
\hline $\mathrm{C}$ & -1.86731000 & 0.42768100 & -0.49879700 \\
\hline $\mathrm{C}$ & -0.58030200 & 0.95804600 & -0.51161200 \\
\hline $\mathrm{C}$ & 0.54928100 & 0.14428500 & -0.32785900 \\
\hline $\mathrm{C}$ & 0.30450700 & -1.23388400 & -0.13349200 \\
\hline $\mathrm{C}$ & -3.34011200 & -1.68776000 & -0.39176400 \\
\hline $\mathrm{C}$ & -4.57535600 & -0.74964000 & -0.63292300 \\
\hline $\mathrm{C}$ & -4.25735300 & 0.60721600 & -1.32962500 \\
\hline $\mathrm{C}$ & -3.08349500 & 1.32796300 & -0.62345500 \\
\hline $\mathrm{C}$ & 1.92718700 & 0.68383000 & -0.32653700 \\
\hline $\mathrm{C}$ & 3.06373000 & -0.22465400 & 0.14715500 \\
\hline $\mathrm{C}$ & 2.78894000 & -1.66934000 & -0.33188800 \\
\hline $\mathrm{C}$ & 1.43093600 & -2.19946100 & 0.13183100 \\
\hline $\mathrm{C}$ & 2.21397000 & 1.95504900 & -0.68826000 \\
\hline $\mathrm{C}$ & 3.55021300 & 2.54828300 & -0.52223800 \\
\hline $\mathrm{O}$ & 4.57798800 & 1.69407700 & -0.25873400 \\
\hline $\mathrm{C}$ & 4.37033900 & 0.28619500 & -0.52912600 \\
\hline $\mathrm{O}$ & -3.54701300 & -2.27785600 & 0.93079500 \\
\hline $\mathrm{C}$ & -4.62821900 & -1.76662700 & 1.57764400 \\
\hline $\mathrm{C}$ & -5.25776700 & -0.66975000 & 0.74714900 \\
\hline $\mathrm{O}$ & -4.96817400 & -2.16506300 & 2.66547000 \\
\hline $\mathrm{C}$ & 5.63913100 & -0.40653000 & -0.12461600 \\
\hline $\mathrm{C}$ & 6.56427700 & 0.04040400 & 0.77471100 \\
\hline $\mathrm{O}$ & 7.60272900 & -0.83843500 & 0.87016500 \\
\hline $\mathrm{C}$ & 7.34060900 & -1.86432700 & 0.01105000 \\
\hline $\mathrm{C}$ & 6.15709200 & -1.65356800 & -0.62849400 \\
\hline $\mathrm{H}$ & -5.24880900 & -1.28882200 & -1.30929400 \\
\hline $\mathrm{O}$ & 3.75955200 & 3.74455800 & -0.55655600 \\
\hline $\mathrm{C}$ & 3.16308400 & -0.15832700 & 1.68912200 \\
\hline $\mathrm{C}$ & -3.28870000 & -2.86286300 & -1.37231400 \\
\hline $\mathrm{O}$ & -3.52174200 & 1.78276900 & 0.66383900 \\
\hline $\mathrm{C}$ & -3.43130400 & 3.26902400 & 2.53345600 \\
\hline $\mathrm{C}$ & -2.71333500 & 2.78229000 & 1.28553700 \\
\hline $\mathrm{C}$ & -3.85125900 & 0.36307100 & -2.80269800 \\
\hline $\mathrm{C}$ & -5.51098500 & 1.50353500 & -1.33660800 \\
\hline $\mathrm{H}$ & -0.46137100 & 2.02701400 & -0.65864000 \\
\hline $\mathrm{H}$ & -2.80883800 & 2.21227500 & -1.22276700 \\
\hline $\mathrm{H}$ & 2.82566000 & -1.69222700 & -1.42994400 \\
\hline $\mathrm{H}$ & 3.58346000 & -2.32851800 & 0.02951800 \\
\hline $\mathrm{H}$ & 1.45050300 & -2.41498000 & 1.20881900 \\
\hline $\mathrm{H}$ & 1.19537900 & -3.15008500 & -0.35604200 \\
\hline $\mathrm{H}$ & 1.46367100 & 2.65849200 & -1.02841700 \\
\hline $\mathrm{H}$ & 4.23656800 & 0.17537600 & -1.61496000 \\
\hline $\mathrm{H}$ & -6.33998300 & -0.81453300 & 0.71170200 \\
\hline $\mathrm{H}$ & -5.06260500 & 0.27497000 & 1.25835600 \\
\hline $\mathrm{H}$ & 6.63741900 & 0.93560900 & 1.37024400 \\
\hline $\mathrm{H}$ & 8.08158600 & -2.64686400 & -0.03345900 \\
\hline $\mathrm{H}$ & 5.71446200 & -2.29562000 & -1.37677200 \\
\hline
\end{tabular}




$\begin{array}{lrrr}\mathrm{H} & 3.47291200 & 0.83808000 & 2.01576400 \\ \mathrm{H} & 2.19938400 & -0.37642300 & 2.15729300 \\ \mathrm{H} & 3.89607900 & -0.88261800 & 2.05648200 \\ \mathrm{H} & -2.46627200 & -3.52963400 & -1.10929300 \\ \mathrm{H} & -4.23090600 & -3.41714500 & -1.32633200 \\ \mathrm{H} & -3.14210700 & -2.50918400 & -2.39733200 \\ \mathrm{H} & -2.83132800 & 4.03600700 & 3.03421500 \\ \mathrm{H} & -4.40430400 & 3.70095400 & 2.28051100 \\ \mathrm{H} & -3.58934700 & 2.44440100 & 3.23499900 \\ \mathrm{H} & -1.72941600 & 2.36939200 & 1.54904700 \\ \mathrm{H} & -2.55265200 & 3.61222900 & 0.57824700 \\ \mathrm{H} & -3.67578600 & 1.31637200 & -3.31362200 \\ \mathrm{H} & -4.65594300 & -0.15437300 & -3.33549800 \\ \mathrm{H} & -2.94249800 & -0.23587200 & -2.90437000 \\ \mathrm{H} & -5.84388600 & 1.75797000 & -0.32964400 \\ \mathrm{H} & -5.30609800 & 2.44086600 & -1.86672700 \\ \mathrm{H} & -6.33285500 & 1.00057700 & -1.85878800\end{array}$

\section{Proposed structure of hainangranatumin G (17-4)-conformer 5}

Zero-point correction=

Thermal correction to Energy=

Thermal correction to Enthalpy=

Thermal correction to Gibbs Free Energy=

Sum of electronic and zero-point Energies=

Sum of electronic and thermal Energies $=$

Sum of electronic and thermal Enthalpies=

Sum of electronic and thermal Free Energies=
0.545341 (Hartree/Particle)

0.576648

0.577593

0.483034

$-1591.288342$

$-1591.257034$

$-1591.256090$

$-1591.350648$

01

$\begin{array}{lrrr}\mathrm{N} & 0.90266800 & -1.70108500 & 0.64135500 \\ \mathrm{C} & 1.96622600 & -0.89741800 & 0.56458100 \\ \mathrm{C} & 1.85897600 & 0.48684700 & 0.34997900 \\ \mathrm{C} & 0.58186100 & 1.00241900 & 0.15973600 \\ \mathrm{C} & -0.55198400 & 0.17575000 & 0.23065000 \\ \mathrm{C} & -0.32609100 & -1.19681300 & 0.48238900 \\ \mathrm{C} & 3.32129600 & -1.57518600 & 0.71547300 \\ \mathrm{C} & 4.55380600 & -0.65923800 & 0.42158600 \\ \mathrm{C} & 4.26687500 & 0.62141300 & -0.42330800 \\ \mathrm{C} & 3.10633300 & 1.35963700 & 0.30031400 \\ \mathrm{C} & -1.92293700 & 0.69860900 & 0.03732300 \\ \mathrm{C} & -3.06407900 & -0.30565300 & -0.13287100 \\ \mathrm{C} & -2.81575800 & -1.51236900 & 0.80169000 \\ \mathrm{C} & -1.46446300 & -2.18350400 & 0.55313100 \\ \mathrm{C} & -2.19988800 & 2.02077000 & -0.03004600 \\ \mathrm{C} & -3.52877100 & 2.54161200 & -0.38974800 \\ \mathrm{O} & -4.56478500 & 1.65652600 & -0.38141900 \\ \mathrm{C} & -4.37035500 & 0.40428800 & 0.32440200 \\ \mathrm{O} & 3.38752200 & -2.62819100 & -0.30177700 \\ \mathrm{C} & 4.63336600 & -2.72772500 & -0.83532500 \\ \mathrm{C} & 5.52566000 & -1.65135600 & -0.23866400\end{array}$




\begin{tabular}{|c|c|c|c|}
\hline $\mathrm{O}$ & 4.92454600 & -3.57013800 & -1.64870200 \\
\hline $\mathrm{C}$ & -5.64276600 & -0.37212300 & 0.16093600 \\
\hline $\mathrm{C}$ & -6.31818100 & -1.02547500 & 1.15163200 \\
\hline $\mathrm{O}$ & -7.43755100 & -1.62549800 & 0.65882100 \\
\hline $\mathrm{C}$ & -7.48662300 & -1.33537500 & -0.67594700 \\
\hline $\mathrm{C}$ & -6.41874700 & -0.57397600 & -1.03656200 \\
\hline $\mathrm{H}$ & 4.95438300 & -0.31528800 & 1.38219100 \\
\hline $\mathrm{O}$ & -3.72460300 & 3.69026200 & -0.73444400 \\
\hline $\mathrm{C}$ & -3.13209200 & -0.75009700 & -1.61312400 \\
\hline $\mathrm{C}$ & 3.42420400 & -2.25410200 & 2.08727800 \\
\hline $\mathrm{O}$ & 2.83515700 & 2.60793800 & -0.32518300 \\
\hline $\mathrm{C}$ & 3.81226300 & 4.45451200 & 0.99490700 \\
\hline $\mathrm{C}$ & 2.55734700 & 3.70951900 & 0.55093500 \\
\hline $\mathrm{C}$ & 5.52262300 & 1.51368600 & -0.40525200 \\
\hline $\mathrm{C}$ & 3.88166000 & 0.32568600 & -1.88855900 \\
\hline $\mathrm{H}$ & 0.48092200 & 2.05224000 & -0.08514100 \\
\hline $\mathrm{H}$ & 3.44039900 & 1.54656000 & 1.33486200 \\
\hline $\mathrm{H}$ & -2.85697300 & -1.16576400 & 1.84369100 \\
\hline $\mathrm{H}$ & -3.62393100 & -2.23956800 & 0.67747100 \\
\hline $\mathrm{H}$ & -1.48360800 & -2.75273900 & -0.38602300 \\
\hline $\mathrm{H}$ & -1.24214000 & -2.91478600 & 1.33646800 \\
\hline $\mathrm{H}$ & -1.44374900 & 2.78906800 & 0.07564400 \\
\hline $\mathrm{H}$ & -4.24498000 & 0.64411800 & 1.38933500 \\
\hline $\mathrm{H}$ & 6.18432600 & -2.13076500 & 0.49425400 \\
\hline $\mathrm{H}$ & 6.16829000 & -1.22829500 & -1.01168100 \\
\hline $\mathrm{H}$ & -6.14356900 & -1.14585200 & 2.20997400 \\
\hline $\mathrm{H}$ & -8.33489000 & -1.73035700 & -1.21242300 \\
\hline $\mathrm{H}$ & -6.21509400 & -0.17428900 & -2.01865300 \\
\hline $\mathrm{H}$ & -3.43324600 & 0.08236400 & -2.25501300 \\
\hline $\mathrm{H}$ & -2.15787100 & -1.10099900 & -1.96399900 \\
\hline $\mathrm{H}$ & -3.85263900 & -1.56369000 & -1.73822800 \\
\hline $\mathrm{H}$ & 2.62206400 & -2.98783500 & 2.18794300 \\
\hline $\mathrm{H}$ & 4.38796500 & -2.76123300 & 2.19893800 \\
\hline $\mathrm{H}$ & 3.32736300 & -1.51357200 & 2.88850700 \\
\hline $\mathrm{H}$ & 3.53243800 & 5.31707700 & 1.61049000 \\
\hline $\mathrm{H}$ & 4.47474400 & 3.81828800 & 1.59041700 \\
\hline $\mathrm{H}$ & 4.37157100 & 4.81779600 & 0.12769200 \\
\hline $\mathrm{H}$ & 1.90831100 & 4.37857900 & -0.02373900 \\
\hline $\mathrm{H}$ & 1.98677000 & 3.36237300 & 1.42428400 \\
\hline $\mathrm{H}$ & 5.33940400 & 2.43960400 & -0.95491200 \\
\hline $\mathrm{H}$ & 6.37259900 & 1.00831800 & -0.87428700 \\
\hline $\mathrm{H}$ & 5.81459800 & 1.77642400 & 0.61862600 \\
\hline $\mathrm{H}$ & 3.03121700 & -0.35555800 & -1.97403300 \\
\hline $\mathrm{H}$ & 3.61594700 & 1.25972500 & -2.39118300 \\
\hline $\mathrm{H}$ & 4.71985200 & -0.11759500 & -2.4345560 \\
\hline
\end{tabular}

Proposed structure of hainangranatumin G (17-4)-conformer 6 Zero-point correction= Thermal correction to Energy= 0.545312 (Hartree/Particle) 0.576635 


$\begin{array}{lc}\text { Thermal correction to Enthalpy= } & 0.577579 \\ \text { Thermal correction to Gibbs Free Energy= } & 0.483016 \\ \text { Sum of electronic and zero-point Energies }= & -1591.288188 \\ \text { Sum of electronic and thermal Energies }= & -1591.256865 \\ \text { Sum of electronic and thermal Enthalpies }= & -1591.255921 \\ \text { Sum of electronic and thermal Free Energies }= & -1591.350485\end{array}$

01

N

C

C

C

C

C

C

C

C

C

C

C

C

C

C

$\mathrm{O}$

C

$\mathrm{O}$

C

C

O

C

C

O

C

C

$\mathrm{H}$

$\mathrm{O}$

C

C

$\mathrm{O}$

C

C

C

C

$\mathrm{H}$

$\mathrm{H}$

$\mathrm{H}$

$\mathrm{H}$

$\mathrm{H}$

$\mathrm{H}$

$\mathrm{H}$

$\mathrm{H}$

$$
\begin{array}{rrr}
0.91283500 & -1.70902100 & 0.62744800 \\
1.97352200 & -0.90116300 & 0.55531700 \\
1.86098700 & 0.48454500 & 0.35291600 \\
0.58168500 & 0.99754000 & 0.17090000 \\
-0.54938400 & 0.16650900 & 0.23727100 \\
-0.31781300 & -1.20715900 & 0.47576800 \\
3.33119500 & -1.57545600 & 0.69781200 \\
4.55986200 & -0.65296400 & 0.40829900 \\
4.26643500 & 0.63353700 & -0.42533000 \\
3.10529300 & 1.36194300 & 0.30732800 \\
-1.92266300 & 0.68632200 & 0.05234500 \\
-3.06512100 & -0.31768000 & -0.11552200 \\
-2.80530300 & -1.53417100 & 0.80350400 \\
-1.45277100 & -2.19735400 & 0.53925000 \\
-2.20032700 & 2.00870600 & -0.00871400 \\
-3.53013400 & 2.52867200 & -0.36197500 \\
-4.56437900 & 1.64143600 & -0.35189400 \\
-4.37081000 & 0.39073400 & 0.35221600 \\
3.39868000 & -2.62041000 & -0.32747600 \\
4.64356800 & -2.71135600 & -0.86491200 \\
5.53346600 & -1.63633600 & -0.26232900 \\
4.93573900 & -3.54662400 & -1.68524500 \\
-5.64385700 & -0.38559000 & 0.17815400 \\
-6.55989000 & -0.24010400 & -0.82385200 \\
-7.60616200 & -1.09652700 & -0.64449100 \\
-7.35827600 & -1.79911800 & 0.49750300 \\
-6.17636500 & -1.40490200 & 1.04693000 \\
4.96167300 & -0.31547800 & 1.37068500 \\
-3.73089300 & 3.67706300 & -0.70438300 \\
-3.15583900 & -0.74769100 & -1.59822300 \\
3.43955900 & -2.26448200 & 2.06418500 \\
2.82835000 & 2.61442300 & -0.30712800 \\
3.80393400 & 4.45332600 & 1.02472700 \\
2.54991200 & 3.70803400 & 0.57874500 \\
-4.51914300 & 1.52998000 & -0.40322100 \\
3.87843000 & 0.34844600 & -1.89196500 \\
0.47713000 & 2.04922900 & -0.06398700 \\
3.44142800 & 1.54145300 & 1.34251100 \\
-2.84322300 & -1.20183400 & 1.85033200 \\
-3.60600500 & -2.26738700 & 0.67037700 \\
-1.47586600 & -2.75396000 & -0.40731300 \\
-1.22466400 & -2.93840400 & 1.31166200 \\
-44426700 & 0.62898100 & 1.41832400
\end{array}
$$

SI274 


$\begin{array}{lrrr}\mathrm{H} & 6.19595500 & -2.11898300 & 0.46499100 \\ \mathrm{H} & 6.17238400 & -1.20489600 & -1.03378800 \\ \mathrm{H} & -6.62105500 & 0.42051200 & -1.67309900 \\ \mathrm{H} & -8.10668300 & -2.52202500 & 0.78158500 \\ \mathrm{H} & -5.74376900 & -1.77991900 & 1.96360000 \\ \mathrm{H} & -3.45521700 & 0.09399100 & -2.22864900 \\ \mathrm{H} & -2.19141200 & -1.10971900 & -1.96453300 \\ \mathrm{H} & -3.89294000 & -1.54688200 & -1.72032000 \\ \mathrm{H} & 2.64015200 & -3.00170600 & 2.16111300 \\ \mathrm{H} & 4.40526600 & -2.76921400 & 2.16973400 \\ \mathrm{H} & 3.34211600 & -1.53047200 & 2.87131800 \\ \mathrm{H} & 3.52345700 & 5.31005900 & 1.64811000 \\ \mathrm{H} & 4.47025400 & 3.81438600 & 1.61299700 \\ \mathrm{H} & 4.35934600 & 4.82529700 & 0.15869700 \\ \mathrm{H} & 1.89700400 & 4.37970300 & 0.01155300 \\ \mathrm{H} & 1.98322600 & 3.35208300 & 1.45107600 \\ \mathrm{H} & 5.33121400 & 2.45979500 & -0.94464700 \\ \mathrm{H} & 6.36958100 & 1.03152300 & -0.87875100 \\ \mathrm{H} & 5.81299600 & 1.78520800 & 0.62201900 \\ \mathrm{H} & 3.03017300 & -0.33507400 & -1.98091700 \\ \mathrm{H} & 3.60815200 & 1.28558700 & -2.38631000 \\ \mathrm{H} & 4.71676100 & -0.08739100 & -2.44371300\end{array}$

\section{Proposed structure of hainangranatumin G (17-4)-conformer 7}

Zero-point correction $=$

Thermal correction to Energy=

Thermal correction to Enthalpy=

Thermal correction to Gibbs Free Energy=

Sum of electronic and zero-point Energies=

Sum of electronic and thermal Energies=

Sum of electronic and thermal Enthalpies=

Sum of electronic and thermal Free Energies=
0.545379 (Hartree/Particle)

0.576638

0.577583

0.483165

$-1591.288756$

$-1591.257496$

$-1591.256551$

$-1591.350969$

01

$\begin{array}{lrrr}\mathrm{N} & 0.97530400 & -1.67194400 & 0.62323200 \\ \mathrm{C} & 2.02328000 & -0.84819000 & 0.54604700 \\ \mathrm{C} & 1.88834600 & 0.53238600 & 0.32229500 \\ \mathrm{C} & 0.60150400 & 1.02464200 & 0.13657500 \\ \mathrm{C} & -0.51533500 & 0.17515000 & 0.20575200 \\ \mathrm{C} & -0.26256900 & -1.19295900 & 0.45558100 \\ \mathrm{C} & 3.38906900 & -1.49631200 & 0.72792700 \\ \mathrm{C} & 4.60671400 & -0.55732200 & 0.44805400 \\ \mathrm{C} & 4.30337600 & 0.70076200 & -0.42221200 \\ \mathrm{C} & 3.11410600 & 1.42981700 & 0.27091300 \\ \mathrm{C} & -1.89652100 & 0.67113200 & 0.01405900 \\ \mathrm{C} & -3.01871500 & -0.35448400 & -0.15530600 \\ \mathrm{C} & -2.74487300 & -1.55961100 & 0.77405000 \\ \mathrm{C} & -1.38092100 & -2.20261300 & 0.52020800 \\ \mathrm{C} & -2.19858800 & 1.98772700 & -0.05338900 \\ \mathrm{C} & -3.53841900 & 2.48328600 & -0.40766600\end{array}$

SI275 


\begin{tabular}{|c|c|c|c|}
\hline $\mathrm{O}$ & -4.55773900 & 1.57876800 & -0.39515700 \\
\hline U & -4.33676400 & 0.32931600 & 0.30771100 \\
\hline $\mathrm{O}$ & 3.49877000 & -2.55913500 & -0.27514600 \\
\hline & 4.75793500 & -2.63902600 & -0.77962800 \\
\hline $\mathrm{C}$ & 5.61418600 & -1.53622800 & -0.17785000 \\
\hline $\mathrm{O}$ & 5.08506500 & -3.48501300 & -1.57546400 \\
\hline $\mathrm{C}$ & -5.59461300 & -0.47108100 & 0.14690400 \\
\hline $\mathrm{C}$ & -6.25395700 & -1.13965400 & 1.13824200 \\
\hline $\mathrm{O}$ & -7.36331500 & -1.75993800 & 0.64772100 \\
\hline $\mathrm{C}$ & -7.42250200 & -1.46759900 & -0.68616000 \\
\hline $\mathrm{C}$ & -6.37074200 & -0.68485500 & -1.04843300 \\
\hline $\mathrm{H}$ & 4.97895700 & -0.19013700 & 1.41163900 \\
\hline $\mathrm{O}$ & -3.75790400 & 3.62809200 & -0.75100800 \\
\hline $\mathrm{C}$ & -3.08260700 & -0.79530100 & -1.63689800 \\
\hline $\mathrm{C}$ & 3.47960400 & -2.15755400 & 2.10937500 \\
\hline $\mathrm{O}$ & 2.79820800 & 2.65648000 & -0.38017600 \\
\hline $\mathrm{C}$ & 2.00524600 & 4.22996900 & 1.35644700 \\
\hline $\mathrm{C}$ & 3.08370100 & 3.86147000 & 0.34159500 \\
\hline $\mathrm{C}$ & 5.53915300 & 1.62147700 & -0.40841800 \\
\hline $\mathrm{C}$ & 3.94444400 & 0.37020600 & -1.88627600 \\
\hline $\mathrm{H}$ & 0.48830200 & 2.07497000 & -0.09834900 \\
\hline $\mathrm{H}$ & 3.42480100 & 1.64852000 & 1.30622400 \\
\hline $\mathrm{H}$ & -2.79068600 & -1.21806200 & 1.81753400 \\
\hline $\mathrm{H}$ & -3.53870900 & -2.30222600 & 0.64853000 \\
\hline $\mathrm{H}$ & -1.38998700 & -2.76584700 & -0.42276300 \\
\hline $\mathrm{H}$ & -1.14350000 & -2.93445900 & 1.29851700 \\
\hline $\mathrm{H}$ & -1.45610800 & 2.76953800 & 0.04918500 \\
\hline $\mathrm{H}$ & -4.21241900 & 0.56954000 & 1.37267700 \\
\hline $\mathrm{H}$ & 6.26719200 & -1.99190200 & 0.57500600 \\
\hline $\mathrm{H}$ & 6.26390400 & -1.10940300 & -0.94291400 \\
\hline $\mathrm{H}$ & -6.07343300 & -1.25923700 & 2.19568100 \\
\hline $\mathrm{H}$ & -8.26483000 & -1.87754500 & -1.22076900 \\
\hline $\mathrm{H}$ & -6.17813000 & -0.27882600 & -2.03015000 \\
\hline $\mathrm{H}$ & -3.40169100 & 0.03326900 & -2.27512500 \\
\hline $\mathrm{H}$ & -2.10274400 & -1.12598600 & -1.99168600 \\
\hline $\mathrm{H}$ & -3.78757200 & -1.62236000 & -1.76269200 \\
\hline $\mathrm{H}$ & 2.69183000 & -2.90756000 & 2.20278900 \\
\hline $\mathrm{H}$ & 4.45186600 & -2.64197300 & 2.24557800 \\
\hline $\mathrm{H}$ & 3.35074900 & -1.41053600 & 2.89998500 \\
\hline $\mathrm{H}$ & 2.27545700 & 5.16313800 & 1.86371000 \\
\hline $\mathrm{H}$ & 1.03949100 & 4.38080000 & 0.86454100 \\
\hline $\mathrm{H}$ & 1.88663900 & 3.45593400 & 2.12259000 \\
\hline $\mathrm{H}$ & 4.06229800 & 3.78102000 & 0.83391100 \\
\hline $\mathrm{H}$ & 3.16341400 & 4.63782300 & -0.42557200 \\
\hline $\mathrm{H}$ & 5.34553700 & 2.53041300 & -0.98427500 \\
\hline $\mathrm{H}$ & 6.40523700 & 1.12719200 & -0.85943600 \\
\hline $\mathrm{H}$ & 5.81739900 & 1.91135400 & 0.61226200 \\
\hline $\mathrm{H}$ & 3.11675200 & -0.33846400 & -1.97048700 \\
\hline $\mathrm{H}$ & 3.65491300 & 1.28809700 & -2.40534100 \\
\hline $\mathrm{H}$ & 4.80203500 & -0.05482700 & -2.41659000 \\
\hline
\end{tabular}


Proposed structure of hainangranatumin G (17-4)-conformer 8

Zero-point correction $=$

Thermal correction to Energy=

Thermal correction to Enthalpy=

Thermal correction to Gibbs Free Energy=

Sum of electronic and zero-point Energies $=$

Sum of electronic and thermal Energies=

Sum of electronic and thermal Enthalpies=

Sum of electronic and thermal Free Energies=
0.545339 (Hartree/Particle)

0.576618

0.577562

0.483127

$-1591.288620$

$-1591.257341$

$-1591.256397$

$-1591.350832$

01

$\begin{array}{lrrr}\mathrm{N} & 0.98540800 & -1.67951000 & 0.60881400 \\ \mathrm{C} & 2.03045400 & -0.85160700 & 0.53669900 \\ \mathrm{C} & 1.89025200 & 0.53039700 & 0.32523100 \\ \mathrm{C} & 0.60134500 & 1.02004100 & 0.14741800 \\ \mathrm{C} & -0.51266900 & 0.16626800 & 0.21164900 \\ \mathrm{C} & -0.25427000 & -1.20284800 & 0.44815100 \\ \mathrm{C} & 3.39880200 & -1.49647100 & 0.71052900 \\ \mathrm{C} & 4.61260100 & -0.55111500 & 0.43530600 \\ \mathrm{C} & 4.30283500 & 0.71304700 & -0.42375900 \\ \mathrm{C} & 3.11289200 & 1.43235100 & 0.27846300 \\ \mathrm{C} & -1.89609800 & 0.65917600 & 0.02815800 \\ \mathrm{C} & -3.01967300 & -0.36619000 & -0.13869000 \\ \mathrm{C} & -2.73410900 & -1.58079800 & 0.77505200 \\ \mathrm{C} & -1.36920500 & -2.21582100 & 0.50528500 \\ \mathrm{C} & -2.19883200 & 1.97597600 & -0.03347000 \\ \mathrm{C} & -3.53960200 & 2.47054100 & -0.38123900 \\ \mathrm{O} & -4.55712800 & 1.56394600 & -0.36650400 \\ \mathrm{C} & -4.33697000 & 0.31615600 & 0.33487400 \\ \mathrm{O} & 3.50989400 & -2.55123700 & -0.30068700 \\ \mathrm{C} & 4.76809800 & -2.62274600 & -0.80891600 \\ \mathrm{C} & 5.62186900 & -1.52142100 & -0.20100500 \\ \mathrm{O} & 5.09628400 & -3.46162800 & -1.61178100 \\ \mathrm{C} & -5.59551600 & -0.48420700 & 0.16386300 \\ \mathrm{C} & -6.51869000 & -0.35318500 & -0.83356000 \\ \mathrm{O} & -7.54741000 & -1.23034900 & -0.65251000 \\ \mathrm{C} & -7.28073300 & -1.93186900 & 0.48591300 \\ \mathrm{C} & -6.10422700 & -1.51662600 & 1.03142900 \\ \mathrm{H} & 4.98600100 & -0.19058200 & 1.40095900 \\ \mathrm{O} & -3.76403500 & 3.61488500 & -0.72260800 \\ \mathrm{C} & -3.10685400 & -0.79310000 & -1.62257500 \\ \mathrm{C} & 3.49459300 & -2.16784400 & 2.08676900 \\ \mathrm{O} & 2.79121200 & 2.66337300 & -0.36140000 \\ \mathrm{C} & 1.99940200 & 4.22045700 & 1.39040800 \\ \mathrm{C} & 3.07573300 & 3.86323900 & 0.36929100 \\ \mathrm{C} & 5.53550400 & 1.63783700 & -0.40552800 \\ \mathrm{C} & 3.94125300 & 0.39337500 & -1.88959500 \\ \mathrm{H} & 0.48462200 & 2.07214700 & -0.07737100 \\ \mathrm{H} & 3.42544500 & 1.64331100 & 1.31481600 \\ & -2.77609000 & -1.25344200 & 1.82330800 \\ & & & \\ \mathrm{H} & & & \end{array}$




$\begin{array}{lrrr}\mathrm{H} & -3.52047100 & -2.32918200 & 0.64076700 \\ \mathrm{H} & -1.38261700 & -2.76622500 & -0.44513900 \\ \mathrm{H} & -1.12582800 & -2.95744000 & 1.27241600 \\ \mathrm{H} & -1.45647000 & 2.75799900 & 0.06710900 \\ \mathrm{H} & -4.21122600 & 0.55505300 & 1.40094500 \\ \mathrm{H} & 6.27870600 & -1.98047400 & 0.54644100 \\ \mathrm{H} & 6.26783400 & -1.08627000 & -0.96454900 \\ \mathrm{H} & -6.59643400 & 0.30900200 & -1.68021800 \\ \mathrm{H} & -8.01364700 & -2.67017300 & 0.77079600 \\ \mathrm{H} & -5.66018200 & -1.88635500 & 1.94476300 \\ \mathrm{H} & -3.42420500 & 0.04470400 & -2.24933900 \\ \mathrm{H} & -2.13675200 & -1.13531900 & -1.99292300 \\ \mathrm{H} & -3.82886100 & -1.60592700 & -1.74509700 \\ \mathrm{H} & 2.70957900 & -2.92123200 & 2.17624700 \\ \mathrm{H} & 4.46876800 & -2.65001400 & 2.21716700 \\ \mathrm{H} & 3.36498900 & -1.42730600 & 2.88333000 \\ \mathrm{H} & 2.26855100 & 5.15019300 & 1.90448200 \\ \mathrm{H} & 1.03173400 & 4.37262700 & 0.90268200 \\ \mathrm{H} & 1.88526600 & 3.43985800 & 2.15055200 \\ \mathrm{H} & 4.05605500 & 3.78144900 & 0.85790000 \\ \mathrm{H} & 3.15095600 & 4.64604000 & -0.39174600 \\ \mathrm{H} & 5.33726300 & 2.55086400 & -0.97328400 \\ \mathrm{H} & 6.40205900 & 1.15031100 & -0.86294000 \\ \mathrm{H} & 5.81549100 & 1.92015900 & 0.61679500 \\ \mathrm{H} & 3.11572700 & -0.31735700 & -1.97762900 \\ \mathrm{H} & 3.64732800 & 1.31450600 & -2.40038500 \\ \mathrm{H} & 4.79890900 & -0.02437500 & -2.42556200\end{array}$

\section{Proposed structure of hainangranatumin G (17-4)-conformer 9}

Zero-point correction=

Thermal correction to Energy=

Thermal correction to Enthalpy=

Thermal correction to Gibbs Free Energy=

Sum of electronic and zero-point Energies=

Sum of electronic and thermal Energies $=$

Sum of electronic and thermal Enthalpies=

Sum of electronic and thermal Free Energies=
0.545440 (Hartree/Particle)

0.576841

0.577785

\subsection{4}

$-1591.287747$

$-1591.256345$

$-1591.255401$

$-1591.351653$

01

$\begin{array}{lrrr}\mathrm{N} & 0.92298900 & -1.76947500 & 0.22834900 \\ \mathrm{C} & 1.99315300 & -0.97583900 & 0.32577900 \\ \mathrm{C} & 1.88086100 & 0.42611100 & 0.37548500 \\ \mathrm{C} & 0.59826600 & 0.96570900 & 0.36517200 \\ \mathrm{C} & -0.53897500 & 0.14800400 & 0.25756100 \\ \mathrm{C} & -0.30569900 & -1.24250900 & 0.16595800 \\ \mathrm{C} & 3.34143800 & -1.69899600 & 0.40835200 \\ \mathrm{C} & 4.58420300 & -0.76082400 & 0.62870600 \\ \mathrm{C} & 4.26067500 & 0.65020400 & 1.20771400 \\ \mathrm{C} & 3.10789300 & 1.31589800 & 0.41755700 \\ \mathrm{C} & -1.91320300 & 0.69589500 & 0.23264700\end{array}$




\begin{tabular}{|c|c|c|c|}
\hline $\mathrm{C}$ & -3.05765500 & -0.23793800 & -0.16493100 \\
\hline $\mathrm{C}$ & -2.79030400 & -1.64320500 & 0.42239200 \\
\hline $\mathrm{C}$ & -1.44102800 & -2.21876200 & -0.01092700 \\
\hline $\mathrm{C}$ & -2.19113400 & 1.99080000 & 0.50646100 \\
\hline $\mathrm{C}$ & -3.52750000 & 2.57849000 & 0.31462100 \\
\hline $\mathrm{O}$ & -4.56293800 & 1.71448800 & 0.12385000 \\
\hline $\mathrm{C}$ & -4.35317600 & 0.32535600 & 0.48619700 \\
\hline $\mathrm{O}$ & 3.54679500 & -2.33125500 & -0.89451700 \\
\hline $\mathrm{C}$ & 4.66411000 & -1.89103200 & -1.53109000 \\
\hline $\mathrm{C}$ & 5.32895000 & -0.79931700 & -0.72128800 \\
\hline $\mathrm{O}$ & 5.00868100 & -2.33914300 & -2.59797600 \\
\hline $\mathrm{C}$ & -5.62885800 & -0.39182200 & 0.16009200 \\
\hline $\mathrm{C}$ & -6.28178700 & -1.27688900 & 0.96942400 \\
\hline $\mathrm{O}$ & -7.41145100 & -1.74052600 & 0.36589900 \\
\hline $\mathrm{C}$ & -7.49071400 & -1.12490700 & -0.85176700 \\
\hline $\mathrm{C}$ & -6.43142300 & -0.29104200 & -1.03269900 \\
\hline $\mathrm{H}$ & 5.21694700 & -1.25367600 & 1.37549800 \\
\hline $\mathrm{O}$ & -3.72846000 & 3.77594900 & 0.26894400 \\
\hline $\mathrm{C}$ & -3.15764700 & -0.28820800 & -1.70797700 \\
\hline $\mathrm{C}$ & 3.28456400 & -2.83868900 & 1.42945200 \\
\hline $\mathrm{O}$ & 3.57449900 & 1.60146400 & -0.91059300 \\
\hline $\mathrm{C}$ & 2.98683900 & 3.97617800 & -1.29119000 \\
\hline $\mathrm{C}$ & 2.80631800 & 2.51602300 & -1.70055000 \\
\hline $\mathrm{C}$ & 3.82210500 & 0.52045300 & 2.68594500 \\
\hline $\mathrm{C}$ & 5.51809200 & 1.54063800 & 1.17524900 \\
\hline $\mathrm{H}$ & 0.48676900 & 2.04338000 & 0.43511500 \\
\hline $\mathrm{H}$ & 2.84632700 & 2.25878900 & 0.92067000 \\
\hline $\mathrm{H}$ & -2.81494000 & -1.57844400 & 1.51905600 \\
\hline $\mathrm{H}$ & -3.59841700 & -2.31910900 & 0.12678800 \\
\hline $\mathrm{H}$ & -1.47218700 & -2.51954500 & -1.06707000 \\
\hline $\mathrm{H}$ & -1.20631800 & -3.12898500 & 0.5490870 \\
\hline $\mathrm{H}$ & -1.43417700 & 2.71248200 & 0.78912200 \\
\hline $\mathrm{H}$ & -4.20322700 & 0.28924500 & 1.57404000 \\
\hline $\mathrm{H}$ & 6.39524500 & -1.01856000 & -0.62608500 \\
\hline $\mathrm{H}$ & 5.22635200 & 0.12738800 & -1.28800000 \\
\hline $\mathrm{H}$ & -6.08355700 & -1.65807600 & 1.9596170 \\
\hline $\mathrm{H}$ & -8.35072400 & -1.37759000 & -1.4516790 \\
\hline $\mathrm{H}$ & -6.25054400 & 0.34387600 & -1.88703800 \\
\hline $\mathrm{H}$ & -3.47036300 & 0.67981800 & -2.10909200 \\
\hline $\mathrm{H}$ & -2.19196100 & -0.53522700 & -2.1573370 \\
\hline $\mathrm{H}$ & -3.88271700 & -1.04469200 & -2.0221200 \\
\hline $\mathrm{H}$ & 2.46209400 & -3.51392300 & 1.19012300 \\
\hline $\mathrm{H}$ & 4.22664600 & -3.39480600 & 1.40726900 \\
\hline $\mathrm{H}$ & 3.13608600 & -2.44591100 & 2.44029800 \\
\hline $\mathrm{H}$ & 2.43820700 & 4.62283400 & -1.98500800 \\
\hline $\mathrm{H}$ & 2.60682300 & 4.17986800 & -0.2846180 \\
\hline $\mathrm{H}$ & 4.04392500 & 4.25752700 & -1.3220610 \\
\hline $\mathrm{H}$ & 3.17082500 & 2.36482900 & -2.7208070 \\
\hline $\mathrm{H}$ & 1.74524500 & 2.23283300 & -1.69133100 \\
\hline $\mathrm{H}$ & 3.60739100 & 1.50749400 & 3.11089100 \\
\hline $\mathrm{H}$ & 4.62700100 & 0.07348700 & 3.27890800 \\
\hline
\end{tabular}

SI279 


$\begin{array}{rrrr}\mathrm{H} & 2.92841500 & -0.09520400 & 2.81696900 \\ \mathrm{H} & 5.86589100 & 1.73059100 & 0.15915600 \\ \mathrm{H} & 5.30961500 & 2.50973200 & 1.64323100 \\ \mathrm{H} & 6.33121400 & 1.06939800 & 1.73902500\end{array}$

Proposed structure of hainangranatumin G (17-4)-conformer 10

Zero-point correction $=$

Thermal correction to Energy=

Thermal correction to Enthalpy=

Thermal correction to Gibbs Free Energy=

Sum of electronic and zero-point Energies $=$

Sum of electronic and thermal Energies $=$

Sum of electronic and thermal Enthalpies=

Sum of electronic and thermal Free Energies=
0.545438 (Hartree/Particle)

0.576834

0.577779

0.481877

$-1591.287586$

$-1591.256189$

$-1591.255245$

$-1591.351147$

01

$\begin{array}{lrrr}\mathrm{N} & 0.93465700 & -1.77265100 & 0.22158700 \\ \mathrm{C} & 2.00184500 & -0.97519300 & 0.32100100 \\ \mathrm{C} & 1.88392200 & 0.42613500 & 0.37674700 \\ \mathrm{C} & 0.59893700 & 0.96028700 & 0.37239300 \\ \mathrm{C} & -0.53529400 & 0.13855900 & 0.26308500 \\ \mathrm{C} & -0.29604000 & -1.25016600 & 0.16352300 \\ \mathrm{C} & 3.35261100 & -1.69389900 & 0.40187800 \\ \mathrm{C} & 4.59242900 & -0.75013700 & 0.61140100 \\ \mathrm{C} & 4.26806300 & 0.65792700 & 1.19679900 \\ \mathrm{C} & 3.10676800 & 1.32201200 & 0.41763800 \\ \mathrm{C} & -1.91188100 & 0.68073000 & 0.24372100 \\ \mathrm{C} & -3.05710500 & -0.25532400 & -0.14836300 \\ \mathrm{C} & -2.77824000 & -1.66371300 & 0.42663000 \\ \mathrm{C} & -1.42778300 & -2.22890700 & -0.01749800 \\ \mathrm{C} & -2.19103800 & 1.97511900 & 0.51902000 \\ \mathrm{C} & -3.52845100 & 2.55906300 & 0.33102900 \\ \mathrm{O} & -4.56173300 & 1.69150600 & 0.14431100 \\ \mathrm{C} & -4.35231400 & 0.30558600 & 0.50997000 \\ \mathrm{O} & 3.55621500 & -2.33397000 & -0.89732900 \\ \mathrm{C} & 4.66501500 & -1.88676000 & -1.54421400 \\ \mathrm{C} & 5.32254700 & -0.78174900 & -0.74664000 \\ \mathrm{O} & 5.00768100 & -2.33926200 & -2.60981900 \\ \mathrm{C} & -5.62838400 & -0.41045600 & 0.17505900 \\ \mathrm{C} & -6.56677200 & -0.02560100 & -0.73914100 \\ \mathrm{O} & -7.60808900 & -0.90605600 & -0.75603200 \\ \mathrm{C} & -7.33425200 & -1.86940100 & 0.16928000 \\ \mathrm{C} & -6.14048700 & -1.61727600 & 0.77387000 \\ \mathrm{H} & 5.23585000 & -1.24182300 & 1.34990100 \\ \mathrm{O} & -3.73478800 & 3.75544800 & 0.28338300 \\ \mathrm{C} & -3.17933000 & -0.29689500 & -1.68951100 \\ \mathrm{C} & 3.30224800 & -2.82781900 & 1.42985300 \\ \mathrm{O} & 3.56326900 & 1.61921500 & -0.91151800 \\ \mathrm{C} & 2.96635000 & 3.99521500 & -1.26929500 \\ \mathrm{C} & 2.78744300 & 2.53787000 & -1.68919800\end{array}$

SI280 


$\begin{array}{lrrr}\mathrm{C} & 3.84103700 & 0.52357800 & 2.67798100 \\ \mathrm{C} & 5.52240600 & 1.55235900 & 1.15654600 \\ \mathrm{H} & 0.48354400 & 2.03706400 & 0.44849400 \\ \mathrm{H} & 2.84315700 & 2.26012500 & 0.92852400 \\ \mathrm{H} & -2.79951000 & -1.60969800 & 1.52401100 \\ \mathrm{H} & -3.57893800 & -2.34440200 & 0.12338500 \\ \mathrm{H} & -1.46292900 & -2.51969900 & -1.07626600 \\ \mathrm{H} & -1.18715900 & -3.14344100 & 0.53289000 \\ \mathrm{H} & -1.43464200 & 2.69877500 & 0.79768600 \\ \mathrm{H} & -4.20179900 & 0.27116200 & 1.59873000 \\ \mathrm{H} & 6.39324400 & -0.98329100 & -0.66327800 \\ \mathrm{H} & 5.19792700 & 0.14147700 & -1.31485600 \\ \mathrm{H} & -6.64767200 & 0.82543800 & -1.39531900 \\ \mathrm{H} & -8.07572900 & -2.64479200 & 0.28048400 \\ \mathrm{H} & -5.68715700 & -2.20608100 & 1.55863800 \\ \mathrm{H} & -3.48909700 & 0.67585600 & -2.08107200 \\ \mathrm{H} & -2.22382100 & -0.55320000 & -2.15509900 \\ \mathrm{H} & -3.92129800 & -1.04092400 & -1.99408400 \\ \mathrm{H} & 2.48058300 & -3.50630500 & 1.19683800 \\ \mathrm{H} & 4.24551400 & -3.38186700 & 1.40725800 \\ \mathrm{H} & 3.15631900 & -2.43008600 & 2.43906300 \\ \mathrm{H} & 2.41124400 & 4.64573400 & -1.95428700 \\ \mathrm{H} & 2.59239900 & 4.18971600 & -0.25864000 \\ \mathrm{H} & 4.02237000 & 4.27996100 & -1.30484900 \\ \mathrm{H} & 3.14599100 & 2.39597100 & -2.71289300 \\ \mathrm{H} & 1.72728000 & 2.25147900 & -1.67581400 \\ \mathrm{H} & 3.63203100 & 1.50961900 & 3.10802400 \\ \mathrm{H} & 4.64940700 & 0.07259800 & 3.26311500 \\ \mathrm{H} & 2.94682600 & -0.09029700 & 2.81373000 \\ \mathrm{H} & 5.86340600 & 1.74284000 & 0.13824900 \\ \mathrm{H} & 5.31384600 & 2.52101400 & 1.62537300 \\ \mathrm{H} & 6.34027700 & 1.08371700 & 1.71560300 \\ & & & \\ & & & \\ & & & \end{array}$

\section{Proposed structure of hainangranatumin G (17-4)-conformer 11}

Zero-point correction=

Thermal correction to Energy=

Thermal correction to Enthalpy=

Thermal correction to Gibbs Free Energy=

Sum of electronic and zero-point Energies=

Sum of electronic and thermal Energies $=$

Sum of electronic and thermal Enthalpies=

Sum of electronic and thermal Free Energies=
0.545427 (Hartree/Particle)

0.576764

0.577709

0.482666

$-1591.286202$

$-1591.254865$

$-1591.253921$

$-1591.348964$

01

$\begin{array}{lrrr}\mathrm{N} & -0.93569300 & -1.79844600 & -0.30576400 \\ \mathrm{C} & -2.01237600 & -1.00599400 & -0.37862000 \\ \mathrm{C} & -1.90991500 & 0.39519400 & -0.40435700 \\ \mathrm{C} & -0.62797100 & 0.93914700 & -0.35943000 \\ \mathrm{C} & 0.51179300 & 0.12767100 & -0.28352500 \\ \mathrm{C} & 0.28805900 & -1.26920400 & -0.24092500\end{array}$

SI281 


\begin{tabular}{|c|c|c|c|}
\hline $\mathrm{C}$ & -3.35243800 & -1.74179600 & -0.44406500 \\
\hline $\mathrm{C}$ & -4.58884900 & -0.78793100 & -0.41994900 \\
\hline $\mathrm{C}$ & -4.36468400 & 0.61270300 & -1.05677900 \\
\hline $\mathrm{C}$ & -3.12243700 & 1.31333900 & -0.43579500 \\
\hline $\mathrm{C}$ & 1.88248600 & 0.68359700 & -0.23749000 \\
\hline $\mathrm{C}$ & 3.03011500 & -0.25469100 & 0.13863600 \\
\hline $\mathrm{C}$ & 2.77792800 & -1.63940800 & -0.50290600 \\
\hline $\mathrm{C}$ & 1.43122500 & -2.24268300 & -0.10081400 \\
\hline $\mathrm{C}$ & 2.15294500 & 1.98664000 & -0.47757200 \\
\hline $\mathrm{C}$ & 3.48235900 & 2.57962500 & -0.25769000 \\
\hline $\mathrm{O}$ & 4.52199900 & 1.71857300 & -0.07464300 \\
\hline $\mathrm{C}$ & 4.32806300 & 0.33906400 & -0.47986000 \\
\hline $\mathrm{O}$ & -3.46583700 & -2.54050400 & 0.77822000 \\
\hline $\mathrm{C}$ & -4.40698800 & -2.05805900 & 1.63370000 \\
\hline $\mathrm{C}$ & -5.01966700 & -0.79913400 & 1.05974800 \\
\hline $\mathrm{O}$ & -4.65394400 & -2.59854000 & 2.68447100 \\
\hline $\mathrm{C}$ & 5.60611400 & -0.37689500 & -0.16022900 \\
\hline $\mathrm{C}$ & 6.27589500 & -1.23240100 & -0.98733600 \\
\hline $\mathrm{O}$ & 7.40266300 & -1.70412500 & -0.38449000 \\
\hline $\mathrm{C}$ & 7.46253500 & -1.12384200 & 0.85153300 \\
\hline $\mathrm{C}$ & 6.39407600 & -0.30448100 & 1.04429600 \\
\hline $\mathrm{H}$ & -5.37755800 & -1.27791500 & -1.00462700 \\
\hline $\mathrm{O}$ & 3.67420000 & 3.77710700 & -0.18202200 \\
\hline $\mathrm{C}$ & 3.11512600 & -0.35954000 & 1.67971100 \\
\hline $\mathrm{C}$ & -3.36722200 & -2.75265900 & -1.59315800 \\
\hline $\mathrm{O}$ & -3.35757500 & 1.77355600 & 0.90664700 \\
\hline $\mathrm{C}$ & -2.23404700 & 3.94748100 & 1.26288500 \\
\hline $\mathrm{C}$ & -3.54342700 & 3.18258700 & 1.09591600 \\
\hline $\mathrm{C}$ & -4.12002600 & 0.48516400 & -2.57955700 \\
\hline $\mathrm{C}$ & -5.63430600 & 1.46336400 & -0.86067100 \\
\hline $\mathrm{H}$ & -0.52337800 & 2.01887700 & -0.36137200 \\
\hline $\mathrm{H}$ & -2.87960400 & 2.18307700 & -1.06346500 \\
\hline $\mathrm{H}$ & 2.80970600 & -1.53258700 & -1.59610400 \\
\hline $\mathrm{H}$ & 3.58989200 & -2.31925500 & -0.22742800 \\
\hline $\mathrm{H}$ & 1.45949000 & -2.58635300 & 0.94213000 \\
\hline $\mathrm{H}$ & 1.20662800 & -3.13118700 & -0.69866400 \\
\hline $\mathrm{H}$ & 1.39207100 & 2.70848800 & -0.74895000 \\
\hline $\mathrm{H}$ & 4.19104900 & 0.33408600 & -1.56999500 \\
\hline $\mathrm{H}$ & -6.10109800 & -0.81175400 & 1.21020400 \\
\hline $\mathrm{H}$ & -4.61238900 & 0.05103600 & 1.61450500 \\
\hline $\mathrm{H}$ & 6.09229800 & -1.58604800 & -1.99048000 \\
\hline $\mathrm{H}$ & 8.31767300 & -1.38695300 & 1.45392900 \\
\hline $\mathrm{H}$ & 6.19753800 & 0.30322800 & 1.91481100 \\
\hline $\mathrm{H}$ & 3.41861700 & 0.59542300 & 2.11761200 \\
\hline $\mathrm{H}$ & 2.14639500 & -0.62663300 & 2.11054300 \\
\hline $\mathrm{H}$ & 3.84112900 & -1.12297300 & 1.97429100 \\
\hline $\mathrm{H}$ & -2.52826500 & -3.44182300 & -1.48194400 \\
\hline $\mathrm{H}$ & -4.30269400 & -3.31947800 & -1.56925700 \\
\hline $\mathrm{H}$ & -3.28507900 & -2.25306500 & -2.56197700 \\
\hline $\mathrm{H}$ & -2.44432600 & 4.99409700 & 1.51106100 \\
\hline $\mathrm{H}$ & -1.63444600 & 3.51508900 & 2.06928500 \\
\hline
\end{tabular}




$\begin{array}{lrrr}\mathrm{H} & -1.63693500 & 3.94292100 & 0.34482500 \\ \mathrm{H} & -4.13381400 & 3.60259900 & 0.27094000 \\ \mathrm{H} & -4.14472200 & 3.26782600 & 2.00698300 \\ \mathrm{H} & -4.07877200 & 1.47830900 & -3.04085900 \\ \mathrm{H} & -4.93719300 & -0.06685000 & -3.05601400 \\ \mathrm{H} & -3.18394100 & -0.02538000 & -2.82009500 \\ \mathrm{H} & -5.85307400 & 1.64175300 & 0.19421900 \\ \mathrm{H} & -5.53561300 & 2.43488600 & -1.35806800 \\ \mathrm{H} & -6.49797200 & 0.95600300 & -1.30533600\end{array}$

Proposed structure of hainangranatumin G (17-4)-conformer 12

Zero-point correction=

Thermal correction to Energy=

Thermal correction to Enthalpy=

Thermal correction to Gibbs Free Energy=

Sum of electronic and zero-point Energies=

Sum of electronic and thermal Energies=

Sum of electronic and thermal Enthalpies=

Sum of electronic and thermal Free Energies=
0.545417 (Hartree/Particle)

0.576755

0.577699

0.482810

$-1591.286084$

$-1591.254746$

$-1591.253802$

$-1591.348692$

01

$\begin{array}{lrrr}\mathrm{N} & -0.94636600 & -1.80229700 & -0.29583700 \\ \mathrm{C} & -2.02004400 & -1.00606900 & -0.37136600 \\ \mathrm{C} & -1.91195800 & 0.39455700 & -0.40498000 \\ \mathrm{C} & -0.62778900 & 0.93362000 & -0.36625300 \\ \mathrm{C} & 0.50908300 & 0.11810200 & -0.28804200 \\ \mathrm{C} & 0.27942500 & -1.27722000 & -0.23635700 \\ \mathrm{C} & -3.36309300 & -1.73688200 & -0.43133700 \\ \mathrm{C} & -4.59563100 & -0.77799500 & -0.40935200 \\ \mathrm{C} & -4.36726600 & 0.61871000 & -1.05331500 \\ \mathrm{C} & -3.12090500 & 1.31738500 & -0.43838400 \\ \mathrm{C} & 1.88215600 & 0.66862800 & -0.24835400 \\ \mathrm{C} & 3.03081700 & -0.27125600 & 0.12273200 \\ \mathrm{C} & 2.76708700 & -1.66021500 & -0.50535000 \\ \mathrm{C} & 1.41903300 & -2.25328800 & -0.09171700 \\ \mathrm{C} & 2.15364900 & 1.97102000 & -0.49116400 \\ \mathrm{C} & 3.48413600 & 2.56073900 & -0.27584900 \\ \mathrm{O} & 4.52183500 & 1.69644700 & -0.09651700 \\ \mathrm{C} & 4.32827000 & 0.32002700 & -0.50404800 \\ \mathrm{O} & -3.47776300 & -2.52994100 & 0.79440000 \\ \mathrm{C} & -4.41553100 & -2.03991100 & 1.64939400 \\ \mathrm{C} & -5.02355600 & -0.78065900 & 1.07120800 \\ \mathrm{O} & -4.66326900 & -2.57510000 & 2.70265900 \\ \mathrm{C} & 5.60672200 & -0.39485000 & -0.17570000 \\ \mathrm{C} & 6.53189900 & -0.02866100 & 0.75933400 \\ \mathrm{O} & 7.58044500 & -0.90079400 & 0.76273100 \\ \mathrm{C} & 7.32460500 & -1.83963900 & -0.19243600 \\ \mathrm{C} & 6.13535800 & -1.58003300 & -0.80272400 \\ \mathrm{H} & -5.38742300 & -1.26763300 & -0.99014700 \\ \mathrm{O} & 3.68120700 & 3.75720900 & -0.19911000 \\ & & & \end{array}$

SI283 


$\begin{array}{lrrr}\mathrm{C} & 3.13858700 & -0.36571800 & 1.66248300 \\ \mathrm{C} & -3.38359500 & -2.75254100 & -1.57613600 \\ \mathrm{O} & -3.35135900 & 1.78484000 & 0.90232500 \\ \mathrm{C} & -2.21769900 & 3.95617000 & 1.24314100 \\ \mathrm{C} & -3.53071900 & 3.19556000 & 1.08539000 \\ \mathrm{C} & -4.12637000 & 0.48294900 & -2.57596800 \\ \mathrm{C} & -5.63307800 & 1.47534600 & -0.85851700 \\ \mathrm{H} & -0.51940300 & 2.01288500 & -0.37498800 \\ \mathrm{H} & -2.87595500 & 2.18309800 & -1.07075600 \\ \mathrm{H} & 2.79583800 & -1.56524200 & -1.59978600 \\ \mathrm{H} & 3.57146600 & -2.34500500 & -0.22164300 \\ \mathrm{H} & 1.45111500 & -2.58652600 & 0.95445600 \\ \mathrm{H} & 1.18854600 & -3.14685700 & -0.67969800 \\ \mathrm{H} & 1.39315100 & 2.69436700 & -0.75915700 \\ \mathrm{H} & 4.19022100 & 0.31607500 & -1.59499100 \\ \mathrm{H} & -6.10472900 & -0.78764400 & 1.22382300 \\ \mathrm{H} & -4.61128700 & 0.07006100 & 1.62142100 \\ \mathrm{H} & 6.59843800 & 0.80385800 & 1.44041100 \\ \mathrm{H} & 8.07363700 & -2.60563300 & -0.31733900 \\ \mathrm{H} & 5.69530600 & -2.14998800 & -1.60867900 \\ \mathrm{H} & 3.43962000 & 0.59464600 & 2.08990000 \\ \mathrm{H} & 2.18001200 & -0.64195900 & 2.10993600 \\ \mathrm{H} & 3.88144600 & -1.11614400 & 1.94861000 \\ \mathrm{H} & -2.54733800 & -3.44468800 & -1.46306700 \\ \mathrm{H} & -4.32133200 & -3.31542500 & -1.54851800 \\ \mathrm{H} & -3.30073700 & -2.25748900 & -2.54721300 \\ \mathrm{H} & -2.42294500 & 5.00481300 & 1.48691300 \\ \mathrm{H} & -1.61640300 & 3.52555500 & 2.04922000 \\ \mathrm{H} & -1.62447100 & 3.94479700 & 0.32262100 \\ \mathrm{H} & -4.12295000 & 3.61386000 & 0.26086500 \\ \mathrm{H} & -4.12779200 & 3.28754800 & 1.99855200 \\ \mathrm{H} & -4.08218900 & 1.47370200 & -3.04210300 \\ \mathrm{H} & -4.94669600 & -0.06811500 & -3.04807500 \\ \mathrm{H} & -3.19279100 & -0.03240300 & -2.81598900 \\ \mathrm{H} & -5.84866200 & 1.65980800 & 0.19597800 \\ \mathrm{H} & -5.53168900 & 2.44399500 & -1.36093800 \\ \mathrm{H} & -6.49977400 & 0.96922600 & -1.29866700\end{array}$

\section{Proposed structure of hainangranatumin G (17-4)-conformer 13}

Zero-point correction $=$

Thermal correction to Energy=

Thermal correction to Enthalpy=

Thermal correction to Gibbs Free Energy=

Sum of electronic and zero-point Energies $=$

Sum of electronic and thermal Energies=

Sum of electronic and thermal Enthalpies=

Sum of electronic and thermal Free Energies=
0.544989 (Hartree/Particle)

$$
0.576402
$$

0.577346

$$
\begin{gathered}
0.482340 \\
-1591.287106 \\
-1591.255693 \\
-1591.254749 \\
-1591.349754
\end{gathered}
$$

01 


\begin{tabular}{|c|c|c|c|}
\hline $\mathrm{C}$ & -1.98825800 & -0.84137200 & -0.68329500 \\
\hline $\mathrm{C}$ & -1.88954800 & 0.52770900 & -0.39309200 \\
\hline $\mathrm{C}$ & -0.61011700 & 1.06493900 & -0.23743200 \\
\hline $\mathrm{C}$ & 0.51140800 & 0.24677000 & -0.39286800 \\
\hline $\mathrm{C}$ & 0.30032600 & -1.11277600 & -0.70771400 \\
\hline $\mathrm{C}$ & -3.34010200 & -1.52540400 & -0.83516000 \\
\hline $\mathrm{C}$ & -4.57529300 & -0.64100700 & -0.46775700 \\
\hline $\mathrm{C}$ & -4.28199100 & 0.58387900 & 0.45168500 \\
\hline $\mathrm{C}$ & -3.14006700 & 1.37902600 & -0.23869700 \\
\hline $\mathrm{C}$ & 1.90232600 & 0.72322200 & -0.30755400 \\
\hline $\mathrm{C}$ & 2.94796500 & -0.19187800 & 0.34248200 \\
\hline $\mathrm{C}$ & 2.52950700 & -1.69105700 & 0.23020900 \\
\hline $\mathrm{C}$ & 1.51269300 & -1.98857900 & -0.88531800 \\
\hline $\mathrm{C}$ & 2.28135500 & 1.91853900 & -0.80639400 \\
\hline $\mathrm{C}$ & 3.66867100 & 2.40314800 & -0.71707400 \\
\hline $\mathrm{O}$ & 4.62190100 & 1.48204000 & -0.39778300 \\
\hline $\mathrm{C}$ & 4.27941000 & 0.06779300 & -0.42406000 \\
\hline $\mathrm{O}$ & -3.37560600 & -2.63102300 & 0.12738000 \\
\hline $\mathrm{C}$ & -4.61214800 & -2.77615600 & 0.67161900 \\
\hline $\mathrm{C}$ & -5.52691300 & -1.68124100 & 0.14591800 \\
\hline $\mathrm{O}$ & -4.88092600 & -3.66427400 & 1.44321300 \\
\hline $\mathrm{C}$ & 5.49684400 & -0.65576300 & 0.06865100 \\
\hline $\mathrm{C}$ & 6.08547500 & -1.73353000 & -0.52899700 \\
\hline $\mathrm{O}$ & 7.17773600 & -2.14055200 & 0.17536300 \\
\hline $\mathrm{C}$ & 7.29945300 & -1.29283000 & 1.24044500 \\
\hline $\mathrm{C}$ & 6.30350400 & -0.36663800 & 1.22742700 \\
\hline $\mathrm{H}$ & -4.99366400 & -0.24135600 & -1.39885800 \\
\hline $\mathrm{O}$ & 3.99194800 & 3.56121700 & -0.88937300 \\
\hline $\mathrm{C}$ & 3.06782000 & 0.18754900 & 1.83888500 \\
\hline $\mathrm{C}$ & -3.46879100 & -2.13372300 & -2.23791200 \\
\hline $\mathrm{O}$ & -2.84875600 & 2.57472100 & 0.47843300 \\
\hline $\mathrm{C}$ & -2.55748900 & 4.94516100 & 0.62498900 \\
\hline $\mathrm{C}$ & -2.89663000 & 3.78079900 & -0.28930200 \\
\hline $\mathrm{C}$ & -5.53837500 & 1.47458200 & 0.51135000 \\
\hline $\mathrm{C}$ & -3.86955000 & 0.19731800 & 1.88776200 \\
\hline $\mathrm{H}$ & -0.49846600 & 2.10615700 & 0.04458800 \\
\hline $\mathrm{H}$ & -3.49921800 & 1.65205100 & -1.24484400 \\
\hline $\mathrm{H}$ & 3.42357000 & -2.30915000 & 0.10634000 \\
\hline $\mathrm{H}$ & 2.07901000 & -1.99568000 & 1.18100600 \\
\hline $\mathrm{H}$ & 1.20622400 & -3.03740300 & -0.86420500 \\
\hline $\mathrm{H}$ & 1.95886100 & -1.80178900 & -1.87329300 \\
\hline $\mathrm{H}$ & 1.58077900 & 2.60216100 & -1.27363400 \\
\hline $\mathrm{H}$ & 4.11208700 & -0.21166800 & -1.47360500 \\
\hline $\mathrm{H}$ & -6.18740900 & -2.12806700 & -0.60567000 \\
\hline $\mathrm{H}$ & -6.16606200 & -1.31080500 & 0.94838700 \\
\hline $\mathrm{H}$ & 5.86386500 & -2.29490300 & -1.42402400 \\
\hline $\mathrm{H}$ & 8.13767400 & -1.47594000 & 1.89407700 \\
\hline $\mathrm{H}$ & 6.16964400 & 0.44324900 & 1.92864700 \\
\hline $\mathrm{H}$ & 3.46624700 & 1.19692500 & 1.97181600 \\
\hline $\mathrm{H}$ & 2.08271100 & 0.14397700 & 2.31360700 \\
\hline $\mathrm{H}$ & 3.72320100 & -0.51774100 & 2.35850200 \\
\hline
\end{tabular}




$\begin{array}{lrrr}\mathrm{H} & -2.66244100 & -2.85257600 & -2.39531200 \\ \mathrm{H} & -4.43007400 & -2.64443700 & -2.35413300 \\ \mathrm{H} & -3.39731600 & -1.35157800 & -3.00129800 \\ \mathrm{H} & -2.59076200 & 5.88480300 & 0.06391300 \\ \mathrm{H} & -3.27232300 & 5.00881400 & 1.45092200 \\ \mathrm{H} & -1.55448300 & 4.83128100 & 1.04721900 \\ \mathrm{H} & -2.18221000 & 3.72354300 & -1.12540900 \\ \mathrm{H} & -3.90139500 & 3.90709800 & -0.71999300 \\ \mathrm{H} & -5.34235600 & 2.36667900 & 1.11202000 \\ \mathrm{H} & -6.37994400 & 0.94526300 & 0.96910700 \\ \mathrm{H} & -5.85174900 & 1.79591700 & -0.48959800 \\ \mathrm{H} & -3.01218900 & -0.48012500 & 1.91315700 \\ \mathrm{H} & -3.60238600 & 1.09942700 & 2.44484500 \\ \mathrm{H} & -4.69404400 & -0.28837200 & 2.41833900\end{array}$

Proposed structure of hainangranatumin G (17-4)-conformer 14

Zero-point correction=

Thermal correction to Energy=

Thermal correction to Enthalpy=

Thermal correction to Gibbs Free Energy=

Sum of electronic and zero-point Energies=

Sum of electronic and thermal Energies=

Sum of electronic and thermal Enthalpies=

Sum of electronic and thermal Free Energies=
0.544904 (Hartree/Particle)

0.576343

0.577287

0.482152

$-1591.286694$

$-1591.255255$

$-1591.254311$

$-1591.349446$

01

$\begin{array}{lrrr}\mathrm{N} & -0.92144700 & -1.63546500 & -0.83712100 \\ \mathrm{C} & -1.99069300 & -0.84051900 & -0.67688600 \\ \mathrm{C} & -1.88988100 & 0.52873500 & -0.38810500 \\ \mathrm{C} & -0.60988300 & 1.06329500 & -0.22897800 \\ \mathrm{C} & 0.51063400 & 0.24250300 & -0.37892100 \\ \mathrm{C} & 0.29737600 & -1.11765600 & -0.69011100 \\ \mathrm{C} & -3.34350400 & -1.52124900 & -0.83467500 \\ \mathrm{C} & -4.57807500 & -0.63361100 & -0.47295000 \\ \mathrm{C} & -4.28551800 & 0.59097600 & 0.44709800 \\ \mathrm{C} & -3.13897400 & 1.38311700 & -0.23914100 \\ \mathrm{C} & 1.90186400 & 0.71830500 & -0.29499400 \\ \mathrm{C} & 2.95235600 & -0.19599600 & 0.34891500 \\ \mathrm{C} & 2.51563100 & -1.69114600 & 0.26698900 \\ \mathrm{C} & 1.50752600 & -1.99967300 & -0.85324100 \\ \mathrm{C} & 2.27998600 & 1.91221700 & -0.79813500 \\ \mathrm{C} & 3.66897000 & 2.39172500 & -0.71661000 \\ \mathrm{O} & 4.62130700 & 1.46496800 & -0.40948900 \\ \mathrm{C} & 4.27499300 & 0.05311000 & -0.43920300 \\ \mathrm{O} & -3.38615000 & -2.62674100 & 0.12761600 \\ \mathrm{C} & -4.62540000 & -2.76858900 & 0.66654900 \\ \mathrm{C} & -5.53496500 & -1.67115000 & 0.13712300 \\ \mathrm{O} & -4.89985000 & -3.65614300 & 1.43678300 \\ \mathrm{C} & 5.49409000 & -0.67794600 & 0.04427200 \\ \mathrm{C} & 6.42726700 & -0.22570800 & 0.93299800\end{array}$

SI286 


\begin{tabular}{|c|c|c|c|}
\hline $\mathrm{O}$ & 7.40997700 & -1.15396200 & 1.11006700 \\
\hline $\mathrm{C}$ & 7.10447200 & -2.21922600 & 0.31544100 \\
\hline $\mathrm{C}$ & 5.94819200 & -1.98337200 & -0.36385100 \\
\hline $\mathrm{H}$ & -4.99148800 & -0.23337000 & -1.40601100 \\
\hline $\mathrm{O}$ & 3.99709800 & 3.54888900 & -0.88525800 \\
\hline $\mathrm{C}$ & 3.11014900 & 0.19838200 & 1.83729200 \\
\hline $\mathrm{C}$ & -3.46732300 & -2.12924000 & -2.23802400 \\
\hline $\mathrm{O}$ & -2.84735000 & 2.57836500 & 0.47856100 \\
\hline $\mathrm{C}$ & -2.55319100 & 4.94836200 & 0.62615100 \\
\hline $\mathrm{C}$ & -2.89220100 & 3.78466100 & -0.28903000 \\
\hline $\mathrm{C}$ & -5.54000900 & 1.48467500 & 0.50143800 \\
\hline $\mathrm{C}$ & -3.87972400 & 0.20402200 & 1.88496100 \\
\hline $\mathrm{H}$ & -0.49703300 & 2.10485800 & 0.05125000 \\
\hline $\mathrm{H}$ & -3.49344200 & 1.65651600 & -1.24684600 \\
\hline $\mathrm{H}$ & 3.39846200 & -2.32885200 & 0.17568100 \\
\hline $\mathrm{H}$ & 2.04647300 & -1.96315900 & 1.21885500 \\
\hline $\mathrm{H}$ & 1.19617100 & -3.04682500 & -0.82162000 \\
\hline $\mathrm{H}$ & 1.96069200 & -1.82613600 & -1.84042800 \\
\hline $\mathrm{H}$ & 1.57895400 & 2.59664700 & -1.26336100 \\
\hline $\mathrm{H}$ & 4.09461000 & -0.22160400 & -1.48827700 \\
\hline $\mathrm{H}$ & -6.19379700 & -2.11621400 & -0.61696700 \\
\hline $\mathrm{H}$ & -6.17618100 & -1.29882100 & 0.93706400 \\
\hline $\mathrm{H}$ & 6.54530500 & 0.70307600 & 1.46690900 \\
\hline $\mathrm{H}$ & 7.79874300 & -3.04424600 & 0.34032500 \\
\hline $\mathrm{H}$ & 5.48430700 & -2.64662700 & -1.08064000 \\
\hline $\mathrm{H}$ & 3.50758100 & 1.21032600 & 1.95070000 \\
\hline $\mathrm{H}$ & 2.13903700 & 0.15365400 & 2.33979100 \\
\hline $\mathrm{H}$ & 3.78718700 & -0.49717900 & 2.34242400 \\
\hline $\mathrm{H}$ & -2.66205700 & -2.85011100 & -2.39178800 \\
\hline $\mathrm{H}$ & -4.42932900 & -2.63759500 & -2.35856100 \\
\hline $\mathrm{H}$ & -3.39049200 & -1.34728200 & -3.0010820 \\
\hline $\mathrm{H}$ & -2.58403700 & 5.88815700 & 0.06519200 \\
\hline $\mathrm{H}$ & -3.26954100 & 5.01287700 & 1.45070000 \\
\hline $\mathrm{H}$ & -1.55118700 & 4.83295900 & 1.05033900 \\
\hline $\mathrm{H}$ & -2.17627500 & 3.72656900 & -1.12380100 \\
\hline $\mathrm{H}$ & -3.89596800 & 3.91242300 & -0.7215940 \\
\hline $\mathrm{H}$ & -5.34425500 & 2.37654500 & 1.10253700 \\
\hline $\mathrm{H}$ & -6.38460200 & 0.95754900 & 0.95614400 \\
\hline $\mathrm{H}$ & -5.84871900 & 1.80633000 & -0.50085800 \\
\hline $\mathrm{H}$ & -3.02427100 & -0.47568300 & 1.9141100 \\
\hline $\mathrm{H}$ & -3.61235000 & 1.10567400 & 2.44267400 \\
\hline $\mathrm{H}$ & -4.70759700 & -0.27922100 & 2.4125070 \\
\hline
\end{tabular}

\footnotetext{
Revised structure of hainangranatumin G (17-7)-conformer 1

Zero-point correction $=$

Thermal correction to Energy=

Thermal correction to Enthalpy=

Thermal correction to Gibbs Free Energy=

Sum of electronic and zero-point Energies=

0.545321 (Hartree/Particle)

0.576713

0.577658

0.482989

$-1591.293664$

SI287
} 
Sum of electronic and thermal Energies $=\quad-1591.262271$

Sum of electronic and thermal Enthalpies $=\quad-1591.261327$

Sum of electronic and thermal Free Energies $=\quad-1591.355996$ 01

$\begin{array}{lrrr}\mathrm{N} & 0.95306800 & -1.43386400 & 0.75152500 \\ \mathrm{C} & 1.99382900 & -0.65903500 & 0.43963600 \\ \mathrm{C} & 1.83998200 & 0.62971400 & -0.09977900 \\ \mathrm{C} & 0.54493100 & 1.07272400 & -0.34108300 \\ \mathrm{C} & -0.56733400 & 0.27355800 & -0.02372900 \\ \mathrm{C} & -0.29370200 & -0.99743600 & 0.53128400 \\ \mathrm{C} & 3.37244400 & -1.25874600 & 0.69454100 \\ \mathrm{C} & 4.57963200 & -0.41865200 & 0.16440300 \\ \mathrm{C} & 4.22624900 & 0.62944400 & -0.93460700 \\ \mathrm{C} & 3.05566400 & 1.48505200 & -0.39223200 \\ \mathrm{C} & -1.95772200 & 0.71725100 & -0.26595800 \\ \mathrm{C} & -3.07890700 & -0.31614100 & -0.14506600 \\ \mathrm{C} & -2.75987900 & -1.26766700 & 1.03145700 \\ \mathrm{C} & -1.40279500 & -1.95660800 & 0.88328900 \\ \mathrm{C} & -2.27068000 & 1.98357200 & -0.62346800 \\ \mathrm{C} & -3.62629900 & 2.38552700 & -1.03385600 \\ \mathrm{O} & -4.63774600 & 1.51130200 & -0.77218700 \\ \mathrm{C} & -4.38238400 & 0.46138700 & 0.19582600 \\ \mathrm{O} & 3.42821600 & -2.51335000 & -0.06478000 \\ \mathrm{C} & 4.65859600 & -2.71276500 & -0.60734100 \\ \mathrm{C} & 5.54830400 & -1.52165100 & -0.29188900 \\ \mathrm{O} & 4.93734700 & -3.70982300 & -1.22802200 \\ \mathrm{C} & -5.64028000 & -0.35054300 & 0.27748300 \\ \mathrm{C} & -6.25558800 & -0.76520400 & 1.42382200 \\ \mathrm{O} & -7.37892200 & -1.48047600 & 1.13746200 \\ \mathrm{C} & -7.49270600 & -1.51007700 & -0.22423000 \\ \mathrm{C} & -6.46140600 & -0.83736500 & -0.80218000 \\ \mathrm{H} & 4.99437200 & 0.14357100 & 1.00392400 \\ \mathrm{O} & -3.86413900 & 3.41792100 & -1.62874700 \\ \mathrm{C} & -3.19801000 & -1.09425000 & -1.47680100 \\ \mathrm{C} & 3.52843500 & -1.60693900 & 2.17969400 \\ \mathrm{O} & 3.50727400 & 2.14832200 & 0.79642200 \\ \mathrm{C} & 3.39278400 & 3.90240900 & 2.41540600 \\ \mathrm{C} & 2.70695700 & 3.24798200 & 1.22757200 \\ \mathrm{C} & 5.44483000 & 1.53858400 & -1.19004800 \\ \mathrm{C} & 3.79633300 & -0.00747000 & -2.27542400 \\ \mathrm{H} & 0.40424200 & 2.04377000 & -0.80659300 \\ \mathrm{H} & 2.79134200 & 2.24706500 & -1.14358600 \\ \mathrm{H} & -2.76706800 & -0.68858700 & 1.96532300 \\ \mathrm{H} & -3.55278800 & -2.01681100 & 1.11728200 \\ \mathrm{H} & -1.44539400 & -2.73024500 & 0.10473400 \\ \mathrm{H} & -1.12824200 & -2.48055000 & 1.80404000 \\ \mathrm{H} & -1.53165800 & 2.76826200 & -0.73190400 \\ \mathrm{H} & -4.21811600 & 0.94507400 & 1.16859000 \\ \mathrm{H} & 6.23503000 & -1.82032400 & 0.50837600 \\ \mathrm{H} & 6.16379400 & -1.27415900 & -1.15798500 \\ \mathrm{H} & -6.03293200 & -0.63291100 & 2.47167500 \\ & & & \mathrm{~S} \\ & & & \\ \mathrm{H} & & & \\ \mathrm{H} & & & \end{array}$




$\begin{array}{lrrr}\mathrm{H} & -8.35270500 & -2.03197800 & -0.61332000 \\ \mathrm{H} & -6.31072200 & -0.67418500 & -1.85877700 \\ \mathrm{H} & -3.90438100 & -1.92348000 & -1.37626900 \\ \mathrm{H} & -3.54465300 & -0.43843400 & -2.28022600 \\ \mathrm{H} & -2.23150700 & -1.50545700 & -1.78043400 \\ \mathrm{H} & 3.44708800 & -0.70123500 & 2.78900200 \\ \mathrm{H} & 2.74416200 & -2.30695200 & 2.47441300 \\ \mathrm{H} & 4.50454300 & -2.06538400 & 2.36773300 \\ \mathrm{H} & 2.80110200 & 4.75367700 & 2.76805900 \\ \mathrm{H} & 3.49908000 & 3.19153700 & 3.24054400 \\ \mathrm{H} & 4.38837800 & 4.26286500 & 2.13964800 \\ \mathrm{H} & 2.59517000 & 3.96604200 & 0.39901700 \\ \mathrm{H} & 1.70116000 & 2.90253900 & 1.50836800 \\ \mathrm{H} & 5.19637500 & 2.31218000 & -1.92603100 \\ \mathrm{H} & 6.28566500 & 0.96540400 & -1.59368200 \\ \mathrm{H} & 5.77119200 & 2.03523800 & -0.27354500 \\ \mathrm{H} & 2.96268500 & -0.70635600 & -2.17295000 \\ \mathrm{H} & 3.49166000 & 0.77404700 & -2.98086900 \\ \mathrm{H} & 4.62773300 & -0.54827300 & -2.73675200\end{array}$

\section{Revised structure of hainangranatumin G (17-7)-conformer 2}

Zero-point correction=

Thermal correction to Energy=

Thermal correction to Enthalpy=

Thermal correction to Gibbs Free Energy=

Sum of electronic and zero-point Energies $=$

Sum of electronic and thermal Energies=

Sum of electronic and thermal Enthalpies $=$

Sum of electronic and thermal Free Energies=
0.545286 (Hartree/Particle)

0.576690

0.577634

0.483018

$-1591.293573$

$-1591.262169$

$-1591.261224$

$-1591.355840$

01

$\begin{array}{lrrr}\mathrm{N} & 0.96188200 & -1.44760000 & 0.73081900 \\ \mathrm{C} & 1.99987300 & -0.66545800 & 0.42816300 \\ \mathrm{C} & 1.84117400 & 0.63131400 & -0.09027100 \\ \mathrm{C} & 0.54436800 & 1.07530900 & -0.31976900 \\ \mathrm{C} & -0.56520100 & 0.26858700 & -0.01176000 \\ \mathrm{C} & -0.28643700 & -1.01033400 & 0.52135000 \\ \mathrm{C} & 3.38075800 & -1.26558300 & 0.66945200 \\ \mathrm{C} & 4.58411100 & -0.41452100 & 0.14809400 \\ \mathrm{C} & 4.22435200 & 0.64927300 & -0.93361400 \\ \mathrm{C} & 3.05390000 & 1.49380600 & -0.37390000 \\ \mathrm{C} & -1.95744900 & 0.71265600 & -0.24237800 \\ \mathrm{C} & -3.07958700 & -0.32110500 & -0.12709700 \\ \mathrm{C} & -2.74999300 & -1.29362400 & 1.02945700 \\ \mathrm{C} & -1.39231200 & -1.97707500 & 0.86007800 \\ \mathrm{C} & -2.27109800 & 1.98291900 & -0.58524800 \\ \mathrm{C} & -3.62733100 & 2.38788800 & -0.98690000 \\ \mathrm{O} & -4.63680800 & 1.51004800 & -0.72961200 \\ \mathrm{C} & -4.38256200 & 0.45434100 & 0.22890300 \\ \mathrm{O} & 3.43708000 & -2.50846300 & -0.10870200\end{array}$

SI289 


\begin{tabular}{|c|c|c|c|}
\hline $\mathrm{C}$ & 4.66619200 & -2.69667500 & -0.65822100 \\
\hline $\mathrm{C}$ & 5.55392100 & -1.50804800 & -0.32814900 \\
\hline $\mathrm{O}$ & 4.94539200 & -3.68377300 & -1.29438100 \\
\hline $\mathrm{C}$ & -5.64111100 & -0.36127800 & 0.29319700 \\
\hline $\mathrm{C}$ & -6.60139500 & -0.46106300 & -0.67234100 \\
\hline $\mathrm{O}$ & -7.61660200 & -1.27108000 & -0.25615000 \\
\hline $\mathrm{C}$ & -7.30343500 & -1.69272300 & 1.00216300 \\
\hline $\mathrm{C}$ & -6.11042500 & -1.16554500 & 1.39328300 \\
\hline $\mathrm{H}$ & 5.00030600 & 0.13591900 & 0.99467500 \\
\hline $\mathrm{O}$ & -3.86997900 & 3.42452500 & -1.57222800 \\
\hline $\mathrm{C}$ & -3.22053300 & -1.07668200 & -1.46901200 \\
\hline $\mathrm{C}$ & 3.54251400 & -1.63556900 & 2.14872400 \\
\hline $\mathrm{O}$ & 3.50831200 & 2.13973700 & 0.82320100 \\
\hline $\mathrm{C}$ & 3.39614200 & 3.86889100 & 2.46898100 \\
\hline $\mathrm{C}$ & 2.70782300 & 3.23168400 & 1.27325300 \\
\hline $\mathrm{C}$ & 5.43990100 & 1.56503300 & -1.17968000 \\
\hline $\mathrm{C}$ & 3.79100800 & 0.03168000 & -2.28232900 \\
\hline $\mathrm{H}$ & 0.40048900 & 2.05353300 & -0.76885400 \\
\hline $\mathrm{H}$ & 2.78516600 & 2.26664500 & -1.11250500 \\
\hline $\mathrm{H}$ & -2.75394500 & -0.73386700 & 1.97512100 \\
\hline $\mathrm{H}$ & -3.53564300 & -2.05118000 & 1.10196200 \\
\hline $\mathrm{H}$ & -1.43899800 & -2.73492900 & 0.06643800 \\
\hline $\mathrm{H}$ & -1.11240700 & -2.51904000 & 1.76870300 \\
\hline $\mathrm{H}$ & -1.53252000 & 2.76843000 & -0.68958500 \\
\hline $\mathrm{H}$ & -4.21812200 & 0.92974200 & 1.20677300 \\
\hline $\mathrm{H}$ & 6.24432700 & -1.81688600 & 0.46506300 \\
\hline $\mathrm{H}$ & 6.16561500 & -1.24597500 & -1.19264100 \\
\hline $\mathrm{H}$ & -6.71500000 & -0.01092900 & -1.64489400 \\
\hline $\mathrm{H}$ & -8.02043100 & -2.34423300 & 1.4763440 \\
\hline $\mathrm{H}$ & -5.63063900 & -1.31614800 & 2.34993900 \\
\hline $\mathrm{H}$ & -3.94311000 & -1.89262100 & -1.37437000 \\
\hline $\mathrm{H}$ & -3.56508100 & -0.40385700 & -2.25902900 \\
\hline $\mathrm{H}$ & -2.26370600 & -1.49946000 & -1.78705400 \\
\hline $\mathrm{H}$ & 3.46093200 & -0.73932000 & 2.77182700 \\
\hline $\mathrm{H}$ & 2.76102600 & -2.34198600 & 2.43548300 \\
\hline $\mathrm{H}$ & 4.52039900 & -2.09428500 & 2.32661100 \\
\hline $\mathrm{H}$ & 2.80448200 & 4.71406700 & 2.83602300 \\
\hline $\mathrm{H}$ & 3.50547500 & 3.14580300 & 3.28303200 \\
\hline $\mathrm{H}$ & 4.39057600 & 4.23460700 & 2.19597700 \\
\hline $\mathrm{H}$ & 2.59286400 & 3.96209400 & 0.45600900 \\
\hline $\mathrm{H}$ & 1.70323200 & 2.88073400 & 1.55154600 \\
\hline $\mathrm{H}$ & 5.18693100 & 2.34914000 & -1.90288500 \\
\hline $\mathrm{H}$ & 6.28052100 & 1.00003100 & -1.59510800 \\
\hline $\mathrm{H}$ & 5.76857800 & 2.04844000 & -0.25693600 \\
\hline $\mathrm{H}$ & 2.95939500 & -0.67068300 & -2.18743900 \\
\hline $\mathrm{H}$ & 3.48193100 & 0.82299200 & -2.97481300 \\
\hline $\mathrm{H}$ & 4.62199500 & -0.50011800 & -2.7547530 \\
\hline
\end{tabular}




$\begin{array}{lc}\text { Zero-point correction }= & 0.545360 \text { (Hartree/Particle) } \\ \text { Thermal correction to Energy= } & 0.576719 \\ \text { Thermal correction to Enthalpy= } & 0.577663 \\ \text { Thermal correction to Gibbs Free Energy= } & 0.482768 \\ \text { Sum of electronic and zero-point Energies }= & -1591.290908 \\ \text { Sum of electronic and thermal Energies }= & -1591.259550 \\ \text { Sum of electronic and thermal Enthalpies }= & -1591.258605 \\ \text { Sum of electronic and thermal Free Energies }= & -1591.353501\end{array}$

01

\begin{tabular}{|c|c|c|c|}
\hline $\mathrm{N}$ & 0.95208300 & -1.52262100 & 0.70384700 \\
\hline $\mathrm{C}$ & 1.99850800 & -0.72684000 & 0.47663900 \\
\hline $\mathrm{C}$ & 1.85502700 & 0.60663600 & 0.05505700 \\
\hline $\mathrm{C}$ & 0.56459500 & 1.07233900 & -0.16714900 \\
\hline $\mathrm{C}$ & -0.55397900 & 0.25158900 & 0.06231300 \\
\hline $\mathrm{C}$ & -0.29093500 & -1.06357900 & 0.50788300 \\
\hline $\mathrm{C}$ & 3.37266000 & -1.35433400 & 0.68560900 \\
\hline $\mathrm{C}$ & 4.58803900 & -0.47608800 & 0.24244600 \\
\hline $\mathrm{C}$ & 4.24759900 & 0.67459500 & -0.75353200 \\
\hline $\mathrm{C}$ & 3.07669100 & 1.47996600 & -0.13817000 \\
\hline $\mathrm{C}$ & -1.93942000 & 0.71858500 & -0.16259400 \\
\hline $\mathrm{C}$ & -3.06359900 & -0.31841200 & -0.15058900 \\
\hline $\mathrm{C}$ & -2.76536000 & -1.36882800 & 0.94448400 \\
\hline $\mathrm{C}$ & -1.40684600 & -2.04613200 & 0.75983700 \\
\hline $\mathrm{C}$ & -2.24492900 & 2.01220200 & -0.41295500 \\
\hline $\mathrm{C}$ & -3.59277800 & 2.45211400 & -0.80946700 \\
\hline $\mathrm{O}$ & -4.60941800 & 1.56087200 & -0.64281200 \\
\hline $\mathrm{C}$ & -4.37200700 & 0.42991900 & 0.23424700 \\
\hline $\mathrm{O}$ & 3.42650700 & -2.53424100 & -0.18576500 \\
\hline $\mathrm{C}$ & 4.65799400 & -2.68883600 & -0.74001100 \\
\hline $\mathrm{C}$ & 5.55242100 & -1.53727700 & -0.31167300 \\
\hline $\mathrm{O}$ & 4.93431200 & -3.62538100 & -1.44975200 \\
\hline $\mathrm{C}$ & -5.63201900 & -0.38283300 & 0.22276700 \\
\hline $\mathrm{C}$ & -6.26667200 & -0.89650000 & 1.31730500 \\
\hline $\mathrm{O}$ & -7.38593600 & -1.58044100 & 0.94988300 \\
\hline $\mathrm{C}$ & -7.47715300 & -1.48823900 & -0.41070300 \\
\hline $\mathrm{C}$ & -6.43566900 & -0.76934200 & -0.90933700 \\
\hline $\mathrm{H}$ & 5.00141100 & 0.00104500 & 1.13348500 \\
\hline $\mathrm{O}$ & -3.81924100 & 3.53335300 & -1.31546500 \\
\hline $\mathrm{C}$ & -3.16100200 & -0.97816300 & -1.54642700 \\
\hline $\mathrm{C}$ & 3.51690500 & -1.83842800 & 2.13324000 \\
\hline $\mathrm{O}$ & 3.52363200 & 2.00034900 & 1.12452200 \\
\hline $\mathrm{C}$ & 3.02623200 & 4.42134000 & 1.05742400 \\
\hline $\mathrm{C}$ & 2.75054000 & 3.06081900 & 1.69442700 \\
\hline $\mathrm{C}$ & 5.47291400 & 1.59646000 & -0.91210200 \\
\hline $\mathrm{C}$ & 3.82499900 & 0.17145600 & -2.15220500 \\
\hline $\mathrm{H}$ & 0.43175700 & 2.07930100 & -0.55153100 \\
\hline $\mathrm{H}$ & 2.82630900 & 2.31061200 & -0.81412900 \\
\hline $\mathrm{H}$ & -2.78740900 & -0.87245300 & 1.92458500 \\
\hline $\mathrm{H}$ & -3.56059800 & -2.12037300 & 0.95210500 \\
\hline $\mathrm{H}$ & -1.43779400 & -2.75097000 & -0.08200100 \\
\hline $\mathrm{H}$ & -1.14776200 & -2.64693200 & 1.63713800 \\
\hline
\end{tabular}




$\begin{array}{lrrr}\mathrm{H} & -1.50332800 & 2.80145900 & -0.43993600 \\ \mathrm{H} & -4.22431000 & 0.82667900 & 1.24813500 \\ \mathrm{H} & 6.23420800 & -1.91340900 & 0.45968000 \\ \mathrm{H} & 6.17285200 & -1.21362200 & -1.14864000 \\ \mathrm{H} & -6.06123700 & -0.85882400 & 2.37628900 \\ \mathrm{H} & -8.33115500 & -1.97114600 & -0.85886300 \\ \mathrm{H} & -6.26726500 & -0.51298100 & -1.94454400 \\ \mathrm{H} & -3.87013200 & -1.81093500 & -1.52976700 \\ \mathrm{H} & -3.49307200 & -0.25442800 & -2.29588400 \\ \mathrm{H} & -2.19004900 & -1.36432300 & -1.86814800 \\ \mathrm{H} & 3.43648800 & -0.99203300 & 2.82263500 \\ \mathrm{H} & 2.72717100 & -2.55815600 & 2.35758300 \\ \mathrm{H} & 4.48944200 & -2.31785600 & 2.28386000 \\ \mathrm{H} & 2.45778100 & 5.19757100 & 1.58206600 \\ \mathrm{H} & 4.08988300 & 4.66936200 & 1.12440400 \\ \mathrm{H} & 2.73224000 & 4.45468100 & 0.00323300 \\ \mathrm{H} & 1.67938100 & 2.81822100 & 1.65295600 \\ \mathrm{H} & 3.03804500 & 3.07678200 & 2.75019500 \\ \mathrm{H} & 5.23550600 & 2.43702800 & -1.57457500 \\ \mathrm{H} & 6.31437000 & 1.05834900 & -1.36027400 \\ \mathrm{H} & 5.79344800 & 2.00262700 & 0.04986500 \\ \mathrm{H} & 2.99055900 & -0.53332000 & -2.12267900 \\ \mathrm{H} & 3.52457200 & 1.01797300 & -2.78033600 \\ \mathrm{H} & 4.65871500 & -0.32281200 & -2.65930400\end{array}$

\section{Revised structure of hainangranatumin G (17-7)-conformer 4}

Zero-point correction=

Thermal correction to Energy=

Thermal correction to Enthalpy=

Thermal correction to Gibbs Free Energy=

Sum of electronic and zero-point Energies $=$

Sum of electronic and thermal Energies=

Sum of electronic and thermal Enthalpies=

Sum of electronic and thermal Free Energies=

01

$\begin{array}{lrrr}\mathrm{N} & 0.96162300 & -1.53308000 & 0.68772900 \\ \mathrm{C} & 2.00515300 & -0.73173600 & 0.46690200 \\ \mathrm{C} & 1.85652800 & 0.60628000 & 0.06176000 \\ \mathrm{C} & 0.56413400 & 1.07129800 & -0.14991500 \\ \mathrm{C} & -0.55161200 & 0.24486000 & 0.07348100 \\ \mathrm{C} & -0.28311900 & -1.07475700 & 0.50136900 \\ \mathrm{C} & 3.38173100 & -1.35765600 & 0.66424100 \\ \mathrm{C} & 4.59314200 & -0.47118600 & 0.22649500 \\ \mathrm{C} & 4.24582300 & 0.68992600 & -0.75488200 \\ \mathrm{C} & 3.07518100 & 1.48503600 & -0.12579600 \\ \mathrm{C} & -1.93910500 & 0.71076100 & -0.14075900 \\ \mathrm{C} & -3.06414500 & -0.32606600 & -0.13140700 \\ \mathrm{C} & -2.75520300 & -1.39202300 & 0.94589200 \\ \mathrm{C} & -1.39565000 & -2.06276100 & 0.74339300\end{array}$

0.545324 (Hartree/Particle)

0.576698

0.577642

0.482805

$-1591.290819$

$-1591.259446$

$-1591.258502$

$-1591.353339$ 


\begin{tabular}{|c|c|c|c|}
\hline $\mathrm{C}$ & -2.24533700 & 2.00650000 & -0.37930400 \\
\hline $\mathrm{C}$ & -3.59378900 & 2.44784700 & -0.76823000 \\
\hline $\mathrm{O}$ & -4.60843500 & 1.55378400 & -0.60444300 \\
\hline $\mathrm{C}$ & -4.37249000 & 0.42002500 & 0.26561000 \\
\hline $\mathrm{O}$ & 3.43576400 & -2.52791300 & -0.21987700 \\
\hline $\mathrm{C}$ & 4.66560000 & -2.67292200 & -0.78042400 \\
\hline $\mathrm{C}$ & 5.55829300 & -1.52336300 & -0.34323400 \\
\hline $\mathrm{O}$ & 4.94196100 & -3.60109300 & -1.50103200 \\
\hline $\mathrm{C}$ & -5.63302200 & -0.39465400 & 0.23779100 \\
\hline $\mathrm{C}$ & -6.57592100 & -0.40873600 & -0.74968200 \\
\hline $\mathrm{O}$ & -7.59965200 & -1.24827100 & -0.42236700 \\
\hline $\mathrm{C}$ & -7.30987400 & -1.77665600 & 0.80075200 \\
\hline $\mathrm{C}$ & -6.12328300 & -1.28843000 & 1.25665500 \\
\hline $\mathrm{H}$ & 5.00863200 & -0.00314000 & 1.12135900 \\
\hline $\mathrm{O}$ & -3.82502300 & 3.53132000 & -1.26705100 \\
\hline $\mathrm{C}$ & -3.18270400 & -0.96697900 & -1.53375800 \\
\hline $\mathrm{C}$ & 3.53233600 & -1.85684500 & 2.10611200 \\
\hline $\mathrm{O}$ & 3.52543000 & 1.99188000 & 1.14120400 \\
\hline $\mathrm{C}$ & 3.02176900 & 4.41227200 & 1.10340400 \\
\hline $\mathrm{C}$ & 2.75192000 & 3.04392400 & 1.72599400 \\
\hline $\mathrm{C}$ & 5.46803400 & 1.61689000 & -0.90752100 \\
\hline $\mathrm{C}$ & 3.81919500 & 0.20170000 & -2.15762400 \\
\hline $\mathrm{H}$ & 0.42777100 & 2.08257000 & -0.52137800 \\
\hline $\mathrm{H}$ & 2.82012700 & 2.32279700 & -0.79111800 \\
\hline $\mathrm{H}$ & -2.77455700 & -0.91244300 & 1.93443500 \\
\hline $\mathrm{H}$ & -3.54288800 & -2.15092100 & 0.94211100 \\
\hline $\mathrm{H}$ & -1.43027700 & -2.75395900 & -0.10949200 \\
\hline $\mathrm{H}$ & -1.13114300 & -2.67708900 & 1.60963800 \\
\hline $\mathrm{H}$ & -1.50408200 & 2.79601400 & -0.40385500 \\
\hline $\mathrm{H}$ & -4.22530200 & 0.81056400 & 1.28299400 \\
\hline $\mathrm{H}$ & 6.24448800 & -1.90584200 & 0.42105800 \\
\hline $\mathrm{H}$ & 6.17417800 & -1.18868600 & -1.17922500 \\
\hline $\mathrm{H}$ & -6.67131700 & 0.12312300 & -1.68210000 \\
\hline $\mathrm{H}$ & -8.03627900 & -2.46405600 & 1.20475200 \\
\hline $\mathrm{H}$ & -5.66118200 & -1.52158900 & 2.20542300 \\
\hline $\mathrm{H}$ & -3.90760600 & -1.78619500 & -1.51968100 \\
\hline $\mathrm{H}$ & -3.51306300 & -0.22985700 & -2.27068500 \\
\hline $\mathrm{H}$ & -2.22098400 & -1.36403200 & -1.86961500 \\
\hline $\mathrm{H}$ & 3.45194900 & -1.01814900 & 2.80486000 \\
\hline $\mathrm{H}$ & 2.74547300 & -2.58126300 & 2.32543200 \\
\hline $\mathrm{H}$ & 4.50676100 & -2.33505600 & 2.24817000 \\
\hline $\mathrm{H}$ & 2.45328500 & 5.18102700 & 1.63890500 \\
\hline $\mathrm{H}$ & 4.08501500 & 4.66231500 & 1.16927600 \\
\hline $\mathrm{H}$ & 2.72378900 & 4.45680400 & 0.05074900 \\
\hline $\mathrm{H}$ & 1.68121200 & 2.79909200 & 1.68589200 \\
\hline $\mathrm{H}$ & 3.04344800 & 3.04867800 & 2.78076500 \\
\hline $\mathrm{H}$ & 5.22595100 & 2.46411000 & -1.55974600 \\
\hline $\mathrm{H}$ & 6.30934300 & 1.08613800 & -1.36464800 \\
\hline $\mathrm{H}$ & 5.79090100 & 2.01320400 & 0.05777300 \\
\hline $\mathrm{H}$ & 2.98714700 & -0.50609300 & -2.13306600 \\
\hline $\mathrm{H}$ & 3.51352700 & 1.05445200 & -2.77468900 \\
\hline
\end{tabular}




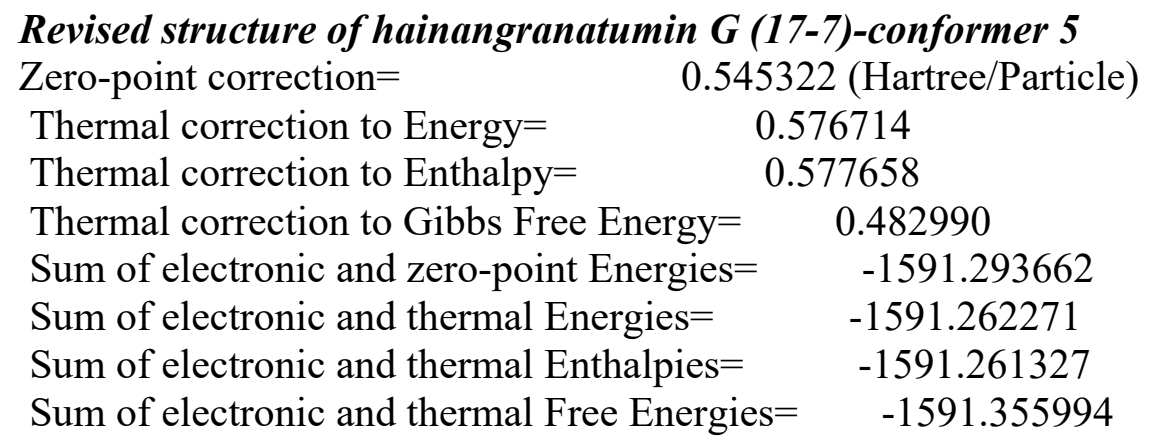
01

$\begin{array}{lrrr}\mathrm{N} & 0.95313100 & -1.43390200 & 0.75144700 \\ \mathrm{C} & 1.99387600 & -0.65900100 & 0.43956800 \\ \mathrm{C} & 1.83996400 & 0.62969600 & -0.09990000 \\ \mathrm{C} & 0.54489900 & 1.07265000 & -0.34128700 \\ \mathrm{C} & -0.56732500 & 0.27346400 & -0.02387100 \\ \mathrm{C} & -0.29364000 & -0.99751500 & 0.53115800 \\ \mathrm{C} & 3.37247700 & -1.25868700 & 0.69452700 \\ \mathrm{C} & 4.57965600 & -0.41849800 & 0.16454300 \\ \mathrm{C} & 4.22633300 & 0.62951500 & -0.93455600 \\ \mathrm{C} & 3.05561300 & 1.48510600 & -0.39235400 \\ \mathrm{C} & -1.95773800 & 0.71717900 & -0.26597700 \\ \mathrm{C} & -3.07890600 & -0.31620100 & -0.14509700 \\ \mathrm{C} & -2.75981100 & -1.26780400 & 1.03135800 \\ \mathrm{C} & -1.40272400 & -1.95673600 & 0.88308000 \\ \mathrm{C} & -2.27068100 & 1.98355100 & -0.62332500 \\ \mathrm{C} & -3.62632600 & 2.38557900 & -1.03356400 \\ \mathrm{O} & -4.63775700 & 1.51128000 & -0.77204100 \\ \mathrm{C} & -4.38234900 & 0.46130200 & 0.19588900 \\ \mathrm{O} & 3.42833400 & -2.51312800 & -0.06484500 \\ \mathrm{C} & 4.65883000 & -2.71258000 & -0.60720600 \\ \mathrm{C} & 5.54843600 & -1.52146100 & -0.29160700 \\ \mathrm{O} & 4.93768300 & -3.70971400 & -1.22767300 \\ \mathrm{C} & -5.64025900 & -0.35060600 & 0.27748300 \\ \mathrm{C} & -6.25568400 & -0.76528300 & 1.42374700 \\ \mathrm{O} & -7.37881000 & -1.48079000 & 1.13720500 \\ \mathrm{C} & -7.49264800 & -1.51011000 & -0.22448000 \\ \mathrm{C} & -6.46119100 & -0.83750300 & -0.80228500 \\ \mathrm{H} & 4.99427200 & 0.14385000 & 1.00404000 \\ \mathrm{O} & -3.86419500 & 3.41812200 & -1.62818300 \\ \mathrm{C} & -3.19794500 & -1.09423300 & -1.47687600 \\ \mathrm{C} & 3.52837800 & -1.60690700 & 2.17969300 \\ \mathrm{O} & 3.50708300 & 2.14857000 & 0.79620000 \\ \mathrm{C} & 3.39202400 & 3.90229500 & 2.41534400 \\ \mathrm{C} & 2.70628400 & 3.24785400 & 1.22748700 \\ \mathrm{C} & 5.44488900 & 1.53871800 & -1.18992100 \\ \mathrm{C} & 3.79666700 & -0.00750200 & -2.27542100 \\ \mathrm{H} & 0.40421600 & 2.04365900 & -0.80688100\end{array}$




$\begin{array}{lrrr}\mathrm{H} & 2.79130400 & 2.24699700 & -1.14385500 \\ \mathrm{H} & -2.76692600 & -0.68878200 & 1.96526500 \\ \mathrm{H} & -3.55270700 & -2.01696300 & 1.11720200 \\ \mathrm{H} & -1.44535500 & -2.73022000 & 0.10437400 \\ \mathrm{H} & -1.12822000 & -2.48081600 & 1.80376500 \\ \mathrm{H} & -1.53161600 & 2.76821600 & -0.73162200 \\ \mathrm{H} & -4.21804700 & 0.94492300 & 1.16868800 \\ \mathrm{H} & 6.23493000 & -1.82014300 & 0.50887000 \\ \mathrm{H} & 6.16415600 & -1.27392700 & -1.15752100 \\ \mathrm{H} & -6.03324700 & -0.63293300 & 2.47164100 \\ \mathrm{H} & -8.35264800 & -2.03195100 & -0.61364900 \\ \mathrm{H} & -6.31034600 & -0.67432500 & -1.85885600 \\ \mathrm{H} & -3.90433700 & -1.92346800 & -1.37651100 \\ \mathrm{H} & -3.54448600 & -0.43836100 & -2.28030500 \\ \mathrm{H} & -2.23140600 & -1.50542200 & -1.78044300 \\ \mathrm{H} & 3.44692400 & -0.70121800 & 2.78901400 \\ \mathrm{H} & 2.74409200 & -2.30692500 & 2.47442100 \\ \mathrm{H} & 4.50448300 & -2.06532000 & 2.36782300 \\ \mathrm{H} & 2.80011300 & 4.75323900 & 2.76835400 \\ \mathrm{H} & 3.49868800 & 3.19117300 & 3.24023900 \\ \mathrm{H} & 4.38745400 & 4.26315400 & 2.13951700 \\ \mathrm{H} & 2.59412600 & 3.96597100 & 0.39903300 \\ \mathrm{H} & 1.70066200 & 2.90200700 & 1.50843900 \\ \mathrm{H} & 5.19639700 & 2.31238600 & -1.92582600 \\ \mathrm{H} & 6.28575200 & 0.96560700 & -1.59358500 \\ \mathrm{H} & 5.77124200 & 2.03530500 & -0.27337300 \\ \mathrm{H} & 2.96298100 & -0.70636700 & -2.17305900 \\ \mathrm{H} & 3.49217500 & 0.77395400 & -2.98101600 \\ \mathrm{H} & 4.62814900 & -0.54839900 & -2.73650800\end{array}$

\section{Revised structure of hainangranatumin G (17-7)-conformer 6}

Zero-point correction=

Thermal correction to Energy=

Thermal correction to Enthalpy=
0.545286 (Hartree/Particle)

$$
0.576689
$$

0.577634

0.483020

$-1591.293573$

$-1591.262169$

$-1591.261225$

$-1591.355838$
Sum of electronic and zero-point Energies=

Sum of electronic and thermal Energies=

Sum of electronic and thermal Enthalpies=

Sum of electronic and thermal Free Energies=
01

$\begin{array}{lrrr}\mathrm{N} & 0.96186800 & -1.44746300 & 0.73111200 \\ \mathrm{C} & 1.99987500 & -0.66533600 & 0.42824800 \\ \mathrm{C} & 1.84115000 & 0.63133600 & -0.09031900 \\ \mathrm{C} & 0.54431800 & 1.07536700 & -0.31974800 \\ \mathrm{C} & -0.56522300 & 0.26874200 & -0.01146500 \\ \mathrm{C} & -0.28643300 & -1.01016100 & 0.52169200 \\ \mathrm{C} & 3.38073000 & -1.26544900 & 0.66962400 \\ \mathrm{C} & 4.58404100 & -0.41456800 & 0.14792000 \\ \mathrm{C} & 4.22418000 & 0.64893700 & -0.93405800\end{array}$




\begin{tabular}{|c|c|c|c|}
\hline $\mathrm{C}$ & 3.05385700 & 1.49373800 & -0.37435500 \\
\hline $\mathrm{C}$ & -1.95750500 & 0.71286400 & -0.24189200 \\
\hline $\mathrm{C}$ & -3.07957800 & -0.32095100 & -0.12692300 \\
\hline $\mathrm{C}$ & -2.75008700 & -1.29356600 & 1.02958800 \\
\hline $\mathrm{C}$ & -1.39232600 & -1.97690500 & 0.86038800 \\
\hline $\mathrm{C}$ & -2.27112800 & 1.98323000 & -0.58441700 \\
\hline $\mathrm{C}$ & -3.62730400 & 2.38837600 & -0.98600100 \\
\hline $\mathrm{O}$ & -4.63676900 & 1.51026500 & -0.72928300 \\
\hline $\mathrm{C}$ & -4.38264900 & 0.45433100 & 0.22898600 \\
\hline $\mathrm{O}$ & 3.43697200 & -2.50852600 & -0.10818600 \\
\hline $\mathrm{C}$ & 4.66604400 & -2.69691500 & -0.65775200 \\
\hline $\mathrm{C}$ & 5.55379700 & -1.50821800 & -0.32811300 \\
\hline $\mathrm{O}$ & 4.94517100 & -3.68425100 & -1.29360000 \\
\hline $\mathrm{C}$ & -5.64114300 & -0.36143600 & 0.29280400 \\
\hline $\mathrm{C}$ & -6.60098700 & -0.46169900 & -0.67310600 \\
\hline $\mathrm{O}$ & -7.61633200 & -1.27159200 & -0.25699500 \\
\hline $\mathrm{C}$ & -7.30337900 & -1.69321700 & 1.00138400 \\
\hline $\mathrm{C}$ & -6.11069700 & -1.16558700 & 1.39288600 \\
\hline $\mathrm{H}$ & 5.00033400 & 0.13614600 & 0.99428200 \\
\hline $\mathrm{O}$ & -3.86999600 & 3.42527400 & -1.57080900 \\
\hline $\mathrm{C}$ & -3.22016000 & -1.07636700 & -1.46894700 \\
\hline $\mathrm{C}$ & 3.54257300 & -1.63502100 & 2.14898400 \\
\hline $\mathrm{O}$ & 3.50864400 & 2.14003000 & 0.82239000 \\
\hline $\mathrm{C}$ & 3.39662500 & 3.86931700 & 2.46810200 \\
\hline $\mathrm{C}$ & 2.70781400 & 3.23149600 & 1.27295700 \\
\hline $\mathrm{C}$ & 5.43975300 & 1.56454600 & -1.18061300 \\
\hline $\mathrm{C}$ & 3.79062100 & 0.03100500 & -2.28255600 \\
\hline $\mathrm{H}$ & 0.40045900 & 2.05353500 & -0.76895700 \\
\hline $\mathrm{H}$ & 2.78503000 & 2.26635900 & -1.11316700 \\
\hline $\mathrm{H}$ & -2.75427000 & -0.73391100 & 1.97530400 \\
\hline $\mathrm{H}$ & -3.53566900 & -2.05121600 & 1.10186200 \\
\hline $\mathrm{H}$ & -1.43884500 & -2.73477800 & 0.06675100 \\
\hline $\mathrm{H}$ & -1.11254400 & -2.51883000 & 1.76907300 \\
\hline $\mathrm{H}$ & -1.53244900 & 2.76869500 & -0.68841100 \\
\hline $\mathrm{H}$ & -4.21850400 & 0.92947900 & 1.20702300 \\
\hline $\mathrm{H}$ & 6.24423200 & -1.81682600 & 0.46518100 \\
\hline $\mathrm{H}$ & 6.16549800 & -1.24638500 & -1.19266600 \\
\hline $\mathrm{H}$ & -6.71442100 & -0.01171000 & -1.64574700 \\
\hline $\mathrm{H}$ & -8.02043700 & -2.34478100 & 1.47539500 \\
\hline $\mathrm{H}$ & -5.63118100 & -1.31582700 & 2.34973100 \\
\hline $\mathrm{H}$ & -3.94272000 & -1.89236500 & -1.37467800 \\
\hline $\mathrm{H}$ & -3.56453200 & -0.40345000 & -2.25897700 \\
\hline $\mathrm{H}$ & -2.26322300 & -1.49906300 & -1.78679400 \\
\hline $\mathrm{H}$ & 3.46112000 & -0.73860300 & 2.77187100 \\
\hline $\mathrm{H}$ & 2.76103300 & -2.34127400 & 2.43603800 \\
\hline $\mathrm{H}$ & 4.52041700 & -2.09378500 & 2.32695700 \\
\hline $\mathrm{H}$ & 2.80475100 & 4.71419500 & 2.83550800 \\
\hline $\mathrm{H}$ & 3.50700700 & 3.14641700 & 3.28218400 \\
\hline $\mathrm{H}$ & 4.39062800 & 4.23560300 & 2.19429900 \\
\hline $\mathrm{H}$ & 2.59166700 & 3.96179800 & 0.45575900 \\
\hline $\mathrm{H}$ & 1.70370100 & 2.87992900 & 1.55214500 \\
\hline
\end{tabular}




$\begin{array}{lrrr}\mathrm{H} & 5.18658600 & 2.34865100 & -1.90374400 \\ \mathrm{H} & 6.28014100 & 0.99942500 & -1.59635400 \\ \mathrm{H} & 5.76888400 & 2.04795900 & -0.25802900 \\ \mathrm{H} & 2.95887100 & -0.67116000 & -2.18743100 \\ \mathrm{H} & 3.48168200 & 0.82217900 & -2.97526800 \\ \mathrm{H} & 4.62149600 & -0.50109100 & -2.75484000\end{array}$

\section{Revised structure of hainangranatumin G (17-7)-conformer 7}

Zero-point correction=

Thermal correction to Energy=

Thermal correction to Enthalpy=

Thermal correction to Gibbs Free Energy=

Sum of electronic and zero-point Energies $=$

Sum of electronic and thermal Energies=

Sum of electronic and thermal Enthalpies=

Sum of electronic and thermal Free Energies=
0.545230 (Hartree/Particle)

0.576730

0.577674

0.482112

$-1591.290305$

$-1591.258805$

$-1591.257861$

$-1591.353423$

01

$\begin{array}{lrrr}\mathrm{N} & 0.92780900 & -1.85467500 & 0.40661600 \\ \mathrm{C} & 2.01678600 & -1.08523000 & 0.30378400 \\ \mathrm{C} & 1.93830100 & 0.30064000 & 0.07741600 \\ \mathrm{C} & 0.66748100 & 0.85997700 & -0.01902900 \\ \mathrm{C} & -0.48623200 & 0.06818400 & 0.08189300 \\ \mathrm{C} & -0.28960400 & -1.31789500 & 0.28193300 \\ \mathrm{C} & 3.35125900 & -1.81662200 & 0.46522900 \\ \mathrm{C} & 4.59997200 & -0.88098600 & 0.34152600 \\ \mathrm{C} & 4.37159100 & 0.60358700 & 0.74855000 \\ \mathrm{C} & 3.18382200 & 1.16209800 & -0.07768000 \\ \mathrm{C} & -1.84851400 & 0.63826300 & -0.01831900 \\ \mathrm{C} & -3.02720900 & -0.32445600 & -0.17203600 \\ \mathrm{C} & -2.77119400 & -1.57779500 & 0.69712300 \\ \mathrm{C} & -1.45295600 & -2.27452800 & 0.35656300 \\ \mathrm{C} & -2.08686100 & 1.96941600 & -0.01679100 \\ \mathrm{C} & -3.41472600 & 2.54263300 & -0.29132800 \\ \mathrm{O} & -4.47623200 & 1.68881300 & -0.26479800 \\ \mathrm{C} & -4.28608800 & 0.40345000 & 0.38035600 \\ \mathrm{O} & 3.46340000 & -2.75539600 & -0.65841300 \\ \mathrm{C} & 4.43477700 & -2.41173100 & -1.53908600 \\ \mathrm{C} & 5.09145500 & -1.11669800 & -1.09940600 \\ \mathrm{O} & 4.68333700 & -3.07137000 & -2.51915300 \\ \mathrm{C} & -5.58863800 & -0.32823200 & 0.25210000 \\ \mathrm{C} & -6.23238100 & -1.00312700 & 1.24944700 \\ \mathrm{O} & -7.39301400 & -1.55006600 & 0.79164000 \\ \mathrm{C} & -7.50131800 & -1.20271500 & -0.52579400 \\ \mathrm{C} & -6.43048100 & -0.45738100 & -0.91045400 \\ \mathrm{H} & 5.36161600 & -1.27829300 & 1.02285400 \\ \mathrm{O} & -3.59033200 & 3.70844700 & -0.58564300 \\ \mathrm{C} & -3.18269200 & -0.70213500 & -1.66416900 \\ \mathrm{C} & 3.36032200 & -2.68265400 & 1.72593800 \\ \mathrm{O} & 2.90271900 & 2.51290900 & 0.28634200\end{array}$

SI297 


$\begin{array}{lrrr}\mathrm{C} & 2.68954100 & 4.84588500 & -0.20257800 \\ \mathrm{C} & 3.01463800 & 3.47445300 & -0.76827900 \\ \mathrm{C} & 4.07147200 & 0.72312400 & 2.25806600 \\ \mathrm{C} & 5.64730700 & 1.41681800 & 0.45216200 \\ \mathrm{H} & 0.59029700 & 1.92932700 & -0.17155400 \\ \mathrm{H} & 3.47227400 & 1.14858500 & -1.13919900 \\ \mathrm{H} & -2.75342100 & -1.27682700 & 1.75379600 \\ \mathrm{H} & -3.60541800 & -2.27624700 & 0.58046100 \\ \mathrm{H} & -1.53151100 & -2.79509700 & -0.60760100 \\ \mathrm{H} & -1.21905500 & -3.04937500 & 1.09298100 \\ \mathrm{H} & -1.30314900 & 2.71004800 & 0.08600900 \\ \mathrm{H} & -4.09948600 & 0.59558000 & 1.44589200 \\ \mathrm{H} & 6.17599100 & -1.20470500 & -1.19024800 \\ \mathrm{H} & 4.77888200 & -0.33995400 & -1.80600500 \\ \mathrm{H} & -6.00786400 & -1.17271900 & 2.29151500 \\ \mathrm{H} & -8.38756500 & -1.55041900 & -1.03279300 \\ \mathrm{H} & -6.26529300 & -0.02247600 & -1.88477300 \\ \mathrm{H} & -3.93493700 & -1.48693500 & -1.78653500 \\ \mathrm{H} & -3.48763700 & 0.16613800 & -2.25480400 \\ \mathrm{H} & -2.23900200 & -1.06761800 & -2.07808900 \\ \mathrm{H} & 3.29428200 & -2.06396700 & 2.62497700 \\ \mathrm{H} & 2.51026800 & -3.36630900 & 1.70710900 \\ \mathrm{H} & 4.28774900 & -3.26157600 & 1.76619100 \\ \mathrm{H} & 2.76702000 & 5.60356500 & -0.98912700 \\ \mathrm{H} & 1.67292600 & 4.87174500 & 0.20111200 \\ \mathrm{H} & 3.38459500 & 5.10776000 & 0.60089700 \\ \mathrm{H} & 4.03420700 & 3.45931100 & -1.18112800 \\ \mathrm{H} & 2.32219500 & 3.21747800 & -1.58508600 \\ \mathrm{H} & 3.96210700 & 1.77516900 & 2.53328700 \\ \mathrm{H} & 4.89446400 & 0.29810200 & 2.84326400 \\ \mathrm{H} & 3.15021500 & 0.21161800 & 2.54830400 \\ \mathrm{H} & 5.90343900 & 1.41902100 & -0.61243000 \\ \mathrm{H} & 5.51811600 & 2.45465100 & 0.77156800 \\ \mathrm{H} & 6.50103300 & 1.00239500 & 1.00022500\end{array}$

\section{Revised structure of hainangranatumin 6 (17-7)-conformer 8}

Zero-point correction=

Thermal correction to Energy=

Thermal correction to Enthalpy=

Thermal correction to Gibbs Free Energy=

Sum of electronic and zero-point Energies $=$

Sum of electronic and thermal Energies=

Sum of electronic and thermal Enthalpies=

Sum of electronic and thermal Free Energies=
0.545190 (Hartree/Particle)

0.576707

0.577651

0.482108

$-1591.290176$

$-1591.258659$

$-1591.257715$

$-1591.353258$ 01

$\begin{array}{lrrr}\mathrm{N} & 0.93866100 & -1.86038800 & 0.39143300 \\ \mathrm{C} & 2.02449900 & -1.08591100 & 0.29339900 \\ \mathrm{C} & 1.94009700 & 0.30148400 & 0.07866400 \\ \mathrm{C} & 0.66700600 & 0.85684900 & -0.00974200\end{array}$

SI298 


\begin{tabular}{|c|c|c|c|}
\hline $\mathrm{C}$ & -0.48362900 & 0.05984600 & 0.08673200 \\
\hline $\mathrm{C}$ & -0.28085400 & -1.32689500 & 0.27355700 \\
\hline $\mathrm{C}$ & 3.36208800 & -1.81319400 & 0.44746300 \\
\hline $\mathrm{C}$ & 4.60688300 & -0.87177100 & 0.32847000 \\
\hline $\mathrm{C}$ & 4.37360700 & 0.60883800 & 0.74700400 \\
\hline $\mathrm{C}$ & 3.18200100 & 1.16883100 & -0.07266200 \\
\hline $\mathrm{C}$ & -1.84839100 & 0.62547700 & -0.00495900 \\
\hline $\mathrm{C}$ & -3.02757100 & -0.33797800 & -0.15595700 \\
\hline $\mathrm{C}$ & -2.75997500 & -1.60047600 & 0.69675200 \\
\hline $\mathrm{C}$ & -1.44053400 & -2.28759500 & 0.34059700 \\
\hline $\mathrm{C}$ & -2.08818900 & 1.95641600 & 0.00283500 \\
\hline $\mathrm{C}$ & -3.41721300 & 2.52740600 & -0.26511700 \\
\hline $\mathrm{O}$ & -4.47624600 & 1.67054100 & -0.23646300 \\
\hline $\mathrm{C}$ & -4.28582600 & 0.38697000 & 0.40697000 \\
\hline $\mathrm{O}$ & 3.47631600 & -2.74365800 & -0.68276800 \\
\hline $\mathrm{C}$ & 4.44500500 & -2.38990000 & -1.56249000 \\
\hline $\mathrm{C}$ & 5.09644100 & -1.09486400 & -1.11512900 \\
\hline $\mathrm{O}$ & 4.69516000 & -3.04202700 & -2.54713100 \\
\hline $\mathrm{C}$ & -5.58903900 & -0.34506100 & 0.26817500 \\
\hline $\mathrm{C}$ & -6.55073700 & -0.13106800 & -0.67717100 \\
\hline $\mathrm{O}$ & -7.61188300 & -0.96453900 & -0.47821800 \\
\hline $\mathrm{C}$ & -7.32669000 & -1.72222800 & 0.61898000 \\
\hline $\mathrm{C}$ & -6.10659300 & -1.38534000 & 1.12099300 \\
\hline $\mathrm{H}$ & 5.37140200 & -1.27123000 & 1.00530900 \\
\hline $\mathrm{O}$ & -3.59861700 & 3.69280300 & -0.55720900 \\
\hline $\mathrm{C}$ & -3.20553000 & -0.70066900 & -1.64871000 \\
\hline $\mathrm{C}$ & 3.37643500 & -2.68794800 & 1.70212200 \\
\hline $\mathrm{O}$ & 2.89655700 & 2.51589800 & 0.30155000 \\
\hline $\mathrm{C}$ & 2.67384800 & 4.85151200 & -0.17038600 \\
\hline $\mathrm{C}$ & 3.00281000 & 3.48533900 & -0.74646700 \\
\hline $\mathrm{C}$ & 4.07609300 & 0.71608300 & 2.25796800 \\
\hline $\mathrm{C}$ & 5.64556600 & 1.42917900 & 0.45409200 \\
\hline $\mathrm{H}$ & 0.58609000 & 1.92723300 & -0.15236900 \\
\hline $\mathrm{H}$ & 3.46820400 & 1.16394100 & -1.13486200 \\
\hline $\mathrm{H}$ & -2.73911700 & -1.31397100 & 1.75745200 \\
\hline $\mathrm{H}$ & -3.58690000 & -2.30532400 & 0.57079800 \\
\hline $\mathrm{H}$ & -1.52273800 & -2.79496700 & -0.63022800 \\
\hline $\mathrm{H}$ & -1.20100800 & -3.07174500 & 1.06526200 \\
\hline $\mathrm{H}$ & -1.30525500 & 2.69794800 & 0.10383200 \\
\hline $\mathrm{H}$ & -4.09809600 & 0.57739100 & 1.47358600 \\
\hline $\mathrm{H}$ & 6.18118200 & -1.17690500 & -1.20894700 \\
\hline $\mathrm{H}$ & 4.77841400 & -0.31470200 & -1.81551300 \\
\hline $\mathrm{H}$ & -6.63577500 & 0.56698400 & -1.49378700 \\
\hline $\mathrm{H}$ & -8.08107300 & -2.43519500 & 0.91222700 \\
\hline $\mathrm{H}$ & -5.63882600 & -1.81124300 & 1.99726400 \\
\hline $\mathrm{H}$ & -3.97289600 & -1.47154300 & -1.76637700 \\
\hline $\mathrm{H}$ & -3.50903400 & 0.17590900 & -2.22752400 \\
\hline $\mathrm{H}$ & -2.27248800 & -1.07523300 & -2.07834200 \\
\hline $\mathrm{H}$ & 3.30928800 & -2.07585400 & 2.60557800 \\
\hline $\mathrm{H}$ & 2.52908100 & -3.37485400 & 1.67971500 \\
\hline $\mathrm{H}$ & 4.30619400 & -3.26346700 & 1.73695900 \\
\hline
\end{tabular}




$\begin{array}{lrrr}\mathrm{H} & 2.74693100 & 5.61501800 & -0.95170200 \\ \mathrm{H} & 1.65797400 & 4.87078700 & 0.23553800 \\ \mathrm{H} & 3.36958000 & 5.11025700 & 0.63351700 \\ \mathrm{H} & 4.02158700 & 3.47685800 & -1.16142700 \\ \mathrm{H} & 2.30965400 & 3.23158500 & -1.56366600 \\ \mathrm{H} & 3.96336200 & 1.76565200 & 2.54117500 \\ \mathrm{H} & 4.90183300 & 0.28984600 & 2.83838900 \\ \mathrm{H} & 3.15732500 & 0.19901900 & 2.54626400 \\ \mathrm{H} & 5.89945000 & 1.44038300 & -0.61097700 \\ \mathrm{H} & 5.51305900 & 2.46407100 & 0.78158200 \\ \mathrm{H} & 6.50202500 & 1.01393400 & 0.99724600\end{array}$

Revised structure of hainangranatumin G (17-7)-conformer 9

Zero-point correction $=$

Thermal correction to Energy=

Thermal correction to Enthalpy=
0.545198 (Hartree/Particle)

0.576605

0.577549

$-1591.288894$

$-1591.257487$

$-1591.256542$

$-1591.351849$

01

$\begin{array}{lrrr}\mathrm{N} & 0.96192800 & -1.51546600 & 0.70850800 \\ \mathrm{C} & 2.00604800 & -0.71729600 & 0.47212300 \\ \mathrm{C} & 1.85803100 & 0.61131600 & 0.04212600 \\ \mathrm{C} & 0.56543600 & 1.07190400 & -0.17742200 \\ \mathrm{C} & -0.54887600 & 0.24854800 & 0.05331100 \\ \mathrm{C} & -0.28143500 & -1.06414100 & 0.50710500 \\ \mathrm{C} & 3.38075300 & -1.33568700 & 0.69664400 \\ \mathrm{C} & 4.59243000 & -0.45372000 & 0.25379600 \\ \mathrm{C} & 4.25241700 & 0.67657000 & -0.76422400 \\ \mathrm{C} & 3.07393400 & 1.49008100 & -0.16501800 \\ \mathrm{C} & -1.93643800 & 0.70838800 & -0.17612600 \\ \mathrm{C} & -3.05715700 & -0.33240400 & -0.15434800 \\ \mathrm{C} & -2.75422500 & -1.37386400 & 0.94783400 \\ \mathrm{C} & -1.39434000 & -2.04873000 & 0.76482200 \\ \mathrm{C} & -2.24728000 & 1.99810200 & -0.43934300 \\ \mathrm{C} & -3.59703900 & 2.42900000 & -0.83888000 \\ \mathrm{O} & -4.61064300 & 1.53648900 & -0.66076100 \\ \mathrm{C} & -4.36734400 & 0.41474300 & 0.22646900 \\ \mathrm{O} & 3.45166400 & -2.52485200 & -0.16108000 \\ \mathrm{C} & 4.69110400 & -2.67873300 & -0.69631900 \\ \mathrm{C} & 5.57243000 & -1.51522400 & -0.27163600 \\ \mathrm{O} & 4.98383100 & -3.62198600 & -1.39054100 \\ \mathrm{C} & -5.62452200 & -0.40249400 & 0.22540800 \\ \mathrm{C} & -6.25528900 & -0.90735400 & 1.32625300 \\ \mathrm{O} & -7.37276500 & -1.59908600 & 0.96790400 \\ \mathrm{C} & -7.46680900 & -1.52097200 & -0.39337600 \\ \mathrm{C} & -6.42887500 & -0.80335700 & -0.90119200 \\ & & & \mathrm{~S} 1300 \\ & & & \end{array}$




$\begin{array}{lrrr}\mathrm{H} & 4.99004700 & 0.04326000 & 1.14169000 \\ \mathrm{O} & -3.82798600 & 3.50380200 & -1.35662600 \\ \mathrm{C} & -3.15455800 & -1.00289600 & -1.54512600 \\ \mathrm{C} & 3.51663400 & -1.80163500 & 2.15115100 \\ \mathrm{O} & 3.45873400 & 2.04834200 & 1.10419000 \\ \mathrm{C} & 2.12822900 & 4.09570900 & 1.50648700 \\ \mathrm{C} & 3.49014300 & 3.47468600 & 1.20909800 \\ \mathrm{C} & 5.47720400 & 1.59719900 & -0.92908600 \\ \mathrm{C} & 3.84126600 & 0.14901300 & -2.15731400 \\ \mathrm{H} & 0.42736700 & 2.08069900 & -0.55376600 \\ \mathrm{H} & 2.81709800 & 2.30423900 & -0.85722800 \\ \mathrm{H} & -2.77541900 & -0.87044700 & 1.92434100 \\ \mathrm{H} & -3.54750100 & -2.12739100 & 0.96247000 \\ \mathrm{H} & -1.42506200 & -2.75772200 & -0.07352600 \\ \mathrm{H} & -1.13248100 & -2.64435100 & 1.64479000 \\ \mathrm{H} & -1.50895000 & 2.78995300 & -0.47469200 \\ \mathrm{H} & -4.21879600 & 0.82147400 & 1.23625400 \\ \mathrm{H} & 6.24631000 & -1.87574100 & 0.51393000 \\ \mathrm{H} & 6.20161600 & -1.19970100 & -1.10521500 \\ \mathrm{H} & -6.04789400 & -0.85833100 & 2.38438800 \\ \mathrm{H} & -8.31985600 & -2.01150400 & -0.83503200 \\ \mathrm{H} & -6.26331600 & -0.55688400 & -1.93925500 \\ \mathrm{H} & -3.86001600 & -1.83862400 & -1.52088100 \\ \mathrm{H} & -3.49125500 & -0.28615800 & -2.29922500 \\ \mathrm{H} & -2.18258000 & -1.38722400 & -1.86594100 \\ \mathrm{H} & 3.42209900 & -0.94772500 & 2.82938300 \\ \mathrm{H} & 2.73067000 & -2.52501200 & 2.37674500 \\ \mathrm{H} & 4.49160400 & -2.27136400 & 2.31626000 \\ \mathrm{H} & 2.23859800 & 5.17352000 & 1.67234400 \\ \mathrm{H} & 1.42719400 & 3.95896800 & 0.67700700 \\ \mathrm{H} & 1.68979200 & 3.65022800 & 2.40458300 \\ \mathrm{H} & 4.18250200 & 3.68146300 & 2.03194300 \\ \mathrm{H} & 3.92305700 & 3.90957200 & 0.29678600 \\ \mathrm{H} & 5.25143600 & 2.42252100 & -1.61456800 \\ \mathrm{H} & 6.32687800 & 1.05195200 & -1.35197100 \\ \mathrm{H} & 5.79018300 & 2.02113500 & 0.02895000 \\ \mathrm{H} & 3.00827800 & -0.55694600 & -2.12072200 \\ & 4.54207100 & 0.98407700 & -2.80153600 \\ & & & \end{array}$

\section{Revised structure of hainangranatumin G (17-7)-conformer 10}

Zero-point correction=

Thermal correction to Energy=

Thermal correction to Enthalpy=

Thermal correction to Gibbs Free Energy=

Sum of electronic and zero-point Energies $=$

Sum of electronic and thermal Energies=

Sum of electronic and thermal Enthalpies=

Sum of electronic and thermal Free Energies=
0.545158 (Hartree/Particle)

0.576582

0.577526

0.482266

$-1591.288811$

$-1591.257388$

$-1591.256444$

$-1591.351703$

SI301 
01

$\mathrm{N}$

C

$0.97117300-1.52624200$

0.69233500

$2.01244800-0.72249500$

0.46236900

$\mathrm{C}$

$1.85941900 \quad 0.61084600$

0.04904600

C

$0.56491200 \quad 1.07098300$

$-0.15962800$

$\mathrm{C}$

$\begin{array}{ll}-0.54664500 & 0.24201500\end{array}$

0.06488200

$-0.27386900-1.07535000$

0.50064000

$3.38950600-1.33967400$

0.67528900

$4.59728700-0.44952500$

0.23811500

4.25049100

0.69153100

$-0.76548700$

C

3.07228100

1.49510700

$-0.15245000$

$-1.93621900$

0.70104600

$-0.15376700$

$-3.05784500-0.33954500$

$-0.13508900$

$-2.74430000 \quad-1.39694500$

0.94916300

$-1.38349000-2.06541300$

0.74805300

$-2.24766700$

1.99311500

$-0.40473100$

$-3.59796700$

2.42578800

$-0.79657800$

$-4.60961700$

1.53029400

$-0.62194100$

$-4.36797300$

0.40533800

0.25796600

$3.46066100-2.51912200$

$-0.19548400$

$\mathrm{O}$

$4.69860200-2.66368600$

$-0.73687600$

$5.57817700-1.50230800$

$-0.30291500$

$\begin{array}{llll}4.99145200 & -3.59865000 & -1.44214400\end{array}$

$\begin{array}{llll}-5.62567400 & -0.41402700 & 0.24003000\end{array}$

$\mathrm{C}$

$-6.57008400-0$.

$-0.44121400$

$-0.74570100$

$\begin{array}{llll}-7.59039100 & -1.28107300 & -0.40843700\end{array}$

$\mathrm{O}$

$-7.29661400-1.79652400$

0.81928000

$-6.11099100-1.29969300$

1.26830900

$\begin{array}{lll}4.99686900 & 0.03833000 & 1.13019500\end{array}$

$\begin{array}{llll}-3.83363500 & 3.50316900 & -1.30657200\end{array}$

$\mathrm{O}$

$-3.17633800 \quad-0.99097100 \quad-1.53265100$

C

$3.53164100-1.82103000$

2.12421600

$3.46010300 \quad 2.03978400$

1.12171300

$2.12916100 \quad 4.08145000$

1.55032900

$3.49070700 \quad 3.46498800$

1.24198900

5.47235000

1.61706200

$-0.92455800$

3.83522600

0.17894000

$-2.16296100$

0.42343700

2.08412800

$-0.52261500$

$\begin{array}{llll}2.81078700 & 2.31640400 & -0.83436700\end{array}$

$\mathrm{H}$

$-2.76265800-0.91047400$

1.93433600

$-3.53009800-2.15781600$

0.95227200

$\begin{array}{lll}-1.41800400 & -2.76047600 & -0.10168600\end{array}$

$\begin{array}{lll}-1.11630300 & -2.67497100 & 1.61680000\end{array}$

$\begin{array}{lll}-1.50958800 & 2.78517700 & -0.43723000\end{array}$

$\begin{array}{lll}-4.22015600 & 0.80552200 & 1.27147000\end{array}$

$\mathrm{H}$

$6.25623300-1.86949700$

0.47594000

$6.20311200-1.17577200-1.13545100$

$\begin{array}{llll}-6.66893600 & 0.08120000 & -1.68308400\end{array}$

$\begin{array}{lll}-8.01986800 & -2.48255000 & 1.23119700\end{array}$

$\begin{array}{llll}-5.64629200 & -1.52198700 & 2.21841600\end{array}$

$\mathrm{H}$

$\begin{array}{llll}-3.89783200 & -1.81306400 & -1.51147700\end{array}$

SI302 


$\begin{array}{lrrr}\mathrm{H} & -3.51100100 & -0.26049100 & -2.27423500 \\ \mathrm{H} & -2.21358700 & -1.38647600 & -1.86737700 \\ \mathrm{H} & 3.43712200 & -0.97486400 & 2.81208700 \\ \mathrm{H} & 2.74848200 & -2.54905300 & 2.34462500 \\ \mathrm{H} & 4.50845900 & -2.28981700 & 2.28083900 \\ \mathrm{H} & 2.23901200 & 5.15749000 & 1.72763400 \\ \mathrm{H} & 1.42572700 & 3.95316700 & 0.72152000 \\ \mathrm{H} & 1.69386800 & 3.62576500 & 2.44482100 \\ \mathrm{H} & 4.18544900 & 3.66346600 & 2.06486100 \\ \mathrm{H} & 3.92035400 & 3.91015800 & 0.33313900 \\ \mathrm{H} & 5.24187000 & 2.44960200 & -1.59964800 \\ \mathrm{H} & 6.32169500 & 1.07882300 & -1.35696800 \\ \mathrm{H} & 5.78810900 & 2.03076000 & 0.03704200 \\ \mathrm{H} & 3.00446200 & -0.52988100 & -2.13128100 \\ \mathrm{H} & 3.53096700 & 1.02047900 & -2.79629000 \\ \mathrm{H} & 4.67232100 & -0.31365200 & -2.66662000\end{array}$

\section{Revised structure of hainangranatumin G (17-7)-conformer 11}

Zero-point correction $=$

Thermal correction to Energy=

Thermal correction to Enthalpy=

Thermal correction to Gibbs Free Energy=

Sum of electronic and zero-point Energies $=$

Sum of electronic and thermal Energies=

Sum of electronic and thermal Enthalpies=

Sum of electronic and thermal Free Energies=
0.545058 (Hartree/Particle)

0.576464

0.577408

0.482610

$-1591.289552$

$-1591.258146$

$-1591.257202$

$-1591.352000$

01

$\begin{array}{lrrr}\mathrm{N} & -0.91257900 & -1.23924300 & -1.02230700 \\ \mathrm{C} & -1.96795300 & -0.56380700 & -0.54467200 \\ \mathrm{C} & -1.84206600 & 0.62965000 & 0.18374000 \\ \mathrm{C} & -0.55319600 & 1.09585800 & 0.44776000 \\ \mathrm{C} & 0.55640700 & 0.39135500 & -0.02886500 \\ \mathrm{C} & 0.31576800 & -0.78193800 & -0.77513300 \\ \mathrm{C} & -3.33141200 & -1.18315600 & -0.83182000 \\ \mathrm{C} & -4.54680900 & -0.49276300 & -0.13233800 \\ \mathrm{C} & -4.18729900 & 0.39106400 & 1.10063100 \\ \mathrm{C} & -3.07741100 & 1.37223200 & 0.65202400 \\ \mathrm{C} & 1.95293100 & 0.82577300 & 0.14020200 \\ \mathrm{C} & 3.02566400 & -0.24437500 & 0.38020800 \\ \mathrm{C} & 2.58904900 & -1.62015100 & -0.21247500 \\ \mathrm{C} & 1.50956800 & -1.53193300 & -1.30493200 \\ \mathrm{C} & 2.31357300 & 2.12397300 & 0.06210500 \\ \mathrm{C} & 3.70800000 & 2.56381200 & 0.23718800 \\ \mathrm{O} & 4.66943900 & 1.60006100 & 0.16623100 \\ \mathrm{C} & 4.31388500 & 0.27691700 & -0.32475700 \\ \mathrm{O} & -3.29918200 & -2.53924500 & -0.26942200 \\ \mathrm{C} & -4.49404800 & -2.87770600 & 0.28268500 \\ \mathrm{C} & -5.44699100 & -1.69767400 & 0.18568800 \\ \mathrm{O} & -4.70196600 & -3.96886200 & 0.75553800\end{array}$

SI303 


\begin{tabular}{|c|c|c|c|}
\hline $\mathrm{C}$ & 5.55065600 & -0.55820300 & -0.17972300 \\
\hline $\mathrm{C}$ & 6.09513200 & -1.35785100 & -1.14381000 \\
\hline $\mathrm{O}$ & 7.22162200 & -1.97004400 & -0.68480300 \\
\hline $\mathrm{C}$ & 7.41079300 & -1.53932100 & 0.59831700 \\
\hline $\mathrm{C}$ & 6.42391500 & -0.67636100 & 0.96069800 \\
\hline $\mathrm{H}$ & -5.02239700 & 0.17029700 & -0.85833600 \\
\hline $\mathrm{O}$ & 4.03009000 & 3.71391700 & 0.45736100 \\
\hline $\mathrm{C}$ & 3.23321400 & -0.39644900 & 1.90708300 \\
\hline $\mathrm{C}$ & -3.54393700 & -1.31357700 & -2.34484100 \\
\hline $\mathrm{O}$ & -3.60942000 & 2.18911200 & -0.39950500 \\
\hline $\mathrm{C}$ & -3.63895200 & 4.17456300 & -1.72935000 \\
\hline $\mathrm{C}$ & -2.87048100 & 3.37422000 & -0.69086700 \\
\hline $\mathrm{C}$ & -5.42886100 & 1.19290500 & 1.53922000 \\
\hline $\mathrm{C}$ & -3.67281400 & -0.42147400 & 2.31030000 \\
\hline $\mathrm{H}$ & -0.41196900 & 1.99191500 & 1.04781200 \\
\hline $\mathrm{H}$ & -2.80941400 & 2.02114300 & 1.50185200 \\
\hline $\mathrm{H}$ & 3.46960500 & -2.14914800 & -0.58856000 \\
\hline $\mathrm{H}$ & 2.18974600 & -2.23543400 & 0.60100000 \\
\hline $\mathrm{H}$ & 1.19558600 & -2.52856700 & -1.62487000 \\
\hline $\mathrm{H}$ & 1.90132500 & -1.01538300 & -2.19358800 \\
\hline $\mathrm{H}$ & 1.59510400 & 2.91932300 & -0.10475400 \\
\hline $\mathrm{H}$ & 4.08471600 & 0.37277900 & -1.39521800 \\
\hline $\mathrm{H}$ & -6.15461800 & -1.90539800 & -0.62509600 \\
\hline $\mathrm{H}$ & -6.03401000 & -1.61371300 & 1.10141500 \\
\hline $\mathrm{H}$ & 5.81858700 & -1.57931300 & -2.16352400 \\
\hline $\mathrm{H}$ & 8.28296800 & -1.92673100 & 1.10090400 \\
\hline $\mathrm{H}$ & 6.33727400 & -0.15861100 & 1.90408000 \\
\hline $\mathrm{H}$ & 3.91162000 & -1.22857900 & 2.11733700 \\
\hline $\mathrm{H}$ & 3.64629300 & 0.51176300 & 2.35400700 \\
\hline $\mathrm{H}$ & 2.27642300 & -0.61194300 & 2.39283100 \\
\hline $\mathrm{H}$ & -3.52987100 & -0.32441900 & -2.81335600 \\
\hline $\mathrm{H}$ & -2.74618100 & -1.92268800 & -2.7742950 \\
\hline $\mathrm{H}$ & -4.50795100 & -1.78567200 & -2.5596210 \\
\hline $\mathrm{H}$ & -3.09509400 & 5.09326100 & -1.97284700 \\
\hline $\mathrm{H}$ & -3.76465400 & 3.59488900 & -2.64893000 \\
\hline $\mathrm{H}$ & -4.63012900 & 4.44740200 & -1.35473500 \\
\hline $\mathrm{H}$ & -2.73958600 & 3.96039900 & 0.23321200 \\
\hline $\mathrm{H}$ & -1.86980500 & 3.11786700 & -1.06865800 \\
\hline $\mathrm{H}$ & -5.17906300 & 1.85641000 & 2.37545200 \\
\hline $\mathrm{H}$ & -6.22696100 & 0.52622400 & 1.88145300 \\
\hline $\mathrm{H}$ & -5.81568600 & 1.80741400 & $0.7232240 \mathrm{C}$ \\
\hline $\mathrm{H}$ & -2.81768600 & -1.05744600 & $2.0693250 \mathrm{c}$ \\
\hline $\mathrm{H}$ & -3.36821800 & 0.25734900 & 3.11515900 \\
\hline $\mathrm{H}$ & -4.46050700 & -1.06371700 & 2.7146650 \\
\hline
\end{tabular}

Revised structure of hainangranatumin G (17-7)-conformer 12

Zero-point correction=

Thermal correction to Energy=

Thermal correction to Enthalpy=
0.545004 (Hartree/Particle)

0.576422

0.577366 


$\begin{array}{lc}\text { Thermal correction to Gibbs Free Energy= } & 0.482564 \\ \text { Sum of electronic and zero-point Energies }= & -1591.289128 \\ \text { Sum of electronic and thermal Energies }= & -1591.257711 \\ \text { Sum of electronic and thermal Enthalpies }= & -1591.256766 \\ \text { Sum of electronic and thermal Free Energies }= & -1591.351568\end{array}$

01

\begin{tabular}{|c|c|c|c|}
\hline $\mathrm{N}$ & -0.91586700 & -1.25285400 & -0.99982400 \\
\hline $\mathrm{C}$ & -1.97059400 & -0.56847400 & -0.53385400 \\
\hline $\mathrm{C}$ & -1.84295400 & 0.63108500 & 0.18420000 \\
\hline $\mathrm{C}$ & -0.55345300 & 1.09503100 & 0.44855500 \\
\hline $\mathrm{C}$ & 0.55564900 & 0.38226400 & -0.01726900 \\
\hline $\mathrm{C}$ & 0.31329900 & -0.79817300 & -0.75187800 \\
\hline $\mathrm{C}$ & -3.33532000 & -1.18462900 & -0.82179800 \\
\hline $\mathrm{C}$ & -4.55081600 & -0.48371100 & -0.13296800 \\
\hline $\mathrm{C}$ & -4.19267200 & 0.40937900 & 1.09369600 \\
\hline $\mathrm{C}$ & -3.07736100 & 1.38244300 & 0.64084000 \\
\hline $\mathrm{C}$ & 1.95241100 & 0.81742800 & 0.14821600 \\
\hline $\mathrm{C}$ & 3.02951300 & -0.24828900 & 0.39012700 \\
\hline $\mathrm{C}$ & 2.57563000 & -1.63491600 & -0.16055600 \\
\hline $\mathrm{C}$ & 1.50575000 & -1.56333100 & -1.26334800 \\
\hline $\mathrm{C}$ & 2.31231400 & 2.11504600 & 0.05635900 \\
\hline $\mathrm{C}$ & 3.70817500 & 2.55345700 & 0.21871600 \\
\hline $\mathrm{O}$ & 4.66763600 & 1.58766600 & 0.14076600 \\
\hline $\mathrm{C}$ & 4.30716300 & 0.26463900 & -0.34302200 \\
\hline $\mathrm{O}$ & -3.31096600 & -2.53635600 & -0.24874800 \\
\hline $\mathrm{C}$ & -4.50928400 & -2.86552000 & 0.30150400 \\
\hline $\mathrm{C}$ & -5.45694500 & -1.68237000 & 0.19178500 \\
\hline $\mathrm{O}$ & -4.72351100 & -3.95213500 & 0.78192400 \\
\hline $\mathrm{C}$ & 5.54467900 & -0.57403100 & -0.20487200 \\
\hline $\mathrm{C}$ & 6.53183400 & -0.43874100 & 0.72923600 \\
\hline $\mathrm{O}$ & 7.51362900 & -1.36237400 & 0.52592300 \\
\hline $\mathrm{C}$ & 7.15245200 & -2.10018900 & -0.56250700 \\
\hline $\mathrm{C}$ & 5.96150100 & -1.66061200 & -1.05488000 \\
\hline $\mathrm{H}$ & -5.02102700 & 0.17486000 & -0.86650400 \\
\hline $\mathrm{O}$ & 4.03580800 & 3.70293400 & 0.43350800 \\
\hline $\mathrm{C}$ & 3.27594100 & -0.37178000 & 1.91317200 \\
\hline $\mathrm{C}$ & -3.54195300 & -1.32596800 & -2.33465800 \\
\hline $\mathrm{O}$ & -3.60212600 & 2.19172100 & -0.42017000 \\
\hline $\mathrm{C}$ & -3.61927600 & 4.16531400 & -1.76776100 \\
\hline $\mathrm{C}$ & -2.85747800 & 3.37123000 & -0.71959800 \\
\hline $\mathrm{C}$ & -5.43283000 & 1.21968300 & 1.52052800 \\
\hline $\mathrm{C}$ & -3.68595300 & -0.39465800 & 2.31229000 \\
\hline $\mathrm{H}$ & -0.41132700 & 1.99634700 & 1.04043300 \\
\hline $\mathrm{H}$ & -2.81033900 & 2.03797500 & 1.48586600 \\
\hline $\mathrm{H}$ & 3.44650900 & -2.19743600 & -0.50617500 \\
\hline $\mathrm{H}$ & 2.15628300 & -2.21258900 & 0.67047200 \\
\hline $\mathrm{H}$ & 1.18726200 & -2.56417600 & -1.56528100 \\
\hline $\mathrm{H}$ & 1.90544000 & -1.06639500 & -2.15960100 \\
\hline $\mathrm{H}$ & 1.59382000 & 2.90950100 & -0.11420600 \\
\hline $\mathrm{H}$ & 4.06405200 & 0.35741000 & -1.41109600 \\
\hline $\mathrm{H}$ & -6.16278100 & -1.89377500 & -0.61961100 \\
\hline
\end{tabular}




$\begin{array}{rrrr}\mathrm{H} & -6.04660400 & -1.58856700 & 1.10485500 \\ \mathrm{H} & 6.68987500 & 0.25671800 & 1.53733900 \\ \mathrm{H} & 7.83881000 & -2.87818000 & -0.85733200 \\ \mathrm{H} & 5.45075200 & -2.04767300 & -1.92563600 \\ \mathrm{H} & 3.97492300 & -1.18853700 & 2.11719000 \\ \mathrm{H} & 3.68800600 & 0.54837000 & 2.33543300 \\ \mathrm{H} & 2.33508700 & -0.59329500 & 2.42640300 \\ \mathrm{H} & -3.52192400 & -0.34052100 & -2.81071500 \\ \mathrm{H} & -2.74487500 & -1.94161400 & -2.75600500 \\ \mathrm{H} & -4.50696000 & -1.79585400 & -2.54983800 \\ \mathrm{H} & -3.07086200 & 5.07955600 & -2.01771600 \\ \mathrm{H} & -3.74435100 & 3.57790200 & -2.68250400 \\ \mathrm{H} & -4.61054100 & 4.44555100 & -1.39888800 \\ \mathrm{H} & -2.72729300 & 3.96510500 & 0.19964900 \\ \mathrm{H} & -1.85660500 & 3.10749300 & -1.09176500 \\ \mathrm{H} & -5.18382600 & 1.88916200 & 2.35221700 \\ \mathrm{H} & -6.23491100 & 0.55897900 & 1.86503000 \\ \mathrm{H} & -5.81396800 & 1.82884500 & 0.69786800 \\ \mathrm{H} & -2.83290300 & -1.03660500 & 2.07995500 \\ \mathrm{H} & -3.38101000 & 0.28986700 & 3.11216500 \\ \mathrm{H} & -4.47792200 & -1.02973400 & 2.71960800\end{array}$

Revised structure of hainangranatumin G (17-7)-conformer 13

Zero-point correction $=$

Thermal correction to Energy=

Thermal correction to Enthalpy=

Thermal correction to Gibbs Free Energy=

Sum of electronic and zero-point Energies $=$

Sum of electronic and thermal Energies=

Sum of electronic and thermal Enthalpies=

Sum of electronic and thermal Free Energies=
0.545541 (Hartree/Particle)

0.576822

0.577767

0.483086

$-1591.287826$

$-1591.256545$

$-1591.255601$

$-1591.350282$

01

$\begin{array}{lrrr}\mathrm{N} & -0.95283600 & -1.83431000 & -0.32391000 \\ \mathrm{C} & -2.03322700 & -1.04740500 & -0.29022000 \\ \mathrm{C} & -1.94091900 & 0.35139700 & -0.16675900 \\ \mathrm{C} & -0.66404400 & 0.90153400 & -0.10582000 \\ \mathrm{C} & 0.48095400 & 0.09103500 & -0.13892200 \\ \mathrm{C} & 0.27033500 & -1.30348200 & -0.23178400 \\ \mathrm{C} & -3.37346100 & -1.77643600 & -0.40684700 \\ \mathrm{C} & -4.61343000 & -0.82174900 & -0.39116800 \\ \mathrm{C} & -4.35393400 & 0.62460800 & -0.90386400 \\ \mathrm{C} & -3.18033100 & 1.23173200 & -0.08523100 \\ \mathrm{C} & 1.84872200 & 0.65275700 & -0.07461700 \\ \mathrm{C} & 3.01531200 & -0.30724500 & 0.16449000 \\ \mathrm{C} & 2.75155900 & -1.62242900 & -0.60553900 \\ \mathrm{C} & 1.42277000 & -2.27597300 & -0.22265000 \\ \mathrm{C} & 2.10159900 & 1.97697200 & -0.18124800 \\ \mathrm{C} & 3.43341400 & 2.55638400 & 0.05856200 \\ \mathrm{O} & 4.48555500 & 1.69191700 & 0.11003600\end{array}$

SI306 


\begin{tabular}{|c|c|c|c|}
\hline $\mathrm{C}$ & 4.28647700 & 0.36150000 & -0.43276700 \\
\hline $\mathrm{O}$ & -3.51250300 & -2.60840200 & 0.79553200 \\
\hline $\mathrm{C}$ & -4.50477700 & -2.18873200 & 1.61757800 \\
\hline $\mathrm{C}$ & -5.15055800 & -0.93955000 & 1.04814400 \\
\hline $\mathrm{O}$ & -4.77741600 & -2.75768800 & 2.64692700 \\
\hline $\mathrm{C}$ & 5.57990300 & -0.37100200 & -0.23525600 \\
\hline $\mathrm{C}$ & 6.22421200 & -1.12999900 & -1.16976700 \\
\hline $\mathrm{O}$ & 7.37536000 & -1.65012100 & -0.65962400 \\
\hline $\mathrm{C}$ & 7.47696100 & -1.19950800 & 0.62671700 \\
\hline $\mathrm{C}$ & 6.41109100 & -0.41516900 & 0.94121700 \\
\hline $\mathrm{H}$ & -5.35988100 & -1.26131100 & -1.06314500 \\
\hline $\mathrm{O}$ & 3.61993300 & 3.73997700 & 0.26083100 \\
\hline $\mathrm{C}$ & 3.15524200 & -0.56781800 & 1.68295800 \\
\hline $\mathrm{C}$ & -3.37461900 & -2.75154800 & -1.58522500 \\
\hline $\mathrm{O}$ & -2.87095500 & 2.55478500 & -0.52067100 \\
\hline $\mathrm{C}$ & -2.20326400 & 3.85709600 & 1.47709400 \\
\hline $\mathrm{C}$ & -3.22509600 & 3.62371800 & 0.36805600 \\
\hline $\mathrm{C}$ & -4.00686300 & 0.62457900 & -2.40807100 \\
\hline $\mathrm{C}$ & -5.63465100 & 1.46270400 & -0.71755100 \\
\hline $\mathrm{H}$ & -0.57771000 & 1.97755000 & -0.03308200 \\
\hline $\mathrm{H}$ & -3.48834400 & 1.28100500 & 0.96976100 \\
\hline $\mathrm{H}$ & 2.74541100 & -1.40530200 & -1.68268100 \\
\hline $\mathrm{H}$ & 3.57682900 & -2.31852200 & -0.42721500 \\
\hline $\mathrm{H}$ & 1.48827000 & -2.72095100 & 0.77959100 \\
\hline $\mathrm{H}$ & 1.18537400 & -3.10307100 & -0.89867100 \\
\hline $\mathrm{H}$ & 1.32646600 & 2.71445600 & -0.35035900 \\
\hline $\mathrm{H}$ & 4.11049600 & 0.47030300 & -1.51180200 \\
\hline $\mathrm{H}$ & -6.23724500 & -1.02724100 & 1.11030900 \\
\hline $\mathrm{H}$ & -4.86598700 & -0.10428200 & 1.69730200 \\
\hline $\mathrm{H}$ & 6.00617000 & -1.38011700 & -2.19688200 \\
\hline $\mathrm{H}$ & 8.35541300 & -1.51439100 & 1.16759800 \\
\hline $\mathrm{H}$ & 6.24275500 & 0.09801500 & 1.87611200 \\
\hline $\mathrm{H}$ & 3.89744100 & -1.34866300 & 1.87323900 \\
\hline $\mathrm{H}$ & 3.46571600 & 0.34099400 & 2.20588300 \\
\hline $\mathrm{H}$ & 2.20430300 & -0.88913500 & 2.11645900 \\
\hline $\mathrm{H}$ & -3.29012900 & -2.21517100 & -2.53441700 \\
\hline $\mathrm{H}$ & -2.53245000 & -3.43900200 & -1.49430700 \\
\hline $\mathrm{H}$ & -4.30797300 & -3.32234100 & -1.5873660 \\
\hline $\mathrm{H}$ & -2.52675100 & 4.69184200 & 2.10920600 \\
\hline $\mathrm{H}$ & -2.09135800 & 2.97751500 & 2.12049300 \\
\hline $\mathrm{H}$ & -1.22262800 & 4.10956100 & 1.06229600 \\
\hline $\mathrm{H}$ & -3.29854700 & 4.50856500 & -0.27172600 \\
\hline $\mathrm{H}$ & -4.22003500 & 3.44229500 & 0.7960930 \\
\hline $\mathrm{H}$ & -3.86336100 & 1.65084800 & -2.7559670 \\
\hline $\mathrm{H}$ & -4.82311800 & 0.17669500 & -2.98563000 \\
\hline $\mathrm{H}$ & -3.09096500 & 0.07227800 & -2.63272200 \\
\hline $\mathrm{H}$ & -5.92375800 & 1.56089500 & $0.3339440 c$ \\
\hline $\mathrm{H}$ & -5.49855400 & 2.46714000 & -1.12773300 \\
\hline $\mathrm{H}$ & -6.47204300 & 0.99813600 & -1.2505230 \\
\hline
\end{tabular}


Revised structure of hainangranatumin G (17-7)-conformer 14

Zero-point correction=

Thermal correction to Energy=

Thermal correction to Enthalpy=

Thermal correction to Gibbs Free Energy=

Sum of electronic and zero-point Energies=

Sum of electronic and thermal Energies=

Sum of electronic and thermal Enthalpies=

Sum of electronic and thermal Free Energies=
0.545515 (Hartree/Particle)

0.576808

0.577753

\subsection{7}

$-1591.287688$

$-1591.256395$

$-1591.255451$

$-1591.350067$

01

$\mathrm{N}$

$\mathrm{C}$

$\mathrm{C}$

$\mathrm{C}$

$\mathrm{C}$

$\mathrm{C}$

$\mathrm{C}$

$\mathrm{C}$

C

C

C

C

C

C

C

$\mathrm{C}$

$\mathrm{O}$

C

$\mathrm{O}$

C

C

O

C

C

$\mathrm{O}$

C

C

$\mathrm{H}$

$\mathrm{O}$

C

C

$\mathrm{O}$

C

C

C

C

$\mathrm{H}$

$\mathrm{H}$

$\mathrm{H}$

$\mathrm{H}$ $\begin{array}{rrr}-0.96383900 & -1.83871100 & -0.31314800 \\ -2.04107000 & -1.04736300 & -0.28250400 \\ -1.94281700 & 0.35186600 & -0.16862500 \\ -0.66367300 & 0.89744500 & -0.11571100 \\ 0.47819400 & 0.08227800 & -0.14627300 \\ 0.26144600 & -1.31172000 & -0.22770800 \\ -3.38443800 & -1.77172500 & -0.39194300 \\ -4.62050000 & -0.81203300 & -0.37752200 \\ -4.35721700 & 0.63035000 & -0.89943500 \\ -3.17848800 & 1.23758700 & -0.08831900 \\ 1.84838300 & 0.63896200 & -0.09008300 \\ 3.01526900 & -0.32206600 & 0.14673800 \\ 2.74048100 & -1.64404300 & -0.60810600 \\ 1.41019800 & -2.28758800 & -0.21253700 \\ 2.10261100 & 1.96244800 & -0.20307600 \\ 3.43528100 & 2.53937700 & 0.03150900 \\ 4.48494000 & 1.67184100 & 0.08277800 \\ 4.28663200 & 0.34335100 & -0.45882400 \\ -3.52375000 & -2.59747000 & 0.81458200 \\ -4.51161600 & -2.16925600 & 1.63763900 \\ -5.15291800 & -0.91952500 & 1.06434800 \\ -4.78403000 & -2.73230000 & 2.67025400 \\ 5.58047100 & -0.38845700 & -0.24880400 \\ 6.53616300 & -0.10804800 & 0.68515500 \\ 7.58976000 & -0.96587700 & 0.56495200 \\ 7.30581300 & -1.80744200 & -0.46965200 \\ 6.09391300 & -1.50006500 & -1.00910300 \\ -5.37108200 & -1.25255600 & -1.04426400 \\ 3.62724500 & 3.72241300 & 0.23140200 \\ 3.17615600 & -0.56939700 & 1.66475200 \\ -3.39236900 & -2.75241000 & -1.56569700 \\ -2.86535800 & 2.55685600 & -0.53234000 \\ -2.18579500 & 3.86775900 & 1.45583800 \\ -3.21224600 & 3.63222400 & 0.35154100 \\ -4.01534500 & 0.62051300 & -2.40478900 \\ -5.63407300 & 1.47437700 & -0.71341300 \\ -0.57351300 & 1.97361900 & -0.05108900 \\ -3.48272100 & 1.29409300 & 0.96739900 \\ 2.73212200 & -1.44025700 & -1.68790200 \\ 3.55816800 & -2.34587700 & -0.42016400\end{array}$

SI308 


$\begin{array}{lrrr}\mathrm{H} & 1.47890100 & -2.72119100 & 0.79442100 \\ \mathrm{H} & 1.16734300 & -3.12153100 & -0.87813400 \\ \mathrm{H} & 1.32819500 & 2.70074500 & -0.37122700 \\ \mathrm{H} & 4.11111600 & 0.45048100 & -1.53906400 \\ \mathrm{H} & -6.23980600 & -1.00103900 & 1.13103600 \\ \mathrm{H} & -4.86131400 & -0.08248200 & 1.70811400 \\ \mathrm{H} & 6.62161300 & 0.65331500 & 1.44303000 \\ \mathrm{H} & 8.05479300 & -2.54968700 & -0.69661600 \\ \mathrm{H} & 5.62904700 & -1.99115800 & -1.85217600 \\ \mathrm{H} & 3.93290000 & -1.33761800 & 1.84945200 \\ \mathrm{H} & 3.48568200 & 0.34612300 & 2.17621500 \\ \mathrm{H} & 2.23496800 & -0.89830900 & 2.11357400 \\ \mathrm{H} & -3.30812800 & -2.22096500 & -2.51767000 \\ \mathrm{H} & -2.55269300 & -3.44275600 & -1.47349200 \\ \mathrm{H} & -4.32794300 & -3.31954400 & -1.56277000 \\ \mathrm{H} & -2.50389900 & 4.70730000 & 2.08431400 \\ \mathrm{H} & -2.07516800 & 2.99139800 & 2.10383000 \\ \mathrm{H} & -1.20556800 & 4.11408100 & 1.03639200 \\ \mathrm{H} & -3.28432900 & 4.51371900 & -0.29299900 \\ \mathrm{H} & -4.20645300 & 3.45717300 & 0.78390000 \\ \mathrm{H} & -3.86973100 & 1.64428700 & -2.75909400 \\ \mathrm{H} & -4.83500400 & 0.17195500 & -2.97697700 \\ \mathrm{H} & -3.10197400 & 0.06400300 & -2.62935900 \\ \mathrm{H} & -5.91926100 & 1.57934600 & 0.33849700 \\ \mathrm{H} & -5.49550200 & 2.47604900 & -1.12947800 \\ \mathrm{H} & -6.47502300 & 1.01016100 & -1.24106300\end{array}$

Revised structure of hainangranatumin G (17-7)-conformer 15

Zero-point correction $=$

Thermal correction to Energy=

Thermal correction to Enthalpy=

Thermal correction to Gibbs Free Energy=

Sum of electronic and zero-point Energies=

Sum of electronic and thermal Energies=

Sum of electronic and thermal Enthalpies=

Sum of electronic and thermal Free Energies=
0.545476 (Hartree/Particle)

0.576819

0.577763

0.482798

$-1591.287253$

$-1591.255910$

$-1591.254966$

$-1591.349931$

01

$\begin{array}{lrrr}\mathrm{N} & 0.87486400 & -1.85648200 & 0.32030200 \\ \mathrm{C} & 1.96843300 & -1.08808000 & 0.28081900 \\ \mathrm{C} & 1.90164000 & 0.31021500 & 0.13755800 \\ \mathrm{C} & 0.63339200 & 0.88064400 & 0.07568500 \\ \mathrm{C} & -0.52577500 & 0.09054600 & 0.11363700 \\ \mathrm{C} & -0.33875100 & -1.30679500 & 0.21571200 \\ \mathrm{C} & 3.29534300 & -1.83441000 & 0.43214500 \\ \mathrm{C} & 4.55043900 & -0.89932700 & 0.41656700 \\ \mathrm{C} & 4.31128700 & 0.56349000 & 0.89406100 \\ \mathrm{C} & 3.15997900 & 1.16908200 & 0.04877400 \\ \mathrm{C} & -1.88407200 & 0.67498400 & 0.04633200 \\ \mathrm{C} & -3.06684000 & -0.26672900 & -0.18689200\end{array}$

SI309 


\begin{tabular}{|c|c|c|c|}
\hline $\mathrm{C}$ & -2.82480000 & -1.58294400 & 0.58836900 \\
\hline $\mathrm{C}$ & -1.50714700 & -2.25987400 & 0.20779000 \\
\hline $\mathrm{C}$ & -2.11539800 & 2.00380100 & 0.14427900 \\
\hline $\mathrm{C}$ & -3.43800300 & 2.60347200 & -0.09760000 \\
\hline $\mathrm{O}$ & -4.50420100 & 1.75634800 & -0.14163900 \\
\hline $\mathrm{C}$ & -4.32598600 & 0.42593900 & 0.40856700 \\
\hline $\mathrm{O}$ & 3.44034000 & -2.69533700 & -0.74835400 \\
\hline $\mathrm{C}$ & 4.45378200 & -2.31077200 & -1.56206700 \\
\hline $\mathrm{C}$ & 5.10860500 & -1.05843500 & -1.01070000 \\
\hline $\mathrm{O}$ & 4.73497400 & -2.90822000 & -2.57276700 \\
\hline $\mathrm{C}$ & -5.63144400 & -0.28649100 & 0.21721500 \\
\hline $\mathrm{C}$ & -6.28659900 & -1.02920300 & 1.15727400 \\
\hline $\mathrm{O}$ & -7.44671300 & -1.53365100 & 0.65187400 \\
\hline $\mathrm{C}$ & -7.54293400 & -1.08933300 & -0.63705100 \\
\hline $\mathrm{C}$ & -6.46496100 & -0.32430900 & -0.95783000 \\
\hline $\mathrm{H}$ & 5.27839200 & -1.33618600 & 1.11006800 \\
\hline $\mathrm{O}$ & -3.60481500 & 3.78865900 & -0.30741900 \\
\hline $\mathrm{C}$ & -3.21273900 & -0.53158800 & -1.70409400 \\
\hline $\mathrm{C}$ & 3.26280100 & -2.78195800 & 1.63261400 \\
\hline $\mathrm{O}$ & 2.89463900 & 2.50896700 & 0.45459600 \\
\hline $\mathrm{C}$ & 3.99618600 & 4.13779100 & -1.04469500 \\
\hline $\mathrm{C}$ & 2.70103900 & 3.47127000 & -0.59276900 \\
\hline $\mathrm{C}$ & 3.94841700 & 0.60404800 & 2.39443400 \\
\hline $\mathrm{C}$ & 5.60694000 & 1.37444800 & 0.69927200 \\
\hline $\mathrm{H}$ & 0.55489700 & 1.95749500 & 0.00064300 \\
\hline $\mathrm{H}$ & 3.48592100 & 1.18643500 & -1.00222800 \\
\hline $\mathrm{H}$ & -2.81469500 & -1.36188000 & 1.66467800 \\
\hline $\mathrm{H}$ & -3.66161200 & -2.26582500 & 0.41290000 \\
\hline $\mathrm{H}$ & -1.57974200 & -2.70585200 & -0.79354000 \\
\hline $\mathrm{H}$ & -1.28388600 & -3.08918500 & 0.88581900 \\
\hline $\mathrm{H}$ & -1.32900000 & 2.73064200 & 0.30759600 \\
\hline $\mathrm{H}$ & -4.14651700 & 0.53804700 & 1.48667900 \\
\hline $\mathrm{H}$ & 6.19474600 & -1.16227700 & -1.05350400 \\
\hline $\mathrm{H}$ & 4.84591300 & -0.23450400 & -1.68313700 \\
\hline $\mathrm{H}$ & -6.07111600 & -1.27658600 & 2.18559200 \\
\hline $\mathrm{H}$ & -8.42720300 & -1.39317600 & -1.17475500 \\
\hline $\mathrm{H}$ & -6.28981400 & 0.18040500 & -1.89607900 \\
\hline $\mathrm{H}$ & -3.96807000 & -1.30078100 & -1.89003400 \\
\hline $\mathrm{H}$ & -3.50862300 & 0.37988100 & -2.23082500 \\
\hline $\mathrm{H}$ & -2.26778800 & -0.87076200 & -2.13710800 \\
\hline $\mathrm{H}$ & 3.17162400 & -2.22220800 & 2.56763000 \\
\hline $\mathrm{H}$ & 2.41195700 & -3.45896100 & 1.54412400 \\
\hline $\mathrm{H}$ & 4.18733200 & -3.36614100 & 1.66294000 \\
\hline $\mathrm{H}$ & 3.77430000 & 4.90595300 & -1.79428200 \\
\hline $\mathrm{H}$ & 4.49819500 & 4.61760100 & -0.19920000 \\
\hline $\mathrm{H}$ & 4.68860900 & 3.41972500 & -1.49498600 \\
\hline $\mathrm{H}$ & 2.19268800 & 3.00233300 & -1.44709700 \\
\hline $\mathrm{H}$ & 2.02105000 & 4.22093000 & -0.17435400 \\
\hline $\mathrm{H}$ & 3.82586800 & 1.64056700 & 2.71918800 \\
\hline $\mathrm{H}$ & 4.74841400 & 0.15020100 & 2.98979500 \\
\hline $\mathrm{H}$ & 3.01787800 & 0.07731800 & 2.62083500 \\
\hline
\end{tabular}




$\begin{array}{lrrr}\mathrm{H} & 5.90537700 & 1.43912900 & -0.35194500 \\ \mathrm{H} & 5.47892800 & 2.39206100 & 1.07529900 \\ \mathrm{H} & 6.43111900 & 0.90994700 & 1.25239400\end{array}$

\section{Revised structure of hainangranatumin G (17-7)-conformer 16 \\ Zero-point correction $=$ \\ Thermal correction to Energy= \\ Thermal correction to Enthalpy= \\ Thermal correction to Gibbs Free Energy= \\ Sum of electronic and zero-point Energies= \\ Sum of electronic and thermal Energies= \\ Sum of electronic and thermal Enthalpies= \\ Sum of electronic and thermal Free Energies= \\ 0.545439 (Hartree/Particle) \\ 0.576797 \\ 0.577741 \\ 0.482808 \\ $-1591.287123$ \\ $-1591.255764$ \\ $-1591.254820$ \\ $-1591.349753$}

01

$\begin{array}{lrrr}\mathrm{N} & 0.88565000 & -1.86126400 & 0.30859700 \\ \mathrm{C} & 1.97614900 & -1.08835300 & 0.27260200 \\ \mathrm{C} & 1.90345000 & 0.31065700 & 0.13935600 \\ \mathrm{C} & 0.63289800 & 0.87665800 & 0.08562000 \\ \mathrm{C} & -0.52325600 & 0.08183600 & 0.12055600 \\ \mathrm{C} & -0.33013100 & -1.31520500 & 0.21070200 \\ \mathrm{C} & 3.30627200 & -1.83037800 & 0.41679700 \\ \mathrm{C} & 4.55764200 & -0.89031700 & 0.40358700 \\ \mathrm{C} & 4.31423500 & 0.56863600 & 0.89069100 \\ \mathrm{C} & 3.15823200 & 1.17489700 & 0.05232300 \\ \mathrm{C} & -1.88405900 & 0.66134500 & 0.06150800 \\ \mathrm{C} & -3.06721900 & -0.28131800 & -0.16932800 \\ \mathrm{C} & -2.81409700 & -1.60484300 & 0.59025200 \\ \mathrm{C} & -1.49492500 & -2.27167900 & 0.19629000 \\ \mathrm{C} & -2.11675200 & 1.98948900 & 0.16591100 \\ \mathrm{C} & -3.44034000 & 2.58669900 & -0.07026000 \\ \mathrm{O} & -4.50412200 & 1.73646500 & -0.11371800 \\ \mathrm{C} & -4.32642300 & 0.40790200 & 0.43498000 \\ \mathrm{O} & 3.45217100 & -2.68437000 & -0.76852500 \\ \mathrm{C} & 4.46208400 & -2.29106700 & -1.58254300 \\ \mathrm{C} & 5.11239700 & -1.03859400 & -1.02617200 \\ \mathrm{O} & 4.74373700 & -2.88214400 & -2.59681600 \\ \mathrm{C} & -5.63234600 & -0.30392600 & 0.23136600 \\ \mathrm{C} & -6.58488100 & -0.01363600 & -0.70282500 \\ \mathrm{O} & -7.65208300 & -0.85336800 & -0.57567600 \\ \mathrm{C} & -7.38021000 & -1.69315300 & 0.46360500 \\ \mathrm{C} & -6.16257700 & -1.40232300 & 0.99929300 \\ \mathrm{H} & 5.28923000 & -1.32862900 & 1.09233800 \\ \mathrm{O} & -3.61270100 & 3.77144900 & -0.27754400 \\ \mathrm{C} & -3.23432100 & -0.53212400 & -1.68614500 \\ \mathrm{C} & 3.27990100 & -2.78450800 & 1.61223000 \\ \mathrm{O} & 2.88892100 & 2.51131800 & 0.46673500 \\ \mathrm{C} & 3.98041000 & 4.15162900 & -1.02754100 \\ \mathrm{C} & 2.68883500 & 3.47895000 & -0.57454100 \\ \mathrm{C} & 3.95542400 & 0.59878200 & 2.39228300\end{array}$




$\begin{array}{lrrr}\mathrm{C} & 5.60624200 & 1.38569200 & 0.69717300 \\ \mathrm{H} & 0.55066900 & 1.95375000 & 0.01925800 \\ \mathrm{H} & 3.48105700 & 1.19960400 & -0.99948200 \\ \mathrm{H} & -2.80162400 & -1.39752400 & 1.66933400 \\ \mathrm{H} & -3.64353900 & -2.29350400 & 0.40521900 \\ \mathrm{H} & -1.57073900 & -2.70559000 & -0.81004600 \\ \mathrm{H} & -1.26622600 & -3.10838100 & 0.86334100 \\ \mathrm{H} & -1.33106300 & 2.71718300 & 0.32810000 \\ \mathrm{H} & -4.14710700 & 0.51815400 & 1.51427300 \\ \mathrm{H} & 6.19889900 & -1.13676200 & -1.07278700 \\ \mathrm{H} & 4.84350200 & -0.21221300 & -1.69315300 \\ \mathrm{H} & -6.65923000 & 0.74441900 & -1.46517900 \\ \mathrm{H} & -8.14083900 & -2.42165200 & 0.69628200 \\ \mathrm{H} & -5.70442900 & -1.89577800 & 1.84465900 \\ \mathrm{H} & -4.00406900 & -1.28833900 & -1.86653500 \\ \mathrm{H} & -3.52923600 & 0.38625300 & -2.20109100 \\ \mathrm{H} & -2.29942000 & -0.87869200 & -2.13483500 \\ \mathrm{H} & 3.18850800 & -2.23022100 & 2.55047000 \\ \mathrm{H} & 2.43151800 & -3.46434700 & 1.52176500 \\ \mathrm{H} & 4.20674000 & -3.36525900 & 1.63745100 \\ \mathrm{H} & 3.75356400 & 4.92320800 & -1.77210900 \\ \mathrm{H} & 4.48417000 & 4.62826500 & -0.18129500 \\ \mathrm{H} & 4.67321300 & 3.43804200 & -1.48431900 \\ \mathrm{H} & 2.17857700 & 3.01339400 & -1.42958700 \\ \mathrm{H} & 2.00836400 & 4.22432300 & -0.14932400 \\ \mathrm{H} & 3.83025800 & 1.63287500 & 2.72370300 \\ \mathrm{H} & 4.75860200 & 0.14405200 & 2.98266300 \\ \mathrm{H} & 3.02728600 & 0.06755000 & 2.61804100 \\ \mathrm{H} & 5.90157700 & 1.45765200 & -0.35444300 \\ \mathrm{H} & 5.47535900 & 2.40058800 & 1.07949200 \\ \mathrm{H} & 6.43368300 & 0.92112900 & 1.24535000\end{array}$

NMR calculations of granatumine A

Proposed structure of granatumine A (1-2)-conformer 1

Zero-point correction=

Thermal correction to Energy=

Thermal correction to Enthalpy=

Thermal correction to Gibbs Free Energy=

Sum of electronic and zero-point Energies=

Sum of electronic and thermal Energies=

Sum of electronic and thermal Enthalpies=

Sum of electronic and thermal Free Energies=
0.517076 (Hartree/Particle)

0.547080

0.548025

0.456847

$-1551.999251$

$-1551.969246$

$-1551.968302$

$-1552.059479$

01

$\begin{array}{lrrr}\mathrm{N} & 1.09394900 & -1.39644000 & 0.62111500 \\ \mathrm{C} & 2.11391400 & -0.54918800 & 0.47173600 \\ \mathrm{C} & 1.92692200 & 0.80787500 & 0.15682900 \\ \mathrm{C} & 0.62252000 & 1.24761600 & -0.03500300 \\ \mathrm{C} & -0.46823500 & 0.37335100 & 0.11503100\end{array}$

SI312 


\begin{tabular}{|c|c|c|c|}
\hline $\mathrm{C}$ & -0.16249400 & -0.96564600 & 0.44958700 \\
\hline $\mathrm{C}$ & 3.50680100 & -1.14254700 & 0.65323500 \\
\hline $\mathrm{C}$ & 4.69502800 & -0.18781900 & 0.30598300 \\
\hline $\mathrm{C}$ & 4.32851000 & 1.02388000 & -0.60461300 \\
\hline $\mathrm{C}$ & 3.11823400 & 1.73607600 & 0.04567300 \\
\hline $\mathrm{C}$ & -1.86809400 & 0.81120000 & -0.07865400 \\
\hline $\mathrm{C}$ & -2.95661700 & -0.25994700 & -0.16332200 \\
\hline $\mathrm{C}$ & -2.62682800 & -1.39108500 & 0.83834400 \\
\hline $\mathrm{C}$ & -1.24527600 & -2.00355800 & 0.60501200 \\
\hline $\mathrm{C}$ & -2.21623800 & 2.11057600 & -0.21880100 \\
\hline $\mathrm{C}$ & -3.57714200 & 2.53764100 & -0.58419800 \\
\hline $\mathrm{O}$ & -4.56366500 & 1.60206800 & -0.50022000 \\
\hline $\mathrm{C}$ & -4.29061300 & 0.40794700 & 0.27718800 \\
\hline $\mathrm{O}$ & 3.61894300 & -2.24419100 & -0.30974400 \\
\hline $\mathrm{C}$ & 4.86555300 & -2.30995400 & -0.84814300 \\
\hline $\mathrm{C}$ & 5.70874900 & -1.16590000 & -0.30961200 \\
\hline $\mathrm{O}$ & 5.18919100 & -3.17541500 & -1.62479500 \\
\hline $\mathrm{C}$ & -5.52238700 & -0.44237200 & 0.18839700 \\
\hline $\mathrm{C}$ & -6.14354100 & -1.06778600 & 1.23131600 \\
\hline $\mathrm{O}$ & -7.23772300 & -1.75487700 & 0.79991700 \\
\hline $\mathrm{C}$ & -7.32689100 & -1.55065000 & -0.54854600 \\
\hline $\mathrm{C}$ & -6.30829800 & -0.75788600 & -0.97766500 \\
\hline $\mathrm{H}$ & 5.07450000 & 0.23245200 & 1.23993700 \\
\hline $\mathrm{O}$ & -3.83825900 & 3.65006600 & -0.99718000 \\
\hline $\mathrm{C}$ & -3.02715300 & -0.79867100 & -1.61172600 \\
\hline $\mathrm{C}$ & 3.64626800 & -1.73784900 & 2.05944700 \\
\hline $\mathrm{O}$ & 3.52466800 & 2.19568100 & 1.34292100 \\
\hline $\mathrm{C}$ & 2.66887200 & 3.15982200 & 1.93652700 \\
\hline $\mathrm{C}$ & 5.51987300 & 2.00054100 & -0.66603900 \\
\hline $\mathrm{C}$ & 3.94865700 & 0.61671300 & -2.04622600 \\
\hline $\mathrm{H}$ & 0.45815700 & 2.27954900 & -0.33090600 \\
\hline $\mathrm{H}$ & 2.84341500 & 2.61000900 & -0.56753000 \\
\hline $\mathrm{H}$ & -2.66963100 & -0.98303900 & 1.85772100 \\
\hline $\mathrm{H}$ & -3.39587000 & -2.16688800 & 0.77522400 \\
\hline $\mathrm{H}$ & -1.24838500 & -2.63137600 & -0.29627900 \\
\hline $\mathrm{H}$ & -0.96987000 & -2.67081100 & 1.42755200 \\
\hline $\mathrm{H}$ & -1.50171200 & 2.92362000 & -0.17305700 \\
\hline $\mathrm{H}$ & -4.15927200 & 0.72020200 & 1.32238500 \\
\hline $\mathrm{H}$ & 6.38929100 & -1.57842600 & 0.44398900 \\
\hline $\mathrm{H}$ & 6.33240500 & -0.75381200 & -1.10420500 \\
\hline $\mathrm{H}$ & -5.94352000 & -1.11317400 & 2.29103700 \\
\hline $\mathrm{H}$ & -8.16251600 & -2.02182500 & -1.0415890 \\
\hline $\mathrm{H}$ & -6.14477100 & -0.40917600 & -1.9863260 \\
\hline $\mathrm{H}$ & -3.70672400 & -1.65380100 & -1.6716830 \\
\hline $\mathrm{H}$ & -3.38230300 & -0.02432300 & -2.2972760 \\
\hline $\mathrm{H}$ & -2.04241400 & -1.12142000 & -1.9603350 \\
\hline $\mathrm{H}$ & 4.63369000 & -2.19219600 & 2.18924100 \\
\hline $\mathrm{H}$ & 3.52283700 & -0.95450800 & 2.81400300 \\
\hline $\mathrm{H}$ & 2.88087900 & -2.50177300 & 2.20958600 \\
\hline $\mathrm{H}$ & 2.54764700 & 4.03807600 & 1.28485500 \\
\hline $\mathrm{H}$ & 1.67737800 & 2.74706700 & 2.16719000 \\
\hline
\end{tabular}

SI313 


$\begin{array}{lrrr}\mathrm{H} & 3.14784500 & 3.47047400 & 2.86743900 \\ \mathrm{H} & 5.26106200 & 2.88143600 & -1.26508600 \\ \mathrm{H} & 6.38900100 & 1.53135300 & -1.13822300 \\ \mathrm{H} & 5.80816600 & 2.34178100 & 0.33079500 \\ \mathrm{H} & 3.14001800 & -0.11695800 & -2.08812500 \\ \mathrm{H} & 3.62871100 & 1.49862200 & -2.61289100 \\ \mathrm{H} & 4.80855100 & 0.19300100 & -2.57299400\end{array}$

Proposed structure of granatumine A (1-2)-conformer 2

Zero-point correction $=$

Thermal correction to Energy=

Thermal correction to Enthalpy=

Thermal correction to Gibbs Free Energy=

Sum of electronic and zero-point Energies=

Sum of electronic and thermal Energies=

Sum of electronic and thermal Enthalpies=

Sum of electronic and thermal Free Energies=
0.517058 (Hartree/Particle)

0.547073

0.548017

0.456910

$-1551.999147$

$-1551.969132$

$-1551.968188$

$-1552.059295$

01

$\begin{array}{lrrr}\mathrm{N} & 1.10316700 & -1.40732400 & 0.60121300 \\ \mathrm{C} & 2.12025400 & -0.55497200 & 0.46168200 \\ \mathrm{C} & 1.92829200 & 0.80590300 & 0.16675500 \\ \mathrm{C} & 0.62209600 & 1.24459900 & -0.01466300 \\ \mathrm{C} & -0.46586400 & 0.36505400 & 0.12555400 \\ \mathrm{C} & -0.15483800 & -0.97749200 & 0.43913200 \\ \mathrm{C} & 3.51535000 & -1.14648700 & 0.63170200 \\ \mathrm{C} & 4.69975000 & -0.18344000 & 0.29443700 \\ \mathrm{C} & 4.32707300 & 1.03946900 & -0.59843200 \\ \mathrm{C} & 3.11658100 & 1.73909500 & 0.06507000 \\ \mathrm{C} & -1.86764700 & 0.80142800 & -0.05745000 \\ \mathrm{C} & -2.95756400 & -0.26877400 & -0.14598900 \\ \mathrm{C} & -2.61632300 & -1.41577700 & 0.83391600 \\ \mathrm{C} & -1.23427000 & -2.01994700 & 0.58105300 \\ \mathrm{C} & -2.21627400 & 2.10211400 & -0.18422100 \\ \mathrm{C} & -3.57792900 & 2.53073300 & -0.54070300 \\ \mathrm{O} & -4.56268000 & 1.59299900 & -0.45984200 \\ \mathrm{C} & -4.29073600 & 0.39566700 & 0.30867900 \\ \mathrm{O} & 3.62845800 & -2.23479500 & -0.34606100 \\ \mathrm{C} & 4.87389600 & -2.28941600 & -0.88852200 \\ \mathrm{C} & 5.71484000 & -1.14984400 & -0.33715700 \\ \mathrm{O} & 5.19825500 & -3.14358200 & -1.67724900 \\ \mathrm{C} & -5.52330800 & -0.45467500 & 0.20346200 \\ \mathrm{C} & -6.46419600 & -0.41201000 & -0.78513300 \\ \mathrm{O} & -7.45951100 & -1.31101200 & -0.53801000 \\ \mathrm{C} & -7.15340400 & -1.93649100 & 0.63425400 \\ \mathrm{C} & -5.98434100 & -1.45162900 & 1.13664200 \\ \mathrm{H} & 5.08045300 & 0.22513800 & 1.23306300 \\ \mathrm{O} & -3.84380100 & 3.64505900 & -0.94519900 \\ \mathrm{C} & -3.05145700 & -0.78603300 & -1.60030900 \\ \mathrm{C} & 3.66007700 & -1.76002400 & 2.02954800\end{array}$

SI314 


$\begin{array}{lrrr}\mathrm{O} & 3.52540700 & 2.18189900 & 1.36740400 \\ \mathrm{C} & 2.66876800 & 3.13549400 & 1.97664200 \\ \mathrm{C} & 5.51535000 & 2.02046000 & -0.64985200 \\ \mathrm{C} & 3.94427300 & 0.65089600 & -2.04438300 \\ \mathrm{H} & 0.45444100 & 2.28036000 & -0.29469900 \\ \mathrm{H} & 2.83743600 & 2.62059900 & -0.53519400 \\ \mathrm{H} & -2.65507900 & -1.02750200 & 1.86121500 \\ \mathrm{H} & -3.37784600 & -2.19718800 & 0.75744900 \\ \mathrm{H} & -1.24201900 & -2.63043700 & -0.33199200 \\ \mathrm{H} & -0.95294600 & -2.70215600 & 1.38918800 \\ \mathrm{H} & -1.50190200 & 2.91497100 & -0.13551400 \\ \mathrm{H} & -4.15850800 & 0.70015600 & 1.35704400 \\ \mathrm{H} & 6.39899600 & -1.57013300 & 0.40883700 \\ \mathrm{H} & 6.33479100 & -0.72508100 & -1.12796500 \\ \mathrm{H} & -6.57646200 & 0.19746900 & -1.66679000 \\ \mathrm{H} & -7.85675100 & -2.68102900 & 0.97242900 \\ \mathrm{H} & -5.51564500 & -1.75301500 & 2.06268300 \\ \mathrm{H} & -3.74747200 & -1.62776200 & -1.66258100 \\ \mathrm{H} & -3.40608200 & 0.00194000 & -2.27028100 \\ \mathrm{H} & -2.07595900 & -1.11823000 & -1.96564600 \\ \mathrm{H} & 4.64917300 & -2.21307800 & 2.15083800 \\ \mathrm{H} & 3.53619700 & -0.98719500 & 2.79479400 \\ \mathrm{H} & 2.89739400 & -2.52824600 & 2.17136100 \\ \mathrm{H} & 2.54317100 & 4.02219200 & 1.33736000 \\ \mathrm{H} & 1.67911300 & 2.71690000 & 2.20467000 \\ \mathrm{H} & 3.14971600 & 3.43477500 & 2.91025800 \\ \mathrm{H} & 5.25218500 & 2.90871200 & -1.23599100 \\ \mathrm{H} & 6.38447300 & 1.56041700 & -1.13094800 \\ \mathrm{H} & 5.80557500 & 2.34884300 & 0.35073700 \\ \mathrm{H} & 3.13779200 & -0.08466100 & -2.09405200 \\ \mathrm{H} & 3.61994900 & 1.53944500 & -2.59802900 \\ \mathrm{H} & 4.80393900 & 0.23711800 & -2.57935500\end{array}$

\section{Proposed structure of granatumine A (1-2)-conformer 3 \\ Zero-point correction= \\ Thermal correction to Energy= \\ Thermal correction to Enthalpy= \\ Thermal correction to Gibbs Free Energy= \\ Sum of electronic and zero-point Energies= \\ Sum of electronic and thermal Energies $=$ \\ Sum of electronic and thermal Enthalpies= \\ Sum of electronic and thermal Free Energies= \\ 0.516964 (Hartree/Particle) 0.547117 \\ 0.548062 \\ 0.455945 \\ $-1551.995630$ \\ $-1551.965477$ \\ $-1551.964532$ \\ $-1552.056649$}

01

$\begin{array}{lrrr}\mathrm{N} & 1.06978200 & -1.65253500 & 0.41752200 \\ \mathrm{C} & 2.13243400 & -0.84851400 & 0.30562000 \\ \mathrm{C} & 2.00715400 & 0.53145900 & 0.06525400 \\ \mathrm{C} & 0.71850900 & 1.04753500 & -0.03659100 \\ \mathrm{C} & -0.40802900 & 0.21868800 & 0.07330900 \\ \mathrm{C} & -0.16497100 & -1.15779100 & 0.28855800\end{array}$




\begin{tabular}{|c|c|c|c|}
\hline $\mathrm{C}$ & 3.49095300 & -1.53296800 & 0.47262500 \\
\hline $\mathrm{C}$ & 4.70733200 & -0.55669200 & 0.34017200 \\
\hline $\mathrm{C}$ & 4.42853300 & 0.92296300 & 0.73352300 \\
\hline $\mathrm{C}$ & 3.22298800 & 1.43213700 & -0.09823100 \\
\hline $\mathrm{C}$ & -1.78875600 & 0.74169300 & -0.03292600 \\
\hline $\mathrm{C}$ & -2.93473900 & -0.26197600 & -0.17261300 \\
\hline $\mathrm{C}$ & -2.63564100 & -1.49526700 & 0.71123200 \\
\hline $\mathrm{C}$ & -1.29563300 & -2.15172200 & 0.37593700 \\
\hline $\mathrm{C}$ & -2.07147500 & 2.06403300 & -0.04900400 \\
\hline $\mathrm{C}$ & -3.41835600 & 2.58834600 & -0.32944500 \\
\hline $\mathrm{O}$ & -4.45058900 & 1.69983800 & -0.28882600 \\
\hline $\mathrm{C}$ & -4.21642500 & 0.43036300 & 0.37294300 \\
\hline $\mathrm{O}$ & 3.63440800 & -2.47686500 & -0.64305700 \\
\hline $\mathrm{C}$ & 4.59376400 & -2.10858200 & -1.52697000 \\
\hline $\mathrm{C}$ & 5.20696800 & -0.78863500 & -1.09857700 \\
\hline $\mathrm{O}$ & 4.86406900 & -2.76775400 & -2.50151400 \\
\hline $\mathrm{C}$ & -5.49388700 & -0.34620800 & 0.25710000 \\
\hline $\mathrm{C}$ & -6.11340400 & -1.02822300 & 1.26489000 \\
\hline $\mathrm{O}$ & -7.25576600 & -1.61986000 & 0.81684500 \\
\hline $\mathrm{C}$ & -7.37741900 & -1.29465900 & -0.50507300 \\
\hline $\mathrm{C}$ & -6.33254100 & -0.51951100 & -0.90200900 \\
\hline $\mathrm{H}$ & 5.48183600 & -0.92143400 & 1.02516900 \\
\hline $\mathrm{O}$ & -3.63343300 & 3.74315400 & -0.64016100 \\
\hline $\mathrm{C}$ & -3.07974100 & -0.66302300 & -1.65973700 \\
\hline $\mathrm{C}$ & 3.52975300 & -2.38718200 & 1.74078500 \\
\hline $\mathrm{O}$ & 2.89218100 & 2.77565000 & 0.25519500 \\
\hline $\mathrm{C}$ & 2.99465100 & 3.72769300 & -0.79719400 \\
\hline $\mathrm{C}$ & 4.12295900 & 1.04648300 & 2.24166600 \\
\hline $\mathrm{C}$ & 5.67594500 & 1.77688500 & 0.43057300 \\
\hline $\mathrm{H}$ & 0.60574000 & 2.11219100 & -0.19991400 \\
\hline $\mathrm{H}$ & 3.51166400 & 1.42133200 & -1.15977500 \\
\hline $\mathrm{H}$ & -2.62584800 & -1.18098000 & 1.76412300 \\
\hline $\mathrm{H}$ & -3.44632600 & -2.22250000 & 0.60502800 \\
\hline $\mathrm{H}$ & -1.35836000 & -2.68546600 & -0.58216300 \\
\hline $\mathrm{H}$ & -1.03485800 & -2.90997600 & 1.12055500 \\
\hline $\mathrm{H}$ & -1.31320200 & 2.83216900 & 0.04280700 \\
\hline $\mathrm{H}$ & -4.03461300 & 0.64268300 & 1.43547100 \\
\hline $\mathrm{H}$ & 6.29386900 & -0.84143300 & -1.18847500 \\
\hline $\mathrm{H}$ & 4.86919900 & -0.02905100 & -1.81222700 \\
\hline $\mathrm{H}$ & -5.88194600 & -1.17563300 & 2.30881200 \\
\hline $\mathrm{H}$ & -8.25230700 & -1.67866800 & -1.00556000 \\
\hline $\mathrm{H}$ & -6.18334900 & -0.09289600 & -1.88255300 \\
\hline $\mathrm{H}$ & -3.80493200 & -1.47450800 & -1.77095200 \\
\hline $\mathrm{H}$ & -3.41521700 & 0.18699000 & -2.26028300 \\
\hline $\mathrm{H}$ & -2.12485200 & -1.00113600 & -2.07125800 \\
\hline $\mathrm{H}$ & 4.47616500 & -2.93416500 & 1.78544700 \\
\hline $\mathrm{H}$ & 3.44325100 & -1.76323400 & 2.63444700 \\
\hline $\mathrm{H}$ & 2.70322400 & -3.09922700 & 1.72855800 \\
\hline $\mathrm{H}$ & 2.69294600 & 4.68982600 & -0.37753600 \\
\hline $\mathrm{H}$ & 4.02347100 & 3.80981500 & -1.17307500 \\
\hline $\mathrm{H}$ & 2.32924200 & 3.47970600 & -1.63648100 \\
\hline
\end{tabular}




$\begin{array}{lrrr}\mathrm{H} & 3.97609700 & 2.09661900 & 2.50663000 \\ \mathrm{H} & 4.96022300 & 0.65683000 & 2.83115400 \\ \mathrm{H} & 3.22039300 & 0.50527300 & 2.53658500 \\ \mathrm{H} & 5.93140700 & 1.78048400 & -0.63422300 \\ \mathrm{H} & 5.51265800 & 2.81187700 & 0.74367400 \\ \mathrm{H} & 6.54343200 & 1.39500200 & 0.98060800\end{array}$

\section{Proposed structure of granatumine A (1-2)-conformer 4}

$\begin{array}{lc}\text { Zero-point correction= } & 0.516935 \text { (Hartree/Particle) } \\ \text { Thermal correction to Energy= } & 0.547102 \\ \text { Thermal correction to Enthalpy= } & 0.548046 \\ \text { Thermal correction to Gibbs Free Energy= } & 0.455963 \\ \text { Sum of electronic and zero-point Energies }= & -1551.995494 \\ \text { Sum of electronic and thermal Energies }= & -1551.965327 \\ \text { Sum of electronic and thermal Enthalpies }= & -1551.964382 \\ \text { Sum of electronic and thermal Free Energies }= & -1552.056466\end{array}$
01

$\begin{array}{lrrr}\mathrm{N} & 1.07974500 & -1.65926300 & 0.39905800 \\ \mathrm{C} & 2.13936800 & -0.85029500 & 0.29438500 \\ \mathrm{C} & 2.00858100 & 0.53185100 & 0.06978100 \\ \mathrm{C} & 0.71797000 & 1.04459200 & -0.02290000 \\ \mathrm{C} & -0.40559400 & 0.21060900 & 0.07968100 \\ \mathrm{C} & -0.15682400 & -1.16708900 & 0.27807500 \\ \mathrm{C} & 3.50063200 & -1.53151700 & 0.45191000 \\ \mathrm{C} & 4.71315300 & -0.54951300 & 0.32706900 \\ \mathrm{C} & 4.43008200 & 0.92487900 & 0.73675000 \\ \mathrm{C} & 3.22086000 & 1.43855300 & -0.08684100 \\ \mathrm{C} & -1.78846200 & 0.72981700 & -0.01730700 \\ \mathrm{C} & -2.93519000 & -0.27390200 & -0.15668800 \\ \mathrm{C} & -2.62466900 & -1.51831300 & 0.70781200 \\ \mathrm{C} & -1.28402000 & -2.16489400 & 0.35520800 \\ \mathrm{C} & -2.07228800 & 2.05206900 & -0.02451300 \\ \mathrm{C} & -3.42009800 & 2.57512200 & -0.29734800 \\ \mathrm{O} & -4.45002700 & 1.68390500 & -0.25629600 \\ \mathrm{C} & -4.21593900 & 0.41477000 & 0.40101400 \\ \mathrm{O} & 3.64558400 & -2.46367400 & -0.67332700 \\ \mathrm{C} & 4.60180600 & -2.08277800 & -1.55537700 \\ \mathrm{C} & 5.21009900 & -0.76443000 & -1.11526100 \\ \mathrm{O} & 4.87315000 & -2.73139800 & -2.53665100 \\ \mathrm{C} & -5.49422900 & -0.36182600 & 0.27300100 \\ \mathrm{C} & -6.46461000 & -0.18976900 & -0.67204000 \\ \mathrm{O} & -7.49687000 & -1.05611800 & -0.46191100 \\ \mathrm{C} & -7.18410300 & -1.79258400 & 0.64219600 \\ \mathrm{C} & -5.97484500 & -1.41001400 & 1.13766000 \\ \mathrm{H} & 5.49062300 & -0.91877200 & 1.00626900 \\ \mathrm{O} & -3.64063000 & 3.73002000 & -0.60353800 \\ \mathrm{C} & -3.10336700 & -0.65712600 & -1.64548300 \\ \mathrm{C} & 3.54476500 & -2.39824400 & 1.71140300 \\ \mathrm{O} & 2.88612800 & 2.77708600 & 0.28132600\end{array}$




$\begin{array}{lrrr}\mathrm{C} & 2.98325500 & 3.74047600 & -0.76124800 \\ \mathrm{C} & 4.12749400 & 1.03144200 & 2.24680600 \\ \mathrm{C} & 5.67382200 & 1.78632000 & 0.44006000 \\ \mathrm{H} & 0.60178900 & 2.11074500 & -0.17317600 \\ \mathrm{H} & 3.50706600 & 1.43980100 & -1.14910000 \\ \mathrm{H} & -2.61116900 & -1.22086600 & 1.76561500 \\ \mathrm{H} & -3.42810500 & -2.25126100 & 0.59063900 \\ \mathrm{H} & -1.35098500 & -2.68313100 & -0.61103300 \\ \mathrm{H} & -1.01763300 & -2.93435800 & 1.08620900 \\ \mathrm{H} & -1.31467100 & 2.82070400 & 0.06712600 \\ \mathrm{H} & -4.03277800 & 0.62319100 & 1.46506300 \\ \mathrm{H} & 6.29698000 & -0.81118800 & -1.20857100 \\ \mathrm{H} & 4.86674200 & 0.00075800 & -1.82022300 \\ \mathrm{H} & -6.57469700 & 0.49667100 & -1.49548100 \\ \mathrm{H} & -7.91358300 & -2.52731100 & 0.94459000 \\ \mathrm{H} & -5.49116000 & -1.81107500 & 2.01701000 \\ \mathrm{H} & -3.84444600 & -1.45461400 & -1.75397800 \\ \mathrm{H} & -3.43740000 & 0.20290300 & -2.23222900 \\ \mathrm{H} & -2.15900900 & -1.00418200 & -2.07350700 \\ \mathrm{H} & 4.49323000 & -2.94219400 & 1.74891400 \\ \mathrm{H} & 3.45756300 & -1.78366600 & 2.61145900 \\ \mathrm{H} & 2.72082900 & -3.11317900 & 1.69339800 \\ \mathrm{H} & 2.67919800 & 4.69712300 & -0.33088600 \\ \mathrm{H} & 4.01101800 & 3.82999800 & -1.13829500 \\ \mathrm{H} & 2.31696000 & 3.49903400 & -1.60173200 \\ \mathrm{H} & 3.97815200 & 2.07826700 & 2.52323600 \\ \mathrm{H} & 4.96718300 & 0.63801900 & 2.83030900 \\ \mathrm{H} & 3.22713900 & 0.48452600 & 2.53796100 \\ \mathrm{H} & 5.92686200 & 1.80206500 & -0.62519900 \\ \mathrm{H} & 5.50764900 & 2.81736300 & 0.76447100 \\ \mathrm{H} & 6.54386800 & 1.40167600 & 0.98409500\end{array}$

Proposed structure of granatumine A (1-2)-conformer 5

Zero-point correction $=$

Thermal correction to Energy=

Thermal correction to Enthalpy=

Thermal correction to Gibbs Free Energy=

Sum of electronic and zero-point Energies=

Sum of electronic and thermal Energies=

Sum of electronic and thermal Enthalpies=

Sum of electronic and thermal Free Energies=
0.516949 (Hartree/Particle)

0.546903

0.547847

0.456903

$-1551.995023$

$-1551.965069$

$-1551.964125$

$-1552.055069$

01

$\begin{array}{lrrr}\mathrm{N} & -1.06227900 & -1.18250400 & -0.96027200 \\ \mathrm{C} & -2.09640700 & -0.41500100 & -0.58713100 \\ \mathrm{C} & -1.93314400 & 0.85227500 & -0.00535300 \\ \mathrm{C} & -0.63061100 & 1.29835800 & 0.22414600 \\ \mathrm{C} & 0.45663400 & 0.49991000 & -0.14374200 \\ \mathrm{C} & 0.17977700 & -0.74516600 & -0.74748500 \\ \mathrm{C} & -3.47938900 & -1.01205900 & -0.82362800\end{array}$

SI318 


\begin{tabular}{|c|c|c|c|}
\hline $\mathrm{C}$ & -4.67612300 & -0.19712500 & -0.23440300 \\
\hline $\mathrm{C}$ & -4.29931900 & 0.81623500 & 0.88885800 \\
\hline $\mathrm{C}$ & -3.14453100 & 1.69148900 & 0.34584200 \\
\hline $\mathrm{C}$ & 1.86695300 & 0.89836500 & -0.00251900 \\
\hline $\mathrm{C}$ & 2.89274600 & -0.17479500 & 0.38451100 \\
\hline $\mathrm{C}$ & 2.41006900 & -1.59459600 & -0.04664900 \\
\hline $\mathrm{C}$ & 1.34987900 & -1.59816100 & -1.16135100 \\
\hline $\mathrm{C}$ & 2.28005500 & 2.16285500 & -0.23013800 \\
\hline $\mathrm{C}$ & 3.68835600 & 2.56764900 & -0.08342500 \\
\hline $\mathrm{O}$ & 4.61143100 & 1.56675900 & -0.01908800 \\
\hline $\mathrm{C}$ & 4.21064900 & 0.20822500 & -0.35364100 \\
\hline $\mathrm{O}$ & -3.50869700 & -2.29102400 & -0.10310600 \\
\hline $\mathrm{C}$ & -4.72284800 & -2.51480900 & 0.46524600 \\
\hline $\mathrm{C}$ & -5.62699000 & -1.32002800 & 0.21061900 \\
\hline $\mathrm{O}$ & -4.97962700 & -3.53215800 & 1.06223300 \\
\hline $\mathrm{C}$ & 5.41106400 & -0.64920100 & -0.08539900 \\
\hline $\mathrm{C}$ & 5.93640700 & -1.58072600 & -0.93491800 \\
\hline $\mathrm{O}$ & 7.03118000 & -2.17444200 & -0.38413800 \\
\hline $\mathrm{C}$ & 7.21975800 & -1.59764600 & 0.84036800 \\
\hline $\mathrm{C}$ & 6.26315000 & -0.66013500 & 1.07688200 \\
\hline $\mathrm{H}$ & -5.11576600 & 0.38969600 & -1.04384100 \\
\hline $\mathrm{O}$ & 4.05269600 & 3.72298600 & 0.00215100 \\
\hline $\mathrm{C}$ & 3.07274800 & -0.14917600 & 1.92214700 \\
\hline $\mathrm{C}$ & -3.67558200 & -1.31368100 & -2.31421600 \\
\hline $\mathrm{O}$ & -3.63097100 & 2.39070100 & -0.80885800 \\
\hline $\mathrm{C}$ & -2.82946500 & 3.48106300 & -1.23645900 \\
\hline $\mathrm{C}$ & -5.51352000 & 1.71339700 & 1.20173300 \\
\hline $\mathrm{C}$ & -3.83571000 & 0.13891400 & 2.19823700 \\
\hline $\mathrm{H}$ & -0.46219500 & 2.25451500 & 0.71439800 \\
\hline $\mathrm{H}$ & -2.86369600 & 2.43198700 & 1.11280000 \\
\hline $\mathrm{H}$ & 3.27396300 & -2.19791600 & -0.34040300 \\
\hline $\mathrm{H}$ & 1.97571500 & -2.09172800 & 0.82739400 \\
\hline $\mathrm{H}$ & 1.00097700 & -2.61352400 & -1.3650880 \\
\hline $\mathrm{H}$ & 1.77375200 & -1.20760600 & -2.09825300 \\
\hline $\mathrm{H}$ & 1.59636300 & 2.95873800 & -0.50537000 \\
\hline $\mathrm{H}$ & 4.00082600 & 0.18203100 & -1.4320130 \\
\hline $\mathrm{H}$ & -6.33193200 & -1.59727800 & -0.5814610 \\
\hline $\mathrm{H}$ & -6.22184600 & -1.10401100 & 1.09927600 \\
\hline $\mathrm{H}$ & 5.66534200 & -1.91448400 & -1.92510800 \\
\hline $\mathrm{H}$ & 8.06883900 & -1.95349500 & 1.40233100 \\
\hline $\mathrm{H}$ & 6.18432600 & -0.02806100 & 1.94855700 \\
\hline $\mathrm{H}$ & 3.71476500 & -0.97478800 & 2.24314700 \\
\hline $\mathrm{H}$ & 3.51525200 & 0.79010800 & 2.26438700 \\
\hline $\mathrm{H}$ & 2.10155700 & -0.26845000 & 2.4124650 \\
\hline $\mathrm{H}$ & -4.65437600 & -1.77140500 & -2.4896190 \\
\hline $\mathrm{H}$ & -3.61584600 & -0.38832700 & -2.8959070 \\
\hline $\mathrm{H}$ & -2.89662200 & -1.99912700 & -2.6536850 \\
\hline $\mathrm{H}$ & -3.36808000 & 3.96125800 & -2.0560980 \\
\hline $\mathrm{H}$ & -2.68545000 & 4.21067100 & -0.4254970 \\
\hline $\mathrm{H}$ & -1.84625500 & 3.15386800 & -1.6008510 \\
\hline $\mathrm{H}$ & -5.24962100 & 2.46383200 & 1.9561130 \\
\hline
\end{tabular}

SI319 


$\begin{array}{rrrr}\mathrm{H} & -6.34332400 & 1.12492900 & 1.60624900 \\ \mathrm{H} & -5.86243000 & 2.23845800 & 0.30967500 \\ \mathrm{H} & -3.00375000 & -0.55441300 & 2.05326400 \\ \mathrm{H} & -3.51553600 & 0.89890700 & 2.92021500 \\ \mathrm{H} & -4.65473000 & -0.41801700 & 2.66247400\end{array}$

Proposed structure of granatumine A (1-2)-conformer 6

Zero-point correction=

Thermal correction to Energy=

Thermal correction to Enthalpy=

Thermal correction to Gibbs Free Energy=

Sum of electronic and zero-point Energies $=$

Sum of electronic and thermal Energies=

Sum of electronic and thermal Enthalpies=

Sum of electronic and thermal Free Energies=
0.516887 (Hartree/Particle)

$$
0.546855
$$

0.547800

0.456774

$-1551.994597$

$-1551.964628$

$-1551.963684$

$-1552.054709$

01

$\begin{array}{lll}-1.06522100 & -1.19318800 & -0.93957600\end{array}$

$-2.09848400 \quad-0.41907200 \quad-0.57816900$

$\begin{array}{llll}\text { C } & -1.93358700 & 0.85245800 & -0.00614600\end{array}$

$\begin{array}{llll}\mathrm{C} & -0.63068300 & 1.29665900 & 0.22423400\end{array}$

$\begin{array}{lllll}\mathrm{C} & 0.45588600 & 0.49218000 & -0.13291400\end{array}$

$\begin{array}{llll}\text { C } & 0.17737500 & -0.75802800 & -0.72546200\end{array}$

$\begin{array}{llll}\text { C } & -3.48235300 & -1.01345000 & -0.81615600\end{array}$

$\begin{array}{llll}\text { C } & -4.67890400 & -0.19029100 & -0.23808000\end{array}$

$\begin{array}{llll}\mathrm{C} & -4.30339800 & 0.83051500 & 0.87885600\end{array}$

$\begin{array}{llll}\text { C } & -3.14383900 & 1.69803300 & 0.33357000\end{array}$

$\begin{array}{llll}\mathrm{C} & 1.86634700 & 0.89126300 & 0.00524800\end{array}$

$\begin{array}{llll}\mathrm{C} & 2.89684200 & -0.17752600 & 0.39293200\end{array}$

$\begin{array}{llll}\mathrm{C} & 2.39704400 & -1.60214800 & 0.00195300\end{array}$

$\begin{array}{llll}\mathrm{C} & 1.34563100 & -1.62271300 & -1.12062100\end{array}$

$\begin{array}{llll}\mathrm{C} & 2.27850300 & 2.15399200 & -0.23420000\end{array}$

$\begin{array}{llll}\mathrm{C} & 3.68807900 & 2.55624300 & -0.09840800\end{array}$

$\begin{array}{llll}\mathrm{O} & 4.60958700 & 1.55289900 & -0.04110700\end{array}$

$\begin{array}{lllll}\mathrm{C} & 4.20461600 & 0.19581800 & -0.37083700\end{array}$

$\begin{array}{llll}\mathrm{O} & -3.51890300 & -2.28701400 & -0.08649500\end{array}$

$\begin{array}{llll}\mathrm{C} & -4.73608400 & -2.50261200 & 0.47853100\end{array}$

$\begin{array}{llll}\text { C } & -5.63518700 & -1.30672500 & 0.21160900\end{array}$

$\begin{array}{llll}\mathrm{O} & -4.99868900 & -3.51480400 & 1.08171200\end{array}$

$\begin{array}{llll}\mathrm{C} & 5.40591500 & -0.66584600 & -0.10933800\end{array}$

$\begin{array}{llll}\mathrm{C} & 6.38315600 & -0.45668200 & 0.82156200\end{array}$

$\begin{array}{llll}\mathrm{O} & 7.33091900 & -1.43380700 & 0.74899600\end{array}$

$\begin{array}{llll}\mathrm{C} & 6.95785900 & -2.28242800 & -0.25109700\end{array}$

$\begin{array}{llll}\mathrm{C} & 5.79274900 & -1.86091900 & -0.81578700\end{array}$

$\mathrm{H} \quad-5.11337900 \quad 0.39169000 \quad-1.05377500$

$\begin{array}{llll}\mathrm{O} & 4.05740600 & 3.71017400 & -0.01635400\end{array}$

$\begin{array}{llll}\mathrm{C} & 3.11536100 & -0.12737400 & 1.92441300\end{array}$

$\begin{array}{llll}\text { C } & -3.67308500 & -1.32535700 & -2.30534300\end{array}$

$\begin{array}{llll}\mathrm{O} & -3.62351500 & 2.38938300 & -0.82866800\end{array}$

$\begin{array}{lllll}\mathrm{C} & -2.81765400 & 3.47462500 & -1.26108100\end{array}$ 


$\begin{array}{lrrr}\mathrm{C} & -5.51603500 & 1.73378900 & 1.17998700 \\ \mathrm{C} & -3.84699700 & 0.16189700 & 2.19521200 \\ \mathrm{H} & -0.46138800 & 2.25655600 & 0.70677400 \\ \mathrm{H} & -2.86384100 & 2.44376700 & 1.09572800 \\ \mathrm{H} & 3.25004200 & -2.23338000 & -0.25928700 \\ \mathrm{H} & 1.94466500 & -2.06124800 & 0.88780700 \\ \mathrm{H} & 0.99231400 & -2.63983400 & -1.30743700 \\ \mathrm{H} & 1.77645500 & -1.25130600 & -2.06210200 \\ \mathrm{H} & 1.59459900 & 2.94861600 & -0.51228400 \\ \mathrm{H} & 3.98147300 & 0.16883900 & -1.44693100 \\ \mathrm{H} & -6.33805300 & -1.58750000 & -0.58107400 \\ \mathrm{H} & -6.23267800 & -1.08213100 & 1.09636200 \\ \mathrm{H} & 6.55605400 & 0.32404300 & 1.54422700 \\ \mathrm{H} & 7.61762800 & -3.11498600 & -0.43772300 \\ \mathrm{H} & 5.28066000 & -2.33002200 & -1.64440800 \\ \mathrm{H} & 3.77814500 & -0.93968400 & 2.23770000 \\ \mathrm{H} & 3.55739400 & 0.82042100 & 2.24231900 \\ \mathrm{H} & 2.15891100 & -0.25035400 & 2.44189600 \\ \mathrm{H} & -4.65254900 & -1.78132900 & -2.48158900 \\ \mathrm{H} & -3.60796600 & -0.40449200 & -2.89354000 \\ \mathrm{H} & -2.89484700 & -2.01572000 & -2.63643400 \\ \mathrm{H} & -2.67564900 & 4.21016000 & -0.45514000 \\ \mathrm{H} & -1.83355400 & 3.14244700 & -1.61852300 \\ \mathrm{H} & -3.35149400 & 3.94963900 & -2.08683800 \\ \mathrm{H} & -5.25281000 & 2.48916900 & 1.92964700 \\ \mathrm{H} & -6.34926500 & 1.15100900 & 1.58568800 \\ \mathrm{H} & -5.85976900 & 2.25305200 & 0.28253600 \\ \mathrm{H} & -3.01641600 & -0.53484000 & 2.05891600 \\ \mathrm{H} & -3.52755100 & 0.92644500 & 2.91268000 \\ \mathrm{H} & -4.66946700 & -0.38916500 & 2.66035300\end{array}$

\section{C3-epi-granatumine A-conformer 1 (17-8)}

$\begin{array}{lc}\text { Zero-point correction }= & 0.516874 \text { (Hartree/Particle) } \\ \text { Thermal correction to Energy= } & 0.546988 \\ \text { Thermal correction to Enthalpy= } & 0.547932 \\ \text { Thermal correction to Gibbs Free Energy= } & 0.455986 \\ \text { Sum of electronic and zero-point Energies }= & -1551.996473 \\ \text { Sum of electronic and thermal Energies }= & -1551.966359 \\ \text { Sum of electronic and thermal Enthalpies }= & -1551.965415 \\ \text { Sum of electronic and thermal Free Energies }= & -1552.057361\end{array}$
01

$\begin{array}{lrrr}\mathrm{N} & -1.07566000 & -1.55610600 & -0.55432200 \\ \mathrm{C} & -2.10501800 & -0.70529200 & -0.54830400 \\ \mathrm{C} & -1.93884500 & 0.68371000 & -0.42455800 \\ \mathrm{C} & -0.64241900 & 1.16087000 & -0.26807500 \\ \mathrm{C} & 0.45530200 & 0.28444800 & -0.26885100 \\ \mathrm{C} & 0.17173900 & -1.09309900 & -0.41531400 \\ \mathrm{C} & -3.48567400 & -1.33115900 & -0.69312200 \\ \mathrm{C} & -4.68195600 & -0.34284600 & -0.50273800\end{array}$




\begin{tabular}{|c|c|c|c|}
\hline $\mathrm{C}$ & -4.35963900 & 0.96889700 & 0.27695100 \\
\hline $\mathrm{C}$ & -3.14251500 & 1.61149400 & -0.44345200 \\
\hline $\mathrm{C}$ & 1.84700600 & 0.76240800 & -0.10908100 \\
\hline $\mathrm{C}$ & 2.94421400 & -0.27209000 & 0.14734200 \\
\hline $\mathrm{C}$ & 2.64686200 & -1.53942000 & -0.68740900 \\
\hline $\mathrm{C}$ & 1.26708600 & -2.12948300 & -0.39393300 \\
\hline $\mathrm{C}$ & 2.17921500 & 2.07296800 & -0.14451100 \\
\hline $\mathrm{C}$ & 3.52851300 & 2.56424300 & 0.17940300 \\
\hline $\mathrm{O}$ & 4.52625900 & 1.63836700 & 0.24617400 \\
\hline $\mathrm{C}$ & 4.28011500 & 0.34316800 & -0.35867300 \\
\hline $\mathrm{O}$ & -3.63341800 & -2.30766800 & 0.38933000 \\
\hline $\mathrm{C}$ & -4.90119400 & -2.31830500 & 0.87934500 \\
\hline $\mathrm{C}$ & -5.72212500 & -1.24678700 & 0.17944100 \\
\hline $\mathrm{O}$ & -5.25917900 & -3.09101700 & 1.73409500 \\
\hline $\mathrm{C}$ & 5.51803300 & -0.47090500 & -0.12750400 \\
\hline $\mathrm{C}$ & 6.16611400 & -1.22998700 & -1.05933500 \\
\hline $\mathrm{O}$ & 7.25792700 & -1.83583300 & -0.51456500 \\
\hline $\mathrm{C}$ & 7.31771700 & -1.44164200 & 0.79279200 \\
\hline $\mathrm{C}$ & 6.28306200 & -0.60879500 & 1.08603500 \\
\hline $\mathrm{H}$ & -5.03136400 & -0.03971100 & -1.49662500 \\
\hline $\mathrm{O}$ & 3.77252100 & 3.72718500 & 0.43317600 \\
\hline $\mathrm{C}$ & 2.99046900 & -0.59721400 & 1.65916400 \\
\hline $\mathrm{C}$ & -3.58005800 & -2.09684000 & -2.01941200 \\
\hline $\mathrm{O}$ & -2.81034100 & 2.86964300 & 0.13779300 \\
\hline $\mathrm{C}$ & -2.80065200 & 3.97224000 & -0.76021700 \\
\hline $\mathrm{C}$ & -5.56256800 & 1.92574700 & 0.16389600 \\
\hline $\mathrm{C}$ & -4.03622000 & 0.74066400 & 1.76867200 \\
\hline $\mathrm{H}$ & -0.50434200 & 2.22287400 & -0.10600700 \\
\hline $\mathrm{H}$ & -3.43698500 & 1.77695000 & -1.49314200 \\
\hline $\mathrm{H}$ & 2.70612500 & -1.28133500 & -1.75392900 \\
\hline $\mathrm{H}$ & 3.42236400 & -2.28805800 & -0.49904500 \\
\hline $\mathrm{H}$ & 1.25819400 & -2.61760000 & 0.59002000 \\
\hline $\mathrm{H}$ & 1.01690600 & -2.91413500 & -1.11462700 \\
\hline $\mathrm{H}$ & 1.45610100 & 2.86138800 & -0.31412300 \\
\hline $\mathrm{H}$ & 4.16680200 & 0.50230400 & -1.43993100 \\
\hline $\mathrm{H}$ & -6.37353900 & -1.74493900 & -0.54738400 \\
\hline $\mathrm{H}$ & -6.37362100 & -0.74687900 & 0.89728400 \\
\hline $\mathrm{H}$ & 5.98799100 & -1.42747500 & -2.10544000 \\
\hline $\mathrm{H}$ & 8.14752700 & -1.82813100 & 1.36324400 \\
\hline $\mathrm{H}$ & 6.09550800 & -0.12300500 & 2.03185200 \\
\hline $\mathrm{H}$ & 3.32461800 & 0.27150900 & 2.23307400 \\
\hline $\mathrm{H}$ & 2.00167500 & -0.87773800 & 2.03190900 \\
\hline $\mathrm{H}$ & 3.67618200 & -1.42703200 & 1.85403100 \\
\hline $\mathrm{H}$ & -2.81087800 & -2.87115300 & -2.04453300 \\
\hline $\mathrm{H}$ & -4.56287800 & -2.56646300 & -2.12858000 \\
\hline $\mathrm{H}$ & -3.42447200 & -1.41800700 & -2.86478400 \\
\hline $\mathrm{H}$ & -3.79352600 & 4.14741800 & -1.19677600 \\
\hline $\mathrm{H}$ & -2.51003500 & 4.84830800 & -0.17637100 \\
\hline $\mathrm{H}$ & -2.07552500 & 3.82873500 & -1.57414100 \\
\hline $\mathrm{H}$ & -6.45396800 & 1.50174800 & 0.63662800 \\
\hline $\mathrm{H}$ & -5.81067800 & 2.13891400 & -0.88320200 \\
\hline
\end{tabular}




$\begin{array}{llll}\mathrm{H} & -5.34230300 & 2.87251400 & 0.66423900 \\ \mathrm{H} & -4.91161000 & 0.36904300 & 2.30975700 \\ \mathrm{H} & -3.22286300 & 0.02657300 & 1.92091100 \\ \mathrm{H} & -3.74133500 & 1.68873900 & 2.22661700\end{array}$

C3-epi-granatumine A-conformer 2 (17-8)

Zero-point correction $=$

Thermal correction to Energy=

Thermal correction to Enthalpy=

Thermal correction to Gibbs Free Energy=

Sum of electronic and zero-point Energies $=$

Sum of electronic and thermal Energies $=$

Sum of electronic and thermal Enthalpies=

Sum of electronic and thermal Free Energies=
0.516839 (Hartree/Particle) 0.546965

0.547909

0.456018

$-1551.996381$

$-1551.966255$

$-1551.965311$

$-1552.057202$

01

$\begin{array}{lrrr}\mathrm{N} & -1.08551600 & -1.56283600 & -0.54228600 \\ \mathrm{C} & -2.11202200 & -0.70858700 & -0.54097200 \\ \mathrm{C} & -1.94072200 & 0.68081500 & -0.42932900 \\ \mathrm{C} & -0.64234500 & 1.15498900 & -0.28067500 \\ \mathrm{C} & 0.45259700 & 0.27495000 & -0.27673900 \\ \mathrm{C} & 0.16362200 & -1.10248800 & -0.41041100 \\ \mathrm{C} & -3.49519800 & -1.33082000 & -0.67721300 \\ \mathrm{C} & -4.68755200 & -0.33688400 & -0.49127300 \\ \mathrm{C} & -4.35845800 & 0.98005600 & 0.27678600 \\ \mathrm{C} & -3.14132800 & 1.61251300 & -0.45251100 \\ \mathrm{C} & 1.84636800 & 0.74937400 & -0.12439800 \\ \mathrm{C} & 2.94491600 & -0.28508200 & 0.12953600 \\ \mathrm{C} & 2.63630000 & -1.55983200 & -0.69004200 \\ \mathrm{C} & 1.25569600 & -2.14133800 & -0.38236400 \\ \mathrm{C} & 2.17911100 & 2.05971600 & -0.16498700 \\ \mathrm{C} & 3.52917400 & 2.54946200 & 0.15344000 \\ \mathrm{O} & 4.52521300 & 1.62161600 & 0.21800100 \\ \mathrm{C} & 4.28044900 & 0.32821100 & -0.38570000 \\ \mathrm{O} & -3.64324800 & -2.29840700 & 0.41307000 \\ \mathrm{C} & -4.90966600 & -2.30088400 & 0.90676200 \\ \mathrm{C} & -5.72882600 & -1.23170900 & 0.20120600 \\ \mathrm{O} & -5.26790800 & -3.06598500 & 1.76818100 \\ \mathrm{C} & 5.51888300 & -0.48489000 & -0.14298900 \\ \mathrm{C} & 6.43847600 & -0.29818200 & 0.84883900 \\ \mathrm{O} & 7.44777900 & -1.20962900 & 0.74413500 \\ \mathrm{C} & 7.17224200 & -1.99060400 & -0.33911100 \\ \mathrm{C} & 6.00907900 & -1.59230900 & -0.92442800 \\ \mathrm{H} & -5.03888000 & -0.04058200 & -1.48654100 \\ \mathrm{O} & 3.77778000 & 3.71160800 & 0.40602200 \\ \mathrm{C} & 3.01369100 & -0.59755700 & 1.64260900 \\ \mathrm{C} & -3.59580600 & -2.10627300 & -1.99736100 \\ \mathrm{O} & -2.80284200 & 2.87426200 & 0.11714500 \\ \mathrm{C} & -2.79491400 & 3.96989500 & -0.78937900 \\ \mathrm{C} & -5.55849800 & 1.93999400 & 0.15946000\end{array}$

SI323 


$\begin{array}{lrrr}\mathrm{C} & -4.03148900 & 0.76286100 & 1.76937600 \\ \mathrm{H} & -0.50092100 & 2.21797000 & -0.12849600 \\ \mathrm{H} & -3.43826100 & 1.77020100 & -1.50271200 \\ \mathrm{H} & 2.69183400 & -1.31535000 & -1.76003200 \\ \mathrm{H} & 3.40435000 & -2.31325900 & -0.49277300 \\ \mathrm{H} & 1.25123800 & -2.61742700 & 0.60744900 \\ \mathrm{H} & 0.99958000 & -2.93388900 & -1.09225500 \\ \mathrm{H} & 1.45612400 & 2.84851400 & -0.33267400 \\ \mathrm{H} & 4.16678300 & 0.48580400 & -1.46810900 \\ \mathrm{H} & -6.38439600 & -1.73301400 & -0.51968900 \\ \mathrm{H} & -6.37616700 & -0.72389300 & 0.91725400 \\ \mathrm{H} & 6.52607300 & 0.42539400 & 1.64264300 \\ \mathrm{H} & 7.88979600 & -2.76488000 & -0.56051300 \\ \mathrm{H} & 5.56241300 & -2.02124300 & -1.81019300 \\ \mathrm{H} & 3.34688100 & 0.27891500 & 2.20498700 \\ \mathrm{H} & 2.03383500 & -0.88774600 & 2.03122500 \\ \mathrm{H} & 3.71585200 & -1.41460400 & 1.83322600 \\ \mathrm{H} & -2.82939500 & -2.88345100 & -2.01866500 \\ \mathrm{H} & -4.58055200 & -2.57328900 & -2.10022900 \\ \mathrm{H} & -3.44023300 & -1.43441700 & -2.84829700 \\ \mathrm{H} & -3.78960900 & 4.14457100 & -1.22196500 \\ \mathrm{H} & -2.49868100 & 4.84957700 & -0.21384600 \\ \mathrm{H} & -2.07456800 & 3.81799000 & -1.60603200 \\ \mathrm{H} & -6.44986600 & 1.52285600 & 0.63832400 \\ \mathrm{H} & -5.80906900 & 2.14542300 & -0.88860200 \\ \mathrm{H} & -5.33362400 & 2.89007100 & 0.65142200 \\ \mathrm{H} & -4.90661800 & 0.39875400 & 2.31597200 \\ \mathrm{H} & -3.22021800 & 0.04717100 & 1.92518400 \\ \mathrm{H} & -3.73194700 & 1.71359100 & 2.21871700\end{array}$

C3-epi-granatumine A-conformer 3 (17-8)

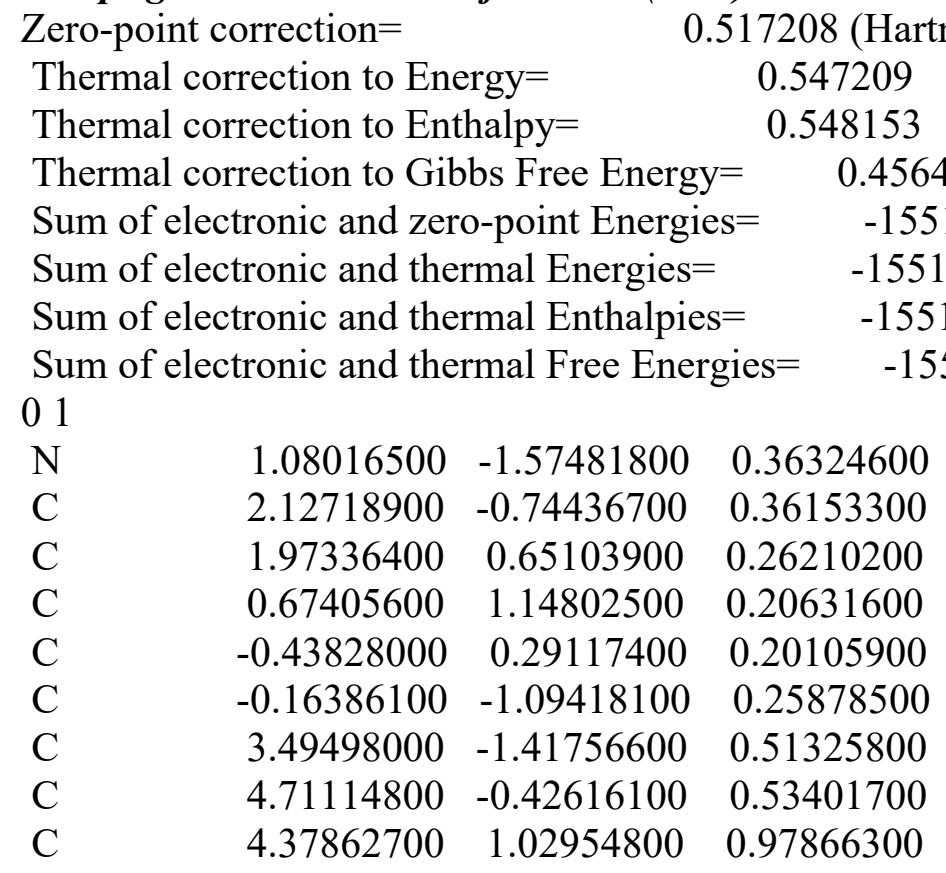




\begin{tabular}{|c|c|c|c|}
\hline $\mathrm{C}$ & 3.16838700 & 1.58398800 & 0.18946100 \\
\hline $\mathrm{C}$ & -1.82870500 & 0.79277600 & 0.13126300 \\
\hline $\mathrm{C}$ & -2.94662800 & -0.21175200 & -0.15311000 \\
\hline $\mathrm{C}$ & -2.63399800 & -1.53585100 & 0.58210300 \\
\hline $\mathrm{C}$ & -1.27080000 & -2.11628500 & 0.20211000 \\
\hline $\mathrm{C}$ & -2.14344000 & 2.10081000 & 0.26807000 \\
\hline $\mathrm{C}$ & -3.49773600 & 2.62573100 & 0.02594600 \\
\hline $\mathrm{O}$ & -4.50764000 & 1.71633000 & -0.06494000 \\
\hline $\mathrm{C}$ & -4.25558700 & 0.38083900 & 0.44302600 \\
\hline $\mathrm{O}$ & 3.68765400 & -2.24941600 & -0.67445900 \\
\hline $\mathrm{C}$ & 4.73655400 & -1.84655300 & -1.44065800 \\
\hline $\mathrm{C}$ & 5.34803200 & -0.59010500 & -0.86033600 \\
\hline $\mathrm{O}$ & 5.06403400 & -2.44256400 & -2.43809000 \\
\hline $\mathrm{C}$ & -5.51078700 & -0.40379900 & 0.20457600 \\
\hline $\mathrm{C}$ & -6.13321100 & -1.21726700 & 1.10765300 \\
\hline $\mathrm{O}$ & -7.25117600 & -1.77488100 & 0.56495600 \\
\hline $\mathrm{C}$ & -7.35436900 & -1.29381800 & -0.71013800 \\
\hline $\mathrm{C}$ & -6.32133700 & -0.45306500 & -0.98603900 \\
\hline $\mathrm{H}$ & 5.41946700 & -0.81690000 & 1.27393100 \\
\hline $\mathrm{O}$ & -3.73448600 & 3.80519100 & -0.14435700 \\
\hline $\mathrm{C}$ & -3.05243300 & -0.43290900 & -1.68066300 \\
\hline $\mathrm{C}$ & 3.49323000 & -2.38122300 & 1.70344000 \\
\hline $\mathrm{O}$ & 3.56549800 & 1.80709900 & -1.17124300 \\
\hline $\mathrm{C}$ & 2.70725700 & 2.64012000 & -1.93673200 \\
\hline $\mathrm{C}$ & 4.01882900 & 1.05546300 & 2.48337500 \\
\hline $\mathrm{C}$ & 5.60923100 & 1.93576000 & 0.77930000 \\
\hline $\mathrm{H}$ & 0.53080800 & 2.22301400 & 0.15692100 \\
\hline $\mathrm{H}$ & 2.88551300 & 2.55730200 & 0.62472200 \\
\hline $\mathrm{H}$ & -2.65432300 & -1.35171800 & 1.66521000 \\
\hline $\mathrm{H}$ & -3.42323100 & -2.26332300 & 0.36965100 \\
\hline $\mathrm{H}$ & -1.29948400 & -2.53269700 & -0.81405500 \\
\hline $\mathrm{H}$ & -1.00529000 & -2.95194700 & 0.85659900 \\
\hline $\mathrm{H}$ & -1.40670600 & 2.87011000 & 0.46596100 \\
\hline $\mathrm{H}$ & -4.10043400 & 0.46634800 & 1.52735400 \\
\hline $\mathrm{H}$ & 6.43569700 & -0.68865000 & -0.83892200 \\
\hline $\mathrm{H}$ & 5.09894800 & 0.23182200 & -1.53478700 \\
\hline $\mathrm{H}$ & -5.91932100 & -1.48571400 & 2.13101300 \\
\hline $\mathrm{H}$ & -8.20919300 & -1.63340800 & -1.27345000 \\
\hline $\mathrm{H}$ & -6.16326700 & 0.09313600 & -1.90386600 \\
\hline $\mathrm{H}$ & -3.39648500 & 0.47604200 & -2.18184900 \\
\hline $\mathrm{H}$ & -2.08196300 & -0.69845200 & -2.10861300 \\
\hline $\mathrm{H}$ & -3.75558900 & -1.24031700 & -1.90494600 \\
\hline $\mathrm{H}$ & 2.68145600 & -3.10199500 & 1.59498800 \\
\hline $\mathrm{H}$ & 4.44707800 & -2.91586500 & 1.74048200 \\
\hline $\mathrm{H}$ & 3.36048600 & -1.83939700 & 2.64464800 \\
\hline $\mathrm{H}$ & 2.53958000 & 3.60436800 & -1.43389500 \\
\hline $\mathrm{H}$ & 3.21454900 & 2.81675200 & -2.88733800 \\
\hline $\mathrm{H}$ & 1.73808100 & 2.16487900 & -2.13585300 \\
\hline $\mathrm{H}$ & 4.84773300 & 0.65602700 & 3.07705900 \\
\hline $\mathrm{H}$ & 3.12473500 & 0.47330500 & 2.72125300 \\
\hline $\mathrm{H}$ & 3.83961600 & 2.08413600 & 2.81548500 \\
\hline
\end{tabular}




$\begin{array}{lrrr}\mathrm{H} & 6.45718100 & 1.55490900 & 1.35981900 \\ \mathrm{H} & 5.90804500 & 2.00422800 & -0.26743100 \\ \mathrm{H} & 5.39582900 & 2.95144100 & 1.13197000\end{array}$

\section{C3-epi-granatumine A-conformer 4 (17-8)}

$\begin{array}{lc}\text { Zero-point correction }= & 0.517190 \text { (Hartree/Particle) } \\ \text { Thermal correction to Energy= } & 0.547196 \\ \text { Thermal correction to Enthalpy= } & 0.548141 \\ \text { Thermal correction to Gibbs Free Energy= } & 0.456562 \\ \text { Sum of electronic and zero-point Energies }= & -1551.996134 \\ \text { Sum of electronic and thermal Energies }= & -1551.966127 \\ \text { Sum of electronic and thermal Enthalpies }= & -1551.965183 \\ \text { Sum of electronic and thermal Free Energies }= & -1552.056762\end{array}$

01

$\begin{array}{lrrr}\mathrm{N} & 1.09032900 & -1.58011900 & 0.35001800 \\ \mathrm{C} & 2.13430500 & -0.74585700 & 0.35359600 \\ \mathrm{C} & 1.97497500 & 0.64982100 & 0.26702800 \\ \mathrm{C} & 0.67372000 & 1.14252600 & 0.22002600 \\ \mathrm{C} & -0.43563700 & 0.28169000 & 0.20990800 \\ \mathrm{C} & -0.15554300 & -1.10277200 & 0.25309400 \\ \mathrm{C} & 3.50486700 & -1.41518400 & 0.49717100 \\ \mathrm{C} & 4.71733500 & -0.41947600 & 0.52075000 \\ \mathrm{C} & 4.38148100 & 1.03145600 & 0.97829200 \\ \mathrm{C} & 3.16621300 & 1.58795400 & 0.19830200 \\ \mathrm{C} & -1.82814000 & 0.77865600 & 0.14881500 \\ \mathrm{C} & -2.94673400 & -0.22589500 & -0.13543400 \\ \mathrm{C} & -2.62317200 & -1.55759700 & 0.58157600 \\ \mathrm{C} & -1.25897900 & -2.12732700 & 0.18801500 \\ \mathrm{C} & -2.14381400 & 2.08557600 & 0.29439800 \\ \mathrm{C} & -3.49877700 & 2.60876000 & 0.05861000 \\ \mathrm{O} & -4.50648100 & 1.69700100 & -0.03354300 \\ \mathrm{C} & -4.25557900 & 0.36222900 & 0.47028600 \\ \mathrm{O} & 3.69759400 & -2.23901800 & -0.69602000 \\ \mathrm{C} & 4.74181700 & -1.82616200 & -1.46343900 \\ \mathrm{C} & 5.34875000 & -0.57010300 & -0.87755900 \\ \mathrm{O} & 5.06887900 & -2.41455000 & -2.46548600 \\ \mathrm{C} & -5.51126600 & -0.42047600 & 0.21759200 \\ \mathrm{C} & -6.46359100 & -0.15694500 & -0.72475500 \\ \mathrm{O} & -7.47873800 & -1.06420000 & -0.64626500 \\ \mathrm{C} & -7.17364000 & -1.92109900 & 0.36953100 \\ \mathrm{C} & -5.98572000 & -1.57506000 & 0.93809900 \\ \mathrm{H} & 5.43030800 & -0.81351100 & 1.25444500 \\ \mathrm{O} & -3.74054200 & 3.78775500 & -0.10718900 \\ \mathrm{C} & -3.07409100 & -0.43140400 & -1.66294700 \\ \mathrm{C} & 3.50950200 & -2.38624500 & 1.68135400 \\ \mathrm{O} & 3.55738500 & 1.82429400 & -1.16185600 \\ \mathrm{C} & 2.69322000 & 2.66068700 & -1.91700900 \\ \mathrm{C} & 4.02738400 & 1.04434100 & 2.48450300 \\ \mathrm{C} & 5.60823800 & 1.94336400 & 0.78121100 \\ & & & \\ & & & 5130\end{array}$




$\begin{array}{lrrr}\mathrm{H} & 0.52689500 & 2.21741600 & 0.18128700 \\ \mathrm{H} & 2.88114400 & 2.55636400 & 0.64295700 \\ \mathrm{H} & -2.64060600 & -1.38915000 & 1.66734500 \\ \mathrm{H} & -3.40480300 & -2.28930500 & 0.35788700 \\ \mathrm{H} & -1.29140700 & -2.53015800 & -0.83345500 \\ \mathrm{H} & -0.98792800 & -2.97076500 & 0.83014800 \\ \mathrm{H} & -1.40757200 & 2.85505700 & 0.49283100 \\ \mathrm{H} & -4.10082400 & 0.44353200 & 1.55593800 \\ \mathrm{H} & 6.43705100 & -0.66233600 & -0.86187500 \\ \mathrm{H} & 5.09166100 & 0.25501700 & -1.54511100 \\ \mathrm{H} & -6.57154800 & 0.62094700 & -1.46273500 \\ \mathrm{H} & -7.89175500 & -2.70230800 & 0.56296000 \\ \mathrm{H} & -5.51269900 & -2.06842300 & 1.77529700 \\ \mathrm{H} & -3.41574500 & 0.48557000 & -2.15078300 \\ \mathrm{H} & -2.11314600 & -0.70536300 & -2.10679900 \\ \mathrm{H} & -3.79379400 & -1.22529600 & -1.88331200 \\ \mathrm{H} & 2.70014700 & -3.10934100 & 1.57015500 \\ \mathrm{H} & 4.46536600 & -2.91762600 & 1.71277600 \\ \mathrm{H} & 3.37694200 & -1.85092900 & 2.62628500 \\ \mathrm{H} & 2.52356400 & 3.61977700 & -1.40506700 \\ \mathrm{H} & 3.19653500 & 2.84769200 & -2.86774000 \\ \mathrm{H} & 1.72523300 & 2.18341900 & -2.11704100 \\ \mathrm{H} & 4.85934300 & 0.64192300 & 3.07186300 \\ \mathrm{H} & 3.13540800 & 0.45834700 & 2.72091800 \\ \mathrm{H} & 3.84717500 & 2.06989000 & 2.82559700 \\ \mathrm{H} & 6.45960800 & 1.56107200 & 1.35574400 \\ \mathrm{H} & 5.90292300 & 2.02066300 & -0.26607700 \\ \mathrm{H} & 5.39270100 & 2.95565000 & 1.14223200\end{array}$

\section{C3-epi-granatumine A-conformer 5 (17-8)}

Zero-point correction=

Thermal correction to Energy=

Thermal correction to Enthalpy=

Thermal correction to Gibbs Free Energy=

Sum of electronic and zero-point Energies $=$

Sum of electronic and thermal Energies=

Sum of electronic and thermal Enthalpies=

Sum of electronic and thermal Free Energies=
0.516737 (Hartree/Particle)

$$
0.546801
$$

0.547745

0.456119

$-1551.992388$

$-1551.962324$

$-1551.961380$

$-1552.053006$

01

$\begin{array}{lrrr}\mathrm{N} & -1.05029200 & -1.39263200 & -0.89009000 \\ \mathrm{C} & -2.09347500 & -0.57489500 & -0.68036700 \\ \mathrm{C} & -1.94840200 & 0.77472500 & -0.32587900 \\ \mathrm{C} & -0.65156400 & 1.26231000 & -0.15103800 \\ \mathrm{C} & 0.44170300 & 0.41594300 & -0.35070000 \\ \mathrm{C} & 0.18479700 & -0.91953800 & -0.72849400 \\ \mathrm{C} & -3.46782300 & -1.20613100 & -0.85757200 \\ \mathrm{C} & -4.67181400 & -0.30038300 & -0.44140200 \\ \mathrm{C} & -4.33460100 & 0.86890800 & 0.53367000 \\ \mathrm{C} & -3.16994700 & 1.65719100 & -0.12483500\end{array}$




\begin{tabular}{|c|c|c|c|}
\hline $\mathrm{C}$ & 1.84803500 & 0.84184600 & -0.25056200 \\
\hline $\mathrm{C}$ & 2.86515000 & -0.13653900 & 0.35058000 \\
\hline $\mathrm{C}$ & 2.39617900 & -1.61404400 & 0.17158700 \\
\hline $\mathrm{C}$ & 1.36701800 & -1.82555200 & -0.95218000 \\
\hline $\mathrm{C}$ & 2.26459000 & 2.04574100 & -0.69581100 \\
\hline $\mathrm{C}$ & 3.66790100 & 2.47922100 & -0.59285100 \\
\hline $\mathrm{O}$ & 4.59105300 & 1.51308300 & -0.32185500 \\
\hline $\mathrm{C}$ & 4.20125100 & 0.11376300 & -0.41099000 \\
\hline $\mathrm{O}$ & -3.53585000 & -2.35483400 & 0.05111300 \\
\hline $\mathrm{C}$ & -4.77424800 & -2.48533400 & 0.59504600 \\
\hline $\mathrm{C}$ & -5.65459600 & -1.33708000 & 0.12754800 \\
\hline $\mathrm{O}$ & -5.06886800 & -3.40010500 & 1.32483100 \\
\hline $\mathrm{C}$ & 5.39581700 & -0.67195100 & 0.04074600 \\
\hline $\mathrm{C}$ & 5.94583700 & -1.73945200 & -0.60976200 \\
\hline $\mathrm{O}$ & 7.02658500 & -2.21502800 & 0.06892400 \\
\hline $\mathrm{C}$ & 7.18065700 & -1.42262400 & 1.17175500 \\
\hline $\mathrm{C}$ & 6.21609100 & -0.46436100 & 1.20741700 \\
\hline $\mathrm{H}$ & -5.08077400 & 0.15658800 & -1.35007400 \\
\hline $\mathrm{O}$ & 4.02910600 & 3.63245600 & -0.71422700 \\
\hline $\mathrm{C}$ & 3.00377100 & 0.16893500 & 1.86218200 \\
\hline $\mathrm{C}$ & -3.62212700 & -1.74169800 & -2.28711300 \\
\hline $\mathrm{O}$ & -2.83479900 & 2.80658200 & 0.64874900 \\
\hline $\mathrm{C}$ & -2.85479400 & 4.04096900 & -0.05668200 \\
\hline $\mathrm{C}$ & -5.55986600 & 1.79751400 & 0.64304500 \\
\hline $\mathrm{C}$ & -3.92916700 & 0.40115900 & 1.94747300 \\
\hline $\mathrm{H}$ & -0.50429600 & 2.28474400 & 0.17956800 \\
\hline $\mathrm{H}$ & -3.52355100 & 1.99203600 & -1.11417100 \\
\hline $\mathrm{H}$ & 3.26862500 & -2.25535600 & 0.01574400 \\
\hline $\mathrm{H}$ & 1.93824200 & -1.94678100 & 1.10932700 \\
\hline $\mathrm{H}$ & 1.02597600 & -2.86351500 & -0.97874400 \\
\hline $\mathrm{H}$ & 1.81633100 & -1.60746300 & -1.93228100 \\
\hline $\mathrm{H}$ & 1.58529500 & 2.77331700 & -1.12666900 \\
\hline $\mathrm{H}$ & 4.02013800 & -0.11134400 & -1.47127100 \\
\hline $\mathrm{H}$ & -6.33246200 & -1.72554500 & -0.64081600 \\
\hline $\mathrm{H}$ & -6.27798100 & -0.98484700 & 0.95033500 \\
\hline $\mathrm{H}$ & 5.70225600 & -2.25058900 & -1.52885600 \\
\hline $\mathrm{H}$ & 8.01479600 & -1.66390200 & 1.81157600 \\
\hline $\mathrm{H}$ & 6.11187000 & 0.31579300 & 1.94634700 \\
\hline $\mathrm{H}$ & 3.43643100 & 1.15719300 & 2.03939500 \\
\hline $\mathrm{H}$ & 2.01962900 & 0.13639200 & 2.33980600 \\
\hline $\mathrm{H}$ & 3.63709500 & -0.58119500 & 2.34505500 \\
\hline $\mathrm{H}$ & -2.84064100 & -2.47825400 & -2.48329300 \\
\hline $\mathrm{H}$ & -4.60024700 & -2.21435100 & -2.42226700 \\
\hline $\mathrm{H}$ & -3.52791100 & -0.92656100 & -3.01258200 \\
\hline $\mathrm{H}$ & -2.14413200 & 4.04388600 & -0.89555100 \\
\hline $\mathrm{H}$ & -3.85810100 & 4.27016900 & -0.44162300 \\
\hline $\mathrm{H}$ & -2.56335900 & 4.81423800 & 0.65746000 \\
\hline $\mathrm{H}$ & -6.41729000 & 1.27498000 & 1.07856700 \\
\hline $\mathrm{H}$ & -5.86571700 & 2.17771500 & -0.33945900 \\
\hline $\mathrm{H}$ & -5.33196100 & 2.65197700 & 1.28579500 \\
\hline $\mathrm{H}$ & -4.76787200 & -0.08008800 & 2.45946400 \\
\hline
\end{tabular}




$\begin{array}{lrrr}\mathrm{H} & -3.09592900 & -0.30607800 & 1.93582100 \\ \mathrm{H} & -3.62848700 & 1.26617500 & 2.54487400\end{array}$

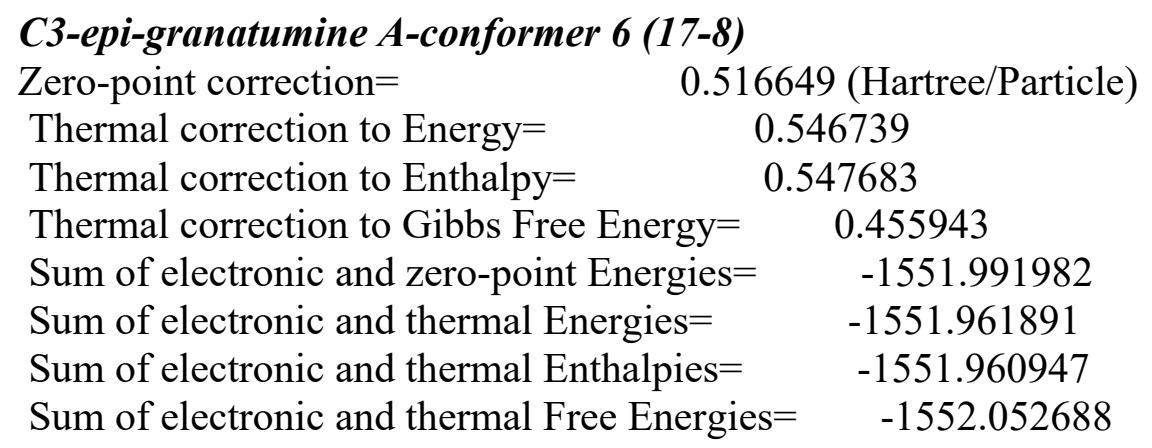
01

$\begin{array}{lrrr}\mathrm{N} & -1.05304500 & -1.39621300 & -0.87442400 \\ \mathrm{C} & -2.09529200 & -0.57536300 & -0.67295800 \\ \mathrm{C} & -1.94869200 & 0.77497300 & -0.32172300 \\ \mathrm{C} & -0.65160300 & 1.26029100 & -0.14338100 \\ \mathrm{C} & 0.44097800 & 0.41115900 & -0.33600000 \\ \mathrm{C} & 0.18243900 & -0.92552800 & -0.70883300 \\ \mathrm{C} & -3.47022100 & -1.20382200 & -0.85528700 \\ \mathrm{C} & -4.67400600 & -0.29439600 & -0.44653100 \\ \mathrm{C} & -4.33835700 & 0.87645200 & 0.52719700 \\ \mathrm{C} & -3.16915600 & 1.66061600 & -0.12823100 \\ \mathrm{C} & 1.84742900 & 0.83705000 & -0.23713800 \\ \mathrm{C} & 2.86979500 & -0.13966700 & 0.35851600 \\ \mathrm{C} & 2.38298600 & -1.61411900 & 0.21199100 \\ \mathrm{C} & 1.36254300 & -1.83829000 & -0.91701700 \\ \mathrm{C} & 2.26275600 & 2.03956300 & -0.68757400 \\ \mathrm{C} & 3.66746700 & 2.46859500 & -0.59300300 \\ \mathrm{O} & 4.58972700 & 1.49766700 & -0.33420500 \\ \mathrm{C} & 4.19614100 & 0.10097200 & -0.42598300 \\ \mathrm{O} & -3.54514500 & -2.35061900 & 0.05516100 \\ \mathrm{C} & -4.78625900 & -2.47707800 & 0.59385700 \\ \mathrm{C} & -5.66169700 & -1.32749400 & 0.12047300 \\ \mathrm{O} & -5.08634400 & -3.38988000 & 1.32387100 \\ \mathrm{C} & 5.39222600 & -0.69203200 & 0.01537200 \\ \mathrm{C} & 6.34428800 & -0.31374600 & 0.91852900 \\ \mathrm{O} & 7.29585400 & -1.28177800 & 1.04560100 \\ \mathrm{C} & 6.95076800 & -2.29761300 & 0.20385700 \\ \mathrm{C} & 5.79998800 & -1.99131200 & -0.45637100 \\ \mathrm{H} & -5.07792900 & 0.16134600 & -1.35806700 \\ \mathrm{O} & 4.03325400 & 3.62062000 & -0.71136800 \\ \mathrm{C} & 3.04776300 & 0.18139000 & 1.86214700 \\ \mathrm{C} & -3.61903700 & -1.74175300 & -2.28453500 \\ \mathrm{O} & -2.83462600 & 2.81117000 & 0.64382900 \\ \mathrm{C} & -2.85157500 & 4.04422600 & -0.06402300 \\ \mathrm{C} & -5.56201900 & 1.80801300 & 0.62916900 \\ \mathrm{C} & -3.93998100 & 0.41115600 & 1.94381200 \\ \mathrm{H} & -0.50364800 & 2.28358100 & 0.18422600\end{array}$




$\begin{array}{lrrr}\mathrm{H} & -3.51772300 & 1.99366200 & -1.11995700 \\ \mathrm{H} & 3.24374500 & -2.27623800 & 0.08913200 \\ \mathrm{H} & 1.90709200 & -1.91233100 & 1.15260500 \\ \mathrm{H} & 1.01694200 & -2.87501200 & -0.93184600 \\ \mathrm{H} & 1.81856200 & -1.63476100 & -1.89713200 \\ \mathrm{H} & 1.58292000 & 2.76740500 & -1.11697100 \\ \mathrm{H} & 4.00143100 & -0.11924300 & -1.48530200 \\ \mathrm{H} & -6.33747500 & -1.71576500 & -0.64982600 \\ \mathrm{H} & -6.28748200 & -0.97202500 & 0.94004300 \\ \mathrm{H} & 6.49628700 & 0.58433200 & 1.49473000 \\ \mathrm{H} & 7.61684800 & -3.14572600 & 0.18567600 \\ \mathrm{H} & 5.31049500 & -2.60405800 & -1.20056700 \\ \mathrm{H} & 3.47996400 & 1.17312100 & 2.01861800 \\ \mathrm{H} & 2.07799300 & 0.14688800 & 2.36805300 \\ \mathrm{H} & 3.70300300 & -0.55883200 & 2.33128400 \\ \mathrm{H} & -2.83833100 & -2.48047700 & -2.47566200 \\ \mathrm{H} & -4.59758600 & -2.21247000 & -2.42331700 \\ \mathrm{H} & -3.51961500 & -0.92823200 & -3.01111900 \\ \mathrm{H} & -2.13897400 & 4.04465300 & -0.90125700 \\ \mathrm{H} & -3.85370400 & 4.27389000 & -0.45172500 \\ \mathrm{H} & -2.56085500 & 4.81851100 & 0.64930200 \\ \mathrm{H} & -6.42242300 & 1.28838300 & 1.06228400 \\ \mathrm{H} & -5.86287800 & 2.18657000 & -0.35551000 \\ \mathrm{H} & -5.33499900 & 2.66347400 & 1.27090600 \\ \mathrm{H} & -4.78202600 & -0.06674800 & 2.45345100 \\ \mathrm{H} & -3.10845700 & -0.29816900 & 1.93743700 \\ \mathrm{H} & -3.63963200 & 1.27686600 & 2.54036700\end{array}$




\section{Reference}

${ }^{1}$ Burgess, E. M.; Penton, H. R., Jr.; Taylor, E. A.; Williams, W. M. Conversion of Primary Alcohols to Urethanes via the Inner Salt of Methyl(carboxysulfamoyl)triethylammonium Hydroxide: Methyl $n$ Hexylcarbamate. Org. Synth. 1977, 56, 40-43.

${ }^{2}$ Schuppe, A. W.; Huang, D.; Chen, Y.; Newhouse, T. R. Total Synthesis of (-)-Xylogranatopyridine B via a Palladium-Catalyzed Oxidative Stannylation of Enones. J. Am. Chem. Soc. 2018, 140, 2062-2066.

${ }^{3}$ Schuppe, A. W.; Zhao, Y.; Liu. Y.; Newhouse, T. R. Total Synthesis of (+)-Granatumine A and Related Bislactone Limonoid Alkaloids via a Pyran to Pyridine Interconversion. J. Am. Chem. Soc. 2019, 141, 9191-9126.

${ }^{4}$ Cui, D.; Lipchock, J.; Brookner, D.; Loria, J. P. Uncovering the Molecular Interactions in the Catalytic Loop that Modulates the Conformational Dynamics in Protein Tyrosine Phosphatase 1B. J. Am. Chem. Soc. 2019, 141, 12634-12647.

${ }^{5}$ Frisch, M. J.; Trucks, G. W.; Schlegel, H. B.; Scuseria, G. E.; Robb, M. A.; Cheeseman, J. R.; Scalmani, G.; Barone, V.; Mennucci, B.; Petersson, G. A.; Nakatsuji, H.; Caricato, M.; Li, X.; Hratchian, H. P.; Izmaylov, A. F.; Bloino, J.; Zheng, G.; Sonnenberg, J. L.; Hada, M.; Ehara, M.; Toyota, K.; Fukuda, R.; Hasegawa, J.; Ishida, M.; Nakajima, T.; Honda, Y.; Kitao, O.; Nakai, H.; Vreven, T.; Montgomery, J. A.; Peralta, J. E.; Ogliaro, F.; Bearpark, M.; Heyd, J. J.; Brothers, E.; Kudin, K. N.; Staroverov, V. N.; Keith, T.; Kobayashi, R.; Normand, J.; Raghavachari, K.; Rendell, A.; Burant, J. C.; Iyengar, S. S.; Tomasi, J.; Cossi, M.; Rega, N.; Millam, J. M.; Klene, M.; Knox, J. E.; Cross, J. B.; Bakken, V.; Adamo, C.; Jaramillo, J.; Gomperts, R.; Stratmann, R. E.; Yazyev, O.; Austin, A. J.; Cammi, R.; Pomelli, C.; Ochterski, J. W.; Martin, R. L.; Morokuma, K.; Zakrzewski, V. G.; Voth, G. A.; Salvador, P.; Dannenberg, J. J.; Dapprich, S.; Daniels, A. D.; Farkas, O.; Foresman, J. B.; Ortiz, J. V.; Cioslowski, J.; Fox, D. J. Gaussian, Inc., Wallingford CT, 2013. Gaussian 09, Revision D.01, Gaussian, Inc., Wallingford CT (2013).

${ }^{6}$ Schuppe, A. W.; Zhao, Y.; Liu, Y.; Newhouse, T. R. Total Synthesis of (+)-Granatumine A and Related Bislactone Limonoid Alkaloids via a Pyran to Pyridine Interconversion. J. Am. Chem. Soc. 2019, 141, 9191-9196.

${ }^{7}$ Willoughby, P. H.; Jansma, M. J.; Hoye, T. R. A Guide to Small-Molecule Structure Assignment Through Computation of $\left({ }^{1} \mathrm{H}\right.$ and $\left.{ }^{13} \mathrm{C}\right) \mathrm{NMR}$ Chemical Shifts. Nature protocols. 2014, 9, 643-660.

${ }^{8}$ Neupane, J. B.; Neupane, R. P.; Luo, Y. H.; Yoshida, W. Y.; Sun, R.; Williams, P. G. Characterization of Leptazolines A-D, Polar Oxazolines from the Cyanobacterium leptolyngbya sp., Reveals a Glitch with the "Willoughby-Hoye" Scripts for Calculating NMR Chemical Shifts. Org. Lett. 2019, 21, 8449-8453.

${ }^{9}$ Schrödinger Release 2015-4: MacroModel, Schrödinger, LLC, New York, NY, 2018.

${ }^{10}$ (a) Becke, A. D. Density-Functional Thermochemistry. III. The Role of Exact Exchange. J. Chem. Phys. 1993, 98, 5648-5652. (b) Becke, A. D. A New Mixing of Hartree-Fock and Local Density-Functional Theories. J. Chem. Phys. 1993, 98, 1372-1377. (c) Lee, C.; Yang, W.; Parr, R. G. Development of the Colle-Salvetti Correlation-Energy Formula into a Functional of the Electron Density. Phys. Rev. B. 1988, 37, 785-789. (d) Stephens, P. J.; Devlin, F. J.; Chabalowski, C. F.; Frisch, M. J. Ab Initio Calculation of Vibrational Absorption and Circular Dichroism Spectra Using Density Functional Force Fields. J. Phys. Chem. 1994, 98, 11623-11627.

${ }^{11}$ Adamo, C.; Barone, V. Exchange Functionals with Improved Long-Range Behaviors and Adiabatic Connection Methods without Adjustable Parameters: The $m \mathrm{PW}$ and $m \mathrm{PW} 1 \mathrm{PW}$ Models. J. Chem. Phys. 1998, 108, 664-675.

${ }^{12}$ Marenich, A. V.; Cramer, C. J.; Truhlar, D. G. Universal Solvation Model Based on Solute Electron Density and on a Continuum Model of the Solvent Defined by the Bulk Dielectric Constant and Atomic Surface Tensions. J. Phys. Chem. B. 2009, 113, 6378-6396.

${ }^{13}$ (a) Lodewyk, M. W.; Siebert, M. R.; Tantillo, D. J. Computational Prediction of ${ }^{1} \mathrm{H}$ and ${ }^{13} \mathrm{C}$ Chemical Shifts: A Useful Tool for Natural Product, Mechanistic, and Synthetic Organic Chemistry. Chem. Rev. 2012, 112, 1839-1862. (b) http://cheshirenmr.info 
${ }^{14}$ Smith, S. G.; Goodman, J. M. Assigning Stereochemistry to Single Diastereoisomers by GIAO NMR Calculation: the DP4 Probability. J. Am. Chem. Soc. 2010, 132, 12946-12959. 